\title{
URBAN NUTRIENT MANAGEMENT HANDBOOK
}

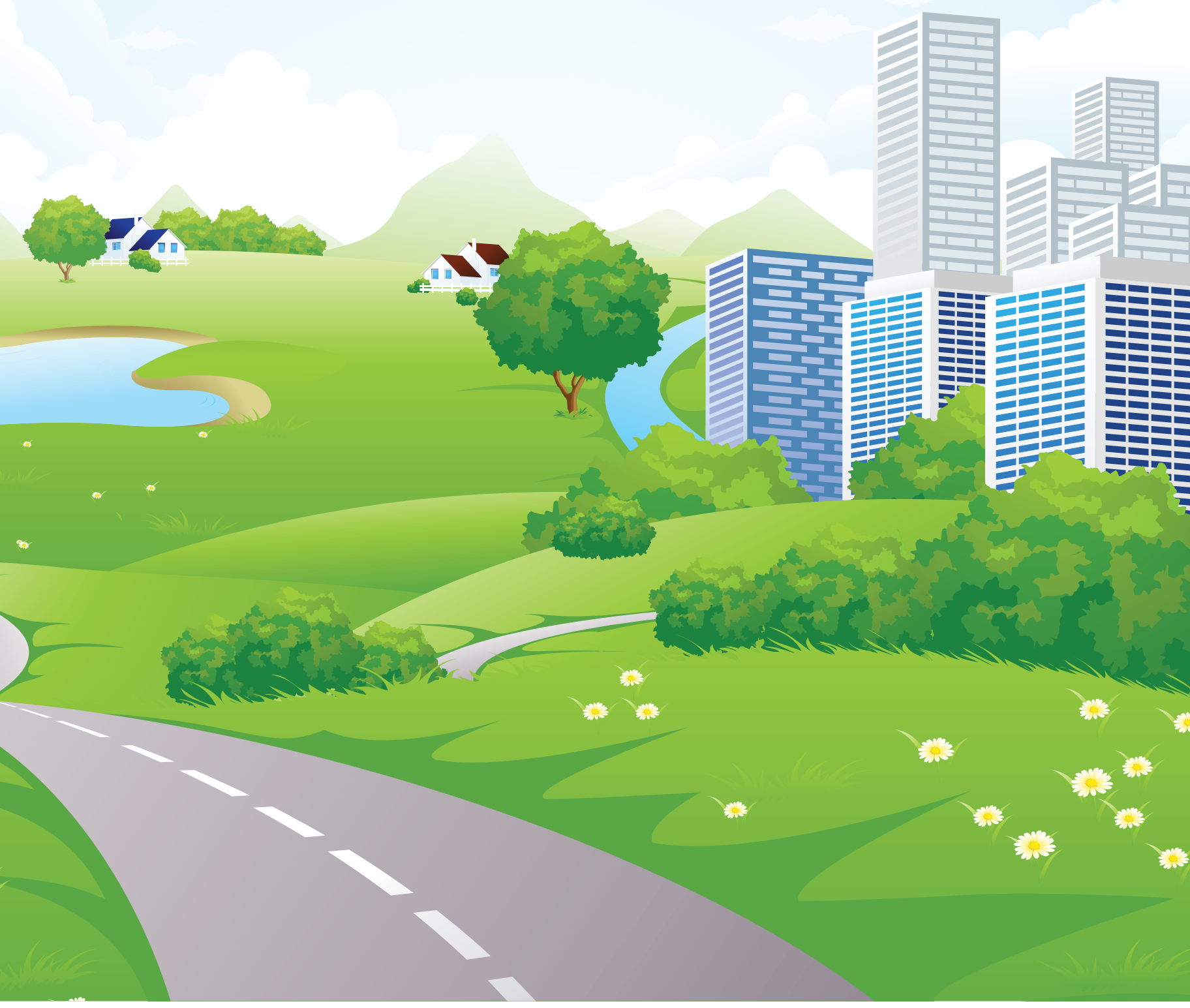

\section{Virginia Cooperative Extension}

III) VirginiaTech
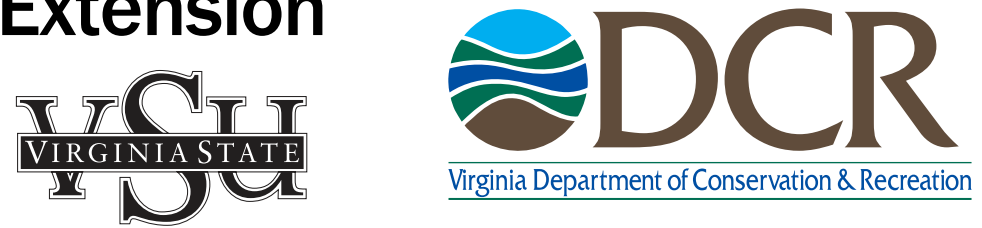



\title{
URBAN NUTRIENT \\ MANAGEMENT HANDBOOK
}

\author{
Content Coordinators: \\ Michael Goatley Jr., Professor, \\ Crop and Soil Environmental Sciences, Virginia Tech \\ Kevin Hensler, Research Specialist Senior, Crop and \\ Soil Environmental Sciences, Virginia Tech \\ Published by: \\ Virginia Cooperative Extension \\ Project funded by: \\ Virginia Department of Conservation and Recreation \\ Produced by: \\ Communications and Marketing, \\ College of Agriculture and Life Sciences, \\ Virginia Polytechnic Institute and State University \\ Director:
}

Thea Glidden

Copy Editor:

Bobbi A. Hoffman

Assistant Editor:

Liz Guinn

Layout:

Christopher Cox

This material is based upon work supported by the Virginia Department of Conservation and Recreation, under Agreement 50301-2009-01-SF. Any opinions, findings, conclusions or recommendations expressed in this publication are those of the author(s) and do not necessarily reflect the view of the Virginia Department of Conservation and Recreation. 



\section{Chapter 1. The Objectives of Turf and Landscape Nutrient Management}

Introduction ....................................... $1-1$

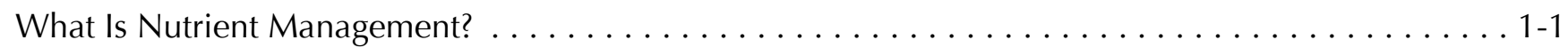

Improving Water Quality Through Turf and Landscape Nutrient Management. .............. 1-4

Literature Cited. . . . . . . . . . . . . . . . . . . . . . . . . . . . . . . . . . 1-4

\section{Chapter 2. General Soil Science Principles}

Soil Formation and Soil Horizons . . . . . . . . . . . . . . . . . . . . . . . . . . .

Soil Physical Properties. . . . . . . . . . . . . . . . . . . . . . . . . . . . . 2-3

Soil Organic Matter ............................................ 2-6

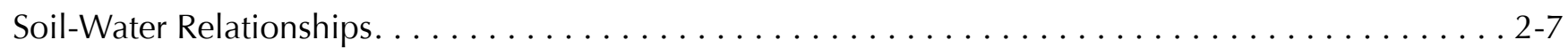

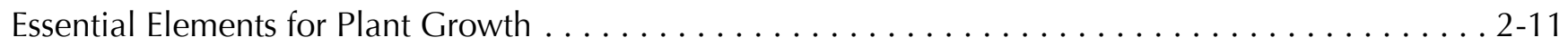

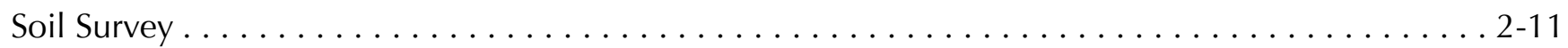

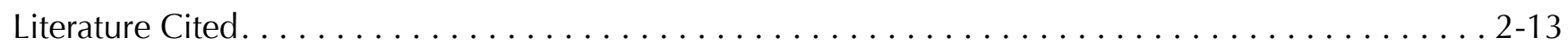

\section{Chapter 3. Managing Urban Soils}

What Is an Urban Soil?. . . . . . . . . . . . . . . . . . . . . . . . . . . . . . . . . 3-1

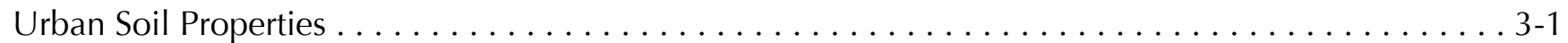

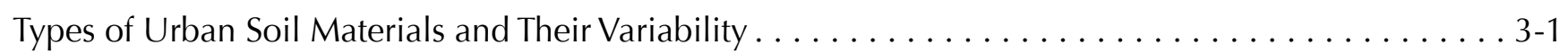

Common Soil Limitations in the Urban Environment . . . . . . . . . . . . . . . . . . . . . 3-2

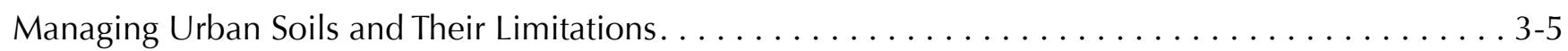

Acid Sulfate Soil Conditions and Management ........................... 3-7

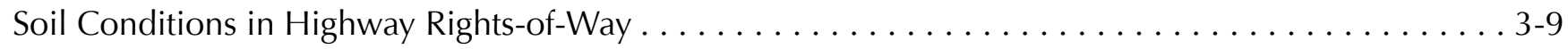

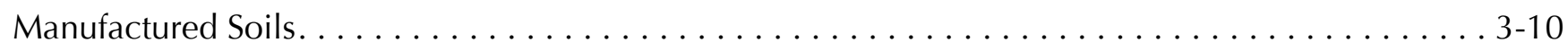

Modified Soils and Mulches ....................................... 3-11

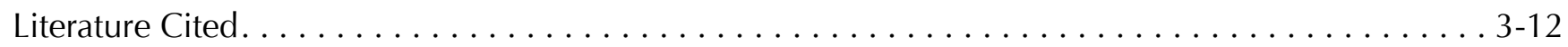

\section{Chapter 4. Basic Soil Fertility}

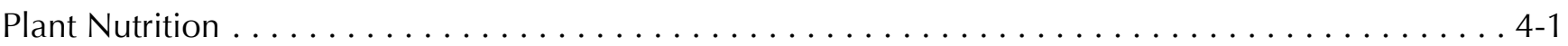

Soil $\mathrm{pH}$, Nutrient Availability, and Liming............................. $4-3$

Nitrogen........................................... 4.6

Phosphorus. ....................................... 4-8

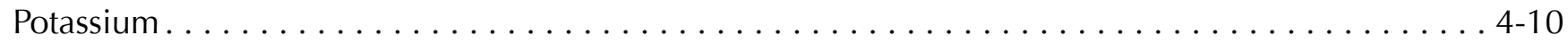

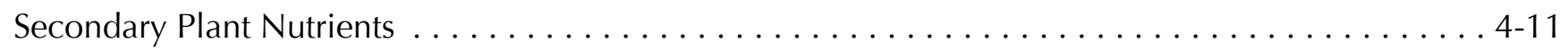

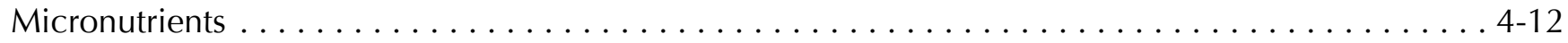

Acknowledgement ......................................... 4-14 


\section{Chapter 5. Soil Sampling and Nutrient Testing}

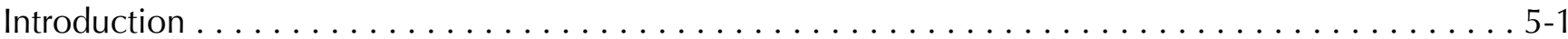

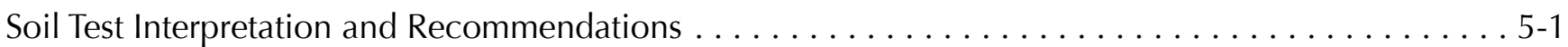

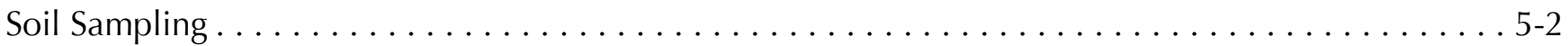

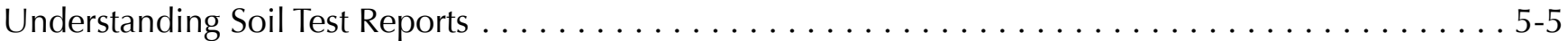

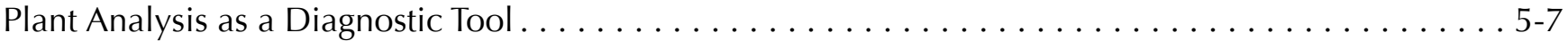

Nutrient Monitoring $\ldots \ldots \ldots \ldots \ldots \ldots \ldots \ldots \ldots \ldots \ldots \ldots \ldots \ldots \ldots \ldots \ldots \ldots \ldots \ldots \ldots \ldots \ldots$

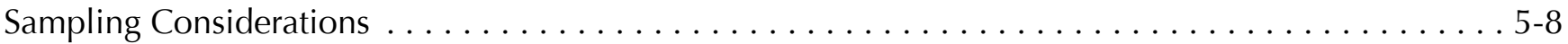

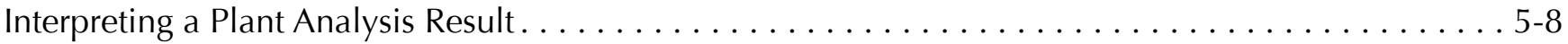

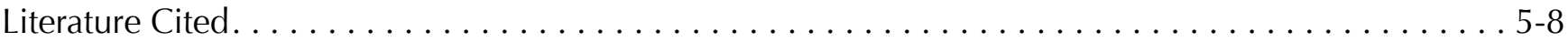

\section{Chapter 6. Mid-Atlantic Turfgrasses and Their Management}

Introduction . . . . . . . . .

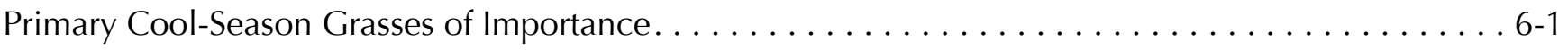

Primary Warm-Season Grasses of Importance. . . . . . . . . . . . . . . . . . . . . 6-4

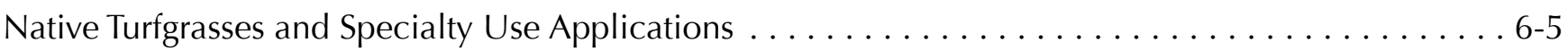

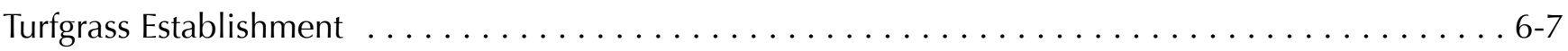

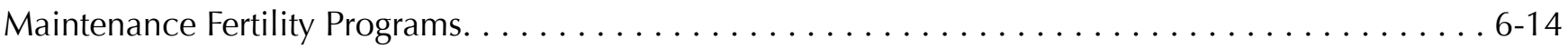

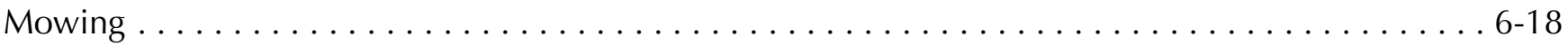

Literature Cited . . . . . . . . . . . . . . . . . . . . . . . . . . . . . . . . . . . 6-19

\section{Chapter 7. The Ornamental Landscape}

Introduction . . . . . . . . .

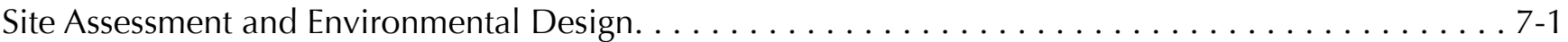

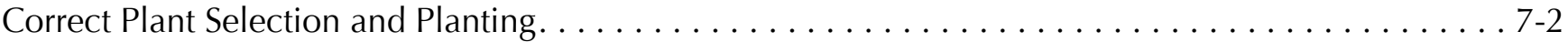

Determining the Need to Fertilize . . . . . . . . . . .

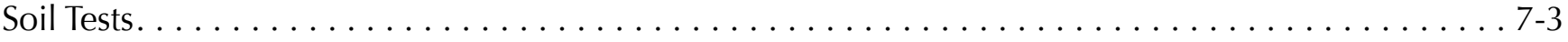

Factors Affecting Nutrient Uptake $\ldots \ldots \ldots \ldots \ldots \ldots \ldots \ldots \ldots \ldots \ldots \ldots \ldots \ldots \ldots \ldots \ldots \ldots \ldots$

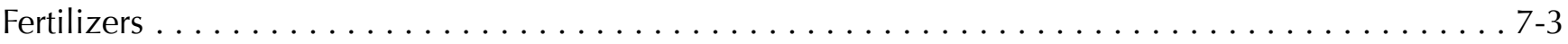

Specific Fertility Needs $\ldots \ldots \ldots \ldots \ldots \ldots \ldots \ldots \ldots \ldots \ldots \ldots \ldots \ldots \ldots \ldots \ldots \ldots$

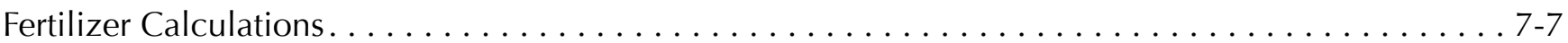

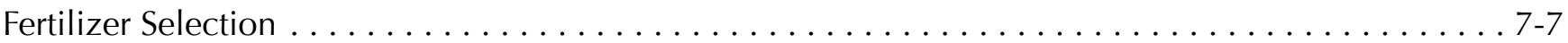

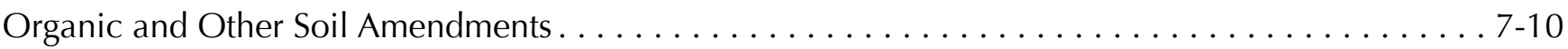

Nutrient Deficiencies . . . . . . . . . . . . . . . . . . . . . . . . . . . . . . 7-10

Literature Cited. . . . . . . . . . . . . . . . . . . . . . . . . . . . . . . . . 7-11

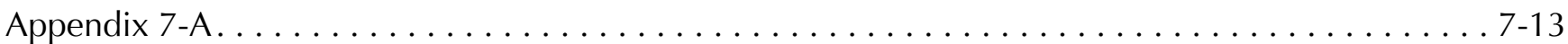

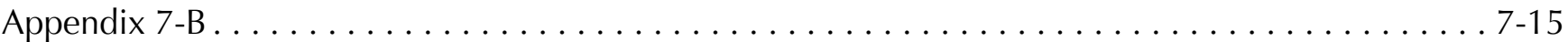




\section{Chapter 8. Fertilizer and Lime Sources for Turf and Landscapes}

Introduction

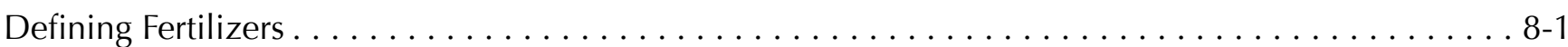

Nitrogen Sources . . . . . . . . . . . . . . . . . . . . . . . . . . . . . . . . . . 8-2

Phosphorus Fertilizer Sources and Fertility Guidelines $\ldots \ldots \ldots \ldots \ldots \ldots \ldots \ldots \ldots$. . . . . . .

Potassium Fertilizer Sources and Fertility Guidelines $\ldots \ldots \ldots \ldots \ldots \ldots \ldots \ldots \ldots$

Calcium, Magnesium, and Sulfur Fertilizer Sources and Fertility Guidelines . . . . . . . . . . . . . 8-9

Micronutrient Fertility Sources and Fertility Guidelines . . . . . . . . . . . . . . . . . . . 8-10

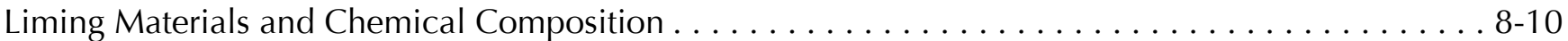

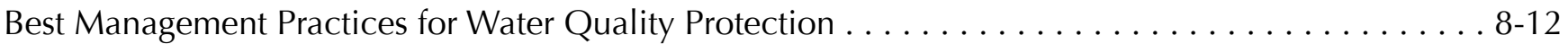

Literature Cited. . . . . . . . . . . . . . . . . . . . . . . . . . . . . . . . . . . . . . . . . . . . . . 8-13

\section{Chapter 9. Organic and Inorganic Soil Amendments}

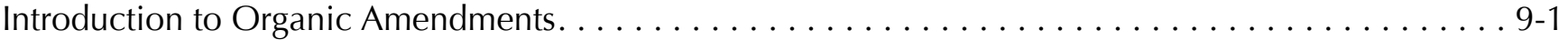

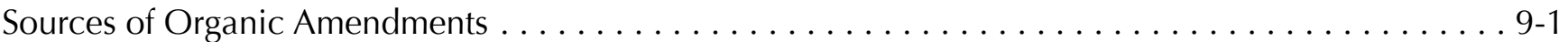

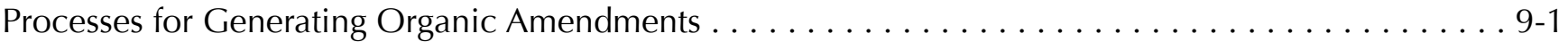

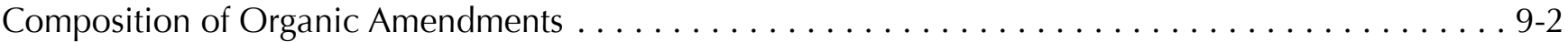

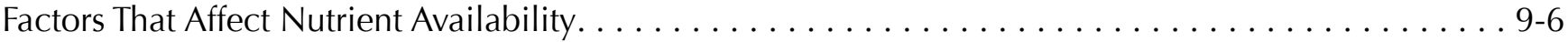

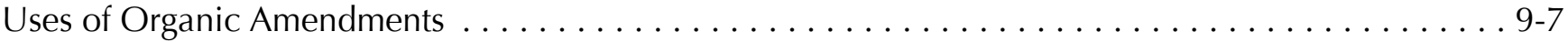

Organic Byproduct Summary With Regard to Water Quality . . . . . . . . . . . . . . . . . 9-13

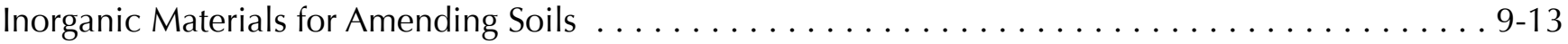

Inorganic Amendment Use Strategies . . . . . . . . . . . . . . . . . . . . . . . . . . 9-14

Topdressing With Inorganic Amendments . . . . . . . . . . . . . . . . . . . . . . . . 9-15

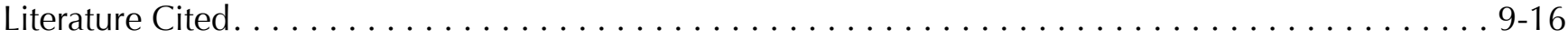

\section{Chapter 10. Equipment Calibration and Fertilizer Application Methods}

Introduction . . . . . . . . . . . . . . . . . . . . . . . . . . . . . . . . . . . . . 10-1

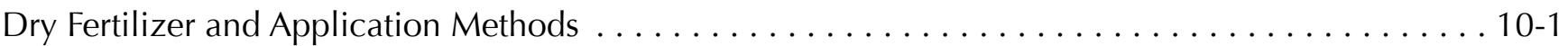

Broadcast (Rotary) Spreader Calibration . . . . . . . . . . . . . . . . . . . . . . . . . . . . 10-4

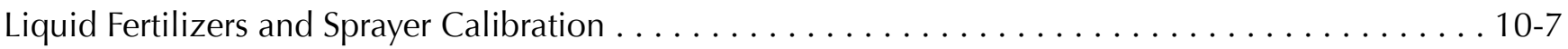

Literature Cited. . . . . . . . . . . . . . . . . . . . . . . . . . . . . . . . . . . . . 10-10

\section{Chapter 11. Soil-Water Budgets and Irrigation Sources and Timing}

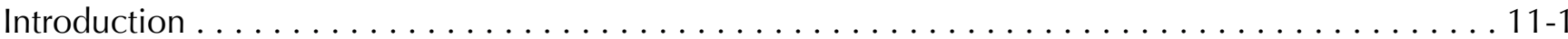

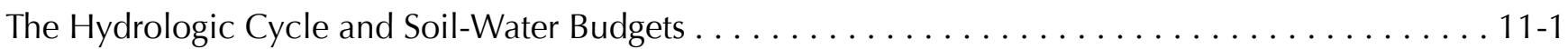

Watering Basics for Turf and Landscape Plantings . . . . . . . . . . . . . . . . . . . . . . 11-3

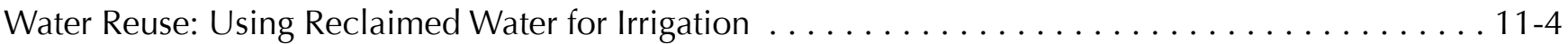

Literature Cited. . . . . . . . . . . . . . . . . . . . . . . . . . . . . . . . . . . . . . . . . . . . . . . 11-7 


\section{Chapter 12. Principles of Stormwater Management for Reducing Nutrients From Urban Landscaped Areas}

Introduction

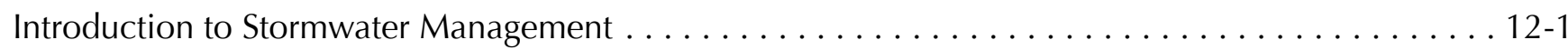

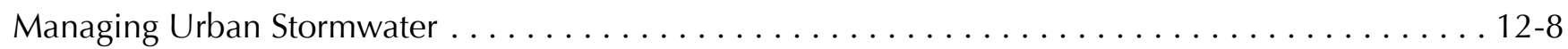

Managing Stormwater on a Residential Lot . . . . . . . . . . . . . . . . . 12-9

Acknowledgements . . . . . . . . . . . . . . . . 12-13

Literature Cited. . . . . . . . . . . . . . . . . . . . . . . . . . . . . . 12-13

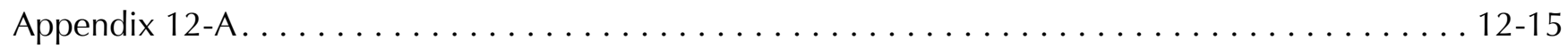

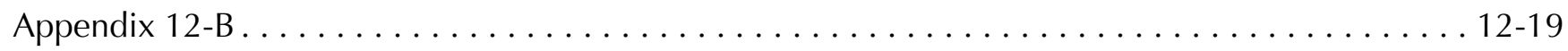

\section{Chapter 13. Turf and Landscape Nutrient Management Planning}

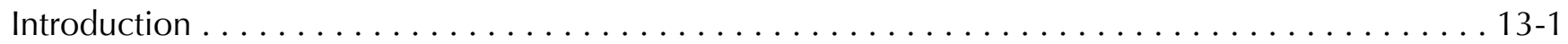

Assessment of Planned Areas . . . . . . . . . . . . . . . . . . . . . . . . . 13-1

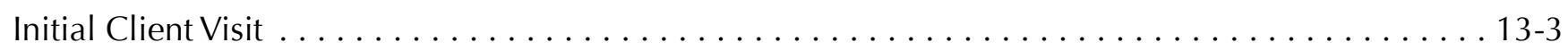

Components of a Nutrient Management Plan . . . . . . . . . . . . . . . . . . 13-5

Sample Nutrient Management Plan . . . . . . . . . . . . . . . . . . . . . . . . 13-9

Plan Implementation . . . . . . . . . . . . . . . . . . . . . . . . . . . . 13-24

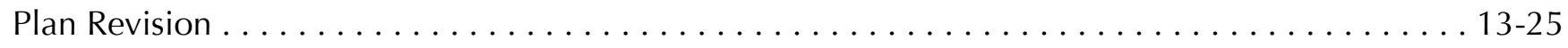

Summary . . . . . . . . . . . . . . . . . . . . . . . . . . . . . . 13-25

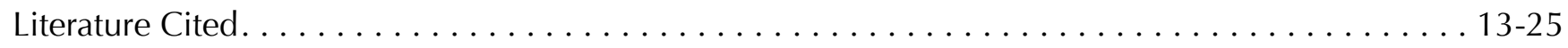




\title{
Chapter 1. The Objectives of Turf and Landscape Nutrient Management
}

\author{
Steven Hodges, Professor, Crop and Soil Environmental Sciences, Virginia Tech \\ Michael Goatley Jr., Professor and Extension Specialist, Crop and Soil Environmental Sciences, Virginia Tech \\ Rory Maguire, Associate Professor, Crop and Soil Environmental Sciences, Virginia Tech
}

\section{Introduction}

The locations of many towns and cities in the mid-Atlantic region are closely linked to a clean, readily available, and abundant water resource. The water source must be sufficient in size and quality to meet the daily life needs of the general population at home (e.g., drinking, cooking, cleaning, leisure, etc.) and its industrial base (e.g., transportation/shipping, cooling/heating, manufacturing applications as a solvent/diluent, etc.).

By nature, urban areas are frequently undergoing either expansion and/or renovation in both commercial and/ or residential development. Expansive development in rolling topography requires significant soil disturbance. Soils that took millions of years to form are quickly altered and/or removed during construction, eliminating sod cover and forested areas that are naturally occurring water filtration and soil stabilization systems. Expansions in roof area and paved surfaces increase the need for comprehensive stormwater management planning. By law, soil disturbance, therefore, must be accompanied by appropriate stormwater management strategies (e.g., silt fences, compost berms, natural and synthetic erosion-control mats, etc.) that are designed to protect water quality and minimize soil erosion and sediment loss.

In the final stages of both commercial and residential development, an urban ecosystem intermingles grasses, groundcovers, shrubs, ornamental plants, and trees with the structural and hardscape (e.g., sidewalks, parking lots, driveways, streets, etc.) components. This myriad of urban landscape components results in many recommendations regarding appropriate plant material selection and management protocol. Due to the complexity of plant materials, the abundance of hardscapes, and the proximity of water sources, urban ecosystems have great potential to negatively impact water quality if managed inappropriately. All plant materials have nutrient requirements, but the levels and timing of applications of nutrients are highly variable and plant-specific. The following factors are a few of the most important to consider in the development and implementation of a nutrient management program (NMP):
1. The overall climate (rainfall patterns) of a particular location and the variability in topography, such as aspect, slope, elevation, etc.

2. An understanding of the plant material's periods of active growth and its inherent growth rate.

3. The physical and chemical characteristics of the soil as determined by soil testing (an absolute requirement for an NMP) and/or review of soil maps (where appropriate).

4. The intended use of the plant material.

5. The selection and application of the nutrient source.

6. Consideration of the surrounding environment and how it can either impact or be impacted by fertilization.

An NMP considers each of these factors and presents a recommendation for the selection and timing of nutrient applications that meets the needs of the plant and minimizes the loss of nutrients to the environment.

\section{What Is Nutrient Management?}

Nutrient management plans serve two primary purposes: (1) ensuring that plants have optimum soil nutrient availability for good productivity and quality, and (2) ensuring minimum movement of nitrogen and phosphorus from the specified area of application to surface and groundwaters where they can potentially have a detrimental effect on water quality. Although NMPs cover more than nitrogen and phosphorus, only these two nutrients are considered a risk for impairing water quality. Other nutrients are essential for plant growth but do not cause water quality problems in the midAtlantic region.

Most soils in the mid-Atlantic are highly weathered and low in plant-available nutrients, particularly nitrogen, phosphorus, and potassium. Some form of fertilization is required for even the lowest quality turfgrass, if only to maintain a functioning turfgrass population that will protect the soil from erosion. Turf stands subjected to high traffic and intensive use require regular 
fertilization to maintain functionally adequate levels of leaf density, vigor, recuperative potential, stress tolerance, and color. Similarly, ornamental landscape plants require appropriate fertilization and cultural management strategies in order to optimize their aesthetic and functional uses. The challenge of nutrient management is to consider the characteristics of the turfgrass and landscape plants being grown on each specific site and then make appropriate decisions regarding the timing, material, and application method of required nutrients.

Nutrient management plans also have economic considerations, because there are both savings and costs involved in the process. One cost may be hiring a certified nutrient management planner to write a plan. Some lawn care companies and other consultants may offer free nutrient management planning as part of their service. Making extra trips to apply nitrogen, purchasing different fertilizer materials to meet specific recommendations, setting aside buffer areas along water bodies, etc., could all potentially increase a client's budget. By implementing an NMP, savings accrue from avoiding the purchase and application of unnecessary fertilizer and lime. There may also be savings from greater plant survival because nutrient deficiency will be avoided. Nutrient management planning is also expected to have a societal economic benefit by maintaining highquality water for drinking, ecological, and recreational purposes.

A brief overview of the basic components of nutrient management planning and implementation follows.

\section{Selection of Nutrient Sources}

There are substantial differences in nutrient requirements between plants and also in the time nutrients are required. For example, legumes can produce their own nitrogen and therefore do not require nitrogen fertilization, making them a popular component of highway rights-of-way vegetation where there is no desire to supply additional nitrogen after establishment. However, cool- and warm-season grasses (discussed in chapter 6) require nitrogen, but their periods of maximum growth differ, resulting in different timing of optimal nitrogen applications.

The age of plants is also important because mature plants with well-developed root systems require fewer nutrients than young plants. This is often realized for phosphorus recommendations when they are typically greater for plant establishment than they are for maintenance.
Knowledge of the physical and chemical characteristics of nutrient sources can prove invaluable in calculating application rates, reducing fertilizer costs, and managing applications to minimize potential for losses through volatilization, runoff, and leaching. Most soil test reports will provide specific recommendations regarding appropriate fertilizer and/or liming materials to address soil limitations. However, a greater understanding of fertilizer sources, their characteristics, and their appropriate use (information presented in chapters 8 and 9) is invaluable in optimizing nutrient management strategies. For instance, knowing that prilled urea can volatilize under existing conditions may lead you to choose another nitrogen source, a different application method, or a best management practice (e.g., irrigating immediately after application) to reduce volatile nitrogen losses. In other situations, a slow-release nitrogen source might be most appropriate because of an anticipated rainy season or the inability to deliver suitable levels of readily available nitrogen sources on a frequent basis.

There is a great deal of interest in expanding the use of organic compounds (both fertilizers and soil amendments), and information in this handbook will detail how to properly utilize these materials in responsible plant management programs. Organic sources are perceived by most to be "environmentally friendly," and generally speaking, this is true. Organic fertilizers and amendments are often an effective way of recycling waste products and they also can improve the physical, chemical, and biological aspects of soils. However, consider that organic sources almost always contain phosphorus, and if a soil test shows that no phosphorus is needed, then an organic fertilizer does not fit the requirements of an NMP. Instead, an inorganic fertilizer containing no phosphorus would be a better fertilizer selection. Knowledge of nutrient sources will greatly improve your management options and capabilities.

\section{Nutrient Application Rates}

Nutrient needs for turfgrasses and landscape materials are based on Virginia Cooperative Extension and landgrant university research. Nutrient application rates for plan development are determined differently for nitrogen compared to phosphorus and potash. Nitrogen rates are determined on an annual basis and are specific to the plant species, the use of the plant material, and the management area. For turf, nitrogen rates are often specific to the plant species; for instance, whether it is a 
heavy or light nitrogen feeder. In cool-season grasses, Kentucky bluegrass has a higher seasonal nitrogen requirement than does fine-leaf fescue. In warm-season grasses, bermudagrass responds to aggressive nitrogen programs whereas zoysiagrass requires much smaller amounts annually. The use of the turf is also an important factor in seasonal application rates, with lawns often utilizing a simple nitrogen program involving relatively low annual nitrogen rates and a limited number of applications per growing season.

On the other hand, athletic fields and golf courses will have higher annual nitrogen application rates with more frequent applications. Higher rates are often required due to the foot and vehicular traffic associated with areas of concentrated play at these facilities. Intensive management of these areas enables the turf to recover from constant, and, in some cases, damaging use and often includes the practice of "spoon feeding" (very low, but frequent applications) nitrogen over the course of the growing season as a key component in maintaining acceptable turf. Experienced turf professionals are constantly evaluating their nitrogen programs as the turf they manage reacts and responds to daily use and seasonal changes. The relationship between nutrient application and overall turf and landscape plant quality (and often density for grasses) is used to make the appropriate adjustments in their fertility programs.

Is it possible for turf to negatively impact the environment if it is inadequately fertilized? Certainly. Inadequately fertilized turfgrass can be too weak to recover from environmental stress or pest attack. Turf that is thin, weak, and spindly due to lack of adequate nitrogen levels is considered to be "hungry" and can experience soil loss due to inadequate soil cover. Experienced turf managers identify a "hungry turf" not just by its color, but also by its growth rate and its ability to recover from pest or environmental stress.

However, the part of turfgrass management that gets the most attention when it comes to environmental impact is excessive fertilization. Excessive nitrogen applications increase plant succulence, making the turf more susceptible to environmental stress (e.g., heat, cold, and moisture extremes) and pest attack, and overall, less wear-tolerant. Overfertilization of nitrogen leads to excessive shoot and stem growth at the expense of root growth. And of course, excessive applications of nitrogen increase the potential that it enters a water source and becomes a pollution hazard.
Sound fertility programs are obviously not based on nitrogen alone, because any excess or deficiency of other nutrients can negatively affect plant health and survival. The annual requirements of most other macronutrients (those required in large quantities) such as phosphorus, potassium, calcium $(\mathrm{Ca})$, and magnesium $(\mathrm{Mg})$ are applied based on current soil test results. In conjunction with an appropriate $\mathrm{pH}$, soil levels of these nutrients are maintained within a range that assures an adequate supply of these nutrients to provide good turf growth and quality. Similar to nitrogen, excessive applications can be damaging to the plant, resulting in nutrient imbalances and, particularly for phosphorus, the potential to negatively impact water quality.

\section{Nutrient Application Timing}

Ideally, nutrient applications should be timed to maximize use efficiency by the targeted plants (VDCR 2005). To minimize losses, it is important to closely match growth cycles and nutrient demands. Proper timing is especially important to prevent losses on soils with high leaching or runoff potential. From the viewpoint of the plant, appropriate timing of the first and last applications in the growing season is crucial to plant health, survivability, disease, stress tolerance, and so forth.

\section{Nutrient Placement and Application Methods}

For turfgrass, a variety of application methods may be used, depending on the situation. For turf establishment, broadcast application followed by incorporation is commonly used for lime and fertilizer amendments. Surface applications of granular fertilizers on new plantings and established turf may be made using truckmounted, push-type rotary, or drop spreaders, depending on the size of the area to be covered. In addition, liquid fertilizers and foliar nutrients may be sprayed. New equipment can even vary the rate of application in conjunction with global positioning systems (GPS) and preprogrammed application maps. Each method has advantages, such as increased labor efficiency, improved application precision, and reduced potential for nutrient losses.

A nutrient management plan should also include the detailing of site characteristics that require changes in management from place to place. Considerations should include environmentally sensitive areas such as buffers and water bodies and significant differences in soils, vegetative cover, management intensity, and potential 
nutrient loss pathways. Finally, best management practices to prevent or reduce losses of soil, nutrients, and plant protection chemicals should be identified for each of these areas and the site as a whole.

\section{Improving Water Quality Through Turf and Landscape Nutrient Management}

A primary goal of turf and landscape nutrient management is water quality protection. Appropriate product selection, delivery rate and timing, and method of application are by far the most important variables in water quality protection in urban landscape management. The development and implementation of a nutrient management plan also provides potentially significant economic savings as applications are made based on soil test recommendations. Similarly, since soil test data are used in developing the plan, plant health and performance will also be enhanced on the basis of scientific data. Nutrient management plans allow for informed decisions to be made regarding fertilization such that plant health and function are optimized in an environmentally responsible manner.
This handbook provides a series of chapters devoted to the challenges associated with water quality protection in an urban environment. It presents extensive information on the basic principles in soil and plant sciences, fertility and fertilizers, plant management, soil amendments, equipment calibration for fertilizer delivery, irrigation sources and quality, and stormwater management. A standard NMP format is provided in the chapter 13. A certified nutrient management planner will combine the information from a soil test with extensive agronomic knowledge of plants, soils, fertilizers, nutrition, and the climate in developing the NMP. Incorporating this information into the design, installation, and management of urban soils and plant materials will greatly improve water quality.

\section{Literature Cited}

Virginia Department of Conservation and Recreation (VDCR), Division of Soil and Water Conservation. 2005. Virginia Nutrient Management Standards and Criteria, 96-107. 


\title{
Chapter 2. General Soil Science Principles
}

\author{
Kathryn C. Haering, Research Associate, Crop and Soil Environmental Sciences, Virginia Tech
}

\section{Soil Formation and Soil Horizons}

\section{Introduction and Soil Composition}

Soil covers the vast majority of the exposed portion of the earth in a thin layer. It supplies air, water, nutrients, and mechanical support for the roots of growing plants. The productivity of a given soil is largely dependent on its ability to supply a balance of these factors to the plant community.

A desirable surface soil in good condition for plant growth contains approximately 50 percent solid material and 50 percent pore space (figure 2.1). The solid material is composed of mineral material and organic matter. Mineral material comprises 45 to 48 percent of the total volume of a typical mid-Atlantic soil. About 2 to 5 percent of the volume is made up of organic matter, which may contain both plant and animal residues in varying stages of decay or decomposition. Under ideal moisture conditions for growing plants, the remaining 50 percent soil pore space would contain approximately equal amounts of air (25 percent) and water ( 25 percent) on a volume basis.

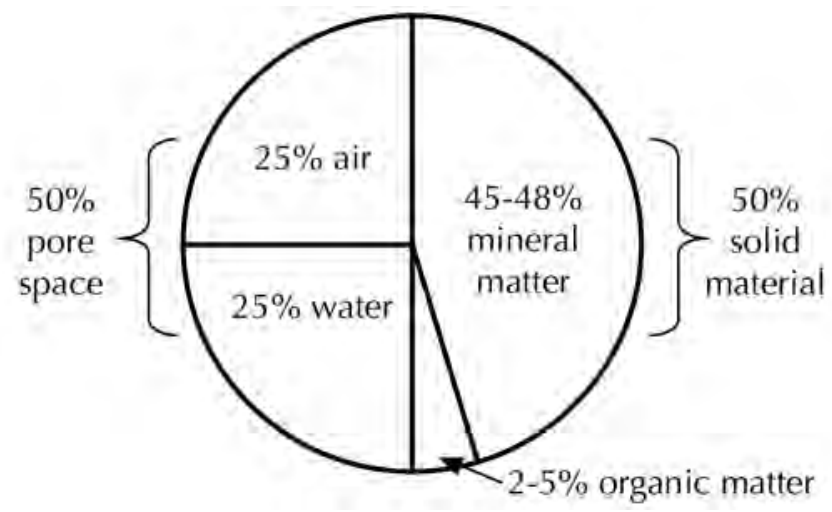

Figure 2.1. Volume composition of a desirable surface soil.

\section{Soil Formation}

The mineral material of a soil is the product of the weathering of underlying rock in place or the weathering of transported sediments or rock fragments. The material from which a soil has formed is called its "parent material." The weathering of residual parent materials to form soils is a slow process that has been occurring for millions of years in most of the mid-Atlantic region. However, certain soil features (such as "A horizons," discussed below) can form in several months to years. More detail on parent material and soil relationships in our area can be found at www.mawaterquality.org/publications/pubs/manhcomplete.pdf.

The rate and extent of parent material and soil weathering depends on:

1. The chemical composition of the minerals that make up the rock or sediment.

2. The type, strength, and durability of the material that holds the mineral grains together.

3. The extent of rock flaws or fractures.

4. The rate of leaching through the material.

5. The extent and type of vegetation at the surface.

Physical weathering is a mechanical process that occurs during the early stages of soil formation as freeze-thaw processes and differential heating and cooling break up rock parent material. After rocks or coarse gravels and sediments are reduced to a size that can retain adequate water and support plant life, the rate of soil formation increases rapidly. As organic materials decompose in the surface soil, the evolved carbon dioxide dissolves in water to form carbonic acid - a weak acid solution that constantly bathes weatherable minerals below. The carbonic acid reacts with and alters many of the primary minerals in the soil matrix to chemically alter and etch the sand and silt fractions and to produce secondary clay minerals. The decomposing organic matter also releases other organic acids (e.g., oxalic, citric, and tartaric) that further accelerate weathering (Brady and Weil 2008).

As soil-forming processes continue, some of the fine clay soil particles (smaller than $0.002 \mathrm{~mm}$ ) are carried, or leached, by percolating water from the upper portions of the soil (topsoil) down into the lower or subsoil layers. As a result of this leaching action, the surface soil texture becomes coarser and the subsoil texture becomes finer as the soil weathers.

\section{Soil Horizons}

Soils are layered because of the combined effects of organic matter additions to the surface soil and longterm leaching. These layers are called "horizons." The 
vertical sequence of soil horizons found at a given location is collectively called the "soil profile" (figure 2.2).

The principal master soil horizons found in managed soil systems are:

- A horizon or mineral surface soil. (If the soil has been plowed, this is called the "Ap horizon.")

- B horizon or subsoil.

- C horizon or partially weathered parent material, which is also part of the subsoil.

- Rock (R layer) or unconsolidated parent materials similar to that from which the soil developed.

Unmanaged and relatively undisturbed forest soils also commonly contain an organic $\mathrm{O}$ horizon (litter layer) on the surface and a light-colored, acid-leached zone (E horizon) just below the A horizon.

In addition to the master soil horizons that are noted by capital letters (e.g., A and B), soil scientists also assign lowercase letters called "subscripts" (e.g., Ap) to describe the nature of the master horizon (U.S. Department of Agriculture (USDA) 1993). There are several dozen commonly used subscripts, but the most common ones in urbanized areas of the mid-Atlantic are Ap (plowed topsoil), "Bt" (clayey subsoil), and "Cd" (very dense, compacted subsoil). Another important combination to recognize is "Btg," which indicates a clayey subsoil with color features (gleying or gray coloration) indicative of poor internal drainage, as discussed later in this chapter.The surface soil horizon(s) or "topsoil" (the Ap or A plus E horizons) is often coarser than the subsoil layer and contains more organic matter than the other soil layers. The organic matter imparts a tan, dark-brownish, or black color to the topsoil. Soils that are high in organic matter (more than 3 percent) usually have very dark surface colors. The A or Ap horizon tends to be more fertile and have a greater concentration of plant roots than any other soil horizon. In unplowed soils, the "eluviated" (E) horizon below the A horizon is often light-colored or gray, coarser-textured, and more acidic than either the A horizon or the horizons below it because of acid leaching over time.

The subsoil (B horizon) is typically finer in texture, denser, and firmer than the surface soil. Organic matter content of the subsoil tends to be much lower than that of the surface layer, and subsoil colors are often stronger and brighter, with shades of red, brown, and yellow predominating due to the accumulation of ironcoated clays. Subsoil layers with high clay accumulation relative to their overlying A horizon are described as Bt horizons. If the B is still observed based on color or structural development but not enriched in clay, it is labeled "Bw" by default.

The $\mathrm{C}$ horizon is partially decomposed and weathered parent material that retains some characteristics of the parent material. It is more like the parent material from which it has weathered than the subsoil above it. By definition, C horizons are "diggable" with a spade or soil auger, while R layers cannot be excavated with hand tools. Images with horizon designations for soils typical of our region (Ultisols), along with distribution maps and information links can be found at $h t t p: / / s o i l s$. cals.uidaho.edu/soilorders/ultisols.htm.

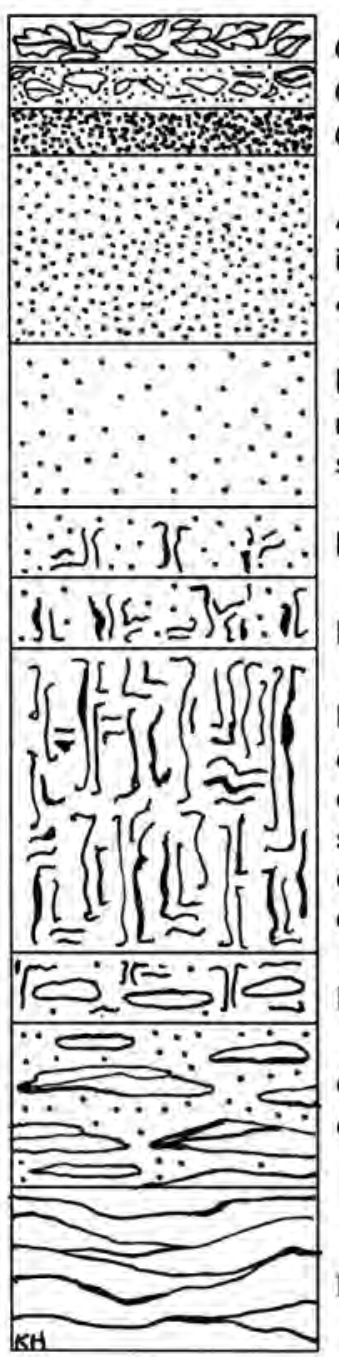

Figure 2.2. Soil profile horizons. Ap
Oi Loose, easily recognizable, organic debris

Oe Partially decomposed organic materials

Oa fully decomposed organic materials

A Surface mineral horizon: darker and higher in organic matter. If plowed, will be designated

E Eluviated horizon; light colored zone of maximum leaching of clay, iron, aluminum, and soluble organic matter. Often mixed into Ap

EB Transition from $E$ to $B$; more like $E$ than $B$

BE Transition from $E$ to $B$ : more like $B$ than $E$ B Subsurface zone of maximum accumulation of clay, iron, etc. Common features include development of blocky and/or prismatic structure, clay coatings on larger particles, red and yellow colors from accumulation of iron oxides

BC Transition from B to C; more like B than C

C Weathered parent material such as saprolite, oxidized sediments, unconsolidated bedrock, etc.

R Hard bedrock; not always seen

Graphic by Kathryn Haering. 
As discussed in greater detail in chapter 3, soils in the urban landscape are frequently highly disturbed and often contain distinct layering due to cut/fill and grading practices that are quite dissimilar from the natural soil horizons discussed above. It is also quite common for the native topsoil (A horizon) layers to be absent and for deeper subsoil materials (Bt) to appear at the surface. Graded and layered urban soils also commonly contain highly compacted subsoil layers $(\mathrm{Cd}$ horizons).

\section{Soil Physical Properties}

The physical properties of a soil are the result of soil parent materials being acted on by climatic factors (such as rainfall and temperature), and being affected by relief (slope and direction or aspect) and by vegetation over time. A change in any one of these soil-forming factors usually results in a difference in the physical properties of the resulting soil. The important physical properties of a soil are texture, aggregation/structure, porosity, and bulk density.

\section{Texture}

The relative amounts of the different soil-sized particles (smaller than $2 \mathrm{~mm}$ ), or the fineness or coarseness of the mineral particles in the soil, is referred to as soil "texture." Mineral grains that are larger than $2 \mathrm{~mm}$ in diameter are called rock fragments and are measured separately. Soil texture is determined by the relative amounts of sand, silt, and clay in the fineearth fraction (smaller than $2 \mathrm{~mm}$ ).

Sand particles vary in size from very fine $(0.05 \mathrm{~mm})$ to very coarse $(2.0 \mathrm{~mm})$ in average diameter. Most sand particles can be seen without a magnifying glass. Sands feel coarse and gritty when rubbed between the thumb and fingers, except for mica flakes, which tend to smear when rubbed.
Silt particles range in size from $0.05 \mathrm{~mm}$ to $0.002 \mathrm{~mm}$. When moistened, silt feels smooth but is not slick or sticky. When dry, it is smooth and floury and if pressed between the thumb and finger, it will retain the imprint. Silt particles are so fine they cannot usually be seen by the unaided eye and are best seen with the aid of a strong hand lens or microscope.

Clay is the finest soil particle size class. Individual particles are finer than $0.002 \mathrm{~mm}$. Clay particles can be seen only with the aid of an electron microscope. They feel extremely smooth or powdery when dry and become plastic and sticky when wet. Clay will hold the form into which it is molded when moist and will form a long ribbon when extruded between the fingers.

There are 12 primary classes of soil texture defined by the USDA (1993). The textural classes are defined by their relative proportions of sand, silt, and clay as shown in the USDA's "textural triangle" (figure 2.3). Each textural class name indicates the size of the mineral particles that are dominant in the soil. Regardless of textural class, all soils in the mid-Atlantic region contain sand-, silt-, and clay-sized particles, although the amount of a particular particle size may be small.

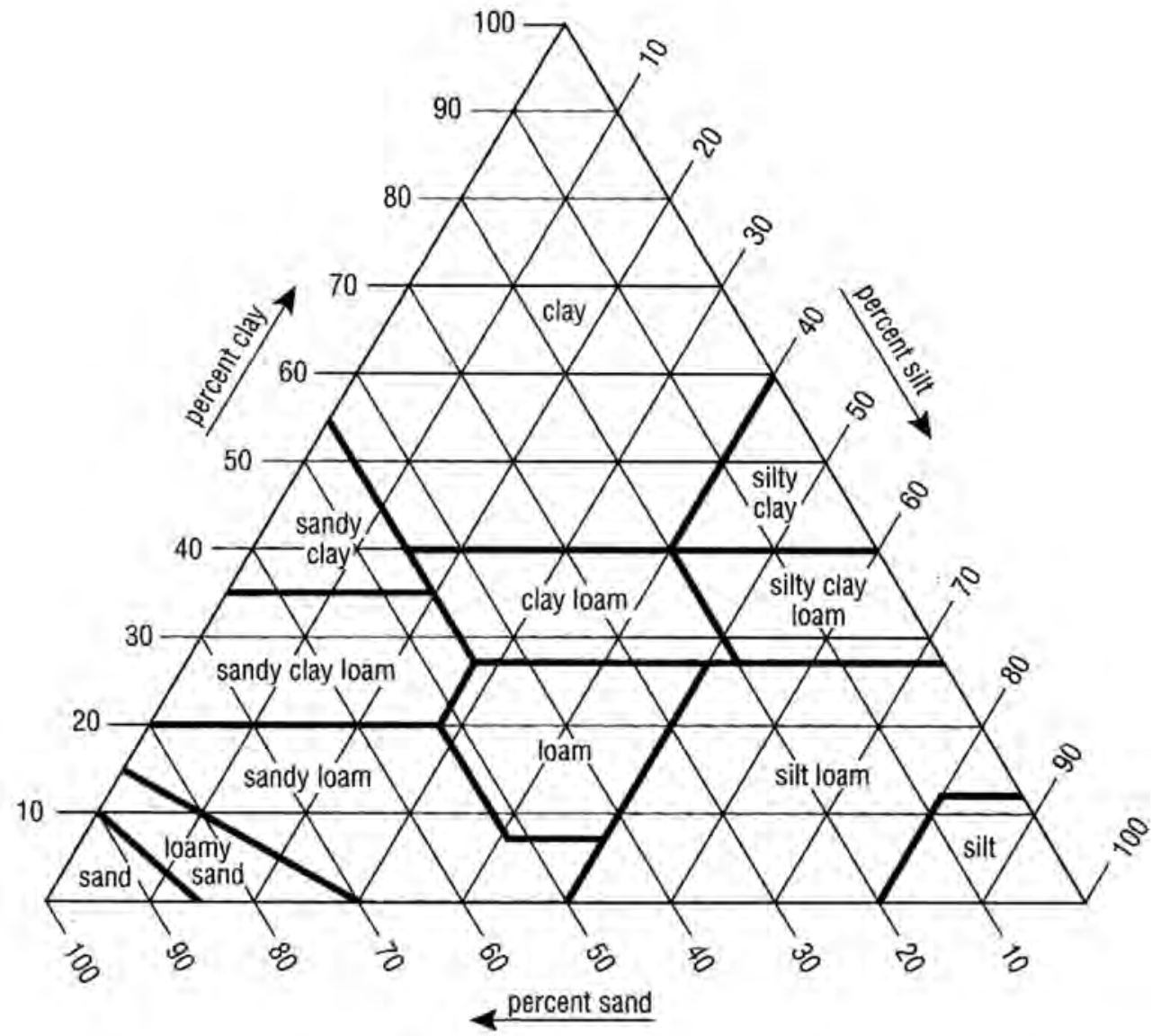

Figure 2.3. The USDA textural triangle (USDA 1993). 
Texture can be estimated in the field after a moderate amount of training by manipulating and feeling the soil between the thumb and fingers. However, for precise measurement and/or prescriptive use, texture should be quantified by laboratory particle-size analysis.

To use the textural triangle:

1. First, you will need to know the percentages of sand, silt, and clay in your soil, as determined by laboratory particle-size analysis.

2. Locate the percentage of clay on the left side of the triangle and move inward horizontally, parallel to the base of the triangle.

3. Follow the same procedure for sand, moving along the base of the triangle to locate your percentage of sand.

4. Then, move up and to the left until you intersect the line corresponding to your clay percentage value.

5. At this point, read the "textural class" written within the bold boundary on the triangle. For example, a soil with 40 percent sand, 30 percent silt, and 30 percent clay will be a clay loam. With a moderate amount of practice, soil textural class can also be reliably determined in the field.

When soil textures fall very close to the boundary between two adjacent classes, it is appropriate to name both (e.g., sandy clay loam to sandy clay). Also, within a given textural class, soils with high clay contents are often referred to as "heavy" versus those low in clay content that are called "light." Thus, a "heavy clay loam" indicates a soil texture in the upper portion of that textural class, close to being clay. This latter convention is not defined or formally accepted by the USDA but is commonly used by field practitioners.

If a soil contains 15 percent or more rock fragments (larger than $2 \mathrm{~mm}$ ), a rock fragment content modifier is added to the soil's texture class. For example, the texture class designated as "gravelly silt loam" would contain 15 to 35 percent gravels within a silt loam (smaller than $2 \mathrm{~mm}$ ), fine-soil matrix. A sample with more than 35 percent gravel would be described as "very gravelly silt loam," etc. More detailed information on USDA particle-size classes and other basic soil morphological descriptors can be found at http://soils.usda.gov/technical/handbook/download.html or in the USDA Soil Survey Manual (USDA 1993).

\section{Effects of Texture on Soil Properties}

The clay fraction in soils is charged and relatively minor amounts (10 to 15 percent) of clay can significantly increase net charge that directly influences both waterholding and nutrient retention in soils. Water infiltrates more quickly and moves more freely in coarse-textured or sandy soils, which increases the potential for leaching of mobile nutrients. Sandy soils also hold less total water and fewer nutrients for plants than finer-textured soils like clays or clay loams. In addition, the relatively low water-holding capacity and the larger amount of air present in sandy soils allow them to warm faster than fine-textured soils. Sandy and loamy soils are also more easily tilled than clayey soils, which tend to be denser.

In general, fine-textured soils hold more water and plant nutrients and therefore require less frequent applications of water, lime, and fertilizer. Soils with high clay content (more than 40 percent clay), however, actually hold less plant-available water than loamy soils. Finetextured soils have a narrower range of moisture conditions under which they can be worked satisfactorily than sandy soils. Soils high in silt and clay may puddle or form surface crusts after rains, impeding seedling emergence. High-clay soils often break up into large clods when worked while either too dry or too wet.

\section{Aggregation and Soil Structure}

Soil "aggregation" is the cementing of several soil particles into a secondary unit or aggregate. Soil particles are arranged or grouped together during the aggregation process to form structural units (known to soil scientists as "peds"). These units vary in size, shape, and distinctness (also known as strength or grade). In topsoils, soil organic matter is the primary material that cements particles together into water-stable aggregates. In subsoil, aluminum and iron oxides play a major role in cementing aggregates, as do finer clay particles which — due to their charge (discussed later in this chapter) - can also bind and stabilize much larger sand and silt particles together. The types of soil structure found in most mid-Atlantic soils are described in table 2.1 and illustrated in figure 2.4 .

\section{Effects of Soil Structure on Soil Properties}

The structure of the soil affects pore space size and distribution, and therefore, rates of air and water movement and overall root proliferation. Well-developed structure allows favorable movement of air and water, 


\begin{tabular}{ll}
\hline Table 2.1. Types of soil structure. \\
\hline Structure type & Description \\
\hline Granular & Soil particles are arranged in small, \\
& rounded units. Granular structure \\
& is very common in surface soils \\
& (A horizons) and is usually most \\
& distinct in soils with relatively high \\
& organic matter content. \\
\hline Blocky & Soil particles are arranged to form \\
& block-like units, which are about \\
& as wide as they are high or long. \\
& Some blocky peds are rounded \\
& on the edges and corners; others \\
are angular. Blocky structure is \\
commonly found in the subsoil, \\
although some eroded fine-textured \\
soils have blocky structure in the \\
surface horizons.
\end{tabular}

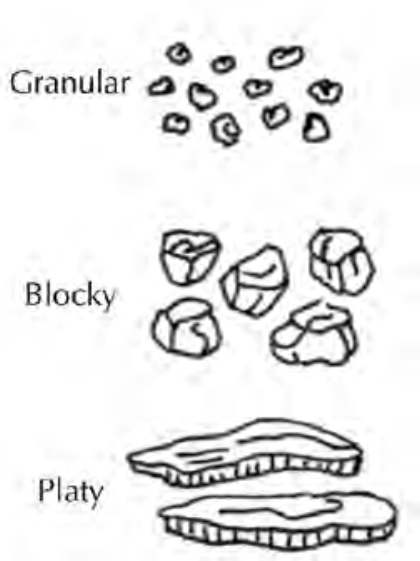

Figure 2.4. Types of soil structures.
Prismatic

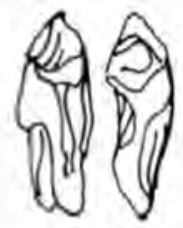

Structureless: massive

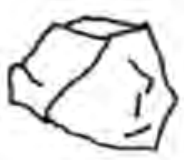

Structureless: single grain

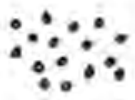

Graphic by Kathryn Haering.

while poor structure retards movement of air and water. Because plant roots move through the same channels in the soil as air and water, well-developed structure also encourages extensive root development. With respect to rooting, the size of the pores and their degree of interconnection are also critically important. In general, the penetration of air, water, and roots through soils is favored by "macropores" (larger than or equal to 0.05 $\mathrm{mm}$, or sand-sized) that are physically interconnected, particularly vertically. In general, soil productivity is favored when water, air, and roots can move readily through the soil. It is also important that soil metabolic gasses (e.g., carbon dioxide) be able to diffuse back into the atmosphere.

Water can enter a surface soil that has well-developed (strong) granular structure (particularly fine-textured soils) more rapidly than one that has relatively weak structure. Surface soil structure is usually granular, but such granules may be indistinct or completely absent if the soil is continuously tilled, the soil is very coarse, or if organic matter content is low.

The size, shape, and strength of subsoil structural peds are particularly important to soil productivity. Sandy soils generally have poorly developed structure relative to finer-textured soils because of their lower clay content. When the subsoil has well-developed blocky structure, there will usually be good air and water movement in the soil. If platy structure has formed in the subsoil, downward water, air movement, and root development in the soil will be slowed. Distinct prismatic structure is often associated with subsoils, but those larger prisms will usually break down into primary blocky peds. Very large and distinct subsoil prisms are also commonly associated with "fragipans" (Bx horizons), which are massive and dense subsoil layers. 


\section{Porosity and Bulk Density}

Soil "porosity," or pore space, is the volume percentage of the total soil that is not occupied by solid particles. Pore space is commonly expressed as a percentage:

$$
\% \text { pore space }=100-\left(\frac{\text { bulk density }}{\text { particle density }}\right) \times 100
$$

"Bulk density" is the dry mass of soil solids per unit volume of soils, and "particle density" is the density of soil solids, which is assumed to be constant at 2.65 grams per cubic centimeter $\left(\mathrm{g} / \mathrm{cm}^{3}\right)$. Bulk densities of mineral soils are usually in the range of 1.1 to $1.7 \mathrm{~g} / \mathrm{cm}^{3}$. A soil with a bulk density of about $1.32 \mathrm{~g} / \mathrm{cm}^{3}$ will generally possess the ideal soil condition of 50 percent solids and 50 percent pore space. Bulk density varies depending on factors such as texture, aggregation, organic matter, compaction/consolidation, soil management practices, and soil horizon. In general, root penetration through soils will be limited in sandy soils when the bulk density approaches $1.75 \mathrm{~g} / \mathrm{cm}^{3}$ and in clayey soils at 1.40 $\mathrm{g} / \mathrm{cm}^{3}$ (Brady and Weil 2008). However, water, air, and roots can penetrate high bulk-density soils that have well-developed structure with interconnected macropores, as discussed above.

Macropores (larger than $0.05 \mathrm{~mm}$ ) allow the ready movement of air, roots, and percolating water. In contrast, micropores (smaller than $0.05 \mathrm{~mm}$ ) in moist soils are typically higher in water content and poorly interconnected, and this does not permit much air movement into or out of the soil. Internal water movement is also very slow in micropores. Thus, the movement of air and water through a coarse-textured sandy soil can be surprisingly rapid despite its low total porosity because of the dominance of macropores.

Under field conditions, the total soil pore space is filled with a variable mix of water and air. If soil particles are packed closely together, as in well-graded surface soils or compact subsoils, total porosity is low and bulk density is high. If soil particles are arranged in porous aggregates, as is often the case in medium-textured soils high in organic matter, the pore space per unit volume will be high and the bulk density will be correspondingly low.

Fine-textured clay soils, especially those without a stable blocky $(\mathrm{Bt})$ or granular (Ap) structure, may have reduced movement of air and water even though they have a large volume of total pore space. In these fine-textured soils, micropores are dominant. Because these small pores often stay full of water, aeration especially in the subsoil - can be inadequate for root development and microbial activity. The loosening and granulation of fine-textured soils promote aeration (gas exchange) by increasing the number of macropores.

\section{Soil Organic Matter}

Soil organic materials consist of plant and animal residues in various stages of decay. Primary sources of organic material inputs are dead roots, root exudates, litter and leaf drop, and the bodies of soil animals such as insects and worms. Earthworms, insects, bacteria, fungi, and other soil organisms use organic materials as their primary energy and nutrient source. Nutrients released from the residues through decomposition are then available for use by growing plants.

Soil "humus" is fully decomposed and stable organic matter that is primarily derived from the bodies of soil microbes and fungi. Humus is the most reactive and important component of soil organic matter and is the form of soil organic material that is typically reported as "organic matter" on soil testing reports. Soil organic matter in Virginia soils typically ranges between 0.5 and 2.5 percent in A horizons and can approach 5 percent in heavily enriched garden soils or soils with poor drainage. Higher levels are typically found only in wetlands. Soil organic matter is so reactive (charged) that when it exceeds 12 to 20 percent by weight, it dominates soil properties and we refer to it as "organic soil material."

\section{Factors That Affect Soil Organic Matter Content}

The organic matter content of a particular soil will depend on:

Type of vegetation: Soils that have been in grass for long periods usually have a relatively higher percentage of organic matter in their surface. Soils that develop under trees usually have a low organic matter percentage in the surface mineral soil but do contain a surface litter layer (O horizon). Organic matter levels are typically higher in a topsoil that supports perennial hay, pasture, or forest than in a topsoil used for cultivated crops.

Tillage: Soils that are tilled frequently are usually lower in organic matter. Plowing and otherwise tilling the soil increases the amount of oxygen in the soil, which increases the rate of organic matter decomposition. This detrimental effect of tillage on organic matter is particularly pronounced in very sandy, well-aerated soils because of the tendency of frequent tillage to promote organic matter oxidation to carbon dioxide. 
Drainage: Soil organic matter is usually higher in poorly drained soils because of limited oxidation, which slows down the overall biological decomposition process.

Soil texture: Soil organic matter is usually higher in fine-textured soils because soil humus forms stable complexes with clay particles and fine-textured soils limit the penetration of atmospheric oxygen in and carbon dioxide out of surface soils.

\section{Effect of Organic Matter on Soil Properties}

Adequate soil organic matter levels benefit soils in several ways. The addition of organic matter improves soil physical conditions, particularly aggregation and macropore space. This improvement leads to increased water infiltration, improved soil tilth, and decreased soil erosion. Organic matter additions also improve soil fertility because plant nutrients are released to plantavailable mineral forms as organic residues are decomposed (or "mineralized"), and soil humus is highly charged and retains nutrients against leaching, as discussed later.

A mixture of organic materials in various states of decomposition helps maintain a good balance of air and water components in the soil. In coarse-textured soils, organic material bridges some of the space between sand grains, which increases water-holding capacity. In fine-textured soil, organic material helps maintain porosity by keeping very fine clay particles from packing too closely to one another, thereby enhancing macroporosity.

\section{Soil-Water Relationships}

\section{Water-Holding Capacity}

Soil water-holding capacity is determined largely by the interaction of soil texture, bulk density/pore space, and aggregation. Sands hold little water because they have little net charge and their large intergranular pore spaces allow water to drain freely from the soils. Clays adsorb a relatively large amount of water, and their small pore spaces retain it against gravitational forces. However, clayey soils hold water much more tightly than sandy soils so that much of the water retained (more than 40 percent) is unavailable to growing plants. As a result, moisture stress can become a problem in fine-textured soils despite their high total water-holding capacity.

\section{Field Capacity and Permanent Wilting Percentage}

The term "field capacity" defines the amount of water remaining in a soil after downward gravitational drainage has stopped. This value represents the maximum amount of water that a soil can hold against gravity following saturation by rain or irrigation. Field capacity is usually expressed as percentage by weight (for example, a soil holding 25 percent water at field capacity contains 25 percent of its dry weight as retained water). On a volumetric basis, values for field capacity range from 8 percent in a sand to 35 percent in a clay (Brady and Weil 2008).

The amount of water a soil contains after plants are wilted beyond recovery is called the "permanent wilting percentage." Considerable water may still be present at this point, particularly in clays, but it is held so tightly that plants are unable to extract it. The amount of water held by the soil between field capacity and the permanent wilting point is the "plant-available water" and is maximized in loamy-textured soils. The volumetric plant-available water for sand is typically less than 5 percent but may approach 25 percent volumetric water for a well-aggregated, loamy soil (see figure 2.1).

\section{Tillage and Moisture Content}

Soils with a high clay content are sticky when wet and form hard clods when dry. Therefore, tilling clayey soils at the proper moisture content is extremely important. Although sandy soils are inherently droughty, they are easier to till at varying moisture contents because they do not form dense clods or other highstrength aggregates. Sandy soils are also far less likely than clays to be compacted if cultivated when moist or wet. However, soils containing high proportions of very fine sand or coarse silts may be compacted by tillage when moist.

\section{Soil Drainage}

The overall hydrologic balance of soils - including infiltration and internal permeability - is discussed in greater detail in chapter 11. However, soil scientists commonly use the term "soil drainage" to describe the rate and extent of vertical or horizontal water movement and internal soil saturation during the growing season. 
Important factors affecting soil drainage class are:

- Slope (or lack of slope).

- Depth to the seasonal water table.

- Texture of surface and subsoil layers and of underlying materials.

- Type and strength of soil structure.

- Problems caused by improper tillage or grading, such as compacted subsoils or lack of surface soil structure.

Another definition of drainage refers to the removal of excess water from the soil to facilitate agriculture, forestry, or other higher land uses. This is usually accomplished through a series of surface ditches or the installation of subsoil drains.

\section{Soil Drainage and Soil Color}

The nature of internal soil drainage in relatively undisturbed soils is usually indicated by soil color patterns and color variations with depth. Clear, bright red, and/or yellow subsoil colors indicate well-drained conditions where iron and other compounds are present in their oxidized forms. A soil is said to be well-drained when the "solum" (A plus E plus B horizons) exhibits strong $\mathrm{red} /$ yellow colors without any gray coloration (mottles or redox depletions). The term "mottle" is used generically to describe any differences in coloration within a given soil horizon. When those differences in coloration are due to wetness, however, the correct term is "redoximorphic features."

When soils become saturated for significant periods of time during the growing season, these oxidized (red/ yellow) forms of iron are biochemically reduced to soluble forms and can be moved with drainage waters. This creates a matrix of drab, dominantly gray colors that are described as "redox depletions." The iron that is mobilized is typically reprecipitated locally into contrasting red/yellow features that are called "redox concentrations." Subsoil zones with mixtures of bright $\mathrm{red} /$ yellow and gray colors are indicative of seasonally fluctuating water tables, where the subsoil is wet during the winter/early spring and unsaturated in the summer/ early fall. Poorly drained soils also tend to accumulate large amounts of organic matter in their surface horizons because of limited oxidation and may have very thick and dark A horizons.

Soils that are wet in their upper 12 inches for considerable amounts of time during the growing season, support hydrophytic vegetation typical of wetlands, and exhibit redoximorphic features are designated as "hydric soils." Further information on mid-Atlantic hydric soils and redox features can be found online at www.epa.gov/reg3esd1/wetlands/hydric.htm.

Interpretation of soil redox features can be highly complicated in an urban environment due to the effects of soil layer mixing via the cut/fill and grading processes and changes in internal soil drainage due to ditching and pavement interception of normal infiltration.

\section{Drainage Classes}

The "drainage class" of a soil defines the frequency of soil wetness as it limits agricultural practices and is usually determined by the depth in soil to significant gray redox depletions. The soil drainage classes in table 2.2 are defined by the USDA Natural Resources Conservation Service (USDA 1993). They refer to the natural drainage condition of the soil without artificial drainage.

Table 2.2. Soil drainage classes.

\begin{tabular}{|c|c|c|}
\hline Drainage class & $\begin{array}{l}\text { Soil } \\
\text { characteristics }\end{array}$ & Effect on cropping \\
\hline $\begin{array}{l}\text { Excessively } \\
\text { drained }\end{array}$ & \multirow[t]{2}{*}{$\begin{array}{l}\text { Water is removed } \\
\text { rapidly from soil. }\end{array}$} & \multirow{2}{*}{$\begin{array}{l}\text { Will probably } \\
\text { require } \\
\text { supplemental } \\
\text { irrigation. }\end{array}$} \\
\hline $\begin{array}{l}\text { Somewhat } \\
\text { excessively } \\
\text { drained }\end{array}$ & & \\
\hline Well-drained & $\begin{array}{l}\text { Water is removed } \\
\text { readily, but not } \\
\text { rapidly. }\end{array}$ & $\begin{array}{l}\text { No drainage } \\
\text { required. }\end{array}$ \\
\hline $\begin{array}{l}\text { Moderately } \\
\text { well-drained }\end{array}$ & $\begin{array}{l}\text { Water is removed } \\
\text { somewhat slowly } \\
\text { at some periods } \\
\text { of the year. }\end{array}$ & $\begin{array}{l}\text { May require } \\
\text { supplemental } \\
\text { drainage if crops } \\
\text { that require good } \\
\text { drainage are } \\
\text { grown. }\end{array}$ \\
\hline $\begin{array}{l}\text { Somewhat } \\
\text { poorly drained }\end{array}$ & \multirow{2}{*}{$\begin{array}{l}\text { Water is removed } \\
\text { so slowly that } \\
\text { soil is wet at } \\
\text { shallow depths } \\
\text { periodically } \\
\text { during the } \\
\text { growing season. }\end{array}$} & \multirow{2}{*}{$\begin{array}{l}\text { Will probably } \\
\text { require } \\
\text { supplemental } \\
\text { drainage for } \\
\text { satisfactory use } \\
\text { in production of } \\
\text { most crops. }\end{array}$} \\
\hline Poorly drained & & \\
\hline $\begin{array}{l}\text { Very poorly } \\
\text { drained }\end{array}$ & $\begin{array}{l}\text { Free water is } \\
\text { present at or near } \\
\text { the surface during } \\
\text { the growing } \\
\text { season. }\end{array}$ & \\
\hline
\end{tabular}




\section{Soil Chemical Properties}

The plant root obtains essential nutrients almost entirely by uptake from the soil solution. The chemistry and nutrient content of the soil solution is, in turn, controlled by the solid material portion of the soil. Soil chemical properties, therefore, reflect the influence of soil minerals and organic materials on the soil solution.

\section{Soil pH}

Soil $\mathrm{pH}$ defines the relative acidity or alkalinity of the soil solution. It is important to note that $\mathrm{pH}$ can only be measured in soil solution that has equilibrated with soil solids; you cannot measure the $\mathrm{pH}$ of a solid. The $\mathrm{pH}$ scale in natural systems ranges from 0 to 14 . A pH value of 7.0 is neutral. Values below 7.0 are acidic and those above 7.0 are alkaline, or basic. Many agricultural soils in the mid-Atlantic region have a soil $\mathrm{pH}$ between 5.5 and 6.5. Any soil $\mathrm{pH}$ value less than 4.0 is indicative of acid-sulfate influenced soils (see chapter 3 ).

Soil $\mathrm{pH}$ is a measurement of hydrogen ion $\left(\mathrm{H}^{+}\right)$activity in soil solution or effective concentration in a soil and water solution. Soil $\mathrm{pH}$ is expressed in logarithmic terms, which means that each unit change in soil $\mathrm{pH}$ amounts to a tenfold change in acidity or alkalinity. For example, a soil with a pH of 6.0 has 10 times as much active $\mathrm{H}^{+}$(or is 10 times more acidic) as one with a $\mathrm{pH}$ of 7.0.

Soils become acidic when basic cations (positively charged ions such as calcium, or $\mathrm{Ca}^{2+}$ ) held by soil colloids are leached from the soil and replaced by aluminum ions $\left(\mathrm{Al}^{3+}\right)$, which then hydrolyze to form aluminum hydroxide $\left(\mathrm{Al}(\mathrm{OH})_{3}\right)$ solids, which then liberate $\mathrm{H}^{+}$ions to solution as water hydrolyzes (splits into $\mathrm{H}^{+}$ and $\mathrm{OH}^{-}$ions). This long-term acidification process is accelerated by the decomposition of organic matter that also releases acids to soil solution. Most soils in the mid-Atlantic region were formed under high rainfall with abundant vegetation and are considerably more acidic than soils of the midwestern and western United States. In fact, very few soils in Virginia were above $\mathrm{pH}$ 6.0 when settlers first arrived in the 17th century.

\section{Cation Exchange Capacity: Our Measure of Soil Charge and Reactivity}

The net ability of a soil to hold, retain, and exchange cations such as calcium $\left(\mathrm{Ca}^{2+}\right)$, magnesium $\left(\mathrm{Mg}^{2+}\right)$, potassium $\left(\mathrm{K}^{+}\right)$, sodium $\left(\mathrm{Na}^{+}\right)$, ammonium $\left(\mathrm{NH}_{4}^{+}\right)$, aluminum $\left(\mathrm{Al}^{3+}\right)$, and hydrogen $\left(\mathrm{H}^{+}\right)$is called "cation exchange capacity," or CEC. All soils contain clay minerals and organic matter that typically possess negative electrical surface charges. These negative charges are present in excess of any positive charges that may exist, which gives soil a net negative charge.

Negative surface charges attract positively charged cations and prevent their leaching. These ions are held against leaching by electrostatic positive charges but are not permanently bound to the surface of soil particles. Positively charged ions are held in a "diffuse cloud" within the water films that are also strongly attracted to the charged soil surfaces. Cations that are retained by soils can thus be replaced, or "exchanged," by other cations in the soil solution. For example, $\mathrm{Ca}^{2+}$ can be exchanged for $\mathrm{Al}^{3+}$ and/or $\mathrm{K}^{+}$and vice versa. The higher a soil's CEC, the more cations it can retain.

There is a direct and positive relationship between the relative abundance of a given cation in solution and the amount of this cation that is retained by the soil CEC. For example, if the predominant cation in the soil solution is $\mathrm{Al}^{3+}, \mathrm{Al}^{3+}$ will also be the predominant exchangeable cation. Similarly, when large amounts of $\mathrm{Ca}^{2+}$ are added to soil solution by lime dissolving over time, $\mathrm{Ca}^{2+}$ will displace $\mathrm{Al}^{3+}$ from the exchange complex and allow it to be neutralized in solution by the alkalinity added with the lime.

The CEC of a soil is expressed in terms of moles of charge per mass of soil. The units used are " $\mathrm{cmol}^{+} / \mathrm{kg}$ " (centimoles of positive charge per kilogram) or "meq/100 g" (milliequivalents per 100 grams; $1.0 \mathrm{cmol}^{+} / \mathrm{kg}=1.0$ $\mathrm{meq} / 100 \mathrm{~g}$ ). Soil scientists have used the former unit in publications since the early $1980 \mathrm{~s}$, while meq/100 $\mathrm{g}$ is commonly used in other disciplines. Numerically, they are the same. Soil CEC is calculated by adding the charge equivalents of $\mathrm{K}^{+}, \mathrm{NH}_{4}^{+}, \mathrm{Ca}^{2+}, \mathrm{Mg}^{2+}, \mathrm{Al}^{3+}, \mathrm{Na}^{+}$, and $\mathrm{H}^{+}$ that are extracted from a soil's exchangeable fraction.

\section{Sources of Negative Charge in Soils}

The mineralogy of the clay fraction and the soil's humus content greatly influence the quantity of negative charges present. One source of negative charge is "isomorphous substitution," which is the replacement of a $\mathrm{Si}^{4+}$ or $\mathrm{Al}^{3+}$ cation in the clay mineral structures with a cation that has a lower surface charge. For example, $\mathrm{Si}^{4+}$ might be replaced with $\mathrm{Al}^{3+}$, or $\mathrm{Al}^{3+}$ might be replaced with either $\mathrm{Mg}^{2+}$ or $\mathrm{Fe}^{2+}$. Clay minerals with a repeating layer structure of two silica sheets sandwiched around an aluminum sheet (two-to-one clays, such as vermiculite or smectite), typically have a higher total negative charge than clay minerals with one silica 
sheet and one aluminum sheet (one-to-one clays, such as kaolinite). Soil humus is also highly charged due to a large number of chemically reactive sites called "functional groups."

Soil $\mathrm{pH}$ also has a direct relationship to the quantity of negative charges contributed by organic matter and, to a lesser extent, from mineral surfaces such as iron oxides. As soil $\mathrm{pH}$ increases, the quantity of negative charges increases due to the reactions of exposed organic matter functional groups and similar reactions that occur on the surfaces of iron and aluminum oxides and the edges of clays. This $\mathrm{pH}$-dependent charge is particularly important in highly weathered topsoils where organic matter dominates overall soil charge.

It is important to point out that while we use CEC as our measure of net charge or reactivity in soils, all soils contain a certain amount of positive charges as well. These positive charges are important in retaining anions (negatively charged ions) like $\mathrm{NO}_{3}^{-}, \mathrm{Cl}^{-}$, or $\mathrm{SO}_{4}{ }^{2-}$ against leaching in certain soils as well. In particular, highly weathered soils that are high in aluminum and iron (very red) and low in $\mathrm{pH}$ (less than 5.5) may actually have more positive charges on their surfaces than negative charges. These soils also have a very strong affinity to bind (or fix) phosphorus in very tight complexes that will be discussed in chapter 4 .

\section{Cation Retention and Leaching in Soils}

The negatively charged surfaces of clay particles and organic matter strongly attract cations. However, the retention and release of these cations, which affects their mobility in soil, is dependent on several factors. Two of these factors are the relative retention strength of each cation and the relative amount or mass of each cation present.

For a given cation, the relative retention strength by soil is determined by the charge of the ion and its size (or diameter). In general, the greater the positive charge and the smaller the ionic diameter of a cation, the more tightly the ion is held (i.e., higher retention strength) and the more difficult it is to remove that cation and leach it down through the soil profile. For example, $\mathrm{Al}^{3+}$ has a positive charge of three and a very small ionic diameter and thus moves through the soil profile very slowly. Potassium $\left(\mathrm{K}^{+}\right)$, on the other hand, has a charge of one and a much larger ionic radius, so it leaches much more readily. This difference in cation retention has important soil fertility implications that will be discussed in chapter 4.
If cations are present in equal amounts, the general strength of adsorption that holds cations in the soil is in the following order:

$$
\mathrm{Al}^{3+}>>\mathrm{Ca}^{2+}>\mathrm{Mg}^{2+}>\mathrm{K}^{+}=\mathrm{NH}_{4}^{+}>\mathrm{Na}^{+}
$$

\section{Effect of CEC on Soil Properties}

A soil with a low CEC value (1-10 meq/100 g) may have some, or all, of the following characteristics:

- High sand and low clay content.

- Low organic matter content.

- Low water-holding capacity.

- Low soil $\mathrm{pH}$.

- Not easily resistant to changes in $\mathrm{pH}$ or other chemical changes.

- Enhanced leaching potential of plant nutrients such as $\mathrm{Ca}^{2+}, \mathrm{NH}_{4}^{+}, \mathrm{K}^{+}$.

- Low productivity.

A soil with a higher CEC value (11-40 meq/100 g) may have some or all of the following characteristics:

- Lower sand and higher silt plus clay content.

- Moderate-to-high organic matter content.

- High water-holding capacity.

- Ability to resist changes in $\mathrm{pH}$ or other chemical properties.

- Less nutrient losses to leaching than low CEC soils.

\section{Base Saturation}

Of the common soil-bound cations, $\mathrm{Ca}^{2+}, \mathrm{Mg}^{2+}, \mathrm{K}^{+}$, and $\mathrm{Na}^{+}$are considered to be basic cations. The base saturation of the soil is defined as the percentage of the soil's CEC (on a charge-equivalent basis) that is occupied by these cations. A high base saturation (more than 50 percent) enhances calcium, magnesium, and potassium availability and prevents soil $\mathrm{pH}$ decline. Low base saturation (less than 25 percent) is indicative of a strongly acidic soil that may maintain $\mathrm{Al}^{3+}$ activity high enough to cause phytotoxicity.

\section{Buffering Capacity}

The resistance of soils to changes in the $\mathrm{pH}$ of the soil solution is called "buffering." In practical terms, buffering capacity for $\mathrm{pH}$ increases with the amount of clay and 
organic matter. Thus, soils with high clay and organic matter content (high buffer capacity) will require more lime to increase $\mathrm{pH}$ than sandy soils with low amounts of organic matter (low or weak buffer capacity).

One laboratory measure of the acid buffering capacity (or lime demand) of a given soil is called "buffer $\mathrm{pH}$ " and will be discussed in more detail in chapters 4 and 5 . It is very important to realize, however, that buffer $\mathrm{pH}$ is quite different from conventional soil-to-water $\mathrm{pH}$, as discussed above.

\section{Essential Elements for Plant Growth}

Higher plants and the microbial biomass in soils need a wide array of essential elements to sustain them and build biomass. The soil biota take carbon, hydrogen, and oxygen from soil, air, and water, so these are not considered soil-supplied nutrients. Six essential elements (nitrogen, phosphorus, potassium, sulfur, calcium, and magnesium) are taken up by plants from the soil in relatively large amounts; these are referred to as "macronutrients." All of the essential elements are taken up primarily as dissolved ions from solution; table 2.3 lists their common forms and sources. The ionic form (i.e., cation versus anion) of each nutrient and its specific charge characteristics directly control its relative sorption and availability from the soil. Higher plants also require a wide range of other elements (boron, chlorine, cobalt, copper, iron, molybdenum, manganese, nickel, and zinc) in much smaller amounts and these are referred to as "micronutrients." More detail on the specific forms and supply of plant nutrients can be found in chapters $4,5,7,8$, and 9 .

\section{Limiting Factors to Plant Growth}

Higher plants rely on the soil for a wide range of services in support of their growth. Physically, the soil must be deep and strong enough to support the plant, hold and supply sufficient plant-available water, be able to moderate extreme air temperatures, and allow for adequate exchange of gasses between the root zone and the atmosphere. Chemically, the soil must maintain an adequate $\mathrm{pH}$ and soluble-salt environment for locally adapted plants and supply all of the soil nutrients detailed above in adequate amounts to meet the plant's demand. The overall productivity of the plant community will be controlled by the soil factor that is present in the lowest relative amount, regardless of the adequacy/availability of the rest of the important soil physical and chemical factors. This concept is known as the "the law of the minimum." For example, overall plant growth in urban soils is commonly directly limited by compaction and associated lack of rooting volume, regardless of the adequacy of soil $\mathrm{pH}$ and nutrient levels. Once you loosen these soils to provide adequate rooting depth, plant growth will increase until it becomes limited by the next limiting factor (e.g., low soil $\mathrm{pH}$ or phosphorus). Therefore, the overall guiding principle underpinning appropriate soil management is that we must manage all important plant growth factors together to maintain adequate plant growth over time.

\section{Soil Survey}

The soils of all counties have been mapped by the USDA-NRCS soil survey (1993), and these maps are available in soil survey reports, although some county reports are quite old and in need of modern recorrelation. A soil survey report reveals the kinds of soils that exist in the county (or other area) covered by the report at a level of detail that is usually sufficient for agricultural interpretations. The soils are described in terms of their location on the landscape, their profile characteristics, their relationships to one another, their suitability for various uses, and their needs for particular types of management. Each soil survey report contains information about soil morphology, soil genesis, soil

\begin{tabular}{lll}
\hline Table 2.3. Soil-supplied macronutrients, sources, and ionic forms for plant uptake. \\
\hline Nutrient & Primary sources & Dominant form in soil solution \\
\hline Nitrogen $(\mathrm{N})$ & Organic matter, manures, fertilizers (N-P-K), legumes & $\mathrm{NH}_{4}^{+}:$low $\mathrm{pH}$ or wet \\
& & $\mathrm{NO}_{3}:$ moderate $\mathrm{pH}$ and oxidized \\
\hline Phosphorus $(\mathrm{P})$ & Organic matter, fertilizers & $\mathrm{H}_{2} \mathrm{PO}_{4}^{-}$: between $\mathrm{pH} 5$ and 7 \\
\hline Potassium $(\mathrm{K})$ & Plant litter, fertilizers, soil minerals (micas and feldspars) & $\mathrm{K}^{+}$ \\
\hline Calcium $(\mathrm{Ca})$ & Limes, plant litter, soil minerals (feldspars and carbonates) & $\mathrm{Ca}^{2+}$ \\
\hline Magnesium $(\mathrm{Mg})$ & Dolomitic limes, soil minerals & $\mathrm{Mg}^{2+}$ \\
\hline Sulfur $(\mathrm{S})$ & Atmospheric and gypsum additions, soil sulfides & $\mathrm{SO}_{4}^{2-}$ \\
\hline
\end{tabular}


conservation, and soil productivity. Soil survey reports are available from county and state USDA-NRCS cooperative Extension offices and online at http://soils. usda.gov/survey/online_surveys/.

\section{Parts of a Soil Survey}

There are two major sections in a soil survey report. One section contains the soil maps. In most reports, the soil map is printed over an aerial photographic base image. In the past, soil mapping was done at scales ranging from 1-to-10,000 to 1-to-50,000, with 1-to15,840 being the most common scale used before the 1980s. Current USDA-NRCS mapping is published at 1-to-24,000 to match U.S. Geologic Survey topographic quadrangle maps.

Each soil area is delineated by an enclosing line on the map. Soil delineation boundaries are drawn wherever there is a significant change in the type of soil. The boundaries often follow natural contours, but they may also cross and incorporate multiple portions of the landscape if the soils are similar across local topographic variations.

The other section of a soil survey report is the narrative portion. Without it, the soil maps would have little meaning. Symbols on each map are keyed to a list of soil mapping units. The nature, properties, and classification and use potentials of all mapping units are described in detail.

\section{Terminology Used in Soil Surveys}

Soil series is a basic unit of soil classification, consisting of soils that are essentially alike in all main profile characteristics. Most soil mapping units in modern cooperative soil surveys are named for their dominant component soil series.

Soil phase is a subdivision of a soil series or other unit of classification having characteristics that affect the use and management of the soil but do not vary enough to merit a separate series. These include variations in slope, erosion, gravel content, and other properties.

Soil complexes and soil associations are naturally occurring groupings of two or more soil series with different use and management requirements that occur in a regular pattern across the landscape but cannot be separated at the scale of mapping that is used. Soil complexes are used to map two or more series that are commonly intermixed on similar landforms in detailed county soil maps. Soil associations are utilized in more general and less detailed regional soil maps.
Map units are the actual units that are delineated on the soil map and are usually named for the dominant soil series and slope phase. Map units generally contain more than one soil series. Units are given the name of the dominant soil series if 85 percent or more of the area is correlated as a single soil series (or similar soils in terms of use and management). Soil complexes are used to name the map unit if the dissimilar inclusions exceed 15 percent. Each map unit is given a symbol (numbers or letters) on the soil map that designates the name of the soil series or complex being mapped and the slope of the soil. More details on how soil mapping units are developed and named can be found in the Soil Survey Manual at http://soils.usda.gov/technical/ manual/.

\section{Using a Soil Survey}

A user interested in an overall picture of a county's soils should probably turn first to the soil association section of the soil survey report. The general soil pattern of the county is discussed in this section. A user interested in the soils of a particular farm must first locate that farm on the soil map and determine what soils are present. Index sheets located with the soil maps help the user find the correct section of the map. The map legend gives the soil map the unit names for each symbol and assists with the location of descriptive and interpretive material in the report.

Detailed soil descriptions that provide information to those who are primarily interested in the nature and properties of the soils mapped are located in the narrative portion of the soil survey report. The section concerned with the use and management of the soils (soil interpretations) is helpful to farmers and others who use the soil or give advice and assistance in its use (e.g., soil conservationists, cooperative Extension agents). Management needs and estimated yields are included in this section. Newer reports have engineering properties of soils listed in tables that are useful to highway engineers, sanitary engineers, and others who design water storage or drainage projects.

It is important for the urban user of soil surveys to understand that very few soil surveys recognize and appropriately interpret the drastically disturbed nature of their landscape. Where the soil survey shows mapping units named for soil series, they represent the dominant undisturbed soils in that landscape that existed predevelopment. Some older soil surveys simply mapped previously developed areas as "made land" or "urban lands." Virginia soil surveys produced after 
1980 often map disturbed soils as "Udorthents," which simply indicates that they are dominantly young soils due to their native profiles being largely destroyed.

\section{Literature Cited}

Brady, N. C., and R. R. Weil. 2008. The Nature and Properties of Soils. 14th ed. Upper Saddle River, N.J.: Pearson Prentice Hall.

U.S. Department of Agriculture (USDA). Natural Resources Conservation Service. Soil Service Division Staff. 1993. Soil Survey Manual. Handbook No. 18. Washington: U.S. Government Printing Office. http://soils.usda.gov/technical/ manual/. 



\title{
Chapter 3. Managing Urban Soils
}

\author{
W. Lee Daniels, Professor, Crop and Soil Environmental Sciences, Virginia Tech
}

\section{What Is an Urban Soil?}

More often than not, the soils we manage for plant growth in urban and suburban areas have been significantly altered from their natural state by excavation (cut and fill), grading, topsoil return, or other operations that fundamentally alter their morphological, physical, and chemical properties (Brown et al. 2000; Scheyer and Hipple 2005). In rural areas, similar disturbances associated with road construction, mining, and utility corridors generate similar soil conditions that frequently limit plant growth (Booze-Daniels et al. 2000). Simply put, urban soils do not contain the natural sequence of intact soil horizons that was described in chapter 2. Therefore, many of our underlying assumptions about soil testing results, plant growth response and overall soil-plant relations may not apply to these materials, and they must be modified to overcome their inherent limitations for plant growth.

\section{Urban Soil Properties}

When we compare these urban soils materials with nearby natural soil profiles (see chapter 2), a number of differences are usually readily apparent (adapted from Craul 1992):

- Highly variable in all directions.

- Abrupt differences in soil texture and density (layering) with depth.

- Presence of high-clay materials at the surface/lack of topsoil.

- Soil structure that has been degraded, leading to loss of large pores (macropores) and their vertical continuity.

- High bulk density due to mechanical compaction and lack of structure/macropores.

- Common occurrence of surface crusts on finer-textured materials.

- Soil pH may be higher or lower than normal.

- Restricted aeration and water drainage.

- Interrupted nutrient cycles and associated microbial populations.

- Very low organic matter and nutrient levels compared to natural topsoils.
- Presence of anthropic materials (e.g., wood, rags, cement) and other contaminants (e.g., oil, metals).

- Higher temperature variability due to lack of natural litter layer or vegetation.

Figure 3.1 depicts a number of these plant-growth limiting soil factors that we commonly encounter around building sites, particularly (1) high variability, (2) layering, (3) presence of acidic and infertile clayey materials at the surface, and (4) issues related to excessive compaction (high bulk density). Recognizing and dealing with these limitations will therefore be the primary focus of this chapter, but other issues and their remedies will be addressed as well.

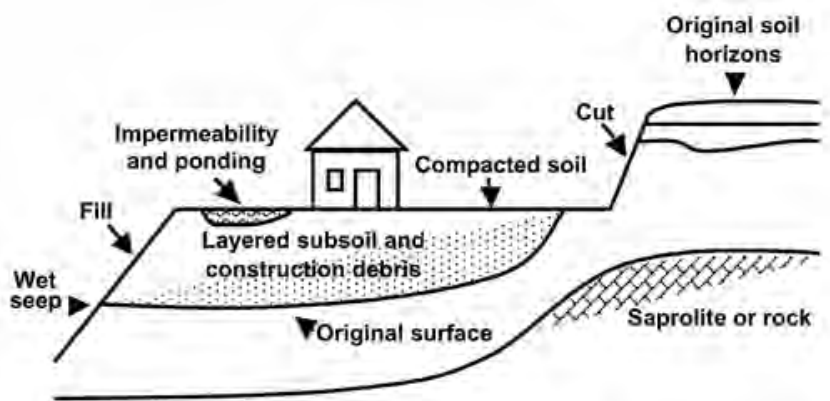

Figure 3.1. Diagram of urban soils and important plant growth limiting features. Note that the soil limitations in one portion of a home lot may be quite different from those encountered in another location of the same lot. Diagram by Kathryn Haering.

\section{Types of Urban Soil Materials and Their Variability}

The entire process of site development for housing, construction, or landscape development results in large amounts of soil disturbance, movement, and mixing. The degree of impact ranges from limited surface soil compaction to complete removal of the native soil profile and its replacement with mixed and dissimilar fill materials (figures 3.1 and 3.2). Thus, while predevelopment native soil properties will be fairly uniform and predictable on a given site due to the long-term effect of the soil-forming factors (see chapter 2) the postdevelopment site will be much more variable and extreme short-range differences in important plant-growth related properties such as compaction, texture, and $\mathrm{pH}$ will be common. While there is an almost endless variety of mechanisms and expressions of soil disturbance, the most common types are (1) exposed subsoil materials, (2) exposed cut materials, and (3) filled materials that are compacted and layered. 


\section{Exposed Subsoil Materials}

The simplest urban soil scenario to recognize and deal with is where the topsoil (A plus E horizons) has been removed. Subsoil materials (B and $\mathrm{C}$ horizons) are frequently encountered at the surface of the ground as a result of erosion of the native topsoil or severe soil disturbance associated with earthmoving and construction activities. In most instances, these materials will be red or yellow in color, but they may range from white to gray in certain instances. Unlike topsoil, this material is often quite clayey and dense, devoid of organic matter, and generally resists plant growth. Subsoils in the midAtlantic region are usually highly leached, acidic, and infertile and may also be gravelly or rocky.

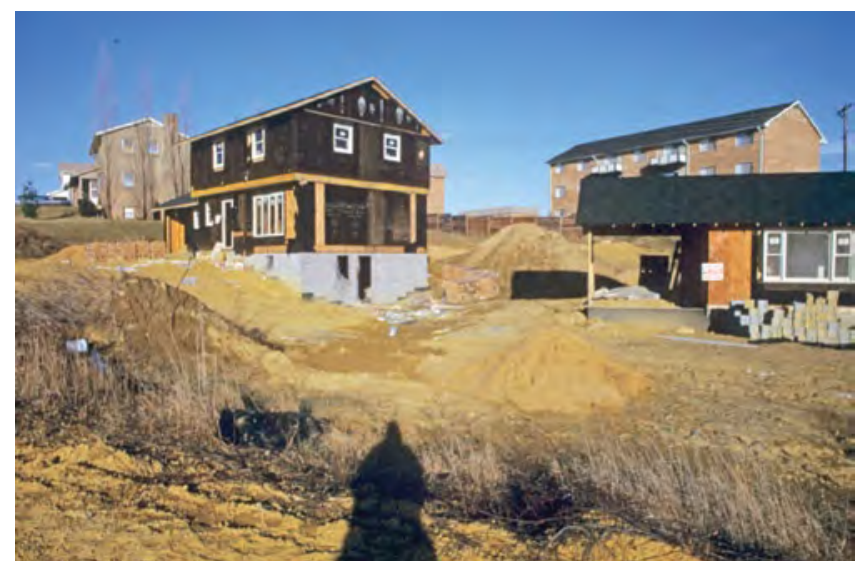

Figure 3.2. Typical soil disturbance in subdivision during construction. Each lot is graded out (cut and filled) to approximately level the area immediately surrounding the house. Note large amounts of sand and other construction debris that will more than likely be graded out and incorporated into fills.

\section{Cut Slopes and Banks}

Cut materials are commonly encountered on sites where the natural topography is rolling or sloping and must be reshaped to accommodate yards, driveways, landscaping, and/or drainage features. Cuts are usually a relatively minor component of subdivision developments but are a dominant feature on highway rights-of-way, as discussed in more detail later. In general, cut materials expose subsoil and/or deeper geologic strata and may therefore be very clayey and/or quite coarse and rock-like. One limitation of these materials is that during grading, cut clays will smear and seal and thereby limit water and root penetration. The lower sections of cut materials may also be subject to the limitations described above for exposed subsoils such as clayey textures and acidic $\mathrm{pH}$. However, due to the fact that they are much less variable, less compacted, and tend to retain their native soil structure, cut slopes are usually superior to fill materials as described next.

\section{Fills}

Overall site development and final land shaping and grading generate extensive areas of filled materials at most sites (figure 3.1). These fills may range from relatively shallow lifts of returned topsoil over intact subsoils to very thick, multi-layered fills of strongly contrasting materials. Fills can often be recognized due to their long linear and uniform slopes or "unnatural" slope shapes and configurations. However, competent grading and landscaping can make fills virtually indistinguishable from natural landforms. Fills are typically much more difficult to manage than either exposed subsoils or cuts for a variety of reasons that are discussed in more detail below. Fill materials tend to be highly variable and layered and compacted, all of which limit plant growth and water movement.

\section{Common Soil Limitations in the Urban Environment}

\section{Compaction}

Simple soil compaction (high bulk density) is the most common plant growth and water movement limitation in urban soils (see figure 3.3). Dense layers in soils are commonly called "pans" and may result from a variety of natural long-term soil processes (e.g., dense Bt horizons), but are most commonly formed by site development and grading machinery. These compacted zones may occur at the surface or deep in the subsoil but are often denser than natural pans or subsoil layers. Artificially induced pans are particularly common where several layers of soil have been disturbed, such as when topsoil is returned to a regraded lawn after house construction, or where cut-and-fill operations have reshaped an area for landscaping. Natural soil structure is usually destroyed by these activities; not only are soils made abnormally dense, but there are no longer any natural channels or planes of weakness for roots, water, and air to penetrate. It is also important to point out that normal foot traffic, game playing, or infrequent tire traffic can also cause compaction of the immediate surface soil, particularly when the soil is moist and readily compressible.

The ability of a growing root tip to penetrate soil is directly dependent on soil strength. Soil strength which essentially is its resistance to deformation or shearing - is controlled primarily by a soil's bulk density and moisture content. Workable, loose soils have bulk densities of 1.0 to 1.4 grams per cubic centimeter 
$\left(\mathrm{g} / \mathrm{cm}^{3}\right)$. In a clayey soil, root penetration is greatly retarded during dry conditions when bulk density exceeds $1.5 \mathrm{~g} / \mathrm{cm}^{3}$. The same soil when moist, however, may not impede rooting because soil strength is then decreased. Sandy soils resist compaction due to their larger packing voids between particles and can support adequate rooting at bulk densities approaching $1.8 \mathrm{~g} / \mathrm{cm}^{3}$, but will still be limiting at higher levels of compaction.

Soils that are compacted also resist water movement and gas exchange, which can seriously hinder plant growth. Compacted soils also lack macropore space, which lessens water-holding capacity and rooting depth. Due to their lack of large pore spaces, water passes very slowly; therefore, dense soils often alternate between being very wet in the winter and very dry in the summer. Compacted soils also perch wet spots in unexpected locations and enhance runoff over infiltration. Finally, a compacted soil can severely limit plant growth, even if other physical and chemical characteristics such as texture and $\mathrm{pH}$ are optimal (see figure 3.4). Thus, soil compaction cannot be recognized by conventional soil testing and is often a "hidden limitation."

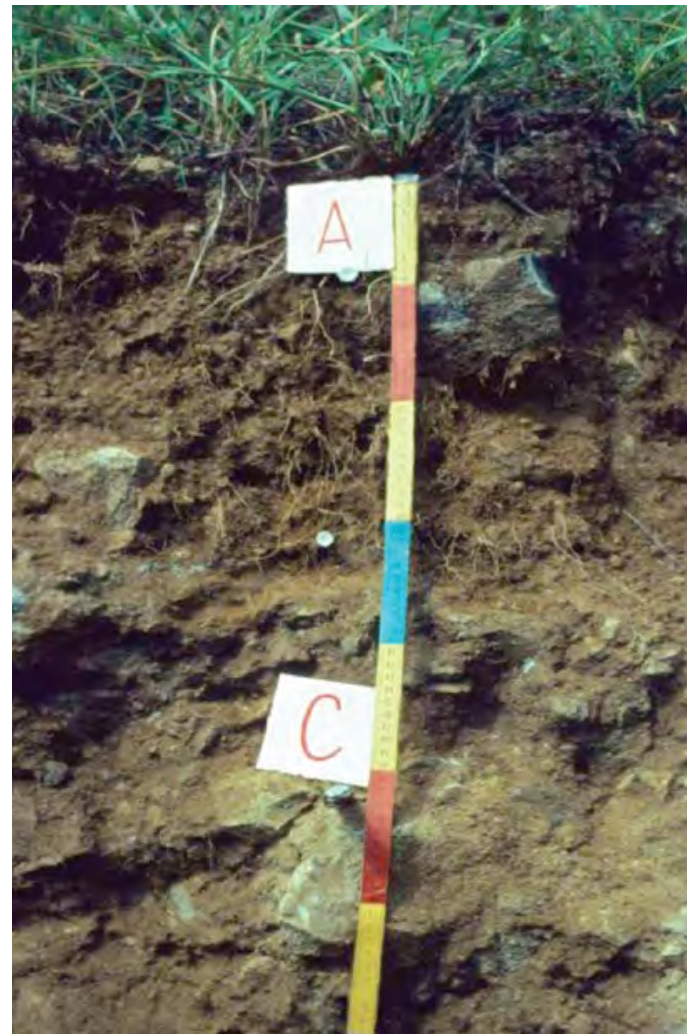

Figure 3.3. High bulk density $\left(2.0 \mathrm{~g} / \mathrm{cm}^{3}\right)$ traffic pan on a mining site under loose spoil materials. Similar traffic pans are routinely found in home construction and highway environments. Roots cannot penetrate or loosen zones that are packed to a bulk density greater than approximately $1.5 \mathrm{~g} / \mathrm{cm}^{3}$ for a clay or $1.9 \mathrm{~g} / \mathrm{cm}^{3}$ for a sandy-textured soil.

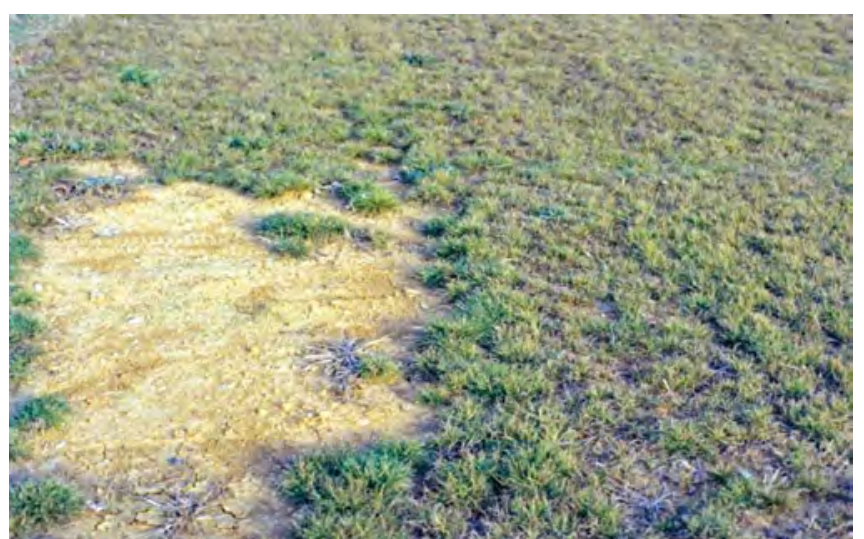

Figure 3.4. Turf growth limited by compaction. The bare soil on the left was pH 6.5 and fertile but heavily compacted and therefore, not capable of supporting viable turf after seed germination. The turf in the rest of this photo is also growing in moderately compacted soil as evidenced by its "clumpy" appearance.

\section{Soil Layering and Associated Problems}

When downward percolating water encounters a compacted zone or a zone of strongly contrasting soil texture (such as sand over clay or vice versa), water will back up or "perch" just above the contact and saturate the zone above it. The nature and quantity of porosity, particularly the amount of large, continuous pores and channels in the soil, is the primary factor controlling the rate of water movement. Temporarily perched water tables may persist close to the soil surface from several days to months, depending on local soil and climatic conditions. A similar perching occurs when water passes through a coarse-textured soil layer with many large pores and then encounters a finer-textured soil layer (even if noncompacted) with much smaller pores. Perching also occurs - but for an altogether different reason - when water passing through a fine-textured layer encounters a coarser sand or gravel stratum. In this case, the finer-textured clay soil actually holds on to its water so tightly (due to capillary forces or suction) that it significantly slows its movement into the coarser material below. Saturated conditions within the rooting zone cause a number of problems for plant growth, including lack of oxygen, loss of available nitrogen, and potential heavy-metal toxicities.

\section{Adverse Soil Texture or Rock Content}

As discussed in detail in chapter 2, loamy textures are optimum for plant growth, and most native A horizons (topsoil) are within this texture class. However, subsoil layers (B horizons) are commonly quite clayey, and deeper $\mathrm{C}$ horizons may be very sandy or rocky. Because of the very fine texture and small pore size of clayey soils, water is so tightly held that uptake by plant roots 
is limited. Clayey soils also limit plant growth due to higher soil strength, their tendency to dry and crack, their tendency to form crusts after rain events, and other adverse chemical properties as discussed below. On the other hand, very coarse-textured (sandy) or rocky soils are also prone to drought and do not retain added fertilizer and lime elements.

\section{Adverse $\mathrm{pH}$ and Nutrient Status}

Most subsoils ( $\mathrm{B}$ and $\mathrm{C}$ horizons) in our region are low in $\mathrm{pH}$ (4.0 to 6.0) due to long-term acid-leaching processes and are very low in available nutrients because they formed well below the zone of active nutrient cycling and/or fertilization and liming. This acidic condition greatly increases the solubility of naturally occurring phytotoxic metals like aluminum and manganese. In certain instances (e.g., Piedmont saprolites), however, deep subsoil materials may actually be quite moderate in $\mathrm{pH}$ and nutrient cations (calcium, magnesium, potassium), but they will still be very low in plant-available nitrogen and phosphorus. The red and yellow colors commonly seen in subsoil materials are due to coatings of iron-oxides, which tend to be ubiquitous in regional subsoils. These amorphous iron coatings along with associated aluminum oxides (which are not readily visible) have the ability to adsorb large amounts of applied phosphorus fertilizers via a process called phosphorus-fixation (see chapter 4), particularly when the soil $\mathrm{pH}$ is less than 6.0 (Brady and Weil 2008).

In certain instances - particularly where high $\mathrm{pH}$ mortar mix or quick lime (see discussion later) have been added to the soil in excessive amounts - the soil $\mathrm{pH}$ may be abnormally high (more than 8.2 ). This can lead to a variety of plant nutrient deficiencies and toxicities and soil physical problems (Brady and Weil 2008). If the soil is alkaline ( $\mathrm{pH}$ more than 8.2) but weakly buffered, the $\mathrm{pH}$ can be readily reduced via addition of aluminum sulfate $\left(\mathrm{Al}_{2}\left(\mathrm{SO}_{4}\right)_{3}\right)$ or by adding acid-forming organic matter like pine needles and leaves and allowing natural decomposition to reacidify the soil. However, if the soil alkalinity is highly buffered (i.e., more than 5 to 10 tons of calcium carbonate equivalence; $\mathrm{CCE}$ ) it will be necessary to add elemental sulfur (flowers of sulfur) to quickly form sulfuric acid in soil solution to neutralize the excess alkalinity. This must be done very carefully because, as discussed later, reduced sulfur is highly reactive in the soil and even a minor over-application can drive the soil $\mathrm{pH}$ below 4.0.

\section{Low Organic Matter and Microbial Activity}

Unless topsoil layers are properly salvaged, stored, and returned, newly constructed urban soils are much lower in their organic matter content and microbial biomass than nearby natural soil profiles. This particularly affects surface soil aggregation, infiltration, and water-holding capacity. The lack of microbial activity may also limit the soils' nitrogen, phosphorus, and sulfur cycles, which are highly dependent on the active microbial biomass for important mineralization transformations. Revegetated urban soils will accumulate stable organic matter levels and microbial communities over time, but their development may also be strongly limited by the combined adverse soil properties discussed above.

\section{Inclusion of Mixed and Foreign Materials}

One of the unique diagnostic features of most urban soils is their inclusion of a wide array of dissimilar natural and man-made (anthropogenic) materials. This is particularly true of soils on residential lots where contractors are unlikely to remove excess sand, gravel or other materials due to the cost of loading and hauling. By definition, these materials usually are found in the fill portions of urban soils, but they may also occur in scattered pockets or thin veneers over exposed subsoils or cut areas. Following is a summary of a few of the more problematic materials:

Gravel and sand are commonly found in layers or pockets related to mortar mix areas, temporary roads, or storage areas. These are usually capped with finertextured fill or topsoil layers, generating a very strong textural discontinuity that limits water drainage.

Cement and mortar mix are usually found in localized areas but may be mixed throughout a given fill layer when materials are bulldozed or moved during final site grading. Mortar mix will impart very high soil $\mathrm{pH}$ (9.0 or more) to localized areas for long periods of time until it fully reacts with natural soil acidity. Poorly cured waste concrete can also cause locally high soil $\mathrm{pH}$.

Waste wood, drywall, nails, rags, etc. tend to be discarded or to fall into the open excavation next to home foundations and block walls and are commonly mixed into the soils that constitute the backfill. As waste wood or rags decompose, they generate locally anaerobic zones that are adverse to the roots of many native and ornamental plants. Drywall, on the other hand, is primarily gypsum and paper and is actually used as an approved soil amendment (after grinding) in several 
southeastern states. Nails, wire, metal flashing, and glass are also commonly encountered in this zone and pose more of a safety hazard to the home gardener than a plant growth limitation.

\section{Managing Urban Soils and Their Limitations}

\section{Soil Sampling, Testing, and Fertilizer Plus Lime Prescriptions}

Appropriate soil sampling and testing is critical to managing urban soils. First of all, you need to take some time to try to understand the nature of your local urban soil landscape. Start by looking for areas of obvious cut slopes and fills. Using a shovel or a tiling spade, try to discern if you have topsoil return over cut subsoils or exposed cut and fill materials. With a little investigation and thought about how your landscape's soil materials were moved around, you should be able to discern a pattern. As you do this, pay attention to whether or not the soil is readily "diggable" or dense and resists penetration. Remember that soils are much stronger and resistant to digging and penetration when they are dry, so try to do this evaluation when the soil is moist (but not too wet).

Next, follow the soil sampling instructions outlined in chapter 5, but try to separate areas of cut, fill, and exposed subsoil where possible into different soil sampling zones. Once a competent lab analyzes the samples, follow the fertilizer and lime prescriptions. If areas of strongly contrasting vegetation patterns occur (see figure 3.4), sample them separately. When possible, resample and retest problematic areas in future years to confirm that soil conditions are improving.

It is important to note that the soil testing procedures and fertilizer/lime recommendation systems used by the majority of university and private-sector laboratories were developed and correlated for use on natural weathered surface soils and therefore may not accurately predict amendment needs for newly disturbed urban soils. This is not to say that soil testing is not appropriate for urban soils, but the results of a given test need to be specifically interpreted for their application to these types of materials. This is particularly true when unweathered sediments or soft rocks are being revegetated or the road cut exposes unusually reactive materials (e.g., sulfidic soils) as discussed later. Once these urban soils have been managed and equilibrated to support vegetation for several years, however, interpretation of soil testing results is more straightforward.

\section{Managing Dense Soils}

Field determination of bulk density is difficult for an untrained person, but a general identification of compacted or dense soils can be estimated via the "calibrated shovel" technique discussed above. Tillage (e.g., rototilling) or deep ripping (via a ripper or chisel plow) is the only practical way to improve soil porosity but may be too expensive or impractical for many home lawns or confined urban situations. Hollow-tine aerification can also be effective for surface compaction in home lawns. However, care must be taken to avoid excessive tillage, which can lead to destruction of large aggregates. Too much tillage also decreases organic matter content by speeding its oxidation and decomposition. Addition of compost and/or other organic amendments into surface soil layers will promote aggregation and macroporosity and thereby decrease bulk density over time.

Gypsum and other soil amendments and conditioners are commonly advertised as being able to "cure compaction." While these products may improve soil aggregation they will have virtually no effect on soil bulk density unless they are actively tilled and mixed into the loosened soil zone. Similarly, certain plants (e.g., switchgrass and alfalfa) are widely touted as being able to root deeply into compacted soils and "loosen" them. This is not a viable solution for highly compacted soils that lack structure and vertical continuous macropores, because the growing root tip of these plants is actually quite pliable and must find an open soil pore to exploit before it can subsequently enlarge and open it further as it penetrates downward and subsequently expands in diameter.

\section{Managing Clayey Subsoils}

First, problems of acidity and infertility must be solved through appropriate soil liming and fertilization strategies as discussed above. Usually, another factor to correct immediately is the low organic matter content. Appropriate amounts of compost or other organic materials (see chapter 9) should be repeatedly mixed in deeply (6 inches or more, if possible). Over time, the organic matter decomposes and stabilizes the new surface soil, aiding in essential soil particle aggregation and building nutrient supplies. Remember that the establishment and maintenance of organic matter in the soil does much to aid long-term fertility as well as physical properties like aggregation, infiltration, and water-holding capacity.

Most subsoils are dense and/or clayey, so particular attention must be paid to the problems of poor drainage 
and water saturation as discussed next. Even the addition of trucked-in topsoil usually will not solve poor drainage problems caused by clayey or compacted subsoils. Before new topsoil is added or created by the addition of organic matter, poorly drained exposed subsoils should be deeply ripped or tilled. In many situations the use of raised beds greatly eases the required modification of surface soil properties.

\section{Preserving and Maintaining Native Shrubs and Trees}

Most of our native woody trees and shrubs in the midAtlantic region are adapted to acidic soil conditions but also rely on the maintenance of a litter layer (O horizon) and its provision of essential nutrients as it decomposes over time. Thus, a large majority of the tree's fine feeder roots exist in the upper 6 inches or so of soil and are generally adapted to a loose and well-aerated surface. Unfortunately, the urban soil development process frequently removes the litter layer and compacts the soil. Furthermore, typical home lawn liming targets (i.e., $\mathrm{pH}$ 6.5 to 7.0) can drive the soil $\mathrm{pH}$ to levels where the trees become deficient in critical micronutrients, particularly iron and manganese. To protect these valuable trees during the construction process, it is important to keep all heavy traffic and fill placement off the soil immediately around and under the tree's canopy. This will usually require placing a temporary fence around the tree (to the extent of the canopy drip line) and continued vigilance by the homeowner or an informed construction supervisor.

After construction is completed, it is best to leave natural litterfall on these areas where possible and to avoid the addition of excess lime or fertilizers to the soil. Unfortunately, many homeowners and landscapers desire to establish turfgrass on these areas, which are often undulating due to shallow roots and other manifestations of the formerly forest soil profile. One particularly damaging practice is the placement of thick (more than 4 inches) lifts of topsoil over the roots in an effort to smooth the surface soil out and establish viable turf. This frequently leads to soil compaction, inadequate gas exchange, and a soil chemical environment that is not suitable for the long-term survival of the native trees or shrubs (see figure 3.5).

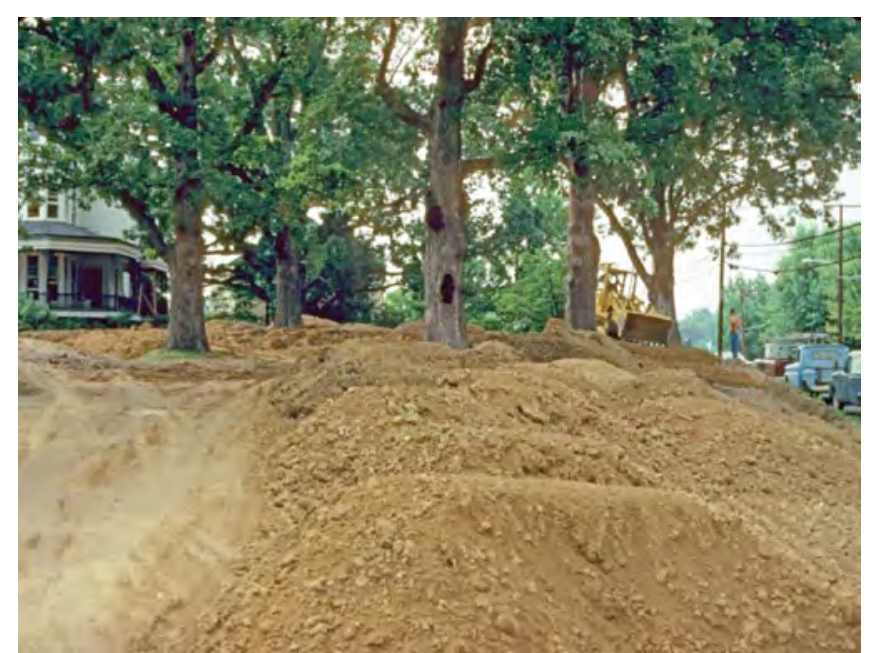

Figure 3.5. Inappropriate addition of topsoil over native trees: The topsoil material was added too thickly (12 inches) and then compacted (as seen at left) to a point that gas exchange by the living tree roots was limited. Most of these white oaks died within two years of this application.

\section{A Common Combination of Problems and a Prescription}

Dense, clayey, acidic soils are commonly found throughout the urban and roadside environment and these materials are usually quite low in plant-available phosphorus when they are freshly graded or exposed in cuts. Because of this, it is always important to sample and soil test these materials. Based on soil tests, it is not uncommon to see recommendations calling for applications of lime at 2 to 4 tons per acre, coupled with enhanced phosphorus fertilization (150 pounds or more per acre as phosphorus oxide $\left.\left(\mathrm{P}_{2} \mathrm{O}_{5}\right)\right)$ to address fertility issues. The addition of high-quality compost (1 inch) and tillage of all amendments to 6 inches will rapidly remediate these problems for turf establishment and growth. This treatment will not correct deeper compaction problems, however, so other soil modification procedures may be necessary for deeper-rooted landscape plantings or to solve problems with water percolation, as discussed below. It is also important to point out that older established home lawns may actually be quite high in plant-available phosphorus due to longterm fertilization, so phosphorus fertilizer rates should always be based on an appropriate soil test.

\section{Managing Wet Soils}

Compacted and/or clayey soils cause numerous watering problems. The most obvious is surface ponding caused by slow water penetration into the ground. When dense or high-clay layers limit downward water movement, the soil becomes saturated and oxygen — which 
moves very slowly through water - cannot reach plant roots. If the saturated condition persists, roots will die from oxygen starvation. Highly compacted soils, even when dry, cause the same problem. Extended periods of water saturation also lead to increased availability of heavy metals such as iron and manganese, which in some soils may actually be phytotoxic. Saturated conditions can also accelerate soil nitrogen losses due to denitrification (see chapter 4).

There are a number of ways to manage saturation problems in soil. One is to increase internal water movement by improving aggregation and pore space. There are several ways to do this: increasing and maintaining organic material levels, changing or keeping $\mathrm{pH}$ in the range between 5.5 and 6.5, adding a soil conditioner such as very coarse sand, cultivation only when moisture levels are ideal, and remediating compaction. However, the addition of organic material and associated mixing and tillage is probably the single most-effective action you can take, assuming the underlying soil zone is well-drained and can accept percolating water.

Another way to increase internal water movement in wet soils is to shatter subsoil pans. If just a few deep cracks for water percolation are made down through the subsoil, large amounts of saturated water will flow through them (assuming the underlying layers will accept the water). Alternatively, subsurface drainage can be installed beneath the soil to carry away excess water. This is usually expensive, but may be the only alternative in many situations. Still another approach is to limit the amount of water entering the soil by diverting surface water away from the poorly drained area or by digging interceptor trenches just uphill from it. Plastic mulch can also be used to decrease total water penetration.

\section{Acid Sulfate Soil Conditions and Management}

Over the past decade, many highway, commercial, and home residential construction activities in the mid-Atlantic region have exposed what are known as "sulfidic materials" that quickly react to produce "acid sulfate soil conditions" (Wagner et al. 1982). Without question, these materials and their associated effects on plant growth, water quality, and construction materials pose the greatest risk of any materials managed in the urban soil environment (Fanning et al. 2007). Even though they are not routinely encountered, their affects are so catastrophic that they deserve detailed coverage here. Sulfidic soil and geologic materials occur throughout the mid-Atlantic region, but are particularly common in the Middle and Upper Coastal Plain region between Richmond and Stafford County, Va. (Orndorff and Daniels 2004).

Acid sulfate soils are earthen materials that have been degraded by oxidation of sulfides (like pyrite, $\mathrm{FeS}_{2}$ ) to produce unusually low soil $\mathrm{pH}$ conditions (less than 3.9) when they are excavated from nonoxygenated zones below the surface and exposed to atmospheric conditions. As they oxidize, a wide array of acidity and soluble-salt-related plant growth and material damage problems are common. Essentially, these materials contain sulfidic minerals that react with water and oxygen to form sulfuric acid. This active set of processes is called "sulfuricization." The vast majority of acid sulfate soils is the result of land-disturbing activities that bring previously unoxidized (reduced) materials up to the surface and allow them to react.

The normal maximum range of $\mathrm{pH}$ for soils in the midAtlantic region is between 4.0 and 7.5. In the absence of liming, the great majority of these soils are naturally acidic with a $\mathrm{pH}$ between 4.5 and 5.5. In almost all instances, any soil with a $\mathrm{pH}$ less than 3.9 in Virginia is indicative of active or historic acid sulfate soil conditions and is quite toxic to plant growth and local receiving streams. In worst-case instances, soil $\mathrm{pH}$ values as low as 1.8 have been measured at locations such as the Stafford Airport in Virginia (Fanning et al. 2004).

\section{Where Do Sulfidic Materials Come From and What Do They Look Like?}

Sulfides precipitate naturally in tidal marshes, accumulate in sediments, and are enriched in certain metamorphic and igneous rocks. Thus, they occur naturally in many of the sediments underlying our Coastal Plain and in other rock types throughout the mid-Atlantic region. For example, most of the soils in the Fredericksburg/ Stafford County, Va., area formed out of parent materials that originally contained sulfides, but they oxidized and weathered out of the surface soil horizons (layers) tens of thousands of years ago. These subsoil horizons are usually bright yellow to red in color and are usually quite acidic ( $\mathrm{pH} 4.0$ to 5.5). However, many deeper cuts (more than 10 to 20 feet) can reveal unoxidized sulfidic materials that are typically gray, steel blue, or sometimes black in color but still have a high $\mathrm{pH}$ (more than 6.5) in situ. Once exposed at the surface, however, the $\mathrm{pH}$ of these materials can drop below 4.0 within several months. 


\section{How Do I Recognize Acid Sulfate Materials?}

Because fresh, unreacted, sulfidic materials have a near-neutral $\mathrm{pH}$, the only way to identify them before disturbance is appropriate testing and lab analyses as described later. Once they react to become "active acid sulfate" soils, distinctive indicators include (1) dead vegetation, (2) red iron staining on concrete and block walls, (3) concrete etching and dissolution, (4) rapid corrosion of iron and galvanized metal, and (5) strong sulfurous odor from rubbed hand samples.

\section{What Is the Potential Risk and Damage From Acid Sulfate Soil Processes?}

Acid sulfate soil conditions and associated sulfuricization reactions generate a number of extreme soil and water quality challenges. First of all, plants are killed by the direct effects of low $\mathrm{pH}$, high heavy-metal solubility, and soluble sulfate salt stress. The extremely acidic ( $\mathrm{pH} 1.8$ to 3.8 ) soil solutions and percolates directly degrade concrete, iron, and galvanized metal via a number of mechanisms. Finally, acid runoff and seepage from these materials can seriously degrade local receiving streams. Thus, it is critically important that these materials be isolated or treated to remediate their acid-producing potential and limit damage.

\section{How Do I Confirm Whether or Not I Have Acid Sulfate Materials in My Soil?}

In addition to the visual symptoms described above, active acid sulfate materials will usually exhibit a combination of low pH (less than 3.9) and high levels of potential acidity (total lime demand) relative to native soils. Fresh, unoxidized, sulfidic materials may have a normal $\mathrm{pH}$ but will have high levels of potential acidity (see below).

\section{What Is Potential Acidity and How Is It Expressed?}

Potential acidity is estimated by several lab techniques that have been used and refined by the mining industry since the 1970s to prevent the formation of "acid mine drainage" from coal and metal mines. The most widely used technique is called "acid-base accounting" (ABA), which assumes that all sulfides in the material will fully react to form sulfuric acid and then balances that against the material's inherent lime or neutralizing capacity. The results are expressed in tons of lime demand per
1,000 tons of material, which handily also happens to be the average weight of 1 acre of soil, 6 inches deep. Reduced sulfur is very reactive and every 1.0 percent of sulfidic sulfur, if fully reacted, generates enough acidity to require approximately 32 tons of agricultural limestone (finely ground calcium carbonate $\left(\mathrm{CaCO}_{3}\right)$ ) per 1,000 tons of soil to fully neutralize! Thus, even 0.3 percent sulfidic sulfur in these materials can generate a lime demand of 10 tons per acre (6 inches deep), which is much higher than we ever apply to "normal" soils. Occasionally, Coastal Plain sediments do contain sufficient lime (as fine shell fragments, etc.) to completely or partially offset their acid-forming potential, but this is a rare occurrence.

At Virginia Tech, we use a similar technique to ABA for potential acidity called the peroxide potential acidity (PPA) technique. In this method, we use strong hydrogen peroxide $\left(\mathrm{H}_{2} \mathrm{O}_{2}\right)$ to force the complete reaction of the sulfides and their internal neutralization by carbonates. In our experience, it correlates very well with ABA for a wide range of Virginia materials. For example, our long-term research results indicate that acid sulfate materials in the Fredericksburg/Stafford County region average between 10 and 20 tons of lime demand per acre (or per 1,000 tons of soil) in their fresh/unoxidized state. On occasion, we have tested small pockets of materials that exceeded 50 tons of lime per 1,000 tons of soil or per acre net acid demand! Once these materials have fully reacted and oxidized, however, they typically require only 4 to 6 tons of lime per acre to bring their low pH (less than 4.0) up to 7.0.

\section{What Can I Do to Remediate Acid Sulfate Soil Conditions?}

First of all, the only way to prevent these reactions from occurring in disturbed cut/fill materials is to keep them out of contact with the oxidizing atmosphere and water. However, once they are placed and graded on a home site, the only practical way to remediate them is to bulk blend sufficient agricultural limestone (or other approved liming materials) with them to offset the full amount of acidity that will be produced over extended periods of time (i.e., their potential acidity). We also recommend applying 25 percent more lime to ensure long-term alkaline buffering in the system. For example, let's assume the soil in your backyard has a net potential acidity of 10 tons per acre of lime demand. With the 25 percent buffer factor added to it, you need to add the equivalent of 12.5 tons of lime per acre, 6 inches deep. Usually, your yard will be much less than 
an acre in size, so we need to convert this to a more practical liming rate per 1,000 square feet. As a matter of convenience, one 50-pound bag of agricultural lime per 1,000 square feet is approximately equivalent to 1 ton per acre. So, the basic liming requirement for your back yard would be $12.5 \times 50$ pounds $=625$ pounds of agricultural lime per 1,000 square feet. These materials would need to be well-mixed (with a rototiller or air knife) to a depth of 6 inches to ensure full reaction and remediation of the surface rooting zone. Once this material is allowed to react following several rainfall or irrigation events, you should be able to use normal plant/lawn establishment procedures, but we recommend adding compost to the surface soil mix whenever possible. It is important to note that the deeper soil layers will not be affected by this treatment, so planting holes for deep-rooted vegetation (e.g., trees) require deeper treatment.

We also recommend a similar remedial treatment for all soils in direct contact with uncoated concrete or foundations, block walls, or metal conduits and pipes. The exception would be where those materials (concrete, metal, etc.) are under the water table or buried deeply enough in the soil that they are beyond the depth of oxygen diffusion.

\section{What Kind of Lime Should I Use?}

The "lime" that we refer to above is "agricultural lime" $\left(\mathrm{CaCO}_{3}\right.$ or $\left.\mathrm{Ca} / \mathrm{MgCaCO}_{3}\right)$ and not hydrated lime $\left(\mathrm{Ca}(\mathrm{OH})_{2}\right)$ or burnt lime $(\mathrm{CaO})$. These two latter materials are commercially available and occasionally used by the geotechnical engineering community for soil cementation or waste treatment. They do have advantages of being more concentrated and quicker to react. However, they are more expensive, can burn your eyes, and can rapidly drive soil $\mathrm{pH}$ to very high values that are also toxic to plants. Therefore, we only recommend the use of certified agricultural lime for this purpose. The use of pelletized lime products is acceptable and may make application of the very high rates easier with minimal dusting issues.

\section{Ideally, How Can We Avoid These Problems in the First Place?}

Based on our work with the Virginia Department of Transportation and others (see website below for details), we have developed a statewide map layer that indentifies all geologic strata that have documented sulfide risk. Predisturbance geologic drill cores by developer's consultants in these units should be evaluated for color, and any gray, blue-gray, or black strata should be tested for total sulfur. If total sulfur is more than 0.25 percent, those same strata should be tested for acid-base-accounting or peroxide potential acidity. Any materials with a net lime demand of more than 5 tons of lime per 1,000 tons of material (or soil) should be isolated from the surface and either heavily compacted in place to limit permeability or bulk limed before placement to offset acidity production over time.

\section{Where Can I Get More Information?}

We maintain current information and reports on this subject posted to our research website at Virginia Tech (www.cses.vt.edu/revegetation/remediation.html). Additionally, the most sophisticated program in the world for recognition and remediation of acid sulfate materials is carried out in Queensland, Australia, due to its preponderance of acid-forming parent materials. Their website (www.nrw.qld.gov.au/land/ass/index.html) is quite comprehensive and informative, with numerous links to their reports, methods, and regulations.

\section{Soil Conditions in Highway Rights-of-Way}

In a typical highway construction corridor, materials lying above the grade of the proposed road are removed (cut) by a variety of earthmoving techniques and hauled to adjacent lower areas for disposal. Whenever possible, the cut materials are utilized as subgrade materials for the roadbed or as fill to span depressions and valleys beneath the corridor. Excess fill materials are usually disposed of in compacted fills as near to the road corridor as possible to minimize hauling costs. The combination of cut and fill activity generates fundamentally different surfaces for revegetation as the road-building project progresses across the landscape. Cut slopes will frequently expose a surficial weathered soil profile and then extend well down into the underlying rock or sediments. These materials will therefore vary considerably in fundamental chemical and physical properties with depth, particularly in regions like the mid-Atlantic United States, where the geochemical weathering profiles are deep and soil horizonation is strong. These gradations with depth are predictable, however, and will tend to recur in a prescribed sequence as the cuts proceed through the landscape.

Fill materials, on the other hand, tend to be quite different from road cuts due to the mixing effects of the earthmoving operations and the fact that they are 
typically heavily compacted in place to meet stability and strength specifications. Fill materials may be more or less variable than adjacent cut areas, depending on how they are handled and placed, but they are typically quite compact and lack the well-developed aggregation or structure that undisturbed soils usually possess. Therefore, soils in highway fill materials as a rule will be less permeable to air, water, and roots than their natural precursors. Fills and fill slopes also are plagued by inclusions of aggregate, rock, concrete, and other construction debris that seriously limit their waterretention characteristics. In contrast, soils on cut slopes generally retain the physical and chemical properties of the original soil/geologic profile, but their surfaces are often compacted to some extent by the earthmoving equipment, and the soil is often "smeared" and sealed, particularly in fine-textured soils.

Regardless of whether you are dealing with cut or fill materials, it is critically important to understand that the vast majority of materials that will be revegetated are composed primarily of subsoil or deeper geologic materials that will be very low in organic matter and associated macronutrients, particularly nitrogen and phosphorus. When highly weathered subsoils are exposed, we are often left with a very clayey and highly acidic substrate that will require significant inputs of lime and phosphorus fertilizers before its basic chemical properties begin to resemble native topsoils. Deeper cuts that extend below the weathered soil zone will frequently contain large amounts of fresh, unweathered rocks and sediments that can be significant sources of calcium, magnesium, potassium, and other nutrient elements as they rapidly weather in their newly exposed geochemical environment. Acid-forming sulfidic materials (as discussed earlier) are also commonly encountered in deeper road cuts in a variety of geologic settings and can generate extremely harsh soil chemical conditions and associated runoff water quality complications as they oxidize.

The cut/fill and site development operations for new highways or other construction activities may cause uncontrolled water flows and sediment loss from bare soil areas. Many small, localized, disturbed areas with seemingly insignificant losses of water and soil will often coalesce into massive and rapid flows of water with high sediment loads, causing severe damage in highway corridors as well as flooding and contamination of receiving streams. Even the initial slow flows of clear water from numerous small areas of disturbance within a highway development corridor can cause progressively larger erosive flows of water. Thus, it is imperative to minimize water flow and sediment losses from the initial stages of grading operations. Uncontrolled erosion also can severely degrade the site quality of the eroded area, particularly if applied topsoil, lime, and fertilizers are lost or a less-hospitable substrate is exposed.

\section{Manufactured Soils}

In certain high-value situations like landscape planting beds and constructed athletic fields, the use of manufactured topsoil materials is a viable alternative to having to manage the pre-existing urban soils (Puhalla et al. 2010). This is particularly true when we consider what is typically available and marketed as topsoil in rapidly developing areas of the mid-Atlantic. The majority of materials that are marketed and sold as topsoil are generated by the land development and construction process and may or may not be true topsoil as defined earlier (A plus E horizons). Additionally, these natural topsoils are highly variable over time as they are hauled from differing sites with different soil properties, soilremoval depths, and handling/storage procedures. Very few of these materials are offered with any guarantee of $\mathrm{pH}$, texture, or nutrient-supplying ability relative to established soil testing standards.

The "ideal" soil for most turf establishment and landscaping applications is loamy in texture to ensure adequate water-holding capacity and aeration without being sticky and plastic when handled and graded. Beyond that, the soil should be moderate in $\mathrm{pH}$ (between 6.5 and 7.5) to ensure maximum beneficial biological activity and moderate to high in plant-available nutrients such as calcium $(\mathrm{Ca})$, magnesium $(\mathrm{Mg})$, potassium $(\mathrm{K})$, and phosphorus $(\mathrm{P})$. Good topsoils also contain small but adequate amounts of plant-essential micronutrients like iron $(\mathrm{Fe})$ and copper $(\mathrm{Cu})$, but should also be low in soluble salts and sodium $(\mathrm{Na})$, which can disperse soil structure and harm plants. Finally, the ideal soil would contain approximately 3 to 5 percent organic matter that serves as a long-term source of plant nutrients (especially nitrogen), maintains biological activity, and greatly enhances physical properties such as waterholding capacity. Perhaps most importantly, the ideal soil for turf and landscaping applications would be consistent over time in all of the above properties so that the user will not have to "fine-tune" establishment and management protocols for each batch of soil received.

There are currently a number of manufactured topsoils available in the region. One example of a manufactured soil developed cooperatively by Luck Stone and 
Virginia Tech (Greene premium topsoil) is described below. This description is not intended as an endorsement of this particular product, but simply as an example of one of many commercially viable products.

The Greene topsoil product is manufactured from native soil saprolite, compost, and mineralized igneous rock dust to produce loamy topsoil that is well-balanced in organic matter, available plant nutrients, and $\mathrm{pH}$. This product was developed cooperatively with the Department of Crop and Soil Environmental Sciences at Virginia Tech, and as seen in table 3.1, is equal to or exceeds natural topsoils in productivity potential for most horticultural, landscaping, and gardening applications. The Greene topsoil is high in organic matter (5 to 7 percent), moderate in $\mathrm{pH}$ (6.0 to 7.5) and soluble salts (up to 2.0 millimhos per centimeter (mmhos/cm)), and low in sodium. Plant-available phosphorus is more than 70 parts per million (ppm), potassium and magnesium are both more than $100 \mathrm{ppm}$, and calcium is more than $1,000 \mathrm{ppm}$. This topsoil also provides balanced levels of plant-available micronutrients (e.g., boron, copper, iron, manganese, and zinc).

The Greene topsoil is higher than natural topsoils in organic matter content and available nutrients because it is carefully blended with fresh, unweathered primary mineral fines and compost to generate the characteristics displayed in table 3.1. Perhaps most importantly, the Greene topsoil product has been tested and proven to be quite consistent over time and has been proven effective in a wide range of plant growth uses in research at Virginia Tech and on-site applications by the producer's client base of landscapers and developers.
Due to the inherent fertility of the Greene topsoil, use of initial or starter fertilizers (especially phosphorus and potassium) is probably not necessary or warranted, particularly in light of current concerns over minimizing losses of nutrients to surface waters. However, initially high levels of available nutrients will be depleted over time by plant uptake, and like any soil, subsequent fertilization will be required. The Greene topsoil product is not recommended for root zone use with acidloving plants such as blueberries, azaleas, and native pines unless it is blended with naturally acidic ( $\mathrm{pH}$ less than 6.0) soil materials.

\section{Modified Soils and Mulches}

Another approach to mitigate the adverse properties of urban soils is via "soil modification" or "conditioning," a process that generally involves the incorporation of inorganic or organic amendments into bulk soil to fundamentally alter important soil physical properties (Wallace and Terry 1998). Certain inorganic amendments (e.g., sand or bottom ash) can be added to clayey soils to reduce their stickiness and plasticity, but the volumes required to generate a loamy texture (10 to 40 percent), coupled with the costs and logistics involved limit this approach to high-value locales. Similarly, waste clays from sand mining operations (e.g., slimes) can be added into extremely coarse-textured soils to convert them to loamy textures but similar issues of cost and logistics apply. Other inorganic amendments (e.g., gypsum and lime) can be added to clayey or dispersed soils to promote aggregation, but this usually involves much lower loading rates than textural modification

\section{Table 3.1. Important soil properties for the Greene topsoil compared to highly productive prime farmland topsoil from Dinwiddie County, Va., and the range of typical topsoil properties found in Virginia.}

\begin{tabular}{llll}
\hline Soil property & Greene topsoil & Prime farmland & Average Virginia topsoil \\
\hline Texture & Sandy loam & Sandy loam & Sandy loam to clay loam \\
\hline $\mathrm{pH}$ (acidity) & $6.6-7.2$ & $6.0-6.5$ & $4.5-7.5$ \\
\hline Organic matter & $5-7 \%$ & $1-2 \%$ & $0.5-3 \%$ \\
\hline Available* calcium $(\mathrm{Ca})$ & $>1,200 \mathrm{ppm}$ & $300-600 \mathrm{ppm}$ & $<50-600 \mathrm{ppm}$ \\
\hline Available potassium $(\mathrm{K})$ & $>250 \mathrm{ppm}$ & $30-60 \mathrm{ppm}$ & $<20-80 \mathrm{ppm}$ \\
\hline Available phosphorus $(\mathrm{P})$ & $75-150 \mathrm{ppm}$ & $20-30 \mathrm{ppm}$ & $<5-30 \mathrm{ppm}$ \\
\hline Available copper $(\mathrm{Cu})$ & $1.5 \mathrm{ppm}$ & $0.6 \mathrm{ppm}$ & $0.2-0.7 \mathrm{ppm}$ \\
\hline
\end{tabular}

Data compiled from research reports by W. Lee Daniels, Virginia Tech.

*Available soil nutrients are those contained in an acid-extractable form that would be expected to contribute to plant uptake needs over the growing season and are typically expressed in parts per million (ppm) of total soil weight. For a common-sense conversion, 100 ppm of available $\mathrm{Ca}$ in a soil would equate to approximately 200 pounds of calcium in the upper 6 inches of topsoil over 1 acre. 
and really differs little from conventional liming practice. Certain inorganic soil conditioners (e.g., fly ash or waste gypsum) may also contain significant levels of soluble salts or potentially phytotoxic elements like boron, so their use must be carefully considered and controlled.A wide array of organics (e.g., composts, biosolids, animal manures, and paper sludges) are also routinely utilized to enhance aggregation, porosity, and water-holding capacity in urban soils. Usually, these materials are most effective when incorporated or bulk blended with surface soil layers, which may require up to 25 percent volumetric addition rates. One potential drawback of many organic amendments (e.g., biosolids and manures) is that addition at these rates may pose significant nutrient runoff or leaching risks (see chapters 2, 9, 10, and 12). Another long-term management factor to consider is that organic amendments will naturally decompose with time, and their "bulking effect" on porosity will thereby decline as well. However, the humus fraction they leave behind will make a very valuable and long-lived contribution to urban soil quality.

Finally, surface mulches can also be utilized to buffer soil temperature, enhance water infiltration and retention, limit traffic-related soil compaction, and reduce weed competition (Brady and Weil 2008). More detail on use of organic mulches is found in chapter 9.

A more thorough discussion of the full array of soil amendments, conditioners, and mulches and their relative advantages and management is beyond the scope of this book. However, greater detail on these topics can be found in the various resources cited below.

\section{Literature Cited}

Booze-Daniels, J. N., J. M. Krouse, W. L. Daniels, D. L. Wright, and R.E. Schmidt. 2000. Establishment of low maintenance vegetation in highway corridors. In Reclamation of Drastically Disturbed Lands, ed. R. I. Barnhisel, W. L. Daniels, and R. G. Darmody, 887-920. Agronomy Monograph No. 41. Madison, Wis.: American Society of Agronomy, Crop Science Society of America, and Soil Science Society of America.

Brady, N. C., and R. R. Weil. 2008. The Nature and Properties of Soils. 14th ed. Upper Saddle River, N.J.: Pearson Prentice Hall.

Brown, R. B., J. H. Huddleston, and J. L. Anderson, eds. 2000. Managing Soils in an Urban Environment. Agronomy Monograph No. 39. Madison, Wis.: American Society of Agronomy.
Craul, P. J. 1992. Urban Soil in Landscape Design. New York: John Wiley \& Sons.

Fanning, D. S., Cary Coppock, Z. W. Orndorff, W. L. Daniels, and M. C. Rabenhorst. 2004. Upland active acid sulfate soils from construction of new Stafford County, Virginia, USA, Airport. Australian Journal of Soil Resources 42:527-36.

Orndorff, Z. W., and W. L. Daniels. 2004. Evaluation of acid-producing sulfidic materials in Virginia highway corridors. Environmental Geology 46:209-16.

Puhalla, J. C., J. V. Krans, and J. M. Goatley Jr. 2010. Sports Fields: Design, Construction, and Maintenance. 2nd edition. Hoboken, N.J.: John Wiley \& Sons.

Scheyer, J. M., and K. W. Hipple. 2005. Urban Soil Primer. USDA-NRCS, National Soil Survey Center. Lincoln, Neb.: USDA. http://soils.usda.gov/ use/urban/primer.html.

Wagner, D. P., D. S. Fanning, J. E. Foss, M. S. Patterson, and P. A. Snow. 1982. Morphological and mineralogical features related to sulfide oxidation under natural and disturbed land surfaces in Maryland. In Acid Sulfate Weathering, ed. J. A. Kittrick, D. S. Fanning, and L. R. Hossner, 109-25. Soil Science Society of America Special Publication No. 10. Madison, Wis.: Soil Science Society of America.

Wallace, A., and R. E. Terry, eds. 1998. Handbook of Soil Conditioners: Substances That Enhance the Physical Properties of Soil. New York: Marcel Dekker. 


\section{Chapter 4. Basic Soil Fertility}

Greg Mullins, Former Professor and Extension Specialist, Crop and Soil Environmental Sciences, Virginia Tech Kathryn C. Haering, Research Associate, Crop and Soil Environmental Sciences, Virginia Tech

David J. Hansen, Associate Professor, Plant and Soil Sciences, University of Delaware

\section{Plant Nutrition}

\section{Essential Elements}

An essential mineral element is one that is required for normal plant growth and reproduction. With the exception of carbon $(\mathrm{C})$ and oxygen $(\mathrm{O})$, which are supplied from the atmosphere, the essential elements are obtained from the soil. The amount of each element required by the plant varies; however, all essential elements are equally important in terms of plant physiological processes and plant growth.

The exact number of elements that should be considered "essential" to plant growth is a matter of some debate. For example, cobalt (Co), which is required for nitrogen (N) fixation in legumes, is not considered to be an essential element by some researchers. Table 4.1 lists 18 elements that are considered essential by many scientists. Other elements that are sometimes listed as essential are sodium (Na), silicon ( $\mathrm{Si}$ ), and vanadium (V).

\section{Categories of Essential Elements}

Essential elements can be grouped into four categories, based on their origin or the relative amount a plant needs in order to develop properly (table 4.2).

1. Nonmineral essential elements are derived from the air and water.

2. Primary essential elements are most often applied in commercial fertilizers or in manures.

3. Secondary elements are normally applied as soil amendments or are components of fertilizers that carry primary nutrients.

Nonmineral, primary, and secondary elements are also referred to as "macronutrients," because they are required in relatively large amounts by plants.

4. "Micronutrients" are required in very small, or "trace," amounts by plants. Although micronutrients are required by plants in very small quantities, they are equally essential to plant growth.
Table 4.1. Eighteen essential elements for plant growth and the chemical forms most commonly taken up by plants.

\begin{tabular}{lcc}
\hline Element & Symbol & $\begin{array}{c}\text { Form absorbed } \\
\text { by plants }\end{array}$ \\
\hline Carbon & $\mathrm{C}$ & $\mathrm{CO}_{2}$ \\
\hline Hydrogen & $\mathrm{H}$ & $\mathrm{H}^{+}, \mathrm{OH}^{2}, \mathrm{H}_{2} \mathrm{O}$ \\
\hline Oxygen & $\mathrm{O}$ & $\mathrm{O}_{2}$ \\
\hline Nitrogen & $\mathrm{N}$ & $\mathrm{NH}_{4}{ }^{+}, \mathrm{NO}_{3}{ }^{-}$ \\
\hline Phosphorus & $\mathrm{P}$ & $\mathrm{HPO}_{4}{ }^{2-}, \mathrm{H}_{2} \mathrm{PO}_{4}{ }^{-}$ \\
\hline Potassium & $\mathrm{K}$ & $\mathrm{K}^{+}$ \\
\hline Calcium & $\mathrm{Ca}$ & $\mathrm{Ca}^{2+}$ \\
\hline Magnesium & $\mathrm{Mg}$ & $\mathrm{Mg}^{2+}$ \\
\hline Sulfur & $\mathrm{S}$ & $\mathrm{SO}_{4}{ }^{2-}$ \\
\hline Iron & $\mathrm{Fe}$ & $\mathrm{Fe}^{2+}, \mathrm{Fe}^{3+}$ \\
\hline Manganese & $\mathrm{Mn}$ & $\mathrm{Mn}^{2+}, \mathrm{Mn}^{4+}$ \\
\hline Boron & $\mathrm{B}$ & $\mathrm{H}_{3} \mathrm{BO}_{3}, \mathrm{BO}_{3}{ }^{-}, \mathrm{B}_{4} \mathrm{O}_{7}{ }^{2-}$ \\
\hline Zinc & $\mathrm{Zn}$ & $\mathrm{Zn}^{2+}$ \\
\hline Copper & $\mathrm{Cu}$ & $\mathrm{Cu}^{2+}$ \\
\hline Molybdenum & $\mathrm{Mo}$ & $\mathrm{MoO}_{4}{ }^{2-}$ \\
\hline Chlorine & $\mathrm{Cl}$ & $\mathrm{Cl}^{-}$ \\
\hline Cobalt & $\mathrm{Co}$ & $\mathrm{Co}^{2+}$ \\
\hline Nickel & $\mathrm{Ni}$ & $\mathrm{Ni}^{2+}$ \\
\hline
\end{tabular}

Table 4.2. Essential elements, their relative uptake, and sources where plants obtain them.

\begin{tabular}{llll}
\hline \multicolumn{3}{c}{ Macronutrients } & \\
\cline { 1 - 2 } Nonmineral & Primary & Secondary & Micronutrients \\
\hline (Mostly from & (Mostly & (Mostly & (Mostly \\
air and water) & from soil) & from soil) & from soil) \\
\hline Carbon & Nitrogen & Calcium & Iron \\
Hydrogen & Phosphorus & Magnesium & Manganese \\
Oxygen & Potassium & Sulfur & Boron \\
& & & Zinc \\
& & & Copper \\
& & & Molybdenum \\
& & & Chlorine \\
& & & Cobalt \\
& & Nickel \\
\hline
\end{tabular}




\section{Functions of Essential Elements in Plants}

Carbon (C), Hydrogen ( $H)$, and Oxygen (O)

- Directly involved in photosynthesis, which accounts for most plant growth.

\section{Nitrogen (N)}

- Found in chlorophyll, nucleic acids, and amino acids.

- Component of protein and enzymes, which control almost all biological processes.

\section{Phosphorus $(P)$}

- Essential component of adenosine triphosphate (ATP) - which is directly responsible for energy transfer reactions in the plant - and of DNA and RNA.

- Essential component of phospholipids, which play critical roles in cell membranes.

- Important for plant development - including development of a healthy root system, normal seed development, and photosynthesis - respiration, cell division, and other processes.

\section{Potassium (K)}

- Responsible for regulation of plants' water usage, disease resistance, and stem strength.

- Involved in photosynthesis, drought tolerance, winter hardiness, and protein synthesis.

\section{Calcium (Ca)}

- Essential for cell elongation and division.

- Specifically required for root and leaf development, function of cell membranes, and formation of cell wall compounds.

- Involved in the activation of several plant enzymes.

\section{Magnesium (Mg)}

- Primary component of chlorophyll, and therefore, actively involved in photosynthesis.

- Structural component of ribosomes, which are required for protein synthesis.

- Involved in phosphate metabolism, respiration, and the activation of several enzyme systems.
Sulfur (S)

- Required for the synthesis of the sulfur-containing amino acids cystine, cysteine, and methionine, which are essential for protein formation.

- Involved with development of enzymes and vitamins, chlorophyll formation, and formation of several organic compounds that give characteristic odors to garlic, mustard, and onion.

Iron $(\mathrm{Fe})$

- Serves as a catalyst in chlorophyll synthesis.

- Involved in many oxidation-reduction reactions during respiration and photosynthesis.

Manganese (Mn)

- Functions primarily as a part of the enzyme systems in plants.

- Activates several important metabolic reactions.

- Plays a direct role in photosynthesis.

- Along with iron, serves as a catalyst in chlorophyll synthesis.

Boron (B)

- Essential for germination of pollen grains and growth of pollen tubes, seed, and cell wall formation.

- Essential for development and growth of new cells in meristematic tissue.

- Sugar/borate complexes associated with translocation of sugars, starches, nitrogen, and phosphorus.

- Important in protein synthesis.

$\operatorname{Zinc}(Z n)$

- Essential for promoting certain metabolic/enzymatic reactions.

- Necessary for the production of chlorophyll, carbohydrates, and growth hormones.

- Aids in the synthesis of plant growth compounds and enzyme systems.

\section{Copper (Cu)}

- Necessary for chlorophyll formation.

- Serves as a catalyst for several enzymes. 


\section{Molybdenum (Mo)}

- Required for the synthesis and activity of the enzyme system that reduces nitrate to ammonium in the plant.

- Essential in the process of symbiotic nitrogen fixation by Rhizobia bacteria in legume root nodules.

\section{Chlorine (Cl)}

- Involved in energy reactions in the plant, breakdown of water, regulation of stomata guard cells, maintenance of turgor, and rate of water loss.

- Involved in plant response to moisture stress and resistance to some diseases.

- Activates several enzyme systems.

- Serves as a counter ion in the transport of several cations in the plant.

\section{Cobalt (Co)}

- Essential in the process of symbiotic nitrogen fixation by Rhizobia bacteria in legume root nodules.

- Not proven to be essential for the growth of all higher plants.

\section{Nickel (Ni)}

- Component of the urease enzyme.

- Essential for plants in which ureides are important in nitrogen metabolism.

\section{Nutrient Deficiency Symptoms}

Visual diagnosis of plant deficiencies can be very risky. There may be more than one deficiency symptom expressed, which can make diagnosis difficult. Both soil and tissue samples should be collected, analyzed, and interpreted before any recommendations are made concerning application of fertilizer.

Terminology used to describe deficiency symptoms (table 4.3) includes:

Chlorosis Yellowing or lighter shade of green.

Necrosis Browning or dying of plant tissue.

Interveinal Between the leaf veins.

Meristem Growing point of a plant.

Internode Distance of the stem between the leaves.
Elements can be either "mobile" or "not mobile" within plants. This determines where symptoms of an element deficiency will first appear in a plant. A mobile element is one that is able to "translocate" (move) from one part of the plant to another depending on its need. Mobile elements generally move from older (lower) plant parts to the meristem, or growing point.

\section{Soil pH, Nutrient Availability, and Liming}

\section{Effect of pH on Nutrient Availability}

Many soil elements change form as a result of chemical reactions in the soil. Plants may or may not be able to use elements in some of these forms. Because $\mathrm{pH}$ influences the soil concentration and, thus, the availability of plant nutrients, it is responsible for the solubility of many nutrient elements. Figure 4.1 illustrates the relationship between soil $\mathrm{pH}$ and the relative plant availability of nutrients.

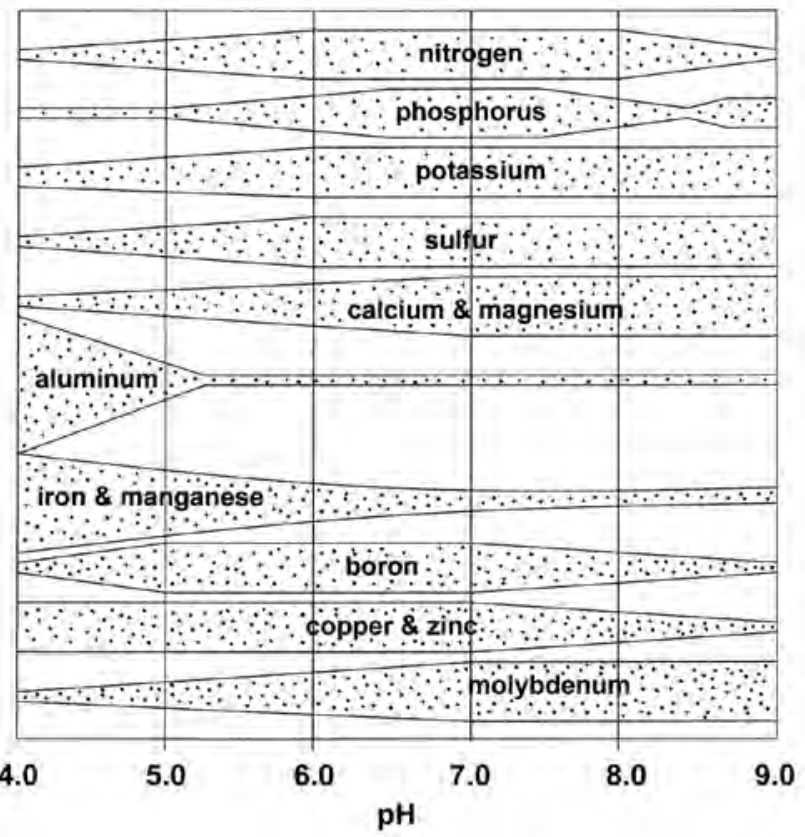

Figure 4.1. Relationship between soil $\mathrm{pH}$ and nutrient availability. Graphic by Kathryn Haering.

Phosphorus solubility and plant availability are controlled by complex soil chemical reactions, which are often $\mathrm{pH}$-dependent. Plant availability of $\mathrm{P}$ is generally greatest in the $\mathrm{pH}$ range of 5.5 to 6.8 . When soil $\mathrm{pH}$ falls below 5.8, $\mathrm{P}$ reacts with $\mathrm{Fe}$ and $\mathrm{Al}$ to produce insoluble iron and aluminum phosphates that are not readily available for plant uptake. At high $\mathrm{pH}$ values, phosphorus reacts with $\mathrm{Ca}$ to form calcium phosphates that are relatively insoluble and have low availability to plants. 
Table 4.3. Element mobility and specific deficiency symptoms.

\begin{tabular}{ll}
\hline Element & Mobility \\
\hline Nitrogen & $\begin{array}{l}\text { Mobile within plants; lower leaves } \\
\text { show chlorosis first. }\end{array}$
\end{tabular}
\begin{tabular}{ll}
\hline Phosphorus & Mobile within plants; lower leaves \\
& show deficiency first.
\end{tabular}

\section{Deficiency Symptoms and Occurrence}

Stunted, slow-growing, chlorotic plants; reduced yield; plants more susceptible to weather stress and disease. Some plants may mature earlier.

Overall stunted plant and a poorly developed root system. Can cause purple or reddish color associated with the accumulation of sugars. Difficult to detect from visual symptoms.

Potassium Mobile within plants; lower leaves
show deficiency first.

Scorching or firing along leaf margins, slow growth, poorly developed root systems, weak stalks, small and shriveled seeds and fruit, and low disease-resistance.

Deficiencies most common on acidic sandy soils or soils that have received large applications of $\mathrm{Ca}$ and/or $\mathrm{Mg}$.

\begin{tabular}{ll}
\hline Calcium & Not mobile within plants; upper \\
& leaves and the growing point show \\
deficiency symptoms first.
\end{tabular}

Poor root growth and failure of terminal buds of shoots and apical tips of roots to develop, causing plant growth to cease.

Most often occurs on very acidic soils where Ca levels are low but other deficiency effects such as high acidity usually limit growth before Ca deficiency becomes apparent.

\begin{tabular}{ll}
\hline Magnesium & $\begin{array}{l}\text { Mobile within plants; lower leaves } \\
\text { show deficiency first. }\end{array}$ \\
\hline Sulfur & $\begin{array}{l}\text { Somewhat mobile within plants, } \\
\text { but upper leaves tend to show } \\
\text { deficiency first. }\end{array}$ \\
\hline Boron & $\begin{array}{l}\text { Not mobile within plants; upper } \\
\text { leaves and the growing point show } \\
\text { deficiency symptoms first. }\end{array}$
\end{tabular}

\begin{tabular}{ll}
\hline Copper & $\begin{array}{l}\text { Not mobile within plants; upper } \\
\text { leaves and the growing point show } \\
\text { deficiency symptoms first. }\end{array}$
\end{tabular}

Iron Not mobile within plants; upper
leaves show deficiency symptoms first.

Yellowish, bronze, or reddish color in leaves while leaf veins remain green.

Chlorosis of the longer leaves and possible chlorosis and stunting of entire plant with severe deficiencies. Symptoms resemble those of $\mathrm{N}$ deficiency; can lead to incorrect diagnoses.

Reduced leaf size and deformation of new leaves, interveinal chlorosis, distorted branches and stems, possible flower and/or fruit abortion, stunted growth.

May occur on very acidic, sandy-textured soils or alkaline soils.

Reduced leaf size, uniformly pale yellow leaves, leaves may lack turgor and can develop a bluish-green cast, become chlorotic, and/or curl. Flower production fails to take place.

Interveinal chlorosis that progresses over the entire leaf. With severe deficiencies, leaves turn entirely white.

Factors contributing to Fe deficiency include imbalance with other metals, excessive soil P levels, high soil pH, wet and cold soils.

\begin{tabular}{ll}
\hline Manganese & $\begin{array}{l}\text { Not mobile within plants; upper } \\
\text { leaves show deficiency symptoms } \\
\text { first. }\end{array}$ \\
\hline Zinc & $\begin{array}{l}\text { Not mobile within plants; upper } \\
\text { leaves and the growing point show } \\
\text { deficiency symptoms first. }\end{array}$
\end{tabular}

\begin{tabular}{ll}
\hline Molybdenum & Not mobile within plants; upper \\
& leaves show deficiency symptoms \\
& first.
\end{tabular}

\begin{tabular}{ll}
\hline Chlorine & Mobile within plant, but deficiency \\
& symptoms usually appear on the \\
& upper leaves first.
\end{tabular}

Cobalt Used by symbiotic N-fixing bacteria in root nodules of legumes and other plants.
Interveinal chlorosis, brownish-black specks.

Occurs most often on high-organic-matter soils and soils with neutral-to-alkaline $\mathrm{pH}$ and low native $\mathrm{Mn}$ content.

Shortened internodes between new leaves, death of meristematic tissue, deformed new leaves, interveinal chlorosis.

Occurs most often on alkaline (high $\mathrm{pH}$ ) soils or soils with high available P levels.

Interveinal chlorosis, wilting, marginal necrosis of upper leaves.

Occurs principally on very acidic soils because Mo becomes less available with low $\mathrm{pH}$.

Chlorosis in upper leaves; overall wilting of plants.

Deficiencies may occur in well-drained soils under high rainfall conditions.

Causes $\mathrm{N}$ deficiency, chlorotic leaves, and stunted plants.

Occurs in areas with soils deficient in native Co. 
Potassium, calcium, and magnesium are most present in soils with $\mathrm{pH}$ levels greater than 6.0. They are generally not as available for plant uptake in acidic soils because they may have been partially leached out of the soil profile.

At $\mathrm{pH}$ values less than 5.0, $\mathrm{Al}, \mathrm{Fe}$, and $\mathrm{Mn}$ may be soluble in sufficient quantities to be toxic to the growth of some plants. Aluminum toxicity limits plant growth in most strongly acidic soils. Aluminum begins to solubilize from silicate clays and Al hydroxides below a $\mathrm{pH}$ of approximately 5.3, which increases the activity of exchangeable $\mathrm{Al}^{3+}$. High concentrations of exchangeable $\mathrm{Al}$ are toxic and detrimental to plant root development.

In general, most micronutrients are more available in acidic than in alkaline soils. As $\mathrm{pH}$ increases, micronutrient availability decreases, and the potential for deficiencies increases. An exception to this trend is Mo, which becomes less available as soil $\mathrm{pH}$ decreases. In addition, $\mathrm{B}$ becomes less available when the $\mathrm{pH}$ is less than 5.0 and again when the $\mathrm{pH}$ exceeds 7.0.

Soil organisms also grow best in near-neutral soil. In general, acidic soil inhibits the growth of most organisms, including many bacteria and earthworms. Thus, acidic soil slows many important activities carried on by soil microbes, including nitrogen fixation, nitrification, and organic matter decay. Rhizobia bacteria, for instance, thrive at near-neutral $\mathrm{pH}$ and are sensitive to solubulized Al.

\section{Soil Acidification and Liming}

Acidification is a natural process that occurs continuously in soils throughout the mid-Atlantic region and is caused by the following factors:

- The breakdown of organic matter can cause acidification of the soil as amino acids are converted into acetic acid, hydrogen gas, dinitrogen gas, and carbon dioxide by the reaction:

$$
2 \mathrm{C}_{3} \mathrm{H}_{7} \mathrm{NO}_{3}+\mathrm{O}_{2} \rightarrow 2 \mathrm{HC}_{2} \mathrm{H}_{3} \mathrm{O}_{2}+3 \mathrm{H}_{2}+\mathrm{N}_{2}+2 \mathrm{CO}_{2} \text {. }
$$

- The movement of acidic water from rainfall through soils slowly leaches basic essential elements such as $\mathrm{Ca}, \mathrm{Ma}$, and $\mathrm{K}$, below the plant root zone and increases the concentration of exchangeable soil Al. Soluble $\mathrm{Al}^{3+}$ reacts with water to form hydrogen ions, which make the soil acidic.

- Soil erosion removes exchangeable cations adsorbed to clay particles.
- Hydrogen is released into the soil by plants' root systems as a result of respiration and ion uptake processes during plant growth.

- Nitrogen fertilization speeds up the rate at which acidity develops, primarily through the acidity generated by nitrification:

$$
2 \mathrm{NH}_{4}^{+}+4 \mathrm{O}_{2} \rightarrow 2 \mathrm{H}_{2} \mathrm{O}+4 \mathrm{H}^{+}+2 \mathrm{NO}_{3}^{-} .
$$

Liming is a critical management practice for maintaining soil $\mathrm{pH}$ at optimal levels for plant growth. Liming supplies the essential elements $\mathrm{Ca}$ and/or $\mathrm{Mg}$, reduces the solubility and potential toxicity of $\mathrm{Al}$ and $\mathrm{Mn}$, and increases the availability of several essential nutrients. Liming also stimulates microbial activity (e.g., nitrification) in the soil, and improves symbiotic nitrogen fixation by legumes. However, over-liming can induce micronutrient deficiencies by increasing $\mathrm{pH}$ above the optimum range.

Most plants grow well in the $\mathrm{pH}$ range 5.8 to 6.5. Leguminous plants generally grow better in soils limed to $\mathrm{pH}$ values of 6.2 to 6.8 . Some plants, such as blueberries, mountain laurel, rhododendron, and others, grow best in strongly acidic ( $\mathrm{pH}$ less than 5.2) soils.

\section{Determining Lime Requirements}

Soil $\mathrm{pH}$ is an excellent indicator of soil acidity; however, it does not indicate how much total acidity is present, and it cannot be used to determine a soil's lime requirement when used alone.

The "lime requirement" for a soil is the amount of agricultural limestone needed to achieve a desired $\mathrm{pH}$ range for the plants that are grown. Soil pH determines only active acidity - the amount of $\mathrm{H}^{+}$in the soil solution at that particular time - while the lime requirement determines the amount of exchangeable or reserve acidity held by soil clay and organic matter (figure 4.2).

Most laboratories use soil $\mathrm{pH}$ in combination with "buffered" solutions to extract and measure the amount of reserve acidity, or "buffering capacity" in a soil. The measured amount of exchangeable/reserve acidity is then used to determine the proper amount of lime needed to bring about the desired increase in soil $\mathrm{pH}$.

The rate of limestone applied to any area should be based on soil test recommendations. A soil test every two to three years will reveal whether or not lime is needed. Sandy soils generally require less lime at any one application than silt loam or clay soils to decrease soil acidity by a given amount. Sandy soils, however, 
usually need to be limed more frequently because their buffering capacity is low.

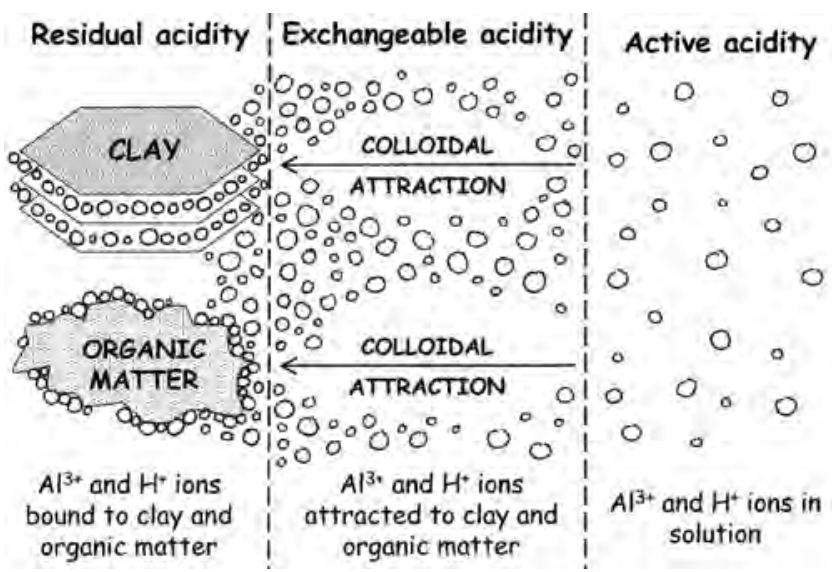

Figure 4.2. Relationship between residual, exchangeable, and active acidity in soils.

Graphic by Kathryn Haering.

\section{Nitrogen}

\section{The Nitrogen Cycle}

Nitrogen is subject to more transformations than any other essential element. These cumulative gains, losses, and changes are collectively termed the "nitrogen cycle" (figure 4.3). The ultimate source of $\mathrm{N}$ is $\mathrm{N}_{2}$ gas, which comprises approximately 78 percent of the earth's atmosphere. Inert $\mathrm{N}_{2}$ gas, however, is unavailable to plants and must be transformed by biological or industrial processes into forms that are plant-available. As a result, the turf and landscape industry is heavily dependent on commercial $\mathrm{N}$ fertilizer. Some of the more important components of the $\mathrm{N}$ cycle are discussed below.

\section{The Nitrogen Cycle}

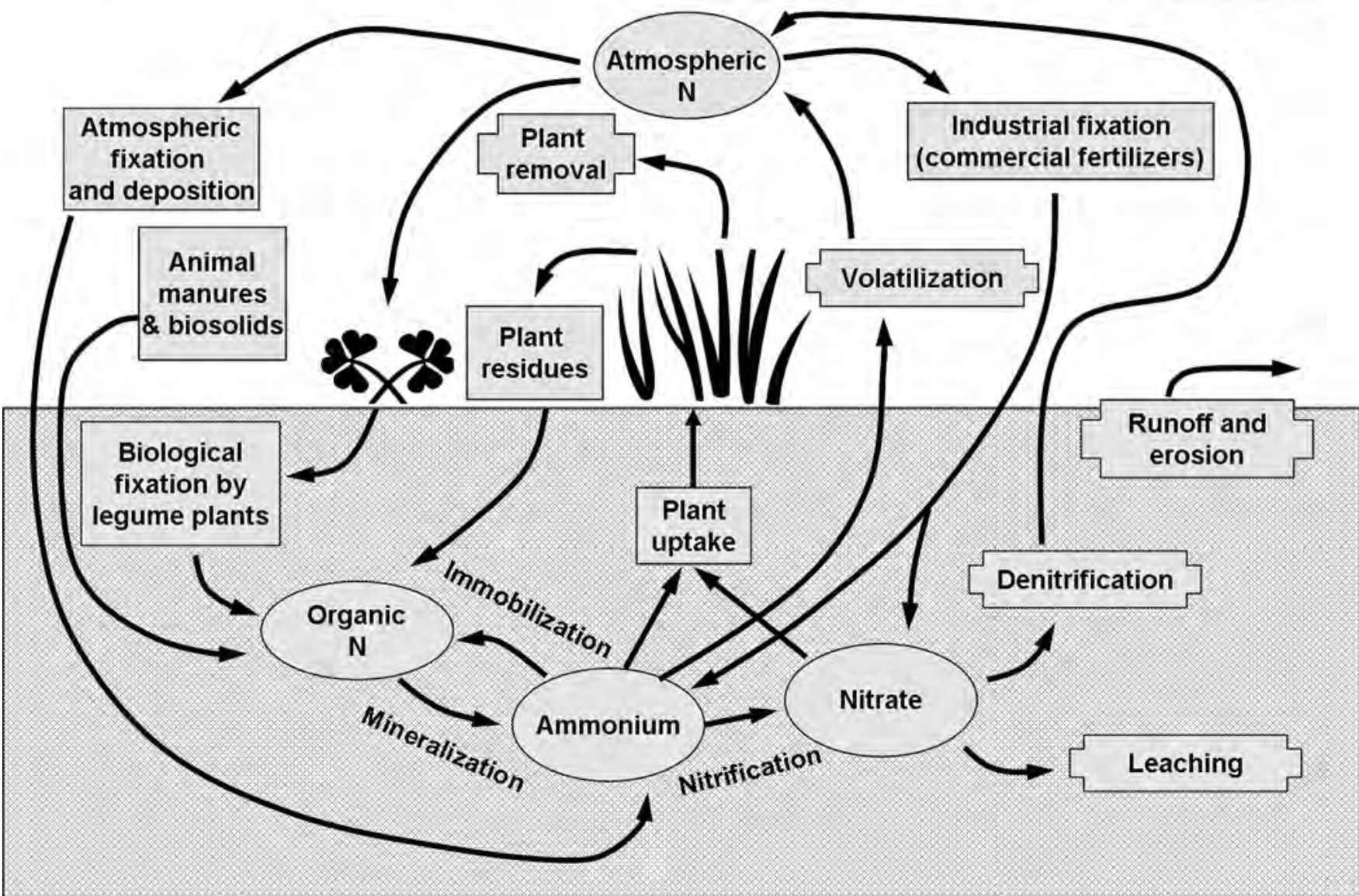

Figure 4.3. The nitrogen cycle (modified from the Potash \& Phosphate Institute website at www.ppi-ppic.org). 


\section{Nitrogen Fixation}

"Nitrogen fixation" is the process whereby inert $\mathrm{N}_{2}$ gas in the atmosphere is transformed into forms that are plant-available, including ammonium $\left(\mathrm{NH}_{4}^{+}\right)$and nitrate $\left(\mathrm{NO}_{3}{ }^{-}\right)$. Fixation can take place by biological or by nonbiological processes.

Biological nitrogen-fixation processes include:

\section{Symbiotic Nitrogen Fixation}

This process is mediated by bacteria with the ability to convert atmospheric $\mathrm{N}_{2}$ to plant-available $\mathrm{N}$ while growing in association with a host plant. Symbiotic Rhizobium bacteria fix $\mathrm{N}_{2}$ in nodules present on the roots of legumes. Through this relationship, the bacteria make $\mathrm{N}_{2}$ from the atmosphere available to the legume as it is excreted from the nodules into the soil.

\section{Nonsymbiotic Nitrogen Fixation}

This is a $\mathrm{N}_{2}$-fixation process that is performed by freeliving bacteria and blue-green algae in the soil. The amount of $\mathrm{N}_{2}$ fixed by these organisms is much lower than that fixed by symbiotic $\mathrm{N}_{2}$ fixation.

Nonbiological N-fixation processes include:

\section{Atmospheric additions}

Small amounts of $\mathrm{N}$ in the order of 5 to 15 pounds per acre per year can be added to the soil in the form of rain or snowfall. This includes $\mathrm{N}$ that has been fixed by the electrical discharge of lightning in the atmosphere and industrial pollution.

\section{Industrial Nitrogen Fixation}

The industrial fixation of nitrogen is the most important source of $\mathrm{N}$ as a plant nutrient. The production of $\mathrm{N}$ by industrial processes is based on the Haber-Bosch process where $\mathrm{H}_{2}$ and $\mathrm{N}_{2}$ gases react to form ammonia $\left(\mathrm{NH}_{3}\right)$. Hydrogen gas for this process is obtained from natural gas and $\mathrm{N}_{2}$ comes directly from the atmosphere. The $\mathrm{NH}_{3}$ produced can be used directly as a fertilizer or as the raw material for other $\mathrm{N}$ fertilizer products, including ammonium phosphates, urea, and ammonium nitrate.

\section{Forms of Soil Nitrogen}

Soil $\mathrm{N}$ occurs in both inorganic and organic forms. Most of the total $\mathrm{N}$ in surface soils is present as organic nitrogen. Organic soil $\mathrm{N}$ occurs in the form of amino acids, amino sugars, and other complex nitrogen compounds. Inorganic forms of soil nitrogen include ammonium $\left(\mathrm{NH}_{4}^{+}\right)$, nitrite $\left(\mathrm{NO}_{2}^{-}\right)$, nitrate $\left(\mathrm{NO}_{3}^{-}\right)$, nitrous oxide $\left(\mathrm{N}_{2} \mathrm{O}_{\text {gas }}\right)$, nitric oxide $\left(\mathrm{NO}_{\text {gas }}\right)$, and elemental nitrogen $\left(\mathrm{N}_{2 \text { gas }}\right)$. Ammonium, nitrite, and nitrate are the most important plant nutrient forms of $\mathrm{N}$ and usually make up 2 to 5 percent of total soil N.

Nitrogen "mineralization" (figure 4.4) is the conversion of organic nitrogen to $\mathrm{NH}_{4}^{+}$. This is an important process in the $\mathrm{N}$ cycle because it results in the liberation of plant-available, inorganic nitrogen forms.

Nitrogen "immobilization" is the conversion of inorganic, plant-available nitrogen $\left(\mathrm{NH}_{4}^{+}\right.$or $\left.\mathrm{NO}_{3}^{-}\right)$by soil microorganisms to organic $\mathrm{N}$ forms (amino acids and proteins). This conversion is the reverse of mineralization, and these immobilized forms of $\mathrm{N}$ are not readily available for plant uptake.
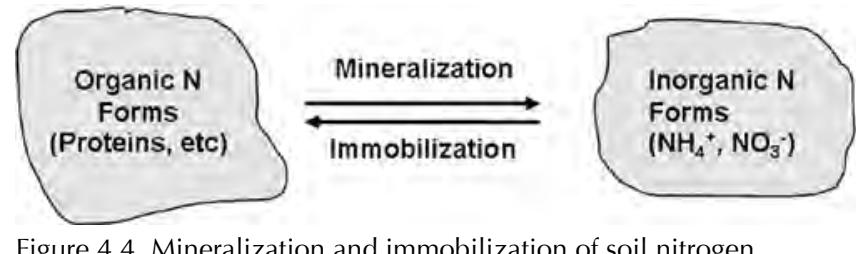

Figure 4.4. Mineralization and immobilization of soil nitrogen. Graphic by Greg Mullins.

\section{Carbon-to-Nitrogen Ratios}

Mineralization and immobilization are ongoing processes in the soil and are generally in balance with one another. This balance can be disrupted by the incorporation of organic materials that have high carbon to nitrogen ratios $(\mathrm{C}: \mathrm{N})$. The ratio of $\% \mathrm{C}$ to $\% \mathrm{~N}$, or the $\mathrm{C}: \mathrm{N}$ ratio, defines the relative quantities of these elements in residues and living tissues. Whether $\mathrm{N}$ is mineralized or immobilized depends on the $\mathrm{C}: \mathrm{N}$ ratio of the organic material being decomposed by soil microorganisms.

- Wide $\mathrm{C}: \mathrm{N}$ ratios of more than 30-to-1: Immobilization of soil $\mathrm{N}$ will be favored. Materials with wide $\mathrm{C}: \mathrm{N}$ ratios include bark mulch, straw, pine needles, dry leaves, and sawdust.

- C:N ratios of 20-to-1 to 30-to-1: Immobilization and mineralization will be nearly equal.

- Narrow C:N ratios of less than 20-to-1: Favor rapid mineralization of $\mathrm{N}$. Materials with narrow $\mathrm{C}: \mathrm{N}$ ratios include manure and biosolids.

The decomposition of an organic material with a high $\mathrm{C}: \mathrm{N}$ ratio is illustrated in figure 4.5. Shortly after incorporation, high $\mathrm{C}: \mathrm{N}$ ratio materials are attacked and used as an energy source by soil microorganisms. As these 


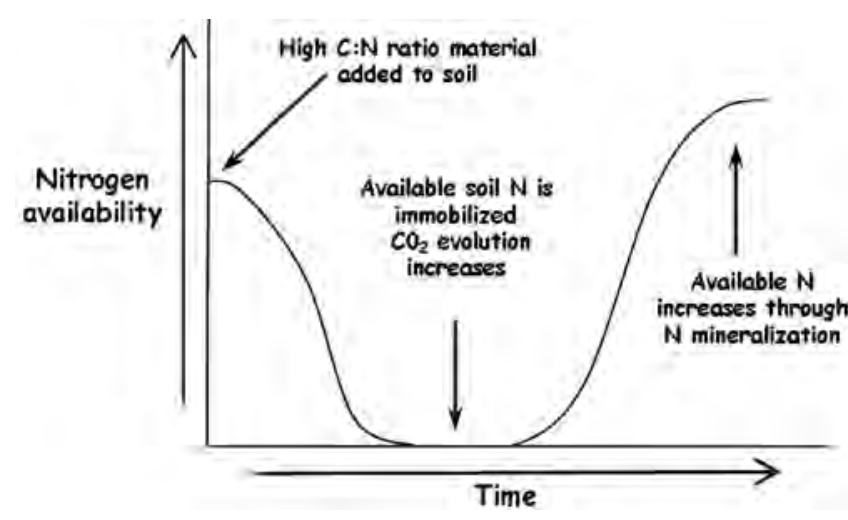

Figure 4.5. Nitrogen immobilization and mineralization after material with a high C:N ratio is added to soil. Graphic by Kathryn Haering.

organisms decompose the material, there is competition for the limited supply of available $\mathrm{N}$ because the material does not provide adequate $\mathrm{N}$ to form proteins in the organisms.

During this process, available soil $\mathrm{N}$ is decreased and the carbon in the decomposing material is liberated as $\mathrm{CO}_{2}$ gas. As decomposition proceeds, the material's $\mathrm{C}: \mathrm{N}$ ratio narrows and the energy supply is nearly exhausted. At this point, some of the microbial populations will die and the mineralization of $\mathrm{N}$ in these decaying organisms will result in the liberation of plant-available N. The timing of this process will depend on such factors as soil temperature, soil moisture, soil chemical properties, fertility status, and the amount of organic material added.

\section{Nitrification}

"Nitrification" is the biological oxidation of ammonium $\left(\mathrm{NH}_{4}^{+}\right)$to nitrate $\left(\mathrm{NO}_{3}^{-}\right)$in the soil. Sources of $\mathrm{NH}_{4}^{+}$ for this process include both commercial fertilizers and the mineralization of organic residues. Nitrification is a two-step process where $\mathrm{NH}_{4}^{+}$is converted first to $\mathrm{NO}_{2}^{-}$, and then to $\mathrm{NO}_{3}{ }^{-}$by two autotrophic bacteria in the soil (Nitrosomonas and Nitrobacter). These bacteria get their energy from the oxidation of nitrogen and their carbon from $\mathrm{CO}_{2}$.

Nitrification is important to $\mathrm{N}$ fertility because nitratenitrogen $\left(\mathrm{NO}_{3}-\mathrm{N}\right)$ is readily available for uptake and use by plants and microbes. However, $\mathrm{NO}_{3}^{-}$is an "anion," or negatively charged ion. Anions usually leach more readily than cations because they are not attracted to the predominantly negative charge of soil colloids. Because of its negative charge and relatively large ionic radius, nitrate is not readily retained in the soil and is easily leached to groundwater and surface waters. Nitrate losses can be minimized through proper $\mathrm{N}$ management, including the proper rate and timing of $\mathrm{N}$ fertilizer applications.
Nitrate-N can be also be lost through denitrification, the process where $\mathrm{NO}_{3}{ }^{-}$is reduced to gaseous nitrous oxide $\left(\mathrm{N}_{2} \mathrm{O}\right)$ or elemental nitrogen $\left(\mathrm{N}_{2}\right)$ and lost to the atmosphere. During nitrification, $2 \mathrm{H}^{+}$ions are produced for every $\mathrm{NH}_{4}^{+}$ion that is oxidized. These $\mathrm{H}^{+}$cations will accumulate and significantly reduce soil $\mathrm{pH}$; thus, any ammonium-containing fertilizer will ultimately decrease soil $\mathrm{pH}$ due to nitrification.

\section{Phosphorus}

\section{The Phosphorus Cycle}

Soil $\mathrm{P}$ originates primarily from the weathering of soil minerals, such as apatite, and from $\mathrm{P}$ additions in the form of fertilizers, plant residues, manure, or biosolids (figure 4.6). Orthophosphate ions $\left(\mathrm{HPO}_{4}^{-2}\right.$ and $\mathrm{H}_{2} \mathrm{PO}_{4}^{-}$) are produced when apatite breaks down, organic residues are decomposed, or fertilizer P sources dissolve. These forms of $\mathrm{P}$ are taken up by plant roots and are present in very low concentrations in the soil solution.

Many soils contain large amounts of $\mathrm{P}$, but most of that $\mathrm{P}$ is unavailable to plants. The types of P-bearing minerals that form in soil are highly dependent on soil $\mathrm{pH}$. Soluble P, regardless of the source, reacts very strongly with $\mathrm{Fe}$ and $\mathrm{Al}$ to form insoluble $\mathrm{Fe}$ and $\mathrm{Al}$ phosphates in acid soils and with $\mathrm{Ca}$ to form insoluble $\mathrm{Ca}$ phosphates in alkaline soils. Phosphorus in these insoluble forms is not readily available for plant growth and is said to be "fixed."

\section{Phosphorus Availability and Mobility}

As discussed earlier, plant roots take up $\mathrm{P}$ in the forms of orthophosphates: $\mathrm{HPO}_{4}^{-2}$ and $\mathrm{H}_{2} \mathrm{PO}_{4}^{-}$. The predominant ionic form of $\mathrm{P}$ present in the soil solution is $\mathrm{pH}$ dependent. In soils with $\mathrm{pH}$ values greater than 7.2 , the $\mathrm{HPO}_{4}^{-2}$ form is predominant, while in soils with a $\mathrm{pH}$ between 5.0 and 7.2, the $\mathrm{H}_{2} \mathrm{PO}_{4}^{-}$form predominates.

Phosphorus has limited mobility in most soils because it reacts strongly with many elements and compounds and the surfaces of clay minerals. Unlike nitrate, $\mathrm{P}$ anions $\left(\mathrm{HPO}_{4}{ }^{2-}, \mathrm{H}_{2} \mathrm{PO}_{4}^{-}\right)$do not easily leach through the soil profile because of their specific complexing reactions with soil components. The release of soil $\mathrm{P}$ to plant roots and its potential movement to surface water is controlled by several chemical and biological processes (figure 4.6). Phosphorus is released to the soil solution as P-bearing minerals dissolve, as $\mathrm{P}$ bound to the surface of soil minerals is uncoupled or "desorbed," and as soil organic matter decomposes or mineralizes (figure 4.7). 
The Phosphorus Cycle

\section{Component}

Input to soil
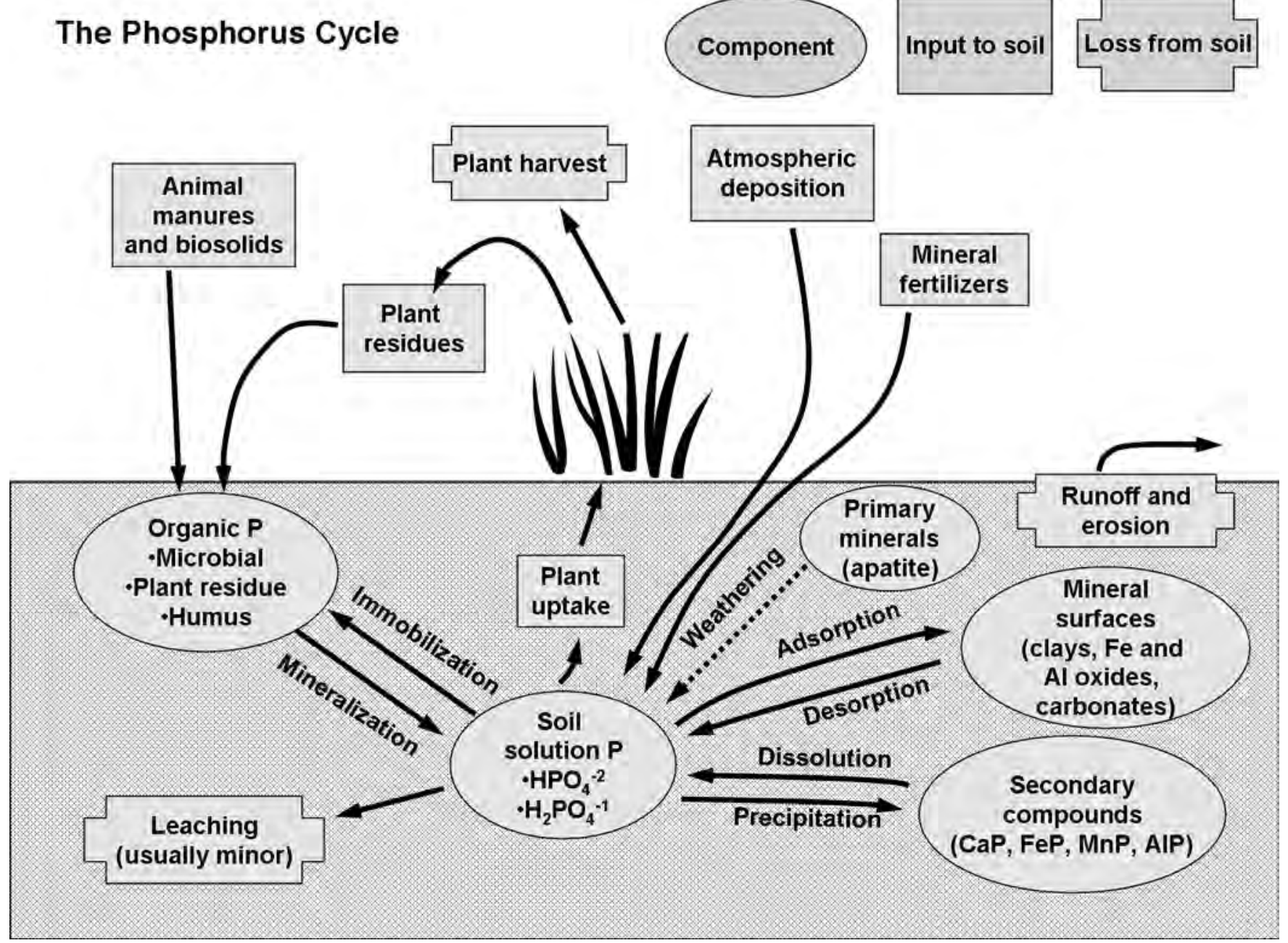

Figure 4.6. The phosphorus cycle (modified from the Potash \& Phosphate Institute website at www.ppi-ppic.org).

Most of the $\mathrm{P}$ added as fertilizer and organic sources is rapidly bound by soil minerals in chemical forms that are not subject to rapid release; thus, soil solution $\mathrm{P}$ concentrations are typically very low (less than 0.01 to $1.00 \mathrm{ppm}$ ). The supply of adequate $\mathrm{P}$ to a plant will depend on the soil's ability to replenish soil solution $\mathrm{P}$ throughout the growing season (figure 4.7).

Phosphorus availability and mobility is influenced by several factors:

\section{Soil $\mathrm{pH}$}

In acidic soils, $\mathrm{P}$ precipitates as relatively insoluble iron and $\mathrm{Al}$ phosphate minerals. In neutral and calcareous soils, $\mathrm{P}$ precipitates as relatively insoluble $\mathrm{Ca}$ phosphate minerals. As illustrated in figures 4.1 and 4.8, soil $\mathrm{P}$ is most available in the $\mathrm{pH}$ range of 5.5 to 6.8 , where the availability of soluble $\mathrm{Al}$ and $\mathrm{Fe}$ is low.

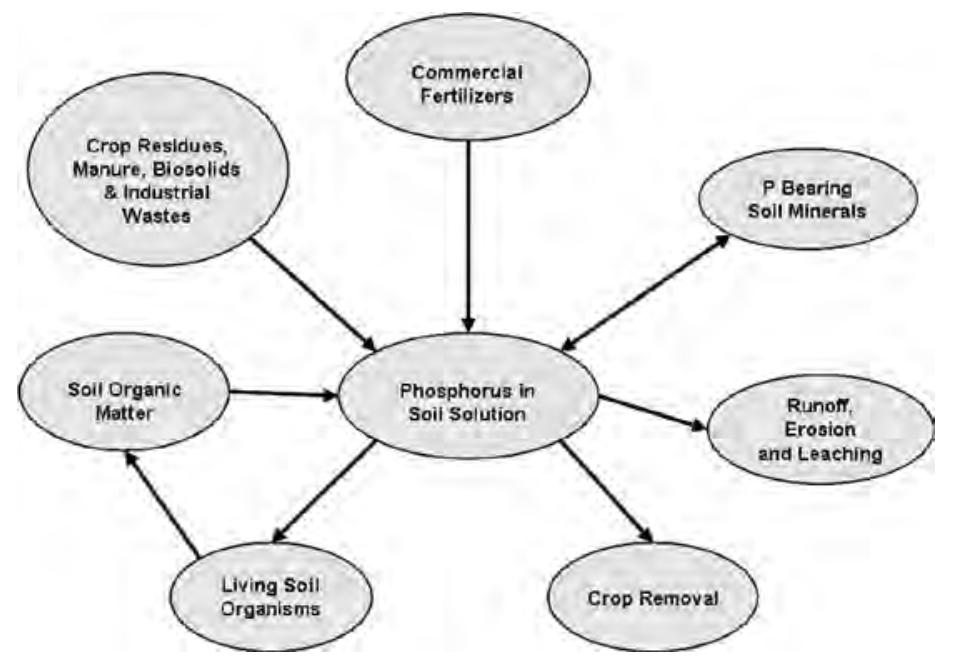

Figure 4.7. Phosphorus content of the soil solution.

Graphic by Greg Mullins. 


\section{Movement of Soil Phosphorus to Plant Roots}

Phosphorus moves from soil solids to plant roots through the process of "diffusion." Diffusion is a slow and short-range process with distances as small as 0.25 inch. This limited movement has important implications because soil P located more than 0.25 inch from a plant root will never reach the root surface. Dry soils reduce the diffusion of $\mathrm{P}$ to roots; therefore, plants take up $\mathrm{P}$ best in moist soils.

\section{Residual Fertilizer Phosphorus Recovery}

A plant uses only 10 to 30 percent of the $\mathrm{P}$ fertilizer applied during the first year following application. The rest goes into reserve and can be used by plants in later years.

\section{Timing and Placement of Phosphorus Fertilizer}

New plants need a highly available P source in order to establish a vigorous root system early in the season. Once the root system begins to explore the entire soil volume, there should be adequate amounts of residual $\mathrm{P}$ to maintain plant growth.

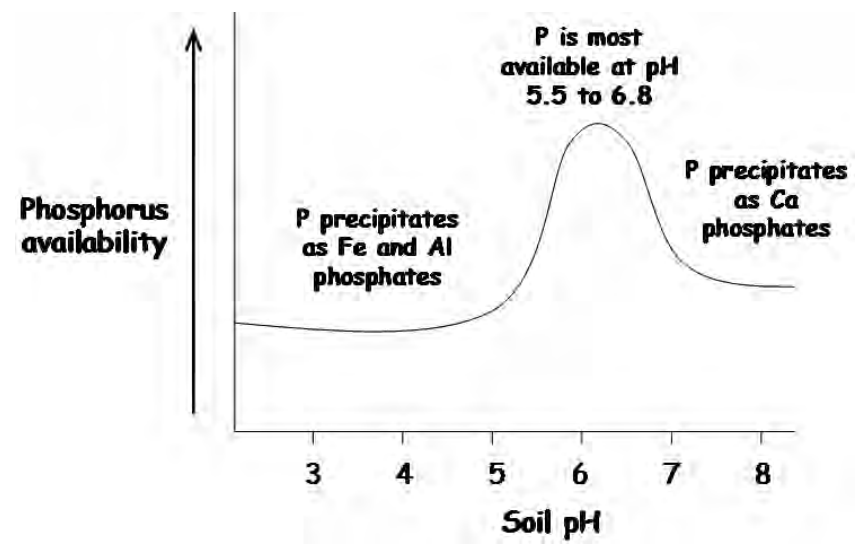

Figure 4.8. Effect of $\mathrm{pH}$ on phosphorus availability to plants.

Graphic by Kathryn Haering

\section{Phosphorus Transport to Surface Waters}

Transport of soil P occurs primarily via surface flow (runoff and erosion), although leaching and subsurface lateral flow may also be possible in soils with high degrees of $\mathrm{P}$ saturation and artificial drainage systems. Water flowing across the soil surface may dissolve and transport soluble $\mathrm{P}$, and erode and transport particulate P. Virtually all soluble P transported by surface runoff is biologically available, but particulate phosphorus that enters streams and other surface waters must undergo solubilization before becoming available for aquatic plants. Thus, both soluble and sediment-bound $P$ are potential pollutants of surface waters and both can contribute to excessive growth of aquatic organisms, which can have detrimental environmental impacts.

Soils have a finite capacity to bind P. When a soil becomes saturated with $\mathrm{P}$, desorption of soluble phosphorus can be accelerated, with a consequent increase in dissolved inorganic $\mathrm{P}$ in runoff. Thus, if the level of residual soil phosphorus is allowed to build up by repeated applications of phosphorus in excess of plant needs, a soil can become saturated with $\mathrm{P}$ and the potential for soluble phosphorus losses in surface runoff will increase significantly.

Research conducted in the mid-Atlantic shows that the potential loss of soluble $\mathrm{P}$ will increase with increasing levels of soil test P. Very high levels of soil-test P can result from over-application of manure, biosolids, or commercial phosphate fertilizer. Soils with these high soil-test $\mathrm{P}$ levels will require several years without $\mathrm{P}$ additions to effectively reduce these high $\mathrm{P}$ levels.

\section{Potassium}

\section{The Potassium Cycle}

Potassium is the third primary plant nutrient and is absorbed by plants in larger amounts than any other nutrient except nitrogen. Plants take up $\mathrm{K}$ as the monovalent cation $\mathrm{K}^{+}$. Potassium is present in relatively large quantities in most soils, but only a small percentage of the total soil $\mathrm{K}$ is readily available for plant uptake.

The $\mathrm{K}$ cycle is illustrated in figure 4.9. In the soil, weathering releases $\mathrm{K}$ from a number of common minerals, including feldspars and micas. The released $\mathrm{K}^{+}$ can be taken up easily by plant roots, adsorbed by the cation exchange complex of clay and organic matter, or "fixed" in the internal structure of certain two-toone clay minerals. Potassium that is fixed by these clay minerals is very slowly available to the plant.

\section{Potassium Availability and Mobility}

Although mineral $\mathrm{K}$ accounts for 90 to 98 percent of the total soil $\mathrm{K}$, readily and slowly available $\mathrm{K}$ represent only 1 to 10 percent of the total soil K. Plant-available K ( $\mathrm{K}$ that can be readily absorbed by plant roots) includes the portion of the soil $\mathrm{K}$ that is soluble in the soil solution and the exchangeable $\mathrm{K}$ held on the soil's exchange complex. Exchangeable $\mathrm{K}$ is that portion of soil $\mathrm{K}$ that is in equilibrium with $\mathrm{K}$ in the soil solution. Potassium is continuously made available for plant uptake through 


\section{The Potassium Cycle}
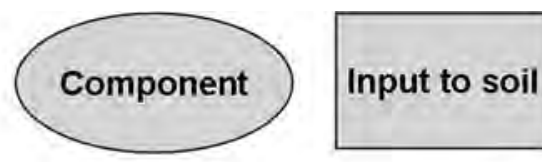

Loss from soil

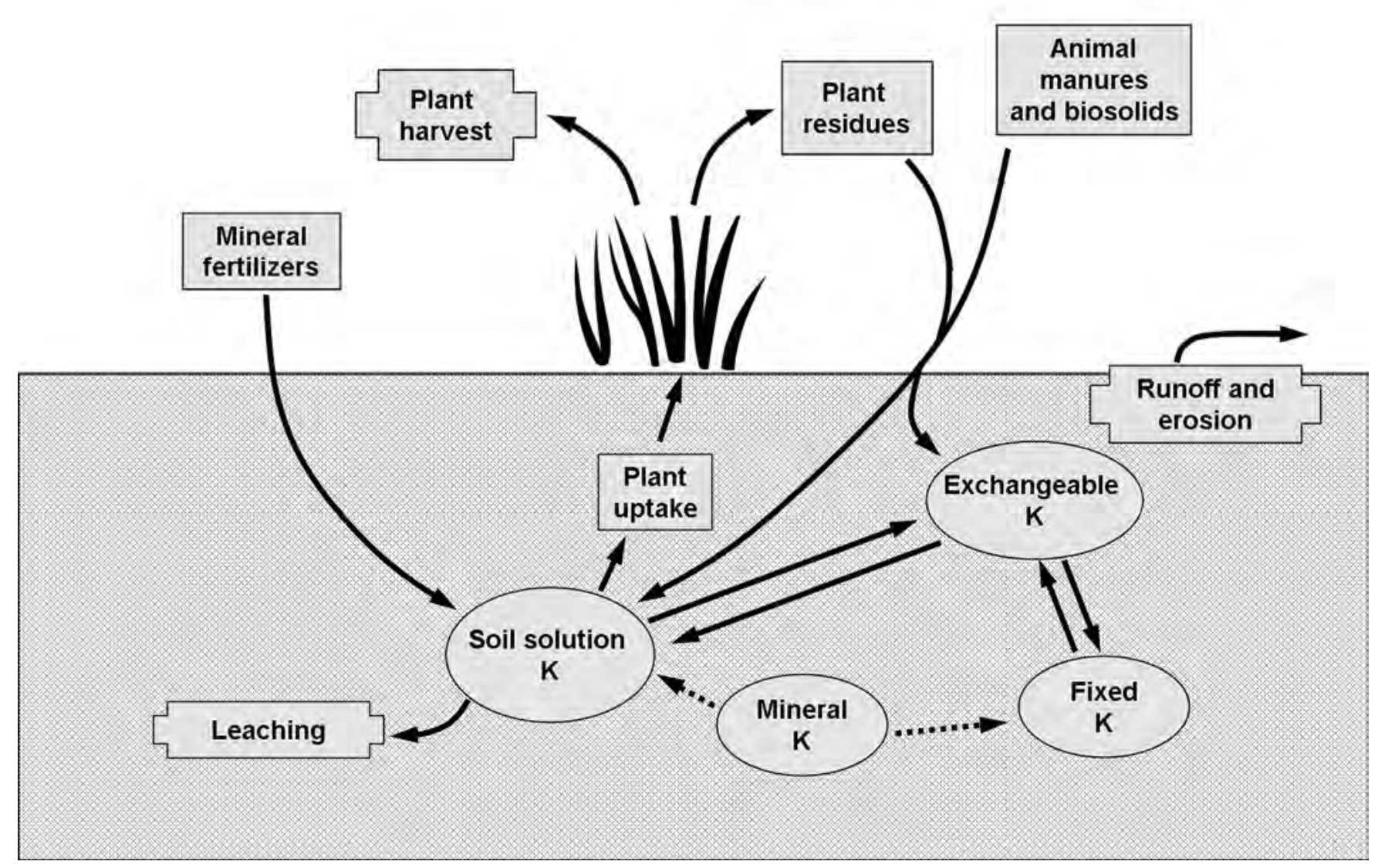

Figure 4.9. The potassium cycle (modified from the Potash \& Phosphate Institute website at www.ppi-ppic.org).

the cation exchange process. There can be a continuous, but slow, transfer of $\mathrm{K}$ from soil minerals to exchangeable and slowly available forms as $\mathrm{K}$ is removed from the soil solution by plant uptake and leaching.

Potassium applied as fertilizer can have various fates in the soil.

- Potassium cations can be attracted to the cationexchange complex where it is held in an exchangeable form and readily available for plant uptake.

- Some of the $\mathrm{K}+$ ions will remain in the soil solution.

- Exchangeable and soluble K may be absorbed by plants.

- In some soils, some K may be fixed by the clay fraction.

- Applied K may leach from sandy soils during periods of heavy rainfall.

Potassium moves more readily in soil than phosphorus does, but less readily than nitrogen. Because potassium is held by cation exchange, it is less mobile in fine-textured soils and most readily leached from sandy soils. Most plant uptake of soil $\mathrm{K}$ occurs by diffusion.

Potassium fertilizers are completely water-soluble and have a high salt index, so they can decrease seed germination and plant survival when placed too close to seed or transplants. The risk of fertilizer injury is most severe on sandy soils, under dry conditions, and with high rates of fertilization. A convenient and usually effective method of applying $\mathrm{K}$ fertilizers is by broadcasting and mixing with the soil before planting. Fertilizer injury is minimized by this method, but on sandy soils, leaching may cause the loss of some K.

\section{Secondary Plant Nutrients}

\section{Introduction}

Secondary macronutrients $\mathrm{Ca}, \mathrm{Mg}$, and $\mathrm{S}$ are required in relatively large amounts for good crop growth. These nutrients are usually applied as soil amendments 
or applied along with materials that contain primary nutrients. Secondary nutrients are as important to plant nutrition as major nutrients, because deficiencies of secondary nutrients can depress plant growth as much as major plant nutrient deficiencies.

\section{Calcium and Magnesium}

Calcium and magnesium have similar chemical properties and behave very similarly in the soil. Both of these elements are cations $\left(\mathrm{Ca}^{2+}, \mathrm{Mg}^{2+}\right)$, and both cations have the same amount of positive charge and a similar ionic radius. The mobility of both $\mathrm{Ca}$ and $\mathrm{Mg}$ is relatively low, especially compared to anions or to other cations such as $\mathrm{Na}$ and $\mathrm{K}$; thus, losses of these cations via leaching are relatively low.

Total Ca content of soils can range from 0.1 percent in highly weathered tropical soils to 30 percent in calcareous soils. Calcium is part of the structure of several minerals and most soil calcium comes from the weathering of common minerals, which include dolomite, calcite, apatite, and calcium-feldspars. Calcium is present in the soil solution and because it is a divalent cation, its behavior is governed by cation exchange, as are the other cations. Exchangeable $\mathrm{Ca}$ is held on the negatively charged surfaces of clay and organic matter. Calcium is the dominant cation on the cation exchange complex in soils with moderate $\mathrm{pH}$ levels. Normally, it occupies 70 to 90 percent of cation exchange sites above $\mathrm{pH} 6.0$.

Total soil $\mathrm{Mg}$ content can range from 0.1 percent in coarse, humid-region soils to 4 percent in soils formed from high-magnesium minerals. Magnesium occurs naturally in soils from the weathering of rocks with Mg-containing minerals such as biotite, hornblende, dolomite, and chlorite. Magnesium is found in the soil solution and because it is a divalent cation $\left(\mathrm{Mg}^{2+}\right)$, its behavior is governed by cation exchange. Magnesium is held less tightly than calcium by cation exchange sites, so it is more easily leached and soils usually contain less $\mathrm{Mg}$ than calcium. In the mid-Atlantic region, $\mathrm{Mg}$ deficiencies occur most often on acidic and coarsetextured soils.

\section{Sulfur}

Soil sulfur is present in both inorganic and organic forms. Most of the sulfur in soils comes from the weathering of sulfate minerals such as gypsum; however, approximately 90 percent of the total sulfur in the surface layers of noncalcareous soils is immobilized in organic matter. Inorganic sulfur is usually present in the sulfate $\left(\mathrm{SO}_{4}^{2-}\right)$ form, which is the form of $\mathrm{S}$ absorbed by plant roots.

Both soluble $\mathrm{SO}_{4}^{2-}$ in the soil solution and adsorbed $\mathrm{SO}_{4}^{2-}$ represent readily plant-available $\mathrm{S}$. Elemental sulfur is a good source of $\mathrm{S}$, but it must first undergo biological oxidation to $\mathrm{SO}_{4}^{2-}$, driven by Thiobacillus thiooxidans bacteria, before plants can assimilate it. This oxidation can contribute to soil acidity by producing sulfuric acid.

Several fertilizer materials contain the $\mathrm{SO}_{4}{ }^{2-}$ form of sulfur, including gypsum $\left(\mathrm{CaSO}_{4}\right)$, potassium sulfate $\left(\mathrm{K}_{2} \mathrm{SO}_{4}\right)$, magnesium sulfate $\left(\mathrm{MgSO}_{4}\right)$, and potassium magnesium sulfate (K-Mag or Sul-Po-Mag). These fertilizer sources are neutral salts and will have little or no effect on soil $\mathrm{pH}$.

In contrast, there are other $\mathrm{SO}_{4}^{2-}$-containing compounds, including ammonium sulfate $\left(\left(\mathrm{NH}_{4}\right)_{2} \mathrm{SO}_{4}\right)$, aluminum sulfate $\left(\left(\mathrm{Al}_{2} \mathrm{SO}_{4}\right)_{3}\right)$, and iron sulfate $\left(\mathrm{FeSO}_{4}\right)$, that contribute greatly to soil acidity. The $\mathrm{SO}_{4}^{2-}$ in these materials is not the source of acidity. Ammonium sulfate has a strong acidic reaction primarily because of the nitrification of $\mathrm{NH}_{4}^{+}$, and aluminum and iron sulfates are very acidic due to the hydrolysis of $\mathrm{Al}^{3+}$ and $\mathrm{Fe}^{3+}$.

Sulfate, a divalent anion $\left(\mathrm{SO}_{4}^{2-}\right)$ is not strongly adsorbed and can be readily leached from most soils. In highly weathered, naturally acidic soils, $\mathrm{SO}_{4}^{2-}$ often accumulates in subsurface soil horizons, where positively charged colloids attract the negatively charged $\mathrm{SO}_{4}^{2-}$ ion. Residual soil $\mathrm{SO}_{4}^{2-}$ resulting from long-term applications of S-containing fertilizers can meet the $\mathrm{S}$ requirements of plants for years after applications have ceased.

\section{Micronutrients}

\section{Introduction}

Eight of the essential elements for plant growth are called micronutrients or trace elements: $\mathrm{B}, \mathrm{Cl}, \mathrm{Cu}$, $\mathrm{Fe}, \mathrm{Mn}, \mathrm{Mo}, \mathrm{Ni}, \mathrm{Zn}$. Cobalt has not been proven to be essential for higher plant growth, but nodulating bacteria need cobalt for fixing atmospheric nitrogen in legumes. Although micronutrients are not needed in large quantities, they are as important to plant nutrition and development as the primary and secondary nutrients. A deficiency of any one of the micronutrients in the soil can limit plant growth, even when all other essential nutrients are present in adequate amounts. 
Micronutrients can exist in several different forms in soil: within structures of primary and secondary minerals, adsorbed to mineral and organic matter surfaces, incorporated in organic matter and microorganisms, and in the soil solution. Many micronutrients combine with organic molecules in the soil to form complex molecules called chelates, which are metal atoms surrounded by a large organic molecule. Plant roots absorb soluble forms of micronutrients from the soil solution.

A micronutrient deficiency, if suspected, can be identified through soil tests or plant analysis. Total soil content of a micronutrient does not indicate the amount available for plant growth during a single growing season, although it does indicate relative abundance and potential supplying power. Micronutrient availability decreases as soil $\mathrm{pH}$ increases for all micronutrients except $\mathrm{Mo}$ and $\mathrm{Cl}$.

Specific soil-plant relationships for $\mathrm{B}, \mathrm{Cu}, \mathrm{Fe}, \mathrm{Mn}, \mathrm{Mo}$, and $\mathrm{Zn}$ are discussed in the next sections.

\section{Boron}

Boron exists in minerals, adsorbed on the surfaces of clay and oxides, combined in soil organic matter, and in the soil solution. Organic matter is the most important potentially plant-available soil source of $\mathrm{B}$.

Factors that affect the availability of $\mathrm{B}$ to plants include:

\section{Soil Moisture and Weather}

Boron deficiency is often associated with dry or cold weather, which slows organic matter decomposition. Symptoms may disappear as soon as the surface soil receives rainfall or soil temperatures increase and root growth continues, but yield potential is often reduced.

\section{Soil $\mathrm{pH}$}

Plant availability of B is maximized between $\mathrm{pH} 5.0$ and 7.0. Boron availability decreases with increasing soil $\mathrm{pH}$, which means that $\mathrm{B}$ uptake is reduced at high $\mathrm{pH}$.

\section{Soil Texture}

Coarse-textured (sandy) soils, which are composed largely of quartz, are typically low in minerals that contain boron. Plants growing on such soils commonly show boron deficiencies. Boron is mobile in the soil and is subject to leaching. Leaching is of greater concern on sandy soils and in areas of high rainfall.
Recommended rates of B fertilization depend on such factors as soil-test levels, plant-tissue concentrations, plant species, weather conditions, soil organic matter, and the method of application.

\section{Copper}

In mineral soils, $\mathrm{Cu}$ concentrations in the soil solution are controlled primarily by soil $\mathrm{pH}$ and the amount of $\mathrm{Cu}$ adsorbed on clay and soil organic matter. A majority of the soluble $\mathrm{Cu}_{2}{ }^{+}$in surface soils is complexed with organic matter, and $\mathrm{Cu}$ is more strongly bound to soil organic matter than any of the other micronutrients. Sandy soils with low organic matter content may become deficient in $\mathrm{Cu}$ because of leaching losses. Heavy, clay-type soils are least likely to be $\mathrm{Cu}$-deficient. The concentrations of $\mathrm{Fe}, \mathrm{Mn}$, and $\mathrm{Al}$ in soil affect the availability of $\mathrm{Cu}$ for plant growth, regardless of soil type.

Like most other micronutrients, large quantities of $\mathrm{Cu}$ can be toxic to plants. Excessive amounts of $\mathrm{Cu}$ depress Fe activity and may cause Fe deficiency symptoms to appear in plants. Such toxicities are not common.

\section{Iron}

Iron is the fourth-most abundant element, but the solubility of $\mathrm{Fe}$ is very low and highly $\mathrm{pH}$-dependent. Iron solubility decreases with increasing soil $\mathrm{pH}$. It can react with organic compounds to form chelates or ironorganic complexes.

Iron deficiency may be caused by an imbalance with other metals, such as $\mathrm{Mo}, \mathrm{Cu}$, or Mn. Other factors that may trigger iron deficiency include excessive phosphorus in the soil; a combination of high-pH, high-lime, wet, cold soils and high bicarbonate levels; and low soil organic matter levels.

Reducing soil $\mathrm{pH}$ in a narrow band in the root zone can correct iron deficiencies. Several S products will lower soil $\mathrm{pH}$ and convert insoluble soil iron to a form the plant can use.

\section{Manganese}

Availability of Mn to plants is determined by the equilibrium among solution, exchangeable, organic, and mineral forms of soil Mn. Chemical reactions affecting Mn solubility include oxidation reduction and complexation with soil organic matter. "Redox" or oxidationreduction reactions depend on soil moisture, aeration, and microbial activity. 
Manganese solubility decreases with increasing soil $\mathrm{pH}$, so Mn deficiencies occur most often on high organic-matter soils and on those soils with neutral-toalkaline $\mathrm{pH}$ that are naturally low in $\mathrm{Mn}$. Manganese deficiencies may also result from an antagonism with other nutrients, such as $\mathrm{Ca}$, magnesium, and Fe. Soil moisture also affects Mn availability. Excess moisture in organic soils favors $\mathrm{Mn}$ availability because reducing conditions convert $\mathrm{Mn} 4+$ to $\mathrm{Mn} 2+$, which is plantavailable.

Manganese deficiency is often observed on sandy Coastal Plain soils under dry conditions that have previously been wet.

\section{Molybdenum}

Molybdenum is found in soil minerals as exchangeable Mo on the surfaces of iron/aluminum oxides and bound soil organic matter. Adsorbed and soluble Mo is an anion $\left(\mathrm{MoO}_{4}^{-}\right)$.

Molybdenum becomes more available as soil $\mathrm{pH}$ increases, so deficiencies are more likely to occur on acidic soils. Since Mo becomes more available with increasing $\mathrm{pH}$, liming will correct a deficiency if the soil contains enough of the nutrient. Sandy soils are deficient in Mo more often than finer-textured soils are, and soils high in Fe/Al oxides tend to be low in available Mo because Mo is strongly adsorbed to the surfaces of $\mathrm{Fe} / \mathrm{Al}$ oxides. Heavy $\mathrm{P}$ applications increase Mo uptake by plants, while heavy $\mathrm{S}$ applications decrease Mo uptake.

\section{Zinc}

The various forms of soil $\mathrm{Zn}$ include soil minerals, organic matter, adsorbed $\mathrm{Zn}$ on the surfaces of organic matter and clay, and dissolved $\mathrm{Zn}$ in the soil solution. Zinc released from soil minerals during weathering can be adsorbed onto the Cation Exchange Complex, incorporated into soil organic matter, or react with organic compounds to form soluble complexes. Organically complexed, or chelated, $\mathrm{Zn}$ is important for the movement of $\mathrm{Zn}$ to plant roots. Soils can contain from a few to several hundred pounds of $Z n$ per acre. Fine-textured soils usually contain more $\mathrm{Zn}$ than sandy soils do.

Total $\mathrm{Zn}$ content of a soil does not indicate how much $\mathrm{Zn}$ is available. The following factors determine its availability:

- Zinc becomes less available as soil pH increases. Coarse-textured soils limed above a $\mathrm{pH}$ of 6.0 are particularly prone to develop $\mathrm{Zn}$ deficiency. Soluble $\mathrm{Zn}$ concentrations in the soil can decrease three-fold for every $\mathrm{pH}$ unit increase between 5.0 and 7.0.

- Zinc deficiency may occur in some plant species on soils with very high $\mathrm{P}$ availability and marginal $\mathrm{Zn}$ concentrations due to $\mathrm{Zn} / \mathrm{P}$ antagonisms. Soil $\mathrm{pH}$ further complicates $\mathrm{Zn} / \mathrm{P}$ interactions.

- Zinc forms stable complexes with soil organic matter. A significant portion of soil $\mathrm{Zn}$ may be fixed in the organic fraction of high organic-matter soils. It may also be temporarily immobilized in the bodies of soil microorganisms, especially when animal manures are added to the soil.

- At the opposite extreme, much of a mineral soil's available $\mathrm{Zn}$ is associated with organic matter. Low organic-matter levels in mineral soils are frequently indicative of low $\mathrm{Zn}$ availability.

Zinc availability is affected by the presence of certain soil fungi, called mycorrhizae, which form symbiotic relationships with plant roots. Removal of surface soil in land leveling may remove the beneficial fungi and limit plants' ability to absorb Zn.

\section{Acknowledgement}

This chapter is dedicated to the memory of Greg Mullins (1955-2009). 


\title{
Chapter 5. Soil Sampling and Nutrient Testing
}

\author{
Rory Maguire, Associate Professor, Crop and Soil Environmental Sciences, Virginia Tech \\ Steven Hodges, Professor, Crop and Soil Environmental Sciences, Virginia Tech \\ Steve Heckendorn, Laboratory Manager, Crop and Soil Environmental Sciences, Virginia Tech
}

\section{Introduction}

Soil testing is a fundamental management practice for turfgrass and the ornamental landscape. A soil analysis provides essential information on relative levels of organic matter, $\mathrm{pH}$, lime requirement, cation exchange capacity (CEC), and levels of plant-available nutrients (nitrogen, phosphorus, potassium, and specific micronutrients) contained in the soil.

The goals of soil testing are to determine existing nutrient levels, predict additional lime and nutrient needs, and evaluate potential excesses or imbalances within a given soil. A soil test report usually includes suggested lime and fertilizer treatments for turf and landscape areas being maintained. Note that soil tests do not measure nitrogen $(\mathrm{N})$, because it is a highly mobile nutrient. Suggested nitrogen rates are general recommendations based on years of research on the nitrogen needs of the turf species or ornamental plant present.

While soil testing has been around for nearly 50 years, soil test results and recommendations may vary from lab to lab. To understand this, you need to understand how labs use chemical extraction procedures to predict nutrient needs and the amounts required to avoid deficiencies. The chemical extraction must be calibrated, that is, tested and proven under actual growing conditions using replicated nutrient response field trials with the plant species of interest. These trials should be conducted under a wide range of soils, water regimes, and climatic conditions. The calibration process is an essential component relating laboratory results to field performance; thus, the quality of the calibration data determines the accuracy of the resulting recommendations.

Soil testing laboratories may also vary in the chemical methods they use to assess soil nutrient levels and the manner in which they report data. Many mid-Atlantic states use the Mehlich-1 extractant, while other laboratories use the newer Mehlich-3. Some states have not adopted the Mehlich-3 extractant because new calibration data are required to relate soil test levels to field performance. Some labs report their results in parts per million, some in pounds per acre, and others as a predictive index. Regardless, most laboratories report a rating indicating the relative status for each nutrient (figure 5.1).
Very low: A plant response is most likely if the indicated nutrient is applied. A large portion of the nutrient requirement must come from fertilization.

Low: A plant response is likely if the indicated nutrient is applied. A portion of the nutrient requirement must come from fertilization.

Medium: A plant response may or may not occur if the indicated nutrient is applied. A small portion of the nutrient requirement must come from fertilization.

High: Plant response is not expected. No additional fertilizer is needed.

Very high: Plant response is not expected. The soil can supply much more than the turf requires. Additional fertilizer should not be added to avoid nutritional problems and adverse environmental consequences.

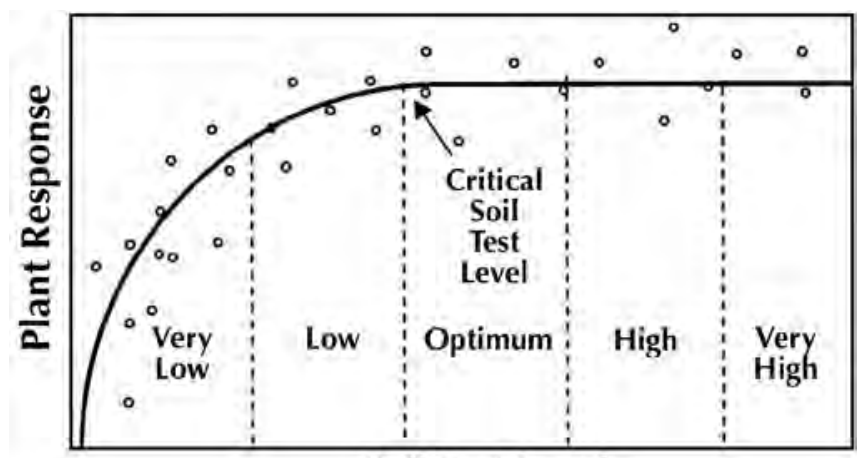

Soil Test Level

Figure 5.1. A typical plant response curve as influenced by varying levels of soil nutrients.

\section{Soil Test Interpretation and Recommendations}

Soil test results must be related to the expected level of plant response and the appropriate rate of fertilizers required to eliminate nutrient deficiency. Soil testing labs may disagree with the manner in which results are interpreted and recommendations are made.

\section{Sufficiency Level Approach}

Most land-grant universities base their recommendations on the "sufficiency level" concept. Basically, this extensively tested approach says "fertilize the crop, not the soil" by ceasing to recommend nutrient additions 
when test levels exceed proven responsive levels. It is also the most conservative approach, and as such, it has been attacked at times as being too conservative. This philosophy is difficult for the home landscape because no yield is taken. However, this philosophy has the greatest potential for producing the most favorable results and is in harmony with the concepts of nutrient management planning. In areas of the mid-Atlantic with highly weathered, low CEC soils, this philosophy minimizes losses of potassium $(\mathrm{K})$, magnesium $(\mathrm{Mg})$, and the more mobile nutrients via leaching.

\section{Buildup and Maintenance Approach}

The "buildup and maintenance" approach recommends that soil test levels be built to the "high" or nonresponsive level. Soil levels are then maintained by annual replacement of nutrients to be removed as clippings or sod, regardless of soil test level. This method assumes that all soils can hold high levels of nutrients, which is not the case for soils having relatively low CEC (less than 10).

\section{Cation Saturation Ratio Approach}

The final approach, the "cation saturation ratio" method, focuses on the ratio of nutrients on the soil exchange sites. Most often, these labs suggest that 5 percent of the CEC be occupied by potassium, 10 to 20 percent by magnesium, and 70 to 85 percent by calcium $(\mathrm{Ca})$. Again, this approach assumes that the soil has sufficient exchange capacity to support these ratios and stay above sufficiency level. For low CEC soils, this approach can result in nutrient additions for the sake of adjusting the soil ratio that are unnecessary for highquality turf production and could result in inadequate levels of potassium for some soils.

Keep in mind that regardless of the approach to fertilization, in a few cases, soil-testing may not accurately predict a response or lack of response in any given situation. Because recommendations are based on many years of data, they may not predict needs in a specific situation because of unique climatic or soil conditions, management practices, or pest pressure.

Regardless of the lab used, familiarize yourself with the reporting system and be especially sure the lab has calibrated their recommendations for the plant material being grown. Unverified recommendations or recommendations based on forages or row crops may prove inadequate for intensively managed turfgrass and other landscape plants.
The following sections will describe proper soil sampling and interpretation of soil test reports.

\section{Soil Sampling}

\section{General Sampling Considerations}

Soil sampling should be done every one to five years, depending on the soil type and management. Completely modified, sand-based soils used on golf greens, tees, and athletic fields should likely be tested on an annual basis. For naturally occurring, coarse-textured (i.e., sandy) soils, a typical sampling frequency is every two to three years. On fine-textured (i.e., loamy or clayey) soil, sampling likely does not need to be done more than every four to five years. If clippings are removed, sample more frequently according to the soil type.

When submitting soils for analysis, it is common to request recommendations for specific plants, i.e., turf or ornamentals. As nutrient requirements vary by plant type, separate soil samples should be submitted for each recommendation that is required - even if the soil looks the same and is in a similar location.

For fine-turf maintenance, divide the property into logical areas. For example, it is logical to divide a single hole on a golf course into green, tee(s), fairway, and rough categories and to conduct a test on each of these areas as a unique entity.

The turf of a football or baseball field should be divided into two to four areas for separate sampling. It is important to remember that the quality of the test report is only as good as the sample submitted; simply testing a single sample that was gathered from a large area does not provide sufficiently detailed information regarding that soil.

Soil samples can be taken at any time of the year but, in general, it is recommended to take samples in advance of planting or the time of regular fertilization. Fall sampling is most common, as this allows time to get results and apply lime and nutrients in advance of spring growth. Limestone takes months to fully react with soil, so liming should be done well in advance of spring growth, while nutrients are more reactive and should be applied closer to the time of plant growth. Soil sampling should not be done for at least two months after fertilization or liming.

Undisturbed areas need to be sampled separately from disturbed areas. Because soils vary with their location 
in the landscape, they should at the very least be separated into upland, side slopes, and lowland or bottomland positions. Disturbed soil areas should be separated into smaller units based on amount of disturbance, soil removal, or soil addition. These soil variations are often visible as different soil colors or as differences in soil texture (sand versus clay).

The upper diagram in figure 5.2 shows how landscape position affects soil properties; the lower diagram shows how soil color can vary. Each soil type, colored differently in these figures, should ideally be sampled separately. Soil samples should accurately represent the area being sampled.

The best way to collect a soil sample is with a soil probe, which is fast and easy and collects an even amount of soil down to the depth sampled. Soil probes can be purchased from many locations, such as garden centers or online, but it is acceptable to sample using a shovel or trowel if you are not going to soil-test frequently. Soil sample containers and information sheets are available from laboratories that analyze the samples.

Once you select uniform areas to sample, the next step is to collect a representative sample from the correct depth. The depth of sampling depends on the land use: It should be 2 to 4 inches for established turf, 6 to 8 inches for vegetable and flower beds, and 6 inches for trees and shrubs, excluding any mulch (Hunnings and Donohue 2009). For any land that is going to be tilled, such as vegetable gardens or during turf establishment, take the sample to the depth you intend to till.
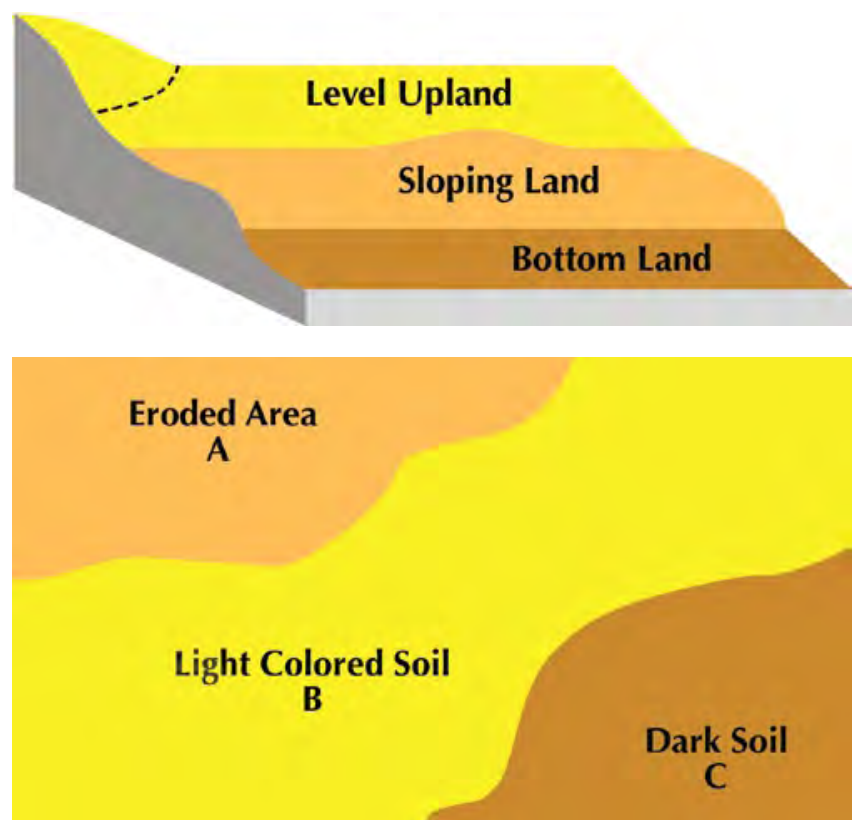

Figure 5.2. Upper: Changes in soils by landscape position. Lower: How soil type and soil color can change spatially.

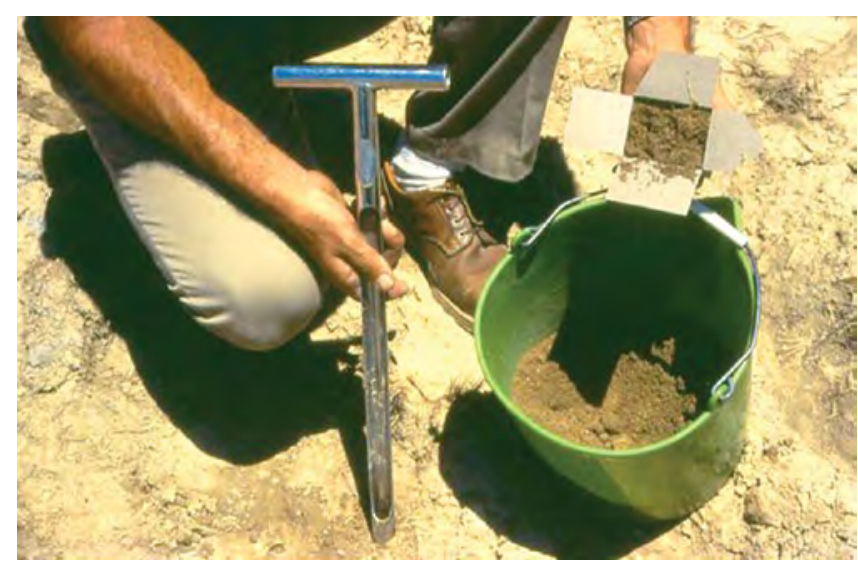

Figure 5.3. Example of a soil probe, mixing bucket, and soil box filled with soil.

A representative soil sample consists of a well-mixed composite of many subsamples. A soil sample from a single spot, instead of the representative sample described here, could result in inaccurate nutrient and lime recommendations. Collect at least 10 subsamples from the uniform area you have identified and mix them together in a clean plastic bucket. It is important the bucket is clean because small amounts of nutrients or lime in the bucket could contaminate your sample.

Push the soil probe into the soil to the desired depth and remove any surface plant material such as turf thatch before placing it in the bucket. Collect the subsamples from random spots within the sample area by following a zigzag pattern as you walk across the landscape (figure 5.4). When you have collected the necessary number of subsamples in your bucket, break up any aggregates or clumps and mix thoroughly. It is this thoroughly mixed composite of your subsamples that you will submit for testing.

There are several private and public soil testing laboratories and each has its own system for submitting samples. Virginia Cooperative Extension also has offices

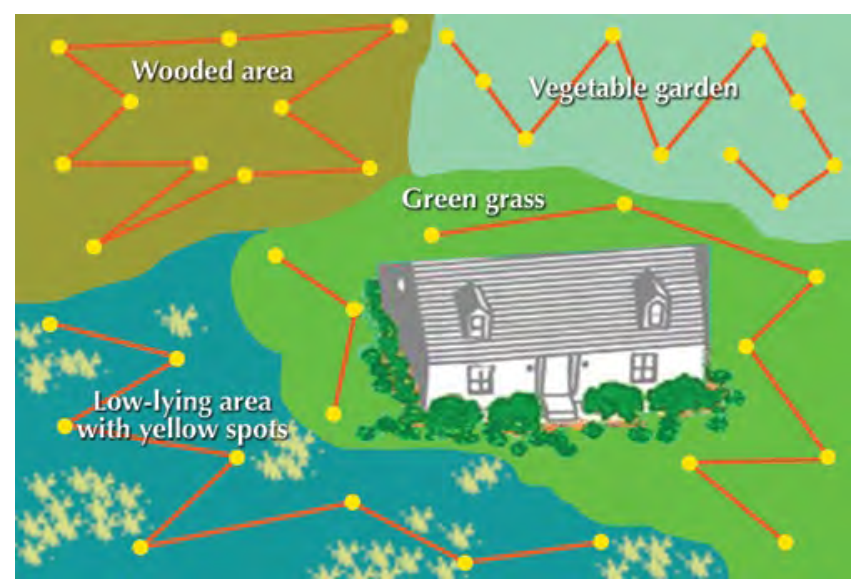

Figure 5.4. Example of soil sampling locations for a homeowner. Yellow dots indicate individual sampling points, and lines collecting dots indicate samples that are pooled and mixed. 
located throughout the state where you can pick up soil testing boxes appropriate for submitting soil samples to the Virginia Tech Soil Testing Laboratory (www.soiltest.vt.edu). These soil boxes hold about a cup or 0.5 pound or more of soil, and you should try to fill them to ensure you submit sufficient soil. An acre contains about 2 million pounds of topsoil, so the importance of collecting a representative subsample cannot be overemphasized.

The sample identification should be placed on the laboratory container and placed on a corresponding map or identification sheet for the areas to be sampled. More information on the appropriate steps in sampling soils, submitting the sample, and interpreting the soil test results can be found in Soil Testing for the Lawn and Landscape, Virginia Cooperative Extension publication 430-540 (Goatley, Mullins, and Ervin 2005; http:// pubs.ext.vt.edu/430/430-540/430-540.html).

\section{Dealing With Thatch}

Thatch is an accumulation of dead and living plant tissue (primarily undecomposed stems) located immediately above the soil surface. Thatch is resistant to chemical change and microbial degradation. As thickness increases, thatch may become a major area of root proliferation and significantly influence the supply of plant nutrients. Grasses that creep by rhizomes (belowground stems) and stolons (aboveground stems) are most likely to produce thatch. High nitrogen rates, in particular, favor thatch development. Because thatch is almost all organic and very lightweight, it becomes a misleading component of a normal soil sample.

In turfgrass areas where thatch thickness exceeds 0.5 inch, the thatch should be removed before taking any soil sample used to measure soil $\mathrm{pH}$ or other nutrients, such as phosphorus and potassium. This suggests that turfgrass areas with thick thatch covers should have two samples taken for analysis to more correctly reflect maintenance nutrient needs. Areas with a thatch thickness of 0.5 inch or less can be analyzed for nutrient needs with the thatch either mixed in as part of the sample or removed before taking the sample cores.

Remember that thatch is an indication of "imbalance" in turfgrass management; low-input turfgrasses, even those with lateral stems, do not produce appreciable thatch because the soil microbial population is able to adequately degrade the stems. Detailed information on thatch management is presented in chapter 6 .

\section{Sampling Problem Areas}

When sampling problem areas, take a representative sample from the problem area and a representative sample from an area adjacent to the problem area. Both samples should be sent to a laboratory for analysis to allow for comparison and more accurate determination of the severity of the problem. Although some conclusions can be drawn from a single sample, having another sample result from soil or growing media near

\section{Table 5.1. Sampling considerations for problem identification and verification.}

\begin{tabular}{lll}
\hline $\begin{array}{l}\text { Suspected } \\
\text { problem }\end{array}$ & Probable cause & Sampling considerations \\
\hline Low pH & Nitrogen fertilization. & Sample as needed to a depth of 3-4 inches. \\
\hline $\begin{array}{l}\text { High pH or } \\
\text { soluble } \\
\text { salts }\end{array}$ & $\begin{array}{l}\text { Large amounts of salts } \\
\text { or carbonates are added } \\
\text { through long-term use of } \\
\text { irrigation water applied to } \\
\text { high management areas. }\end{array}$ & $\begin{array}{l}\text { Periods of high rainfall will reduce the problem, so sample during dryer } \\
\text { periods of the season to assess the maximum severity. CEC should be } \\
\text { determined as part of any test for "salt" problems, especially on low CEC }\end{array}$ \\
\hline $\begin{array}{l}\text { Nutrient } \\
\text { deficiency }\end{array}$ & $\begin{array}{l}\text { Inadequate fertilization, } \\
\text { especially where } \\
\text { clippings are removed; } \\
\text { excessive irrigation; low } \\
\text { CEC leading to leaching. }\end{array}$ & $\begin{array}{l}\text { Sample more frequently on modified or very sandy soils (at least } \\
\text { annually). Analysis may indicate a need for more-frequent application of } \\
\text { nutrients or modification of other management factors to reduce nutrient } \\
\text { losses. Unfortunately, few soil test correlations are available for turf } \\
\text { grown in these modified soils. Sample cores should be taken to a depth } \\
\text { of 3-4 inches. }\end{array}$ \\
& $\begin{array}{l}\text { Low pH; excessive } \\
\text { fertilization; sludge, } \\
\text { manures, or other } \\
\text { biosolids application. }\end{array}$ & $\begin{array}{l}\text { Soil pH is the most important factor in determining the availability of } \\
\text { these nutrients to the turfgrasses. Most grasses are quite tolerant to trace } \\
\text { metals, but careful monitoring is important to prevent buildup of toxic } \\
\text { levels. Subsample cores should be taken to a depth of 3-4 inches. }\end{array}$ \\
\hline $\begin{array}{l}\text { Nutrient } \\
\text { toxicity }\end{array}$ & &
\end{tabular}


the problem allows evaluation of results on like materials. See table 5.1 for probable causes of a suspected problem area.

\section{General Crop Nutrient Deficiency Symptoms}

Nitrogen (N): Restricted growth of tops and roots; growth is upright and spindly; leaves pale and yellowgreen in early stages, more yellow and even orange or red in later stages; deficiency shows up first on lower leaves.

Phosphorus (P): Restricted growth of tops and roots; growth is upright and spindly; leaves bluish-green in early stages with green color sometimes darker than plants supplied with adequate phosphorus; more purple in later stages with occasional browning of leaf margins; defoliation is premature, starting at the older leaves.

Potassium (K): Browning of leaf tips; marginal scorching of leaf edges; development of brown or light-colored spots in some species that are usually more numerous near the margins; deficiency shows up first on lower foliage.

Calcium (Ca): Deficiency occurs mainly in younger leaves near the growing point; younger leaves distorted with tips hooked back and margins curled backward or forward; leaf margins may be irregular and display brown scorching or spotting.

Magnesium (Mg): Interveinal chlorosis with chlorotic areas separated by green tissue in earlier stages, giving a beaded, streaking effect; deficiency occurs first on lower foliage.

Sulfur (S): Younger foliage is pale yellowish-green, similar to nitrogen deficiency; shoot growth somewhat restricted.

Zinc (Zn): Interveinal chlorosis followed by dieback of chlorotic areas.

Manganese (Mn): Light-green to yellow leaves with distinctly green veins; in severe cases, brown spots appear on the leaves and the leaves are shed; usually begins with younger leaves.

Boron (B): Growing points severely affected; stems and leaves may show considerable distortion; upper leaves are often yellowish-red and may be scorched or curled.

Copper (Cu): Younger leaves become pale-green with some marginal chlorosis.
Iron (Fe): Interveinal chlorosis of younger leaves.

Molybdenum (Mo): Leaves become chlorotic, developing rolled or cupped margins; plants deficient in this element often become nitrogen-deficient.

Chlorine (Cl): Deficiency not observed under field conditions.

Source: Brann, Holshouser, and Mullins (2000).

\section{Understanding Soil Test Reports}

\section{Fertilizer Recommendation}

Fertilizer recommendations may be used for the same lawn or landscape situation for two to three years. When the soil tests "very high" for phosphorus or potassium, no fertilizer for these nutrients is recommended.

\section{Lime Recommendation}

If needed, a lime recommendation is given to neutralize soil acidity and should last two to three years. The measured soil test levels of calcium and magnesium are used to determine the appropriate type of limestone to apply. If neither dolomitic nor calcitic lime is mentioned, or just "ag" type or "agricultural" limestone is stated on the report, then it does not matter what type is used. When no information on the soil sample information sheet is provided regarding the last lime application, the lab assumes you have not applied lime in the past 18 months. Do not overlime! Too much lime can be as harmful as too little. For best results, apply lime, when possible, several months ahead of the crop/plant to be planted to allow time for a more complete soil reaction.

\section{Methods and Meanings}

For more detail on the lab procedures used, go to $w w w$. soiltest.vt.edu and click on "Laboratory Procedures."

Soil pH (or soil reaction) measures the "active" acidity in the soil's water (or hydrogen ion activity in the soil solution), which affects the availability of nutrients to plants. It is determined on a mixed suspension of a 1-1, volume-to-volume ratio of soil material to distilled water.

Virginia soils naturally become acidic, and limestone periodically needs to be applied to neutralize some of this acidity. A slightly acid soil is where the majority of nutrients become most-available to plants and where soil organisms that decompose organic matter 
and contribute to the general "overall health" of soils are the most active. When a soil is strongly acidic $(<$ 5.0 to $5.5 \mathrm{pH}$ ), many herbicides lose effectiveness and plant growth is limited by aluminum toxicity. When soils are overlimed and become alkaline $(>7.0 \mathrm{pH})$, micronutrients such as manganese and zinc become much less-available to plants.

For most agronomic crops and landscaping plants, lime recommendations are provided to raise the soil $\mathrm{pH}$ to a slightly acid level of between 5.8 and 6.8. Blueberries and acid-loving ornamentals generally prefer a 4.5 to $5.5 \mathrm{pH}$, and an application of liming material is suggested when the soil $\mathrm{pH}$ drops below 5.0.

For the majority of other plants, lime may be suggested before the $\mathrm{pH}$ gets below 6.0 ; this is to keep the soil $\mathrm{pH}$ from dropping below the ideal range because lime is slow to react and it affects only a fraction of an inch of soil per year, when the lime is not incorporated into the soil. If the soil $\mathrm{pH}$ is above the plant's target $\mathrm{pH}$, then no lime is recommended. If the $\mathrm{pH}$ is well above the ideal range, then sometimes an application of sulfur is recommended to help lower the $\mathrm{pH}$ faster; however, most of the time one can just let the soil $\mathrm{pH}$ drop on its own.

The Buffer Index, which provides an indication of the soil's total (active and reserve) acidity and ability to resist a change in $\mathrm{pH}$, is determined by a Mehlich buffer solution. This buffer measurement is the major factor in determining the amount of lime to apply. The Buffer Index starts at 6.6 and goes lower as the soil's total acidity increases and more lime is needed to raise the soil $\mathrm{pH}$. A sandy soil and a clayey soil can have the same soil $\mathrm{pH}$; however, the clayey soil will have greater reserve acidity (and a lower Buffer Index) as compared to the sandy soil, and the clayey soil will require a greater quantity of lime be applied in order to raise the soil $\mathrm{pH}$ the same amount as the sandy soil. A reported Buffer Index of "N/A" means that it was not measured because the soil (water) $\mathrm{pH}$ was either neutral or alkaline and not acidic (soil $\mathrm{pH} \geq 7.0$ ) and therefore requires no lime.

Nutrients available for plant uptake are extracted from the soil with a Mehlich-1 solution using a 1-5, volume-to-volume, soil-to-extractant ratio and are then analyzed by Inductively Coupled Plasma-Atomic Emission Spectrometry (commonly referred to as an ICP-AES instrument). An extractable Mehlich-1 level of phosphorus from 12 to 35 pounds per acre is rated as medium or optimum. A medium level of potassium is from 76 to 175 pounds per acre. Medium levels of calcium and magnesium are 721 to 1,440 and 73 to 144 pounds per acre, respectively. Calcium and magnesium are normally added to the soil through the application of limestone. It is rare for very high fertility levels of phosphorus, potassium, calcium, and magnesium to cause a reduction in crop yield or plant growth. Levels of micronutrients, (zinc, manganese, molybdenum, copper, iron, and boron) are typically present in the soil at adequate levels for plants if the soil $\mathrm{pH}$ is in its proper range. See Soil Test Note 4 for documented micronutrient deficiencies that occur in Virginia (www.soiltest. vt.edu/stnotes).

Soluble salts or fertilizer salts are estimated by measuring the electrical conductivity of a 1-2, volume-tovolume ratio of soil material to distilled water. Injury to plants may start at a soluble-salts level above 844 parts per million when grown in natural soil, especially under dry conditions and to germinating seeds and seedlings. Established plants will begin to look wilted and show signs related to drought. This test is used primarily for greenhouse, nursery, and home garden soils where very high application rates of fertilizer may lead to an excessive buildup of soluble salts.

Soil organic matter (SOM) is the percentage by weight of the soil that consists of decomposed plant and animal residues and is estimated by using either the weight Loss-on-Ignition (LOI) method from 150 to 360 degrees Celsius (C) or a modified Walkley-Black method. Generally, the greater the organic matter level, the better the overall soil tilth or soil quality, because nutrient and water-holding capacities are greater, and improved aeration and soil structure enhance root growth.

The percentage of soil organic matter in a soil can affect the application rate and performance of some pesticides, but this is not usually a problem in lawn and landscape situations. Soil organic matter levels from 0.5 percent to 2.5 percent are ordinary for natural, well-drained soils. For completely modified, sand-based soils, it is typically recommended that SOM levels become no greater than 3 percent because large SOM levels can greatly reduce water infiltration and percolation rates in these soils. Due to relatively large amounts of organic materials being commonly added to gardens, the SOM in garden soils can be raised into the range of 5 percent to 10 percent.

The remaining values that are reported under the "Lab Test Results" section are calculated from the previously measured values and are of little use to most turf and landscape managers. 
Estimated cation exchange capacity (Est-CEC) gives an indication of a soil's ability to hold some nutrients against leaching. Natural soils in the mid-Atlantic usually range in CEC from 1 to 12 millequivalent (meq) per 100 grams (g). A very sandy soil will normally have a CEC of 1 to 3 meq per $100 \mathrm{~g}$. The CEC value will increase as the amount of clay and organic matter in the soil increases. This reported CEC is an estimate because it is calculated by adding the Mehlich-1 extractable cations (calcium plus magnesium plus potassium) and the acidity estimated from the Buffer Index and converting to units commonly used for CEC. This value can be erroneously high when the soil $\mathrm{pH}$ or soluble-salts level is high.

The percentage of acidity is a ratio of the amount of acid-generating cations (as measured by the Buffer Index) that occupy soil cation-exchange sites to the total CEC sites. The higher this percentage, the higher the amount of reserve acidity in the soil, the higher the amount of acidity there will be in the soil solution, and the lower the soil $\mathrm{pH}$ will be. A reported acidity percentage of "N/A" means that a Buffer Index was not determined, the acidity is probably less than 1 meq per $100 \mathrm{~g}$ and/or 5 percent, and the soil $\mathrm{pH}$ is alkaline (> 7.0).

The base saturation percentage is the ratio of the quantity of nonacid-generating cations (i.e., the exchangeable bases calcium, magnesium, and potassium) that occupy the cation exchange sites.

The percentage of calcium, magnesium, or potassium saturation refers to the relative number of CEC sites that are occupied by that particular nutrient and is a way of evaluating for any gross nutrient imbalance.

\section{Plant Tissue Analysis}

Tissue analysis has two main applications:

- To confirm a suspected nutrient element deficiency when visual symptoms are present.

- To monitor plant nutrient element status in order to determine whether each tested nutrient is in sufficient concentration for optimum performance.

\section{Plant Analysis as a Diagnostic Tool}

Whenever turfgrasses fail to meet color and quality expectations in response to nutrient applications, plant analysis is the tool used by many managers to diagnose the problem. Visual symptoms can offer helpful clues but can also be easily confused and misinterpreted, especially where micronutrients or sulfur are involved. Turf and landscape managers should confirm a suspected deficiency by plant analysis before applying a corrective treatment. Numerous cases can be given where incorrect diagnosis in the field has led to turf problems as well as costly and ineffective corrective treatments.

\section{Nutrient Monitoring}

It is important to remember that tissue-sufficiency ranges used by most labs are based on values common in turfgrasses and landscape plants with acceptable quality under a wide range of growing conditions and management levels. It is not, at this point, refined to the point that it can ensure quality for your specific growing conditions, management practices, and quality demands. Some golf course superintendents currently submit samples bimonthly or monthly - especially for creeping bentgrass grown on completely modified, sand-based putting greens. Upward or downward trends can be observed and adjustments in lime and fertilizer treatments made before deficiencies or excesses develop that would reduce quality.

Establishing your own routine monitoring program using these recommendations as a base will allow you to follow the effectiveness of your nutrient management practices while making corrective treatments before significant loss in quality occurs. In addition, by comparing plant analysis results with turf quality, nutrient applications, and soil test levels samples over time, you can refine the nutrient sufficiency ranges and nutrient management practices required to maintain turf quality for your specific site, climatic conditions, and management constraints.

Monitoring does not need to be done for every possible situation. Carefully decide the areas you may need to sample. Choose areas representative of the turf quality, use, composition, and soils to be managed. Take plant samples at regular intervals from each representative area prior to and during growth cycles. Record turf quality (clipping yields, if available), weather situation, and any known problems at the time of sampling. Track nutrient additions on each monitored site and collect routine soil samples at least once a year (prior to phosphorus and potassium fertilization) to supplement your records. 


\section{Sampling Considerations}

Sample the aboveground portion of the plant, clipped just above ground level no more than two days after mowing. As a general rule, monitoring samples can be taken from turfgrass clippings. When whole plants are sampled, cut off and discard the roots and wash the shoots to remove soil particles. Under normal conditions, rainfall is frequent enough to keep leaf surfaces fairly free from dust and soil particles. If recently sprayed or if iron is of primary interest, a quick wash in a dilute ( 0.3 percent) detergent solution followed by a quick rinse in a strainer or colander will help remove residues and soil particles that could bias the sample.

To prevent decay during transport to the lab, reduce excess moisture by partially air-drying plant tissue samples before shipment to the laboratory. Never put fresh samples in a tightly sealed or plastic bag unless they will be kept cold during transport. Decayed samples will not be analyzed.

It is a good idea to have recent soil test results available when interpreting the results of a plant tissue analysis. If none are available, submit a soil sample along with the tissue sample.

For diagnostic samples, obtain samples as soon as symptoms appear. Plants showing severe deficiency symptoms are often the most difficult to interpret correctly because a difficult-to-detect deficiency of one element may result in deficiencies or excess accumulation of other elements if uncorrected. Plants under prolonged stress of any kind can also display unusual nutrient contents. This would include damage from heat, cold, drought, flooding, disease, insects, or mechanical treatments.

Comparative sampling can improve diagnosis accuracy. Collect both plant and soil samples from "good" and "bad" areas in close proximity to each another. Both areas should have similar soil types, species composition, and management (mowing height, irrigation, etc.). Because the recommended ranges of plant nutrient content are somewhat general, a "good" sample offers a measure of what should be expected for your site and management conditions. Differences in nutrient concentrations can then be compared with soil samples to determine if the problem is related to fertility management or is an uptake problem, such as disease, water, compaction, or root damage. For example, differences in magnesium and manganese between plants could be related to differences in soil $\mathrm{pH}$.

\section{Interpreting a Plant Analysis Result}

Plant analysis indicates only what the root and internal transport system is able to deliver to the sampled tissue. Tissue analysis is excellent for determining nutrient deficiencies, but as previously discussed, the analysis does not tell you why the limitation is occurring; that is the importance of usually submitting a soil sample at the same time as a tissue sample. Levels below the sufficiency range can result from low or excessive soil test levels, inadequate or excessive fertilization, and improper $\mathrm{pH}$. Even where soil fertility levels are correctly managed, biotic factors (e.g., nematodes, disease, herbicide injury, etc.) and physical conditions (e.g., compaction, flooding, drought, root injury, incorrect mowing) can limit nutrient uptake and distribution in the plant. In other cases, visual symptoms might not even be nutrient-related (for example, pesticide injury).

The effects of the time of sampling, turf species, traffic and use, and environmental factors such as soil moisture, temperature, light quality, and intensity may significantly affect the relationship between nutrient concentration and turf quality. It is important that the time of sampling, stage of growth, and character of growth prior to sampling be known and considered when interpreting a plant analysis result.

Table 5.2 offers general guidelines on interpretations of plant analysis results for turfgrasses. Other landscape plant materials would also likely fall within these ranges, but there are exceptions for particular categories of plants. Ornamental landscape plant management is covered in chapter 7. A complete discussion of fertilizer sources and programs is provided in chapter 8 .

\section{Literature Cited}

Brann, D. E., D. L. Holshouser, and G. L. Mullins. 2000. Agronomy Handbook. Virginia Cooperative Extension Publication 424-100. http://pubs.ext. vt.edu/424/424-100/424-100.pdf.

Goatley, M., G. Mullins, and E. Ervin. 2005. Soil Testing for the Lawn and Landscape. Virginia Cooperative Extension Publication 430-540. http://pubs. ext.vt.edu/430/430-540/430-540.html.

Hunnings, J. R., and S. J. Donohue. 2009. Soil Sampling for the Home Gardener. Virginia Cooperative Extension Publication 452-129. http://pubs. ext.vt.edu/452/452-129/452-129.pdf. 


\section{Table 5.2. Typical nutrient sufficiency ranges, interpretations, and recommendations for the analysis of turfgrass tissues.}

\begin{tabular}{|c|c|c|}
\hline Element & $\begin{array}{l}\text { Sufficiency } \\
\text { range } \\
\text { (\% or ppm) }\end{array}$ & Interpretation and recommendation \\
\hline Nitrogen $(\mathrm{N})$ & $2.2-4.0 \%$ & $\begin{array}{l}\text { Nitrogen is the nutrient most commonly found to be low in turfgrasses, which is } \\
\text { generally due to inadequate fertilization, heavy leaching rains, overirrigation, or } \\
\text { possible root damage. } \mathrm{N} \text { deficiency may be manifested with a light-green color, } \\
\text { slow growth rate, or excessive seedhead production. If a deficiency is detected, } \\
\text { apply } \mathrm{N} \text { according to soil test recommendations, being sure to split applications } \\
\text { where leaching may be a problem. }\end{array}$ \\
\hline Phosphorus (P) & $0.3-0.7 \%$ & $\begin{array}{l}\text { Deficiency is usually due to low soil P; cool, wet growing conditions; or } \\
\text { excessively low soil pH. If deficiency is detected, apply P and limestone based } \\
\text { on soil test recommendations. High levels of P generally pose more problems } \\
\text { with intensively managed turf than deficiencies do. Excessive P levels in the } \\
\text { leaves can cause deficiencies of other nutrients, particularly iron. High P-K } \\
\text { ratios in leaf tissue increase winterkill in bermudagrass and St. Augustinegrass. } \\
\text { When high P is detected, omit P from the fertilization program until P is within } \\
\text { acceptable limits. In most instances, three or more years may be required. }\end{array}$ \\
\hline Potassium (K) & $1.5-3.0 \%$ & $\begin{array}{l}\text { Low } \mathrm{K} \text { is generally due to low soil test } \mathrm{K} \text { levels, inadequate } \mathrm{K} \text { fertilization, or } \\
\text { when grass is grown on coarse-textured, sandy soil that is subject to leaching. } \\
\text { Low } \mathrm{K} \text { may also be associated with low } \mathrm{N} \text { fertilization. When soil } \mathrm{K} \text { is adequate, } \\
\mathrm{N} \text { fertilization increases the uptake of } \mathrm{K} \text { by the grass. When low } \mathrm{K} \text { is detected } \\
\text { in the tissue, apply potash and nitrogen based on soil test recommendations. } \\
\text { When } \mathrm{K} \text { drops below } 1.0 \text { percent in the tissue, deficiency symptoms appear } \\
\text { and are characterized by spindly growth (narrow leaves, thin turf), leaf tip burn, } \\
\text { reduced wear, cold and disease tolerance, and reduced growth rate. Excessive } \\
\mathrm{K} \text { levels may induce } \mathrm{Mg} \text { deficiency. If high } \mathrm{K} \text { levels are detected in the tissue, } \\
\text { reduce the K fertilization rate or omit } \mathrm{K} \text { from the program until } \mathrm{K} \text { is within the } \\
\text { sufficiency range. }\end{array}$ \\
\hline Calcium (Ca) & $0.20-1.25 \%$ & $\begin{array}{l}\text { Grasses are able to take up Ca under a wide range of soil conditions and } \\
\text { it is rarely deficient. May be drought induced. Heavy } \mathrm{N} \text { and } \mathrm{K} \text { fertilization } \\
\text { will decrease Ca levels but not cause deficiencies in well-limed soils. If low } \\
\text { levels are detected, check for low soil pH and apply limestone based on } \\
\text { recommendations. A high Ca level may indicate some other nutrient deficiency } \\
\text { or disorder. }\end{array}$ \\
\hline Magnesium (Mg) & $0.15-0.60 \%$ & $\begin{array}{l}\text { Low levels may occur on sandy soils, soils with low } \mathrm{pH} \text { and low } \mathrm{Mg} \text {, where } \\
\text { high rates of } \mathrm{NH} 4-\mathrm{N} \text { and } \mathrm{K} \text { fertilizers have been applied, and where clippings } \\
\text { are continuously removed. If low levels are detected, include } \mathrm{Mg} \text { in the } \\
\text { fertilization program at the rate of } 0.5 \text { pounds } \mathrm{Mg} \text { per } 1,000 \mathrm{sq} \mathrm{ft} \text {. If soil } \mathrm{pH} \text { is } \\
\text { low and limestone is required, apply dolomitic limestone according to soil test } \\
\text { recommendations. Excessively high } \mathrm{Mg} \text { in tissue is not a common occurrence. }\end{array}$ \\
\hline Sulfur (S) & $0.2-0.4 \%$ & $\begin{array}{l}\text { Low } S \text { may occur on sandy soils low in organic matter where } S \text {-free fertilizers } \\
\text { have been used following extensive periods of heavy rainfall, where grass has } \\
\text { been overirrigated, and where high application rates of } N \text { have been applied. } \\
\text { The ratio of } N \text { to } S \text { is as important as the } S \text { content itself and should not exceed } \\
20 \text {-to- } 1 \text {. Ideally, the } N \text { - } S \text { ratio should be approximately } 14 \text {-to- } 1 \text { for optimum } \\
\text { growth and turf quality. If } S \text { is low and/or the } N \text { - } S \text { ratio exceeds } 20 \text {-to- } 1 \text {, include } \\
0.25-0.50 \text { pound } S \text { per } 1,000 \text { sq } \mathrm{ft} \text { in the fertilization program. Sulfur may be } \\
\text { supplied as gypsum, elemental sulfur or sulfur-containing fertilizers. }\end{array}$ \\
\hline
\end{tabular}




\section{Table 5.2. Typical nutrient sufficiency ranges, interpretations, and recommendations for the} analysis of turfgrass tissues. (cont.)

\begin{tabular}{|c|c|c|}
\hline Element & $\begin{array}{l}\text { Sufficiency } \\
\text { range } \\
(\% \text { or ppm) }\end{array}$ & Interpretation and recommendation \\
\hline Manganese (Mn) & 20-300 ppm & $\begin{array}{l}\text { Deficiencies are rare but may occur occasionally on sandy soils that are low } \\
\text { in Mn, high in organic matter, and when the soil } \mathrm{pH} \text { is }>6.8 \text {. Mn deficiencies } \\
\text { can be corrected by applying a foliar application of manganese sulfate or } \\
\text { manganese chelate by dissolving } 2 \text { ounces of manganese sulfate or } 1 \text { ounce } \\
\text { of manganese chelate in } 1 \text { gallon of water and spraying at the rate of } 0.5 \text { gal } \\
\text { per } 1,000 \text { sq ft. Color should improve within } 24 \text { hours. Repeated applications } \\
\text { will be required to prevent reoccurrence of the deficiency. Excessive Mn levels } \\
\text { can occur in some turfgrasses when the soil pH is }<5.5 \text { or where soils are } \\
\text { consistently overwatered. High Mn levels can be corrected by proper liming, } \\
\text { proper irrigation practices, and by improving drainage on waterlogged soils. }\end{array}$ \\
\hline Iron (Fe) & 50-200 ppm & $\begin{array}{l}\text { Iron determinations are invalid unless samples are properly washed to remove } \\
\text { soil contaminates. Generally if Fe and Al levels are both high, it is due to } \\
\text { contamination rather than inherent levels in the grass. Iron deficiency can occur } \\
\text { on high pH soils }(\geq 7.0) \text {, during periods of cool temperatures, where grasses } \\
\text { are overwatered, and where soil P levels are excessively high. Iron deficiency } \\
\text { is best controlled by applying a foliar application of iron as iron sulfate or iron } \\
\text { chelate at a rate of } 0.5 \text { ounce of Fe per } 1,000 \text { sq ft. Repeated applications may } \\
\text { be needed indefinitely to prevent reoccurrence of the deficiency. Do not apply } \\
\text { foliar applications of iron to grasses in the heat of the day. Soil applications of Fe } \\
\text { materials are not recommended for correcting Fe deficiencies. }\end{array}$ \\
\hline Boron $(B)$ & $5-60 \mathrm{ppm}$ & $\begin{array}{l}\text { Grasses have very low B requirements. Deficiency is unlikely; however, toxicity } \\
\text { is possible with some sources of irrigation water, particularly along the coastal } \\
\text { areas. Boron content of irrigation water should be less than } 0.5 \mathrm{ppm} \text { to guard } \\
\text { against the possible development of toxic soil levels. }\end{array}$ \\
\hline Copper $(\mathrm{Cu})$ & $5-20$ ppm & $\begin{array}{l}\text { Deficiency is not likely to occur unless high levels of organic matter are added } \\
\text { or } \mathrm{pH} \text { is excessively high. }\end{array}$ \\
\hline Zinc $(Z n)$ & $15-50$ ppm & $\begin{array}{l}\text { Deficiencies are not common on turfgrasses unless grown under alkaline soil } \\
\text { conditions. In some cases, low } \mathrm{Zn} \text { levels will be detected in grass grown on soils } \\
\text { that are excessively high in P or when grown on compacted or waterlogged } \\
\text { soils. Deficiency symptoms do not show up unless the Zn content is less than } 10 \\
\text { ppm. Zinc deficiencies can be corrected with foliar applications of zinc sulfate } \\
\text { or zinc chelate at the rate of } 0.5 \text { ounce per gal of water per } 1,000 \mathrm{sq} \mathrm{ft} \text {. }\end{array}$ \\
\hline Aluminum (Al) & & $\begin{array}{l}\text { Aluminum is not an essential plant nutrient but can be a factor affecting plant } \\
\text { growth. High Al levels (soil-free samples) result from very low soil pH }(<5.0) \text { or } \\
\text { anaerobic soil conditions such as flooded or heavily compacted soils. Plants do } \\
\text { not readily absorb Al; its presence indicates an extreme soil condition. }\end{array}$ \\
\hline
\end{tabular}




\title{
Chapter 6. Mid-Atlantic Turfgrasses and Their Management
}

\author{
Michael Goatley Jr., Professor and Extension Specialist, Crop and Soil Environmental Sciences, Virginia Tech
}

\section{Introduction}

Much of the mid-Atlantic climate falls into what is commonly termed the "transition zone" of the United States. This region is noted for its hot summers, cold winters, and varying levels of moisture. In terms of selecting appropriate turfgrasses, it means that almost any warm- or cool-season turfgrass can be grown in much of the region, but not necessarily grown well, given the possible environmental extremes of winter and summer. Most species grown in the mid-Atlantic offer a wide variety of cultivars from which to select. The U.S. Department of Agriculture's National Turfgrass Evaluation Program (NTEP) presents regularly updated field research data on numerous turfgrass variety trials from around the country (www.NTEP. org). Within the mid-Atlantic, the research efforts of turfgrass scientists at Virginia Tech and the University of Maryland result in an annual Turfgrass Variety Recommendations list that features the top-performing cultivars in the region. This report can be found at http://pubs.ext.vt.edu.

\section{Primary Cool-Season Grasses of Importance}

The primary cool-season grasses used in this region are Kentucky bluegrass (Poa pratensis L.); hybrid bluegrass (Poa pratensis x P. arachnifera); tall fescue (Festuca arundinacea Schreb.); perennial ryegrass (Lolium perenne L.); the fine-leaf fescues of creeping red (Festuca rubra L.), chewings [F. rubra L. ssp. fallax (Thuill.) Nyman], and hard fescue (F. brevipila Tracey)]; creeping bentgrass (Agrostis stolonifera var. palustris L.); and annual ryegrass (Lolium multiflorum L.).

\section{Kentucky Bluegrass (figure 6.1)}

Description: A fine-to-medium-textured grass noted for its dark green color and aggressive lateral growth habit from rhizomes (below-ground stems).

Primary uses: Lawns, athletic fields, golf course fairways, tees, and roughs; commonly mixed with perennial ryegrass for athletic fields, and with ryegrass and fine fescue for sun/shade lawns.

Primary establishment method(s): Seed readily available for many improved cultivars; sod also available.

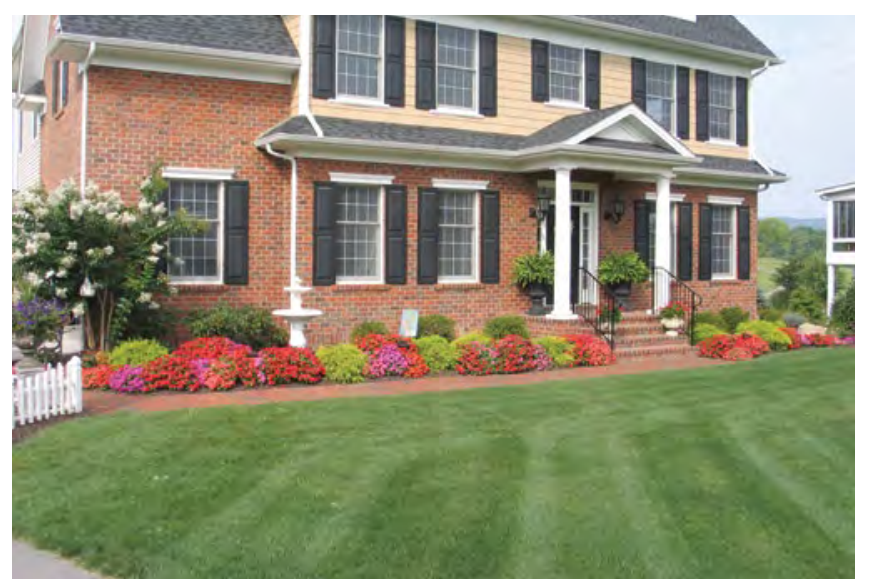

Figure 6.1. Kentucky bluegrass is a highly desirable lawn grass in the cooler regions of the mid-Atlantic, but it requires intensive maintenance to perform as desired.

Strengths: Excellent cold tolerance; excellent density; rapid recuperation potential due to aggressive lateral growth habit; summer dormancy during drought.

Weaknesses: Poor shade tolerance; 14 to 21 days for seed germination; aggressive lateral growth habit from rhizomes can make it a weed in plant beds; heavy thatch (an organic layer primarily composed of nondecomposed stems) under aggressive maintenance programs; disease and insect pressures can be high under intensive maintenance programs.

Typical seasonal nitrogen requirements: 1 to 2 pounds per 1,000 square feet for low-maintenance lawns; 3 to 4.5 pounds per 1,000 square feet for golf- and sportsturf uses.

\section{Hybrid Bluegrasses}

Similar descriptive and maintenance characteristics as for Kentucky bluegrass, but these grasses potentially have genetic improvements in heat and drought tolerance. See more comments below in the section on tall fescue.

\section{Tall Fescue (figure 6.2)}

Description: "Turf-type" varieties are fine- to mediumtextured, older varieties are medium- to coarse-textured; managed primarily as a bunch/clump-forming grass with little spreading potential, but newer varieties with more aggressive rhizome formation are in development; deepest root system of the cool-season grasses. 


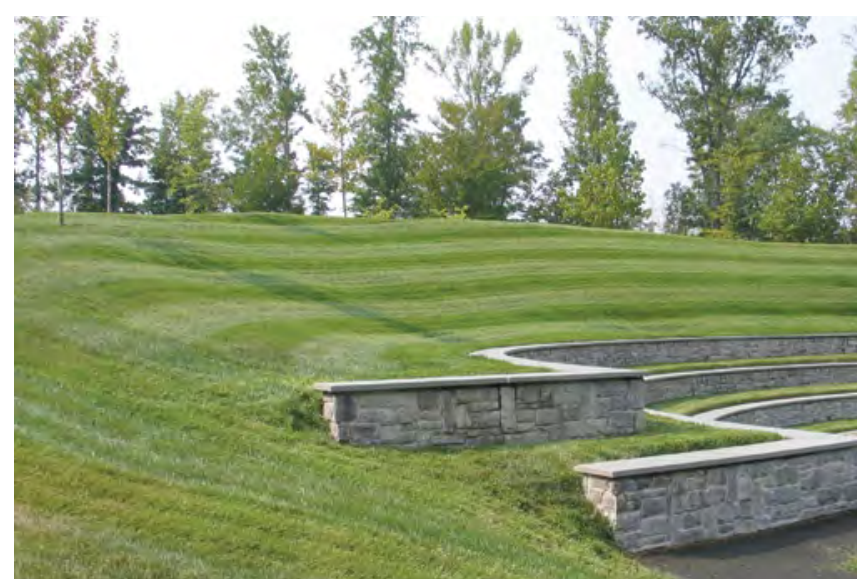

Figure 6.2. A general purpose, turf-type tall fescue turf at a business park in Richmond, Va.

Primary uses: Most important lawn and "all purpose" turf for the mid-Atlantic; low-maintenance athletic fields, golf course roughs; turf-type varieties are commonly mixed with either Kentucky bluegrass or hybrid bluegrass in sod production systems. Preliminary research in the warmer, coastal regions of the mid-Atlantic suggest that 90 percent $/ 10$ percent (by weight) seed mixtures of tall fescue and hybrid bluegrass provide a more diseasetolerant lawn turf than single species plantings.

Primary establishment method(s): Seed readily available for many improved cultivars; sod available also.

Strengths: Excellent drought avoidance characteristics; rapid germination rates (four to seven days); early spring greening; moderate shade tolerance; adapted to a wide range of soils.

Weaknesses: High mowing requirement during active growing periods; limited to no recuperative potential; Rhizoctonia blight is a common disease problem under aggressive spring fertility programs.

Typical seasonal nitrogen requirements: 0.5 to 1 pound per 1,000 square feet for low-maintenance lawns; up to 3.5 pounds per 1,000 square feet for higher-maintenance lawns and golf/sports turfs.

\section{Perennial Ryegrass}

Description: A shallow-rooted, fine-textured, bunchtype grass noted for its dark green color and exceptional visual appeal due to "striping" when clipped.

Primary uses: Not recommended as a monostand except at elevations above 2,000 feet, where it can be used for lawns and golf and sports turf; also commonly mixed with Kentucky bluegrass for lawns and athletic fields; primary cool-season grassing option for overseeding bermudagrass for winter color/playability.
Primary establishment method(s): Seed readily available for many improved cultivars.

Strengths: Rapid germination (four to seven days) and establishment from seed; exceptional visual appeal due to glossy leaf surface that results in striping by mowing; excellent wear tolerance as a mature turf; tolerates cutting heights as low as $0.5 \mathrm{inch}$.

Weaknesses: No recuperative potential; poor cold tolerance; poor drought tolerance; high disease pressure.

Typical seasonal nitrogen requirements: 1 to 2 pounds per 1,000 square feet for low-maintenance lawns; 3 to 4.5 pounds per 1,000 square feet for golf- and sportsturf uses.

\section{Fine-Leaf Fescues (figure 6.3)}

Three species of fine-leaf fescues predominate in the mid-Atlantic: creeping red, chewings, and hard fescue.

Description: All species have exceptionally fine leaf blades commonly referred to as "needle-like." Chewings and hard fescues are bunch-type grasses, while creeping red possesses short rhizomes; all are managed as bunchgrasses.

Primary uses: Excellent low-maintenance turf with the best shade tolerance of cool-season grasses; often mixed with Kentucky bluegrass as the "shade component" of sun/shade seed mixtures.

Primary establishment method: Seed available for limited number of varieties.

Strengths: Good shade tolerance; excellent cold tolerance; good drought tolerance; minimal fertility and liming requirement; reduced mowing requirement compared to other grasses.

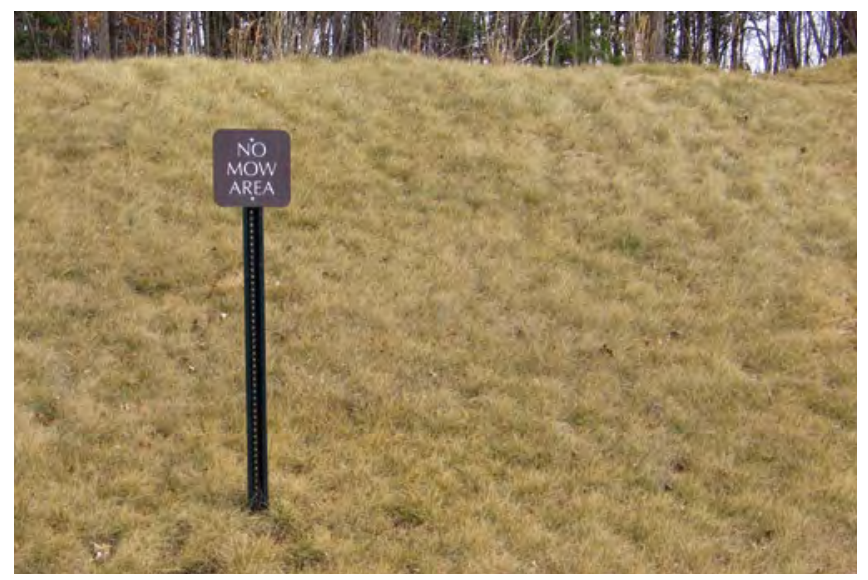

Figure 6.3. Fine-leaf fescues are ideal for minimal-maintenance turfs where limited fertility and mowing are desired. 
Weaknesses: Intolerant of persistently wet soils; poor traffic tolerance and recuperative potential; 10 to 14 day germination from seed.

Typical seasonal nitrogen requirements: 0.5 to 2 pounds nitrogen per 1,000 square feet.

\section{Creeping Bentgrass (figure 6.4)}

Description: a very shallow-rooted, fine-textured grass with an aggressive stoloniferous (aboveground stem) growth habit; many cultivars have a characteristic pale blue-green color.

Primary uses: Almost exclusively for golf turf as bentgrass is the primary choice on putting greens; also receives extensive use on tees and is used for fairways at high-maintenance/well-budgeted golf facilities.

Primary establishment method: Seed available for many improved cultivars; sod available from regional producers.

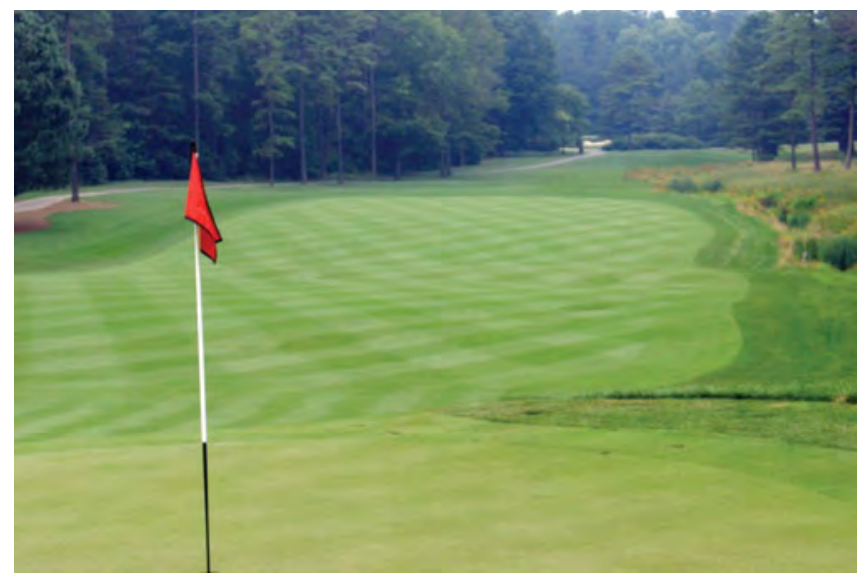

Figure 6.4. Owing to its ability to be maintained at cutting heights of 0.1 to 0.5 inch, creeping bentgrass is a popular grass for golf putting greens, tees, and fairways.

Strengths: Surface smoothness, density, and its tolerance to cutting heights as low as 0.1 inch are predominate reasons for bentgrass use; excellent cold tolerance.

Weaknesses: Very poor heat and drought tolerance; poor traffic tolerance; high disease and insect pressure.

Typical seasonal nitrogen requirements: 2.5 to 4.5 pounds nitrogen per 1,000 square feet.

\section{Annual Ryegrass}

Description: A bunch-type, mediumto-coarse-bladed grass typically having a very light green color.
Primary uses: Cost-effective temporary soil stabilization, either seeded alone or as a nurse grass for perennial species; winter overseeding of lawns or sports fields.

Primary establishment method: Exclusively by seed with most cultivars available having been developed as a temporary forage grass; the first releases of annual ryegrass varieties developed for turfgrass use are now available; there are also intermediate ryegrass hybrids (Lolium perenne x L. multiflorum) for which early releases were of similar quality to annual ryegrass, but later releases display quality characteristics more comparable to perennial ryegrass.

Strengths: The most rapid germination from seed results in quick establishment and soil stabilization.

Weaknesses: A very fast growth rate results in a very high mowing requirement; poor cold tolerance; dies quickly the following summer (but note that some might consider this a strength when used for winter overseeding and a rapid, natural transition is desired).

Typical seasonal nitrogen requirements: 1 to 2.5 pounds nitrogen per 1,000 square feet.

Figure 6.5 details the seasonal anticipated shoot and root growth and carbohydrate (i.e., stored food) levels across the seasons. Optimal temperatures for coolseason grass growth are 65 to $75^{\circ} \mathrm{F}$, resulting in the primary period for nitrogen fertilization being late summer through midfall, followed by early to midspring. Under the cooling temperatures and shorter days of fall, fertilization optimizes root development and carbohydrate storage rather than excessive shoot growth, and the benefits of fall fertilization continue into the spring by delivering a steady and sustained spring greening and growth response.

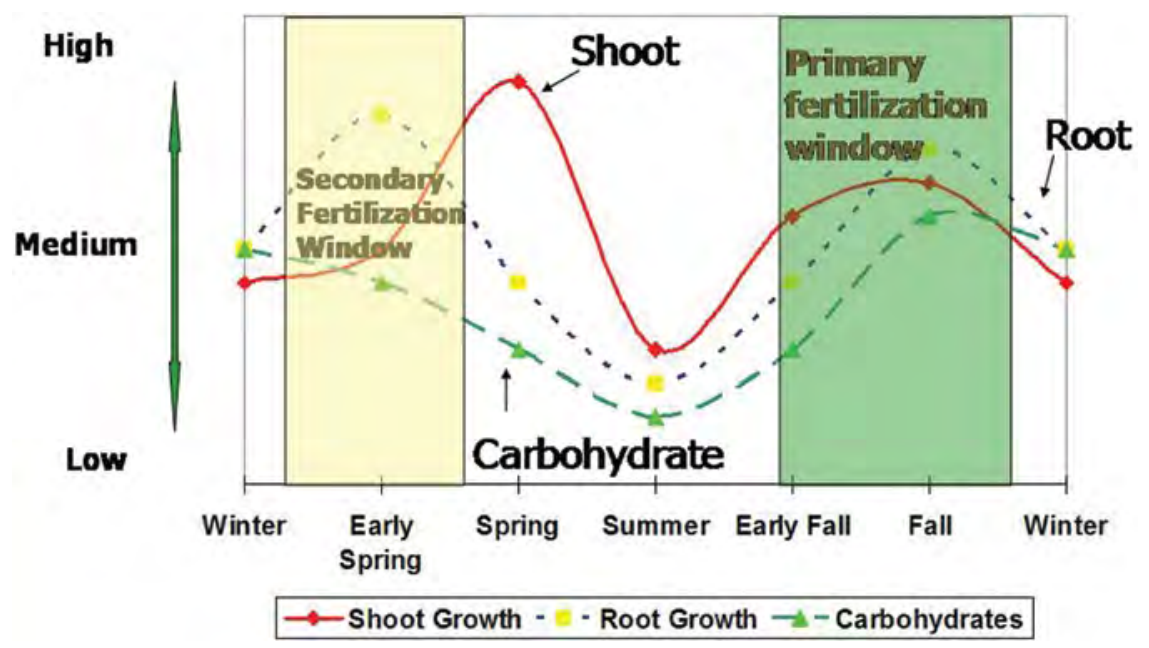

Figure 6.5. The anticipated seasonal root and shoot growth patterns and carbohydrate levels of cool-season turfgrasses. 
During the secondary window for fertilizing coolseason grasses during the spring, limited amounts of nitrogen ( 0.5 to 1 pound nitrogen per 1,000 square feet total) can support the period when the largest increase in root development occurs. However, as indicated in the figure, spring shoot development very quickly responds to the increasing temperatures and can exceed root development if promoted by heavy nitrogen fertilization. Excessive shoot growth, while resulting in a great-looking turf for the spring months, promotes a shallow-rooted turf that will struggle in the summer months when environmental extremes are likely. Carbohydrate levels begin to decline in the spring (and continue to decline throughout the summer) as the plant utilizes stored food to support early season root and shoot growth; the decline can be exaggerated by excessive spring nitrogen applications. For most purposes, summer nitrogen fertilization is discouraged because temperatures exceed optimal growing conditions for the turfgrasses.

\section{Primary Warm-Season Grasses of Importance}

The primary warm-season grasses used in the midAtlantic are bermudagrass (Cynodon spp.), zoysiagrass (Zoysia spp.), centipedegrass [Eremochloa ophiuroides (Munro) Hack], and St. Augustinegrass [Stenotaphrum secundatum (Walter) Kuntze]. Bermudagrass and zoysiagrass can be found throughout the region, while centipedegrass and St. Augustinegrass are primarily found in the southern Piedmont and coastal plains.

\section{Bermudagrass (figure 6.6)}

Description: A highly diverse species with ecotypes varying in leaf textures from very fine to coarse; aggressive lateral growth habit from both rhizomes and stolons.

Primary uses: An important lawn grass in central to southern Piedmont and coastal regions, with uses ranging from roadside turf to manicured lawns; major advancements in the cold tolerance and quality of seeded (Cynodon dactylon L.) and vegetative bermudagrasses (C. dactylon $\mathrm{x}$ transvaalensis) have greatly expanded bermudagrass use throughout the mid-Atlantic, especially on golf and sports turfs.

Primary establishment method: Improved common varieties now available from seed; vegetative-only cultivars are sterile and can only be established by sod, sprigs (i.e., stems), or plugs.

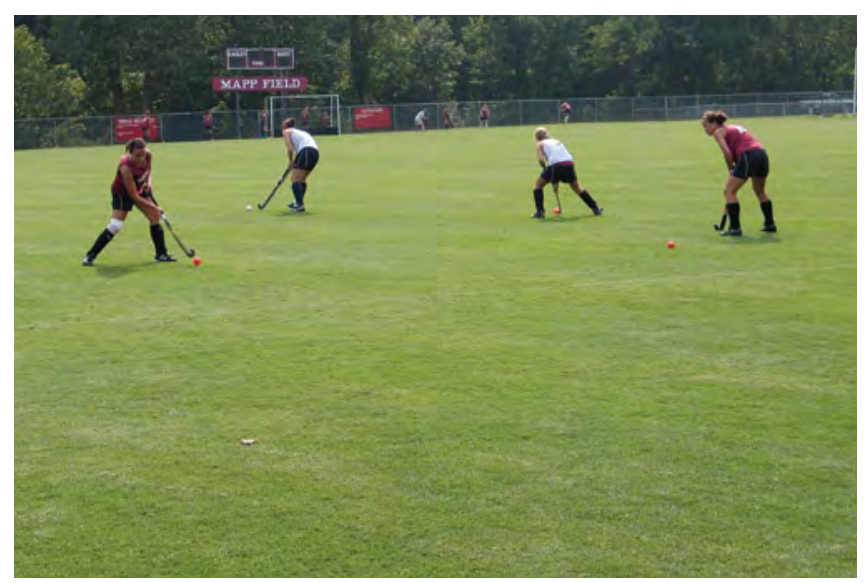

Figure 6.6. Improvements in density and cold tolerance of bermudagrasses, coupled with its rapid recuperative potential and tolerance to close clipping, have made bermudagrass a popular sports turf throughout the mid-Atlantic.

Strengths: Exceptional heat and drought tolerance; rapid establishment and recuperation rates; exceptional density; cutting heights as low as 0.1 inch for golf green ecotypes, 0.5 to 0.75 inch for golf and fairway uses, to 2.5 inches for lawn use; minimal pest pressure.

Weaknesses: Rapid lateral and foliar growth rates result in high mowing requirement and weed potential in ornamental beds, gardens, etc.; cold tolerance a concern in extreme winter conditions; poor shade tolerance; loss of color due to winter dormancy.

Typical seasonal nitrogen requirements: 1 to 2 pounds per 1,000 square feet for low-maintenance lawns and 4 to 6 pounds of nitrogen per 1,000 square feet for intensively maintained golf and sports turfs, higher rates being used for ryegrass-overseeded turf.

Zoysiagrass (figure 6.7)

Description: An extremely dense, fine-to-mediumtextured species that spreads by both rhizomes and stolons.

Primary uses: Lawns, golf fairways and tees.

Primary establishment method(s): Improved cultivars are mostly established by sod, sprigs, or plugs (sod is available throughout the region); a limited number of seeded cultivars now available.

Strengths: Exceptional heat tolerance and moderate drought tolerance; exceptional density; slow vertical and lateral growth rates result in reduced mowing requirement and limited invasiveness; moderate shade tolerance; minimal pest pressure.

Weaknesses: Slow to establish from seed, sprigs, or plugs; sod very expensive; loss of color due to winter dormancy. 


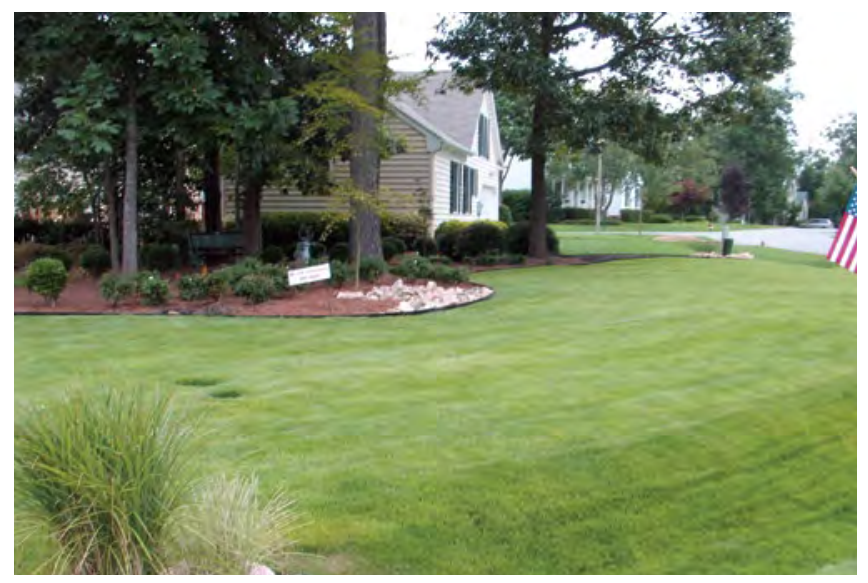

Figure 6.7. Zoysiagrass provides one of the highest-quality, lowestmaintenance lawn turfs in the mid-Atlantic, while also being used for golf fairways and tees.

Typical seasonal nitrogen requirements: 1 to 2 pounds per 1,000 square feet.

\section{Centipedegrass (figure 6.8)}

Description: Medium-to-coarse-textured species with a stoloniferous growth habit.

Primary uses: Lawns and other low-maintenance turfs, primarily in the coastal regions.

Primary establishment method(s): Both seed and sod are available; very limited variety selection.

Strengths: Good-quality, low-maintenance turf that is well-adapted to acidic soils; moderate shade tolerance; slow vertical and lateral growth rates that reduce mowing requirement and its ability to become a weed.

Weaknesses: Poor traffic tolerance; slow to establish; marginal cold tolerance.

Typical seasonal nitrogen requirements: 1 to 2 pounds per 1,000 square feet.

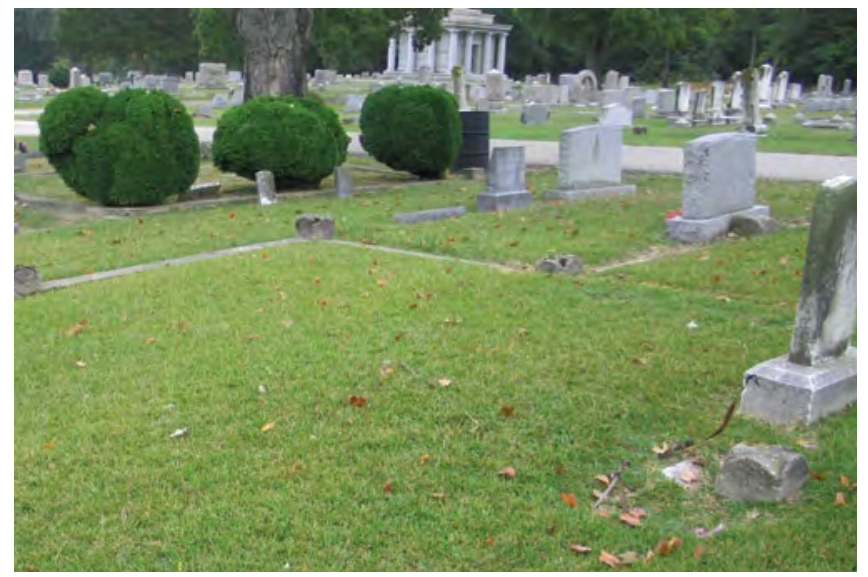

Figure 6.8. Centipedegrass is an excellent choice for low-input turfgrass sites such as cemeteries in the southern coastal plain of the mid-Atlantic.

\section{St. Augustinegrass}

Description: Coarse-textured species with a stoloniferous growth habit.

Primary uses: Lawns and general-purpose turf in the Tidewater region.

Primary establishment method: Sod or plugs; limited varieties available in the region.

Strengths: Best shade tolerance of warm-season grasses; good quality, very dense turf with an aggressive growth rate; good heat and drought tolerance.

Weaknesses: Poor cold tolerance; requires frequent mowing; the most insect and disease pressures of the warm-season grasses.

Typical seasonal nitrogen requirements: 3 to 4 pounds per 1,000 square feet.

The growth rates for warm-season grasses are optimized at 85 to $95^{\circ} \mathrm{F}$. Their seasonal root and shoot growth patterns and stored carbohydrate levels are detailed in figure 6.9. The grasses enter dormancy after frost events in the fall and do not resume active growth until early to midspring the following season. Nitrogen fertilization is preferably initiated in the spring after complete greening, but - at the least - after 50 percent spring greening for situations where fertilizers are applied in combination with pre-emergent herbicides in traditional "weed and feed" products. Fertilization can continue through the summer and into early fall during periods of active growth. As the persistently cool temperatures of fall arrive, nitrogen fertilization ceases as the plants prepare for winter dormancy.

Warm-season grasses have inherent advantages in water-use efficiency over cool-season grasses, and for this reason alone, their use is increasing. However, the winter dormancy period that results in the complete loss of green color (figure 6.10) continues to be a primary reason why many homeowners are reluctant to establish and maintain warm-season lawns.

\section{Native Turfgrasses and Specialty Use Applications}

A native plant evolved in a particular climate and where it can be grown, there are logical advantages to utilizing plant materials that evolved in a site's specific climate and soils. Since the climax vegetation of the mid-Atlantic is primarily hardwood forest, there are no native turfgrasses of significance for turfgrass use. 


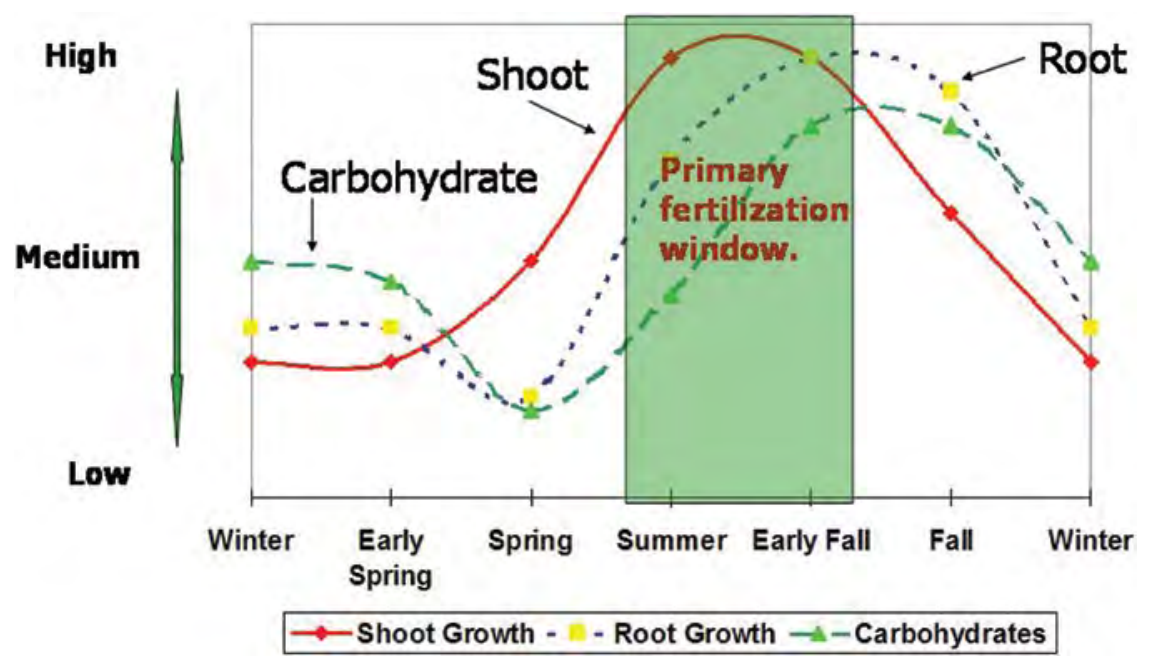

Figure 6.9. The anticipated seasonal root and shoot growth patterns and carbohydrate levels of warm-season turfgrasses.

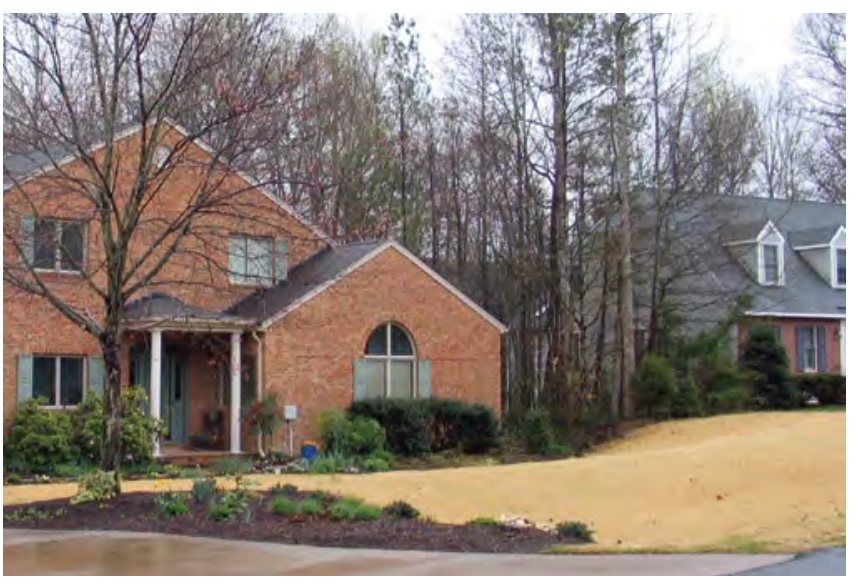

Figure 6.10. Warm-season grasses have a winter dormancy period ranging from four to five months in the mid-Atlantic.

However, there are native grasses that evolved in the arid (less than 15 inches of annual rainfall) plains states of the Midwestern United States that have desirable characteristics as potential turfgrasses for low-input management situations.

Buffalograss [Bouteloua dactyloides (Nutt.) J.T. Columbus] is a plains grass that has had a great deal of breeding work to improve its quality as a managed turf. Buffalograss has many highly desirable characteristics, such as outstanding heat, cold, and drought tolerance and slow lateral growth by stolons. Improved varieties tolerate regular clipping as low as 1.5 inches. However, even with all of these desirable features of a low-input turf, buffalograss has struggled to persist as an acceptably dense turf under the much higher rainfall conditions of the mid-Atlantic (30 to 45 inches per year on average). Recently released seeded and vegetatively established cultivars and experimental lines show promise in this region, but they have not yet withstood the test of time.
Blue grama [Bouteloua gracilis (Willd. ex Kunth) Lag. ex Griffiths] is a minimal-maintenance native that has consistently performed well in Virginia Tech's low-input turf trials. This fastestablishing, bunch-type, seeded warmseason native of the Midwestern plains is likely not suitable as a fine turf where aesthetics and/or traffic tolerance are important. However, it has persisted for multiple seasons in low-input turf variety trials at Virginia Tech with minimal invasion by weedy species. Blue grama will require mowing only a few times per year as a low-input turf.

In research that simulated a cemetery setting at Virginia Tech, a cool-season native turfgrass called Prairie junegrass [Koeleria macrantha (Ledeb.) J. A. Schultes, variety "Barleria"] that was mixed at 95 percent junegrass to 5 percent "Baron" Kentucky bluegrass (by weight) at establishment was one of the highest-quality, lowest-input turfgrasses in the trial. After three years in the field, this was one of the highest-rated cool-season grass plots that particularly withstood the extreme drought of 2007 in this region. By the end of the trial, no Kentucky bluegrass was visibly evident in the plots. There are very few choices in cultivars of prairie junegrass, but it is anticipated there will be future development in this area.

Other native grasses that are used for minimalmaintenance, no-mow situations are little bluestem [Schizachyrium scoparium (Michx.) Nash], big bluestem (Andropogon gerardii Vitman, figure 6.11), Indiangrass [Sorghastrum nutans (L.) Nash], and switchgrass (Panicum virgatum L.). These tall-grass prairie species are intended for lowmaintenance sites that will typically receive only an annual "cleanup" mowing event to control woody species that develop in

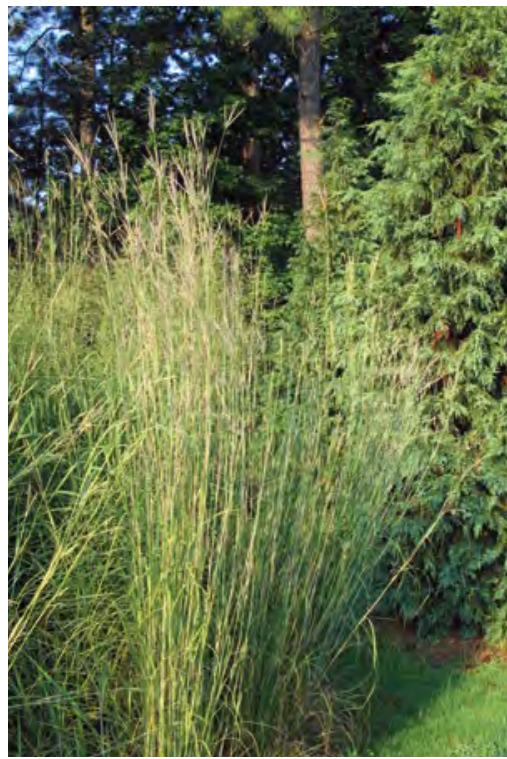

Figure 6.11. Big bluestem serves as a wildlife-friendly, visually appealing, lowinput perennial groundcover in out-ofplay areas on this golf course. 
these minimal-maintenance conditions. They are noted for the color of their foliage and seedheads and serve as a refuge for animal life. They can be found in turfed areas as divergent as highway rights of ways and secondary roughs on golf courses. Their establishment to desirable quality stands takes patience, because two to three years are often required to achieve the "look" associated with a tall-grass prairie. During this establishment period, herbicide applications are often required to reduce weed invasion in these relatively low-density grasses.

In summary, the best way to achieve long-term success with low-input grasses is to select adapted species that have demonstrated perennial success in this region, rather than those classified as natives because they originate in the United States. The native grasses detailed here are outstanding performers in the arid prairie states of this country. In the aforementioned simulated cemetery trial at Virginia Tech, the highestquality, lowest-input turfgrasses were hard fescue, prairie junegrass, and either seeded or sodded zoysiagrass. Of this group, only prairie junegrass is native to the United States and it is still considered somewhat of an "experimental" turfgrass with very limited availability. The other grasses - while not native by definition are well adapted to the mid-Atlantic and have better performance characteristics than most natives.

\section{Turfgrass Establishment}

\section{Soil Preparation}

Whether it is a new establishment or a spot renovation, it is important to ensure that soil, Äôs physical or chemical properties are suitable for turfgrass establishment and long-term success. If a turf stand has failed, is it possibly due to the soil? For native soils, conducting a soil test is an inexpensive and logical preventative maintenance step that should accompany almost any establishment scenario, especially if a soil test has not been conducted for the past three years. Applying recommended levels of lime and fertilizer will ensure the turf has maximum opportunity to establish.

For new establishments in many urban settings, the physical properties of the existing soil (often a "B" horizon subsoil remaining after construction) are an immediate limitation to turf establishment (see chapter 4 for a complete discussion on the challenges of urban soils). Whenever possible, stockpile the top 4 to 6 inches of the topsoil before construction begins for later redistribution across the site after construction is complete (figure 6.12).

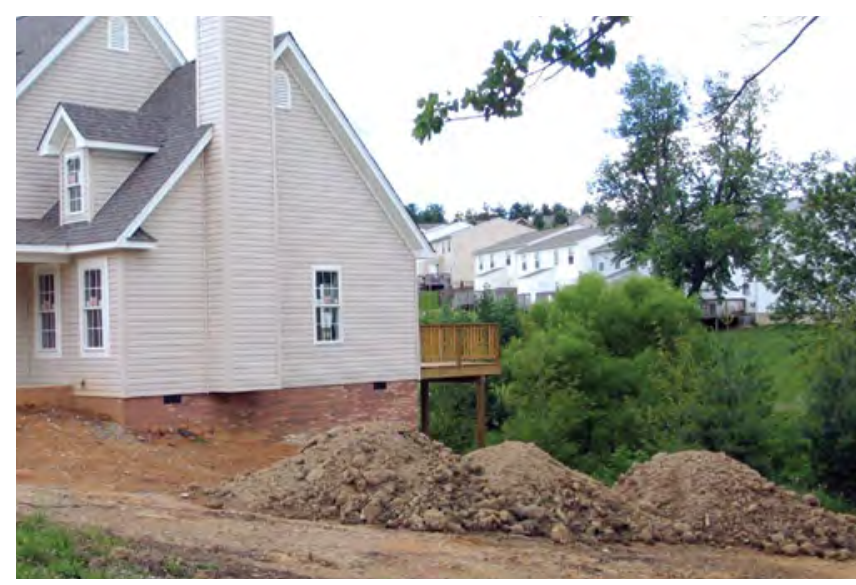

Figure 6.12. Stockpile topsoil prior to construction for later distribution before turf and landscape planting.

Unfortunately, stockpiled topsoil is often not available in urban settings and what remains is a nutrientdeficient, compacted, poorly drained subsoil material that is to be used for turf and landscape plant establishment. Far too often, the unsuitable soil is masked by a sod installation that provides immediate cover but ultimately fails as environmental extremes (heat, cold, drought, or saturated conditions) arrive.

No amount of water, fertilizers, and pesticides can overcome an unsuitable soil, and the potential for turfgrass management to impact water quality is exaggerated as homeowners attempt to overcome the soil limitations with excessive water and chemical inputs. Instead of utilizing the benefits of turfgrass as a filter and soil stabilizer to protect water quality, the end result is a declining stand of turfgrass that negatively impacts water quality by the likely movement of sediment and unused nutrients during heavy rainfall events.

Remove and dispose of all rocks and construction debris (brick, piles of gravel, lumber, spilled concrete, electrical wire, etc.) from the site - do not bury it in the soil. Any utility, irrigation, drainage, or sewer lines for the site should be installed well before the installation of turf or ornamentals. Be sure to confirm that these lines have been installed to appropriate depths so they won't be hit by tillage equipment during final soil preparation. Ensure that the grade on the property is suitable so that surface drainage moves water away from buildings, sidewalks, etc. This is also the time to consider the feasibility (and/or design and installation) of rain gardens or other stormwater retention systems.

Conduct soil tests for the lawn and ornamental beds in order to address any chemical limitations ( $\mathrm{pH}$ and nutrient levels) of the growing medium (Goatley, Mullins, and Ervin 2009). Prior to planting, recommended lime 
and fertilizer materials should then be incorporated into the top 4 to 6 inches of soil. This will also be the time to incorporate any organic or inorganic amendments recommended to improve the soil (discussed in chapter 9). Thoroughly till the soil but do not attempt to turn the lawn seedbed into a fine powder typically equated to garden soil - some clods are fine for turf establishment! The soil can then be smoothed and firmed with a lightweight roller prior to planting, but avoid extensive surface compaction. If additional construction traffic occurs prior to planting, conduct another light tillage to remove surface compaction.

Little (or no) soil preparation of thinning or degraded turf areas most often leads to failed turfgrass establishment, even though it might seem logical that sowing seed or installing sod into/on a sparse turf canopy could work. Seed applied into thin turfs usually germinate, but many of the newly emerging roots do not adequately penetrate the soil such that the new plants persist. For spot seed renovations, it is recommended to core aerate the soil in multiple directions, seed, and then drag the cores back into the area after seeding to improve soilto-seed contact. For sod installations, success is usually achieved through complete soil preparation.

\section{Timing}

Across the mid-Atlantic, the optimum period to seed cool-season grasses is late summer to early fall. This timing optimizes root development and carbohydrate storage in the young plants because of more favorable environmental conditions that maximize plant development before summer arrives. Early to midspring is the secondary window for seed establishments. Seed readily germinates as the soil warms, but the root system is rarely developed sufficiently to ensure survival during a hot, dry summer season. Seed is readily available for all cool-season grasses.

For seeded warm-season grasses, the ideal establishment period is midspring to early summer. These grasses perform optimally during hot weather conditions as long as they receive adequate moisture to maintain growth. The first winter survival of plants established from seed later than mid-July can be greatly reduced in extreme winters; the more mature a warm-season turf is, the better its chance of surviving the first winter. There are seeded varieties for bermudagrass, zoysiagrass, and centipedegrass but not all varieties of these grasses are available from seed (i.e., they must be established vegetatively by sprigs, plugs, or sod). St. Augustinegrass is almost exclusively established from sod or plugs (seed is viable but of limited availability since it cannot easily be extracted from the seedhead). Sprigging (inserting vegetative stems into a prepared seedbed) establishments should follow these same timing guidelines.

Sod establishments are much more flexible in terms of timing success, but the ideal establishment period follows the previous guidelines for both warm- and cool-season grasses. However, both warm- and coolseason sods can be successfully established as long as they are not applied to frozen soils. The key to success is to remember that these sods, while having reduced moisture needs, still require some water to prevent desiccation of the newly emerging roots. Dormant sods of warm-season grasses should have minimal moisture requirements but should be checked regularly during abnormally dry winters. Establishing cool-season sods in the summer is possible, but it requires regular monitoring and applications of soil moisture because evapotranspiration losses are so high. No nitrogen fertilizer should be applied to sods when established outside the optimal establishment window.

\section{Nutrient Management and Fertility Recommendations}

Successful turfgrass establishments are closely linked to responsible nutrient management programs, regardless of the turfgrass and its use. These nutrient management recommendations were developed in a cooperative effort between the turfgrass faculty at Virginia Tech and representatives of the Virginia Department of Conservation and Recreation that ultimately resulted in the Virginia Nutrient Management Standards and Criteria (2005). Fertility recommendations for establishment consider that the following criteria are met: (1) selection of appropriate grass for the climate and its intended use, and (2) establishment occurs under optimal planting conditions.

Nutrient management strategies for new plantings will vary widely depending on the grass and its intended use. For instance, consider the inherent differences in growth rates between grasses, even within the groupings of cool-season and warm-season species. Bermudagrass and St. Augustinegrass (warm-season grasses) or tall fescue and perennial ryegrass (cool-season grasses) are noted for quick establishment, whereas zoysiagrass and centipedegrass (warm-season) or Kentucky bluegrass and fine fescue (cool-season) are very slow. Similarly, consider differences in establishment challenges between roadside vegetation being seeded on cut-andfill soils high in B- or C-horizon material versus seeding 
on completely modified, sand-based systems for golf and sports turfs. Regardless of the site characteristics, the newly established sites planted from seed, sprigs (i.e., rhizomes or stolons), plugs, or sod have immature root systems that are limited in both size and depth. These limitations in initial root development place an even greater importance on the need for soil testing in order to correct chemical deficiencies - especially $\mathrm{pH}$ and plant-available phosphorus and nitrogen. Consult with a certified nutrient management planner or with local cooperative Extension office personnel when developing a suitable nutrient management program for turf establishment in your area.

\section{Phosphate and Potash Recommendations for Establishment}

Soil testing is appropriate for adjusting soil phosphorus and potassium levels prior to planting. Table 6.1 details general phosphate and potash recommendations for turfgrass establishments.

\begin{tabular}{|c|c|c|}
\hline \multirow[b]{2}{*}{ Soil test level* } & \multicolumn{2}{|c|}{ Nutrient needs $(\mathrm{lb} / 1,000 \mathrm{sq} \mathrm{ft})$} \\
\hline & $\begin{array}{c}\text { Phosphorus } \\
\left(\mathrm{P}_{2} \mathrm{O}_{5}\right)\end{array}$ & $\begin{array}{c}\text { Potassium } \\
\left(\mathrm{K}_{2} \mathrm{O}\right)\end{array}$ \\
\hline Low & $3-4$ & $2-3$ \\
\hline Medium & $2-3$ & $1-2$ \\
\hline High & $1-2$ & $.5-1$ \\
\hline Very high & 0 & 0 \\
\hline \multicolumn{3}{|c|}{$\begin{array}{l}\text { *For low soil test levels within a category (e.g., L-), use the } \\
\text { higher side of the range of nutrient needs. For high soil tes } \\
\text { levels (e.g., } \mathrm{H}+\text { ) use the lower side of the range of nutrient } \\
\text { needs. }\end{array}$} \\
\hline
\end{tabular}

Research in Maryland (Turner 2005) has demonstrated that there are limited advantages in turfgrass establishment at seeding from utilizing traditional high phosphorus-analysis "starter fertilizers" (e.g., 5-15-5, etc.), with the advantages being realized primarily when soil temperatures are suboptimal for establishment. Similarly, the same advantages in the use of starter fertilizers can apply to overseeding, spot renovations, and sodding as well, but their importance is minimal on soils with adequate phosphorus and optimal temperature and moisture conditions for establishment.

\section{Nitrogen}

Establishing turfgrasses in an environmentally responsible manner is a challenge in any situation. When possible (or affordable), establishing by sod provides immediate soil stabilization; sediment loss is essentially negated. However, seed, sprig, or plug establishments present the challenge of applying relatively large amounts of water and fertilizer to promote quick establishment (i.e., reduce sediment loss), but not at the expense of leaching or movement of the fertilizer into nearby water sources.

Nitrogen amounts during grow-in will vary depending on the turfgrass, water solubility of the nitrogen source, soil characteristics, and timing of the establishment. At establishment, there are at least three factors that require fertility programs to be adjusted for the specifics of a planting situation:

1. All new establishments, even sod, lack a fully developed root system to efficiently utilize nutrients and water soon after planting.

2. The requirement for frequent irrigation during turf establishment to sustain the emerging root and shoot systems increases the potential for nutrient loss.

3. With seed, plug, or sprig establishments, the lack of a dense turf canopy increases water quality concerns due to the potential lateral movement of nutrients and sediment.

Immediate soil coverage is an inherent advantage in sod establishments and even where complete installation is not possible due to cost, using sod strips in predominantly seed establishments is often an affordable way to slow the speed of water on slopes and reduce soil loss (figure 6.13).

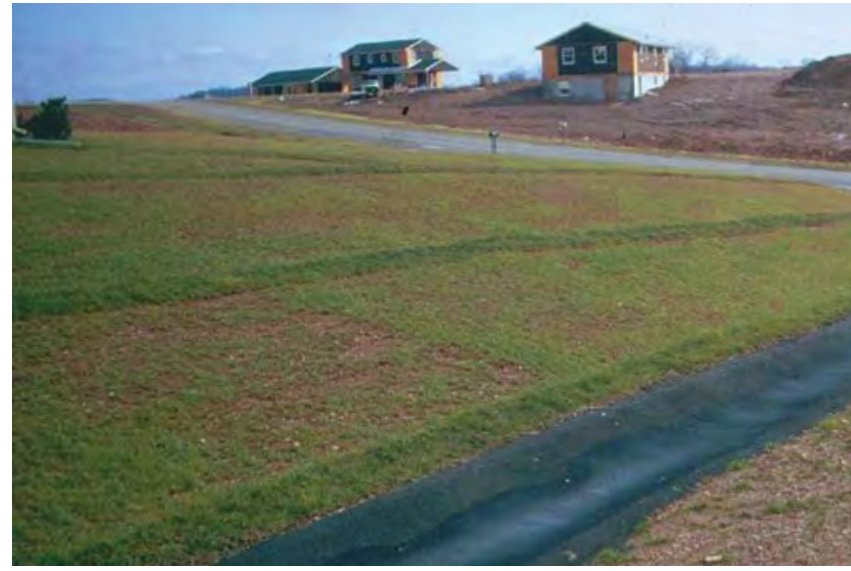

Figure 6.13. Adding single strips of sod to seed establishments on sloped sites is a highly effective means of reducing soil erosion potential. 
One nitrogen fertility strategy that promotes the development of newly established turfgrasses with less potential impact on water quality is to utilize "slowly available nitrogen" (SAN) sources during grow-in. The Virginia Department of Conservation and Recreations' Nutrient Management Training and Certification Regulations (4 VAC 5-15) (http://www.dcr.virginia.gov/documents/nmtraincertregs.pdf) define SAN as "sources that have delayed plant availability involving compounds which dissolve slowly, materials that must be microbially decomposed, or soluble compounds coated with substances highly impermeable to water, such as polymer-coated products, methylene urea, isobutylidene diurea (IBDU), urea formaldehyde based (UF), sulfur-coated urea, and natural organics." Ideally, these sources should contain 50 percent or more SAN in order to realize the full benefits of sustained nitrogen feeding with little nitrogen loss potential. Such sources should be the focal point of grow-in programs on sandbased soils. However, it is possible - and sometimes desirable due to cost or desired rate of turf coverage to utilize predominantly water-soluble nitrogen (WSN) sources during grow-in by way of frequent, low-level ( 0.25 to 0.5 pound of nitrogen per 1,000 square feet) nitrogen applications. Many times, a successful growin program that combines both desirable turfgrass coverage and quality with environmental protection is one that employs a range of nitrogen sources with varying degrees of water solubility.

\section{Grow-In Strategies for Lawns and General Turf}

Nitrogen applications for establishment of home lawns and general turf areas should not exceed 1 pound of nitrogen per 1,000 square feet at planting, followed by one or two applications initiated at 30 days after planting, not to exceed a total of 2 pounds of nitrogen per 1,000 square feet for the establishment. Slow-release nitrogen sources containing 50 percent or greater SAN will reduce leaching potential and should be used whenever possible for establishments on sand-based soils. Split applications of WSN at 0.25 to 0.5 pound per 1,000 square feet per application on one- to two-week intervals will further improve nitrogen-use efficiency, but consider that these applications can be difficult given the likelihood of wet soils during the grow-in period.

\section{Grow-In Strategies for Golf Course, Athletic Field, or Sod Production Systems}

With the wide range of grasses that can be used and the diversity in soils found across the mid-Atlantic region, there is a great deal of variability in fertilization strategies for turfgrass establishments. Successful establishments are best achieved by planting grasses during their optimum establishment windows (late summer to early fall for cool-season grasses and late spring through midsummer for warm-season grasses). For any grass on any soil type, utilize a soil test to determine lime, phosphorus, and potassium needs and incorporate all needed amendments into the top 4 to 6 inches of the soil profile prior to planting.

First, consider nitrogen-based establishment fertility programs for cool- or warm-season grasses on heaviertextured, predominantly silt/clay soils. These programs apply to most soils used for golf fairways and roughs, athletic fields, and sod farms in the region. Up to 1 pound of nitrogen per 1,000 square feet can be applied in a single application at planting with a 50 percent or greater SAN source that will feed the turf for up to four weeks. For sources containing predominantly WSN, apply no more than 1 pound of nitrogen per 1,000 square feet over the first four weeks by splitting the applications into regular intervals. At four weeks after planting, apply 0.25 to 0.5 pound of WSN per 1,000 square feet per week for the next four weeks.

Next, consider nitrogen-based establishment fertility programs for cool- or warm-season grasses on naturally occurring or modified sand-based soils. In these highly leachable soils, it is important to use a 50 percent or greater SAN source at up to 1 pound of nitrogen per 1,000 square feet for the first four weeks of establishment for either type of grass. For warm-season grasses, apply 0.25 to 0.50 pound of WSN per 1,000 square feet per week for the next four weeks. On cool-season grasses, apply up to 0.25 pound of nitrogen per 1,000 square feet per week (or 0.5 pound of a 50 percent or greater SAN source every two weeks) after germination is complete for the next eight weeks.

Large-scale grow-ins on golf courses are sometimes achieved with fertigation systems (the application of low levels of nutrients through an inground irrigation system). For a properly installed and functioning irrigation system, fertigation is an extremely efficient method of nutrient delivery through the irrigation water.

\section{Irrigation and Water Conservation Strategies for Establishments}

Light and frequent irrigation is required for optimal seed establishments. Keep the seedbed moist but don't apply so much water that the seed might drown or be 
washed away. A somewhat more aggressive watering strategy is required for sprig establishments, as these tissues are particularly prone to rapid desiccation. Initiate irrigation as soon as possible on newly planted sprigs and keep the sprigs moist but not saturated. Excessive watering can drown plants and promote fertilizer losses, due to either runoff or leaching loss. Even with immediate irrigation, anticipate a possible total loss of color due to leaf desiccation on the sprigs, but don't let this deter watering as healthy sprigs will almost always rapidly initiate new roots and shoots if their planting is appropriately timed and irrigation and fertility requirements are met. As establishment progresses, gradually reduce irrigation to a deep and infrequent strategy recommended for established turf.

Sod and rooted plugs provide more flexibility in supplemental irrigation requirements for establishment, not requiring nearly as much attention as seed or sprig plantings. As a rule of thumb, sod installations during optimal establishment periods should receive up to 1 inch of water (either from irrigation or rainfall) during establishment. However, the ideal water management approach is to keep the soil moist and not saturated; during periods of low evapotranspiration, supplemental water needs will be greatly reduced. Roots require both water and oxygen to establish properly, and overwatering sod greatly reduces establishment. Periodically tugging on the sod or plugs to assess root development is a good way to monitor moisture needs, and as rooting progresses, reduce supplemental irrigation to a deep and infrequent strategy as one would for an established turf.

An important way to conserve moisture and reduce soil-erosion potential for seed establishments (and it could work for sprig plantings as well) is to mulch the seedbed. Small-grain (e.g., wheat, barley, etc.) straw is an ideal mulch for seed establishments (figure 6.14). A

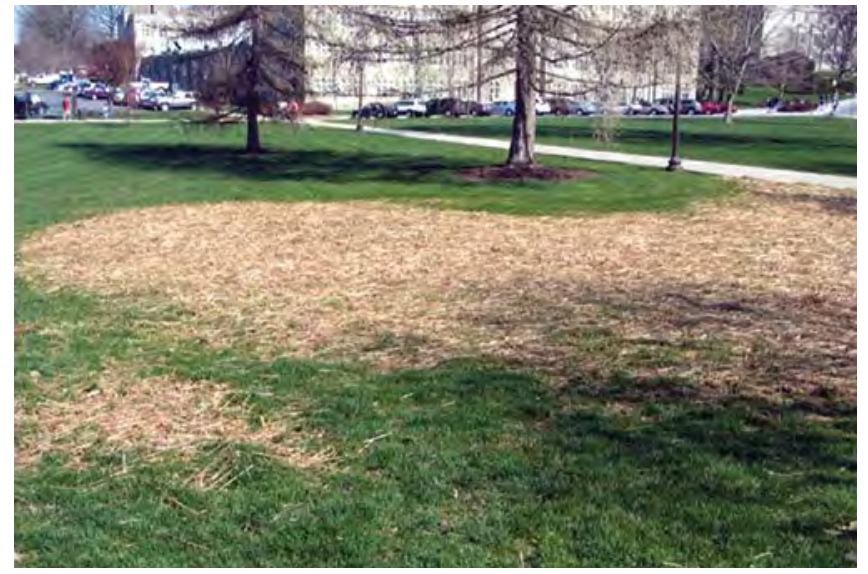

Figure 6.14. Mulching newly seeded areas with weed-free straw is very effective in conserving moisture for seed establishments. general application level is one bale of straw per 1,000 square feet, and it can be applied by hand or by power equipment that chops and blows the straw. Avoid using hay as a mulch source; a clean (weed-free) wheat straw is a preferred mulching material. Straw can simply be mulched right back into the canopy as the new grass establishes, and any of the small-grain seed that germinates can be mowed and will die during the first summer season.

There are numerous paper-based and wood-fiber mulches available for mulching as well. Shredded paper mulch is very popular when turf is established by "hydroseeding" - a motorized, pump-driven planting strategy that applies a fertilizer, seed, mulch, and tackifier slurry to a prepared seedbed. There is also a wide variety of erosion control blankets that are primarily designed for vegetation establishments on sloped sites. These materials and their application strategies are further discussed in chapter 11.

\section{Seeding Levels and Planting Strategies}

Seed provides the most popular means of establishment because of the availability of improved cultivars for many species and the relative affordability of seed. Many improved varieties of bermudagrass do not produce viable seed and must be established vegetatively. Seed is readily available for many improved varieties of cool-season turfgrasses. Select certified (blue-tag) seed whenever possible, as this ensures that what is indicated on the tag is what is in the bag. Apply fertilizers and lime as detailed above, utilizing soil tests whenever possible to best correct deficiencies. For lawns, seed at the recommended levels detailed in table 6.2, using the higher seeding levels during suboptimal establishment periods.

\section{Establishment Methods}

The most common equipment to deliver seed in surface applications to prepared seedbeds is either rotary (often referred to as "broadcast" or "centrifugal") or drop (gravity-fed) spreaders. A rotary spreader can be used for large-scale plantings because it can cover a lot of ground in a short period of time. However, uniform seed distribution can be disrupted on windy days. Drop spreaders allow for precision in seed application because the seed falls precisely over the area covered by the spreader. Seed distribution is not affected by the wind, but this delivery method takes a great deal more time because it covers a much smaller area in a single pass. Apply seed in at least two directions (especially 
Table 6.2. Recommended seeding levels for turfgrasses used in home lawns.

\section{Seeding level}

Grass (lb pure live seed/1,000 sq ft)

\begin{tabular}{lc}
\hline Fine-leaf fescue & $3-5$ \\
\hline Kentucky bluegrass & $2-3$ \\
\hline Perennial ryegrass & $3-5$ \\
\hline Tall fescue & $6-8$ \\
\hline Perennial ryegrass & $3-5$ \\
\hline Bermudagrass & $.5-1$ \\
\hline Centipedegrass & $.25-.50$ \\
\hline Zoysiagrass & $2-3$ \\
\hline $\begin{array}{l}\text { Cool-season } \\
\text { mixtures depend on } \\
\text { percent of individual } \\
\text { species in mix. }\end{array}$ & $\begin{array}{l}\text { Use recommendations on the } \\
\text { (percent by weight) mixture of } \\
\text { tall fescue/Kentucky bluegrass } \\
\text { is seeded at 3-4 lb/1,000 sq ft. }\end{array}$ \\
\hline
\end{tabular}

Table 6.3. Recommended establishment levels for specific uses of grasses for golf and sports turfs.

Seeding level

(lb pure live

seed/1,000

\begin{tabular}{|c|c|}
\hline Grass and use & $\mathrm{sq} \mathrm{ft})$ \\
\hline $\begin{array}{l}\text { Creeping bentgrass (golf putting greens } \\
\text { and tees) }\end{array}$ & $.5-1$ \\
\hline Creeping bentgrass (golf fairways) & $.25-.50$ \\
\hline $\begin{array}{l}\text { Kentucky bluegrass (golf fairways and } \\
\text { tees, sports fields) }\end{array}$ & $2-3$ \\
\hline $\begin{array}{l}\text { Perennial ryegrass (golf fairways and } \\
\text { tees, sports fields) }\end{array}$ & $3-5$ \\
\hline $\begin{array}{l}\text { Perennial ryegrass/Kentucky bluegrass } \\
\text { mixtures, } 90 \%-10 \% \text { by weight (golf } \\
\text { fairways and roughs, sports fields) }\end{array}$ & $2-4$ \\
\hline Tall fescue (golf roughs) & $4-6$ \\
\hline Tall fescue (sports fields) & $6-8$ \\
\hline $\begin{array}{l}\text { Tall fescue/Kentucky bluegrass } \\
\text { mixtures, } 90 \%-10 \% \text { by weight (golf } \\
\text { roughs) }\end{array}$ & $2-4$ \\
\hline $\begin{array}{l}\text { Tall fescue/Kentucky bluegrass mixtures, } \\
90 \%-10 \% \text { by weight (athletic fields) }\end{array}$ & $3-4$ \\
\hline $\begin{array}{l}\text { Bermudagrass (golf fairways and tees, } \\
\text { athletic fields) }\end{array}$ & $.5-1$ \\
\hline Bermudagrass (golf roughs) & $.25-.50$ \\
\hline Zoysiagrass (fairways or tees) & $2-3$ \\
\hline
\end{tabular}

with drop spreaders) to avoid skips. The previously mentioned method of hydroseeding is an excellent means of rapidly covering large areas of prepared soil with a seed, fertilizer, and mulch slurry using water as a carrier.

There also are a host of mechanized seeders that slice or lightly till the soil in front of a seed hopper that drops the seed into the soil, thus ensuring soil-to-seed contact. The primary concern with mechanized planters is being sure the seed is not planted so deep in the soil that it cannot emerge. Smaller-seeded grasses (bluegrass, bermudagrass, bentgrass, zoysiagrass, centipedegrass) should be planted on or just below the soil surface. Larger-seeded grasses (tall fescue, perennial ryegrass, fine-leaf fescues) can be planted into the top 0.5 inch of soil.

\section{Sodding}

An inherent advantage of sodding is that the soil attached to the sod serves as a nutrient and moisture reservoir to aid in establishment. Another consideration in the choice of sod is that it is an extremely effective means of almost eliminating soil erosion (and potential movement of sediment into waterways) during turf establishment. Appropriate use of a high-phosphorus starter fertilizer can benefit initial rooting, but the responses are not likely to be as significant as those encountered from seed establishments. Fertilizers can also be applied postestablishment to the sod itself. Sod offers significant advantages in lower water requirements (and attention to watering during establishment), has virtually no soil-erosion potential, and provides almost immediate gratification and use potential. Roll the sod after planting to ensure soil-to-plant material contact. Water frequently enough to maintain a moist (not saturated) sod. Periodically check for rooting by tugging on sod to see how well it is tacked to the soil; reduce irrigation frequency and amount after establishment is complete.

\section{Plugging or Sprigging}

Any grass that produces lateral stems (rhizomes and/ or stolons) can be established by plugging or sprigging (planting stems directly into the soil, figure 6.15). However, due to the ready availability of seed for many coolseason grass varieties and their slower lateral growth rates, only warm-season grasses are commonly established by plugs or sprigs. Plugs of 2 inch to 4 inch in diameter are planted on 6- to 12-inch centers. Rapidly spreading grasses like bermudagrass and St. Augustine- 


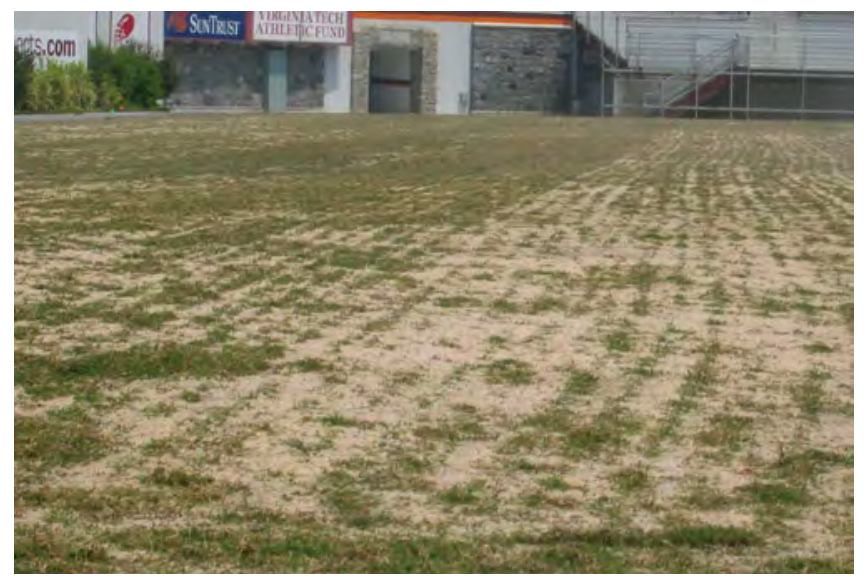

Figure 6.15. Bermudagrass sprigs (i.e., shredded stems) planted in rows on a sand-based athletic field.

grass can be planted on 12-inch centers and will achieve complete coverage within one summer growing season; faster coverage rates of 30 to 60 days are likely with plugging on 6-inch centers. Slow-spreading grasses like centipedegrass and zoysiagrass should be planted on 6-inch centers and even then might not cover within one growing season. Plugs have the advantage of usually being fully rooted, and therefore, they require less-intensive maintenance at establishment.

The shredded stems used as sprigs require regular and frequent irrigation until the growing points on the stems have produced a functioning rooting system. The moisture requirement for sprigs is very high during the first seven to 14 days of establishment.

For those who have never established turf in this manner, the first impression is that the stems have died because most of the leaf material at planting browns and decays. Be persistent with providing regular irrigation during this seven- to 14-day window, and new leaves and roots will emerge. Logically, the more plant material used at establishment, the quicker the establishment rate. Sprigging levels of 10 to 25 stems per square foot are typical planting levels, but higher levels of up to 50 stems per square foot will likely be required to establish slowergrowing grasses, such as zoysiagrass or centipedegrass in one growing season (table 6.4).

It is common for sprigging specifications to be presented in units of bushels of sprigs per acre. However, there is no clear definition of what constitutes a bushel. As a point of reference, numerous custom planting company personnel equate 25 stems per square foot to a planting rate of 500 bushels per acre. Specifying a precise number of stems per square foot is the easiest way to quantify a vegetative planting rate of stems per unit area.
Table 6.4. Vegetative planting recommendations for various grasses and their respective uses.

\begin{tabular}{lc}
\hline Grass and intended use & Stems/sq ft \\
\hline Bermudagrass (lawns) & $10-25$ \\
\hline Bermudagrass (golf fairways) & $10-50$ \\
\hline Bermudagrass (golf greens) & $35-50$ \\
\hline Zoysiagrass (lawns) & $25-35$ \\
\hline Zoysiagrass (fairways and tees) & $35-50$ \\
\hline
\end{tabular}

\section{Winter Overseeding}

Winter overseeding is defined in this publication as the early-to-midfall seeding of an adapted cool-season turfgrass into an existing warm-season turfgrass for the purpose of winter color and possibly improved playability of sports fields. Note that overseeding is sometimes used as a general term to describe any general seeding or renovation event that is conducted on existing stands of turfgrass.

Most often, the choice in cool-season turf for overseeding is an annual, perennial, or intermediate ryegrass. For most purposes, only bermudagrass is recommended to be overseeded, because other warm-season grasses are generally not viewed as being competitive enough the following season to outcompete the winter overseeding. The bermudagrass might be lightly verticalmowed or slightly scalped prior to overseeding in order to enhance seed movement through the canopy to the soil. Obviously, this is potentially detrimental to the bermudagrass, and the level of vertical mowing should be kept to a minimum and not used as a dethatching event late in the bermudagrass growing season. Optimum soil-to-seed contact can be achieved by topdressing the overseeded grass with sand or a similar topsoil material. For winter overseeding of bermudagrass, home lawns are seeded at 5 to 10 pounds of pure live seed per 1,000 square feet. Athletic fields or golf fairways and tees are typically seeded at 10 to 20 pounds of pure live seed per 1,000 square feet.

Fertilization strategies for overseeded turfs can be problematic in trying to balance the needs of the germinating, cool-season grass seedlings with those of a warm-season grass that will soon enter winter dormancy. Overly aggressive nitrogen fertilization during fall overseeding periods can reduce ryegrass establishment by promoting excessive late-season bermudagrass competition, and high nitrogen levels can also reduce the winter hardiness of the bermudagrass. Using 
reduced nitrogen application levels of 0.25 pound of nitrogen per 1,000 square feet per week during establishment allows the manager to maintain control of the growth rates of bermudagrass and the establishing ryegrass seedling. Nitrogen fertilization levels totaling from 0.5 to 1 pound of nitrogen per 1,000 square feet in early September should suffice to feed the germinating ryegrass seedlings while not excessively stimulating the bermudagrass. Apply an additional 0.5 pound of nitrogen per 1,000 square feet in October or November and then again in February or March of the following year. These levels should suffice to promote ryegrass growth with limited effects on the bermudagrass turf.

While overseeding is generally considered to negatively affect the health and quality of warm-season grasses, there are inherent advantages to its use in grassing systems. Color and playability of golf and sports turfs might warrant the necessity of winter overseeding in some golf-turf and sports-turf situations. Another possible reason to overseed is if the turf is irrigated with reclaimed water. The ryegrass can effectively serve as a sink for nutrients applied in the reclaimed water that the dormant bermudagrass turf otherwise would not utilize.

\section{Maintenance Fertility Programs}

\section{Phosphorus and Potassium}

Applications of phosphorus and potassium in maintenance application programs for cool- and warm-season turfgrasses should be based on soil tests. Soil tests should be conducted at least every three years on high silt/clay soils and every year on high sand-content soils. Table 6.5 provides recommended fertilization levels for phosphorus and potassium.

\begin{tabular}{|c|c|c|}
\hline \multirow[b]{2}{*}{ Soil test level* } & \multicolumn{2}{|c|}{ Nutrient needs $(\mathrm{lb} / 1,000 \mathrm{sq} \mathrm{ft})$} \\
\hline & Phosphorus $\left(\mathrm{P}_{2} \mathrm{O}_{5}\right)$ & Potassium $\left(\mathrm{K}_{2} \mathrm{O}\right)$ \\
\hline Low & $2-3$ & $2-3$ \\
\hline Medium & $1-2$ & $1-2$ \\
\hline High & $.5-1$ & $.5-1$ \\
\hline Very high & 0 & 0 \\
\hline \multicolumn{3}{|c|}{$\begin{array}{l}\text { *For low soil test levels within a category (e.g., L-), use the } \\
\text { higher side of the range of nutrient needs. For high soil tes } \\
\text { levels (e.g., } \mathrm{H}+\text { ), use the lower side of the range of nutrien } \\
\text { needs. }\end{array}$} \\
\hline
\end{tabular}

\section{Nitrogen}

As detailed previously in this chapter describing the predominant grasses of the region and their uses, the annual nitrogen requirement varies greatly depending on the species of grass being grown, site characteristics, intended use of the grass, and expectations of the clientele growing the turf. The following tables detail general seasonal nitrogen fertilization strategies for both cool- and warm-season turfgrasses.

\section{Table 6.6. General seasonal nitrogen fertilization strategies for cool-season turfgrasses.}

\begin{tabular}{|c|c|c|}
\hline Time of year & $\begin{array}{l}\text { Relative } \mathrm{N} \text { rate/ } \\
\text { application, per growing } \\
\text { month }\end{array}$ & Comments \\
\hline Early spring & $\begin{array}{l}\text { None to low } \\
(.25 \mathrm{lb} \mathrm{N} / 1,000 \mathrm{sq} \mathrm{ft})\end{array}$ & $\begin{array}{l}\text { - Never apply to frozen ground. } \\
\text { - If following aggressive fall fertilization, probably not necessary. }\end{array}$ \\
\hline Mid-late spring & $\begin{array}{l}\text { Low to medium } \\
(.25-.5 \mathrm{lb} \mathrm{N} / 1,000 \mathrm{sq} \mathrm{ft})\end{array}$ & $\begin{array}{l}\text { - Have been shown to benefit root growth with responsible } \\
\text { applications. } \\
\text { - Exceeding these levels promotes shoots at expense of roots. }\end{array}$ \\
\hline Summer & $\begin{array}{l}\text { None to low } \\
(.25 \mathrm{lb} \mathrm{N} / 1,000 \mathrm{sq} f t)\end{array}$ & $\begin{array}{l}\text { - In general, refrain from } \mathrm{N} \text { fertility, but small amounts can aid } \\
\text { recovery from stress/pest pressures. } \\
\text { - Avoid applications during high heat/drought pressures. }\end{array}$ \\
\hline $\begin{array}{l}\text { Late summer } \\
\text { through early } \\
\text { winter }\end{array}$ & $\begin{array}{l}\text { Medium to high } \\
(.5-1 \mathrm{lb} \mathrm{N} / 1,000 \mathrm{sq} \mathrm{ft})\end{array}$ & $\begin{array}{l}\text { - Promotes recovery from summer stress with early fall applications. } \\
\text { - Continue program (while grass is still green without much shoot } \\
\text { growth) to promote roots, color, turf density, and carbohydrate } \\
\text { levels. }\end{array}$ \\
\hline
\end{tabular}


Table 6.7. General seasonal nitrogen fertilization strategies for warm-season turfgrasses.

\begin{tabular}{lll}
\hline Time of year & $\begin{array}{l}\text { Relative N rate/ } \\
\text { application, per growing } \\
\text { month }\end{array}$ & Comments \\
\hline Early spring & $\begin{array}{l}\text { None to low } \\
(.25 \mathrm{lb} \mathrm{N} / 1,000 \mathrm{sq} \mathrm{ft}), \\
\text { pending emergence from } \\
\text { winter dormancy }\end{array}$ & $\begin{array}{l}\text { - Never apply to frozen ground. } \\
\text { - Ideally, wait until complete greening, but strategy doesn't fit } \\
\text { standard weed and feed products designed for PRE-crabgrass } \\
\text { control }\end{array}$ \\
\hline Mid-late spring & $\begin{array}{l}\text { Low to medium } \\
(.25-.5 \mathrm{lb} \mathrm{N} / 1,000 \mathrm{sq} \mathrm{ft})\end{array}$ & $\begin{array}{l}\text { - Excessive levels promote shoots at expense of roots. } \\
\text { - Be aware of average "last frost" dates for the area. }\end{array}$ \\
\hline Summer & $\begin{array}{l}\text { Medium to high } \\
(.5-1 \mathrm{lb} \mathrm{N} / 1,000 \mathrm{sq} \mathrm{ft})\end{array}$ & $\begin{array}{l}\text { - Primary season for fertilization, but still wise to avoid applications } \\
\text { under severe environmental stress. }\end{array}$ \\
\hline $\begin{array}{l}\text { Late summer } \\
\text { to winter } \\
\text { dormancy }\end{array}$ & $\begin{array}{l}\text { Low } \\
(.25-1 \mathrm{lb} \mathrm{N} / 1,000 \mathrm{sq} \mathrm{ft})\end{array}$ & $\begin{array}{l}\text { Maintaining active growth until dormancy promotes late-season } \\
\text { rooting and carbohydrate storage, but } \mathrm{N} \text { applications terminated } \\
\text { prior to first frost date. }\end{array}$ \\
\hline
\end{tabular}

\section{Lawns and Commercial Turf}

Cool-season grasses can receive up to 3.5 pounds of water-soluble nitrogen (WSN) per 1,000 square feet or 4 pounds of slowly available nitrogen (SAN) per 1,000 square feet on an annual basis. Warm-season grasses can receive up to 4 pounds of WSN per 1,000 square feet or 5.5 pounds SAN per 1,000 square feet. Applications of water-soluble nitrogen should not exceed 1 pound of nitrogen per 1,000 square feet every 30 days. When using WSN on sandy soils, split applications to no more than 0.5 pound of nitrogen per 1,000 square feet every 15 days. Slowly available nitrogen sources (defined as any nitrogen source containing 50 percent or more SAN) can be applied at up to 1.5 pounds per 1,000 square feet on heavier-textured (high clay or silt) soils per application at a recommended timing or 1 pound of nitrogen per 1,000 square feet on predominantly sand soils. However,

\section{Table 6.8. Seasonal nitrogen requirements} to deliver satisfactory levels of turfgrass performance for cool- and warm-season lawns.

\begin{tabular}{lc}
$\begin{array}{l}\text { 2.5-5.5 lb N/1,000 sq ft } \\
\text { annually }\end{array}$ & $\begin{array}{c}\mathbf{1 - 2} \mathbf{l b ~ N / 1 , 0 0 0 ~ s q ~ f t ~} \\
\text { annually }\end{array}$ \\
\hline Kentucky/hybrid bluegrass & Fine-leaf fescues \\
\hline Creeping bentgrass & Centipedegrass \\
\hline Bermudagrass* & Zoysiagrass \\
\hline Tall fescue* & Bermudagrass* \\
\hline Perennial ryegrass & Tall fescue* \\
\hline $\begin{array}{l}\text { St. Augustinegrass* } \\
\text { *Certain varieties within species perform well under either } \\
\text { annual nitrogen program. }\end{array}$ \\
\hline
\end{tabular}

remember that the seasonal requirements of varying species are highly variable and some of the region's turfgrasses would actually decline in health and/or quality if aggressively fertilized. Table 6.8 details typical seasonal nitrogen requirements to achieve anticipated levels of desirable turfgrass performance.

\section{Golf Courses}

Golf turf is some of the most intensively managed grass grown, requiring maintenance cutting heights as low as 0.1 inch for some putting greens with expectations to deliver a dense, smooth-playing surface. Furthering the need for additional nutrition is that clippings are collected on all greens, most tees, and even some fairways. For sand-based greens and tees, care especially needs to be taken regarding the potential for leaching loss of nitrates and phosphates due to the sandy soil and the likelihood that the greens contain subsurface drains that likely channel leachate to a water source. When greens are mature and healthy, nitrate and phosphate leaching concerns are minimal. When greens are immature (i.e., being grown-in) or are stressed due to pest or environmental pressures, the potential for nutrient loss is greatly increased. Table 6.9 presents general seasonal nitrogen applications for all aspects of golf turf management. Consider that while the total annual nitrogen rates stay the same, the maximum nitrogen rate per application (and therefore, the number of applications) might vary when 50 percent or more SAN sources are used on heavier-textured (predominantly clay or silt) soils, and levels of up to 1.5 pounds of nitrogen per 1,000 square feet can be applied in a single application. 
Table 6.9. General seasonal nitrogen strategies for golf turf management.

\begin{tabular}{|c|c|c|c|}
\hline Turf use & Grass type & $\begin{array}{l}\text { Maximum } \mathbf{N} \text { rate/ } \\
\text { application } \\
(\mathrm{lb} / 1,000 \mathrm{sq} \mathrm{ft})^{\mathrm{a}}\end{array}$ & $\begin{array}{c}\text { Total annual N rate } \\
(\mathrm{lb} / 1,000 \mathrm{sq} \mathrm{ft})^{\mathrm{b}}\end{array}$ \\
\hline Greens & & $.5-1$ & $3-6$ \\
\hline Tees & & $.5-1$ & $2-5$ \\
\hline \multirow{2}{*}{$\begin{array}{l}\text { Fairways } \\
\text { (standard management) }^{\mathrm{c}}\end{array}$} & Cool-season & 1 & $2-3$ \\
\hline & Warm-season & 1 & $2-4$ \\
\hline \multirow{2}{*}{$\begin{array}{l}\text { Fairways } \\
\text { (intensive management) }^{d}\end{array}$} & Cool-season & $.5-1$ & $3-4$ \\
\hline & Warm-season & $.5-1$ & $3.5-4.5$ \\
\hline Overseeding fairways & Warm-season & .5 & 1.5 \\
\hline Roughs & & 1 & $1-3$ \\
\hline \multicolumn{4}{|c|}{$\begin{array}{l}\text { a For naturally occurring sand or modified sand-based soils on greens and/or tees, apply no more than } 0.5 \mathrm{lb} \text { water-soluble } \\
\text { nitrogen per } 1,000 \mathrm{sq} \mathrm{ft} \text { every } 15 \text { days, or } 1 \mathrm{lb} \text { nitrogen from sources containing } 50 \text { percent or greater SAN every } 30 \mathrm{days} \text {. } \\
\text { b Use the higher levels for intensively managed turf where accelerated growth and/or rapid recovery are required; use lower } \\
\text { rates for maintenance of lesser used areas. } \\
\text { 'Standard management fairways may or may not have irrigation and likely are mowed at heights of } 0.75-1.25 \text { inch, one to two } \\
\text { times per week. } \\
\text { dIntensively managed fairways are irrigated and are likely mowed at heights of } 0.75 \text { inch or shorter, three or more times per week. } \\
\text { elnitiate nitrogen applications of no more than } 0.5 \mathrm{lb} \text { per } 1,000 \mathrm{sq} \mathrm{ft} \text { after ryegrass is well-established and bermudagrass has } \\
\text { entered dormancy. In spring, up to two applications of nitrogen at } 0.5 \mathrm{lb} \text { per } 1,000 \mathrm{sq} \mathrm{ft} \text { can be used in February or March if } \\
\text { growth and color enhancement are required. }\end{array}$} \\
\hline
\end{tabular}

\section{Athletic Fields}

There is likely no turf management situation more challenging than maintaining a safe, high-quality playing surface on an athletic field. A fertility program is only one component of a successful management program, because appropriate cultivation, irrigation, and field use management strategies have similar importance. However, applying fertilizer at the appropriate levels and timing pending the grass, soil, and field use is critical to sustain turf coverage and encourage its recovery. The following tables (adapted from Goatley et al. 2008, and the 2005 Virginia DCR Standards and Criteria) provide general recommendations for nitrogen fertility strategies on cool-season athletic fields in this region. As stated previously, the maximum nitrogen rate per application (and therefore, the number of applications) might vary when 50 percent or more SAN sources are used on heavier-textured (predominantly clay or silt) soils and levels of up to 1.5 pounds nitrogen per 1,000 square feet can be applied in a single application. The application timing and frequency would be adjusted accordingly.

\section{Table 6.10. Suggested nitrogen fertility programs for a cool-season athletic field.}

Maintenance program ${ }^{\mathrm{a}}(\mathrm{lb} \mathrm{N} / 1,000 \mathrm{sq} \mathrm{ft})$

Maintenance program ${ }^{\mathrm{a}}(\mathrm{lb}$
Normal

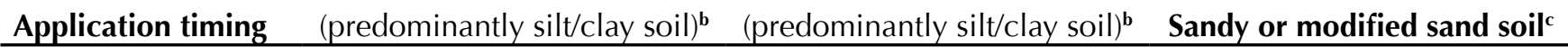

\begin{tabular}{lccc}
\hline After August 15 & - & .5 & .5 \\
\hline September & 1 & 1 & 1 \\
\hline October & 1 & 1 & 1 \\
\hline November & .5 & 1 & 1 \\
\hline April 15-May 15 & .5 & .5 & .5 \\
\hline June 1-15 & - & .5 & .5 \\
\hline Seasonal N total & Up to $3 \mathrm{lb}$ & Up to $4.5 \mathrm{lb}$ & Up to $4.5 \mathrm{lb}$ \\
\hline
\end{tabular}

antensively managed native soil- and sand-based fields require supplemental irrigation.

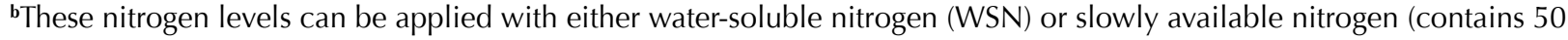
percent or more SAN) sources.

'On sand-based systems, any application more than $0.5 \mathrm{lb}$ nitrogen per 1,000 sq ft should be made with 50 percent or more SAN sources on a 30-day minimum interval. Where WSN is used, levels should not exceed $0.5 \mathrm{lb}$ per 1,000 sq ft every 15 days. 


\begin{tabular}{|c|c|c|}
\hline \multirow[b]{2}{*}{$\begin{array}{l}\text { Application } \\
\text { timing }\end{array}$} & \multicolumn{2}{|c|}{$\begin{array}{l}\text { Maintenance Program } \\
\quad(\mathrm{lb} N / 1,000 \mathrm{sq} \mathrm{ft})\end{array}$} \\
\hline & $\begin{array}{l}\text { Predominantly } \\
\text { silt/clay soil }^{\mathbf{b}}\end{array}$ & $\begin{array}{c}\text { Sandy or } \\
\text { modified sand } \\
\text { soil }^{\mathbf{c}} \\
\end{array}$ \\
\hline April 15-May 15 & $.5-1$ & .5 \\
\hline June & 1 & 1 \\
\hline July & $.5-1$ & 1 \\
\hline August & $.5-1$ & 1 \\
\hline Sept $1-15^{d}$ & $.5-1$ & - \\
\hline $\begin{array}{l}\text { Seasonal } N \\
\text { total for non- } \\
\text { overseeded } \\
\text { fields }\end{array}$ & $3-5$ & Up to 3.5 \\
\hline
\end{tabular}

If overseeded

with ryegrass ${ }^{\mathrm{e}}$

\begin{tabular}{lcc}
\hline $\begin{array}{l}\text { October- } \\
\text { November }\end{array}$ & .5 & $.5-1$ \\
\hline February-March & $.5-1$ & $.5-1$ \\
\hline $\begin{array}{l}\text { Seasonal N total } \\
\text { for overseeded } \\
\text { fields }\end{array}$ & $4-6.5$ & $4.5-5.5$ \\
\hline
\end{tabular}

antensively managed native soil- and sand-based fields require supplemental irrigation.

bThese nitrogen levels can be applied with either watersoluble nitrogen (WSN) or sources containing 50 percent or more SAN.

'Any application more than $0.5 \mathrm{lb}$ nitrogen per 1,000 sq ft should be made with a SAN source (containing 50 percent or more SAN) on a 30-day minimum interval. When WSN is used, levels should not exceed $0.5 \mathrm{lb}$ per $1,000 \mathrm{sq} f t$ every 15 days.

dThe September application is suitable only if anticipated first fall killing frost date is after Oct. 20.

eUse the higher nitrogen levels on intensively trafficked fields only.

\section{Sod Production Systems}

Growing sod is quite simply a specialized form of "production agriculture," with a similar goal (i.e., yield) of any other crop. A harvestable sod of acceptable turf quality (high density, dark green and uniform color, pest-free, etc.) is the sign of a successful crop. Revenues are optimized by achieving rapid coverage of the turf; to accelerate harvest, it is common to net the sod either prior to planting or at harvest. As for any growing system, proper timing and appropriate application levels of nutrients are crucial to optimize nutrient use efficiency. Prior to seed or sprig establishment, soil tests should be performed to adjust $\mathrm{pH}$ and supplemental nutrient requirements (phosphorus and potassium, etc.) at planting using the standard guidelines presented in table 6.1. Netted sods can likely be produced within a calendar year, whereas non-netted sods will likely require some portion of a second growing season to complete establishment. Recommended nitrogen levels at the establishment of both cool- and warm-season turfgrasses were presented earlier in this chapter. Tables 6.12 and 6.13 detail seasonal nitrogen levels in the production of cool-season or warm-season sods.

\section{Table 6.12. Recommended nitrogen levels for} production of a cool-season turfgrass sod.

\begin{tabular}{|c|c|}
\hline Timing of planting & Actual N (lb/acre) \\
\hline At seeding ${ }^{a}$ & $40-60^{b}$ \\
\hline \multicolumn{2}{|c|}{$\begin{array}{l}\text { In seeding year of fall } \\
\text { plantingc }\end{array}$} \\
\hline Nov. 15-Dec. 15 & $40-60$ \\
\hline \multicolumn{2}{|l|}{$\begin{array}{l}\text { First full year of } \\
\text { establishment }\end{array}$} \\
\hline April 1-June 15 & $20-40$ \\
\hline Aug. 15-Oct. 1 & $40-60$ \\
\hline Nov 1-Dec. 1 & 40 \\
\hline Second year ${ }^{d}$ & $\begin{array}{c}\text { 20-40/growing-month } \\
\text { as needed to complete } \\
\text { coverage }\end{array}$ \\
\hline \multicolumn{2}{|c|}{$\begin{array}{l}\text { bApply no more than } 40 \mathrm{lb} \text { of water-soluble nitrogen per } \\
\text { acre in any single application; for levels more than } 40 \mathrm{lb} \text {, } \\
\text { use materials that are } 50 \text { percent or more SAN. } \\
\text { cDo not apply fertilizer to frozen soil. } \\
\text { dSecond-year fertilization likely only required for non-netted } \\
\text { sod. }\end{array}$} \\
\hline
\end{tabular}




\section{Table 6.13. Recommended nitrogen levels for production of bermudagrass or zoysiagrass sods.}

\begin{tabular}{|c|c|c|}
\hline \multirow{2}{*}{$\begin{array}{l}\text { Timing of } \\
\text { application }\end{array}$} & Bermudagrass & Zoysiagrass \\
\hline & \multicolumn{2}{|c|}{ lb N/acre ${ }^{a}$} \\
\hline $\begin{array}{l}\text { Establishment by } \\
\text { seed or sprigs in } \\
\text { late spring/early } \\
\text { summer }\end{array}$ & $40-60$ & $40-60$ \\
\hline June & 40 & - \\
\hline July & 40 & 40 \\
\hline August & 40 & - \\
\hline \multicolumn{3}{|c|}{$\begin{array}{l}\text { aApply no more than } 40 \mathrm{lb} \text { of water-soluble nitrogen per } \\
\text { acre in any single application; for levels greater than } 40 \mathrm{lb} \\
\text { use materials that are } 50 \text { percent or greater SAN. }\end{array}$} \\
\hline
\end{tabular}

\section{Mowing}

\section{Standard Mowing Heights}

The recommended mowing heights detailed in table 6.14 are recommendations for optimal growing periods and will vary depending on the cultivar and the use of the grass (lawn, golf or sports turf). In almost every instance, the listed grasses can be mowed taller than heights listed. However, maintaining turfgrasses within their recommended clipping height range during periods of optimal growth promotes turfgrass density by promoting lateral growth through tillers (i.e., daughter plants), rhizomes (belowground stems), or stolons (aboveground stems). Prior to and/or during environmental stress periods, raising the clipping height is a standard recommendation for all grasses in order to enhance survival. Therefore, prior to summer stress periods, the recommendation is to raise the cutting heights of cool-season grasses, and for non-irrigated turf, it is often suggested to refrain from mowing at all. For warm-season grasses, raise the cutting heights a few weeks prior to an anticipated frost date (and initiation of winter dormancy) in order to promote winter survival.

The standard recommendation is to never remove more than one-third of the leaf blade at any cutting event. Limiting leaf blade removal to this level prevents scalping and a drain on carbohydrate reserves to replenish the shoot system.
Table 6.14. Typical maintenance cutting heights for turfgrasses grown in the midAtlantic. ${ }^{\mathrm{a}}$

\begin{tabular}{|c|c|}
\hline Species & Cutting heights (inches) ${ }^{\mathrm{b}}$ \\
\hline Creeping bentgrass & $0.1-0.19$, greens; $0.25-0.75$, fairways \\
\hline Fine-leaf fescues & $1.5-2.5$ \\
\hline $\begin{array}{l}\text { Kentucky bluegrass, } \\
\text { hybrid bluegrass }\end{array}$ & $1.5-2.5$ \\
\hline Perennial ryegrass & $0.75-2$ \\
\hline Bermudagrass & $\begin{array}{l}0.5-1 \text { on athletic fields, golf } \\
\text { fairways and tees; up to } 2 \text { on } \\
\text { lawns and general-purpose turf }\end{array}$ \\
\hline Centipedegrass & $1.5-2.5$ \\
\hline St. Augustinegrass & $2-3$ \\
\hline Zoysiagrass & $\begin{array}{c}0.5-1 \text { on golf fairways and tees; } \\
\text { up to } 2 \text { on lawns and general- } \\
\text { purpose turf }\end{array}$ \\
\hline Tall fescue & $2-3$ \\
\hline \multicolumn{2}{|c|}{$\begin{array}{l}{ }^{\mathrm{a} C} \text { Cutting height recommendations for optimal growing } \\
\text { periods. } \\
\text { bCutting heights shorter than } 1 \text { inch require a reel mower. }\end{array}$} \\
\hline
\end{tabular}

\section{Equipment}

Rotary mowers are the prevalent cutting units for the most acreage because they are generally inexpensive to both purchase and maintain. Rotary units clip grass by spinning a metal blade with a sharpened edge at high speed under a stationary deck. The cut is actually more of a "tear," because the grass blades are removed simply by the impact of a solid object striking the leaf blade at a high speed. Maintaining a sharp and properly balanced blade is crucial to maintaining high turf quality and plant health. Mowing with a dull blade creates jagged wounds in the leaves that result in a low-quality turf that has increased potential for disease and environmental stress.

Flail mowers have multiple-levered blades on a spinning horizontal shaft. The blades are not intended to be sharpened and are designed to "give" if they hit a solid object; the deck is fully self-contained with no discharge point. Flail units are popular in maintaining unimproved turf areas such as highway rights of way where turf quality is not critical.

The cutting unit that provides the highest quality of cut is the reel unit that features a cylinder of curved blades that gathers and pinches leaves between the blade and a stationary, sharpened bedknife. Reel units are used on the 
highest-quality turf where cutting heights shorter than 1 inch are desired and the highest level of surface smoothness is required. Maintaining properly adjusted and sharpened blades and bedknives is crucial to achieving the high-quality cut desired with this type of cutting unit.

\section{Clipping Management}

Returning clippings is desirable whenever possible, and the only situation where clippings are recommended for collection is in putting green management for golf turf where they would disrupt playability of the putting surface. Clippings are essentially controlled-release fertilizer, containing approximately 4 percent nitrogen, 0.5 to 1 percent phosphorus and 2 percent potassium by weight.

A common misconception is that clippings contribute to thatch - a layer comprised primarily of slow-to-decay stems that forms between the turfgrass canopy and the soil surface. Thatch is primarily composed of stems (rhizomes, stolons, and crowns) that resist microbial degradation. Therefore, all grasses capable of lateral growth by way of rhizomes and/or stolons can become thatchy, especially if they are aggressively fertilized. If properly mowed (i.e., following the " $1 / 3$ mowing rule" of leaf removal), clippings readily degrade and do not contribute to thatch. However, if mowing is sporadic and the turf is allowed to produce seedheads, thatch buildup is likely to occur over multiple seasons. Another tempting reason to collect clippings is to reduce the potential of spreading weeds or diseases throughout the lawn. However, research has shown that the advantages of returning clippings far exceed any concerns with promoting weed or disease pressure in the turf.

It is now common that many versions of the standard rotary mowers can serve as "mulching mowers" by way of modifications of their decks and blades (figure 6.16).

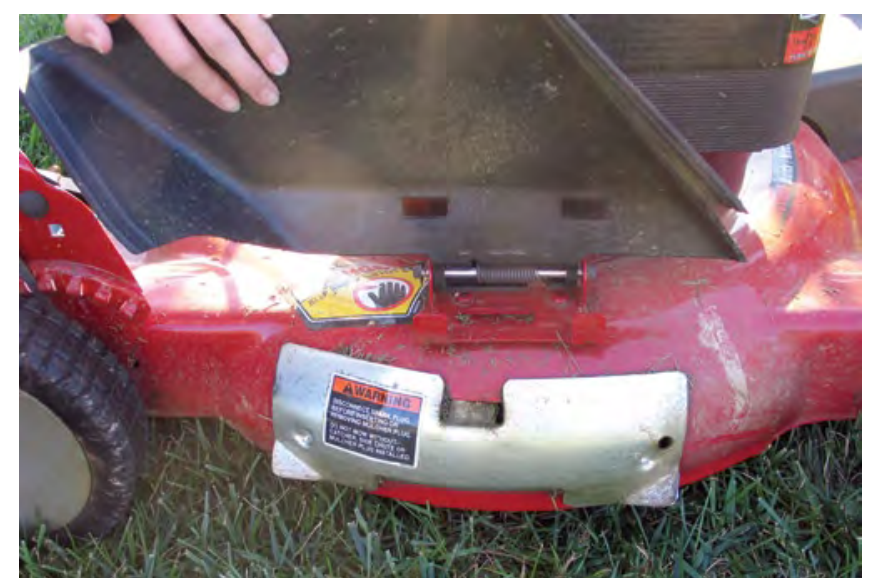

Figure 6.16. A mulching mower chops turfgrass clippings into fine particles that are quickly decomposed by microbes in the soil.
The ability to chop clippings into very small leaf pieces accelerates leaf decomposition in the soil, thus improving lawn appearance and promoting a healthy soil microbial population. If the $1 / 3$ rule cannot be followed for a mowing event and piles of clippings remain on the lawn (figure 6.17), it is important to remove them because they block sunlight and encourage disease due to the elevated temperature and moisture under the pile. In all cases where clippings are collected, they should be properly composted (detailed in chapter 9) rather than piled in waste areas and/or bagged for deposit in landfills.

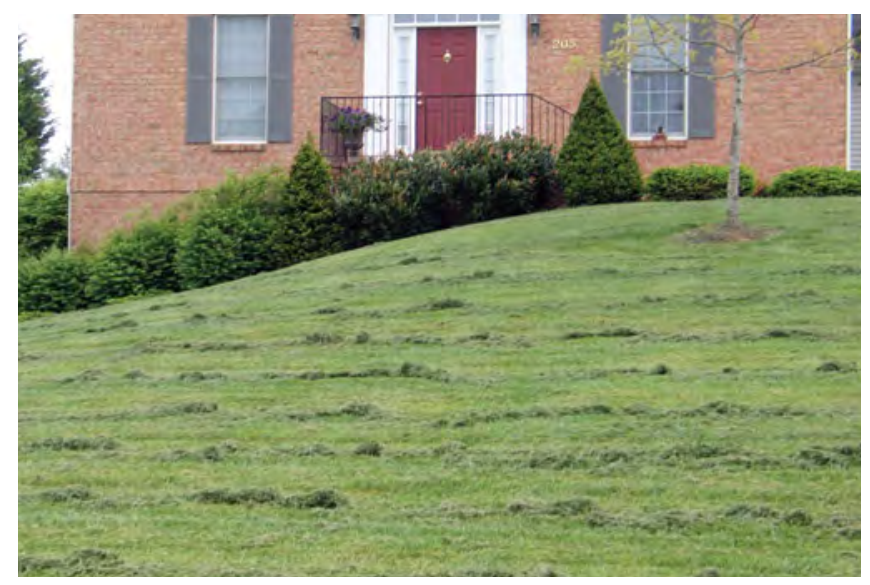

Figure 6.17. When the "1/3 mowing rule" is violated, it is important not to leave the piled clippings on the lawn because they can damage the underlying turf. Collect and compost this material.

\section{Literature Cited}

Goatley, M., S. Askew, E. Ervin, D. McCall, R. Studholme, P. Schultz, and B. Horvath. 2008. Sports Turf Management in the Transition Zone. Blacksburg, Va.: Pocahontas Press.

Goatley, M., G. Mullins, and E. Ervin. 2009. Soil Testing for the Lawn and Landscape. Virginia Cooperative Extension Publication 430-540. www.pubs. ext.vt.edu/430-540.

Turner, T. R. 2005. Nutrient Management Guidelines for Commercial Turfgrass Seeding. University of Maryland Technical Turfgrass Update, TT-116.

Virginia Department of Conservation and Recreation, Division of Soil and Water Conservation. 2005. Virginia Nutrient Management Standards and Criteria, 96-107. 



\section{Chapter 7. The Ornamental Landscape}

Laurie Fox, Research Associate, Hampton Roads Agriculture Research and Extension Center, Virginia Tech

\section{Introduction}

Fertilization is an important part of landscape management. Plants need nutrients to survive, and while many of the essential elements are already in the soil, fertilizer is often added to supplement those nutrients. Fertilization is a common cultural practice often made complex and confusing by the wide variety of fertilizer products on the market. The simple objective is to supply plants with nutrients in a form they can use at the time they most need them in a way that produces a healthy, attractive landscape while being environmentally sound.

\section{Site Assessment and Environmental Design}

\section{Site Assessment}

A site assessment provides critical information for any landscape nutrient management plan. The information from a site assessment supports short- and long-term nutrient planning as well as the environmental sustainability of the overall plan. A site assessment should be conducted every five to seven years and should include information that will assist the landscape manager in making the best nutrient management decisions. Information to include in a site assessment:

- Site boundaries.

- Rainfall amount and distribution throughout the year.

- Water movement (on and through/off site for runoff and leaching potential).

- Management area delineation and size (e.g., turf, annuals, natural areas, etc.).

- Categories of plants (both existing and future additions; see "Plant Categories," later in this chapter).

- Condition of existing plants (healthy, stressed, etc.).

- Previous management strategies.

- Results of soil test(s).

- Site accessibility.

- Site management goals, short- and long-term.

- Special landscape situations.
- Overall site goals and objectives.

- Location relative to environmentally sensitive areas or proximity to storm drainage and bodies of water.

\section{Urban Soils}

There are many special situations to consider in the ornamental landscape, and one of the most pressing issues is the fact that the growing medium is usually a drastically altered urban soil where much of the native topsoil is removed during development (see chapter 3). Subsoil - deficient in essential nutrients and lacking desirable physical properties - becomes the new topsoil in many situations. Or perhaps soil of unknown origin and composition is brought onto the site. Construction is also a factor affecting the performance of these soils. Urban soils tend to be heavily compacted, poorly aerated, poorly drained, and low in organic matter. Fertilization of landscape plants will not be effective until these adverse growing conditions are corrected. In fact, unhealthy soil cannot sustain healthy plants and can lead to nutrient pollution of surface and groundwater through runoff and leaching of the applied nutrients.

\section{Site Design}

Nutrient management is also affected by proper environmental design. Plants with similar nutrient needs should be grouped together in the landscape when possible to avoid improper rates of fertilizer application and to utilize fertilizer most efficiently. Landscape areas with mixed categories of plants are more challenging to manage. These areas may need to be subdivided into smaller management areas based on plant category and nutrient needs, or they may need to be fertilized using a "middle-of-the-road" approach where all plants get some nutrients but none is managed optimally because of the diverse plant mix.

\section{BMPs}

Special landscape design features such as buffers, bioretention or rain gardens, and green roofs are commonly used in landscapes to manage stormwater (see chapter 12). They are called landscape best management practices (BMPs) and are used to slow down stormwater and provide an opportunity for it to be filtered by the plants, soil, and microorganisms before it either runs 
into natural surface water sources or percolates down to recharge groundwater sources. Plants in these BMPs should be fertilized only once when they are planted (usually in the individual planting hole) in order to get them established. These plants act as biofilters, absorbing nutrients from the stormwater; they DO NOT need any additional nutrient applications.

\section{Correct Plant Selection and Planting}

\section{Plant Selection}

Correct plant selection is the first critical step to a successful landscape.

- Choose plants that are adapted to the environmental and site conditions.

- Select plants that naturally have few pest problems or are pest-resistant.

- Choose plants that meet the landscape goals and design parameters.

- Install plants at the correct spacing to account for their mature size, avoid crowding, and reduce longterm maintenance.

\section{Plant Categories}

Following are some basic definitions that apply specifically to landscape plants:

- Annuals are plants that complete their entire life cycle in one growing season. They germinate from seed, flower, set seed, and die in the same year.

- Biennials are plants that live for two years. They usually form vegetative growth in the first year and flowers and fruit/seed the second year.

- Perennials are plants that live for three or more years.

- Bulbs are short, modified, underground stems surrounded by (usually) fleshy, modified leaves that contain stored food for the shoot within.

- Herbaceous plants lack a permanent woody stem and die back to the ground every winter.

- Woody plants have permanent woody stems, are perennial, and go dormant in the winter but do not die back to the ground. These plants grow from aboveground stems year after year and include shrubs, trees, and some vines.

\section{Planting}

No amount of fertilizer will improve a plant's health or growth if that plant is installed incorrectly. Correct planting is essential for growing healthy roots and getting a plant established quickly in a landscape. Without a healthy root system, a plant can't absorb nutrients efficiently or effectively. In addition, many nutrient applications are made at the time of planting, either in the planting hole or to the planting bed area. See Appendix 7-A, Tree and Shrub Planting Guidelines, Virginia Cooperative Extension publication 430-295 for details on correct planting.

\section{Determining the Need to Fertilize}

Plants need 17 elements for normal growth. These are divided into two groups based on the amount of each needed by plants. Carbon, hydrogen, and oxygen are found in air and water. Nitrogen, potassium, magnesium, calcium, phosphorous, and sulfur are found in the soil. The six elements found in soil are used in relatively large amounts by plants and are called macronutrients. There are eight other elements that are used in much smaller amounts and are called micronutrients, or trace elements. The micronutrients, which are found in the soil, are iron, zinc, molybdenum, manganese, boron, copper, cobalt, and chlorine. All 17 elements both macronutrients and micronutrients - are essential for plant growth. See chapter 4 for more detailed information.

Fertilizer should be applied when plants need it, when it will be most effective, and when plants can readily absorb it.

How and when to fertilize landscape plants depends on factors like:

- Maintenance objectives: stimulate new versus maintain existing growth.

- Plant age: generally more for younger and less for older woody plants.

- Plant stress levels: stressed plants can sometimes benefit from additional fertilizer.

In addition to soil testing (see chapter 5), a visual inspection of plants is often used in making fertilization decisions. Look for:

- Poor or chlorotic leaf color (pale green to yellow).

- Reduced leaf size and retention. 
- Premature fall coloration and leaf drop (shrubs and trees).

- Overall reduced plant growth and vigor.

Foliar or tissue analysis can also be used to help determine whether supplemental fertilization is needed (see chapter 5). Avoid late-summer or early-fall fertilization while plants are still actively growing because this stimulates late-fall growth, which can be killed by freezing temperatures.

\section{Soil Tests (See chapter 5.)}

The purpose of a soil test is to provide information to make wise choices regarding fertilizer and soil amendment. An initial soil test will provide baseline information on the condition of the soil and can include soil type; $\mathrm{pH}$; available phosphorus, potassium, calcium, and magnesium; organic matter; and soluble-salt levels. Soil tests can also provide fertilizer and lime recommendations based on the specific crop being grown. Subsequent tests can be used to monitor changes and improvements in soil health.

For ornamental landscape areas, soil testing should be done every three to five years. Each management area in the landscape should have its own test in order to customize the nutrient management plan for that area and avoid incorrect applications. For example, separate tests should be done for the turf, perennial beds, tree and shrub or naturalized areas, and annual beds. Soil test guidelines should be closely followed to assure the greatest plant response with the least chance of plant damage or possibility of water pollution. Many soils in Virginia have adequate phosphorus levels, making it unnecessary to apply more through fertilizers.

Soil sample kits are available at local Extension offices and most libraries. There are private companies that also do soil testing. Fees vary. For best results, carefully follow the instructions given in the soil sample kit. The accuracy of the test is a reflection of the soil sample taken. Be sure the sample is representative of the area to be treated.

Soil $\mathrm{pH}$, a measure of acidity, has a significant impact on the plant's ability to use nutrients. Most ornamental landscape plants prefer a $\mathrm{pH}$ range of 5.5 to 7.0. Within this range, the essential nutrients are available to most plants, and soil microorganisms can carry out their beneficial functions.

If the soil is too acidic (i.e., low $\mathrm{pH}$ ), the $\mathrm{pH}$ can be raised by adding lime. Lime applications can be made at any time of the year, but it is ideal to apply lime in the fall and winter months when there are several weeks to months for the chemical reactions to take place before the next growing season.

If the soil is too alkaline (i.e., high $\mathrm{pH}$ ), the $\mathrm{pH}$ can be lowered by adding sulfur. It is not practical or advisable to change the soil $\mathrm{pH}$ more than one to two levels. Whenever possible, it is best to select plants that grow well in the existing conditions.

\section{Factors Affecting Nutrient Uptake}

Numerous factors affect nutrient uptake by plants. The most important factors include:

- Fertilizer form: inorganic, fast-release, or liquid forms are usually absorbed faster than organic, slowrelease, or dry forms.

- Soil type: clay particles and organic matter adsorb or bind more nutrients than sand, so fertilizer application needs to be more frequent in sandy soils but with lower rates each time due to leaching potential.

- Soil moisture content and soil temperature: nutrient uptake is faster in moist, warm soils.

- Fertilizer placement and application timing and method.

- Plant vigor: plants under stress are less able to take up available nutrients due to damaged or reduced root systems.

\section{Fertilizers}

\section{Forms (See chapter 8.)}

All fertilizers are labeled with three numbers that give the percentage by weight of nitrogen $(\mathrm{N})$, phosphate $\left(\mathrm{P}_{2} \mathrm{O}_{5}\right)$, and potash $\left(\mathrm{K}_{2} \mathrm{O}\right)$.

1. Nitrogen is important for leaf and stem growth and provides the rich green color in a plant.

2. Phosphorous (derived from phosphate) provides for root, flower, and fruit growth.

3. Potassium (derived from potash) helps build plant tissue and aids in disease resistance, cold hardiness, and the production of chlorophyll.

Proper use of nutrients can control rate and character of plant growth.

The analysis, or grade, of a fertilizer refers to the minimum amounts of nitrogen, phosphorus (in the form 
$\mathrm{P}_{2} \mathrm{O}_{5}$ ), and potassium (in the form $\mathrm{K}_{2} \mathrm{O}$ ) in the fertilizer. The analysis is always printed on the fertilizer label. A fertilizer with a 10-10-10 analysis contains 10 percent nitrogen, 10 percent $\mathrm{P}_{2} \mathrm{O}_{5}$, and 10 percent $\mathrm{K}_{2} \mathrm{O}$. For example, in 100 pounds of $4-8-12$, there are 4 pounds of nitrogen, 8 pounds of $\mathrm{P}_{2} \mathrm{O}_{5}$, and 12 pounds of $\mathrm{K}_{2} \mathrm{O}$.

Fertilizers may be divided into two broad categories: natural and synthetic. Natural fertilizers generally originate from unprocessed organism sources such as plants or animals. Synthetic fertilizers are manmade or processed. Synthetic fertilizers can be organic (e.g., urea) or inorganic (e.g., superphosphate). Natural fertilizers commonly misnamed "organic" can also contain inorganic ores such as rock phosphate.

Most nutrients from living or once-living organisms are not readily available for plant growth because they are bound in organic molecules such as proteins and amino acids and in structures such as cell walls. These nutrients are released only by microorganisms decomposing the organic matter. Cottonseed meal, blood meal, bone meal, hoof and horn meal, fish emulsion, and all manures are examples of organic fertilizers. Organic fertilizers usually contain relatively low concentrations of actual nutrients, but they perform other important functions that the synthetic formulations do not. These functions include increasing organic content of the soil, improving physical structure of the soil, and increasing bacterial and fungal activity.

"Slow-release" fertilizers may be synthetic or natural. Because nutrients are released over an extended period of time, slow-release fertilizers do not have to be applied as frequently as other fertilizer types. Also, higher amounts of slow-release fertilizer can be added at each application without risking injury to plant roots. Slowly released nitrogen is used more efficiently because a higher percentage is absorbed by plants. The higher efficiency of slow-release fertilizers means less nitrogen is available to contribute to pollution of surface and groundwater. While slow-release fertilizers are generally more expensive, when an analysis is done to determine the cost of the nitrogen absorbed by the plant, the unit cost is actually less for slow-release materials.

"Water-soluble" or "liquid" fertilizers (which are not the same) are applied either to the soil or foliage. Numerous water-soluble fertilizer formulations are available, from plant starter, high-nitrogen fertilizers to minor element formulations. Chelated iron is used extensively for prevention and control of iron deficiency in azalea, rhododendron, and other popular ornamentals.
"Combination" products that contain fertilizer mixed with a herbicide, insecticide, or fungicide should be considered carefully. Herbicides, insecticides, and fungicides should be selected and applied based on the crop being grown and the pest(s) being managed. Often, the timing for a fertilizer application does not coincide with that of another product, and off-target or unintentional injury to the plant could result from a combined application.

\section{Placement}

Because most landscape plant roots grow in the top 12 inches of soil, surface or shallow application (6 to 9 inches) is recommended. Fertilizer can be added to an individual planting hole, incorporated into the planting hole backfill or into an entire bed area, or spread over the plant's root zone. With the last method, the fertilizer should not be concentrated around the stem or trunk of a plant but where the majority of the absorbing roots are actively growing. For annuals, this is from the canopy edge extended out by 6 inches. For perennials, this is from the canopy edge extended out 6 to 12 inches. For trees and shrubs, fertilizer should be applied over an area extending two to three times the canopy spread. Research has shown that tree roots grow far beyond the drip line of established trees. Do not concentrate fertilizer in holes drilled under the tree canopy, but instead use a broadcast application beyond the tree canopy for better growth.

\section{Application Timing}

Research shows that plants actively absorb nutrients from the soil during the growing season and require few nutrients during the dormant winter season. In general, apply fertilizer as soon as plants begin breaking dormancy in the spring and avoid fertilizing after the first fall frost, which signals plants to slow growth in preparation for winter dormancy. Late-summer and early-fall fertilization may stimulate new growth that is not winter hardy.

Do not fertilize during stressful environmental conditions. Drought causes plants to slow their growth. That, combined with insufficient soil moisture, reduces nutrient absorption and could increase the potential for root injury from fertilizers. Too much rainfall or irrigation can cause nutrients to run off or leach, potentially contaminating water sources. Incorporate the fertilizer into the bed or planting hole when there is frequent rain or irrigation to avoid runoff or leaching problems. 
The frequency of fertilization depends on the type of plants being fertilized and the type of fertilizer used. Slow-release fertilizers are commonly recommended so that one application lasts for the entire growing season. If general-purpose, water-soluble fertilizers are used, two or three applications applied four to six weeks apart may be needed to make it through the growing season. Fertilizer should be applied to newly planted landscape ornamentals to help them establish quickly.

\section{Application Methods}

Five methods - (1) liquid injection, (2) drill hole or punch bar, (3) surface application or fertilizer stakes or spikes, (4) foliar spraying, and (5) tree-trunk injection or implants - are discussed here. Each serves a specific role depending on the site and plant health. Table 7.1 summarizes the advantages and disadvantages of the five application methods. Regardless of the method selected, the soil should be moist at the time of fertilization to prevent fertilizer injury to the plant.

1. Liquid injection (primarily for trees). Through liquid injection into the soil, fertilizer solutions are placed in the root zone. This is an excellent method for correcting nutrient deficiencies. Injection sites should be 2 to 3 feet apart - depending on pressure - and 6 to 9 inches deep. Fertilizing deeper than 9 inches may place the fertilizer below the absorbing roots, preventing plant use. When using this method in summer or during periods of drought, the soil should be moist before application.

2. Drill hole or punch bar (primarily for trees). A major advantage of the drill-hole system is the opening of heavy, compacted soils, which allows air, moisture, and fertilizer to move into the soil. The drill holes should be placed in concentric circles or in a grid system around the main stem beginning 3 to 4 feet from the main stem and extending beyond the drip line (see figure 7.1). Space the holes 2 feet apart and drill them 6 to 9 inches deep. The recommended rate of fertilizer for the area should be uniformly distributed among the holes and is based on the root-zone space under the tree (and not the trunk diameter). The holes can be filled either with organic material such as compost or inorganic materials such as gravel, sand, or calcined clay.

3. Surface application. A broadcast application of granular fertilizer at the appropriate rate and time is made to the ground surface or on top of mulch in landscape beds. It is best to water the fertilizer in

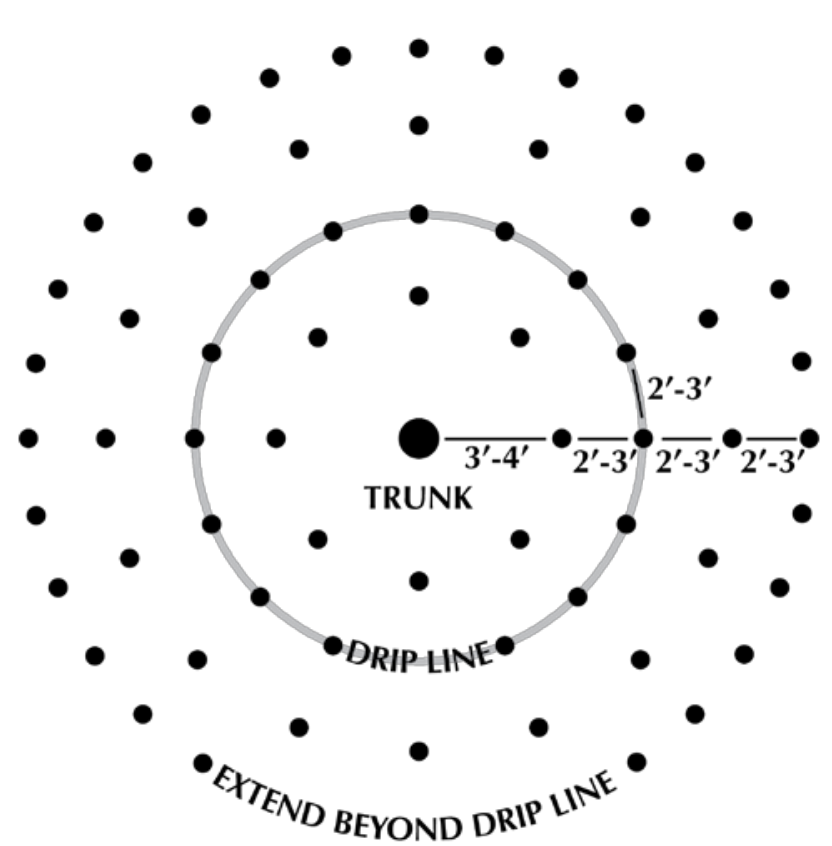

Figure 7.1. Liquid injection drill hole or stake diagram.

slowly, soon after application. This method is very common, but the results can be slow because it takes time for the nutrients to filter into the soil and to the absorbing roots.

4. Fertilizer stakes or spikes. Fertilizer in the form of stakes or spikes, is driven into the soil in a grid pattern similar to that made with liquid injection fertilizer applications. Because lateral fertilizer movement is limited in soil, root system to fertilizer contact is reduced with this method. The general product recommendation of one or two stakes per inch of trunk diameter often does not provide an adequate fertilizer amount or efficient distribution.

5. Foliar spraying. Spraying liquid or water-soluble fertilizer on the foliage is best for correcting deficiencies of minor elements, especially of iron and manganese. Absorption begins within minutes after application, and with most nutrients, it is completed within one to two days. Foliar nutrition can be a supplement at a critical time for the plant but cannot replace soil fertilization. This method should not be used as a means of providing all the nutrients required by plants. Several applications during a growing season may be necessary. This method is generally not practical for large landscape trees.

6. Tree-trunk injection or implants. The infusion of liquid or implants of fertilizer directly to the tree trunk is often the best method for correcting iron and manganese problems in large landscape trees. This method is especially useful in areas of adverse soil $\mathrm{pH}$, high moisture, or where other means of applica- 
tion are not practical. The wounds or holes caused by the injections to the trunk should close within a growing season. Monitoring the wounds until they are healed is recommended to make sure insects or diseases do not become a problem.

\begin{tabular}{|c|c|c|}
\hline $\begin{array}{l}\text { Application } \\
\text { method }\end{array}$ & Advantages & Disadvantages \\
\hline Subsurface & $\begin{array}{l}\text { - Aerates soil. } \\
\text { - Convenient. }\end{array}$ & $\begin{array}{l}\text { - Special fertilizer } \\
\text { and drilling or } \\
\text { soil injection } \\
\text { equipment } \\
\text { needed. } \\
\end{array}$ \\
\hline Foliar sprays & $\begin{array}{l}\text { - Relieves } \\
\text { symptoms of } \\
\text { micronutrient } \\
\text { deficiencies. }\end{array}$ & $\begin{array}{l}\text { - Temporary } \\
\text { benefits. } \\
\text { - Doesn't address } \\
\text { underlying soil } \\
\text { problem. }\end{array}$ \\
\hline $\begin{array}{l}\text { Injection and } \\
\text { implantation }\end{array}$ & $\begin{array}{l}\text { - Relieves } \\
\text { deficiency } \\
\text { symptoms. }\end{array}$ & $\begin{array}{l}\text { - Temporary } \\
\text { benefits. } \\
\text { - Wounds create } \\
\text { entry for insects/ } \\
\text { diseases. }\end{array}$ \\
\hline
\end{tabular}

Source: Virginia Cooperative Extension publication 430-018 (VCE 2009a).

\section{Overfertilization}

Many synthetic fertilizers are salts, much like our familiar table salt, except that they contain various plant nutrients. If the concentration of fertilizer is too high, and if tender plant roots are close to the fertilizer granules, water is drawn from these roots. Plant cells in these roots begin to dehydrate and collapse. The plant roots are "burned" or dried out to a point where they cannot recover. Foliar injury, often in the form of marginal leaf burn, is also a result of too much fertilizer. Newly transplanted ornamentals are under stress while they are trying to adapt to their new location, and they can be easily injured by overfertilization. Reduce fertilizer rates when plants are growing in restricted areas (sidewalk cuts, parking lot islands) or where roots of multiple plants overlap. It is important to apply fertilizer at the proper time and rate.

Overfertilization can cause other problems in addition to plant injury. Avoid getting fertilizer on sidewalks and driveways where it can easily wash into storm drains and, eventually, into creeks, streams, and rivers. Nutrients, particularly nitrogen, become a water quality problem through leaching or run-off.

\section{Specific Fertility Needs}

\section{Annuals and Bedding Plants}

Generally, a slow-release, complete fertilizer at a rate of 2 to 4 pounds of nitrogen per 1,000 square feet is incorporated into the bed at planting time for seasonlong nutrients. Sometimes a liquid or water-soluble fertilizer is applied at $0.5-1.0$ pound of nitrogen per 1,000 square feet at planting to jump-start the annuals until the slow-release fertilizer takes effect. Additional overthe-top fertilizer applications are not recommended because damage can occur to the plants when fertilizer contacts the stems, blooms, or foliage.

\section{Bulbs}

Avoid high-nitrogen fertilizers, which can cause foliage growth at the expense of blooms. A single fall application of 1 to 2 pounds of nitrogen per 1,000 square feet of a slow-release, complete fertilizer incorporated into the bed or planting hole at planting time is best. Several formulations of bulb fertilizer are available, like 9-9-6, $4-10-6,5-10-20$, or 10-10-20. They often go by names like "bulb food," "bulb booster," or "bulb tone." The common formulation 9-9-6 is ideal for most types of bulbs, including garden lilies, tulips, etc. For daffodils, use slow-release $5-10-20$ or 10-10-20, if it is available. A topdressing of well-rotted manure or compost applied in the fall is also beneficial for bulbs (see chapter 9).

\section{Perennials}

Generally, a slow-release, complete fertilizer at a rate of 1 to 4 pounds of nitrogen per 1,000 square feet is incorporated into the bed or planting hole at planting time. If planting in the fall (September through November), use 1 pound of nitrogen incorporated, followed by a second application of 2 to 3 pounds of nitrogen broadcast the following spring (March or April). Always water the bed after applying fertilizer to established plants to wash the fertilizer off the foliage and prevent injury. If planting in the spring, use 3 to 4 pounds of nitrogen per 1,000 square feet incorporated. This should be enough to carry plants through the summer. Do not exceed 4 pounds of nitrogen per 1,000 square feet per year.

\section{Shrubs and Trees}

Generally, a slow-release, complete fertilizer at a rate of 1 to 4 pounds of nitrogen per 1,000 square feet is incorporated into the bed or planting hole at planting time or surface-applied around the canopy edge or drip line 
of the plant. If planting in the fall (September through November), use 1 pound of nitrogen per 1,000 square feet, followed by a second application of 2 to 3 pounds of nitrogen the following spring (March or April).

Additional applications of 2 to 3 pounds of nitrogen can be made each spring for the first three to five years, particularly on young trees to encourage establishment and quick growth. For established shrubs and trees, use 2 to 4 pounds of nitrogen per 1,000 square feet in the spring (March or April), every three years. Do not exceed 4 pounds of nitrogen per 1,000 square feet per year. Trees growing in turf areas will obtain nutrients from the fertilizer that is applied to the turfgrass. Do not apply excess fertilizer to turf in an effort to fertilize trees because injury to the turf may occur.

Some species such as roses (Rosa spp.), red-tip photinia (Photinia x fraseri), and English laurel (Prunus laurocerasus) are more demanding, while others like ornamental grasses, silver maple (Acer saccharinum), willow (Salix spp.), privet (Ligustrum spp.), forsythia (Forsythia spp.), hollies (Ilex spp.), and junipers (Juniperus spp.) require less fertilization. Species like azalea, dogwood, hemlock, and rhododendron have shallow root systems that are easily damaged by fertilizers. Here, split- or low-rate applications of slow-release fertilizers are recommended. A low-rate application (1 pound of nitrogen per 1,000 square feet) may also be appropriate for shrubs and trees under stress, such as from disease, drought, construction, or storm damage.

Plants growing in shade generally require less fertilizer than those growing in the sun, while those growing in sandy soils generally require more frequent fertilization than those in clay soils, due to nutrients leaching from sandy soils. Water-soluble fertilizers should be applied in split applications to minimize leaching potential and, where possible, use slow-release nitrogen sources on sandy soils.

\section{Fertilizer Calculations (See chapter 10.)}

The quantity of fertilizer applied on established ornamentals depends on:

- The analysis of the fertilizer used.

- The area fertilized.

- The amount of growth desired.

Nitrogen controls vegetative growth, so application rates are based on this primary nutrient. Low rates of fertilizer are recommended, particularly for a lower maintenance landscape. As the application rate of fertilizer increases, so does the amount of new growth, which requires more water, more fertilizer, and more pruning.

\section{Area}

To determine how much fertilizer to apply, first measure the area to be fertilized. This involves measuring the length and width of a bed in linear feet and multiplying the two numbers to obtain the square footage. Landscape beds can be addressed individually, or several can be added together for total square footage. Few plant beds are perfectly square or rectangular, so square off the rounded areas to simplify the calculations. See Appendix 7-B, Maryland Cooperative Extension publication, How to Measure Your Yard for additional information ( $w w w$. hgic.umd.edu/_media/documents/hg306.pdf).

Trees growing within a bed can be included in the bed estimate or, if they require special fertilization, estimate their canopy area by measuring the distance from the trunk to the drip line (this is called the radius). Then use the geometric formula for the area of a circle to calculate the area of the canopy $\left(3.14 \mathrm{x}\right.$ radius $\left.^{2}\right)$. For example, if the distance from the main trunk to the drip line of a tree is 20 feet, the area beneath the canopy is $3.14 \times(20 \times 20)=1,256$ square feet. See the guidelines above for additional recommendations on tree fertilization amounts and placement.

\section{Conversions}

To convert from actual amount of nitrogen recommended to amount of fertilizer, divide the amount of nitrogen desired per 1,000 square feet by the fertilizer analysis or grade. For example, if you have an 18-612 fertilizer, how much is needed to apply 3 pounds of nitrogen per 1,000 square feet? Divide 3 pounds of nitrogen by 0.18 ( percentage of nitrogen in fertilizer) to get 17 pounds of fertilizer.

\section{Fertilizer Selection}

Fertilizers differ in nutrient content and release duration. The type of fertilizer selected is based on:

- Cost.

- The types of plants being fertilized.

- The type of growth response desired.

- Time of year.

- Application methods. 
- Equipment cost.

- Proximity to water sources.

- Effect of soil type and $\mathrm{pH}$.

- Type of deficiency.

- The existing nutrient content of the soil.

To determine whether a granular fertilizer has slowrelease properties, check the analysis label. Nitrogen listed in the form of ammoniacal nitrogen indicates that the product probably isn't slow-release. If the nitrogen is listed as being derived from urea, urea-formaldehyde, IBDU (isobutylenediurea), or sulfur-coated urea, the release duration of the product will be increased.
Granular slow-release fertilizers can last from three to twelve months after application.

Other commonly available, slow-release fertilizers on the market include Osmocote granules, Osmocote tablets, Jobe's Spikes, Woodace briquettes, Agriform tablets, and Milorganite. These fertilizers generally cost more per pound than general-purpose granular fertilizers such as $10-10-10$ or 12-4-8, but they also last longer and don't need to be applied as frequently. Organic fertilizer sources such as bone meal, cottonseed meal, and animal manures can also be used. Compost is another good source of slowly available nutrients.

Tables 7.2 - 7.5 will help with fertilizer selection.

\section{Table 7.2. Chemical fertilizers, analysis, speed of reaction, and effect on soil pH.}

\begin{tabular}{lcccc}
\hline Fertilizer & Analysis & $\begin{array}{c}\text { Speed of reaction } \\
\text { and leaching }\end{array}$ & Soil reaction & $\begin{array}{c}\text { Pounds of each } \\
\text { fertilizer required } \\
\text { to get } \mathbf{1} \text { lb N/1,000 } \\
\text { sq ft }\end{array}$ \\
\hline Ammonium nitrate & $33-0-0$ & Rapid & Acidic & 3.0 \\
\hline Ammonium sulfate & $20-0-0$ & Rapid & Very acidic & 5.0 \\
\hline Urea & $46-0-0$ & Rapid & Slightly acidic & 2.0 \\
\hline Ureaformaldehyde & $38-0-0$ & Slow & Slightly acidic & 2.5 \\
\hline Di-ammonium phosphate & $18-46-0$ & Rapid & Acidic & 5.5 \\
\hline Calcium nitrate & $15-0-0$ & Rapid & Alkaline & 6.5 \\
\hline Potassium nitrate & $13-0-44$ & Rapid & Neutral & 7.5 \\
\hline $10-10-10$ & $10-10-10$ & Rapid & Varies with N source & 10.0 \\
\hline Osmocote & $18-6-12$ & Slow & Acidic & 5.5 \\
\hline
\end{tabular}

Source: Virginia Cooperative Extension publication 430-018 (VCE 2009a).

Table 7.3 Average nutrient content of various organic fertilizer sources.

\begin{tabular}{lccc}
\hline Fertilizer source & \% Nitrogen $(\mathbf{N})$ & \% Phosphorus $\left(\mathbf{P}_{\mathbf{2}} \mathbf{O}_{\mathbf{5}}\right)$ & \% Potash $\left(\mathbf{K}_{\mathbf{2}} \mathbf{O}\right)$ \\
\hline Blood, dried & 13.0 & - & - \\
\hline Bone meal, raw & 3.5 & 22.0 & - \\
\hline Bone meal, steamed & 2.0 & 28.0 & - \\
\hline Cottonseed meal & 6.6 & 2.5 & 1.5 \\
\hline Fish scrap, dried & 9.5 & 6.0 & - \\
\hline Soybean meal & 7.0 & 1.2 & 1.5 \\
\hline Horse manure & 0.7 & 0.3 & 0.6 \\
\hline Cow manure & 0.6 & 0.2 & 0.6 \\
\hline Pig manure & 0.5 & 0.3 & 0.5 \\
\hline Sheep manure & 0.8 & 0.3 & 0.9 \\
\hline Chicken manure & 1.1 & 0.8 & 0.5 \\
\hline Duck manure & 0.6 & 1.4 & 0.5
\end{tabular}

Source: Georgia Cooperative Extension bulletin 1065 (2009). 


\section{Table 7.4. Recommended fertilization rates for newly planted ornamental plants during the} first growing season (use only one of the fertilizers listed at the rate recommended).

\begin{tabular}{|c|c|c|c|c|}
\hline \multirow[b]{2}{*}{ Plant type/size } & $12-4-8$ & $16-4-8$ & $10-10-10$ & \multirow{2}{*}{$\begin{array}{l}\text { Application } \\
\text { frequency }\end{array}$} \\
\hline & \multicolumn{3}{|c|}{ Application rate*/plant } & \\
\hline 1-gallon shrubs & 1 tsp & 1 tsp & $1 \mathrm{tbsp}$ & March, May, July \\
\hline 3-gallon shrubs & 2 tsp & 2 tsp & 2 tbsp & March, May, July \\
\hline 5-gallon shrubs & 3 tsp & 3 tsp & 3 tbsp & March, May, July \\
\hline Trees under 4 feet & 1 tbsp & 1 tbsp & 2 tbsp & March, July \\
\hline Trees 4-6 feet & 3 tbsp & 3 tbsp & 5 tbsp & March, July \\
\hline Trees 6-8 feet & 4 tbsp & 4 tbsp & 6 tbsp & March, July \\
\hline \multicolumn{5}{|c|}{ Application rate $100 / \mathrm{sq} \mathrm{ft}$} \\
\hline $\begin{array}{l}\text { Ground covers, } \\
\text { annuals, and } \\
\text { herbaceous } \\
\text { perennials }\end{array}$ & $0.5 \mathrm{lb}$ & $0.5 \mathrm{lb}$ & $1.0 \mathrm{lb}$ & Each 4-6 weeks \\
\hline
\end{tabular}

Source: Georgia Cooperative Extension bulletin 1065 (2009).* When using slow-release or soluble fertilizers, follow label recommendations for application rate.

\section{Table 7.5. Recommended application rates of various general-purpose granular fertilizers on established ornamental plants in the landscape.}

\begin{tabular}{|c|c|c|c|c|c|}
\hline \multirow[b]{3}{*}{ Source } & \multicolumn{5}{|c|}{ Application rate $^{\mathrm{a}}$} \\
\hline & \multicolumn{2}{|c|}{$1,000 \mathrm{sq} \mathrm{ft}$} & \multicolumn{2}{|c|}{$100 \mathrm{sq} f t$} & \multirow{2}{*}{$\begin{array}{c}10 \mathrm{sq} f t \\
\text { Tablespoons }\end{array}$} \\
\hline & Pounds & Cups & Pounds & Cups & \\
\hline 10-10-10 & 10.0 & 20.0 & 1.0 & 2.0 & 4.0 \\
\hline 8-8-8 & 12.5 & 25.0 & 0.5 & 2.5 & 5.0 \\
\hline 13-13-13 & 6.0 & 12.0 & 0.75 & 1.5 & 3.0 \\
\hline $12-3-6$ & 6.0 & 12.0 & 0.75 & 1.5 & 3.0 \\
\hline $12-4-8$ & 6.0 & 12.0 & 0.75 & 1.5 & 3.0 \\
\hline $12-6-6$ & 6.0 & 12.0 & 0.75 & 1.5 & 3.0 \\
\hline $16-4-8$ & 6.0 & 12.0 & 0.5 & 1.0 & 2.0 \\
\hline $4-12-12$ & 25.0 & 50.0 & 2.5 & 5.0 & 10.0 \\
\hline $5-10-10$ & 20.0 & 40.0 & 2.0 & 4.0 & 8.0 \\
\hline
\end{tabular}

Source: Georgia Cooperative Extension bulletin 1065 (2009).

aThis rate will supply 1 pound of actual nitrogen per 1,000 square feet. For optimum growth of young shrubs, ground covers, and trees, three to five applications are recommended at six- to 10-week intervals from March to August. Application frequency varies with the amount of slow-release nitrogen in the product, so consult the label for specific recommendations. Established trees and shrubs will benefit from one to two applications during the growing season. Annual flowers and roses should receive applications at four- to six-week intervals from March to August. When using slow-release or specialty fertilizers, follow the manufacturer's recommendation on the container. 


\section{Organic and Other Soil Amendments (See chapter 9.)}

Amendments can improve soil structure, drainage, and nutrient-holding capacity, making the soil a more favorable place for root development and nutrient uptake. Soil improvement or building is a continual process in the landscape. The regular addition of manures, compost, cover crops, other organic matter, and amendments can raise the soil nutrient level to a point where the addition of synthetic fertilizers is greatly reduced, and in some cases, no longer needed. This highly desirable soil quality does not come about with a single or even several additions of organic material, but rather requires a serious, long-term program.

\section{Nutrient Deficiencies}

Each of the 17 essential elements has a specific role in plant growth. A deficiency or an excess of any one will impair plant growth until the problem is corrected. Iron and manganese are the micronutrients most often deficient in landscape plants. An adjustment in soil pH usually corrects deficiencies of the micronutrients. Some symptoms of nutrient deficiency in woody plants are listed below (North Carolina Cooperative Extension Service 1996).

\begin{tabular}{|c|c|}
\hline Element & Foliar deficiency symptoms \\
\hline Nitrogen $(\mathrm{N})$ & $\begin{array}{l}\text { - General yellowish-green; more severe on older leaves. } \\
\text { - Stunted growth with small and fewer leaflets. } \\
\text { - Early leaf drop. } \\
\text { - Dark green to blue-green; slightly smaller leaves. } \\
\text { - Veins, petioles, or lower surface may become reddish-purple, especially when young. } \\
\text { - Death of lower needles in pines. }\end{array}$ \\
\hline Potassium (K) & $\begin{array}{l}\text { - Partial chlorosis of most recently matured leaves in interveinal area beginning at tips, } \\
\text { followed by necrosis. } \\
\text { - Older leaves may become brown and curl downward. }\end{array}$ \\
\hline Calcium (Ca) & $\begin{array}{l}\text { - Death of terminal buds. } \\
\text { - Tip die-back. } \\
\text { - Chlorosis of young leaves. } \\
\text { - Leaves may become hard and stiff. } \\
\text { - Root injury is the first apparent symptom. }\end{array}$ \\
\hline Magnesium (Mg) & $\begin{array}{l}\text { - Marginal chlorosis on older leaves, followed by interveinal chlorosis. } \\
\text { - Margins may become brittle and curl upward. }\end{array}$ \\
\hline Sulfur (S) & $\begin{array}{l}\text { - Uniform chlorosis of new leaves. } \\
\text { - Older leaves are usually not affected. }\end{array}$ \\
\hline Iron (Fe) & $\begin{array}{l}\text { - Interveinal chlorosis of young leaves (sharp distinction between green veins and yellow } \\
\text { tissue between veins). } \\
\text { - Older basal leaves greener, exposed leaves blanched. }\end{array}$ \\
\hline Manganese (Mn) & $\begin{array}{l}\text { - Interveinal chlorosis of young leaves beginning at margins and progressing toward midribs, } \\
\text { followed by necrotic spots. }\end{array}$ \\
\hline Zinc $(Z n)$ & $\begin{array}{l}\text { - Young leaves may be yellow, small, deformed, or mottled with necrotic spots. } \\
\text { - May be a tuft of leaves at shoot tips. }\end{array}$ \\
\hline Boron (B) & $\begin{array}{l}\text { - Terminal growth dies; later growth that develops has sparse foliage. } \\
\text { - Young leaves may be red, bronzed, or scorched. } \\
\text { - Leaves may be small, thick, distorted, or brittle. }\end{array}$ \\
\hline Copper (Cu) & $\begin{array}{l}\text { - Rosetting of foliage, terminal growth may die. } \\
\text { - Leaf symptoms not usually pronounced, but veins may be lighter than blades. }\end{array}$ \\
\hline Molybdenum (Mo) & $\begin{array}{l}\text { - Cupping of the older leaves. } \\
\text { - Marginal chlorosis followed by interveinal chlorosis. }\end{array}$ \\
\hline
\end{tabular}




\section{Literature Cited}

Georgia Cooperative Extension. 2009. Care of Ornamental Plants in the Landscape. Bulletin 1065. www.caes. uga.edu/publications/pubDetail.cfm?pk_id $=6180$.

Maryland Cooperative Extension. 2009. How to Measure Your Yard. Home and Garden Mimeo No. HG 306. www.hgic.umd.edu/_media/documents/publications/measure yard.pdf.

North Carolina Cooperative Extension Service. 1996. Fertilizer Recommendations and Techniques to Maintain Landscapes and Protect Water Quality. Publication No. AG-508-5. www.bae.ncsu.edu/bael programs/extension/publicat/wqwm/wqwm 127. html.

Virginia Cooperative Extension. 2009a. Fertilizing Landscape Trees and Shrubs. VCE Publication 430-018. http://pubs.ext.vt.edu/430/430-018/430018.html.

Virginia Cooperative Extension. 2009b. Tree and Shrub Planting Guidelines. VCE Publication 430-295. http://pubs.ext.vt.edu/430/430-295/430-295.pdf. 



\title{
Appendix 7-A
}

Original publication available at: $h t t p: / / p u b s . e x t . v t . e d u / 430 / 430-295 / 430-295 . h t m l$

\section{Virginia Cooperative Extension}

\section{Tree and Shrub Planting Guidelines}

\author{
Susan French, Extension Technician, AREC, Hampton Roads; Virginia Tech
}

\section{Plant and Site Selection}

Select trees and shrubs well-adapted to conditions of individual planting sites. Poorly-sited plants are doomed from the start, no matter how carefully they're planted.

Test soil drainage before planting. Dig a test hole as deep as your planting hole and fill with water. If water drains at a rate of less than one inch per hour, consider installing drainage to carry water away from the planting hole base, or moving or raising the planting site (berm construction).

Also consider using more water-tolerant species. For trees, try red maple, sycamore, bald cypress, willow oak, or river birch. For shrubs, try inkberry, redtwig dogwood and buttonbush. Avoid dogwoods, azaleas, boxwoods, Japanese hollies, and other plants that don't like "wet feet" where drainage is poor.

Examine soil for compaction before planting. If soils are compacted, consider replacement with a good loam soil, or incorporation of several inches of an organic material such as composted yard waste to a depth of at least 8 inches over the entire planting area. Do not incorporate small quantities of sand - compaction will increase and drainage decrease.

\section{Site Preparation}

Dig shallow planting holes two to three times as wide as the root ball. Wide, shallow holes encourage horizontal root growth that trees and shrubs naturally produce.

In well-drained soil, dig holes as deep as the root ball. In poorly-drained heavy clay soil, dig holes one to two inches shallower than the root ball. Cover the exposed root ball top with mulch.

Don't dig holes deeper than root balls or put loose soil beneath roots because loose soil will compact over time, leaving trees and shrubs planted too deep. Widen holes near the soil surface where most root growth occurs. Score walls of machine-dug (auger, backhoe) holes to prevent glazing.

Backfill holes with existing unamended soil. Do not incorporate organic matter such as peatmoss into backfill for individual planting holes. Differences in soil pore sizes will be created causing problems with water movement and root growth between the root ball, planting hole, and surrounding soil.

Backfill half the soil, then water thoroughly to settle out air pockets. Finish backfilling, then water again. Cover any exposed root ball tops with mulch.

Incorporate slow-release granular fertilizers into backfill soil to provide nitrogen, or if a soil test indicates a need for phosphorus or potassium. Avoid using fast-release agronomic fertilizers that can dehydrate tree roots. Use no more than $1 \#$ actual nitrogen per 1,000 ft. of planting hole surface. (Example - if using 18-6-12 with a 5 ' diameter hole, incorporate 0.3 oz. per planting hole.)

\section{Tree and Shrub Preparation}

Closely inspect the wrapping around root balls of B\&B (balled and burlapped) trees and shrubs. Growers use many synthetic materials, as well as burlap treated to retard degradation, to wrap root balls. Many of these materials will not degrade. To insure root growth into surrounding soil, remove pinning nails or rope lacing, then cut away or drop the wrapping material to the bottom of the planting hole, backfilling over it.

Wire baskets used to protect root balls degrade very slowly underground. Remove the top 8-12 inches of wire to keep equipment from getting caught in wire loops, and surface roots from girdling.

Remove all rope, whether jute or nylon, from trunks. Again, degradation is slow or nonexistent, and ropes can girdle trunks and roots.

Remove plastic containers from container-grown trees and shrubs. For plants in fiber pots, break away the top or remove the pot entirely. Many fiber pots are coated to extend their shelf life, but this slows degradation below ground and retards root extension.

If roots are circling around the root ball exterior, cut through the roots in a few places. Cutting helps prevent circling roots from eventually girdling the trunk. Select trees grown in containers with vertical ribs or a copper-treatment on the interior container wall. These container modifications and treatments minimize circling root formation.

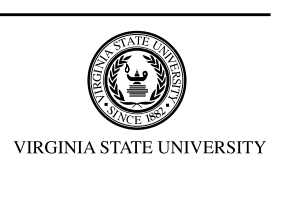




\section{Tree Care After Planting}

Remove tags and labels from trees and shrubs to prevent girdling branches and trunks.

Good follow-up watering helps promote root growth. Drip irrigation systems and water reservoir devices can facilitate watering.

Mulch, but don't over mulch newly planted trees and shrubs. Two to three inches of mulch is best - less if a fine material, more if coarse. Use either organic mulches (shredded or chunk pine bark, pine straw, composts) or inorganic mulches (volcanic and river rocks).

Keep mulch from touching tree trunks and shrub stems. This prevents disease and rodent problems if using organic mulches, and bark abrasion if using inorganic mulches.

Don't use black plastic beneath mulch around trees and shrubs because it blocks air and water exchange. For added weed control, use landscape fabrics that resist weed root penetration. Apply only one to two inches of mulch atop fabrics to prevent weeds from growing in the mulch.
Only stake trees with large crowns, or those situated on windy sites or where people may push them over. Stake for a maximum of one year. Allow trees a slight amount of flex rather than holding them rigidly in place. Use guying or attaching material that won't damage the bark. To prevent trunk girdling, remove all guying material after one year.

Most trees should not have their trunks wrapped. Wrapping often increases insect, disease, and water damage to trunks. Thin-barked trees planted in spring or summer into hot or paved areas may benefit from wrapping if a white wrap is used. To avoid trunk girdling, do not attach wraps with wire, nylon rope, plastic ties, or electrical tape. If wraps must be used, remove within one year.

For protection against animal or equipment damage, install guards to protect the trunk. Be sure the guards are loosefitting and permit air circulation.

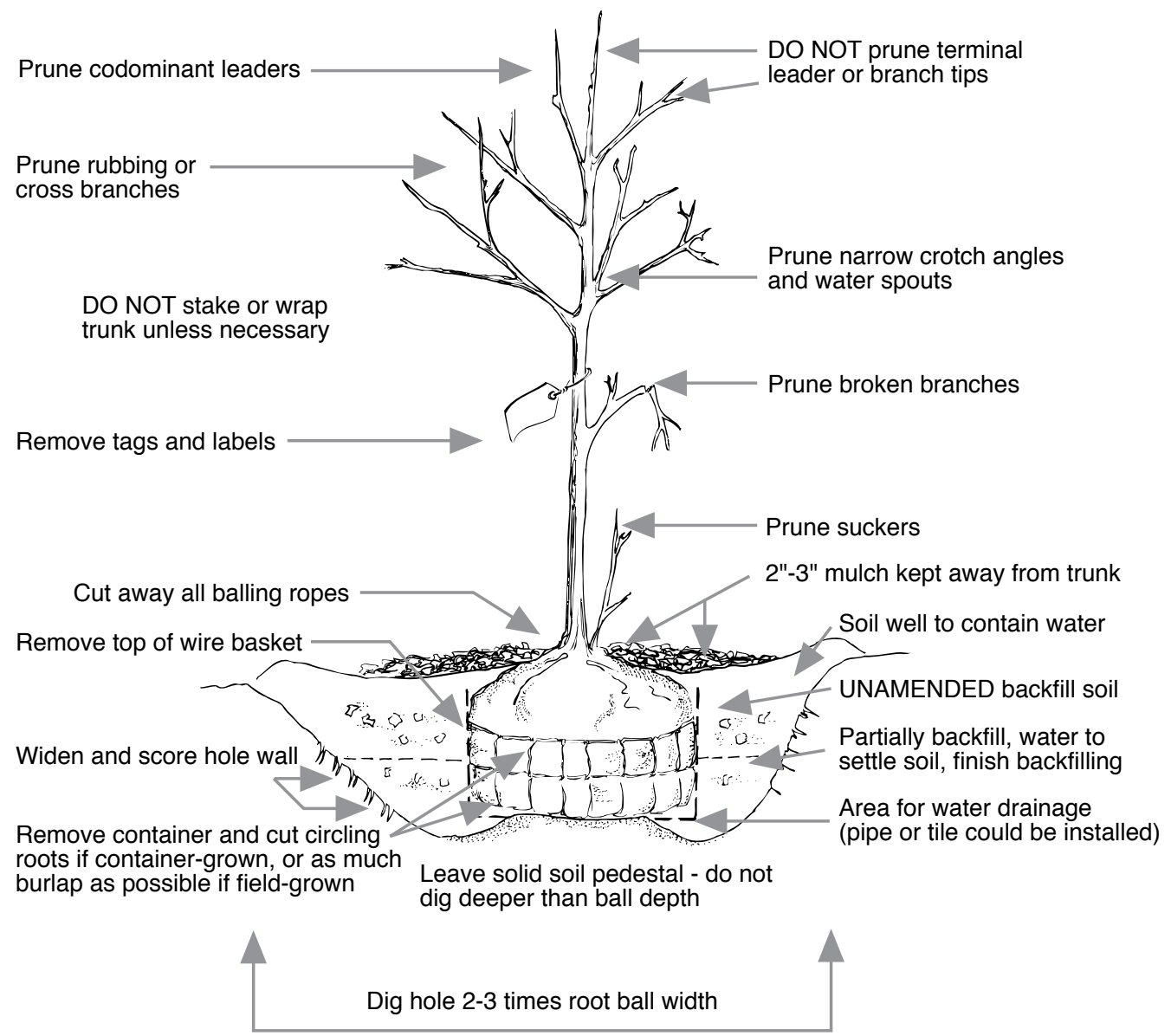




\section{Appendix 7-B}

Original PDF file available at: http://www.hgic.umd.edu/_media/documents/hg306.pdf

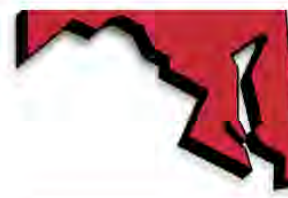

MARYLAND

COOPERATIVE

EXTENSION

UNIVERSITY OF MARYLAND

COLLEGE PARK • EASTERN SHORE

HOME AND GARDEN INFORMATION CENTER • 12005 HOMEWOOD ROAD • ELLICOTT CITY, MD 21042 • 1-800-342-2507

Home \& Garden Mimeo \# HG 306

\section{How to Measure Your Yard}

To apply the correct amount of fertilizer on your lawn, you need to know its surface area.

First, determine the total area of your property. Second, subtract the areas not to be fertilized. The remaining square footage is the number needed to determine how much fertilizer is needed. (See Figure 1)

Total lot:

Lot, $125^{\prime} \times 100$ '

$=12,500$ sq. ft.

Subtract:

$$
\begin{array}{ll}
\text { House, } 44^{\prime} \times 26^{\prime} & =1,144 \text { sq. ft. } \\
\text { Deck, 12' } \times 12^{\prime} & =144 \text { sq. ft. } \\
\text { Drive, 40' } \times 10^{\prime} & =400 \text { sq. ft. } \\
\text { Garden, 25' } \text { x } 15^{\prime} & =375 \text { sq. ft. } \\
\text { Walk, 4' } \times 20^{\prime} & =80 \text { sq. ft. }
\end{array}
$$

Total to subtract

Remainder: Yard

$=2,143$ sq. ft.

$=10,357$ sq. $\mathrm{ft}$.

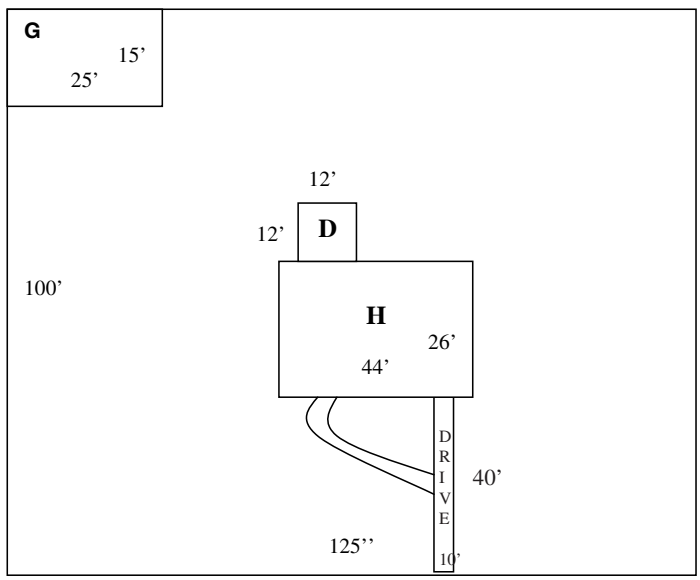

Figure 1.
How to determine the square footage of some familiar shapes

\section{Squares, rectangles}

Area $=$ Length $\mathrm{x}$ width

Length $=50^{\prime}$

Width $=30^{\prime}$

Area: $50^{\prime}$ x $30^{\prime}=1,500$ sq. ft.

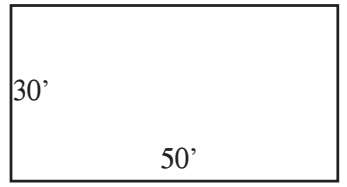

\section{Triangles}

Area $=.5 \times$ base $\mathrm{x}$ height

Base $=40$

Height $=80^{\prime}$

Area: $.5 \times 40^{\prime}$ x $80^{\prime}=1,600$ sq. ft.

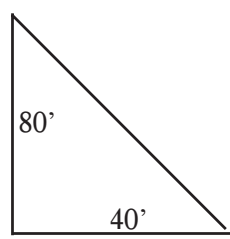

Circles

Area $=Đ \times$ r $^{2}$

$(\mathrm{D}=3.14)$

$\mathrm{r}$ (radius) $=20$

Area; 3.14 x $\left(20^{\prime}\right.$ x $\left.20^{\prime}\right)=1,256$ sq. ft.

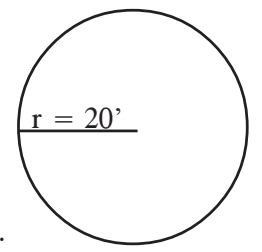





\title{
Chapter 8. Fertilizer and Lime Sources for Turf and Landscapes
}

\author{
Mike Goatley Jr., Professor and Extension Specialist, Crop and Soil Environmental Sciences, Virginia Tech
} Steven Hodges, Professor, Crop and Soil Environmental Sciences, Virginia Tech

\section{Introduction}

Soil or tissue test results provide the basis for fertility programs in the management of turf and landscape materials. A standard soil test (described in chapter 5) provides information on soil $\mathrm{pH}$ and the levels of the macronutrients phosphorus $(\mathrm{P})$, potassium $(\mathrm{K})$, calcium $(\mathrm{Ca})$, and magnesium $(\mathrm{Mg})$. The test will also likely provide levels of the micronutrients iron $(\mathrm{Fe})$, zinc $(\mathrm{Zn})$, copper $(\mathrm{Cu})$, and boron (B). Missing from soil test results by nature of its constant fluctuations from plantavailable to -unavailable forms and back is nitrogen (N). However, depending on the plant material being grown, the soil test will provide a recommendation for nitrogen levels and timing of application.

\section{Defining Fertilizers}

State regulatory agencies ensure the integrity of fertilizer sources. For example, in Virginia, the Office of Product and Industry Standards in the Department of Agriculture and Consumer Services analyzes samples of fertilizer and agricultural lime sources to ensure that labeling guarantees are met and that the product is safe for the environment. A labeled fertilizer has five criteria that must be met: brand, grade, guaranteed analysis, net weight, and name and address of the registrant and licensee (figure 8.1). This information applies whether the source is in liquid or granular form.

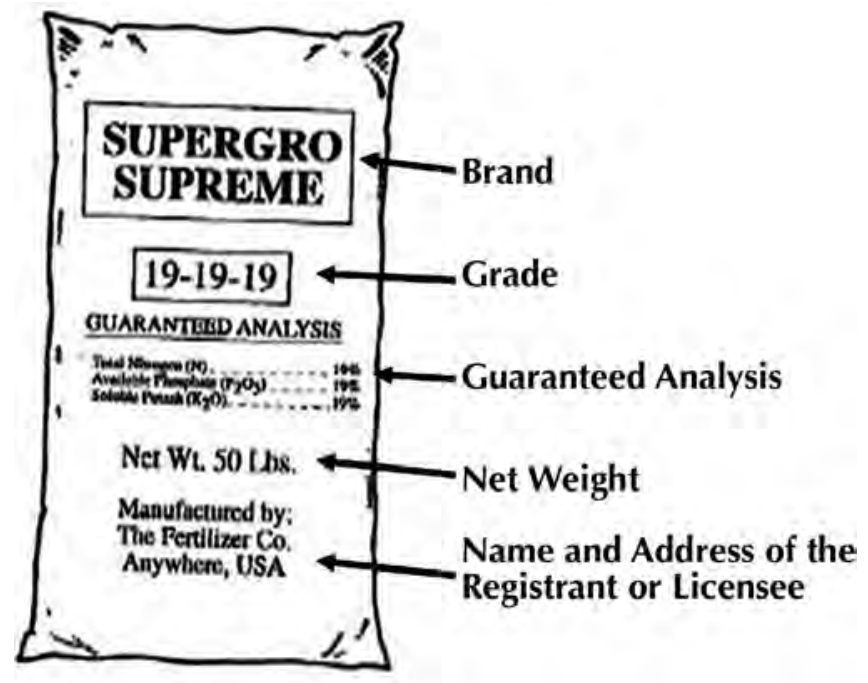

Figure 8.1. The five components required on a fertilizer label.
The information of most importance to end users in fertilizer selection is usually the grade (e.g., 19-19-19) and the guaranteed analysis. The grade presents the percentages by weight of nitrogen, phosphate $\left(\mathrm{P}_{2} \mathrm{O}_{5}\right)$, and potash $\left(\mathrm{K}_{2} \mathrm{O}\right)$. Note that the grade is not nitrogen, phosphorus, and potassium; the percentages of the actual (or elemental) phosphorus and potassium nutrients can be determined by multiplying the $\mathrm{P}_{2} \mathrm{O}_{5}$ level by a constant of 0.44 , and the $\mathrm{K}_{2} \mathrm{O}$ level by 0.83 . While most soil test recommendations for these nutrients will be provided in units of $\mathrm{P}_{2} \mathrm{O}_{5}$ and $\mathrm{K}_{2} \mathrm{O}$ per 1,000 square feet, sometimes levels are given in pounds of the actual nutrient instead. The guaranteed analysis will detail all nutrients in the product (in addition to nitrogen, phosphate, and potash) on a percentage-by-weight basis. These rules apply regardless of whether the product is a granular or liquid material.

Another common way of defining fertilizers is to classify them as either inorganic or organic. By definition, "organic" fertilizers contain carbon, and those defined as "inorganic" contain no carbon. Strictly following these definitions reveals that an organic fertilizer source may be composed of naturally occurring animal or plant byproducts/waste materials or synthetic products such as urea and any urea-based compound (ureaformaldehyde, methylene urea, isobutyraldehyde urea, etc.). This distinction is very important in both defining and developing what are commonly referred to as "organic fertilizer programs." In almost all instances where organic fertilizer programs are desirable, the intent for the program is very likely to be the utilization of "naturally occurring" organic sources and not the synthetic organic products.

At this time, the U.S. Department of Agriculture (USDA) does not offer specifications on what defines a "certified organic program" in turfgrass management as it does for crop production programs. The Northeast Organic Farming Association of Connecticut (www. ctnofa.org) offers a program that certifies organic lawn care practitioners but not their programs. This program might be of interest for lawn care managers interested in defining their overall fertility, cultural, and pest management programs as "organic." 
Other ways of describing fertilizers include those defined as complete or incomplete and balanced or unbalanced sources. There are a host of possibilities in developing various analyses of fertilizer sources in terms of nutrient content.

"Complete" fertilizers contain some level each of nitrogen, phosphate, and phosphate, while "incomplete" fertilizers are designed to address only one or two specific nutrient needs $(45-0-0,0-20-0,0-0-50$, and $18-46-0$ are all examples of incomplete fertilizers).

A "balanced" fertilizer contains equal amounts of nitrogen, phosphate, and potash (products such as 8-8-8, 10-10-10, or 19-19-19 and so forth). Often, balanced fertilizers are referred to as "garden fertilizers" because they are traditionally used in gardening applications and the plants respond to the additional phosphate and potassium in order to optimize bloom or fruit yield. An "unbalanced" fertilizer will have varying levels of nutrients (analyses such as 29-3-7 are common in many turf-specific products). Unbalanced fertilizers are very common in turfgrass management programs because nitrogen is the focal point of seasonal fertility programs. Additional $\mathrm{P}_{2} \mathrm{O}_{5}$ and $\mathrm{K}_{2} \mathrm{O}$ are often not needed and their applications should be based on soil testing, particularly phosphate, because misapplication and overapplication are possible concerns for water quality. Other unbalanced fertilizers are developed for specific uses. Consider the classic "starter" fertilizers, such as 5-1510 (discussed further in chapter 6). Sources that emphasize $\mathrm{P}_{2} \mathrm{O}_{5}$ are ideal for establishing plants because they provide an additional boost of phosphorus that can be important for the developing root system.

\section{Nitrogen Sources}

Nitrogen sources are frequently categorized according to their water solubility, which will be detailed in this chapter as "readily available" and "slowly available." A fertilizer label must state the percentage of total nitrogen as well as the varying percentages of water-soluble and slowly available nitrogen (SAN). Slowly available nitrogen can also be identified as water-insoluble nitrogen (WIN) or controlled-release nitrogen (CRN), depending on the nitrogen source. If there is no detail regarding SAN, WIN, or CRN, it is assumed that all nitrogen is water-soluble.

Because turf and landscape plant materials are usually not being grown for yield (the exception being sod and container/field landscape production systems) and are confined to relatively small land areas as compared to row crop production systems, slowly available nitrogen sources often provide sensible management, cost, and environmental advantages to readily available nitrogen sources. It is important to understand that all nitrogen sources will gradually lower soil $\mathrm{pH}$. However, readily available nitrogen sources will drop $\mathrm{pH}$ much more quickly than slowly available nitrogen sources - a management point that needs to be addressed by soil testing. Each source has different strengths and weaknesses.

\section{Readily Available Nitrogen}

Readily available sources are also referred to as "watersoluble," "quick-release," or "fast-acting" to designate how quickly they become available following application. The rapid conversion of the fertilizer to the plant-available forms of ammonium $\left(\mathrm{NH}_{4}^{+}\right)$and nitrate $\left(\mathrm{NO}_{3}{ }^{-}\right)$is why they provide such a quick growth and color response. As described previously regarding soil test information for nitrogen, these forms are readily transformed by chemical and microbial processes into plant-unavailable forms as well.

Readily available sources are less expensive than slowly available sources of nitrogen and can be applied as either liquid or dry formulations. Light and frequent applications of 0.25 to 0.50 pound of nitrogen per 1,000 square feet are desirable, but up to 1 pound of nitrogen per 1,000 square feet in a single application is suitable. The level and frequency of the application typically depends on the grass being grown, its intended use, the soil, and the climate (detailed in chapters 6 and 7).

In order to optimize nutrient utilization by the turf, reduce potential injury due to their high salt concentrations, and lessen potential environmental impact from nutrient leaching (especially the highly leachable nitrate), an increased frequency of application at lower levels is often desirable. Excessive salt accumulations in the soil can damage roots and/or reduce their function; however, because most areas of the mid-Atlantic receive periodic rainfall, concerns about salt accumulations in the soil from quickly available fertilizers are limited. The primary concern with turf damage from quickly available, high-salt-content fertilizers is the potential for "foliar burn" caused by tissue desiccation. In this scenario, the water-soluble, typically high-saltcontent fertilizer that remains on the turfgrass leaves actually attracts water from the cells of the plant; this causes cell and leaf tissue desiccation in localized areas, resulting in the visual foliar burn. 
Some of the most common forms of inorganic, readily available nitrogen sources used in turf and landscape management are ammonium nitrate, ammonium sulfate, potassium nitrate, calcium nitrate, diammonium phosphate, and monoammonium phosphate. The sources with the highest water solubilities (ammonium nitrate, urea, and ammonium sulfate) are often dissolved in water and are foliar-applied. The water solubilities and salt indices for these sources are provided in table 8.1.

\section{Table 8.1. The grade, salt index, and water solubility of the most common, readily available nitrogen sources used in turf and landscape management fertility programs (after Turgeon 1985).}

\begin{tabular}{|c|c|c|c|}
\hline Fertilizer & Grade & Salt index ${ }^{a}$ & $\begin{array}{c}\text { Water } \\
\text { solubility }^{b} \\
{[\mathrm{~g} / \mathrm{l}(\mathrm{lb} / \mathrm{gal})]}\end{array}$ \\
\hline $\begin{array}{l}\text { Ammonium } \\
\text { nitrate }\end{array}$ & $34-0-0$ & 3.2 & $1810(15.0)$ \\
\hline $\begin{array}{l}\text { Ammonium } \\
\text { sulfate }\end{array}$ & $21-0-0$ & 3.3 & $710(5.9)$ \\
\hline Potassium nitrate & $13-0-44$ & 5.3 & $130(1.1)$ \\
\hline $\begin{array}{l}\text { Monoammonium } \\
\text { phosphate }\end{array}$ & $11-48-0$ & 2.7 & $230(1.9)$ \\
\hline $\begin{array}{l}\text { Diammonium } \\
\text { phosphate }\end{array}$ & $20-50-0$ & 1.7 & $430(3.6)$ \\
\hline Urea & $45-0-0$ & 1.7 & $780(6.5)$ \\
\hline \multicolumn{4}{|c|}{$\begin{array}{l}\text { a The salt index scale is: }<1.0=\text { low, } 1.0 \text { to } 2.5=\text { moderate, and } \\
>2.5=\text { high. }\end{array}$} \\
\hline \multicolumn{4}{|c|}{$\begin{array}{l}{ }^{\text {b }} \text { Water solubility expressed in grams per liter (pounds per gallon in } \\
\text { parentheses). }\end{array}$} \\
\hline
\end{tabular}

Ammonium nitrate is the most soluble of the quickly available nitrogen sources, providing the fastest growth and color response potential due to its rapid conversion to plant-available ammonium and nitrate. Its high water solubility also means it has the greatest potential for foliar burn and leaching. Ammonium nitrate supplies for the turf and landscape market are restricted because it may also be used as a strong oxidizing agent for explosives.

Ammonium sulfate is significantly less water-soluble than ammonium nitrate and was a popular alternative to ammonium nitrate in professional lawn care management long before supplies of ammonium nitrate dwindled. This source provides a rapid growth and color response from two macronutrients - nitrogen and sulfur. Its lower water solubility is advantageous, particularly for lawn applicators who ask their hom- eowner clientele to water the applied fertilizer into the soil but recognize that this simply does not happen soon enough to minimize foliar burn potential. Due to its high sulfur content ( 24 percent) and the fact that all nitrogen is in the ammoniacal form, ammonium sulfate causes the quickest decline in soil $\mathrm{pH}$.

Potassium nitrate is a popular lawn and landscape fertilizer due to its combination of nitrogen and potassium nutrients. This source is frequently used in spring and fall applications as a treatment to increase potassium levels in plant material. Potassium - the second-highest nutrient content in plant tissues that is typically supplemented by fertilizer applications - regulates water movement into and out of cells. Its function is often described as the "summer coolant" and "winter antifreeze" of plants due to its ability to improve environmental stress tolerance. Its low water solubility results in much less foliar burn and leaching potential, but it is also difficult to dissolve and apply as a liquid.

Monoammonium phosphate (commonly called MAP) and diammonium phosphate (DAP) are popular sources for preparing blended fertilizers, but they also are used in turf and landscape applications, particularly for establishment situations. DAP has the greater water solubility of the two, but even its water solubility is so low that it is not a concern for fertilizer burn.

Urea has the unique property of being a synthetic organic (i.e., carbon-containing) source with a low salt index. Urea is available in granular and prilled forms that have the same chemical composition, but the granular forms are larger and harder while the prilled forms are softer and easier to blend with other fertilizers. Due to the high nitrogen content and water solubility, urea is often sprayed on turf provided there is adequate moisture available following application. In the presence of the enzyme "urease" (commonly present on leaves and dead plant residues), urea is rapidly converted to ammonium-nitrogen. Some volatile losses may occur under windy or hot, dry conditions if not watered into the soil. Approximately 60 percent will be converted the first day, with the remainder converted within a week. There is ongoing interest in ways to improve nitrogenuse efficiency of quickly available urea.

Row-crop production systems have had a great deal of research devoted to chemical additives with the urea that reduces the rate of its conversion to plant-available nitrogen (nitrification inhibitors) or gaseous loss (volatilization). The additives are extremely effective in the laboratory setting, but their levels of effectiveness in 
the field are variable and the factors affecting response not yet clearly understood. Research in this area continues in order to better understand chemical approaches to improve the nitrogen-use efficiency of urea. While these products affect the rate of conversion to plantavailable nitrogen, they do not alter the water solubility of the urea, and they are still defined as readily available nitrogen sources.

\section{Slowly Available Nitrogen}

A unique aspect of nitrogen fertilization programs in turf and ornamental management is the use of a vast array of slowly available nitrogen sources that provide very controlled growth and color responses, along with inherent environmental advantages due to the slowrelease characteristics. Their use in turf and ornamental systems is typically more economically viable than in production agriculture systems because "yield" is generally not a consideration (except in sod or nursery production systems) and quality, appearance, and playability (in the case of turf) are the driving factors in management programs. The incremental release characteristics of these materials are particularly valuable in turfgrass systems with completely modified, sand-

\section{Table 8.2. A list of slowly available nitrogen ${ }^{a}$ (SAN) sources, their typical chemical analyses, and general comments regarding the source.}

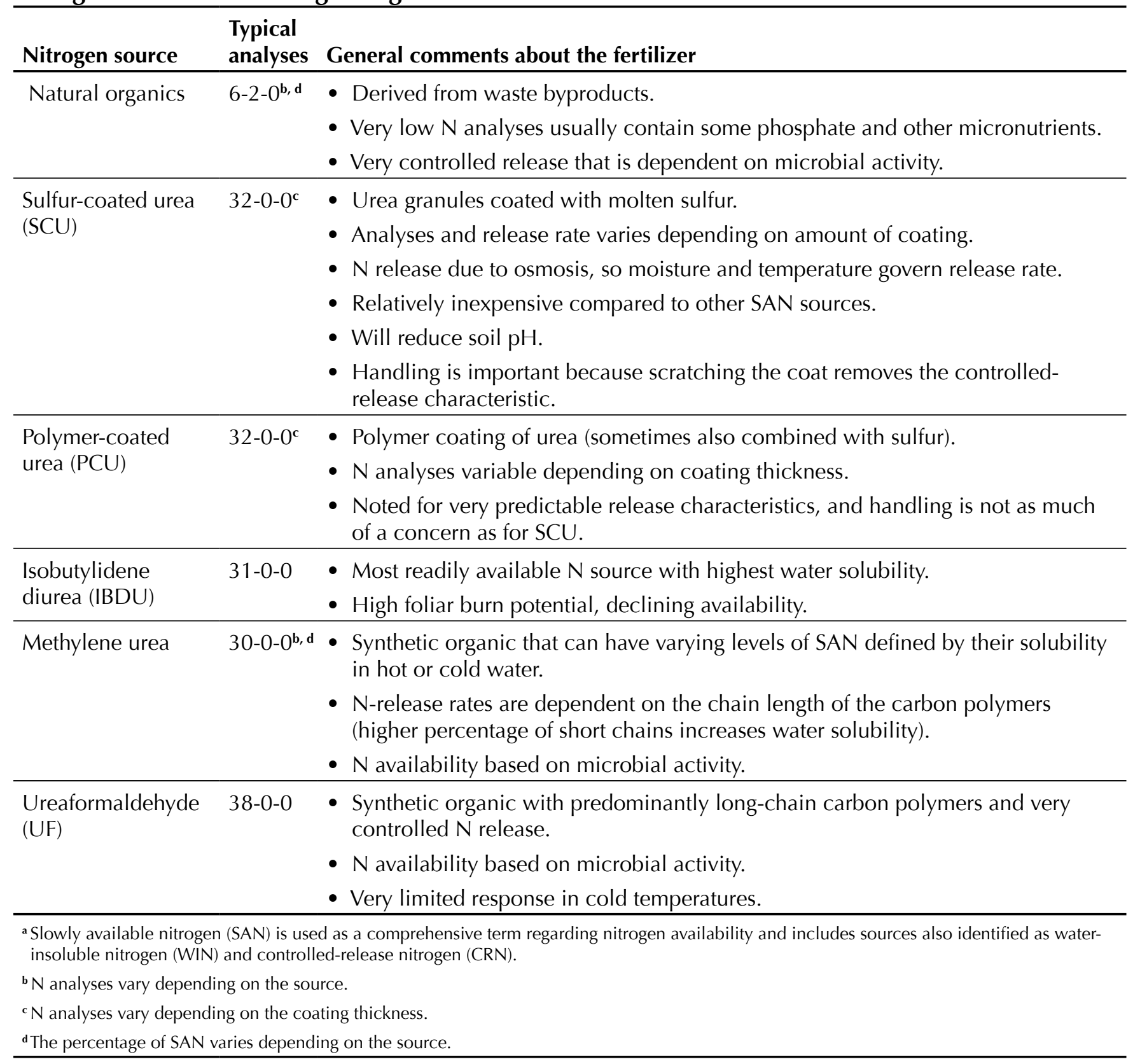


based soils (e.g., sand-based golf greens, tees, and athletic fields) that possess inherently low cation exchange capacities (CEC; discussed in chapter 2) and high nitrogen leaching potential.

Slowly available sources of nitrogen are also referred to as water-insoluble, controlled-release, slow-release, and slow-acting to designate their ability to meter out nitrogen over a certain length of time, similar to timedrelease cold capsules. Using the Virginia Department of Conservation and Recreation's (VDCR 2005) Nutrient Management Training and Certification Regulations 4 VAC 5-15 criteria, SAN is defined as "nitrogen sources that have delayed plant availability involving compounds that dissolve slowly, materials that must be microbially decomposed, or soluble compounds coated with substances highly impermeable to water such as polymer-coated products, methylene urea, isobutylidene diurea (IBDU), urea formaldehyde based (UF), sulfur (S)-coated urea, and natural organics."

Slowly available nitrogen sources provide a sustained growth and color response that lasts for weeks to months rather than providing a quick surge in growth and greening response. Slowly available nitrogen sources also have a very low salt index; hence, they do not contribute to a buildup of soluble salts in the soil that might affect root system development. These sources also have minimal foliar burn potential. Because of the added steps involved in their production, they are typically more expensive than quick-release fertilizers.

The primary SAN sources used in turf management systems and a further description of the products are listed in table 8.2.

\section{Natural Organic}

These fertilizer sources are byproducts of plant and animal industries or waste products such as municipal sewage sludge; hoof, horn, seed, bone, and feather meal; and chicken and cow manures, among others. They can be categorized by their low (typically less than 10 percent) nitrogen content and the presence of mostly water-insoluble nitrogen. They are highly dependent on microbial activity for breakdown and release of nitrogen. For this reason, neutral $\mathrm{pH}$, adequate moisture and oxygen, and temperatures above 55 degrees Fahrenheit enhance release.

A specialty organic product that also has activity as a pre-emergent herbicide is corn gluten. This product — approximately 8 percent nitrogen by weight - is applied on the basis of its pre-emergent herbicide activ- ity and delivers approximately 1 pound of nitrogen per 1,000 square feet. It is an extremely effective, broadspectrum herbicide but is relatively short-lived in its weed control activity.

\section{Ureaform and Methylene Urea}

Ureaformaldehyde is made by reacting urea with formaldehyde to produce nitrogen fertilizers that vary in release rate. UF products, like natural organic fertilizers, are dependent on microbial activity and subject to similar environmental conditions. Defining these products can become quite technical, but the information has value in making an informed decision regarding the selection of these very specialized SAN sources.

The term "water-insoluble nitrogen" (WIN) found on fertilizer bags containing UF refers to the amount of coldwater-insoluble nitrogen (CWIN) and hot-water-insoluble nitrogen (HWIN) present in the bag. Both CWIN and HWIN represent the slow-release portion of the fertilizer. The CWIN typically releases over several months while the HWIN can continue to release at a slower rate over several years. Products with the same WIN value can differ in the amount of CWIN and HWIN present, which in turn determines their release characteristics.

The activity index (AI) can be used to distinguish different UF fertilizers with identical WIN values. The AI represents the amount of CWIN that is soluble in hot water. In other words, AI is a measure of relative solubility with solubility increasing as AI values increase. According to the Association of the American Plant Food Control Officials (AAPFCO), UF fertilizers should contain at least 35 percent nitrogen and have an $\mathrm{AI}$ of at least 40 percent.

The remainder of the products are composed of coldwater-soluble nitrogen (CWSN) as free urea (quickrelease nitrogen) and short-chain polymers that provide a quick response, yet offer some degree of safety regarding salt injury compared to quick-release fertilizers. Higher AI values represent sources that will provide faster nitrogen responses.

Ureaform is manufactured by reacting urea with formaldehyde using a 1.3-1.0 ratio. It consists of equal fractions of CWSN, CWIN and HWIN. It is often necessary to supplement the ureaform with quick-release nitrogen or increase the rate the first couple of years because of the extremely slow release of nitrogen. This is especially true in the cooler portions of the season because it might require three to four weeks to achieve a significant turf greening response. 
Methylene urea is manufactured by reacting urea with less formaldehyde using a 1-9-1 ratio. This results in more CWSN (64 percent) and less CWIN (23 percent) and HWIN (13 percent). The difference results in quicker response yet shorter residual nitrogen compared to ureaform.

Other UF products are made with higher ratios of urea to formaldehyde. These products contain 35 to 40 percent nitrogen and are classified as "slowly available" by the AAPFCO. They provide a much quicker response compared to methylene urea and ureaform, but the response is shorter. Some products are available in liquid formulation as flowable products (they require tank agitation). These products contain no WIN, but instead contain short-chain reaction products that give a response somewhat comparable to free urea, though the chance of salt injury to turf is much less. Products claiming controlled-release nitrogen will also release nitrogen quickly.

\section{IBDU}

Isobutylidene diurea is made by reacting isobutyraldehyde and urea and is slowly soluble in water. Approximately 90 percent of the nitrogen is in the WIN form. Higher soil moisture and smaller particle size result in more rapid release. Nitrogen release is somewhat depressed in alkaline soils and is independent of microbial activity. For this reason, IBDU will release more readily during cooler temperatures than will UF products.

\section{Triazones}

These products are water-soluble, liquid, cyclic compounds derived by combining ammonia with urea and formaldehyde. Although considered to be slow-release by the AAPFCO, they act much like the "slowly available" UF products described above rather than IBDU, ureaform, or methylene urea because the greening response is quicker and the residual time is shorter. The major benefit is that salt injury is lessened using these products compared to using urea. Triazones have not established a major role in turfgrass fertilization programs, but they have the potential to expand in use in the turf and landscape industry.

\section{Sulfur-Coated Urea}

Sulfur-coated urea (SCU) products are made by spraying molten sulfur on urea particles. A sealant (wax or oil) is usually added to seal the imperfections, followed by a conditioner to reduce stickiness. Particles often contain a nitrogen-to-sulfur ratio of 2-to-1. Nitrogen is released by the microbial degradation of the coating and/or diffusion through the coating. Sulfur-coated urea products without sealants often release slower because of the thicker sulfur coating. Release rate increases as coating thickness decreases and temperature increases. It is the variability in coating thickness and particle size differences that allow for initial greening residual response.

Breaking of particles (with a spreader, traffic, or mower) results in the immediate release of nitrogen. A seven-day dissolution rate in water (lab procedure) is commonly used to characterize the quickly available fraction of SCU products. Most products have dissolution rates in the range of 25 to 35 percent. Controlledrelease soluble urea nitrogen (CRSUN) is a term used on certain SCU labels and refers to the total percentage of nitrogen as SCU in the product. Another term, "controlled-release nitrogen," refers to the amount or percentage of SCU particles that are not broken and at least covered with a sealant.

\section{Polymer-Coated Nitrogen}

These products are coated with a synthetic polymer coating that is sometimes plastic-like in its composition. Sometimes the polymer coating is also supplemented with sulfur coating. Polymer-coated urea products are not microbially dependent because there is no wax sealant. Nitrogen is released through cracks in the sulfur and diffusion through the plastic. In plastic-coated urea, nitrogen is dissolved by water absorbed through the coating. Nitrogen is then gradually released through the coating by osmosis. Release increases with temperature and is influenced very little by soil moisture content, irrigation, soil $\mathrm{pH}$, or microbes. Coating thickness determines the release rate for polymer-coated products.

\section{Combinations of Quickly and Slowly Available Nitrogen}

Many manufacturers combine quick- and slow-release sources of nitrogen to take advantage of the strengths of both. The quick-release source provides quick green up, but it is at a sufficiently low rate to prevent salt injury and reduce the potential for leaching. The slow-release source is available to provide a greening response for a longer duration. 


\section{Practical Considerations in Interpreting and Applying Slowly Available Nitrogen Sources}

The slowly available nitrogen sources offer advantages from an environmental perspective as well as reductions in application frequency and controlled plant response. In cooperation with the Virginia Department of Conservation and Recreation, the following application criteria were developed for SAN sources (all categories and combinations of WIN, CRN, etc., apply) in order to optimize plant nutrient use efficiency and environmental responses.

If the fertilizer is 50 percent SAN or more, then up to 1.5 pounds of nitrogen per 1,000 square feet is acceptable in a single application during optimal growing periods.

If the fertilizer is 25 to 49 percent SAN, then up to 1.25 pounds of nitrogen per 1,000 square feet is acceptable in a single application during optimal growing periods.

If the fertilizer is less than 25 , then no more than 1 pound of nitrogen per 1,000 square feet should be applied in a single application during optimal growing periods.

Determining the percentage of SAN in a fertilizer source that contains varying forms of water-soluble and slowly available nitrogen can be tricky. As an example, use the guaranteed analysis of a complete, balanced fertilizer detailed in figure 8.2 to determine its SAN percentage and a recommended maximum application rate. The material is 32-4-4 with the two forms of readily available (watersoluble) nitrogen being ammoniacal (3.5 percent) and urea (17.2 percent), for a total of 20.7 percent of the total nitrogen being readily available. For the SAN sources, 5.7 percent is clearly defined as WIN. The remaining 5.6 percent is where the analysis can be confusing. The top of the analysis details the 5.6 percent as "other water-soluble nitrogen," and an asterisk indicates that more information is provided in a footnote. The footnote specifies that the "other water-soluble nitrogen" is derived from methylene urea. As previously discussed, this SAN source contains highly variable percentages of nitrogen solubilities, ranging from very slowly available to readily available (which, because it contains readily available nitrogen, is why it is classified as "other" water-soluble nitrogen).

Therefore, the total SAN in this source is:

$$
5.7 \text { percent }+5.6 \text { percent }=11.3 \text { percent } \mathrm{SAN} \text {. }
$$

The percentage of SAN is:

$$
11.3 \text { percent } \div 32 \text { percent }=35 \text { percent } \mathrm{SAN},
$$

and this product could be applied at up to 1.25 pounds per 1,000 square feet in a single application. Note that for some states, the only thing required by law on the label is percentage of total nitrogen, but for most specialty turf fertilizer materials, there likely will be a listing of the percentages of varying nitrogen sources according to their solubilities.

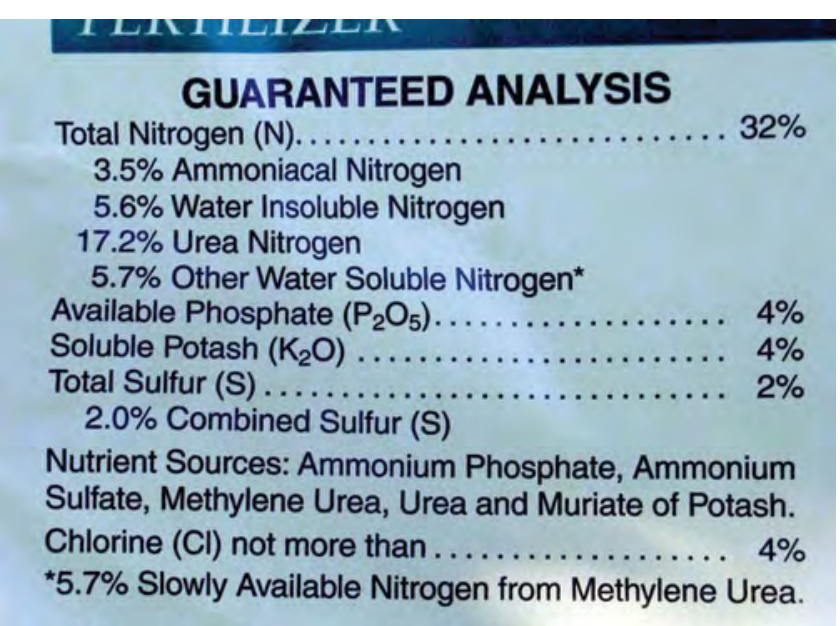

Figure 8.2. A fertilizer label detailing the guaranteed analysis of some of the various sources of slowly available nitrogen and how it is defined.

\section{Phosphorus Fertilizer Sources and Fertility Guidelines}

As previously defined, phosphorus does not actually occur as phosphate in the fertilizer or the soil. (This is an artifact from early analytical methods and laws used to assess phosphorus content and regulate fertilizer sales that has remained in use to keep records comparable across years.) Most scientific literature now uses percentage of elemental phosphorus (percentage of phosphorus) instead. To convert from percentage of $\mathrm{P}_{2} \mathrm{O}_{5}$ to percentage of phosphorus, multiply by 0.44 . The standard phosphorus fertilizer sources are provided in table 8.3. Natural organic fertilizer sources are usually 0.5 percent to 2.0 percent $\mathrm{P}_{2} \mathrm{O}_{5}$ by weight. One of the most significant changes in lawn fertilization programs in the 21 st century is the ready availability of phosphate-free fertilizers.

In most soils, phosphorus quickly binds with other elements to form water-insoluble compounds that are slowly released into the soil solution as phosphate anions $\left(\mathrm{HPO}_{4}^{2-}\right.$ or $\left.\mathrm{H}_{2} \mathrm{PO}_{4}^{-}\right)$on an "as needed" basis due to plant uptake. Water quality issues bring phosphorus applications to the forefront of environmental concerns due to the potential for eutrophication in water sources affected by phosphorus. Phosphorus is critical for energy transformations in plants and root develop- 
ment; therefore, it is an extremely important nutrient to optimize establishment. Typical application rates for turf and landscape plant establishment might be 1 to 2 pounds of phosphorus per 1,000 square feet. For maintenance of a healthy canopy, it should be applied as recommended by soil test results. Many soils in the southeastern United States are inherently low in phosphorus, and appropriate phosphorus applications that support a healthy turfgrass will actually improve water quality because the turf minimizes sediment losses.

On the other hand, on heavier-textured soils where phosphorus has been regularly applied for many years, additional phosphorus is not likely required. When present in its anionic form, phosphate is highly leachable, but due to its immobilization with other compounds, its mobility is much less than that of $\mathrm{NO}_{3}$-. However, phosphate leaching can and does occur in two situations: (1) soils that contain excessive phosphorus levels, likely due to persistent overapplication of synthetic or organic phosphorus sources, and (2) modified sandbased soils, particularly during turfgrass establishment. All this being said, the major source of phosphate contamination in our waterways comes from fertilizer misapplications where granules are erroneously applied to hardscapes. This material quickly and easily enters water supplies through stormwater drains.

\section{Table 8.3. The typical grade, salt index, and water solubility of the most common phosphorus sources used in turf and landscape management fertility programs (after Turgeon 1985).}

\begin{tabular}{|c|c|c|c|}
\hline Fertilizer & Grade & $\begin{array}{c}\text { Salt } \\
\text { index }\end{array}$ & $\begin{array}{c}\text { Cold-water } \\
\text { solubilityb } \\
{[\mathrm{g} / \mathrm{l}(\mathrm{lb} / \mathrm{gal})]}\end{array}$ \\
\hline Superphosphate & $0-20-0$ & 0.4 & $20(0.16)$ \\
\hline Treblesuperphosphate & $0-45-0$ & 0.2 & $40(0.32)$ \\
\hline $\begin{array}{l}\text { Monammonium } \\
\text { phosphate }\end{array}$ & $11-48-0$ & 3.2 & $230(1.8)$ \\
\hline $\begin{array}{l}\text { Diammonium } \\
\text { phosphate }\end{array}$ & $20-50-0$ & 1.7 & $430(3.4)$ \\
\hline Rock phosphate & $0-30-0^{\mathbf{c}}$ & NA & NA \\
\hline Bone meal & $4-12-0$ & NA & NA \\
\hline \multicolumn{4}{|l|}{ Note: $\mathrm{NA}=$ not applicable. } \\
\hline \multicolumn{4}{|c|}{$\begin{array}{l}\text { a The salt index scale is: }<1.0=\text { low, } 1.0 \text { to } 2.5=\text { moderate, and } \\
>2.5=\text { high. }\end{array}$} \\
\hline \multicolumn{4}{|c|}{ 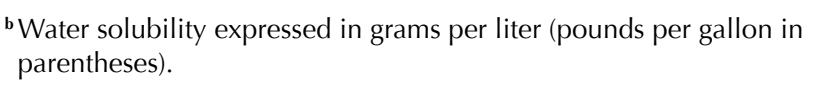 } \\
\hline \multicolumn{4}{|c|}{ c Rock phosphate levels of $\mathrm{P}_{2} \mathrm{O}_{5}$ can range from 27 to 41 percent. } \\
\hline
\end{tabular}

\section{Potassium Fertilizer Sources and Fertility Guidelines}

The most common forms of potassium fertilizer sources are presented in table 8.4. Remember that the last of the three numbers that appear in the fertilizer grade represents potash; to convert this value to elemental potassium, multiply by 0.83 .

\begin{tabular}{|c|c|c|c|}
\hline \multicolumn{4}{|c|}{$\begin{array}{l}\text { Table 8.4. The typical grade, salt index, and } \\
\text { water solubility of the most common potassium } \\
\text { sources used in turf and landscape management } \\
\text { fertility programs (after Turgeon 1985). }\end{array}$} \\
\hline Fertilizer & Grade & $\begin{array}{c}\text { Salt } \\
\text { index }^{\mathrm{a}}\end{array}$ & $\begin{array}{l}\text { Cold water } \\
\text { solubility } \\
\text { [g/l (lb/gal)] }\end{array}$ \\
\hline $\begin{array}{l}\text { Potassium chloride } \\
\text { (muriate of potash) }\end{array}$ & $0-0-60$ & 1.9 & $350(2.8)$ \\
\hline $\begin{array}{l}\text { Potassium sulfate } \\
\text { (sulfate of potash) }\end{array}$ & $0-0-50$ & 0.9 & $120(1.0)$ \\
\hline Potassium nitrate & $13-0-44$ & 5.3 & $130(1.0)$ \\
\hline \multicolumn{4}{|c|}{$\begin{array}{l}\text { a The salt index scale is: } \angle 1.0=\text { low, } 1.0 \text { to } 2.5=\text { moderate, and } \\
>2.5=\text { high. }\end{array}$} \\
\hline \multicolumn{4}{|c|}{$\begin{array}{l}\text { 'Water solubility expressed in grams per liter (pounds per gallon in } \\
\text { parentheses). }\end{array}$} \\
\hline
\end{tabular}

Potassium is involved in a host of biochemical responses in a plant but is not a direct component of any organic compound. In particular, potassium is recognized as the nutrient that most impacts water relations within the plant, sometimes being referred to as the "antifreeze" and "coolant" nutrient of the plant world.

There are many unrefined and manufactured sources of potassium, but plants always absorb potassium in the same form: $\mathrm{K}^{+}$. Potassium is required in the secondhighest quantity by plants after nitrogen. As a cation, $\mathrm{K}^{+}$can be temporarily bound and exchanged for other cations in soils that contain significant anionic (negatively charged) exchange sites (i.e., soils with significant amounts of clay and/or organic matter). Even as a cation, $\mathrm{K}^{+}$can still leach depending on soil type (especially sand-based soils) and under heavy rainfall and/ or irrigation. In general, application rates of potassium should not exceed 1 pound of $\mathrm{K}_{2} \mathrm{O}$ per 1,000 square feet. Lower rates and more frequent applications are desired on sandy soils low in organic matter.

At this time, potassium is not considered to be an environmental concern that negatively impacts water quality, so it does not receive as much attention as nitrogen and phosphorus from this perspective. Potassium 
chloride $(\mathrm{KCl})$ is the most commonly used potassium source, primarily because it is a cheaper material. The other sources (potassium sulfate, potassium magnesium sulfate, and potassium nitrate) contain other macronutrients that can provide additional desirable plant responses. Potassium sulfate has a very low salt index and is less water-soluble than the other sources, meaning it has low foliar-desiccation potential. Potassium nitrate is a popular spring and fall fertilizer material used to prepare landscape plants for the environmental extremes of the summer and winter. Potassium magnesium sulfate (commonly called sul-po-mag) is somewhat underutilized in turf management programs as compared to production agriculture systems. It promotes turfgrass color without a lot of growth, but it is a very water-soluble product that must be quickly watered in to prevent foliar burn.

\section{Calcium, Magnesium, and Sulfur Fertilizer Sources and Fertility Guidelines}

There are numerous sources of calcium, magnesium, and sulfur detailed in table 8.5; the table lists the most common fertilizer sources. In addition, materials such as bone meal, wood ash, manures, and sludge can contain significant amounts of these elements.

Many of these sources will be recognized also as chemicals applied to alter $\mathrm{pH}$. Therefore, if calcium, magnesium, or sulfur is required due to nutrient deficiency but a $\mathrm{pH}$ change is not desired, standard liming sources and elemental sulfur should be avoided.

Calcium and magnesium are often overlooked regarding their importance as macronutrients because they are most commonly associated with adjusting $\mathrm{pH}$ levels. However, both have important activities in the plant, with calcium serving as a primary component of cell walls and magnesium being the central atom of the chlorophyll molecule. They behave very much the same in the soil due to similar chemical properties, but magnesium is typically much lower in soils than calcium. Both are divalent cations $\left(\mathrm{Ca}^{2+}\right.$ and $\left.\mathrm{Mg}^{2+}\right)$ and are of very similar size. It is important to monitor the balance of magnesium, calcium, and potassium and many soil test reports will include this information as part of their results. The mobility of both calcium and magnesium is relatively low, especially compared to anions or even other cations, such as sodium or potassium. Therefore, loss of these two cations through leaching is relatively low, especially when applied in the form of lime. Leaching is primarily limited to sandy soils with low CEC and is enhanced by low $\mathrm{pH}$. Applications of these nutrients to soils do not result in any known water quality problems in this region.

Similar to nitrogen, sulfur is highly mobile in the soil because its plant-available form is the sulfate $\left(\mathrm{SO}_{4}{ }^{2-}\right)$ anion. Tissue sampling is usually the best way to diag-

\section{Table 8.5. Common inorganic sources of calcium, magnesium, and sulfur.}

\begin{tabular}{|c|c|c|c|c|}
\hline Material & Chemical formula & $\begin{array}{l}\mathrm{Ca} \\
(\%)\end{array}$ & $\begin{array}{l}\mathrm{Mg} \\
(\%)\end{array}$ & $\begin{array}{c}\mathbf{S} \\
(\%)\end{array}$ \\
\hline $\begin{array}{l}\text { Calcium } \\
\text { chloride }\end{array}$ & $\mathrm{CaCl}_{2}$ & 36.0 & 0 & 0 \\
\hline $\begin{array}{l}\text { Burned } \\
\text { lime or } \\
\text { calcium } \\
\text { oxide }\end{array}$ & $\mathrm{CaO}$ & 70.0 & 0 & 0 \\
\hline $\begin{array}{l}\text { Calcitic } \\
\text { limestone }\end{array}$ & $\mathrm{CaCO}_{3}$ & 32.0 & 3.0 & 0.1 \\
\hline $\begin{array}{l}\text { Dolomitic } \\
\text { limestone }\end{array}$ & $\mathrm{CaCO}_{3}, \mathrm{MgCO}_{3}$ & $\begin{array}{r}21.0 \\
-30.0\end{array}$ & $\begin{array}{r}6.0 \\
-12.0\end{array}$ & 0.3 \\
\hline Gypsum & $\mathrm{CaSO}_{4}$ & 22.0 & 0.4 & 17.0 \\
\hline $\begin{array}{l}\text { Hydrated } \\
\text { lime }\end{array}$ & $\mathrm{Ca}(\mathrm{OH})_{2}$ & 50.0 & 0 & 0 \\
\hline $\begin{array}{l}\text { Magnesium } \\
\text { ammonium } \\
\text { phosphate }\end{array}$ & $\mathrm{MgNH}_{4} \mathrm{PO}_{4} \cdot 6 \mathrm{H}_{2} \mathrm{O}$ & 0 & 15.0 & 0 \\
\hline $\begin{array}{l}\text { Magnesium } \\
\text { oxide }\end{array}$ & $\mathrm{MgO}$ & 0 & 45.0 & 0 \\
\hline $\begin{array}{l}\text { Magnesium } \\
\text { sulfate }\end{array}$ & $\mathrm{MgSO}_{4} \cdot 7 \mathrm{H}_{2} \mathrm{O}$ & 2.0 & 10.0 & 14.0 \\
\hline $\begin{array}{l}\text { Potassium } \\
\text { magnesium } \\
\text { sulfate }\end{array}$ & $\mathrm{K}_{2} \mathrm{SO}_{4} \cdot 2 \mathrm{MgSO}_{4}$ & 0 & 11.0 & 22.0 \\
\hline $\begin{array}{l}\text { Ammonium } \\
\text { sulfate }\end{array}$ & $\left(\mathrm{NH}_{4}\right)_{2} \mathrm{SO}_{4}$ & 0.3 & 0 & 24.0 \\
\hline $\begin{array}{l}\text { Ammonium } \\
\text { thiosulfate }\end{array}$ & $\left(\mathrm{NH}_{4}\right)_{2} \mathrm{~S}_{2} \mathrm{O}_{3}$ & 0 & 26.0 & 0 \\
\hline $\begin{array}{l}\text { Elemental } \\
\text { sulfur }\end{array}$ & S & 0 & $\begin{array}{r}52.0 \\
-70.0 \\
\end{array}$ & 0 \\
\hline $\begin{array}{l}\text { Flowable, } \\
\text { wettable } \\
\text { flowers }\end{array}$ & & & $\begin{array}{r}90.0 \\
-100.0\end{array}$ & \\
\hline $\begin{array}{l}\text { Potassium } \\
\text { sulfate }\end{array}$ & $\mathrm{K}_{2} \mathrm{SO}_{4}$ & 0.7 & 1.0 & 18.0 \\
\hline $\begin{array}{l}\text { Sulfuric } \\
\text { acid }\end{array}$ & $\mathrm{H}_{2} \mathrm{SO}_{4}$ & 0 & 0 & $\begin{array}{r}20.0 \\
-33.0\end{array}$ \\
\hline
\end{tabular}


nose sulfur deficiency, but deficiencies are most common on sand-based, low-organic-matter soils. For landscape plants that require an acidic soil $\mathrm{pH}$ (for instance, achieving a certain bloom color of hydrangea), elemental sulfur is often used to lower $\mathrm{pH}$. For lawn applications intended to lower $\mathrm{pH}$, elemental sulfur applications should not exceed 5 pounds per 1,000 square feet and should promptly be watered in.

\section{Micronutrient Fertility Sources and Fertility Guidelines}

Micronutrients are required in very small quantities but they are equally important to overall plant health as the macronutrients. The list of plant-required micronutrients comprises iron, manganese (Mn), boron, copper, zinc, chlorine $(\mathrm{Cl})$, and molybdenum (Mo). Micronutrients are rarely deficient in terms of soil quantities with the only exception being very sandy soils (natural or modified) with low organic matter or high turnover systems, such as sod farms. Maintaining an appropriate soil $\mathrm{pH}$ is the most important factor in managing soils to ensure adequate micronutrient availability.

Iron is by far the most important micronutrient in turfgrass management programs, having uses in all segments of the turfgrass industry. The most popular sources of iron are detailed in table 8.6.

\begin{tabular}{lc}
\hline \multicolumn{2}{l}{ Table 8.6. Standard iron fertilizer sources } \\
used in lawn and landscape settings. \\
\hline \multicolumn{3}{l}{ Source } & \% iron \\
\hline Iron sulfates & $19-23$ \\
\hline Iron oxides & $69-73$ \\
\hline Iron ammonium sulfate & 14 \\
\hline Iron chelates & $5-14$ \\
\hline
\end{tabular}

Whereas nitrogen deficiencies are often uniform across the turf, iron deficiencies are often scattered randomly throughout the turf, and appear more severe on closely mowed surfaces. The most severe deficiencies occur with warm days and cool nights, when shoot growth is favored over root growth. Total iron levels in most mid-Atlantic soils range from 0.5 percent to 5.0 percent. Yet iron is the micronutrient most likely to be deficient. Iron occurs primarily as oxides and hydroxides that are sparingly soluble in well-aerated soils above $\mathrm{pH}$ 4.0. Root exudates from deeply rooted plants are generally able to solubilize sufficient iron to optimize plant growth, but high nitrogen rates and close mowing decrease root growth relative to shoot growth and limit uptake capability. The inherently low levels of iron in high-sand green mixes and some of our native sandy sands, along with the relatively high supply of nitrogen and phosphorus in these management systems can further complicate iron uptake.

The most popular forms of iron applied in turf and landscape applications are the chelates applied as sprays over the top of the turf canopy. Granular iron sources are beneficial in increasing soil iron levels where needed, but they do not provide rapid color response. These liquid organic chelates are easy to handle, mix, and apply, and they can be tank-mixed with most pesticides. Chelation reduces the rate of complexing of iron into insoluble compounds in the soil, thereby improving plant uptake. However, the benefit most turf managers seek from foliar applications of any form of iron is a rapid, deep-green color without a surge in shoot growth. The immediacy of the "iron response" is mostly due to "staining" of the foliage, but there also will be a promotion of internal chlorophyll production within the leaves over time. The color response from foliar applications is relatively short-lived (might last up to two weeks) and is lost as the turf is clipped. Typical iron application levels are 5 to 10 pounds per acre ( 0.12 to 0.25 pounds per 1,000 square feet).

Deficiencies of other micronutrients are rare except on mostly sand soils. Maintaining appropriate soil $\mathrm{pH}$ is of utmost importance in ensuring satisfactory availability and/or preventing potential phytotoxicity issues. For instance, where copper or galvanized zinc roofs are used, there is the potential for metal toxicity to lawn and landscape plants, particularly where water from the roof is concentrated near a downspout. The easiest way to manage the elevated soil copper or zinc content is to reduce their solubility by liming to maintain the $\mathrm{pH}$ above 6.0. Where supplemental micronutrient applications are needed (most often indicated by tissue testing), chelated formulations are very effective.

\section{Liming Materials and Chemical Composition}

Why is there such a constant need for lime in this region? Most of the soils of the mid-Atlantic essentially act as weak acids, with only a small portion of their potential acidity present in the active, or soil solution, form. Exchangeable aluminum (Al), manganese, and iron metals, along with $\mathrm{pH}$-dependent charges on organic matter and clay edge sites, constitute the major sources of potential acidity (also called the reserve or 
total acidity). The reserve acidity, in conjunction with the exchangeable bases, helps to buffer or to enable the soil to resist rapid changes in soil solution $\mathrm{pH}$. Plants growing in acid soils must be able to contend with high levels of aluminum and manganese, and low availability of phosphorus, calcium, and magnesium. Because most turfgrasses are intolerant of these conditions, acidic soil must be limed to make the rooting environment hospitable for root exploration and development.

A number of materials are available for liming acid soils (table 8.7). The selection of a liming material should be based on its ability to neutralize soil acidity, chemical composition, fineness of grind, ease of handling, and cost. Limestone is a naturally occurring sedimentary rock rich in the minerals calcite $(\mathrm{CaCO} 3)$ or dolomite $\left[\mathrm{CaMg}\left(\mathrm{CO}_{3}\right)_{2}\right]$. Most limestone is formed in thick, compacted deposits of calcareous skeletons and shells of sea animals on the ocean bed. Relatively pure deposits of calcite are called "calcitic" limestone, while materials containing more magnesium are called "dolomitic" limestone. Dolomitic limestone is widely used as a lime (and magnesium) source in the mid-Atlantic. When either calcitic or dolomitic lime is heated, the carbonate is driven off and calcium (magnesium) oxide is formed. When treated with water, or "slaked," calcium oxide forms $\mathrm{Ca}(\mathrm{OH})_{2}$, also called slaked or hydrated lime. These are very reactive and caustic materials and are seldom if ever used for turf. These materials are occasionally used when very rapid changes in $\mathrm{pH}$ are needed, such as immediately prior to planting.

\begin{tabular}{lc}
$\begin{array}{l}\text { Table 8.7. The neutralizing value (calcium } \\
\text { carbonate equivalent, CCE) of the pure } \\
\text { forms of commonly used liming materials. }\end{array}$ \\
\hline $\begin{array}{l}\text { Neutralizing } \\
\text { value }(\%)\end{array}$ \\
\hline $\mathrm{CaO}($ calcium oxide) & 179 \\
\hline $\mathrm{Ca}(\mathrm{OH})_{2}$ (calcium hydroxide) & 136 \\
\hline $\mathrm{MgCO}$ (magnesium carbonate) & 119 \\
\hline $\left.\mathrm{CaMg}_{(} \mathrm{CO}_{3}\right)_{2}$ (dolomitic limestone) & 109 \\
\hline $\mathrm{CaCO}_{3}($ calcium carbonate) & 100 \\
\hline
\end{tabular}

Source: Data from Tisdale, Nelson, and Beaton 1985.

As with most sedimentary materials, limestone varies in purity and chemical composition. In order to compare the acid-neutralizing value of various liming materials of differing purity levels, the calcium carbonate equivalent (CCE) test uses pure calcite $\left(\mathrm{CaCO}_{3}\right)$ as the standard, with an arbitrarily assigned value of 100 percent. ACCE value greater than 100 is possible and simply indicates that the material has a higher neutralizing capacity than pure calcite. Note that the neutralizing values for magnesium carbonate $\left(\mathrm{MgCO}_{3}\right)$, dolomitic limestone $\left[\mathrm{CaMg}\left(\mathrm{CO}_{3}\right)_{2}\right]$, calcium hydroxide $\left(\mathrm{CaOH}_{2}\right)$, and calcium oxide $(\mathrm{CaO})$ are all greater than 100 percent (table 8.7).

Apply this information in the selection and application of the lime source as recommended by the soil test. For example, if the soil test recommendation indicates that 50 pounds of lime is recommended per 1,000 square feet (the recommendation is on the basis of pure calcite) and the lime source available has a CCE of 90 percent, 55.5 pounds of the source ( 50 pounds per 0.9 $=55.5$ pounds) per 1,000 square feet will be necessary to achieve the recommended liming rate. Conversely, if dolomitic limestone (with a CCE on the label of 109 percent) is selected, only 46 pounds (50 pounds per $1.09=46$ pounds) per 1,000 square feet are required.

\section{Fineness of Grind}

Because liming materials have a limited solubility, the rate of reaction is largely determined by the amount of surface area exposed to acid soil. As fineness increases, the rate of reaction increases. Agricultural lime (having a wide variety of particle sizes) is particularly costeffective for new establishment sites where it can be incorporated into the seedbed prior to planting. Ag-lime is more difficult to apply because of its nonuniform particle size. Powdered lime provides a rapid response but is extremely difficult to handle and apply. Pelletized lime - finely ground limestone made into pellets by using a binding agent - is commonly used in turf settings. The large pellets retain the quick reaction time of fine particles but without the dust of the powdered form. Pelletized forms are more expensive than powdered lime, but the ease in handling and application makes it a very popular choice. Pellets break down when wetted to release the finely ground particles. When applied to bare ground, pelletized lime should be wetted and allowed time for particles to break down prior to tillage or incorporation. Otherwise, the particles will be in contact with much less of the soil surface and will not be as effective in neutralizing soil acidity.

\section{Managing Lime Applications}

The general recommendation is to apply no more than 50 pounds of lime per 1,000 square feet at any one time to established turf ( 25 pounds per application to golf putting greens). If the soil test suggests more, then the amount should be applied monthly in incremental amounts. 
All the beneficial effects of liming occur only where lime and soil are in contact. Liming materials are sparingly soluble and react strongly with the soils with which they come in contact. As a result, lime is relatively immobile in the soil and surface applications generally affect no more than the surface 2 or 3 inches during a growing season. For this reason, it is imperative to adjust the $\mathrm{pH}$ of soils prior to establishment and to incorporate the lime early enough so that neutralization of the acidity has time (two to four weeks for finely ground lime) to take place. Thorough incorporation throughout the rooting zone increases the rate of reaction and treats a larger volume of the soil, maximizing the benefits of lime.

Attempting to change the $\mathrm{pH}$ in the deep rooting zone of an established turf is difficult at best. One method of getting lime somewhat deeper in established turf areas is to apply lime in conjunction with core aeration events. Applying lime in the fall and winter months is also possible because the foliar burn potential (i.e., leaf desiccation) is very low and the freezing and thawing of the soil aid in mixing lime throughout the root zone.

\section{Overliming}

In this region, the target $\mathrm{pH}$ for turf and most ornamentals is 6.0 to 6.5. Overliming dramatically reduces availability of micronutrients and can result in deficiencies that are very difficult to correct. Turfgrass areas that have excessively high $\mathrm{pH}$ can be amended over time with use of an acid-forming fertilizer such as ammonium sulfate. Where $\mathrm{pH}$ is too high, the only alternative is to reduce the $\mathrm{pH}$ using elemental sulfur or aluminum sulfate.

Lime application should be based on soil tests to ensure that excessive lime is not added. While a good liming program usually provides adequate levels of calcium and magnesium, there are times when lime is not recommended but additional calcium and/or magnesium are required. Sources such as gypsum (calcium sulfate), magnesium sulfate, and potassium-magnesium sulfate should be used in this instance to supply needed nutrients without the addition of $\mathrm{pH}$-increasing lime.

\section{Best Management Practices for Water Quality Protection}

The following list details steps that can reduce the impact of nutrient management practices on water quality.

- Base fertilization practices on a soil test.
- Supplement the soil test with a plant tissue test when necessary.

- Core or aerate compacted soil to reduce runoff and aid phosphorus and lime in entering the soil.

- Minimize fertilizer rates on slopes. If using quickly available sources of nitrogen on deep, sandy soils or near shallow water tables, use no more than 0.25 to 0.50 pound of nitrogen per 1,000 square feet per application.

- Establish and maintain a buffer zone of reduced- to zero-input vegetation around bodies of water (figure 8.3). In some cases, native vegetation might be appropriate, but whatever plant material is selected, it must persist indefinitely to serve as a functional buffer zone. Florida has established a very successful public awareness campaign called the "Ring of Responsibility" that promotes best management practices in maintaining and fertilizing turf near water resources (Florida Department of Environmental Protection 2008). In Oklahoma, researchers simulated intensively managed golf fairway turf bordering water sources and reported that a graduated buffer system where turf cutting heights were raised from 1 to 2 inches as the slope approached the water significantly reduced total runoff volume as well as nitrogen and phosphorus movement (Moss et al. 2006). This approach utilizing a simple graduated buffer improves water quality protection and still meets playability needs from a golfer's perspective.

- Consider using iron as a supplement to nitrogen for greening response.

- Use at least 50 percent slowly available sources of nitrogen on soils subject to leaching.

- Time applications carefully. Do not apply fertilizer before a heavy rainfall.

- Irrigate lightly (0.10 to 0.25 inch) after each application of quick-release fertilizer so it is washed off the foliage and moved into the soil.

- Avoid overirrigation.

- Return grass clippings to the lawn to improve nutrient cycling and reduce the amount of fertilizer needed to produce healthy plants (figure 8.4 ). Use a mulching mower whenever possible and consider that a mulching mower can even be used to manage fall leaves (Goatley 2006).

- When collected, compost grass clippings rather than disposing of them in landfills. 


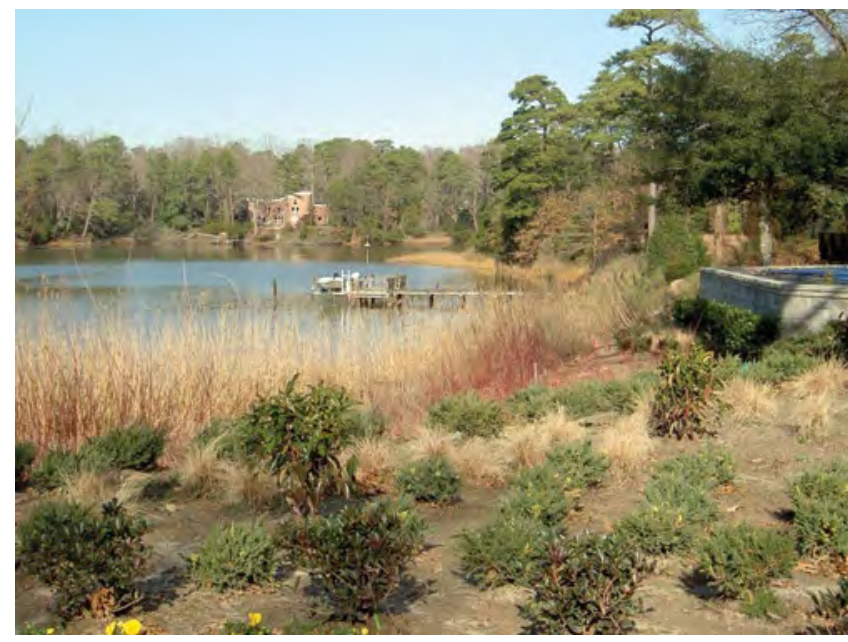

Figure 8.3. This buffer zone near the water's edge features low-input native grasses and shrubs.

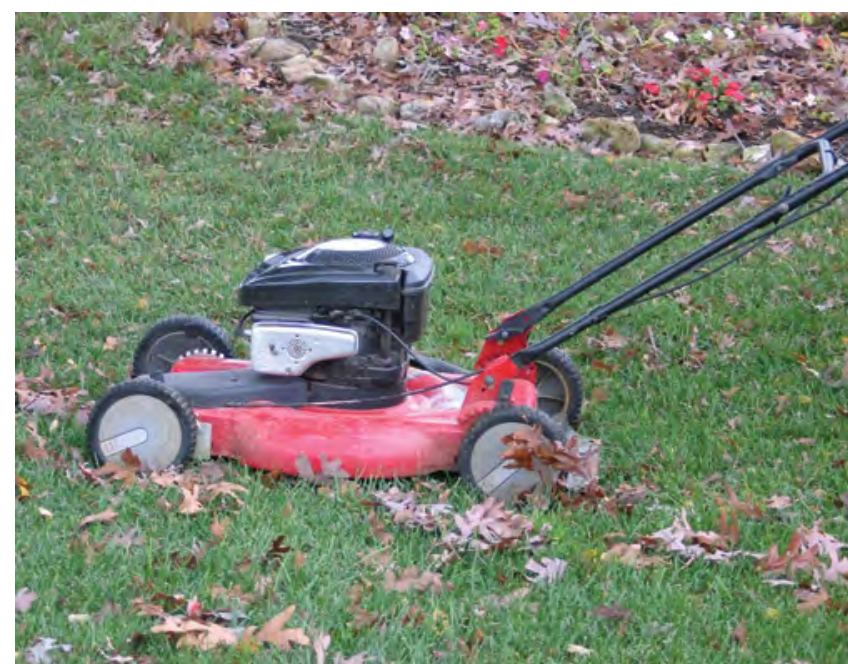

Figure 8.4. A mulching mower being used to recycle both grass clippings and tree leaves in a single mowing event.

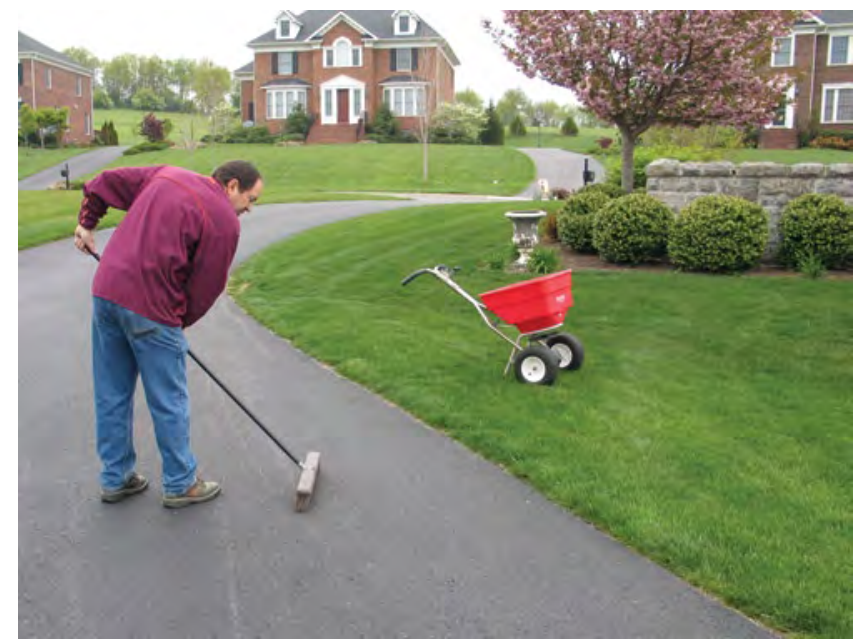

Figure 8.5. Sweeping or blowing fertilizer and/or grass clippings on hardscapes back into the turf canopy is one of the most important steps in protecting water quality.
- Use a drop (gravity) spreader near bodies of water or impenetrable areas to lessen the chance of spreading material on these surfaces.

- Perhaps the most important best management practice toward improving water quality is to simply sweep or blow fertilizers and grass clippings off hardscape surfaces and back into the turf (figure 8.5).

\section{Literature Cited}

Florida Department of Environmental Protection. 2008. Florida Friendly Best Management Practices for Protection of Water Resources by the Green Industries, 32-33. Tallahassee: Florida Department of Environmental Protection. www.dep.state. fl.us/water/nonpoint/docs/nonpoint/grn-ind-bmpen-12-2008.pdf.

Goatley, M. 2006. "Leave" Them Alone: Lawn Leaf Management. Virginia Cooperative Extension Publication 430-521. http://pubs.ext. vt.edu/430/430-521/430-521.html.

Moss, J. Q., G. E. Bell, M. A. Kizer, M. E. Payton, H. Zhang, and D. L. Martin. 2006. Reducing nutrient runoff from golf course fairways using grass buffers of multiple heights. Crop Science 46:72-80.

Tisdale, S. L., W. L. Nelson, and J. D. Beaton. 1985. Soil Fertility and Fertilizers, 500-09. 4th ed. New York: MacMillan. Turgeon, A. J. 1985. Turfgrass Management, 164-65. Englewood Cliffs, N.J.: Prentice-Hall.

Virginia Department of Conservation and Recreation (VDCR), Division of Soil and Water Conservation. 2005. Virginia Nutrient Management Standards and Criteria, 96-107. Richmond: VDCR.

\section{Additional Resources}

Hunnings, J. R., and S. J. Donohue. 2002. Soil Sampling for the Home Gardener. Virginia Cooperative Extension Publication 452-129. http://pubs. ext.vt.edu/452/452-129/452-129.html.

Little, C., and M. Watson. 2002. Understanding Value in Lime. Ohio State University Extension Fact Sheet ANR-9-02. http://ohioline.osu.edu/anr-fact/0009. html. 



\title{
Chapter 9. Organic and Inorganic Soil Amendments
}

\author{
Greg Evanylo, Professor, Crop and Soil Environmental Sciences, Virginia Tech \\ Mike Goatley Jr., Professor and Extension Specialist, Crop and Soil Environmental Sciences, Virginia Tech
}

\section{Introduction to Organic Amendments}

Organic amendments can be applied to soils to provide nutrients and/or as soil conditioners. The nutrients in organic amendments can either be readily available or complexed in organic forms that must first undergo mineralization in order to become plant-available. Because the nutrient concentrations in many organic amendments are often low (relative to inorganic fertilizers) and are typically less than 100 percent plant-available, higher application rates than those of inorganic fertilizers are necessary to supply a plant's nutrient requirements. Therefore, organic amendments are often not applied to supply a plant's entire nutrient needs.

Organic amendments can also be applied as soil conditioners, relying on the organic matter content to improve such soil physical properties as water-holding capacity, plant-available water, aggregation, tilth, bulk density, porosity, drainage, and hydraulic conductivity. Chemical property improvements from organic matter include $\mathrm{pH}$ buffering, increased cation exchange capacity, and increased nutrient availability. Organic matter is also a source of energy for soil microbes that increases aeration, reduces bulk density, and facilitates nutrient cycling.

\section{Sources of Organic Amendments}

Organic amendments are produced from agricultural, municipal, and industrial byproducts (table 9.1). Agricultural sources of organic amendments include poultry and livestock manure and rotten or unusable animal feed, hay, and forage plants. Municipal wastes include sewage sludge/biosolids, landscape trimmings (e.g., leaves, grass clippings, brush), and food waste (postconsumer or preconsumer). Industrial byproducts such as paper mill sludge, food processing sludge, and brewery waste can also be converted to organic amendments appropriate for use on turfgrass and landscapes. Such byproducts require treatment that enables the finished amendment to be used in a safe, nuisance-free, and environmentally sound manner in areas where human contact is frequent and/or constituents in the amendment may pose environmental risks if not managed correctly.

\begin{tabular}{ll}
\hline Table 9.1. Sources of organic amendments. \\
\hline Type & Examples of byproducts \\
\hline Agricultural & - Livestock and poultry manures. \\
& - Rotten/unusable plant material such \\
& as feed, hay, silage, and forages. \\
& - Wood chips. \\
& - Slaughterhouse wastes and animal \\
& mortalities. \\
\hline Municipal & Wastewater sewage sludge/biosolids. \\
& - Water treatment residuals. \\
& - Landscape trimmings such as leaves, \\
& brush, and grass clippings. \\
& - Food waste. \\
- Newspaper and other paper waste. & - Paper mill sludge. \\
& - Food processing sludge such as \\
& poultry dissolved air flotation sludge, \\
& brewery waste, and peanut hulls. \\
- Wood shavings, sawdust.
\end{tabular}

\section{Processes for Generating Organic Amendments}

Byproducts generated from animal manures and biosolids used in landscapes with public contact must first be treated to eliminate disease-causing organisms (pathogens) and vector attraction factors (viz., odors), which can exacerbate nuisance and health issues. Most biosolids applied to agricultural lands are termed "Class B" and have reduced (but detectable) levels of pathogens. Class B products are generated by processes to significantly reduce pathogens, such as aerobic and anaerobic digestion and lime stabilization. The land application of Class B products requires site restrictions to ensure that disease organisms do not pose health or environmental problems (http://pubs.ext.vt.edu/452/452-302/452-302. $h t m l)$.

Class A products have undetectable levels of pathogens and can be used without restriction as long as regulated pollutant concentrations meet appropriate standards. Class A biosolids are treated by processes to further reduce pathogens. Such commonly used processes include heat treatment (i.e., pasteurization), drying, 
advanced alkaline stabilization, and composting. Animal manures can also be treated by the same processes to enable their use on lands with high public contact.

Waste residuals that are physically and chemically homogenous - such as some manures, biosolids, and industrial sludges - are well-suited to be heat-treated, dried, and pelletized/granulated or alkaline-stabilized. The end product can be applied at rates marginally above inorganic fertilizer rates and often with fertilizeror lime-spreading equipment. Residuals that are physically and chemically heterogeneous, on the other hand, are usually processed in large volumes to enable uniformity in the end product. Composting is well-suited for such treatment processing and application because the low-analysis nutrient content of the finished product is typically applied at considerably higher rates than heattreated, dried, and pelletized or granulated products.

\section{Heat Treatment, Drying, and Pelletizing or Granulating}

This process can be used for treating liquid sewage sludge obtained from a wastewater treatment plant or from animal manure for the development of an organic fertilizer pellet or granule. Heat treatment produces an organic fertilizer by combining a dewatered sludge with dry fines and simultaneously drying and pelletizing the mixture. Alternatively, animal manures may be dried and pasteurized by heating and then either pelletized or granulated to produce a fertilizer. Such sludgeand manure-based products typically have low carbon (C)-to-nitrogen $(\mathrm{N})$ ratios; thus, a high portion of their organic nitrogen is rapidly mineralized.

\section{Advanced Alkaline Stabilization}

This process involves mixing a waste byproduct, typically sewage sludge, with a dry, $\mathrm{pH}$-raising material such as lime, kiln dust, or fly ash to meet Class A pasteurization criteria (i.e., maintain a $\mathrm{pH}$ of 12.0 or more for at least 72 hours, with a temperature of $52^{\circ} \mathrm{C}$ for at least 12 hours or with a temperature of $70^{\circ} \mathrm{C}$ for 30 minutes) via exothermic reaction. A similar process except that it does not use heat - can be used to process animal manures into Class A products. In this process, high concentrations of gaseous ammonia that form at the high $\mathrm{pH}$ level disinfect the manure. The resulting products contain essential plant nutrients but are often applied as liming agents.

\section{Composting}

Composting is the controlled, aerobic, thermophilic, biological decomposition of organic materials that results in a stable end product that can be used as a soil amendment called "compost." Compost contains essential plant nutrients in low concentrations and is typically applied as a soil conditioner or mulch.

\section{Composition of Organic Amendments}

\section{Heat-Treated Biosolids}

The concentrations of constituents in typical heattreated biosolids are presented in table 9.2. These materials are very dry (i.e., more than 90 percent solids), and their fine particle size permits their application as commercial fertilizer. The total Kjeldahl nitrogen (TKN) concentrations in such products are usually between 4 and 6 percent, nearly all of which is in the organic nitrogen form; thus, little of the nitrogen is readily plant-available.

Water-insoluble and water-soluble nitrogen are similar indicators of slowly available organic nitrogen forms and readily available inorganic nitrogen forms, respectively. These residuals are largely organic (40 percent carbon, 70 percent organic matter) and possess carbonto-nitrogen ratios that favor rapid mineralization of the organic nitrogen. Biosolids products are typically rich in phosphorus $(\mathrm{P})$, but the phosphorus solubility is often lower than in manure products because of the presence of high concentrations of phosphorus-binding iron $(\mathrm{Fe})$, manganese $(\mathrm{Mn})$, and other metal oxides in biosolids. Potassium $(\mathrm{K})$ is low in biosolids products because the soluble $\mathrm{K}^{+}$is separated from the solids during wastewater treatment and exits the system with the treated wastewater effluent. Such materials are usually near-neutral in $\mathrm{pH}$ because the heating process drives off $\mathrm{pH}$-elevating ammonia $\left(\mathrm{NH}_{3}\right)$.

Electrical conductivity (EC) is an indirect measurement of soluble-salt concentration. It is lower in heat-treated biosolids than in synthetic fertilizer and similar to that of compost. Organic residuals are good sources of sulfur (S) and other secondary and micronutrients, including such regulated plant-essential trace elements as copper $(\mathrm{Cu})$ and zinc $(\mathrm{Zn})$. The byproducts must meet the Code of Federal Regulations Title 40 (40 CFR) Part 503 pollutant concentration limits (PCL) set by the U.S. Environmental Protection Agency (EPA 1993) for the inorganic trace elements arsenic (As), cadmium $(\mathrm{Cd})$, 
chromium $(\mathrm{Cr})$, copper, mercury $(\mathrm{Hg})$, molybdenum $(\mathrm{Mo})$, nickel $(\mathrm{Ni})$, lead $(\mathrm{Pb})$, selenium $(\mathrm{Se})$, and zinc.

\section{Table 9.2. Concentrations of constituents in typical heat-treated and pelletized biosolids}

(Pinegro, Winston-Salem, N.C.; Tuscarora, Leesburg, Va.; Granulite (Synagro), Houston, Texas).

\begin{tabular}{|c|c|c|c|}
\hline Parameter & Pinegro & Tuscarora & Granulite \\
\hline Solids (\%) & 93.00 & & 96.00 \\
\hline $\mathrm{pH}$ & 7.12 & & 6.00 \\
\hline $\mathrm{EC}(\mathrm{dS} / \mathrm{m})^{\mathrm{a}}$ & 3.62 & & \\
\hline TKNb/total N (\%) & 5.51 & 6.00 & 5.00 \\
\hline$\left(\mathrm{NH}_{4}-\mathrm{N}\right)^{\mathrm{c}}(\%)$ & 0.26 & & \\
\hline Organic N (\%) & 5.25 & & \\
\hline Water-soluble N (\%) & 0.56 & 1.00 & 1.00 \\
\hline Water-insoluble N (\%) & 4.95 & 5.00 & 4.00 \\
\hline Total organic C (\%) & 40.00 & & \\
\hline $\mathrm{C}: \mathrm{N}$ ratio & 7.30:1 & & \\
\hline $\mathrm{P}(\%)$ & 2.32 & 2.62 & 1.30 \\
\hline K (\%) & 0.17 & 0.50 & \\
\hline $\mathrm{Ca}(\%)$ & 2.26 & 2.00 & 1.00 \\
\hline $\mathrm{Mg}(\%)$ & 0.36 & 0.40 & \\
\hline$\left(\mathrm{SO}_{4}-\mathrm{S}\right)^{\mathrm{d}}(\%)$ & 1.68 & 2.25 & 0.40 \\
\hline $\mathrm{Fe}(\%)$ & 2.86 & 1.00 & 1.00 \\
\hline $\mathrm{Cu}\left(\mathrm{ppm}^{\mathbf{e}}\right)$ & 262 & & 300 \\
\hline Zn (ppm) & 1,830 & 200 & 400 \\
\hline Mn (ppm) & 1,030 & 100 & 100 \\
\hline \multicolumn{4}{|c|}{ 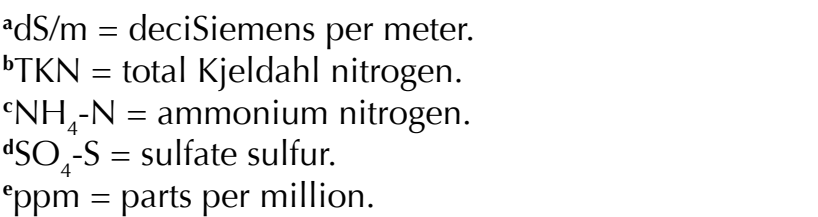 } \\
\hline
\end{tabular}

\section{Heat-Treated Manures}

With the excessive concentrations of nutrients, especially phosphorus, in areas dominated by confinedanimal feeding operations, manure is frequently being processed via heating, drying, pasteurizing, and pelletizing or granulating. This is particularly true for poultry manures, which contain especially unbalanced concentrations of nitrogen and phosphorus that necessitate their transport from regions with phosphorus-saturated soils. The analytical data for typical pelletized poultry litter in table 9.3 can be used to compare and contrast with the composition of heat-dried biosolids (table 9.2).
Table 9.3. Concentrations of constituents in typical heat-treated and pelletized manure.

\begin{tabular}{|c|c|c|}
\hline Parameter & $\begin{array}{c}\text { Perdue } \\
\text { Agrirecycle } \\
\text { Microstarter } 60 \\
\text { Plus } \\
\end{array}$ & $\begin{array}{c}\text { Pelletized } \\
\text { poultry litter } \\
\text { (Hammac et al. } \\
\text { 2007) }\end{array}$ \\
\hline Solids (\%) & $>85.00$ & \\
\hline TKN (\%) & 3.00 & 3.51 \\
\hline $\mathrm{NH}_{4}-\mathrm{N}(\%)$ & & 0.20 \\
\hline$\left(\mathrm{NO}_{3}-\mathrm{N}\right)^{\mathrm{a}}(\%)$ & & 0.10 \\
\hline Total organic C (\%) & 36.0 & \\
\hline $\mathrm{C}: \mathrm{N}$ ratio & $12: 1$ & \\
\hline $\mathrm{P}(\%)$ & 2.00 & 2.45 \\
\hline WSPb $(\%)$ & & 0.25 \\
\hline $\mathrm{K}(\%)$ & 3.00 & \\
\hline $\mathrm{Ca}(\%)$ & 2.50 & \\
\hline $\operatorname{Mg}(\%)$ & 0.50 & \\
\hline $\mathrm{SO}_{4}-\mathrm{S}(\%)$ & 0.76 & \\
\hline $\mathrm{Fe}(\%)$ & 0.13 & \\
\hline $\mathrm{Cu}(\mathrm{ppm})$ & 0.07 & \\
\hline Zn (ppm) & 0.07 & \\
\hline $\mathrm{Mn}(\%)$ & 0.07 & \\
\hline $\begin{array}{l}\text { a } \mathrm{NO}_{3}-\mathrm{N}=\text { nitrate nit } \\
\text { b } \mathrm{WSP}=\text { water-solub }\end{array}$ & $\begin{array}{l}\text { trogen. } \\
\text { ble phosphorus. }\end{array}$ & \\
\hline
\end{tabular}

All heat-dried, pelletized or granulated products are very dry, permitting easy spreading with fertilizer equipment. Nitrogen and phosphorus contents are similar, but manures are significantly higher than biosolids in potassium. It is difficult to estimate plant-available nitrogen (PAN) in organic fertilizers that do not list various inorganic and organic nitrogen fractions, but the nitrogen availability should be similar to that of unpelletized manure (Hammac et al. 2007). Manure products usually contain less iron and, thus, bind phosphorus less strongly than biosolids. Manure products, like heat-dried biosolids, contain other macronutrients (e.g., calcium, magnesium, sulfur) and micronutrients (e.g., copper, zinc, iron, manganese, etc.).

\section{Advanced Alkaline-Stabilization} Products

- Advanced alkaline-stabilized (AAS) products have high pH values (i.e., more than 12.0) due to their strong alkalinity. 
- Much of the content of such materials that utilize calcium oxide $(\mathrm{CaO})$ as the liming agent is calcium. One such example is N-Viro Soil (table 9.4), whose calcium concentration can be as high as 40 percent of the product.

- The carbon concentration of AAS biosolids is about half that of digested biosolids due to dilution by the liming agent.

- Nearly all of the nitrogen in AAS products is in the organic form because the inorganic nitrogen has been driven off as ammonia due to the high $\mathrm{pH}$.

- Phosphorus is present as a mixture of organic phosphorus and calcium phosphates.

- Potassium content can vary widely depending on the potassium content in the source of alkalinity used to treat the biosolids.

- Sulfur is present as a combination of gypsum and organic sulfur.

- Trace element concentrations are lower than digested biosolids due to the dilution of the biosolids by the liming agent and are typically lower than 40 CFR Part 503 pollutant concentration limits (EPA 1993; table 9.5).

- The calcium carbonate equivalent of such AAS products typically ranges from 40 to 50 percent.

\section{Compost Properties and Quality Standards}

Compost is used primarily as a soil conditioner and secondarily as a supplier of nutrients. Thus, the properties of compost that are usually tested and listed include those that improve soil conditions for plant growth and environmental effects (e.g., water quality; table 9.6). Composting is a $\mathrm{pH}$-neutralizing process; therefore, most high-quality composts have $\mathrm{pH}$ values near 7.0 (table 9.7). Stabilized organic matter tends to buffer soil $\mathrm{pH}$, so adding compost to soil often reduces the need for frequent liming. Only where acid-loving plants are grown are such compost application effects not desirable.

Electrical conductivity can vary greatly in compost, depending on the source of the feedstock(s) (table 9.6). Composts produced primarily from animal manures are usually higher in soluble salts and hence, higher in EC than yard and woody waste-based composts (table 9.7). High soluble salts and EC can impair the growth of sensitive plants, particularly seedlings; thus, it is important
Table 9.4. Typical composition of N-Viro Soil (advanced alkaline-stabilized biosolids) produced in Toledo, Ohio.

\begin{tabular}{lr}
\hline Property & Value \\
\hline $\mathrm{pH}$ & 12.2 \\
\hline $\mathrm{N}(\%)$ & 1.0 \\
\hline $\mathrm{P}(\%)$ & $0.2-1.1$ \\
\hline $\mathrm{K}(\%)$ & 1.0 \\
\hline $\mathrm{Ca}(\%)$ & $10.0-40.0$ \\
\hline $\mathrm{Mg}(\%)$ & 1.0 \\
\hline $\mathrm{S}(\%)$ & 5.0 \\
\hline $\mathrm{Na}(\%)$ & $<0.2$ \\
\hline $\mathrm{As}(\mathrm{ppm})$ & 27.4 \\
\hline $\mathrm{Cd}(\mathrm{ppm})$ & $<1.4$ \\
\hline $\mathrm{Cr}(\mathrm{ppm})$ & 65.4 \\
\hline $\mathrm{Cu}(\mathrm{ppm})$ & 74.0 \\
\hline $\mathrm{Hg}(\mathrm{ppm})$ & $<0.7$ \\
\hline $\mathrm{Mo}(\mathrm{ppm})$ & 9.2 \\
\hline $\mathrm{Ni}(\mathrm{ppm})$ & 61.1 \\
\hline $\mathrm{Pb}(\mathrm{ppm})$ & 28.4 \\
\hline $\mathrm{Se}(\mathrm{ppm})$ & 8.5 \\
\hline $\mathrm{Zn}(\mathrm{ppm})$ & 188.0 \\
\hline $\mathrm{Calcium}$ carbonate & 45.0 \\
$\mathrm{equivalent}(\%)$ & \\
\hline
\end{tabular}

Table 9.5. Biosolids trace element pollutant concentration limits (EPA 1993) and mean concentrations from the National Sewage Sludge Survey (NSSS; EPA 1990).

Class A products must meet pollutant concentration limits in order to be deemed "exceptional quality" for uses in areas of frequent public contact.

\begin{tabular}{ccc}
\hline Pollutant & PCL $($ ppm) & NSSS $($ ppm $)$ \\
\hline $\mathrm{As}$ & 41 & 10 \\
\hline $\mathrm{Cd}$ & 39 & 7 \\
\hline $\mathrm{Cu}$ & 1,500 & 741 \\
\hline $\mathrm{Pb}$ & 300 & 134 \\
\hline $\mathrm{Hg}$ & 17 & 5 \\
\hline $\mathrm{Mo}$ & ${ }^{*}$ & 9 \\
\hline $\mathrm{Ni}$ & 420 & 43 \\
\hline $\mathrm{Se}$ & 100 & 5 \\
\hline $\mathrm{Zn}$ & 2,800 & 1,202 \\
\hline
\end{tabular}

*No current federal EPA pollutant concentration limits (PCL), but the Virginia Department of Environmental Quality has adopted a limit of 40 parts per million. 
to limit the portion of high soluble-salt-containing compost mixed with soil when seeding or transplanting will occur soon after soil amending.

The higher the concentration of organic matter in compost, the greater will be the beneficial soil physical and chemical property effects. The water-holding capacity of the compost can vary depending on the quality and particle size distribution of the organic matter (table 9.6). The compost's water-holding capacity is directly proportional to the water-holding capacity of compostamended mineral soil. Bulk density of the compost is an indirect measure of the proportion of organic to mineral matter in the compost (mineral matter having a higher specific density than organic matter) and particle size distribution. An intermediate bulk density will have a balance between coarse and fine particles.

Because the primary purpose of compost used in landscapes is as a soil conditioner, there are no ideal concentrations of nutrients. Normal landscape application rates of compost do, however, provide considerable amounts of nutrients, even at the low concentrations that typically occur in compost (table 9.6). For instance, 1 inch of compost ( 3 cubic yards or approximately 1,350 pounds of dry matter per 1,000 square feet) having a nitrogen-to-phosphorus-to-potassium ratio of 1-to-1-to 1 (1:1:1) will provide 13.5 pounds each of nitrogen, phosphorus, and potassium per 1,000 square feet. Only a small portion of the nitrogen - but most of the phosphorus and potassium - will be plant-available.

Carbon-to-nitrogen ratios can provide useful information (e.g., potential degree of nitrogen mineralization or immobilization) about compost and other organic waste byproducts, although by themselves, they are not good indicators of compost quality. Most stabilized composts that are produced from well-designed starting recipes have carbon-to-nitrogen ratios between $12: 1$ and $20: 1$.
Table 9.6. Typical and preferred values of compost properties.

\begin{tabular}{lcc}
\hline Property & Typical & \multicolumn{1}{c}{ Preferred } \\
\hline $\mathrm{pH}$ & $5.0-8.5$ & $6.0-7.5$ \\
\hline $\mathrm{EC}(\mathrm{dS} / \mathrm{m})$ & $1-10$ & $\leq 5$ \\
\hline $\begin{array}{l}\text { Organic } \\
\text { matter (\%) }\end{array}$ & $30-70$ & $\geq 50$ \\
\hline $\begin{array}{l}\text { Water-holding } \\
\text { capacity (\%) }\end{array}$ & $75-200$ & \multicolumn{1}{c}{$\geq$} \\
\hline $\begin{array}{l}\text { Moisture } \\
\text { content (\%) }\end{array}$ & $30-60$ & \multicolumn{1}{c}{$40-50$} \\
\hline $\begin{array}{l}\text { Bulk density } \\
\text { (lb/cu yd) }\end{array}$ & $700-1,200$ & 800-1,000 \\
\hline $\begin{array}{l}\text { Nutrients } \\
0.5-2.5 \% \mathrm{~N}\end{array}$ & $\begin{array}{l}\text { No minimum } \\
\text { required for ideal } \\
\text { compost. }\end{array}$ \\
\hline $\begin{array}{l}\text { Inorganic } \\
\text { trace elements }\end{array}$ & $0.2-2 \% \mathrm{P}$ & $\begin{array}{l}\text { As, Cd, Cu, Hg, Mo, } \\
\text { Ni, Pb, Se, and Zn } \\
\text { must meet 40 CFR } \\
\text { Part 503 pollutant } \\
\text { concentration limits. }\end{array}$ \\
\hline $\begin{array}{l}\text { Growth } \\
\text { screening }\end{array}$ & $\begin{array}{l}\text { Should be measured } \\
\text { as "stable" to } \\
\text { "highly stable" by } \\
\text { appropriate tests. }\end{array}$ \\
\hline Stability & $\begin{array}{l}\text { Should pass seed } \\
\text { germination and } \\
\text { plant growth assays. }\end{array}$ \\
\hline
\end{tabular}

Table 9.7. Properties of various composts.

\begin{tabular}{lccrrrr}
\hline Feedstocks & $\begin{array}{c}\text { No. of } \\
\text { samples }\end{array}$ & $\mathbf{p H}$ & $\begin{array}{c}\text { EC } \\
(\mathrm{dS} / \mathrm{m})\end{array}$ & $\begin{array}{c}\text { Soluble } \mathbf{P} \\
(\mathrm{mg} / \mathrm{kg})\end{array}$ & $\begin{array}{c}\text { Water- } \\
\text { soluble N } \\
(\mathrm{mg} / \mathrm{kg})\end{array}$ & C:N ratio \\
\hline Biosolids and woodchips & 6 & 6.20 & 5.49 & 236 & 1,936 & $14.9: 1$ \\
\hline Yard waste & 1 & 6.75 & 6.40 & 139 & 534 & $32.2: 1$ \\
\hline Dairy manure & 3 & 7.50 & 8.52 & 204 & 448 & $14.6: 1$ \\
\hline Poultry litter & 5 & 7.53 & 19.80 & 1,092 & 979 & $9.9: 1$ \\
\hline $\begin{array}{l}\text { Various combinations of manures, } \\
\text { yard and woody waste }\end{array}$ & 11 & 6.57 & 11.50 & 94 & 1,359 & $12.9: 1$ \\
\hline
\end{tabular}

Source: Data from John C. Bouwkamp and Catherine Ku. Unpublished data. University of Maryland. 
Most feedstocks contain concentrations of inorganic trace elements (e.g., heavy metals, arsenic, and selenium; see tables 9.5 and 9.6) that will not pose a food chain, phytotoxicity, or direct ingestion concern, but the concentrations of these potential pollutants should be reported for all composts, particularly those produced from manure, biosolids, and other sludges. The concentrations of these pollutants should be lower than the EPA (1993) 40 CFR Part 503 pollutant concentration limits (table 9.5).

Because the ultimate purpose of compost application to soil is often to improve plant growth response, compost quality can also be assessed by the product's ability to support plant growth (i.e., biological properties). Incomplete and/or improper composting can generate a product with properties that can adversely affect plant growth and vigor. Incompletely composted material may possess bioactive carbon and a high carbon-tonitrogen ratio; its continued decomposition upon addition to soil can deplete plant root-zone oxygen $\left(\mathrm{O}_{2}\right)$ and/ or immobilize plant-available soil nitrogen via rapid microbial respiration.

The biological property "stability" should be assessed to ensure that only stabilized compost is used where plant growth is important. Stability is a measure of the degree of decomposition of carbon, where greater decomposition (i.e., greater stability) prevents high rates of oxygen-depleting, carbon-dioxide-producing $\left(\mathrm{CO}_{2}\right)$ microbial respiration and net soil nitrogen immobilization. Stability can be tested via various microbial respiration techniques that measure oxygen assimilation or carbon dioxide production. The Dewar's selfheating test employs an insulated container to measure the difference in temperature between ambient air and a compost sample maintained under conditions conducive to microbial activity (i.e., 50 to 60 percent moisture, optimal bulk density, and porosity). The extent of temperature change between ambient air and the "finished" compost provides an indirect test of the respiratory potential of the organic matter.

A second biological assessment method involves direct measure of such plant-growth parameters as seed germination and seedling vigor. Electrical conductivity was previously discussed as an abiotic property that could reduce plant vigor. Feedstocks being composted under anaerobic (i.e., oxygen-free) conditions can produce simple organic acids such as acetic (vinegar), butyric (rancid butter), and propionic that are the products of fermentation rather than composting. Such organic acids can be phytotoxic. Immature compost may also contain phytotoxic concentrations of ammonia and unstable, oxygen-depleting carbon.

Various chemical tests or bioassays can be used to evaluate compost or soil-compost mixes for the media's potential to support plant growth. There are several quick test methods that measure carbon dioxide and ammonia production, such as the Solvita compost maturity test (www.solvita.co.uk/products/compost-maturity-test-kit. $\mathrm{htm}$ ). Specialized compost laboratories offer tests for stability and growth screening in addition to the previously discussed physical and chemical properties. A list of some compost laboratories can be found on the U.S. Composting Council website at www.compostingcouncil.org/programs/sta/labs.php. These laboratories are also certified to perform analyses for the Composting Council's Seal of Testing Assurance Program ( $w w w$. compostingcouncil.org/programs/sta/), a composttesting, labeling, and information-disclosure program designed to provide information needed to maximize benefit from the use of compost.

Woods End Research Laboratory (www.woodsend. org/index.html) also performs testing of compost and natural soil amendments for certified organic farming acceptance. The Organic Materials Review Institute in Oregon conducts an independent review process according to the standards established in the U.S. Department of Agriculture's (USDA) National Organic Program of October 2002.

\section{Factors That Affect Nutrient Availability}

\section{Nitrogen}

Nitrogen in organic residuals is present in organic and inorganic (ammonium nitrogen: $\mathrm{NH}_{4}-\mathrm{N}$; nitrate nitrogen: $\mathrm{NO}_{3}-\mathrm{N}$ ) forms. Inorganic nitrogen is immediately plant-available, although nitrogen in the ammonium $\left(\mathrm{NH}_{4}\right)$ form can be lost via volatilization as ammonia $\left(\mathrm{NH}_{3}\right)$ if the residual has an alkaline $\mathrm{pH}$ and is applied to the soil surface.

Most of the nitrogen in heat-treated residuals and nearly all of the nitrogen in compost is organically complexed. Such nitrogen requires the organic matter to be mineralized in order to transform the nitrogen into plant-available nitrogen. The main factor that affects the portion of the organic nitrogen that mineralizes to PAN is the byproduct carbon-to-nitrogen ratio, which is inversely related to the fraction of PAN. Typically, net nitrogen mineralization occurs at a carbon-to-nitrogen ratio of 
less than 20:1, and net nitrogen immobilization occurs at a carbon-to-nitrogen ratio of more than 30:1. Littleto-no mineralization/immobilization occurs between carbon-to-nitrogen ratios of 20:1 and 30:1.

The form of the carbon in the residual also affects the extent and rate of mineralization. The mineralization rate decreases in relation to the stability of the organic matter in the residual. For example, the organic nitrogen in sewage sludges that have undergone waste activation and biosolids that have been decomposed by microbial (anaerobic, aerobic) digestion processes will mineralize slower than the organic nitrogen in livestock and poultry manures that have not first been subjected to microbial decomposition. Composted manures and sludges undergo intensive decomposition that reduces mineralization rates even further.

The data in table 9.8 summarize measured values for carbon-to-nitrogen ratios and calculated (estimated) values for total plant-available nitrogen (100 percent of inorganic nitrogen forms plus the plant-available fractions of the organic nitrogen in the various residuals). The higher PAN fractions are found in residuals that have a higher portion of their nitrogen in inorganic forms and a lower portion of their carbon in less decomposed (stable) forms.

\section{Table 9.8. Typical carbon-to-nitrogen ranges and first-year organic nitrogen mineralization rates of organic residuals in the mid-Atlantic states.}

\begin{tabular}{lcc}
\hline Residual & C:N range & $\begin{array}{c}\text { Nmin* } \\
\text { (first year \%) }\end{array}$ \\
\hline Manure, uncomposted & $6-25$ & $35-60$ \\
\hline Biosolids, uncomposted & $5-16$ & $25-35$ \\
\hline $\begin{array}{l}\text { Biosolids and manure, } \\
\text { heat-treated, dried, and } \\
\text { pelletized or granulated }\end{array}$ & $6-8$ & $35-50$ \\
\hline $\begin{array}{l}\text { Compost } \\
* \text { Nitrogen mineralization rate. }\end{array}$ & $5-15$ \\
\hline
\end{tabular}

\section{Phosphorus}

Phosphorus in organic byproducts is largely 100 percent plant-available, but the phosphorus in byproducts that contain considerable amounts of iron, manganese, and aluminum will be less-available than the phosphorus in byproducts containing lower amounts of these phosphorus-binding elements. The phosphorus in organic wastes is typically present in greater concentrations, relative to plant needs, than nitrogen. The application of organic wastes at rates to supply a plant's nitrogen need will usually supply more phosphorus than required by the plant. Therefore, organic waste byproducts must be applied judiciously to prevent soil phosphorus buildup to concentrations that promote phosphorus runoff and resulting surface-water impairment.

\section{Other Macronutrients and Micronutrients}

Organic wastes, being the eventual products of plant materials, contain every plant-essential element. The application of organic waste byproducts is rarely based on fertilizer elements other than nitrogen, phosphorus, or sometimes lime. However, there can be value to vegetative growth and quality by increasing the soil content of potassium, calcium, magnesium, sulfate sulfur $\left(\mathrm{SO}_{4}-\mathrm{S}\right)$, and micronutrients with such byproducts. One caveat is that byproducts could contain elements in concentrations that may be phytotoxic (e.g., boron).

\section{Uses of Organic Amendments}

\section{Pelletized and Granulated Products}

Heat-treated, dried, and pelletized or granulated products are essentially low-grade, organic fertilizers that can be applied in the same manner as inorganic fertilizers. Because such materials have fixed nitrogento-phosphorus-to-potassium ratios (unlike specially blended inorganic fertilizers), care must be taken not to overapply phosphorus when applying these products to meet nitrogen needs.

\section{Advanced Alkaline-Stabilized Materials}

Advanced alkaline-stabilized products can be used as liming agents, as topsoil blends, and to supply essential plant nutrients. These products are often physically granular and can be applied with standard fertilizer applicators.

\section{Compost and Blended Products}

\section{Compost as a Soil Amendment}

Residential soils are typically low in organic matter and have high bulk density because their topsoil has usually been removed and the underlying soil horizons compacted by earth-moving equipment. Such soils typically support poor vegetation, even when fertilized and watered (figure 9.1). For incorporation into disturbed or 
degraded soils as a soil conditioner and nutrient source for establishment of turfgrass, ornamentals, trees, and shrubs, a thickness of 1 to 2 inches of compost ( 3 to 6 cubic yards per 1,000 square feet or 135 to 270 cubic yards per acre) is recommended. Such rates can be surface-applied (figures 9.2 and 9.3) and incorporated into the soil surface prior to planting (figure 9.4). Turfgrass and other plants can then be established by seeding, sprigging, sodding, or transplanting. Seed germination and seedling vigor are typically improved with the use of compost (figure 9.5).

Compost can replace topsoil, peat, sand, and woody fines mix in conjunction with core aeration and reseeding or as a topdressed treatment only (figure 9.6). Compost should be applied at a depth of 0.125 inch to 0.250

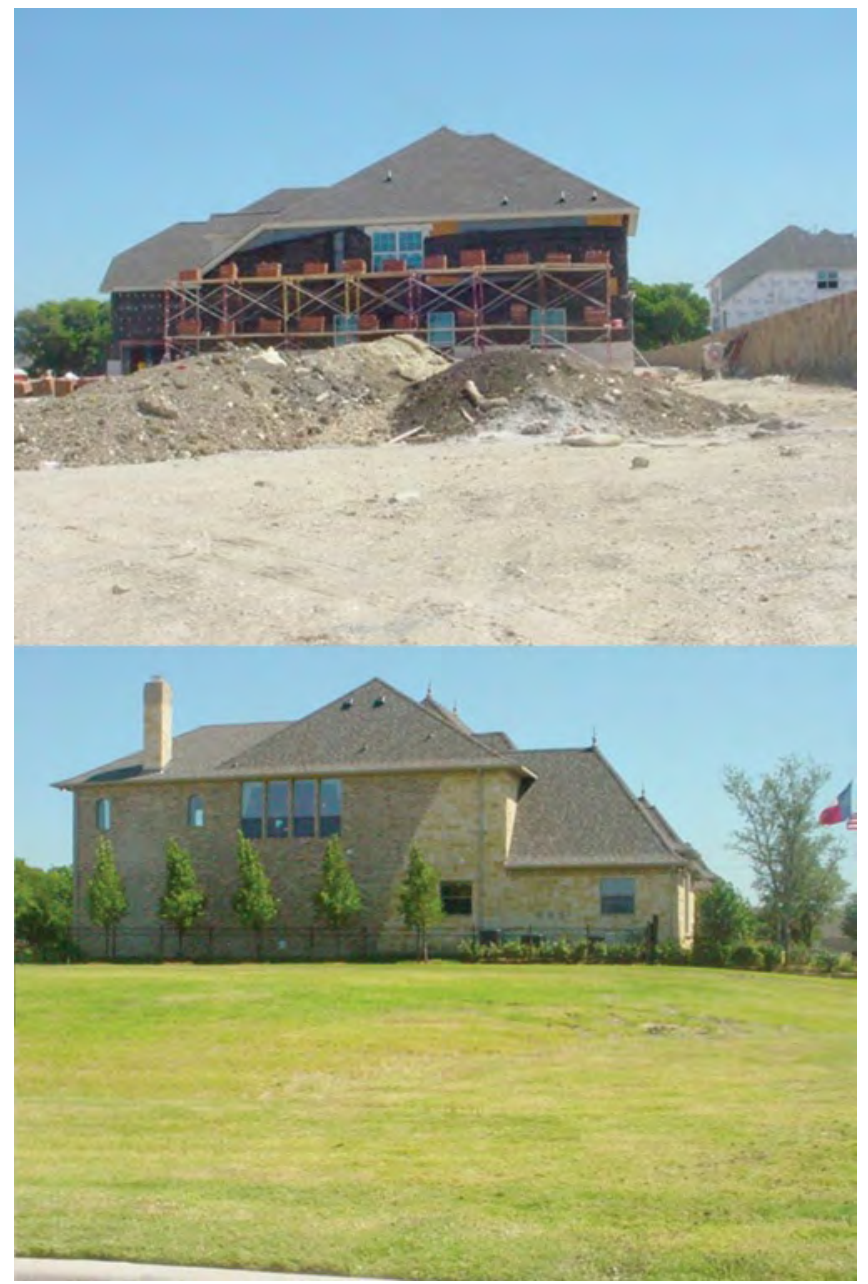

Figure 9.1. Ramifications of poor soil quality. Upper: Poor soil preparation.

Lower: Poor turf establishment.

Photos courtesy of John Sloan, Texas A\&M inch after aeration and moved into the holes by raking or dragging a chain. Such use of compost promotes seed germination and improves soil properties by placing compost several inches into the soil (figure 9.7).

In a review of 21 short- and long-term research studies, Shiralipour, McConnell, and Smith (1992) summarized the quantitative soil benefits of applications of 10 to 30 tons of mature municipal solid waste (MSW) compost per acre. The physical and chemical properties of most soils were improved with MSW (table 9.9; McConnell, Shiralipour, and Smith 1993). These studies demonstrate the consistent beneficial effects of compost as a soil amendment, especially for degraded environments. Additional benefits have been summarized by Alexander (2001).

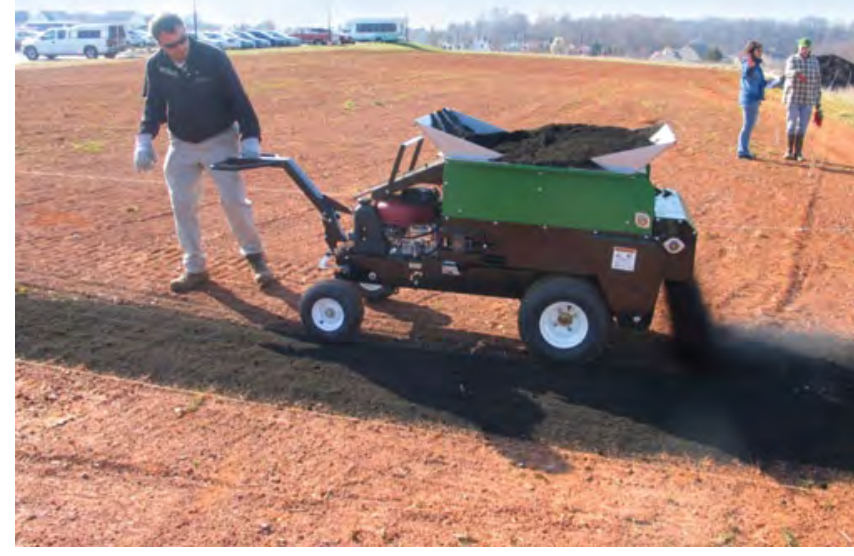

Figure 9.2. Applying compost to disturbed soil using a hand-operated spreader. Photo courtesy of Greg Evanylo.

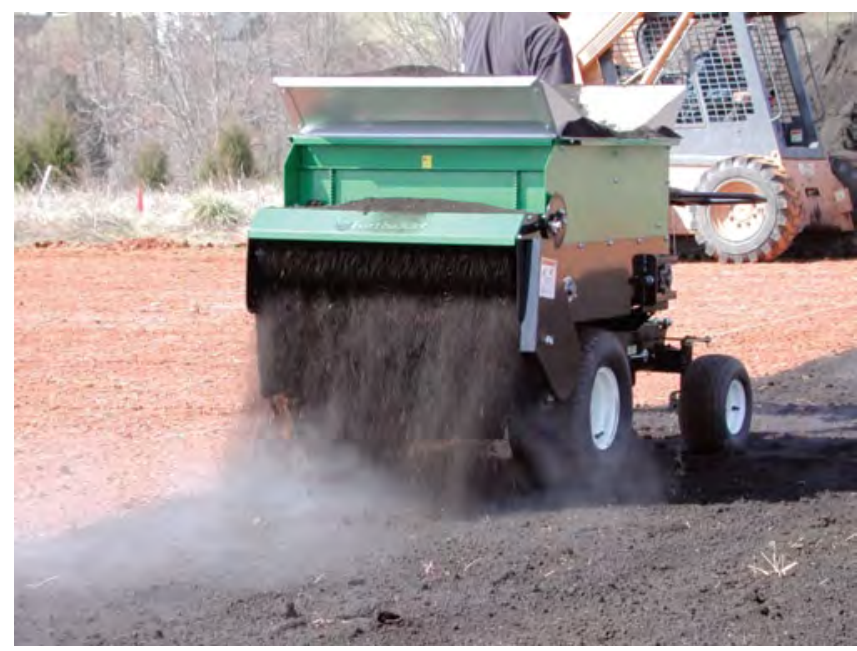

Figure 9.3. Close-up of compost application.

Photo courtesy of Greg Evanylo. 


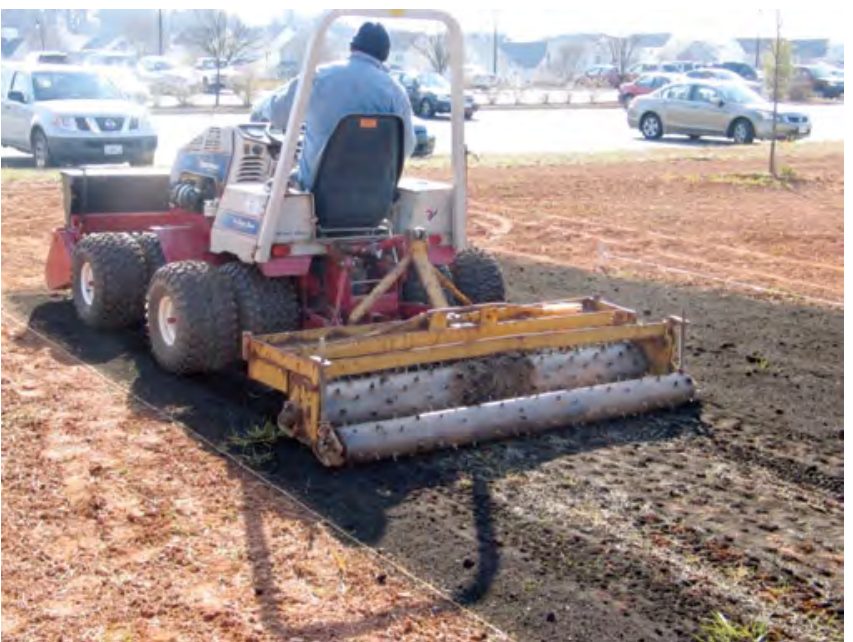

Figure 9.4. Applying turfgrass seed to compost-mulched disturbed soil. Photo courtesy of Greg Evanylo.

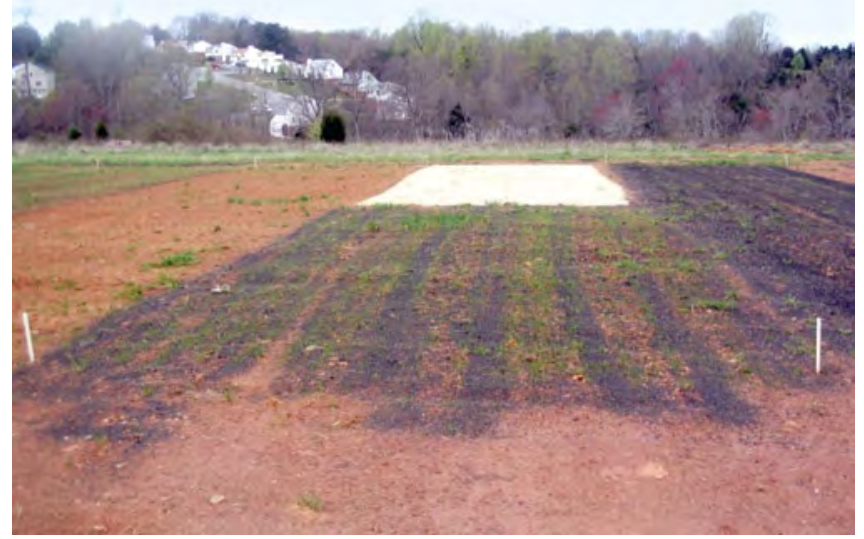

Figure 9.5. Comparison of turfgrass establishment on disturbed soil with various compost and standard treatments.

Photo courtesy of Greg Evanylo.

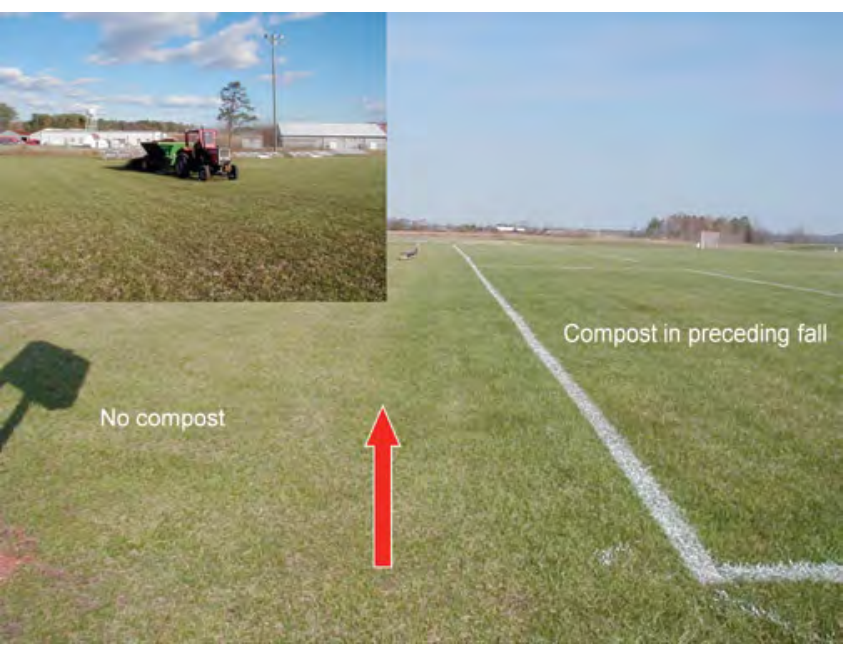

Figure 9.6. Effect of compost on athletic field. Inset showing compost being topdressed. Main picture showing difference between turfgrass color with and without compost. Photos courtesy of Mike Goatley.
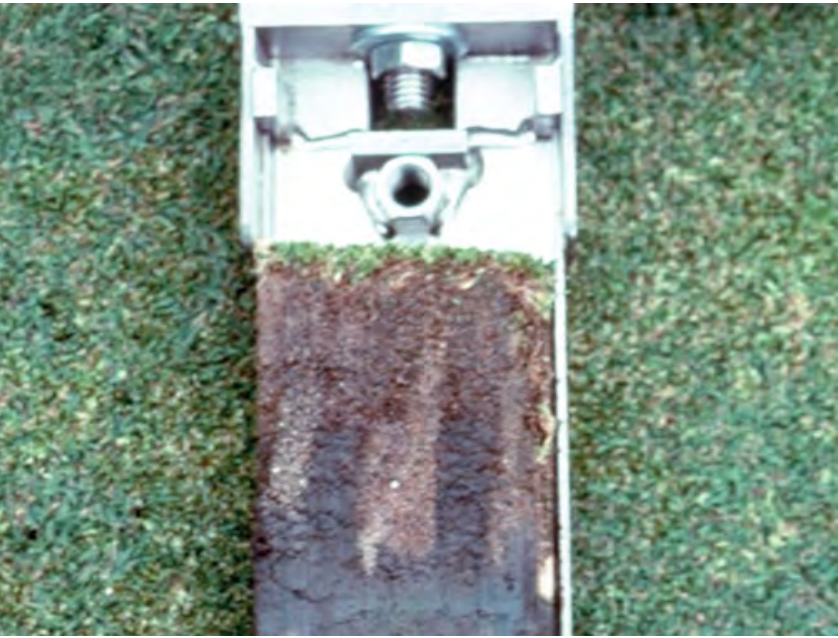

Figure 9 7. Topdressing compost after core aeration is a good practice for getting organic matter into soil under established turfgrass.

Photo courtesy of Ron Alexander, Alexander and Associates.

\section{Table 9.9. Effects of various rates of municipal solid waste (MSW) on soil properties (McConnell, Shiralipour, and Smith 1993).}

\begin{tabular}{lcc}
\hline & $\begin{array}{c}\text { Compost } \\
\text { application rate } \\
\text { (cubic yards/ } \\
\text { Soil property }\end{array}$ & $\begin{array}{c}\text { Change in } \\
\text { soil property }\end{array}$ \\
\hline Organic matter & 1.000 sq $\mathrm{ft}$ ) & $6.0-163.0 \% \uparrow$ \\
\hline $\begin{array}{l}\text { Cation exchange } \\
\text { capacity }\end{array}$ & $2.5-10.5$ & $31.0-94.0 \% \uparrow$ \\
\hline pH & $1.0-6.5$ & $0.8-1.4 \uparrow$ \\
\hline Bulk density & $1.0-6.5$ & $4.0-71.0 \% \downarrow$ \\
\hline $\begin{array}{l}\text { Water-holding } \\
\text { capacity }\end{array}$ & $0.5-6.5$ & $5.0-143.0 \% \uparrow$ \\
\hline $\begin{array}{l}\text { Essential plant } \\
\text { elements }\end{array}$ & $1.0-20.0$ & $0-500.0 \% \uparrow$ \\
\hline
\end{tabular}

Composts and other organic amendments have also been shown to provide beneficial biological effects, particularly suppression of plant disease. Nelson and Boehm (2002) summarized the results of studies that quantified turfgrass disease control from various organic amendments (table 9.10). While the maximum disease-control percentages were often high, there was considerable variation in control among different compost feedstocks, different batches of the same feedstock, and at different experiment locations.

Compost can be used as an amendment for various inground infiltration and filtration systems, such as bioretention systems and pervious pavement. Bioretention systems are shallow, landscaped depressions designed 


\section{Table 9.10. Turfgrass disease control by various organic amendments}

(Nelson and Boehm 2002).

\begin{tabular}{|c|c|c|}
\hline Amendment & $\begin{array}{c}\text { Disease } \\
\text { controlled }\end{array}$ & $\begin{array}{c}\text { Maximum \% } \\
\text { control }\end{array}$ \\
\hline $\begin{array}{l}\text { Activated sewage } \\
\text { sludge }\end{array}$ & Dollar spot & 99 \\
\hline \multirow{5}{*}{$\begin{array}{l}\text { Composted } \\
\text { biosolids }\end{array}$} & Brown patch & 42 \\
\hline & Dollar spot & 40 \\
\hline & Pythium root rot & 63 \\
\hline & Red thread & 51 \\
\hline & Typhula blight & 70 \\
\hline \multirow{5}{*}{$\begin{array}{l}\text { Composted } \\
\text { brewery sludge }\end{array}$} & Brown patch & 25 \\
\hline & Dollar spot & 15 \\
\hline & Pythium root rot & 68 \\
\hline & Red thread & 36 \\
\hline & Typhula blight & 70 \\
\hline \multirow{5}{*}{$\begin{array}{l}\text { Composted cow } \\
\text { or horse manure }\end{array}$} & Brown patch & 25 \\
\hline & Dollar spot & 73 \\
\hline & Pythium root rot & 31 \\
\hline & Red thread & 9 \\
\hline & Typhula blight & 55 \\
\hline \multirow{6}{*}{$\begin{array}{l}\text { Composted } \\
\text { poultry litter }\end{array}$} & Brown patch & 75 \\
\hline & Dollar spot & 55 \\
\hline & Necrotic ringspot & 86 \\
\hline & Pythium root rot & 94 \\
\hline & Red thread & 79 \\
\hline & Typhula blight & 15 \\
\hline \multirow{3}{*}{$\begin{array}{l}\text { Composted yard } \\
\text { trimmings }\end{array}$} & Brown patch & 39 \\
\hline & Dollar spot & 5 \\
\hline & Red thread & 0 \\
\hline $\begin{array}{l}\text { Composted grass } \\
\text { clippings }\end{array}$ & Brown patch & $50-80$ \\
\hline \multirow{3}{*}{$\begin{array}{l}\text { Spent mushroom } \\
\text { compost }\end{array}$} & Brown patch & 25 \\
\hline & Dollar spot & 0 \\
\hline & Red thread & 0 \\
\hline \multirow{6}{*}{$\begin{array}{l}\text { Uncomposted } \\
\text { organic fertilizer } \\
\text { (consisting of } \\
\text { soybean meal, } \\
\text { feather meal, } \\
\text { blood meal, bone } \\
\text { meal, etc.) }\end{array}$} & Brown patch & 75 \\
\hline & Dollar spot & 74 \\
\hline & Necrotic ringspot & 96 \\
\hline & Pythium root rot & 56 \\
\hline & Red thread & 57 \\
\hline & Typhula blight & 0 \\
\hline
\end{tabular}

to receive and filter stormwater runoff (figure 9.8). Such systems are typically incorporated into parking lot islands and residential landscapes. As the stormwater infiltrates the bioretention media, pollutants such as sediment, nutrients, polycyclic aromatic hydrocarbons, heavy metals, and bacteria are removed by filtration, adsorption, ion exchange, biological degradation, and volatilization (Davis 2007). Bioretention rain gardens are commonly composed of a natural well-drained soil (sandy loams or loamy sands are best) underlaid with coarse sand or gravel and covered with an organic mulch layer (compost). The role of the compost is to protect the soil bed from erosion, provide a medium that holds moisture in the plant root zone for vegetative growth, biological decomposition, volatilization of organics, treatment of bacteria, and pollutant filtering.

Use of pervious pavement is a practice for increasing the permeability of surfaces in residential and urban areas to increase infiltration and reduce stormwater runoff. Compost can be used as a partial amendment in pervious pavement for reducing erosion and filtering pollutants (figure 9.9).

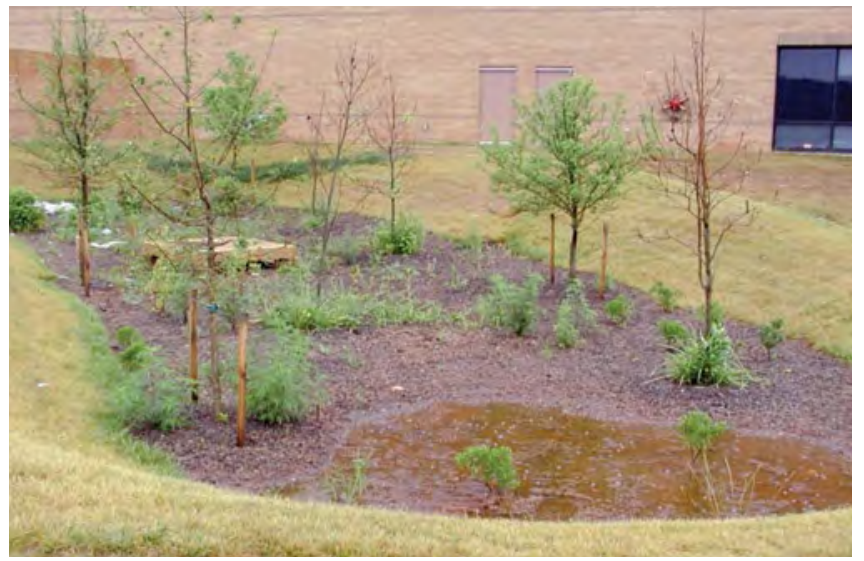

Figure 9.8. Bioretention rain garden. Photo courtesy of A. P. Davis, University of Maryland.

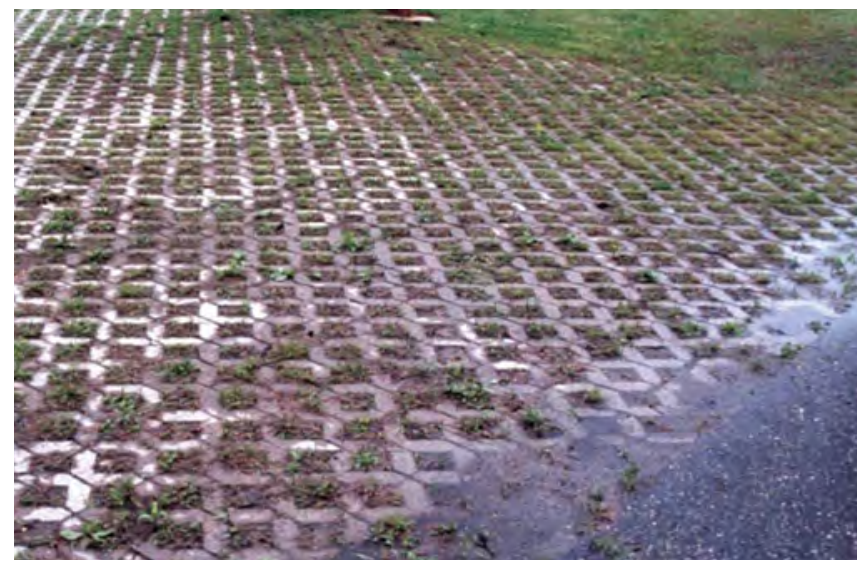

Figure 9.9. Compost can be used as partial growth and filtering medium in pervious pavement.

Photo courtesy of Dwayne Stenlud, MnDOT. 


\section{Using Compost as Landscape Mulch}

Compost can be used to mulch landscape vegetation to conserve soil moisture and prevent runoff and erosion. As an alternative to ground wood pallets, mulch compost conserved soil moisture and increased soil organic matter equally well as the woody waste; however, the soil nitrogen mineralization rate, plant-available nitrogen, and plant growth were higher with the compost (Lloyd et al. 2002). The benefits of compost were due largely to its lower carbon-to-nitrogen ratio (20:1) than that of the ground pallets $(100: 1)$.

Other well-researched uses of compost as mulch are for erosion and sediment control and as a cellulosic hydromulch substitute for highway roadsides. Roadsides and construction site "cut and fill" areas often leave steep, erosion-prone, low-fertility soils that can be difficult to vegetate and to physically stabilize. Applying compost (figure 9.10) at thicknesses of 1 to 2 inches to such sites can provide erosion- and runoff-reducing mulch whose organic matter and nutrient content reduce the longterm risk of vegetation establishment and maintenance failure (figure 9.11).

Even level, disturbed soils can be difficult to vegetate owing to the poor physical and chemical properties of such soils. Compost has also been used successfully to revegetate such highway roadsides with application thicknesses of 1 to 2 inches (figure 9.12).

\section{Using Compost as Filtering Amendment}

Due to its high organic matter content and variable distribution of particle-sized fractions, compost possesses a suite of attributes (e.g., porosity, chemical adsorption, biological activity) that permit its use as a filtering and processing agent for waterborne pollutants.

Filter berms are small windrows that can be constructed around disturbed land to reduce the transport of suspended and dissolved inorganic and organic solids and biological agents (figure 9.13). Compost filter berms can be used as recyclable, biodegradable, "living" filter silt fence substitutes. Upon stabilization of the adjacent disturbed land, compost berms present no disposal costs and are excellent growth media for vegetating the site perimeter.

Filter socks are mesh (sausage-like) containment systems into which can be stuffed compost possessing the appropriate physical and chemical properties to permit water flow, suspended solids filtering, and dissolved constituents' adsorption and biological degradation (figure 9.14). The EPA has touted such products

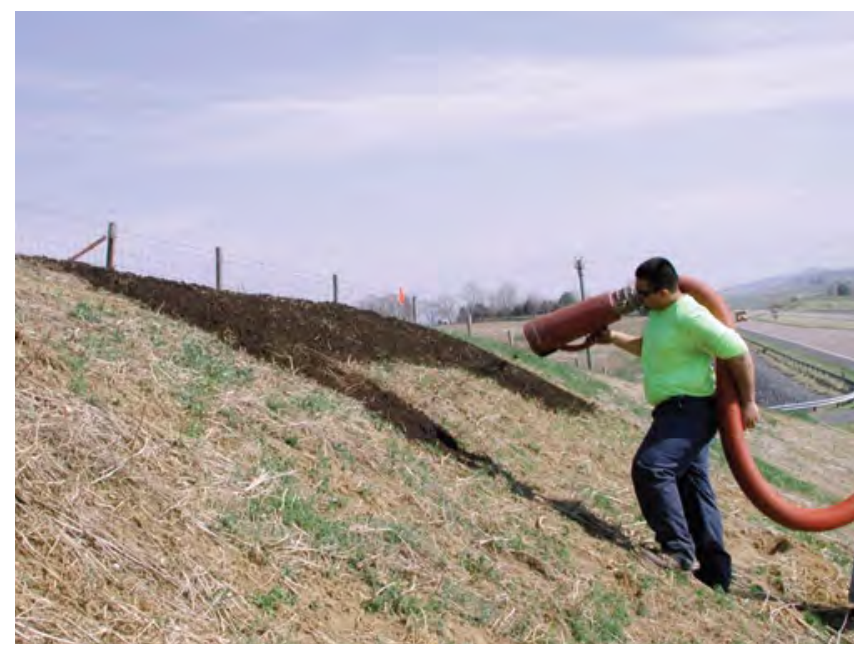

Figure 9.10. Compost applied pneumatically to steep slopes adjacent to highway to establish medium for erosion controlling and hillside stabilizing vegetation.

Photo courtesy of Greg Evanylo.

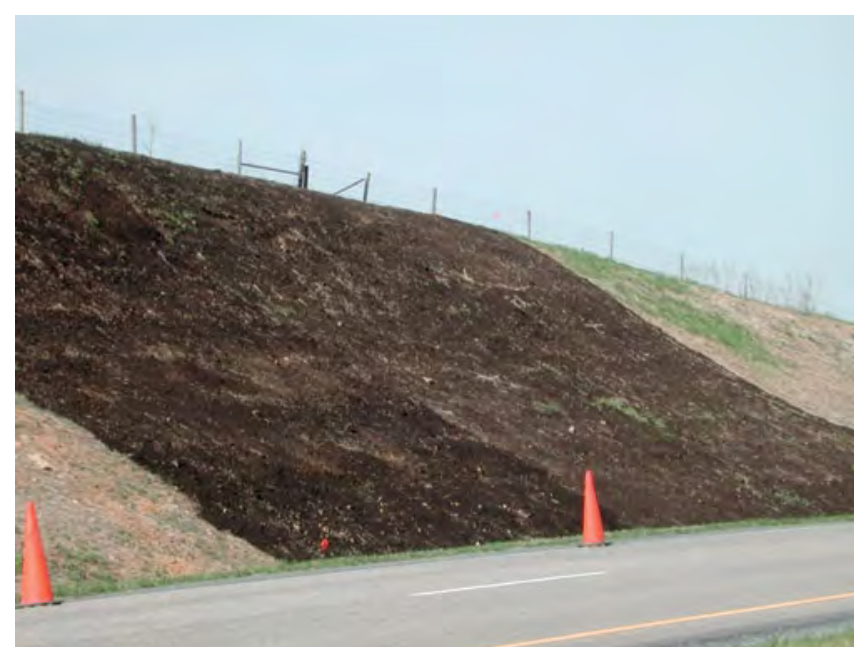

Figure 9.11. Compost-mulched roadside hill.

Photo courtesy of Greg Evanylo.

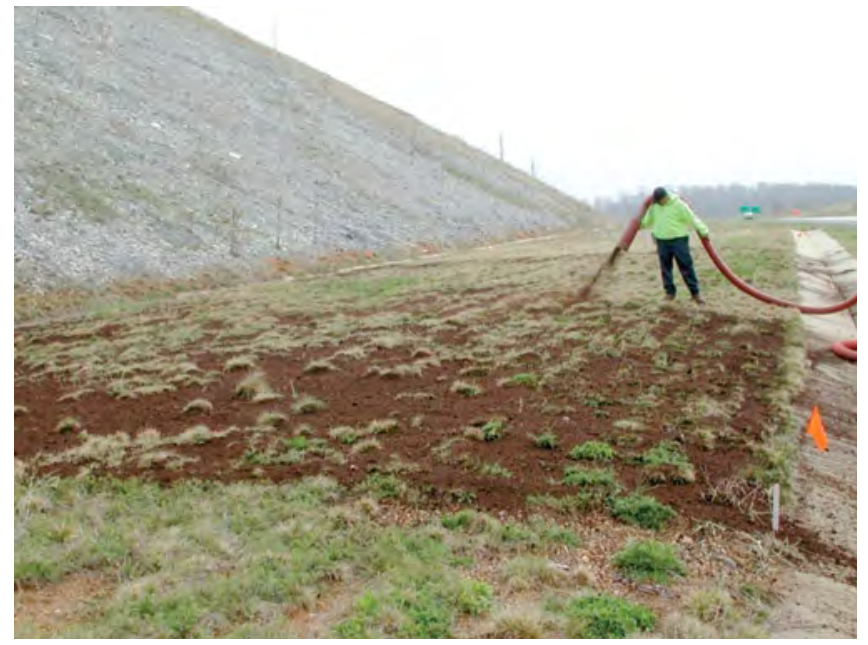

Figure 9.12. Applying compost to highway roadside to revegetate poorly established turfgrass. Photo courtesy of Greg Evanylo. 


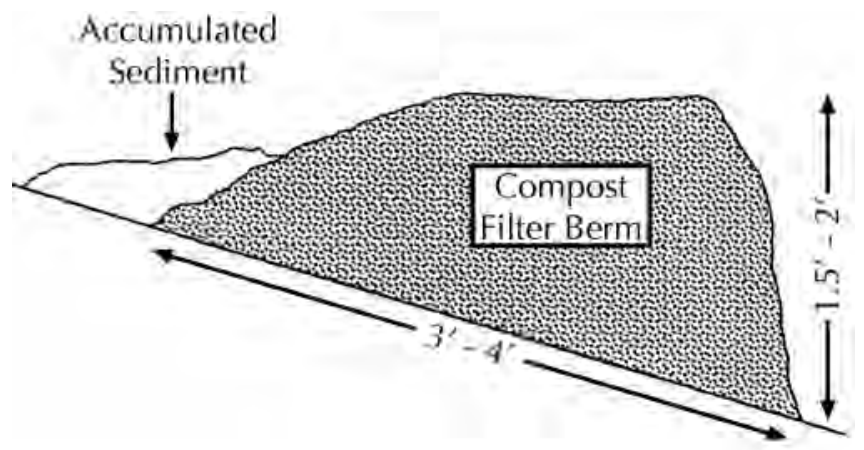

Figure 9.13. Compost filter berms can reduce the transport of suspended and dissolved water-borne constituents.

Illustration courtesy of Ron Alexander, Alexander and Asssociates.

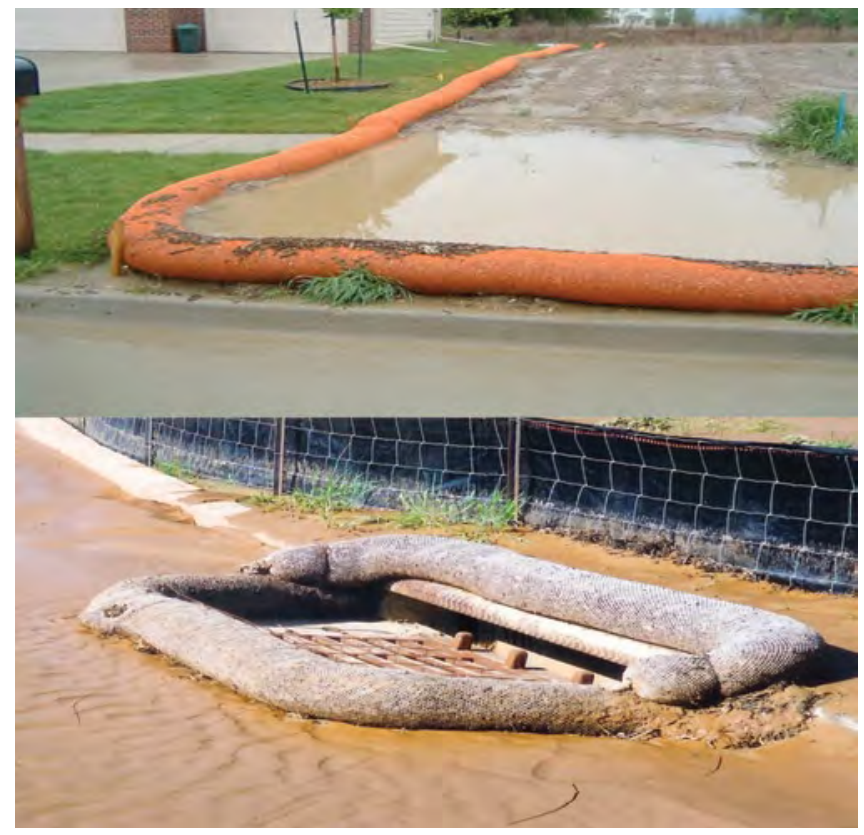

Figure 9.14. Compost in filter socks reduces runoff and protects stormwater quality.

Photos courtesy of Rod Tyler, Filtrexx International LLC.

revolutionized by Filtrexx International LLC ( $w w w$. epa.gov/waste/conserve/rrr/greenscapes/projects/filtrexx.htm). The environmental value of a specific compost source used in these systems is quantified in table 9.11, where certified test pollutant reductions have been listed. The compost removed most of the suspended solids and significant portions of dissolved pollutants via filtering and adsorption, while allowing a flow rate adequate to prevent excessive ponding behind the Soxx.

Additional uses of compost from yard waste can be found in The Virginia Yard-Waste Management Manual (VCE publication 452-055).

\section{Compost Application Rates}

Desirable application rates for compost vary depending on the purpose for its use and the cost of the product.

\section{Table 9.11. Filtrexx International-certified results for a specific compost product used as a filtering medium in a Filtrexx Soxx product.}

\begin{tabular}{ll}
\hline Parameter & Numeric value \\
\hline Flow-through rate & 16 gpm* \\
\hline Leach test & NPK: none \\
\hline Chemical removal & Total N: $29.0 \%$ reduction \\
\cline { 2 - 2 } & Total P: $14.0 \%$ reduction \\
\cline { 2 - 2 } & Total K: $14.0 \%$ reduction \\
\hline Motor oil test & $\begin{array}{l}98.5 \% \text { reduction } \\
\text { (absorption) }\end{array}$ \\
\hline Turbidity & $27.0 \%$ reduction \\
\hline Large solids removal & $100.0 \%$ reduction \\
\hline Suspended solids removal & $52.0 \%$ reduction \\
\hline $\begin{array}{l}\text { Suspended solids } \mathrm{w} / \\
\text { floculant }\end{array}$ & $96.0 \%$ reduction \\
\hline *gpm = gallons per minute. \\
\hline
\end{tabular}

The U.S. Composting Council (1996) published a valuable field guide for using compost, but the guide did not account for concentrations of potentially water-impacting nutrients that could be transported to surface water. Because composts produced from different feedstocks have different concentrations of soluble and potentially soluble carbon, nitrogen, and phosphorus, the composition of total and readily available, potentially waterimpairing nutrients in the compost and the proximity to water bodies must be assessed prior to planning application rates.

An understanding of how compost use affects soil properties that influence nutrient transport is also important. For instance, despite the application of considerably higher-than-needed phosphorus in five consecutive years of compost application, Spargo et al. (2006) measured no significant increase in runoff phosphorus compared to a control treatment fertilized according to soil testing recommendations because the high rates of compost increased infiltration and decreased runoff and erosion.

The conversions in table 9.12 can be used to estimate the volume of compost needed to apply varying thicknesses of compost to a given area. The required mass of compost can be calculated from the measured bulk density, which normally varies between 700 and 1,200 pounds per cubic yard. A general rule of thumb is that 
there are approximately 2 cubic yards in 1 ton of compost. Additional conversions are listed in The Field Guide to Compost Use (U.S. Composting Council 1996).

\begin{tabular}{ccc}
\hline Table 9.12. Compost use estimator. \\
\hline $\begin{array}{c}\text { Compost } \\
\text { thickness } \\
\text { (inches) }\end{array}$ & $\begin{array}{c}\text { Cubic } \\
\text { yards/1,000 } \\
\text { sq ft }\end{array}$ & $\begin{array}{c}\text { Cubic yards/ } \\
\text { acre }\end{array}$ \\
\hline 0.25 & 0.75 & 34.00 \\
\hline 0.50 & 1.50 & 67.00 \\
\hline 1.00 & 3.00 & 134.00 \\
\hline 2.00 & 6.00 & 269.00 \\
\hline
\end{tabular}

\section{How compost quality affects its fitness for use}

Although use of the highest quality compost will ensure the fewest agronomic/horticultural problems, all uses do not require compost of the highest quality. The information in table 9.13 shows the relative importance of quality attributes for various compost uses. For example, compost properties that influence plant growth are very important if the compost will be used where establishing vegetation is the primary purpose (e.g., land reclamation, soil amendment for horticultural crop), but such properties are not important if the primary purpose of the compost is as a vegetation-free, soil-erosion-controlling mulch. Conversely, particle size is important when considering compost as mulch, but not so for amending drastically disturbed soils for reclamation purposes.

\section{Table 9.13. Relative importance of quality attributes for various uses.}

\begin{tabular}{|c|c|c|c|}
\hline Attribute & $\begin{array}{c}\text { Land } \\
\text { reclamation }\end{array}$ & $\begin{array}{c}\text { Soil } \\
\text { amendment } \\
\text { for } \\
\text { horticultural } \\
\text { crop } \\
\end{array}$ & Mulch \\
\hline $\begin{array}{l}\text { Plant } \\
\text { growth }\end{array}$ & ++ & ++ & - \\
\hline $\begin{array}{l}\text { Nutrient } \\
\text { content }\end{array}$ & + & + & - \\
\hline $\begin{array}{l}\mathrm{pH} \text { and } \\
\text { soluble salts }\end{array}$ & + & + & - \\
\hline Maturity & - & + & - \\
\hline Particle size & - & + & + \\
\hline
\end{tabular}

\section{Organic Byproduct Summary With Regard to Water Quality}

1. The slow nitrogen-release nature of organic amendments can either reduce or increase water contamination risk. Although nitrogen from most organic byproducts will not be supplied in such high concentrations in the soil water as nitrogen from inorganic fertilizers, organic sources may continue to slowly release nitrogen during the season (i.e., winter) when plant uptake is greatly reduced or has ceased.

2. Organic amendments typically supply more phosphorus than is required by the growing vegetation when the amendment is applied at a rate to supply the plant's nitrogen needs. This can result in an accumulation of soil phosphorus at concentrations that may increase the risk of phosphorus runoff and surfacewater impairment.

3. The increase in soil organic matter with the application of organic amendments increases soil tilth (including aggregation), infiltration, and waterholding capacity, which reduces runoff volume and decreases the risk of surface water impairment by sediment, nitrogen, and phosphorus.

4. The increase in soil infiltration and water-holding capacity with the application of organic amendments increases vegetative biomass production and nutrient utilization, thus decreasing the risk of water impairment by nitrate leaching and nitrogen and phosphorus runoff.

\section{Inorganic Materials for Amending Soils}

There are a variety of inorganic materials used to amend soils, with the most common source being sand (Bigelow 2006). Based on particle size, sand is classified into five textural classes: very fine, fine, medium, coarse, and very coarse (see chapter 3 ). There are many possibilities in both composition and particle shape that further define sand and its particular uses. In the mid-Atlantic, calcareous and silica sands predominate, and they have varying shapes ranging from spherical to angular. Sand composition and shape is extremely important when selecting sands for completely modified root zones for golf putting greens or athletic fields. Consult the U.S. Golf Association's USGA Recommendations for a Method for Putting Green Construction (2004) if interested in putting green construction, or refer to a book such as Sports Fields: Design, Construction 
and Maintenance (Puhalla, Krans, and Goatley 2010) for recommendations in building a sand-based sports field.

Calcined and vitrified clays (also called porous ceramics) are naturally occurring materials that are mined in various parts of the country. The clays are heat-treated in a rotary kiln where they expand to significantly larger end products, similar to the size of sands. The end products are physically very stable and both retain some degree of cation exchange capacities (e.g., nutrient-holding capacity), but the temperature differences in their formation result in very different moisture-retention properties. Calcined clays, fired to temperatures up to $760^{\circ}$ $\mathrm{C}$, are noted for strong water-absorption properties. On the other hand, vitrified clays, fired at temperatures up to $1,100^{\circ} \mathrm{C}$, have significantly less water-holding capacity. Combinations of these products as wetting and drying agents are the staple for managing the skin (grass-free) areas of baseball and softball fields with calcined clay products serving as a wetting agent and vitrified clays serving as a drying agent. These materials can also be used in completely modified, sand-based soils if they meet particle size specifications.

Zeolites are either synthetic or naturally occurring mined aluminosilicates that provide greater cation exchange capacity than calcined clays but not quite as high a water-holding capacity. Zeolite compounds have been used as amendments in modified sand-based soils since the mid-1980s and their ability to capture and hold $\mathrm{NH}_{4}^{+}$and $\mathrm{K}^{+}$ions enhance turfgrass establishment and reduce nutrient leaching.

Diatomaceous earth is mined from deposits of the fossilized shell remains of diatoms - single-celled aquatic organisms whose shells are primarily silica. These fossilized remains contain a high percentage of micropores and have the ability to hold significant amounts of water. The physical stability of diatomaceous earth is questionable if used as an amendment on heavily trafficked soils, but calcining the product improves its strength.

Another inorganic amendment that has application primarily on sports turfs but could be utilized on any heavily trafficked area is crumb rubber. Use of crumb rubber presents a recycling opportunity because it is produced from ground-up tires. Developing a turfgrass canopy up to a 0.75 -inch depth has improved turf wear tolerance, reduced surface compaction, and improved shear resistance of the sod (Sorochan and Vanini 2003; Goddard et al. 2008). However, no more than 0.25 inch should be applied as a topdressing application, and the crumb should be sized to no more than 10- to 20-mesh material. It can float to the surface during heavy rain events and it is not a replacement strategy for implementing regular, hollow-tine, core cultivation programs to relieve compaction.

Incorporating crumb rubber into the existing soil has not been as successful as its benefits when used as surface topdressing. The best results on reducing surface compaction have been obtained when it is used preventively (pre-traffic) rather than as a curative (post-traffic) treatment. Given its black color, the heating of crumb rubber from radiant energy can benefit early- and lateseason turfgrass growth but can result in excessive heating in thin turfgrass canopies during the hottest months of the year, especially on cool-season turfgrasses.

\section{Inorganic Amendment Use Strategies}

Based on its comparatively large particle size, it is logical that sand can be added to fine-textured soils to improve drainage and soil aeration. Many potential mistakes and/or concerns exist about amending soils with inorganic materials. What is the size and uniformity of the proposed amendment? In general, uniform medium-to-coarse-textured amendments are desired, and well-graded materials (e.g., concrete sand that contains equal percentages of fine-, medium-, and coarsetextured materials) are discouraged.

Next, just how much of the amendment is required to achieve the desired results? The only way to precisely determine this is to conduct a physical analysis of mixtures of the existing soil material and proposed amendments, something that will likely have to be done by consulting with a soil testing laboratory.

The most common mistakes in modifying existing soils with sands (or other coarse-textured amendments) are (1) using an inappropriately sized material, and (2) not adding enough coarse-textured amendment to affect the desired changes in porosity. As a rule of thumb, uniform, medium-to-coarse-textured inorganic materials are desirable for amending soils. Well-graded amendments such as "concrete sand" have very limited potential in increasing porosity when added to heaviertextured soils because the relatively equal percentages of fine, medium, and coarse aggregates are intended to produce a firm medium. 
A quick review of the soil textural triangle (figure 9.15) demonstrates how specified ranges in the percentages of sand, silt, and clay are used to define soil texture. Soils that are very high in percentage of silt and clay will require large additions of sand to change their textures; for any soil to even have "sand" in its textural name (sandy clay, sandy clay loam, etc.), it will have to contain approximately 50 percent sand by volume.

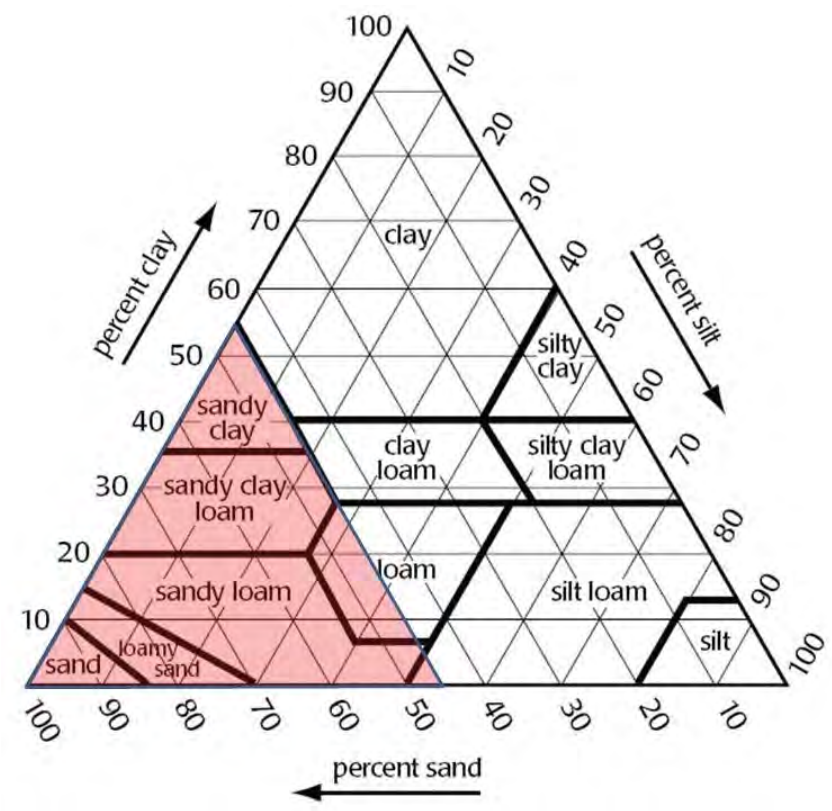

Figure 9.15. The soil textural triangle.

Table 9.14 demonstrates how adding up to 40 percent by volume of either a uniform medium-textured sand or calcined clay to a silt loam soil alters porosity and water-holding capacity. In this example, adding either the medium sand or the calcined clay essentially doubles the percentage of air porosity and reduces the percentage of plant-available water by one-third as compared to the silt loam soil. However, the two amendments vary widely in their effects on the percentage of plantunavailable water and total porosity. The calcined clay doubles the percentage of plant-unavailable water (water is held so tightly by the calcined clay particles that plants cannot utilize it) but increases the percentage of total porosity. The sand-modified soil has virtually no change in the percentage of plant-unavailable water and an actual decrease in the percentage of total porosity (table 9.14). The data reveal the difficulty in predicting how adding what seems to be an appreciable amount of coarse-textured amendment actually affects the physical properties of the soil. A physical soil test is required to precisely determine how much amendment is needed to blend with a specified depth of the existing soil. Even with these data, the actual performance of the blended soil in the field will still be greatly influenced by how thoroughly the mixing of amendment and existing soil is conducted.

\section{Topdressing With Inorganic Amendments}

Periodic (one to two times annually), light (0.25-inch depth or less) topdressing (i.e., surface applications) of inorganic amendments offers the potential benefits of surface smoothing and improved thatch control in turf. It is ideal to conduct the topdressing event with hollowtine core aeration events in order to better incorporate the material into the soil profile. Topdressing is a cultural practice that is quite common on sand-based golf greens and athletic fields. Although not common in lawn turf management, the benefits are the same. Due to economics, sand is the logical inorganic material of choice. In general, a uniform, medium-to-coarse-textured material is preferable, but even well-graded concrete sands have been successfully used in topdressing lawn turf if they are applied one to two times annually at depths of 0.25 inch or less. The possibilities of topdressing with crumb rubber on heavily trafficked sites are detailed above.

\section{Table 9.14. Alterations in soil porosity and available water percentages of a silt loam topsoil amended with inorganic materials.}

\begin{tabular}{lcccc}
\hline $\begin{array}{c}\text { Amendment added } \\
(\% \text { by volume })\end{array}$ & $\begin{array}{c}\text { Air porosity } \\
(\%)\end{array}$ & $\begin{array}{c}\text { Plant-available water Plant-unavailable water } \\
(\%)\end{array}$ & $\begin{array}{c}\text { Total porosity } \\
(\%)\end{array}$ \\
\hline None & 9 & 35 & 9 & 53 \\
\hline $40 \%$ medium sand & 18 & 22 & 8 & 48 \\
\hline $40 \%$ calcined clay & 16 & 25 & 20 & 61 \\
\hline
\end{tabular}

Source: Data provided by D. V. Waddington, professor emeritus of soil science, Pennsylvania State University. 


\section{Literature Cited}

Alexander, R. 2001. Compost utilization in landscapes. In Compost Utilization in Horticultural Cropping Systems, ed. P. J. Stoffella and B. A. Kahn, 151-75. Boca Raton: Lewis Publishers.

Bigelow, C. A. 2006. Making amends: Here's what to expect when choosing an amendment for soils. Grounds Maintenance 41 (7): 35-39.

Davis, A. P. 2007. Bioretention and rain gardens. Presentation at 2007 Mid-Atlantic Composting Association Conference. Beltsville, Md. http://preview. tinyurl.com $/ 25 \mathrm{se} 3 \mathrm{z} v$.

Environmental Protection Agency (EPA). 1990. National sewage sludge survey: Availability of information and data, and anticipated impacts on proposed regulations. Proposed Rule 40 CFR, Part 503. Federal Register 55 (218): 47,210-283.

Environmental Protection Agency (EPA). 1993. Standards for the use or disposal of sewage sludge: Final rules. Code of Federal Regulations. Title 40 Parts 257, 403, and 503; 9,248-415.

Evanylo, G. K., C. A. Sherony, J. H. May, T. W. Simpson, and A. H. Christian. 2003 (reviewed 2009). The Virginia Yard-Waste Management Manual. 2nd ed. Virginia Cooperative Extension Publication 452-055. http://pubs.ext.vt.edu/452/452-055/452-055.pdf.

Goddard, M. J. R., J. C. Sorochan, J. S. McElroy, D. E. Karcher, and J. W. Landreth. 2008. The effects of crumb rubber topdressing on hybrid Kentucky bluegrass and bermudagrass athletic fields in the transition zone. Crop Science 48 (5): 2,003-09.

Hammac II, W. A., C. W. Wood, B. H. Wood, O. O. Fasina, Y. Feng, and J. N. Shaw. 2007. Determination of bioavailable nitrogen and phosphorus from pelletized broiler litter. Scientific Research and Essay 2 (4): 89-94. www.academicjournals.org/ SRE (http://preview.tinyurl.com/2g2lsu2).
Lloyd, J. E., D. A. Herms, B. R. Stinner, and H. A. J. Hoitink. 2002. Comparing composted yard trimmings and ground wood as mulches. BioCycle 43 (9): 52-56.

McConnell, D. B., A. Shiralipour, and W. H. Smith. 1993. Compost application improves soil properties. BioCycle 34 (4): 61-63.

Nelson, E. B., and M. J. Boehm. 2002. Compost induced suppression of turf grass diseases. BioCycle 43 (6): 51-55.

Puhalla, J. C., J. V. Krans, and J. M. Goatley Jr. 2010. Sports Fields: Design, Construction, and Maintenance. 2nd ed. Hoboken, N.J.: John Wiley \& Sons.

Shiralipour, A., D. B. McConnell, and W. H. Smith. 1992. Physical and chemical properties of soils as affected by municipal solid waste compost application. Biomass and Bioenergy 3 (3-4): 261-66.

Sorochan, J. C., and J. T. Vanini. 2003. Managing fields using crumb rubber and varietal selection. SportsTurf 19 (5): 14-16.

Spargo, J. T., G. K. Evanylo, and M. M. Alley. 2006. Repeated compost application effects on phosphorus runoff in the Virginia Piedmont. Journal of Environmental Quality 35:2342-51.

U.S. Composting Council. 1996. The Field Guide to Compost Use. Alexandria, Va.: U.S. Composting Council.

U.S. Golf Association. Green Section. Revised 2004. Recommendations for a Method of Putting Green Construction. Far Hills, N.J.: U.S. Golf Association. http://tinyurl.com/36rjqau. 


\section{Chapter 10. Equipment Calibration and Fertilizer Application Methods}

Michael Goatley Jr., Professor and Extension Specialist, Crop and Soil Environmental Sciences, Virginia Tech

Steven Hodges, Professor, Crop and Soil Environmental Sciences, Virginia Tech

\section{Introduction}

After determining the source and form of nutrients that best fit the situation, it is necessary to have an accurate assessment (size, surrounds, plant materials, etc.) of the area planned for fertilization. Square footage of areas can usually be calculated by assessing site characteristics for typical shapes and using some basic geometric formulas for the different shapes detailed in figure 10.1 to calculate square footage. For example, using the formula for the circle below, one could calculate the square footage of a circular courtyard with a diameter of 25 feet as having a total square footage of

\section{$3.14 \times(12.5)^{2}=490.6$ square feet.}

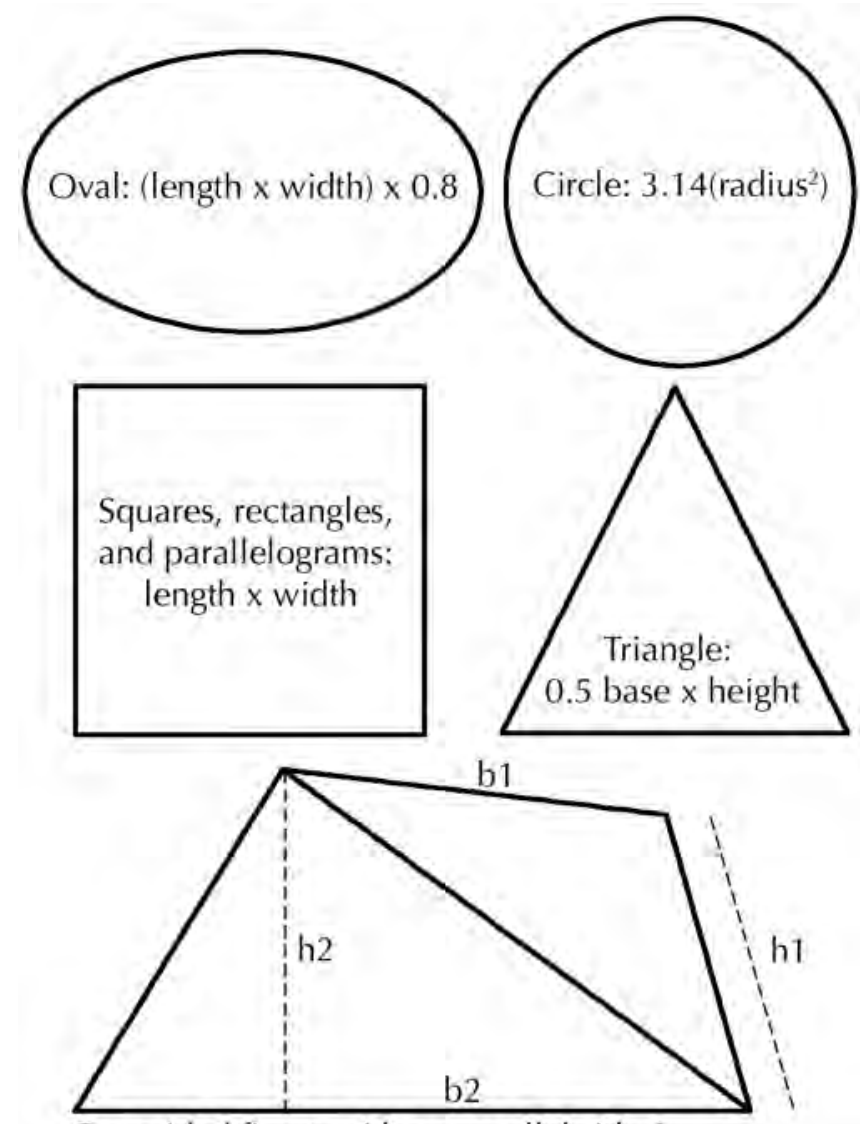

Four-sided figure with no parallel sides?

Divide into two triangles and calcuate both areas as triangles using the 0.5 base $\mathrm{x}$ height formula.

Figure 10.1. Mathematical formulas for calculating the square footage of various shapes found in turf and landscape management situations.
The next step to consider is the basic calculation of how much product is needed to deliver the desired amount of nutrient. The three numbers that make up the fertilizer grade on the label represent the percentages of nitrogen $(\mathrm{N})$, phosphate $\left(\mathrm{P}_{2} \mathrm{O}_{5}\right)$, and potash $\left(\mathrm{K}_{2} \mathrm{O}\right)$ by weight, and the label will list any other nutrients contained within the fertilizer on a percentage-by-weight basis as well.

\section{Dry Fertilizer and Application Methods}

Fertilizers are available in either dry or liquid formulations. First, consider dry formulations and their standard delivery methods. For dry formulations, the percentage of each nutrient by weight will be indicated in the Guaranteed Analysis section of the label. To determine the amount needed for a given area, use the following basic formula (and note that nitrogen is generally used because it is usually the most limiting nutrient).

$$
=\frac{\begin{array}{c}
\text { Pounds of fertilizer per area } \\
\text { Pounds of } \mathrm{N} \text { needed per area }
\end{array}}{\begin{array}{c}
\mathrm{N} \text { from fertilizer formula as a decimal } \\
\text { (i.e., the number divided by } 100 \text { ) }
\end{array}}
$$

Example: Using a 16-4-8 fertilizer to supply 1 pound of nitrogen per 1,000 square feet gives:

$$
\begin{aligned}
& \text { Pounds of fertilizer per area } \\
& =\frac{1 \mathrm{lb} \text { of } \mathrm{N} \text { per } 1,000 \mathrm{sq} \mathrm{ft}}{0.16} \\
& =6.25 \mathrm{lb} \text { of fertilizer per } 1,000 \mathrm{sq} \mathrm{ft}
\end{aligned}
$$

Because the numbers on the fertilizer grade represent their percentage by weight, the amounts of phosphate and potash that would be delivered to the area would be:

$$
\begin{aligned}
& 6.25 \times 0.04=0.25 \mathrm{lb} \text { of } \mathrm{P}_{2} \mathrm{O}_{5} \text { per } 1,000 \mathrm{sq} f t \\
& 6.25 \times 0.08=0.50 \mathrm{lb} \text { of } \mathrm{K}_{2} \mathrm{O} \text { per } 1,000 \mathrm{sq} f t
\end{aligned}
$$

Notice that the proportion of the nutrients remains constant: A 16-4-8 product has a 4-1-2 proportion of nitrogen to phosphate to potash.

Product requirements for larger or smaller areas can simply be made by calculating standard proportions. 
Using the basic algebraic steps of "cross multiply, divide, and solve for the unknown" is a popular way to perform fertilizer calculations. For example, for the proportion of $1 / 2=\mathrm{Y} / 4$, cross-multiplying results in:

$$
\begin{gathered}
(1 \times 4)=(2 \times Y) \\
4=2 Y
\end{gathered}
$$

Dividing each side by 2 results in $Y=2$. Apply this same proportion concept to fertilizer calculations with the only requirement being that the units in the numerators (top number in the proportion) and the denominators (bottom number of the proportion) must match.

Assume the goal is to deliver 1 pound of nitrogen per 1,000 square feet to a 10,000-square-foot area with the 16-4-8 fertilizer previously considered. The previous calculation determined that 6.25 pounds of $16-4-8$ total are needed to deliver a desired level of 1 pound of nitrogen per 1,000 square feet to the 10,000 -squarefoot area. Carefully keeping the proportion rules for similar units in numerators and denominators in place, the basic proportion is:

$$
\begin{aligned}
\frac{6.25 \mathrm{lb} \text { of } 16-4-8}{1,000 \mathrm{sq} \mathrm{ft}} & \times \frac{\mathrm{Y} \mathrm{lb} \text { of } 16-4-8}{10,000 \mathrm{sq} \mathrm{ft}} \\
52,500 & =1,000 \mathrm{Y} \\
\mathrm{Y} & =62.5 \mathrm{lb} \text { of } 16-4-8
\end{aligned}
$$

\section{Drop Spreader Calibration}

Drop spreaders (figure 10.2) allow granules to drop out of a hopper by gravity and provide the most accurate distribution because the material falls directly below its release point. Wind is of minimal concern with distribution uniformity, but applications take longer because only limited areas are being covered in a single pass. Drop spreaders are preferred when applying very fine material or a mix of nutrients of differing sizes, and they are ideal to use around impervious surfaces as a means of ensuring that the product is kept off hardscapes.

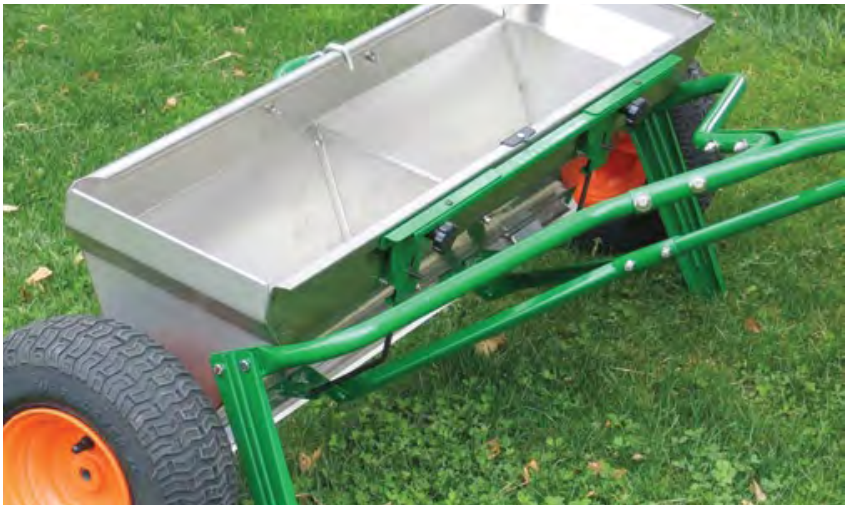

Figure 10.2. A typical 3-foot-wide drop (gravity-fed) spreader.
To calibrate the spreader, you will need to collect and weigh the amount of product actually dropped in a known area at a given spreader setting. It is strongly recommended to apply material at one-half the desired rate in perpendicular directions to reduce the possibility of skips and to avoid fertilizer application disasters such as the example in figure 10.3.

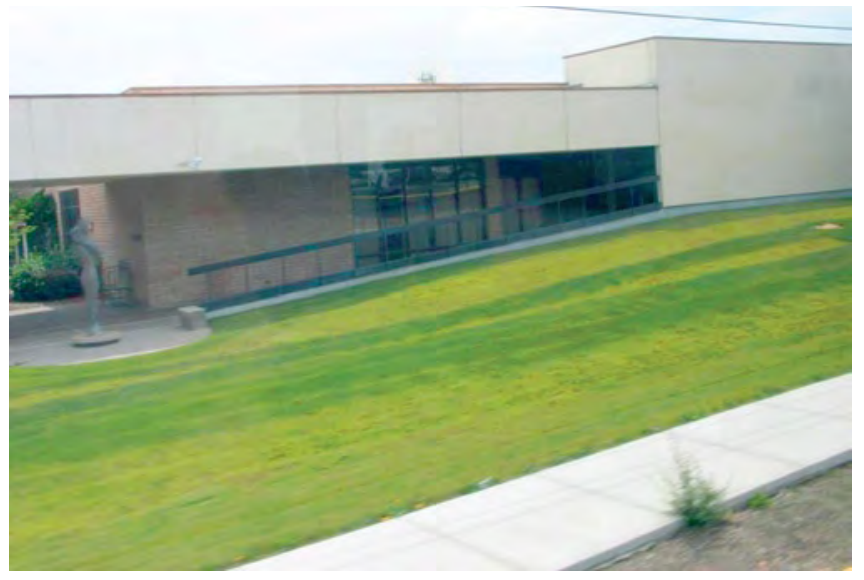

Figure 10.3. Striping is evidence of either a poorly calibrated drop spreader or an inexperienced operator who did not properly apply the fertilizer.

\section{Steps in Drop Spreader Calibration}

1. Determine a known area for the calibration: Measure the width of your spreader (feet) and the distance you will walk during the calibration process (figure 10.4). For this example, assume a 2-foot-wide spreader (drop width, not overall width of spreader) and plan on walking a 50-foot length for a calibration area of 2 feet by 50 feet $=100$ square feet.

2. Prepare a collection device: A huge timesaver in calibrating a drop spreader is to hang a "catch pan" from the base of the spreader frame to collect all product that falls through the hopper. A catch pan made by cutting an appropriate length of 4-inchdiameter PVC pipe and fitting it with two end caps is shown in figure 10.5. An alternative method to collect product is to drop the material on a piece of plastic or on a clean, hard surface that can be swept to collect the product after it is dropped. (Note: For lengths longer than 10 feet, you will want to use a catch pan rather than dropping it on plastic or a hard surface and collecting.)

3. Ensure normal spreader operation: Place enough of your dry product in the spreader to completely cover the base and make sure the particle size is small enough to readily flow through the spreader. Specialty turf fertilizers usually work well, but many agricultural-grade materials (for example, 10-1010) are too large to flow through a drop spreader. 
4. Make the calibration "run": Select a low-to-medium setting on the spreader (figure 10.6). Begin walking a few paces behind the calibration starting point in order to establish a consistent speed. Open the spreader as you reach the starting point and walk the desired, known length. Collect the product in the catch pan, sweep it off the hard surface or collect it off the plastic, and place it in a container of a known weight.

5. Weigh the product (figure 10.7) and calculate the amount of product (total weight minus weight of the container) being delivered per unit area: If the amount delivered does not match the amount you are trying to apply, adjust the spreader setting and repeat the calibration steps until you collect the desired amount. Note: One of the biggest limitations when using a small area for calibration is the accuracy of the scales. Accurate calibrations are possible in small areas with very precise scales as pictured in figure 10.7, but if you want to use standard scales from around the house, the calibration area (and therefore, the amount of product collected) will have to be much larger.

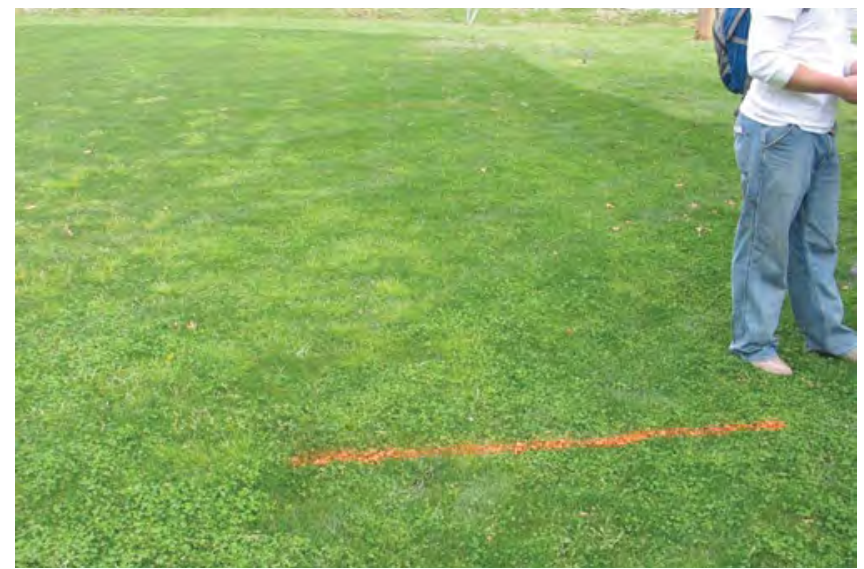

Figure 10.4. A calibration run length of 20 feet has been marked with paint in this photo.

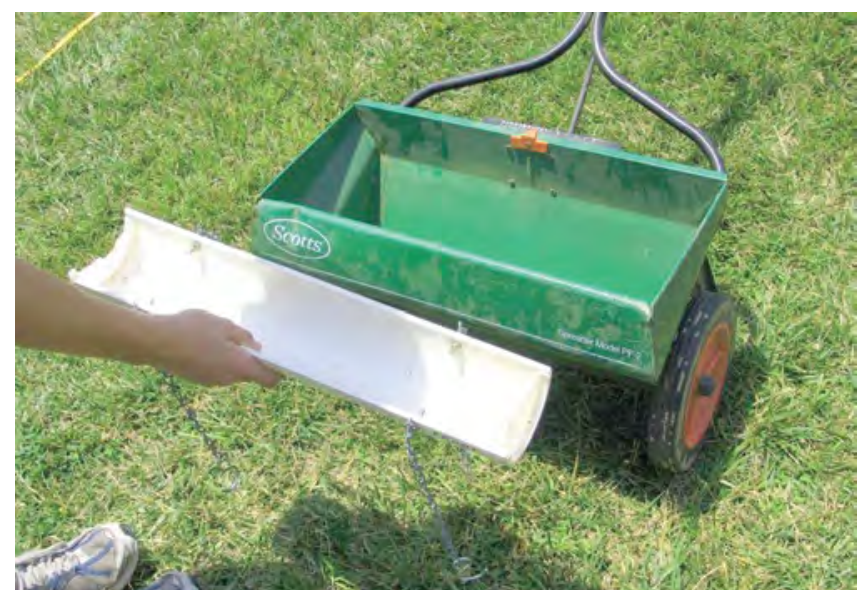

Figure 10.5. A homemade catch pan made from a piece of PVC pipe.

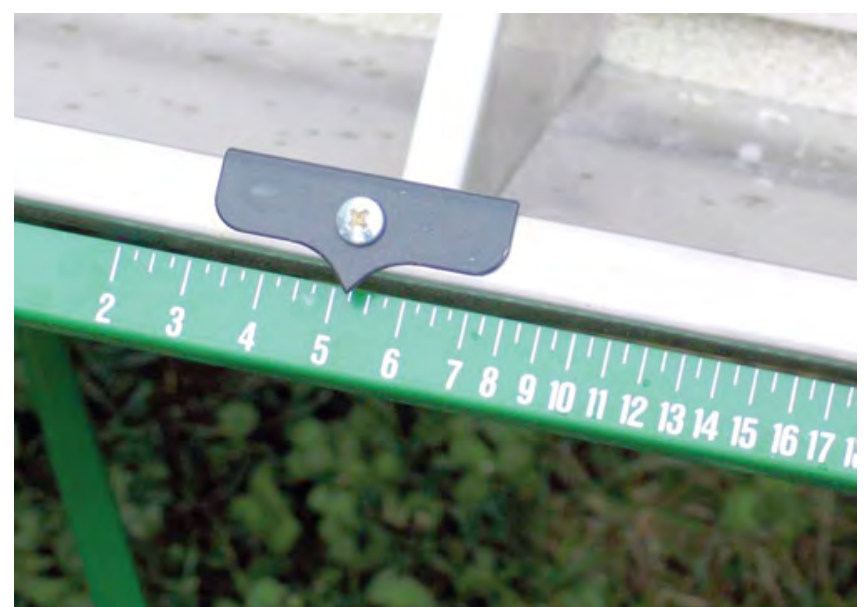

Figure 10.6. Adjusting the setting on the spreader will increase or decrease the size of the openings at the base of the spreader.

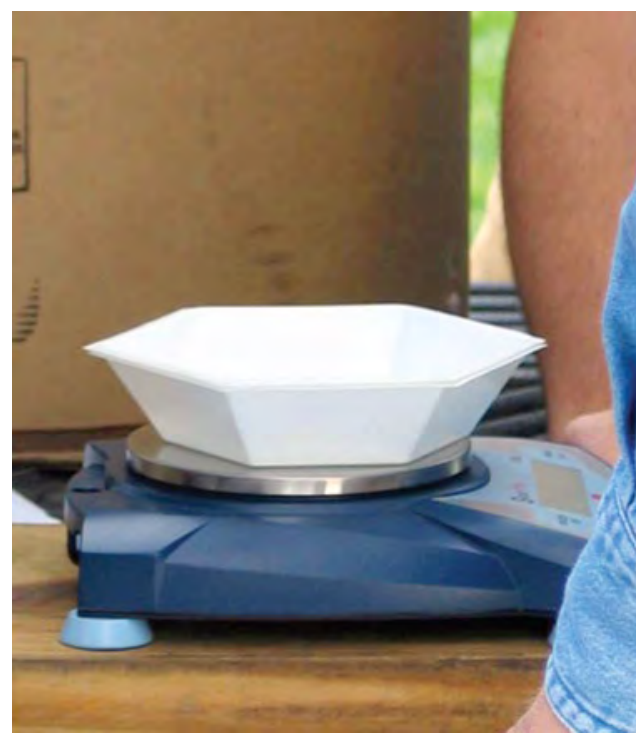

Figure 10.7. Scales that measure in units of ounces or grams allow for accurate spreader calibration on relatively small areas.

Example: The fertilizer selected for application is a 6-2-0 organic material (containing 6 percent nitrogen, 2 percent phosphate, and 0 percent potash by weight). The desired level of application for this slowly available nitrogen source is 1.5 pounds of nitrogen per 1,000 square feet, so the formula is $1.5 \div 0.06=25$ pounds of 6-2-0 fertilizer required per 1,000 square feet. The spreader is 2-feet wide (and is equipped with a catch pan) and a length of 25 feet has been measured, resulting in a 50-square-foot calibration area (25 feet in length $\mathrm{x} 2$-foot drop spreader width $=50$ square feet of area covered in a single pass). The setup for the proportion is:

$$
\begin{aligned}
\frac{25 \mathrm{lb} \text { of } 6-2-0}{1,000 \mathrm{sq} \mathrm{ft}} & \times \frac{\mathrm{Y} \mathrm{lb} \text { of } 6-2-0}{50 \mathrm{sq} \mathrm{ft}} \\
1,250 & =1,000 \mathrm{Y} \\
\mathrm{Y} & =1.25 \mathrm{lb} \text { of } 6-2-0
\end{aligned}
$$


Continue to adjust the setting on the spreader until 1.25 pounds of 6-2-0 is collected during the calibration run. (If you want to work in ounces or grams, the calculations will be 1.25 pounds $\times 16$ ounces per pound $=20$ ounces of the product, or 1.25 pounds $\mathrm{x} 454$ grams per pound $=567.5$ grams.)

To avoid skips in application, it is recommended to calibrate for one-half rate and make two perpendicular passes over the treatment area in order to improve application uniformity. Therefore, the calibration for a one-half-rate application that will be made in two directions would be:

$$
1.25 \div 2=\text { approx } 0.63 \mathrm{lb} \text { of } 6-2-0
$$

\section{Broadcast (Rotary) Spreader Calibration}

Broadcast spreaders (figure 10.8) deliver product by dropping a dry granule onto a spinning impeller. The spread pattern of a broadcast spreader is not as precise as a drop spreader but it is usually the preferred means to rapidly deliver fertilizer to a large area. A consistent walking speed is important to optimize uniform delivery, and wind is much more of a concern for distribution uniformity - especially with lightweight materials.

The potential for materials landing on hardscapes is much greater with broadcast spreaders due to the wide throw of the materials in the spread pattern. Particular care needs to be taken when using these spreaders near sidewalks, streets, etc., to ensure that product does not land on hardscapes and potentially end up in a nearby water source. Many of these spreaders have deflector attachments that should be employed around hardscapes to minimize the potential for fertilizer ending up on the hard surfaces; however, even when deflectors are used, the site should be inspected after application and product should be swept up or blown back onto the turf.

Spreading mixed materials of different sizes can be a problem because larger, heavier particles are thrown farther than smaller particles, thus reducing even distribution of nutrients. As with drop spreaders, application uniformity can often be improved by applying one-half rates in two directions (detailed in the following).

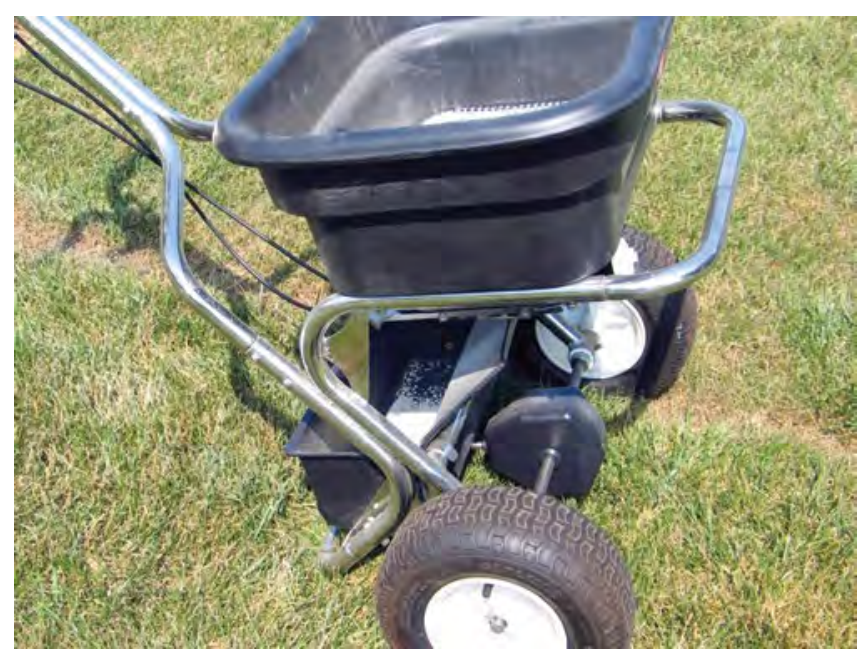

Figure 10.8. A broadcast spreader can hold relatively large volumes of fertilizer and is a useful tool to rapidly apply granular fertilizers to large areas.

\section{Steps in Broadcast (Rotary) Spreader Calibration}

1. Ensure that the spreader is operating normally: Place enough product in the spreader to completely cover the base of the spreader.

2. Determine uniformity and the effective spreader width (ESW): Product can be propelled 15 feet or more in a semicircle around the spreader, with the amount delivered decreasing with distance from the spreader. It is important to know how the spreader distributes product. Use catch pans (inexpensive aluminum baking pans as pictured in figure 10.9) spaced uniformly every 2 to 3 feet from the center of the spreader and perpendicular to its line of motion. Depending on the size of the spreader, anticipate product spread distance to range from 12 to 20 feet. Begin walking a few paces behind the calibration starting point in order to establish a consistent walking speed prior to opening the hopper (figure 10.10). Open the spreader in time to distribute product across the catch pans and close it as soon as you pass the line of pans.

3. Collect results: Collect the fertilizer that is captured in each pan and place the product in small clear cups or tubes to make a visual evaluation of the spreader pattern (figure 10.11). Be sure to keep the samples in the same order - by distance from the spreader - as the pans. The desired distribution for a standard application should be essentially a bellshaped pattern, with the largest amount of product in the middle catch pan and uniform amounts extending away from the center. 


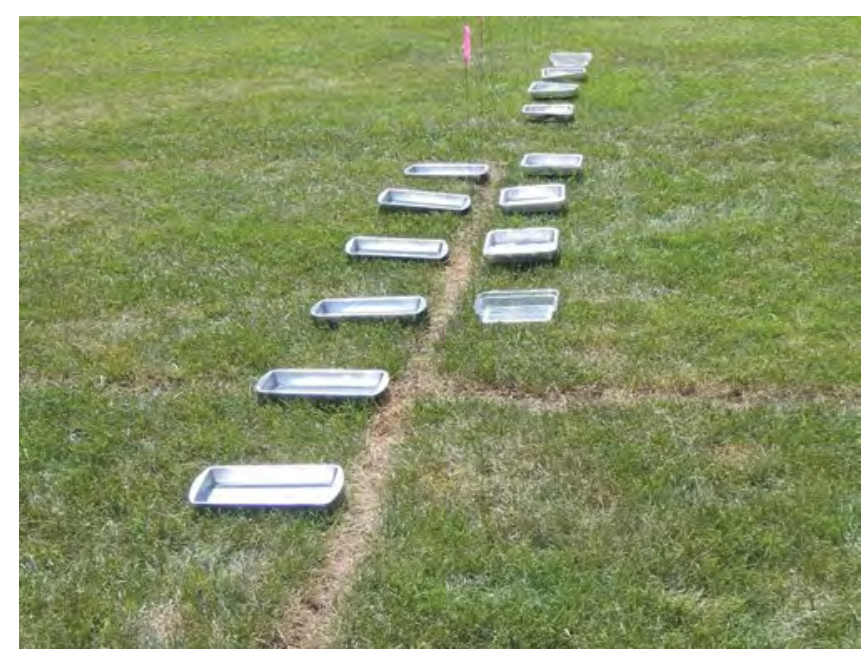

Figure 10.9. Fertilizer catch pans are being placed at regular intervals in order to determine the fertilizer's effective distribution width.

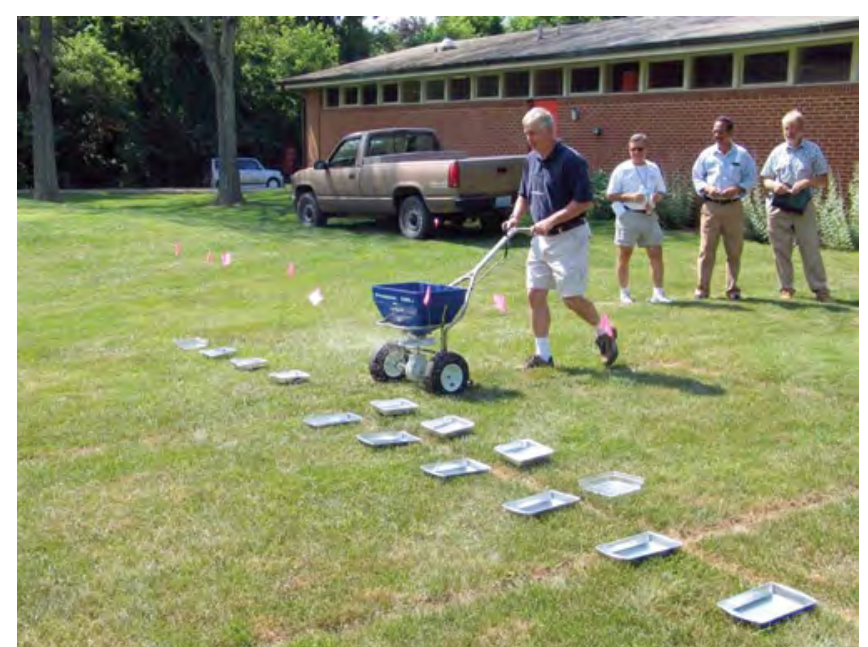

Figure 10.10. Establish a consistent walking speed prior to fertilizer delivery in the calibration run.

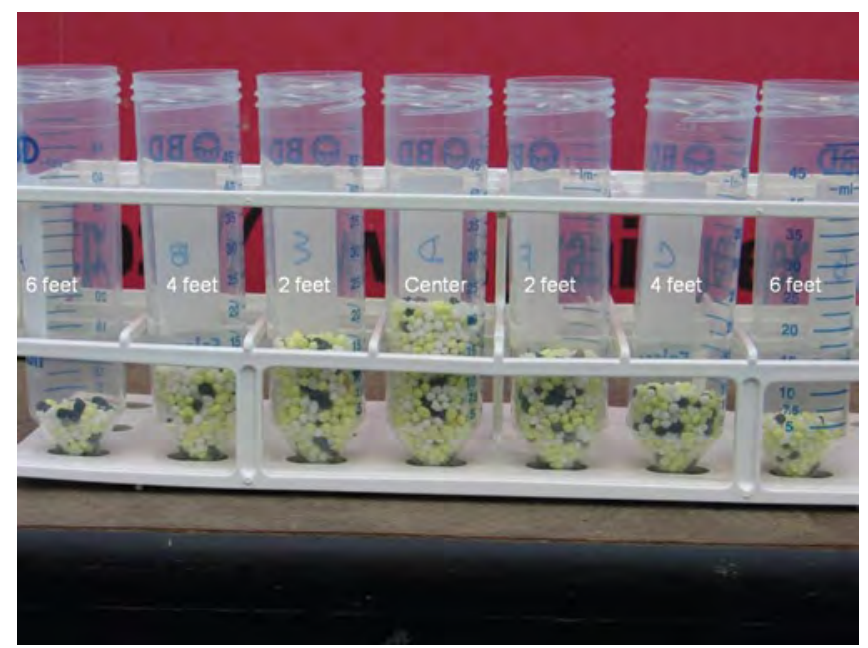

Figure 10.11. The collection of fertilizer from catch pans at 2-foot spacing from the center demonstrates an effective spreader width of 12 feet in this example.

4. Evaluate spread pattern and determine effective spreader width: By visually evaluating the fertilizer collected from the catch pans, the effective spreader width can be determined as being that distance where the fertilizer product is approximately 50 percent of the total collected from the center catch pan. Using the example in figure 10.11, that point occurs at approximately 6 feet, so in this example, the ESW is 6 feet on either side of center, for a total ESW of 12 feet. The application strategy will be to overlap distribution by 6 feet in order to uniformly achieve 100 percent coverage. If the distribution is not uniform, the spreader might need an adjustment or repair or the nonuniform distribution will have to be accounted for in the delivery of the product. Note that some professional spreaders intentionally have adjustments and/or shields to deflect granular products from being discharged in a certain direction (e.g., in order to restrict fertilizer from being thrown onto a hardscape).

5. Calibrate weight delivered: Now that the ESW and the overlap width of the spread are known, the spreader will be calibrated to determine an appropriate setting to deliver a desired amount of material. The use of a collection bag - an attachment that encloses the impeller and captures the product as it is being delivered (figure 10.12) - greatly speeds the calibration process and prevents product from repeatedly being delivered to an area during the calibration run. Consider the goal in this example is to deliver a total of 1 pound of nitrogen per 1,000 square feet using urea (45-0-0). If possible, perform the calibration using a calibration run length that results in 1,000 square feet of coverage. If the ESW is 12 feet, then the desired calibration length is 83.3 feet $(1,000$ square feet $\div 12$ feet $\mathrm{ESW}=83.3$ feet in length). If 45-0-0 is the fertilizer of choice, the formula for how much product is needed is $(1 \mathrm{x}$ $100) \div 45=2.2$ pounds urea per 1,000 square feet to deliver 1 pound of nitrogen per 1,000 square feet. Set the spreader setting to a low-to-medium range; establish a comfortable, repeatable walking speed that is initiated several feet before the beginning of your calibration course; and collect fertilizer in the collection bag over the 83-foot distance. Weigh the material collected and adjust the spreader setting up or down depending on the amount collected. Repeat the process until approximately 2.2 pounds of urea are collected. Just as for drop spreaders, the uniformity in distribution can be improved by applying the fertilizer in two directions. If this strategy were employed, the calibration run would collect 1.1 pounds of urea (one-half the full rate). 


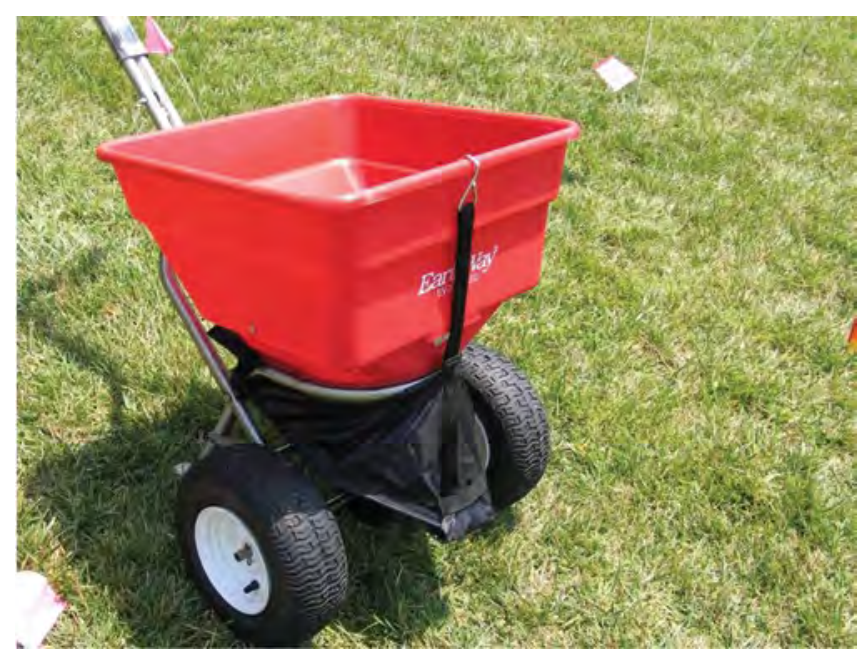

Figure 10.12. This rotary spreader is equipped with a collection bag to capture all granular product that is applied during calibration.

In the absence of a collection bag, it is possible to simply weigh out a known amount of fertilizer to place in the hopper, apply product to a length of at least 25 feet, and then determine how much fertilizer remains in the hopper in order to determine the level of nutrient applied. For example, 2 pounds of urea is placed in the fertilizer hopper with a previously determined ESW of 12 feet and a calibration run length of 25 feet. The total area covered in a single pass is 12 feet $\times 25$ feet $=$ 300 square feet. It was previously determined that 2.2 pounds of urea per 1,000 square feet was required to deliver 1 pound of nitrogen per 1,000 square feet. The proportion would be:

$$
\begin{aligned}
\frac{2.2 \mathrm{lb} \text { of } 45-0-0}{1,000 \mathrm{sq} \mathrm{ft}} & \times \frac{\mathrm{Y} \mathrm{lb} \text { of } 45-0-0}{300 \mathrm{sq} \mathrm{ft}} \\
660 & =1,000 \mathrm{Y} \\
\mathrm{Y} & =0.66 \mathrm{lb} \text { of } 45-0-0
\end{aligned}
$$

Choose a low spreader setting, apply the fertilizer over the 25-foot calibration run length, and collect and weigh the remaining fertilizer in the hopper. If 2 pounds of urea was placed in the hopper before the application, then the desired amount remaining in the hopper is 2.00 pounds -0.66 pounds $=1.34$ pounds of urea. Repeat the process until you determine the appropriate spreader setting. The obvious disadvantage of this method is the application of product in the calibration area.

Another method is to apply the dry product to a clean, paved area where the product can be collected by sweeping after delivery. Again, determine a suitable length based on the ESW. Of course, having to sweep up product over an 83.3-foot length is quite labor intensive; therefore, a shorter length is typical but some precision in calibration is likely sacrificed. Apply the prod- uct, collect it with a broom and dust pan, and weigh to determine a rate of product per unit area covered in the calibration run. Because all the product is collected, it is not necessary to start with a known quantity. As before, keep adjusting the spreader settings until the appropriate amount of product is delivered per unit area.

Finally, a fourth method of delivery that does not involve calibration is what is sometimes referred to as the "exercise method." For this method, divide the lawn up into logical areas of known square footage. Next, weigh precise amounts of fertilizer to cover the known area. For example, if an area measures 5,000 square feet and the goal is to deliver 2.2 pounds of urea per 1,000 square feet (i.e., 1 pound of nitrogen per 1,000 square feet), then 11 pounds of urea are needed for the lawn based on the following proportion:

$$
\begin{aligned}
\frac{2.2 \mathrm{lb} \text { of } 45-0-0}{1,000 \mathrm{sq} f t} & \times \frac{\mathrm{Y} \mathrm{lb} \text { of } 45-0-0}{5,000 \mathrm{sq} \mathrm{ft}} \\
11,000 & =1,000 \mathrm{Y} \\
\mathrm{Y} & =11 \mathrm{lb} \text { of } 45-0-0
\end{aligned}
$$

Weigh 11 pounds of urea and place it in the spreader. Select a very low spreader setting and cover the lawn in multiple directions until the spreader hopper is emptied. No calibration is required, but the only way to ensure uniform spread is to get plenty of exercise covering the lawn in multiple directions, delivering small amounts of product. This method is very suitable for someone who infrequently fertilizes small lawn areas but obviously is not an efficient use of time for professional applicators who may be fertilizing several acres per day.

\section{Spread Patterns}

The spread pattern with a rotary spreader will never be completely uniform because of the variability in spread due to wind, speed, equipment operation, and for some fertilizers, the different sizes and weights of particles. To manage the lack of spread uniformity, most textbooks suggest calibrating the spreader to deliver onehalf the desired rate of product and apply the product in two passes at right angles to each other. Other published information suggests that similar (if not better) delivery results can be obtained by applying granular products at one-half application rates in a parallel delivery pattern (figure 10.13). 


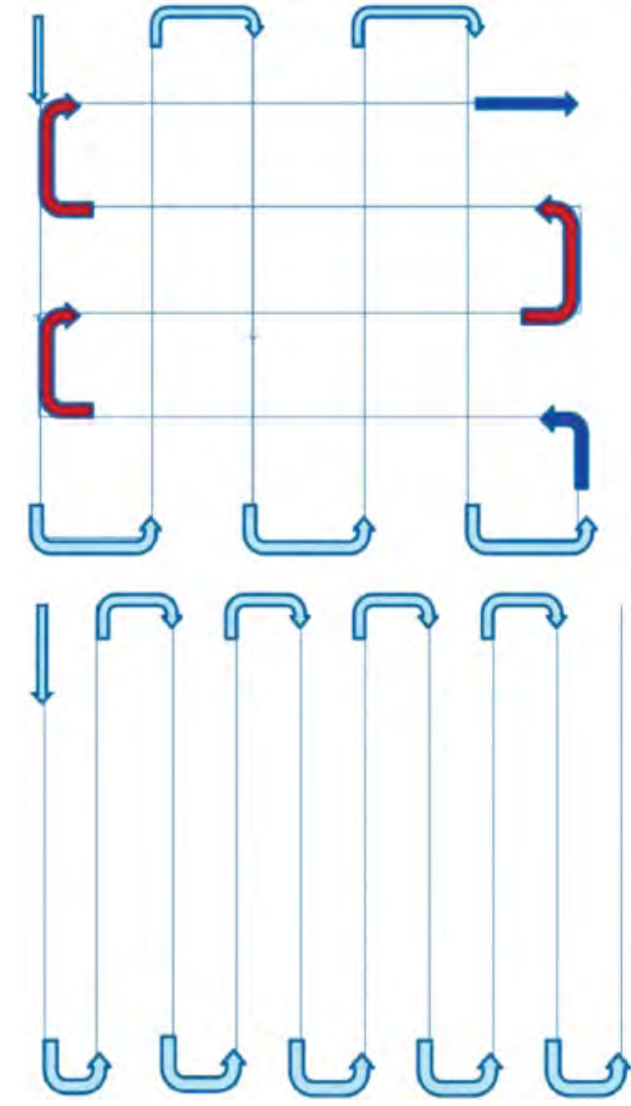

Figure 10.13. Standard right-angle application method (top) and the overlap delivery method (bottom).

\section{Final Thoughts on Spreader Calibration}

Several national lawn product retailers sell spreaders specifically designed for their products. Part of the advantage of using these specialty products is the "cookbook" nature of the application instructions. However, it is still wise to use their recommended settings only as guidelines for beginning your own calibration steps rather than taking the suggested spreader settings and application levels as guarantees. Not all spreaders deliver product alike, and over time (and with use), spreader performance is likely to change. Record all information involved in calibration steps (amount and type of product, spreader settings, etc.) for future reference. This will make future calibrations that much quicker and easier.

\section{Liquid Fertilizers and Sprayer Calibration}

Many specialty products are marketed as liquid formulations that quickly go into solution or are easily suspended in water. Many micronutrient formulations are sold as chelates - organic forms of the nutrient that are in a liquid formulation. Also, several common granu- lar forms of fertilizers are highly water-soluble and can be quickly dissolved in water to make their own spray solution, while others are quite insoluble and unsuitable for liquid feeding (see the water solubility information in tables $8.1,8.3$, and 8.4 in chapter 8).

Before adding different fertilizers and/or pesticides to a tank, check the label very carefully for specific comments regarding tank mixing and/or conduct a test of the compatibility of the two products by adding small, proportional amounts of the products that simulate what will be added to the spray tank. If the product blends into a uniform solution, mixing in the tank should be fine. If the combination becomes a sludge-like consistency, tank-mixing should be avoided.

\section{Sprayer Components}

All spray systems will have a tank, a pump, a boom, nozzles, and sprayer tips. The system will logically be mobile, whether it is by way of someone walking or a motorized vehicle. While it is beyond the scope of this handbook to provide exhaustive detail on all these components, there are some basic elements about the sprayer components that will suffice in obtaining accurate calibration. Additional information is available in Fine Tuning a Sprayer with "Ounce" Calibration Method, Virginia Cooperative Extension publication 442-453 (Grisso et al. 2009).

The pump is used to create pressure (whether the pump is powered by hand or by an engine), and it is important that the pressure be optimal for the system and the product and that it is consistent and repeatable. Most products will have pressure and spray-volume recommendations on their labels.

Next, choose an appropriate nozzle and tips for the system and the application. Again, this information is usually provided on the product label or as a recommendation provided by the sprayer system and/or the nozzle and tip supplier. True foliar feeding of nutrients that are intended to primarily enter a plant through the leaves is accomplished with spray volumes of 45 gallons per acre (GPA) or less. In other situations where a liquid fertilizer might be mixed with an insecticide intended to enter the soil in order to control a groundborne pest, the recommended volume of liquid delivery might be 100 to 200 GPA.

Other factors to consider when selecting and optimizing the use of nozzles and tips for multinozzle booms (often used in golf turf management) are their appropriate spacing and height off the ground. Some tips require 
up to a 33 percent overlap of the spray pattern to ensure 100 percent coverage. The manufacturers of the nozzles and tips provide helpful charts for these criteria, with much of the information being available on the Internet.

Routinely check the system and its components to ensure proper working condition. Check that hoses and fittings are securely attached, nozzles and tips are not clogged, and spray pressure generated by the pump is constant. A great place to run a preliminary inspection of the system is to conduct a sprayer test by applying water on a driveway or parking lot that makes it easy to evaluate that boom height, nozzle selection, and nozzle spacing are all appropriate to provide uniform application (figure 10.14). After this initial check, gather all the equipment you will need for the calibration: a stopwatch, measuring tape or wheel, flags to mark your course, and containers to collect and measure the liquid discharge (figure 10.15).

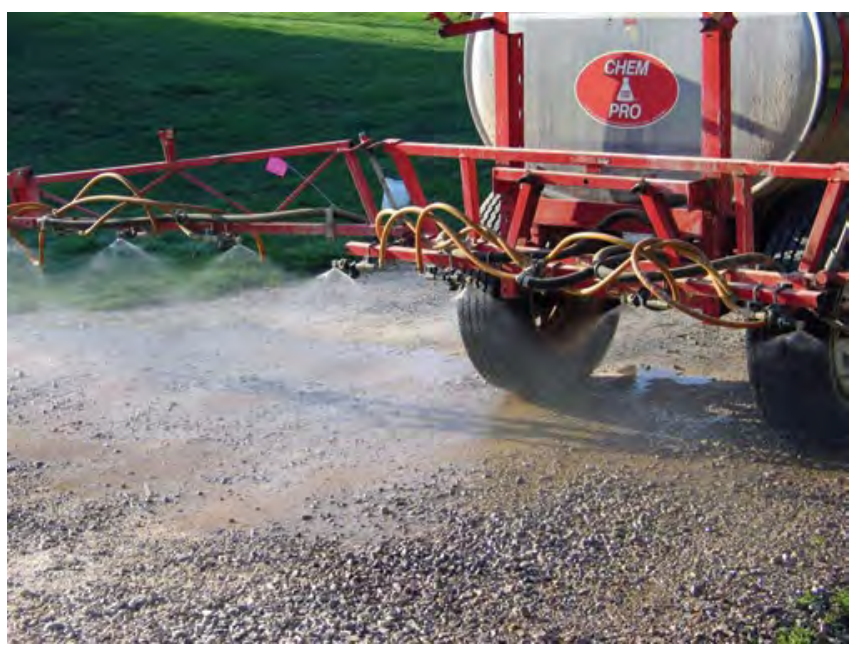

Figure 10.14. Evaluating nozzle and tip performance prior to calibration is easily accomplished by spraying water on a road or driveway to evaluate boom nozzle height and overlap.

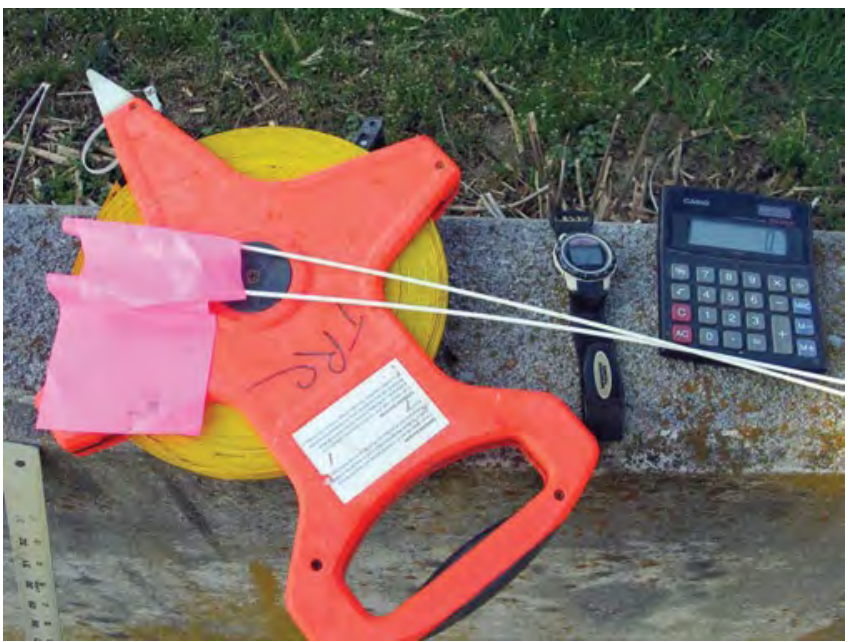

Figure 10.15. The basic equipment needed for sprayer calibration.

\section{The "Ounce" Calibration Method}

This method of calibration is very popular because it eliminates a lot of the math in the calibration calculations. A gallon equals 128 ounces, so if a sprayer is calibrated on an area of 1/128th of an acre ( 1 acre $=43,560$ square feet $\div 128=340$ square feet), then the ounces collected during calibration equate to gallons per acre.

Begin by measuring the nozzle spacing on the boom (figure 10.16) because this determines the course length required to cover $1 / 128$ th of an acre. For example, with a 20-inch nozzle spacing as depicted in figure 10.16 (20 inches equals 1.67 feet), the calculation will be 340 square feet $\div 1.67$ feet nozzle spacing $=$ approximately 204 linear feet (see table 10.1 for course lengths based on standard nozzle spacing). When calibrating a single nozzle such as for a hose end or backpack sprayer, determine the spray width (in feet) for the single nozzle and divide this into 340 square feet to determine the course length for calibration.

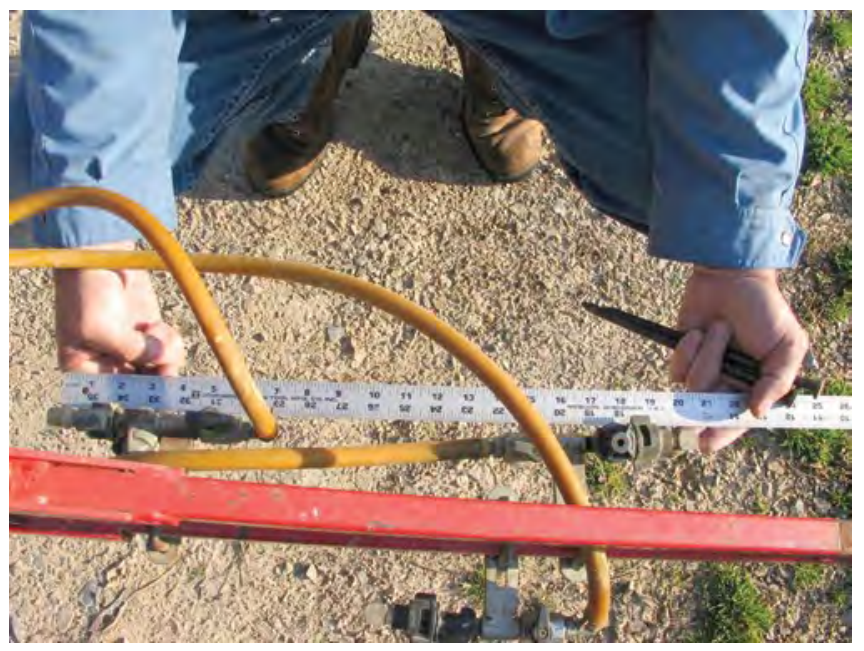

Figure 10.16. Nozzles should be equally spaced on the boom according to manufacturer recommendations. By measuring the spacing, you can then calculate the test course length in order to calibrate the sprayer according to the ounce calibration method.

Table 10.1. Course lengths required to calibrate 1/128th of an acre (340 square feet).

\begin{tabular}{cc}
\hline $\begin{array}{c}\text { Boom nozzle spacing } \\
\text { (inches) }\end{array}$ & $\begin{array}{c}\text { Course length } \\
\text { (feet) }\end{array}$ \\
\hline 12 & 340 \\
\hline 16 & 255 \\
\hline 20 & 204 \\
\hline 24 & 170 \\
\hline 28 & 146 \\
\hline 32 & 127 \\
\hline 36 & 113 \\
\hline 40 & 102 \\
\hline
\end{tabular}


If the boom has 20-inch nozzle spacings, then table 10.1 indicates that a course length of 204 feet is required to cover $1 / 128$ th of an acre. Fill the tank at least half way with water, determine an optimum speed for the terrain and product delivery (usually 3 to $4 \mathrm{mph}$ ), set the power takeoff (PTO) at an appropriate rate of RPMs for the pump to deliver the desired pressure and volume of spray solution, and operate the sprayer system as if product was being applied. Be sure the test course terrain is comparable to the area that you will be treating so your calibration run equates well with the actual area to cover.

Time how long it takes to travel the 204 feet for this particular spray system setup. Then, operate the sprayer in a stationary position, capturing the discharge from a single nozzle for the time period it took to drive the 204foot test course in this example (figure 10.17). Using a measuring cup marked in ounces, what is collected in ounces simply equals gallons per acre.

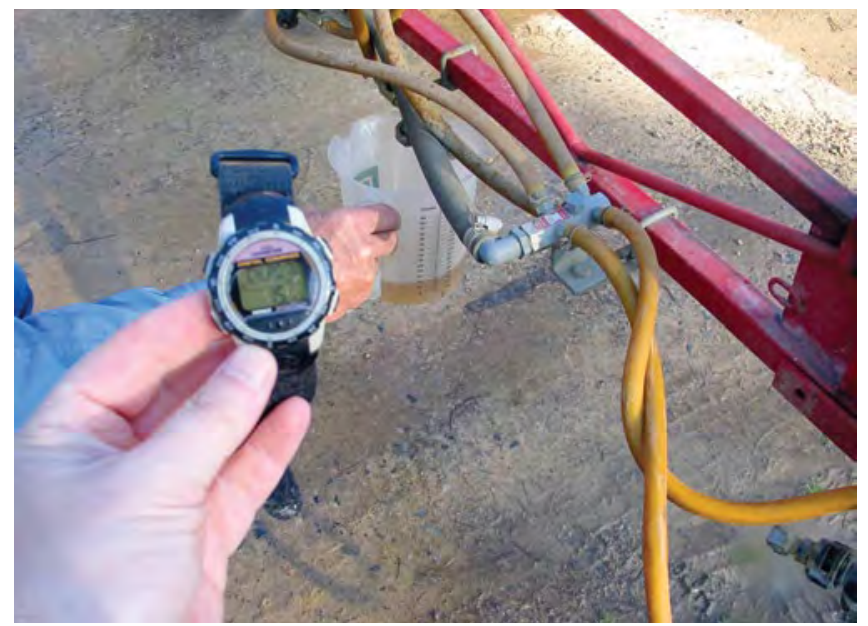

Figure 10.17. Capture the discharge from a nozzle for the same time duration it took to drive the test course.

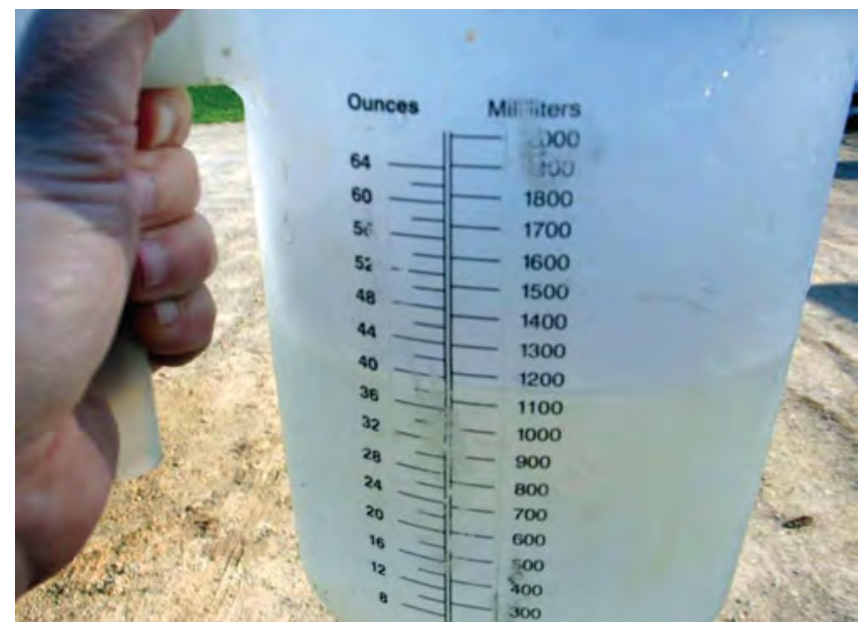

Figure 10.18. The amount captured in ounces equals the gallons per acre the sprayer is delivering. In this example. the sprayer is calibrated to deliver 40 GPA.
In the example presented, the 40 ounces of discharge collected for the known time period equates to a sprayer calibrated to deliver 40 GPA. Catch the output from at least three nozzles for the required duration to ensure that all nozzles are performing comparably. If a nozzle does not deliver an output that is within plus/ minus 5 percent of the average nozzle output, check the filter and tip to see if they are clogged and/or damaged. Replace any suspect nozzle or tip.

\section{Example of How Much Product to Add}

The label of a popular 15-0-0 liquid fertilizer that is also 4 percent sulfur and 6 percent iron by weight recommends an application range of 2 to 8 fluid ounces per 1,000 square feet. If 4 ounces per 1,000 square feet is selected, how much is added to the sprayer system that was just calibrated in the preceding example?

If relatively large areas are to be treated, it is logical to prepare full tanks of spray solution. Assume the system has a 100-gallon tank. As calibrated at 40 GPA, then a full tank can cover 100 gallons $\div 40 \mathrm{GPA}=2.5$ acres. How many square feet are in 2.5 acres? One acre is 43,560 square feet, so $2.5 \times 43,5460=108,900$ square feet. Using a basic proportion, the setup is:

$$
\begin{aligned}
\frac{4 \text { fluid oz of product }}{1,000 \mathrm{sq} \mathrm{ft}} & \times \frac{\mathrm{Y} \text { fluid oz of product }}{108,900 \mathrm{sq} \mathrm{ft}} \\
435,600 & =1,000 \mathrm{Y} \\
\mathrm{Y} & =\text { approx } 436 \mathrm{fl} \mathrm{oz} \mathrm{of} \mathrm{product} \\
\frac{436 \mathrm{fluid} \mathrm{oz}}{128 \mathrm{fl} \mathrm{oz} / \mathrm{gal}} & =\text { approx } 3.4 \text { gal of } 15-0-0
\end{aligned}
$$

So, 3.4 gallons is the amount of 15-0-0 liquid fertilizer to be added to the tank of a sprayer calibrated to deliver 40 GPA. To prepare a full tank, fill the tank partially with water, add the fertilizer, and then add the remaining water to bring the tank to the 100-gallon level.

What if the goal were to cover only 20,000 square feet of area? It was just calculated that a full sprayer holding 100 gallons will cover 108,900 square feet. There would be no point in mixing a full tank but instead, just enough to cover 20,000 square feet. A simple proportion would be:

$$
\begin{aligned}
\frac{100 \mathrm{gal}}{108,900 \mathrm{sq} \mathrm{ft}} & \times \frac{\mathrm{Y} \mathrm{gal}}{20,000 \mathrm{sq} \mathrm{ft}} \\
2,000,000 & =108,900 \mathrm{Y} \\
\mathrm{Y} & =\text { approx } 18.4 \text { gal of water }
\end{aligned}
$$


How much fertilizer is needed to treat the 20,000 -squarefoot area using a rate of 4 fluid ounces per 1,000 square feet?

$$
\begin{aligned}
\frac{4 \text { fluid oz of product }}{1,000 \mathrm{sq} f t} & \times \frac{\text { Y fluid oz of product }}{20,000 \mathrm{sq} f \mathrm{ft}} \\
80,000 & =1,000 \mathrm{Y} \\
\mathrm{Y} & =80 \text { fluid oz of product }
\end{aligned}
$$

Add a few gallons of water to the tank, add the 80 fluid ounces of fertilizer, and then fill the tank to a final volume of approximately 18.4 gallons.

How about adding dry products or powders? Many commercially available powdered fertilizers are highly water-soluble and even some bulk fertilizer materials may be sufficiently soluble to deliver in liquid form (see chapter 8 , table 8.1 ). For example, up to 6.5 pounds of urea is soluble in a gallon of water (from table 8.1; note that rapid mixing and even heat may be needed to speed dissolution of some materials unless dilute solutions are desired). Consider an example where the goal is to use the calibrated sprayer above to provide a nitrogen level of 0.25 pound per 1,000 square feet (using urea) to 20,000 square feet of turf.

It will take 0.25 pounds of nitrogen $\div 0.45=0.56$ pounds of urea per 1,000 square feet to deliver the desired level of nitrogen. The area to be covered is 20,000 square feet.

$$
\begin{aligned}
\frac{0.56 \mathrm{lb} \text { of } 45-0-0}{1,000 \mathrm{sq} \mathrm{ft}} & \times \frac{\mathrm{Y} \mathrm{lb} \text { of } 45-0-0}{20,000 \mathrm{sq} \mathrm{ft}} \\
11,200= & 1,000 \mathrm{Y} \\
\mathrm{Y} & =11.20 \mathrm{lb} \text { of } 45-0-0
\end{aligned}
$$

It was previously determined (see above) that a sprayer calibrated to deliver 40 GPA would need approximately
18.4 gallons of total spray volume to treat 20,000 square feet. Fill the tank with approximately 9 gallons of water, add the 11.2 pounds of urea (stirring or agitating to ensure the product fully dissolves), and bring the final tank volume to approximately 18.4 gallons. The sprayer is calibrated to deliver 0.25 pound of nitrogen per 1,000 square feet.

\section{Other Considerations With Sprayable Fertilizers}

Because of the high volumes applied and the relatively dilute concentration of nutrients, liquid fertilizer applications are often very uniform and precise. However, you should pay very close attention to the label recommendations regarding spray volume, nozzles, and tips and the requirement for sprayer agitation. Also, be sure to record your own observations regarding sprayer performance and plant response for future reference. Watering in of many liquid fertilizers may be recommended after application to reduce leaf burn potential or to improve uptake efficiency. Be very careful regarding the compatibility of tank mixtures of fertilizers, pesticides, and other spray additives because they can cause undesired changes in physical and/or chemical properties of the materials.

\section{Literature Cited}

Grisso, R., P. Hipkins, S. D. Askew, L. Hipkins, and D. McCall. 2009. Nozzles: Selection and Sizing. Virginia Cooperative Extension Publication 442-032. http://pubs.ext.vt.edu/442/442-032/442-032.html.

Grisso, R., M. Weaver, K. Bradley, S. Hagood, and H. Wilson. 2009. Fine Tuning a Sprayer with "Ounce" Calibration Method. Virginia Cooperative Extension Publication 442-453. http://pubs. ext.vt.edu/442/442-453/442-453.html. 


\title{
Chapter 11. Soil-Water Budgets and Irrigation Sources and Timing
}

\author{
W. Lee Daniels, Professor, Crop and Soil Environmental Sciences, Virginia Tech \\ Greg Evanylo, Professor, Crop and Soil Environmental Sciences, Virginia Tech \\ Kathryn Haering, Research Associate, Crop and Soil Environmental Sciences, Virginia Tech \\ Laurie Fox, Research Associate, Hampton Roads Agricultural Research and Extension Center, Virginia Tech \\ David Sample, Assistant Professor, Biological Systems Engineering, Virginia Tech
}

\section{Introduction}

The successful establishment and management of turfgrass and landscape plantings are highly dependent on the maintenance of adequate soil moisture over time, particularly during periods of drought. Ideally, the soil's physical properties allow for rapid infiltration and retention of rain and applied irrigation waters. When adverse soil properties such as excessive compaction and lack of aggregation (see chapters 2 and 3 ) limit soil infiltration rates, valuable water is lost to runoff and may carry excess nutrients away with it in stormwater discharge.

Conversely, when excess soil water percolates down through the soil profile, particularly during the winter, it may also carry away soluble nutrients such as nitratenitrogen to local groundwater. Thus, the relative risk of nutrient movement to groundwater and surface waters in any managed soil landscape is strongly controlled by the physical nature of the soil profile coupled with the nature of the vegetation and associated management practices. These site-specific factors then interact
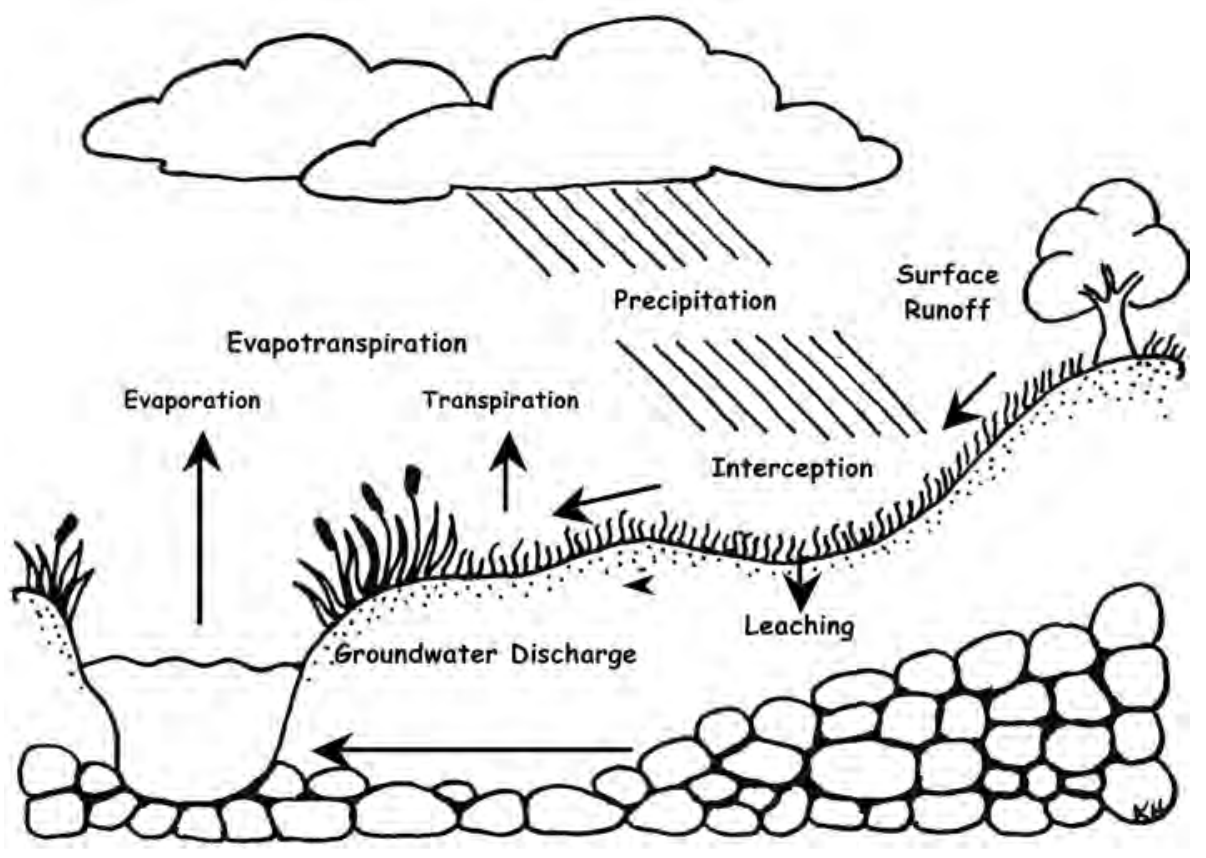

Figure 11.1. The hydrologic cycle. Figure by Kathryn Haering with local climate - particularly rainfall intensity and snowmelt - resulting in different infiltration and runoff rates.

In this chapter, we will focus on understanding how water applied as rainfall or irrigation moves into and out of the soil profile on a local (e.g., home lot) basis. Greater detail on larger scale (e.g., subdivision or watershed level) stormwater and nutrient runoff issues and best management practices is presented in chapter 12 .

\section{The Hydrologic Cycle and Soil- Water Budgets}

A basic understanding of the hydrologic cycle (illustrated in figure 11.1) is necessary to understand nutrient loss mechanisms and to develop management strategies to reduce nutrient losses to groundwater and surface water. The primary components of the hydrologic cycle that are most important to nutrient transport in surface water and groundwater are:

- Precipitation.

- Interception of rainfall on plants.

- Surface runoff.

- Evapotranspiration (evaporation plus plant transpiration).

- Net leaching to groundwater and eventual discharge into streams (base flow).

Nutrients move into the groundwater system via leaching and to surface water via runoff or groundwater discharge to springs and seeps. Any contaminants dissolved in surface runoff, such as nitrate $\left(\mathrm{NO}_{3}{ }^{-}\right)$or ortho-phosphorus, can contribute to surface water contamination. In addition, discharge of groundwater into surface water often occurs in 
stream beds and tidal portions of the Chesapeake Bay system.

\section{Precipitation}

Long-term annual precipitation averages range from 35 inches to more than 50 inches in different areas of the mid-Atlantic region. Although timing and amount of precipitation will vary in each individual year, these deviations from the average cannot be reliably predicted.

\section{Interception}

From 5 percent to 40 percent of precipitation is intercepted by the leaves of plants, depending on the intensity of rainfall and the morphology of the canopy. This water never reaches the soil surface to contribute to either infiltration or runoff, but it does cool and wet the plant's leaves, which can decrease transpiration losses over the short term. Higher interception rates are associated with light rains falling on dense multistoried canopies (e.g., mature woody trees over complete herbaceous groundcovers), while lower interception rates are associated with heavy rains on thinly vegetated surfaces, such as newly established lawns.

\section{Surface Runoff}

Precipitation that falls onto the soil surface in excess of the infiltration rate will run off to lower portions of the landscape or to surface streams. Soil infiltration rates vary widely, from several inches of rainfall per hour on gently sloping, well-vegetated, and aggregated surfaces to less than 0.10 inch per hour on sloping, compacted, clayey, poorly vegetated areas. Infiltration is also affected by whether or not the soil surface is wet or dry at the start of the rainfall event (antecedent moisture conditions).

\section{Evapotranspiration}

Evapotranspiration (ET) is the sum of surface evaporation of moisture (from puddles, ponds, etc.) plus the removal of soil moisture by the root uptake and subsequent transpiration of water through the leaves of living vegetation. For example, ET accounts for 25 to 40 inches of the total precipitation in Virginia and is highest in Eastern Virginia, where the long growing season and higher air temperatures combine for maximum plant water demand. The removal of soil water by ET decreases significantly when air temperatures drop below 45 degrees Fahrenheit (F) and/or when the active vegetation goes dormant for the winter. Long-term average rainfall by month does not vary significantly throughout the year for most areas, but it is slightly higher in the late summer and early fall due to infrequent (but extreme) effects of hurricanes. Evapotranspiration, however, is much greater during the late spring, summer, and early fall because water use by vegetation is much higher during this period (see figure 11.2).

\section{Leaching and Groundwater Discharge}

Water that infiltrates upland soils during the growing season is largely removed by evapotranspiration (figure 11.2); water losses beyond the rooting zone to groundwater are very rare. Consequently, the risk of leaching or runoff losses of water and soluble nutrients is much less during the summer than during the winter. However, during the late fall and winter, any added or remaining soil water - particularly that held in large macropores - is subject to leaching below the rooting zone and will eventually reach groundwater.

During leaching, soluble nutrients such as nitrate percolate through the soil with water because they are not readily bound to soil surfaces. The relative amounts of surface runoff, interception, and leaching from an area are influenced by storm intensity, storm duration, slope, soil type, type of vegetation, and amount of plant or crop residue on the soil surface.

During the winter months, the amounts of rainfall and snowmelt that infiltrate most upland soils greatly exceeds the rate of evapotranspiration. During this period (nominally November to March), water leaches completely through the soil profile and contributes to local groundwater "recharge." Groundwater that infiltrates upland soils as recharge eventually discharges into local streams and is also termed "base flow."

Figure 11.3 depicts an example of a landscape-level water budget and net groundwater discharge to streams for a typical Ridge and Valley Province watershed. In this area, long-term leaching and discharge accounts for about 5 inches per acre of watershed area, while direct-surface runoff losses account for 7 inches per acre annually. Surface runoff contributions to stream water occur during and after rainfall events or snowmelt and are therefore highly variable over time.

In contrast, base flow is usually a continuous contributor to stream flow throughout the year. During dry periods, base flow is the primary contributor to stream flow, which vividly demonstrates the interconnection of groundwater and surface waters. 


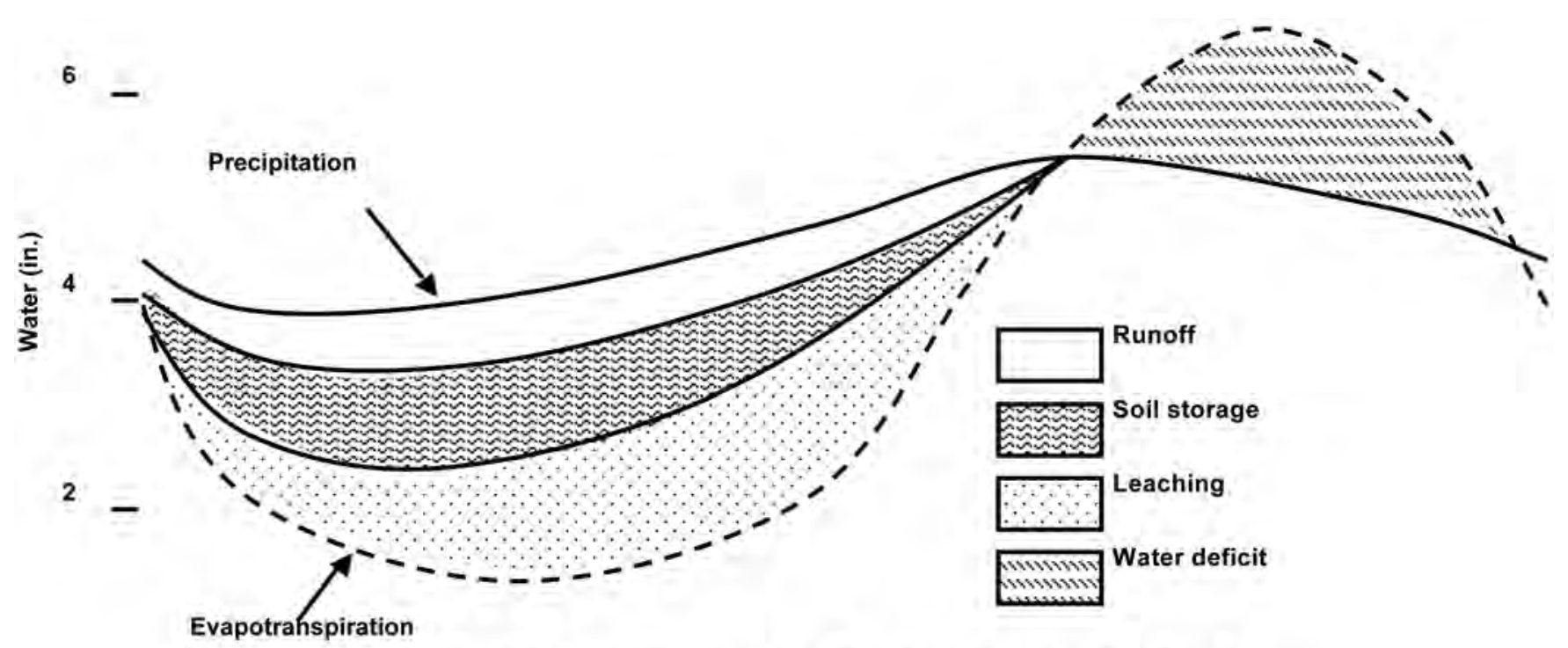

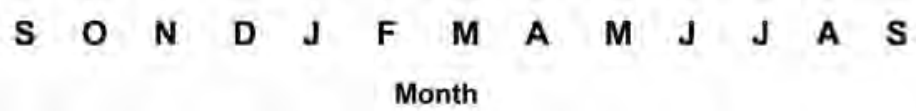

Figure 11.2. The soil water budget. This figure depicts the overall balance of water inputs (as precipitation) and losses (as runoff, evapotranspiration, and leaching) for a typical upland soil in the mid-Atlantic region. The annual period shown here runs from September (S) to September. Note that while average precipitation inputs are fairly even across the year, net evapotranspiration demand varies directly with the season as driven by temperature and day length. In midsummer (J, J, and A), potential evapotranspiration greatly exceeds rainfall and the difference between the two results in a soil water deficit that must be made up via supplemental watering/irrigation for optimal plant growth. By late fall ( $\mathrm{N}$ and $\mathrm{D})$, however, evapotranspiration drops with falling temperatures and the soil holds and stores water against leaching up to its water-holding capacity as soil storage. Once that capacity to retain water is exceeded, additional infiltrating rainwater and snowmelt is transmitted down through the soil and is lost as leaching to groundwater recharge.

Figure by Kathryn Haering; based on data from Carroll County, Va.

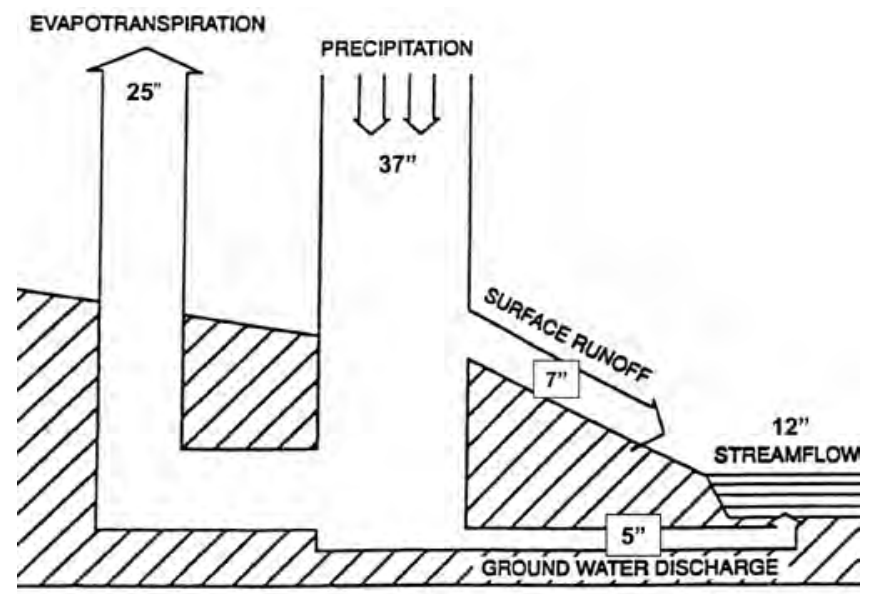

Figure 11. 3. General water budget, Upper South Fork of the Shenandoah River (adapted from Virginia Department of Conservation and Recreation 1993).

Base flow and subsurface seepage of groundwater contribute more than surface runoff to surface water bodies in the Atlantic Coastal Plain Province due to much flatter terrain, highly permeable soils, and relatively high water table levels. In some areas of the Coastal Plain, groundwater discharge may account for as much as 80 percent of total annual contributions to surface water. Groundwater in the Coastal Plain Province typically moves in a downwardly arcing path from uplands toward discharge points at a rate of several inches to as much as 2 feet per day.

\section{Watering Basics for Turf and Landscape Plantings}

As pointed out in the preceding section, plant transpirational demands for water during the summer usually exceed rainfall, which can lead to water stress, poor plant growth, and even death of established turf and landscape plantings. Water stress is amplified in urban soils that are limited by compaction and poor aggregation/infiltration (chapter 3 ) and in very sandy or rocky native soils with inherently low water-holding capacities (chapter 2). Therefore, we commonly supplement rainfall with watering/irrigation during the summer and early fall months.

\section{Water Application Rate, Timing, and Frequency}

The amount of water needed by established turf or ornamental plants depends on the type of turf or plant, the soil type, the amount of existing moisture in the soil, and the time of year. Overwatering is a leading cause of problems with landscape plants and can also damage established turf - especially when applied to soils with limited permeability that locally perch shallow, saturated zones in soils (see chapter 3 ) or cause local ponding. Where feasible, rain sensors should be 
installed on large or commercial irrigation systems to prevent overwatering and waste and to reduce costs.

\section{Application Rate}

One-time irrigation rates for turf should be sufficient to wet, but not saturate, the entire rooting depth as described below. This may vary from 0.5 to 1.5 inches or more of water per event, depending on the porosity, aggregation, and bulk water-holding capacity of the soil. An easy way to check this is to use a shovel to examine the wetting depth approximately 30 minutes after the irrigation event ends. Obviously, the application rate will also need to be managed to ensure complete infiltration and limited runoff.

As a general guide, water should be applied to landscape plantings at the rate of 1.0 inch per week ( 60 gallons per 100 square feet) in a single application. This amount will wet most soils to a depth of about 12 inches (the area containing 80 percent of the roots of most landscape plants). Because water moves readily within the plant, you do not need to water the entire root zone. Twenty-five percent of the root area can absorb enough water for the entire plant. Irrigation should stop when water begins to run off. If necessary, 0.5 inch of water can be applied, followed by an additional 0.5 inch several hours later to prevent runoff. This rate is a general recommendation for established annuals, perennials, and woody plants in landscape beds.

\section{Application Timing}

The best time to water is in the early morning, whether using a hand-held hose, drip or trickle system, microsprinklers, soaker or ooze hose, or overhead sprinklers. As much as 30 percent of the water applied overhead during midday can be lost to interception and evaporation. Also, overhead applications made early in the day allow time for the foliage to dry, which prevents diseases.

\section{Application Frequency for Landscaping Plants}

For established turfgrass, the watering regime should be managed to provide enough water to wet the soil throughout the normal rooting zone (i.e., 6 to 12 inches) but not more than twice per week to avoid overwatering. Deep, infrequent watering promotes downward turfgrass root proliferation while more frequent, shallow irrigation events are detrimental to long-term turf rooting patterns and the sod's inherent ability to withstand drought in the absence of watering.
Slow, deep, soaking applications once a week are best for landscaping plants. Avoid short, frequent, shallow applications that can actually stress landscape plants or cause a buildup of ions or salts from the water in the soil that may be toxic to certain plants. Newly installed plants may require more frequent irrigation. This depends mainly on the plant species, soil type, and mulch.

In general:

- Water annuals every two days for the first two weeks.

- Water perennials and woody plants every three to four days for the first three weeks.

- Irrigation frequency should return to once a week as needed after the plants have been established.

\section{Water Reuse: Using Reclaimed Water for Irrigation}

"Reclaimed water," also known as "recycled water," is water recovered from domestic, municipal, and industrial wastewater treatment plants that has been treated to standards that safely allow most uses except human consumption (figure 11.4). "Wastewater" (untreated liquid industrial waste and/or domestic sewage from residential dwellings, commercial buildings, and industrial facilities) is not reclaimed water. "Gray water," or untreated wastewater from bathing or washing, is one form of wastewater. Wastewater may be land-applied, but this is considered to be land treatment rather than water reuse.

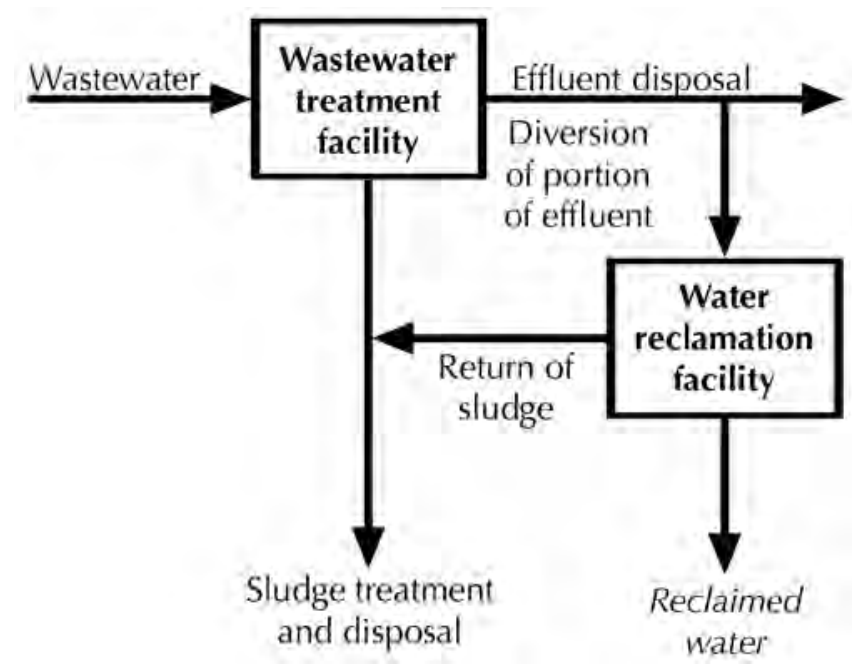

Figure 11.4. Water reclamation process at a wastewater treatment facility. (adapted from Environmental Protection Agency [EPA] 2004). 


\section{How Is Reclaimed Water Produced?}

During primary treatment at a wastewater treatment plant, inorganic and organic suspended solids are removed from plant influent by screening and settling. The decanted effluent from the primary treatment process is then subjected to secondary treatment, which involves biological decomposition of organic material and settling to further separate water from solids. If a wastewater treatment plant is not equipped to perform advanced treatment, water is disinfected and discharged to natural water bodies following secondary treatment.

Advanced treatment or tertiary treatment consists of further removal of suspended and dissolved solids, including nutrients, and disinfection. Advanced treatment can include:

- Nutrient (nitrogen and/or phosphorus) removal by biological or chemical methods.

- Removal of organics and metals by carbon adsorption or chemical precipitation.

- Further removal of suspended and dissolved solids by filtration, coagulation, ion exchange, reverse osmosis, and other techniques.

- Removal of organic chemicals by oxidation with hydrogen peroxide or ozone.

Water that has undergone advanced treatment is disinfected prior to being released or reused. Reclaimed water often requires greater treatment than effluent that is discharged to local streams or rivers, because users will typically have more direct contact with undiluted, reclaimed water than with undiluted effluent.

\section{Why Reuse Water?}

The demand for fresh water can potentially exceed supply during times of even moderate drought. The potential for developing new sources of potable water is limited. Conservation measures such as irrigating with reclaimed water are one way to help ensure existing water supplies are utilized as efficiently as possible.

\section{Water Reuse Regulations}

There are no federal regulations governing reclaimed water use, but the Environmental Protection Agency (EPA; 2004) has established guidelines to encourage states to develop their own regulations. The primary purpose of federal guidelines and state regulations is to protect human health and water quality. To reduce disease risks to acceptable levels, reclaimed water must meet certain disinfection standards by reducing the concentrations of constituents that may affect public health and/or limiting human contact with reclaimed water.

The EPA (2004) recommends that water intended for reuse should:

- Be treated to achieve biochemical oxygen demand and total suspended solids levels of less than 30 milligrams per liter $(\mathrm{mg} / \mathrm{l})$ during secondary or tertiary treatment.

- Receive additional disinfection by means such as chlorination or other chemical disinfectants, UV radiation, ozonation, and membrane processing.

Biochemical oxygen demand (BOD) is an indicator of the presence of reactive organic matter in water. Total suspended solids (TSS) are measures of the amount of organic and inorganic particulate matter in water.

In Virginia, water reuse means direct beneficial reuse, indirect potable reuse, or a controlled use in accordance with the Water Reclamation and Reuse Regulation (9 VAC 25-740-10 et seq.; available at the Virginia Administrative Code website at http://leg1.state.va.us/000/ reg/TOC09025.htm, chapter 740).

The Virginia Water Reclamation and Reuse Regulations are designed to protect both water quality and public health while encouraging the use of reclaimed water. The primary determinants of how reclaimed water of varying quality can be used are based on treatment processes to which the water has been subjected and on quantitative chemical, physical, and biological standards. Further detail on the water reclamation process and reclaimed water quality standards can be found at http://pubs.ext.vt.edu/452/452-014/452-014.html.

\section{Reclaimed Water Quality Considerations for Irrigation}

Water quality must be considered when using reclaimed water for irrigation. The following properties are critical to plant and soil health and environmental quality.

\section{Salinity Levels}

Salinity, or salt concentration, is probably the most important consideration in determining whether water is suitable for reuse (EPA 2004). Water salinity is the sum of all elemental ions (e.g., sodium, calcium, chloride, boron, sulfate, nitrate) and is usually measured by determining the electrical conductivity (EC; units = 
deciSiemens per meter $[\mathrm{dS} / \mathrm{m}])$ or total dissolved solids (TDS; units $=\mathrm{mg} / \mathrm{l}$ ) concentration of the water. Water with a TDS concentration of $640 \mathrm{mg} / \mathrm{l}$ will typically have an EC of approximately $1 \mathrm{dS} / \mathrm{m}$.

Most reclaimed water from urban areas is slightly saline (TDS $\leq 1,280 \mathrm{mg} / 1$ or EC $\leq 2 \mathrm{dS} / \mathrm{m}$ ). High salt concentrations reduce water uptake in plants by lowering the osmotic potential of the soil. For example, residential use of water adds approximately 200 to $400 \mathrm{mg} / \mathrm{l}$ dissolved salts (Lazarova, Bouwer, and Bahri 2004a). Plants differ in their sensitivity to salt levels, so the salinity of the particular reclaimed water source should be measured so that appropriate crops and/or application rates can be selected. Most turfgrasses can tolerate water with 200 to $800 \mathrm{mg} / 1$ soluble salts, but salt levels above $2,000 \mathrm{mg} / 1$ may be toxic (Harivandi 2004). For further information on managing turfgrasses when irrigating with saline water, see Carrow and Duncan (1998).

Many other crop and landscape plants are more sensitive to high soluble-salt levels than turfgrasses and should be managed accordingly. See $\mathrm{Wu}$ and Dodge (2005) for a list of landscape plants with their relative salt tolerance and Maas (1987) for information on salttolerant crops.

\section{Concentration of Sodium, Chloride, and Boron}

Specific dissolved ions may also affect irrigation water quality. For example, irrigation water with a high concentration of sodium (Na) ions may cause dispersion of soil aggregates and sealing of soil pores. This is a particular problem in golf course irrigation (Sheikh 2004), because soil compaction is already a concern due to persistent foot and vehicular traffic. The sodium adsorption ratio (SAR), which measures the ratio of sodium to other ions, is used to evaluate the potential effect of irrigation water on soil structure. For more information on how to assess and interpret SAR levels, see Harivandi (1999).

High levels of sodium can also be directly toxic to plants, both through root uptake and accumulation of plant leaves following sprinkler irrigation. The specific concentration of sodium that is considered to be toxic will vary by plant species and type of irrigation system. Turfgrasses are generally more tolerant of sodium than most ornamental plant species.

Although boron (B) and chlorine $(\mathrm{Cl})$ are necessary at low levels for plant growth, dissolved boron and chloride ions can cause toxicity problems at high concentrations. Specific toxic concentrations will vary depending on plant species and type of irrigation method used. Levels of boron as low as 1 to $2 \mathrm{mg} / 1$ in irrigation water can cause leaf burn on ornamental plants, but turfgrasses can often tolerate levels as high as $10 \mathrm{mg} / \mathrm{l}$ (Harivandi 1999). Very salt-sensitive landscape plants such as crape myrtle (Lagerstroemia sp.), azalea (Rhododendron sp.), and Chinese privet (Ligustrum sinense) may be damaged by overhead irrigation with reclaimed water containing chloride levels more than $100 \mathrm{mg} / \mathrm{l}$, but most turfgrasses are relatively tolerant to chloride if they are mowed frequently (Harivandi 1999; Crook 2005).

\section{Nutrient Levels}

Reclaimed water typically contains more nitrogen and phosphorus than drinking water. The amount of nitrogen and phosphorus provided by the reclaimed water can be calculated as the product of the estimated irrigation volume and the nitrogen and phosphorus concentration in the water. To prevent nitrogen and phosphorus leaching into groundwater, the Virginia Water Reclamation and Reuse Regulation requires that a nutrient management plan be written for bulk use of reclaimed water not treated to achieve biological nutrient removal (BNR), which the regulation defines as treatment which achieves an annual average of $8.0 \mathrm{mg} / 1$ total nitrogen and $1.0 \mathrm{mg} / 1$ total phosphorus. Water that has been subjected to BNR treatment processes contains such low concentrations of nitrogen and phosphorus that the reclaimed water can be applied at rates sufficient to supply a crop's water needs without risk of surface or groundwater contamination.

\section{Other Plant Growth and Water Quality Concerns}

- High suspended solids (TSS) concentrations may clog irrigation systems and can fill pore spaces near the soil surface, resulting in reduced drainage. Acceptable TSS levels will vary depending on the type of suspended solids and type of irrigation system. Generally, TSS levels less than 50 to $100 \mathrm{mg} / \mathrm{l}$ are safe for drip irrigation.

- Free chlorine $\left(\mathrm{Cl}_{2}\right)$ is necessary for disinfection, but can damage plants at high concentrations $(>5 \mathrm{mg} / \mathrm{l})$. Storage for a short time reduces the residual freechlorine concentration in water.

- High or low $\mathrm{pH}$ is an indicator of the presence of phytotoxic ions, and $\mathrm{pH}$ should be approximately 6.5 to 7.0 , if possible. 
- High bicarbonate (> $120 \mathrm{ml})$ and carbonate $(15 \mathrm{mg} / \mathrm{l})$ levels can clog sprinklers and cause white lime deposits on plant leaves; it may increase soil $\mathrm{pH}$ and decrease permeability.

- Heavy metals can be a concern in wastewater that has high industrial input, but such metals (for example, cadmium, copper, molybdenum, nickel, and zinc) are typically strongly bound to the solid fraction, or biosolids portion, of the wastewater and are rarely found in high enough concentrations to pose a reclaimed water quality problem.

(Harivandi 1999; Landschoot 2007; Lazarova et al. 2004a)

\section{Application Rates}

Irrigation rates for reclaimed water are site- and cropspecific and will depend on the following factors (EPA 2004; Lazarova, Papadopoulous, and Bahari 2004b).

1. Seasonal irrigation demands must be determined. These can be predicted with:

- An evapotranspiration estimate for the particular crop being grown.

- Determination of the period of plant growth.

- Average annual precipitation data.

- Data for soil permeability and water-holding capacity.

Methods for calculating such irrigation requirements can be found in the U.S. Department of Agriculture's (USDA) National Engineering Handbook at http://www.info.usda.gov/CED/ftp/CED/neh-15.htm (USDA 2003) and in Reed, Crites, and Middlebrooks (1995). Turfgrass irrigation rates in Virginia can also be calculated using the website $h t t p: / / w w w . t u r f . c s e s$. vt.edu/Ervin/et_display.html. These calculations are more complicated for landscape plantings than for agricultural crops or turf because landscape plantings consist of many different species with different requirements.

2. The properties of the specific reclaimed water to be used, as detailed in the section above, must be taken into account because these may limit the total amount of water that can be applied per season.

3. The availability of the reclaimed water should also be quantified, including:
- The total amount available.

- The time of year, when available.

- Availability of water storage facilities for the nongrowing season.

- Delivery rate and type.

\section{Literature Cited}

Carrow, R. N., and R. R. Duncan. 1998. Salt-Affected Turfgrass Sites: Assessment and Management. New York: John Wiley \& Sons.

Crook, J. 2005. St. Petersburg, Florida, dual water system: A case study. In Water Conservation, Reuse, and Recycling. Proceedings of an Iranian-American Workshop. Washington, D.C.: The National Academies Press.

Environmental Protection Agency (EPA). 2004. Guidelines for Water Reuse. EPA 645-R-04-108. Washington, D.C.: EPA. www.epa.gov/ORD/NRMRL/ pubs/625r04108/625r04108.pdf.

Harivandi, M. A. 1999. Interpreting Turfgrass Irrigation Water Test Results. Publication 8009. Oakland: University of California, Division of Agriculture and Natural Resources. http://anrcatalog.ucdavis. $e d u / p d f / 8009 . p d f$.

Harivandi, M. A. 2004. Evaluating Recycled Waters for Golf Course Irrigation. U.S. Golf Association Green Section Record 42(6): 25-29. http://turf.lib. msu.edu/2000s/2004/041125.pdf.

Landschoot, P. 2007. Irrigation Water Quality Guidelines for Turfgrass Sites. Department of Crop and Soil Sciences, Cooperative Extension. State College: Penn State University. http://turfgrassmanagement.psu.edu/irrigation_water_quality_ for_turfgrass_sites.cfm.

Lazarova, V., H. Bouwer, and A. Bahri. 2004a. Water quality considerations. In Water Reuse for Irrigation: Agriculture, Landscapes, and Turf Grass, ed. V. Lazarova and A. Bahri, 31-60. Boca Raton, Fla.: CRC Press.

Lazarova, V., I. Papadopoulous, and A. Bahri. 2004b. Code of successful agronomic practices. In Water Reuse for Irrigation: Agriculture, Landscapes, and Turf Grass, ed. V. Lazarova and A. Bahri, 104-150. Boca Raton, Fla.: CRC Press. 
Maas, E. V. 1987. Salt tolerance of plants. In Vol. 2 of CRC Handbook of Plant Science in Agriculture, ed. B. R. Christie, 57-75. Boca Raton, Fla.: CRC Press.

Reed, S. C., R. W. Crites, and E. J. Middlebrooks. 1995. Natural Systems for Waste Management and Treatment. 2nd ed. New York: McGraw-Hill.

Sheikh, B. 2004. Code of practices for landscape and golf course irrigation. In Water Reuse for Irrigation: Agriculture, Landscapes, and Turf Grass, ed. V. Lazarova and A. Bahri, 152-161. Boca Raton, Fla.: CRC Press.

U.S. Department of Agriculture (USDA). 2003. Irrigation water requirements. In National Engineering Handbook, 2-i-2-284. Part 623, Section 15, Chapter 2. Washington, D.C.: USDA Natural Resources Conservation Service. www.info.usda.gov/CED/ ftp/CED/neh-15.htm.
Virginia Department of Conservation and Recreation. 1993. Nutrient Management Handbook. 2nd ed. Richmond: VDCR.

Wu, L., and L. Dodge. 2005. Landscape Plant Salt Tolerance Guide for Recycled Water Irrigation. Slosson Research Endowment for Ornamental Horticulture, Department of Plant Sciences, University of California-Davis. http://ucce.ucdavis.edu/files/ filelibrary/5505/20091.pdf. 


\title{
Chapter 12. Principles of Stormwater Management for Reducing Nutrients From Urban Landscaped Areas
}

\author{
David Sample, Assistant Professor, Biological Systems Engineering, Virginia Tech \\ Laurie Fox, Research Associate, Hampton Roads Agricultural Research and Extension Center, Virginia Tech
}

\section{Introduction}

The objective of this chapter is to provide a summary of current urban stormwater management issues and practices relevant to the mid-Atlantic region. One of the goals of a nutrient management plan is to reduce nutrient loads in stormwater runoff from urban landscaped areas. Nutrient management efforts have typically addressed agricultural, industrial, and commercial sites and impervious or paved surfaces. There appeared to be very little, if any, overlap with urban stormwater management.

However, Virginia's regulatory approach to stormwater management now includes urban stormwater runoff from both pervious and impervious areas, so many of the newer, "greener" stormwater management practices may become part of the landscape of an average urban site. Thus, a background in stormwater quantity and quality may be beneficial for the nutrient management planner.

This chapter provides an introduction to stormwater and discusses aspects related to stormwater quality, with an emphasis on nutrient loading to downstream receiving waters. The current regulatory approach and available practices for managing urban stormwater runoff are summarized. A list of practices and an assessment tool to examine the risk of urban water quality problems from a single site are provided in appendix B of this chapter.

\section{Introduction to Stormwater Management}

\section{What Is Stormwater?}

Stormwater is a hybrid term used to describe runoff (usually from urban areas) caused by precipitation in the form of rain, snow, or ice. In urban areas, runoff can occur from both impervious and pervious areas, although much more runoff comes from impervious areas.

Factors that affect stormwater runoff:

- Quantity and intensity of precipitation.

- Amount of impervious surface on the site (rooftops, driveways, patios and decks, roadways, parking lots, etc.).
- Type and condition of soil: Water infiltrates clay soils slower than sandy soils.

- Soil saturation level at the time of the precipitation: More runoff from pervious areas can occur if soil is already saturated before precipitation.

- Vegetative canopy layers and coverage: Runoff is reduced on sites with a higher percentage of vegetative coverage and multiple canopy layers.

- Extent and steepness of slopes.

Figure 12.1 describes a simplified hydrologic cycle for a residential lot. Precipitation, usually in the form of rainfall, falls on the land. On pervious areas, infiltration occurs until soil saturation has been reached. Runoff occurs almost immediately from impervious surfaces and after saturation from pervious land. Living vegetation creates water vapor that is released to the atmosphere; this is known as evapotranspiration (ET).

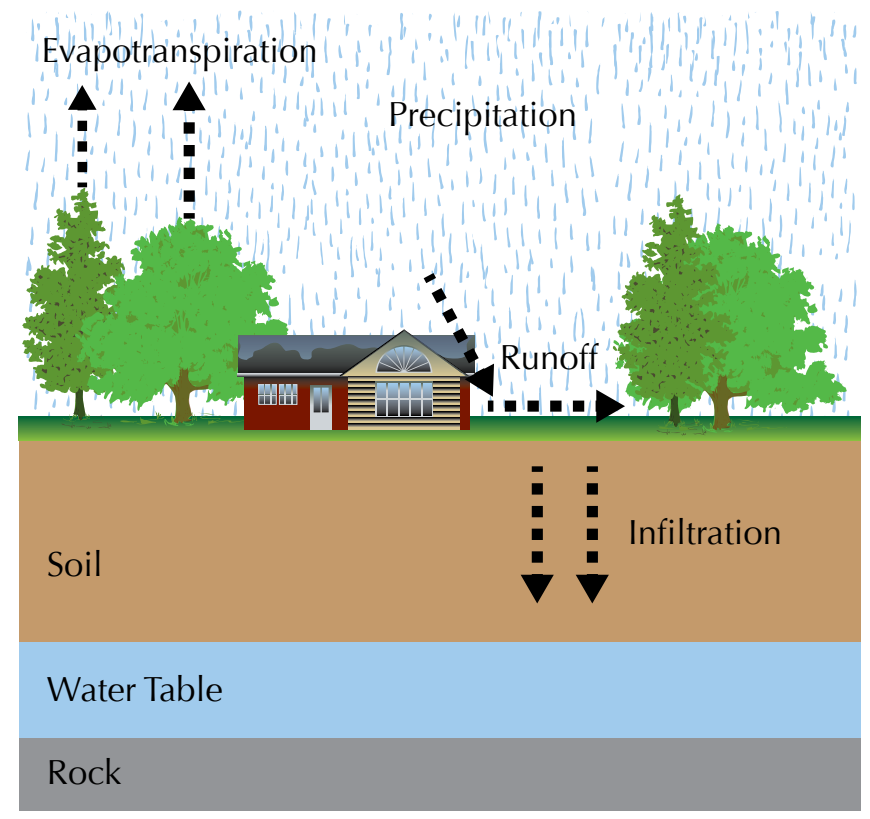

Figure 12.1. Simplified hydrologic cycle of a residential lot.

\section{Where Does Stormwater Go?}

Figure 12.2 illustrates the water pathways in a typical urban system. Potable water is shown entering homes (blue water system) while wastewater is shown leaving homes. Wastewater from laundry, bathroom sinks, 
and showers is often classified as "gray water" and can be recycled; however, in most homes, gray water is discharged to the wastewater or "black water" system. Typical stormwater from streets and impervious areas enters a catch basin and is transported to a storm sewer. In some cases, stormwater is also classified as a gray water system.

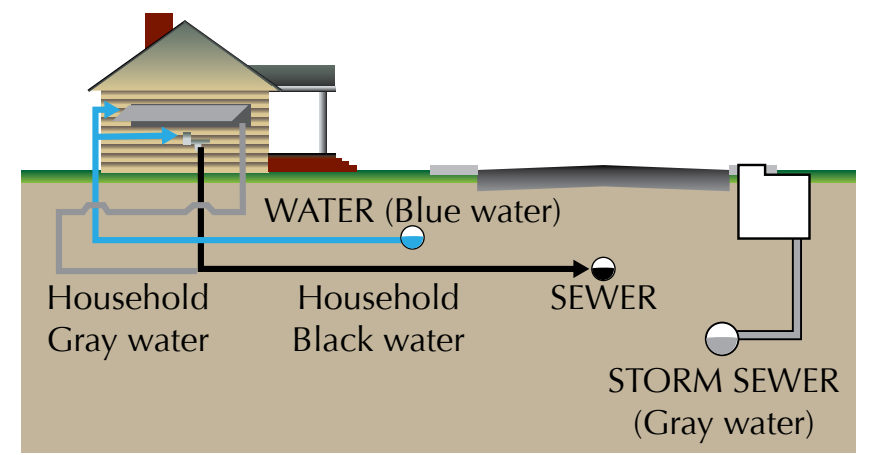

Figure 12.2. Definitions of urban water systems.

Many people who live in urban areas believe that stormwater flows through storm drains to a treatment facility. This is only the case in a "combined sewer system" (CSS), where one pipeline is used to convey both stormwater and wastewater (gray and black water). This type of system is often found in older urban areas. A major problem of a CSS is overflows of partially treated wastewater that occur when peak runoff exceeds storage capacity in the system. This discharge is known as a "combined sewer overflow." The more common type of system is a "separate storm sewer system." Here, one pipeline conveys stormwater from storm drains directly into receiving waters, which are usually smaller streams and/or lakes, wetlands, bays, estuaries, or reservoirs. A separate pipeline conveys sanitary wastewater - household water and waste from toilets, sinks, and showers - to a wastewater treatment facility. Wastewater receives treatment and is discharged to receiving waters as authorized with permit conditions in the National Pollutant Discharge Elimination System (NPDES). Stormwater discharges from urbanized areas are also regulated via an NPDES permit; a system of this type is known as a "municipally separate storm sewer system," or MS4.

\section{Watersheds}

A key concept necessary for understanding how water flows to receiving waters is a watershed. A watershed is a contiguous portion of land that sheds water into a single lowest point called an outlet or pour point. Ridgelines or areas of higher elevation separate one watershed from another.

Figure 12.3 illustrates a typical watershed. All upstream land uses and practices contribute to downstream water quality. Parks, open spaces, "low-impact development"

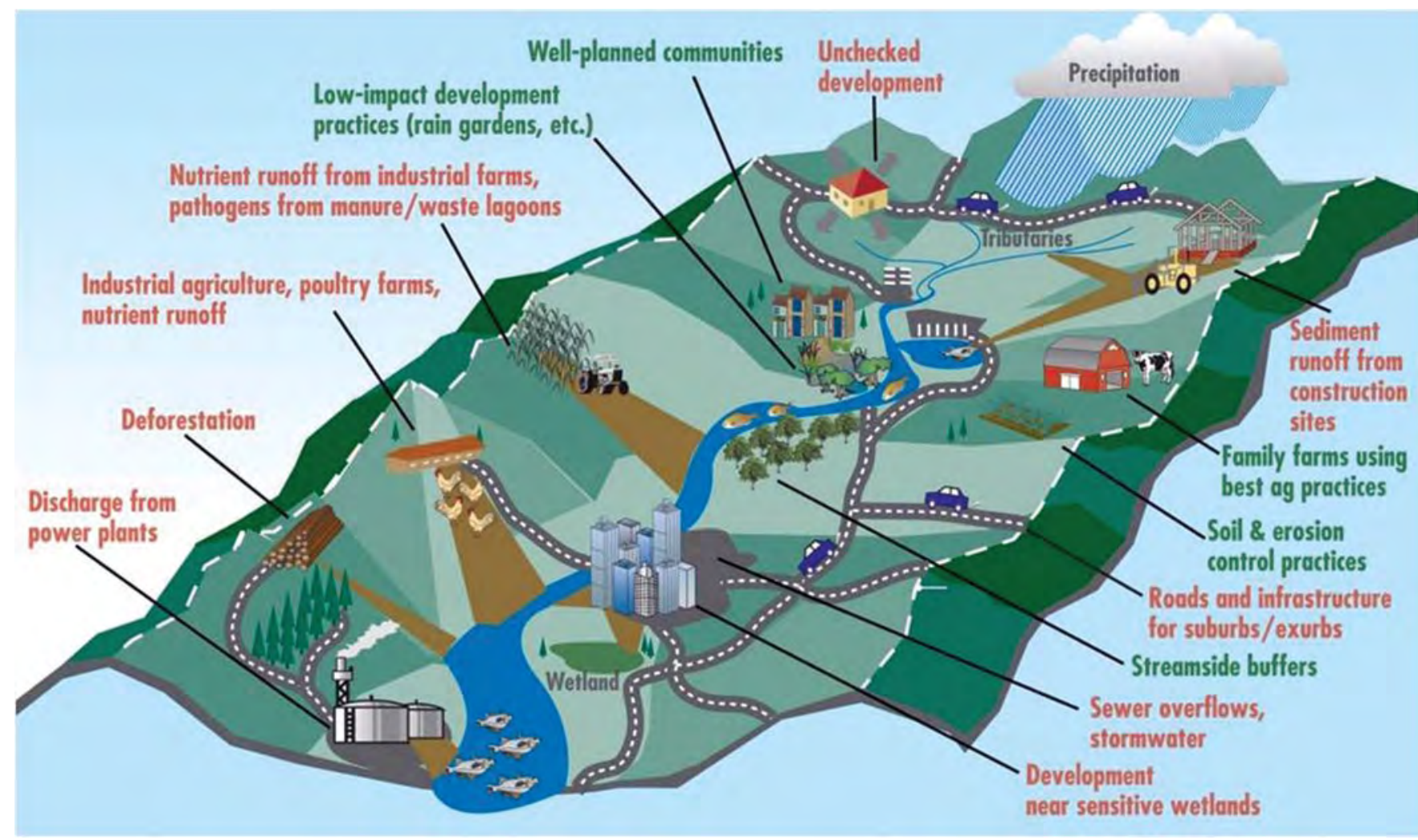

Figure 12.3. Watershed model. Green = positive factors; red = negative factors .

Source: Potomac Conservancy 2007. 
(LID) areas, riparian buffers, streams, and wetlands connect aquatic and forested ecosystems within the watershed. This connected natural system is also known as "green" infrastructure. In essence, urban nutrient planners are stewards of the green infrastructure system.

For more information on watersheds, see What is a Watershed? (Gilland et al. 2009), Virginia Cooperative Extension publication 426-041, in appendix 12-A of this chapterorathttp://pubs.ext.vt.edu/426/426-041/426-041. $p d f$.

\section{Stormwater Quantity and Quality Issues}

In undisturbed areas, stormwater runoff is generally not an issue because rainwater is quickly absorbed into the soils or utilized by vegetation. Water that infiltrates the soil is either released into the atmosphere by plants through the evapotranspiration process or percolated down through the soil profile to recharge the groundwater aquifers.

During urban development, the land is impacted in two ways:

1. During site preparation, when vegetation is stripped away leaving exposed soils that easily erode during rainfall events, causing an increase in sediment loading and downstream deposition. Sediment- and erosion-control practices and products are used at this stage of development.

2. During construction, as impervious surfaces are created (roofs and paved surfaces), infiltration is reduced and runoff is increased. Best management practices (BMPs) are used at this stage of development to offset the increased runoff. Because runoff is the primary transport mechanism for pollutants including sediment and nutrients, these pollutants will increase with the runoff increase if nothing is done to prevent it.

Both point and nonpoint source pollution are regulated under the federal Clean Water Act (CWA).

- "Point sources" may be classified as publicly owned treatment works, privately owned treatment facilities, industrial discharges, and sometimes, agricultural operations. Point sources are regulated through the National Pollutant Discharge Elimination System permitting program.

- "Nonpoint sources" consist primarily of runoff from urban, suburban, and developing areas and some agriculture sites. Because of the numerous and diffuse nature of these sources, they have not previously been regulated. In order to achieve the goals of the CWA, pollution from urban runoff is now becoming more strictly regulated through the municipally separate storm sewer system NPDES stormwater permits. Other nonpoint source pollution problems have also been addressed through a variety of incentive programs.

\section{Stormwater Quantity Issues}

Figure 12.4 illustrates one of the most fundamental concepts in urban stormwater - a hydrograph — which is a plot of stream discharge over time during a rainfall event. Urban development causes multiple impacts on the stormwater hydrograph.

1. The peak runoff rate increases due to lack of infiltration.

2. Water travel time decreases, resulting in a shortening of the hydrograph when compared to predevelopment hydrology.

3. After the storm event is over, base flow does not recover when comparing postdevelopment with predevelopment curves. This is due to the lack of infiltration and recharge from impervious areas.

Traditional stormwater management functions by providing a facility with additional storage volume that slowly releases water at the predevelopment rate of discharge. However, the volume of this discharge is greater than before development. This is shown as the dotted green line in figure 12.4. The increased stormwater volume causes an increase in sheer stress as it reaches a stream, which then causes erosion and increased transport capacity for pollutants. Low-impact development attempts to replicate the predevelopment hydrograph by increasing infiltration volume. A perfect LID system would therefore be very close to the blue line on figure 12.4 or the predevelopment hydrograph.

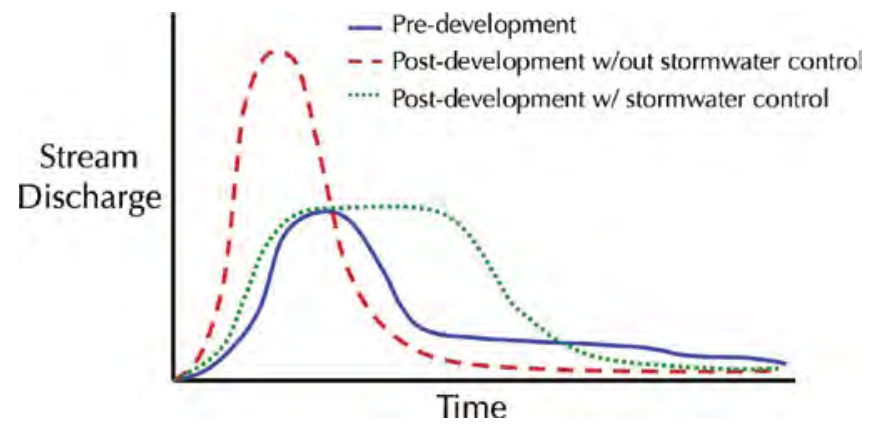

Figure 12.4. A typical urban hydrograph. 
Figure 12.5 illustrates the net impact of these changes across an annual hydrologic cycle in Virginia. The horizontal portion shows the continuum of urbanization from left to right, with natural groundcover on the left, moving through suburban, then urban development to 75 to 100 percent imperviousness on the right. The top part of the figure shows the annual change in the typical year's water budget. Significant changes occur with recharge decreasing from 11 to 2 inches and runoff increasing from 4 to 23 inches. A moderate decrease in ET from 17 to 13 inches occurs.

Figure 12.6 illustrates the subsequent geomorphic effects of urbanization on a receiving stream. A continuum of urbanization is shown from left to right. As development increases, significant changes occur in stormwater runoff peak flows and frequencies. The resultant stream shape changes are also shown. Urban streams are subjected to more frequent and increased peak flows and have much higher sheer stresses during bankfull events. This results in increased erosion of the channel. Also, urban streams tend to dry out due to the lack of recharge, resulting in a loss of stream length. The urban stream widens, deepens, and dries out, seriously impacting or destroying aquatic ecosystems and associated green infrastructure.

\section{Stormwater Quality Issues}

Higher stream flows cause increased stream erosion and higher loads of sediment, nutrients, and other pollutants in downstream receiving waters. The pollutants are present due to practices on the land but are carried by storm runoff and adversely impact downstream receiving waters. When receiving waters deteriorate to the point of not meeting their designated use, they are listed as "impaired." A current map of impaired streams for Virginia is provided in figure 12.7.

For each of these impacted streams, the Virginia Department of Environmental Quality (VDEQ) has or is establishing a Total Maximum Daily Load (TMDL) of the identified pollutant to the receiving stream. Once a TMDL has been established, the VDEQ develops an allocation amount for each of the identified sources for the pollutant in the upstream watershed. VDEQ then revises the surface water discharge permits from identified point sources at the time of permit renewal. Then, the Virginia Department of Conservation and Recreation (VDCR) develops an implementation plan for how these allocations will be achieved for nonpoint sources, including stormwater discharges.
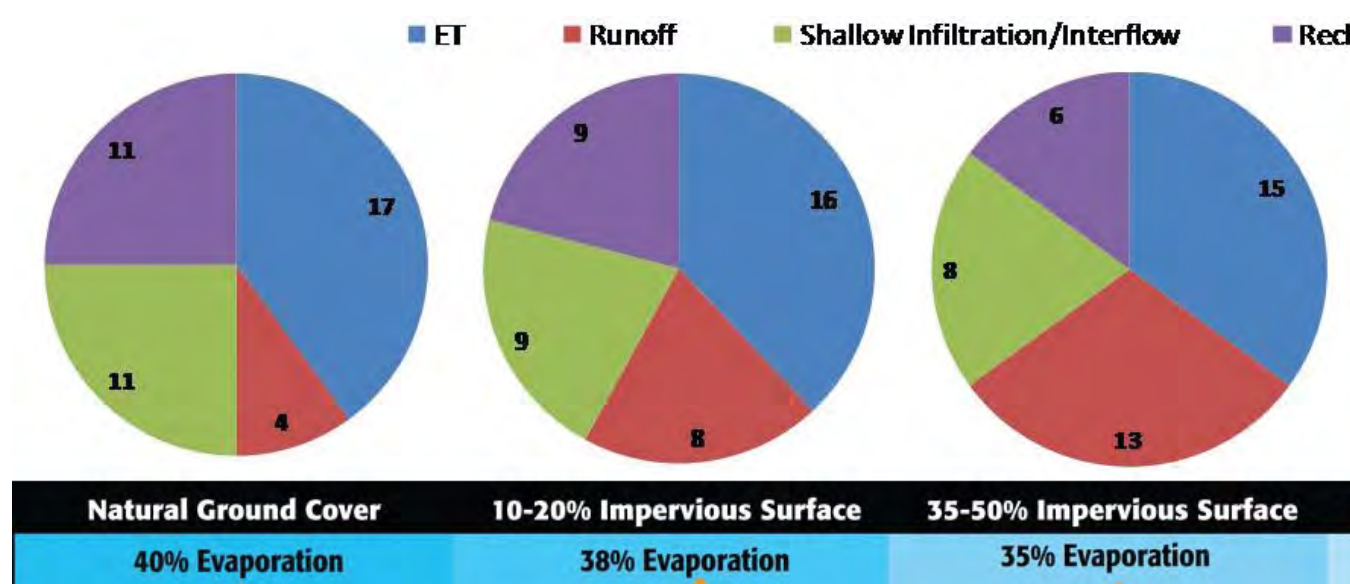

35-50\% Impervious Surface $35 \%$ Evaporation
Recharge

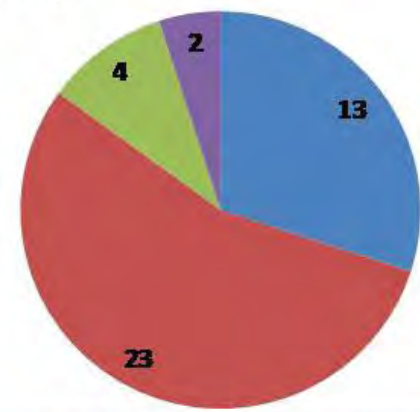

75-100\% Impervious Surface $30 \%$ Evaporation

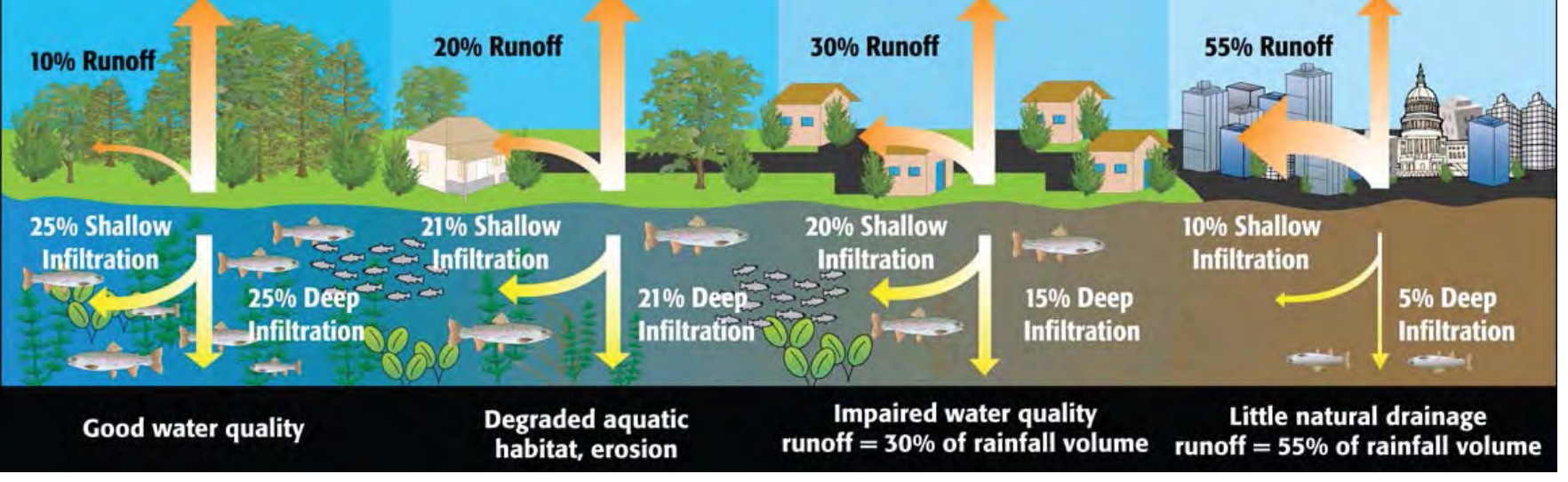

Figure 12.5. Virginia average annual water budget with urbanization.

Source: Potomac Conservancy 2008. 


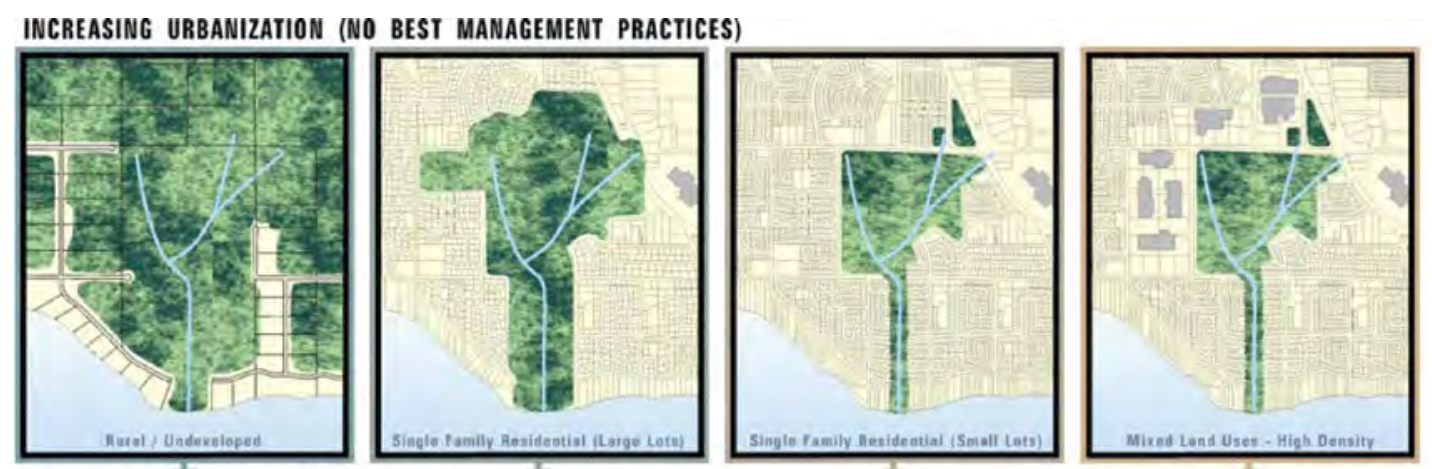

PROPORTION OF IMPERVIOUS LAND AREA (\%)
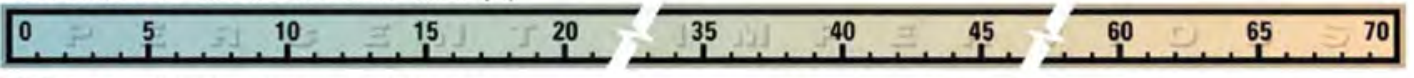

EFFECT ON TYPICAL YEAR HYDROGRAPH

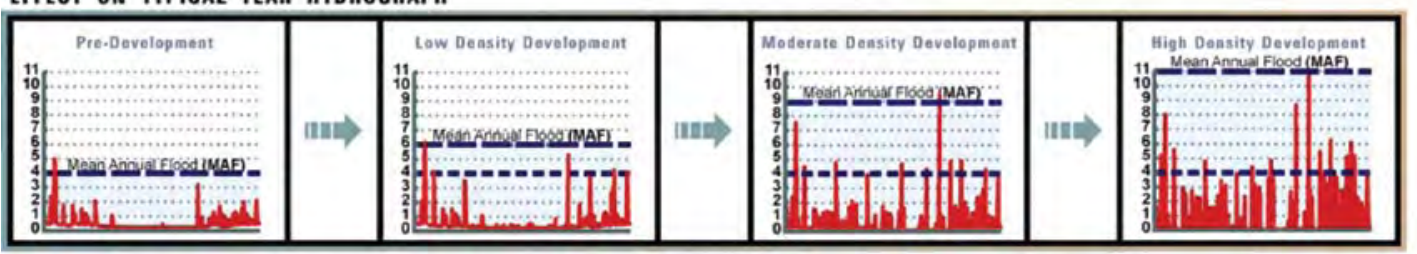

EFFECT ON WAIERCOURSE EROSION

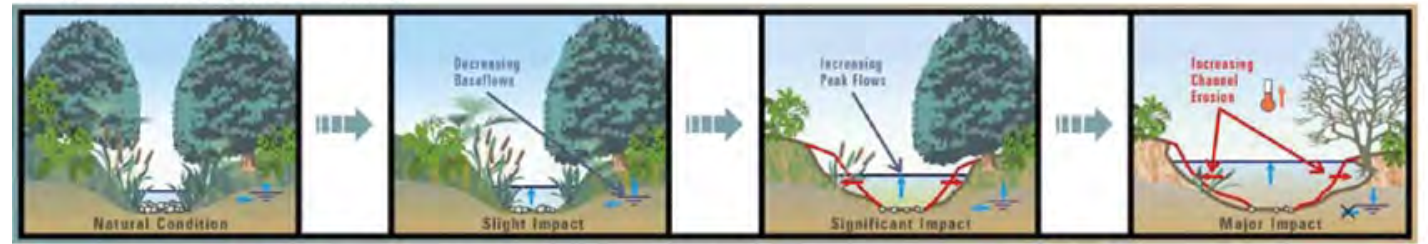

NUMBER OF STORM EVENTS AT OR ABOVE PREDEVELOPMENT MEAN ANNUAL FLOOD

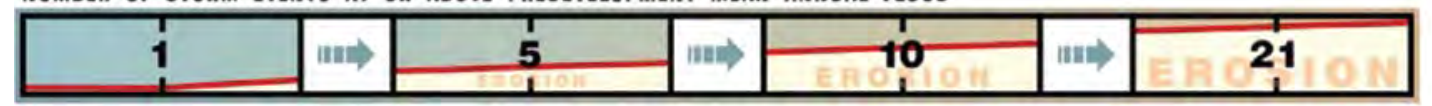

RATIO OF MEAN ANNUAL FLOOD TO WINTER BASE FLOW

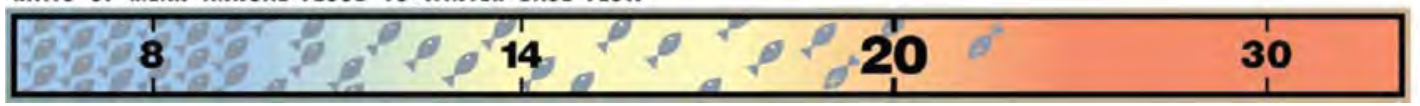

Figure 12.6. Urbanization and its effect on stream geomorphology.

Source: Ministry of Water, Land and Air Protection, Copyright 2002 Province of British Columbia. All rights reserved. Reprinted with permission of the Province of British Columbia.
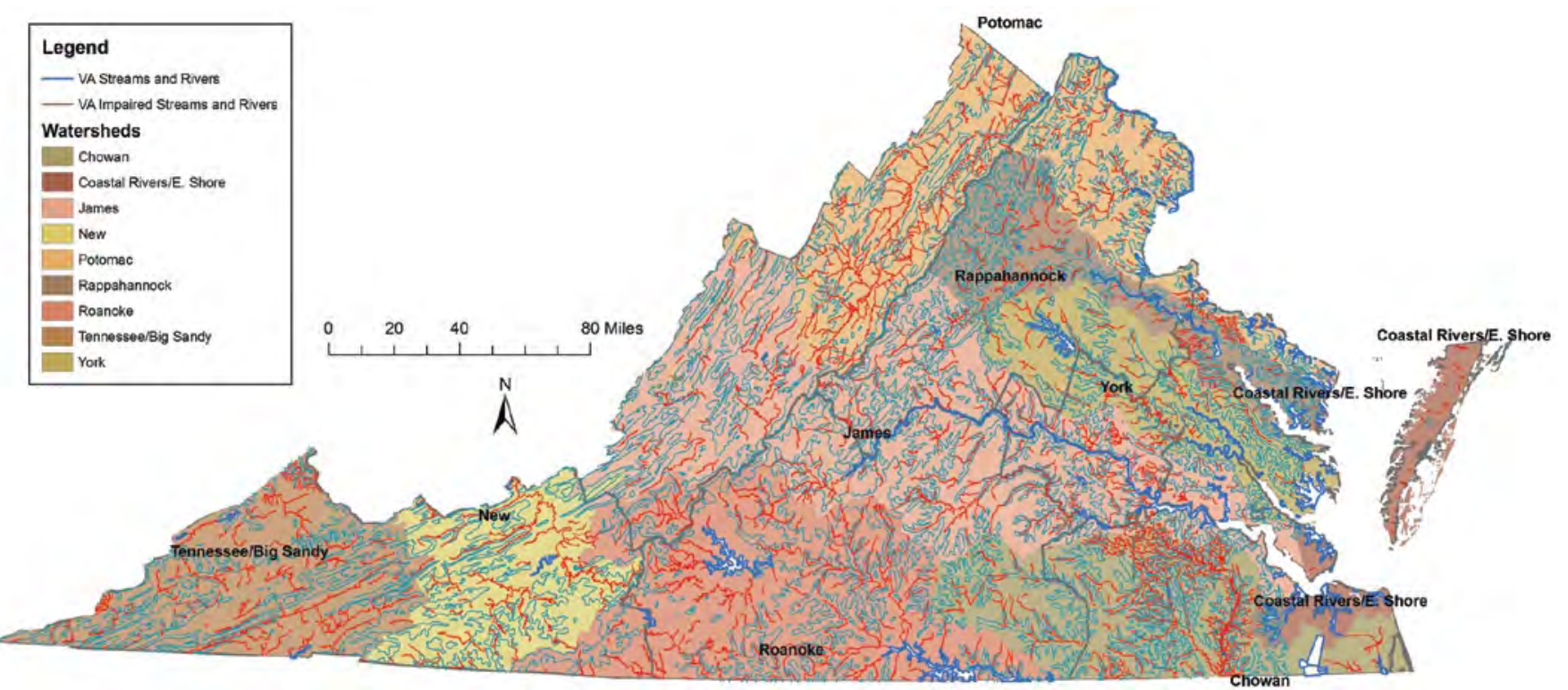

Figure 12.7. Currently impaired water bodies, Virginia.

Source: Virginia Department of Environmental Quality 2008 
Regional water quality issues can also significantly affect local water quality programs. The Chesapeake Bay receives runoff from most of Virginia, including the watersheds associated with the Shenandoah, Potomac, Rappahannock, James, and York rivers. These watersheds are shown in figure 12.7. The bay also receives runoff from the states of Maryland, Pennsylvania, Delaware, and New York, creating a watershed of 64,000 square miles.

An assessment of the health of tributary streams to the bay is provided in figure 12.8. Once a rich and productive estuary, the Chesapeake Bay has declined due to pollution generated from urban and industrial development and agricultural practices. Within the bay, sediment, nutrients, and other pollutants cause a variety of problems such as excess algae growth, reduced dissolved oxygen levels, and decreased water clarity. These conditions cause changes in aquatic organisms, often decimating desirable species and creating dead zones in the bay (figure 12.9). A recent assessment of water quality and ecosystem health of the bay estuary is provided in figure 12.10.

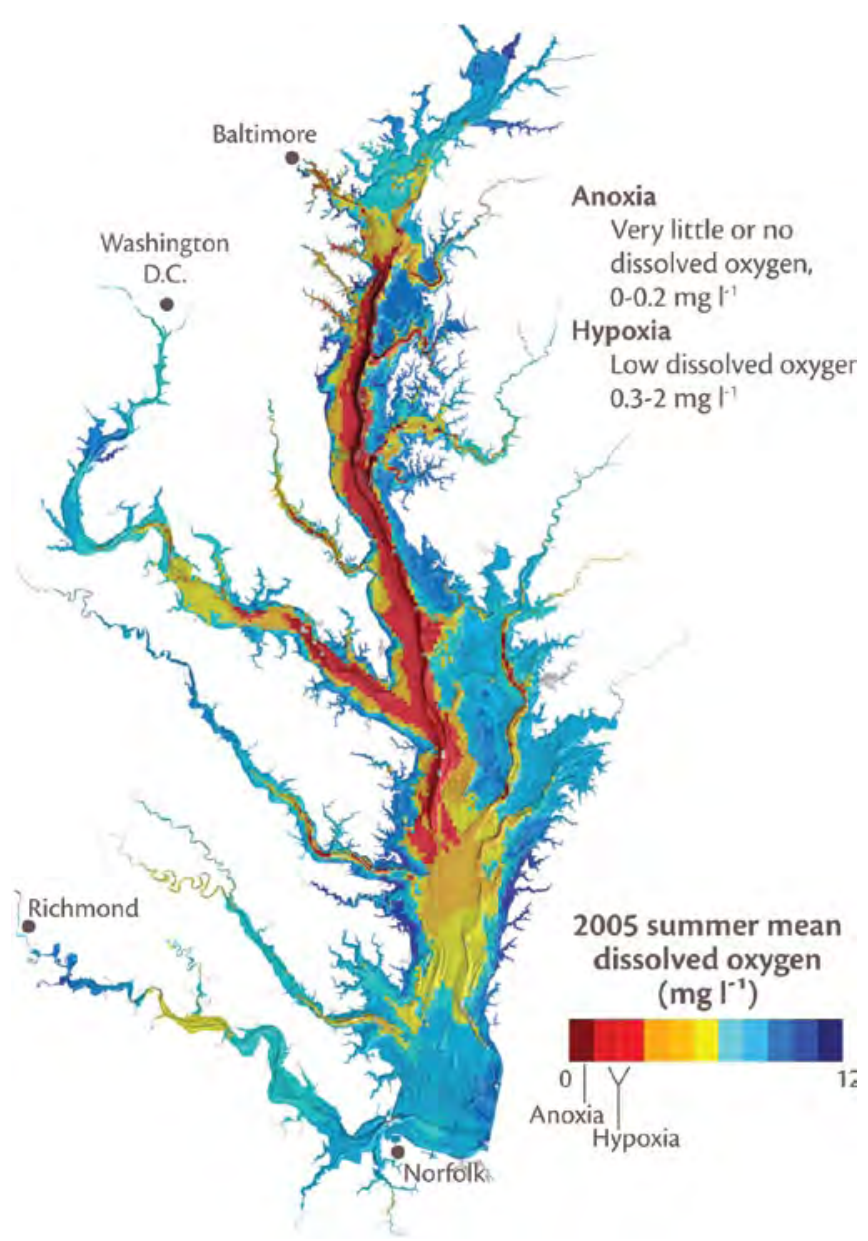

Figure 12.9. Chesapeake Bay dead zones, August 2005. Source: Chesapeake Bay Program 2005.
Nitrogen and phosphorus are the primary nutrients of concern. As a benchmark, for illustrative purposes, existing loadings from various land uses were computed from the Chesapeake Bay Nutrient and Sediment Reduction Tributary Strategies (Commonwealth of Virginia 2005) and disaggregated for Virginia. Figures 12.11 and 12.12 depict nitrogen and phosphorus loadings, respectively, from different land uses, with urban areas separated into impervious and pervious (or landscaped) areas. These figures show that while urban impervious areas are the source of increased flows, urban pervious areas may be a source for excess nutrients, on par with loadings from agricultural areas. Thus, nutrient management in the landscape should reduce loadings from urban areas and eventual pollution to receiving waters and the Chesapeake Bay.

\section{Bay Health Index 2008}

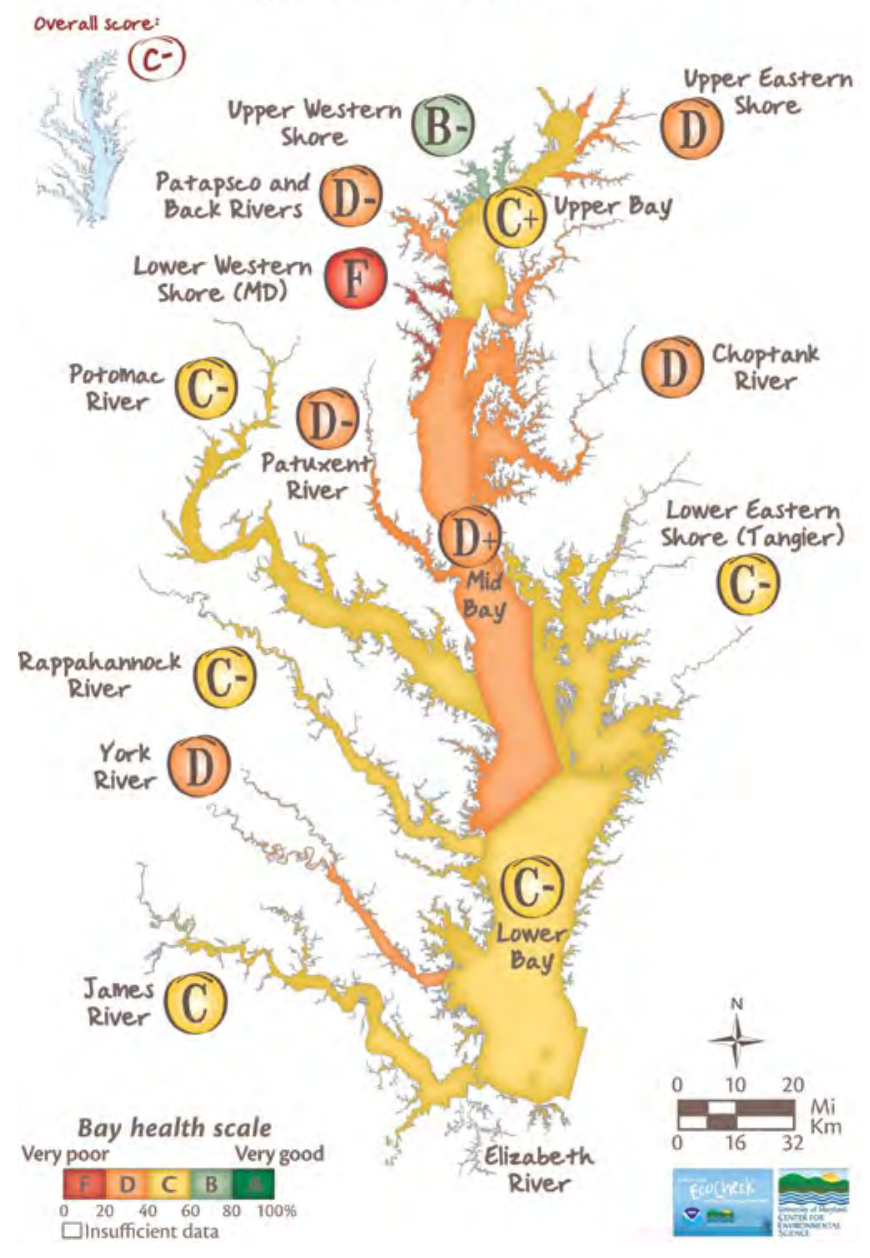

Figure 12.10. Chesapeake Bay Report Card 2008: Bay Health Index. Source: University of Maryland Center for Environmental Science (UMCES) and EcoCheck 2008. 
Upper Potomac River: Predominantly forested

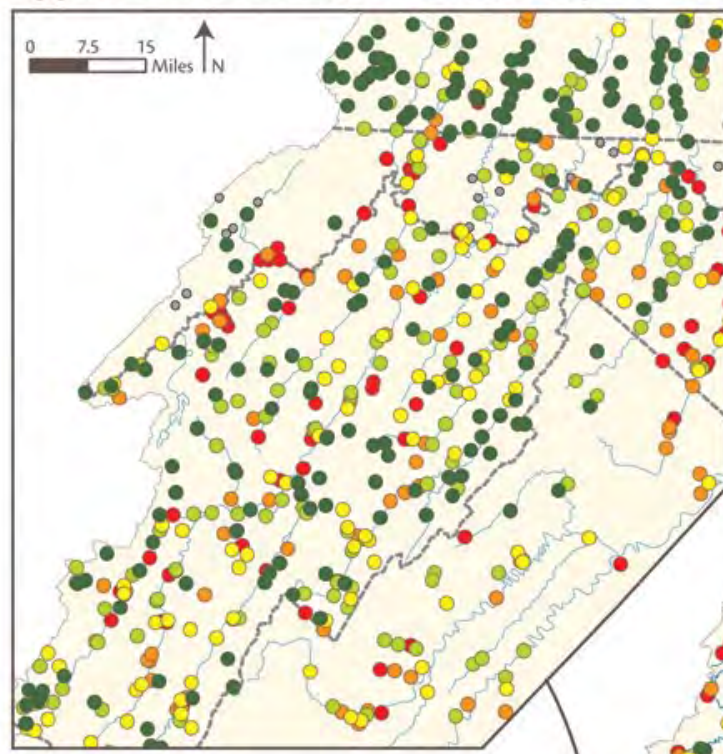

Lower Potomac River:

Predominantly urban

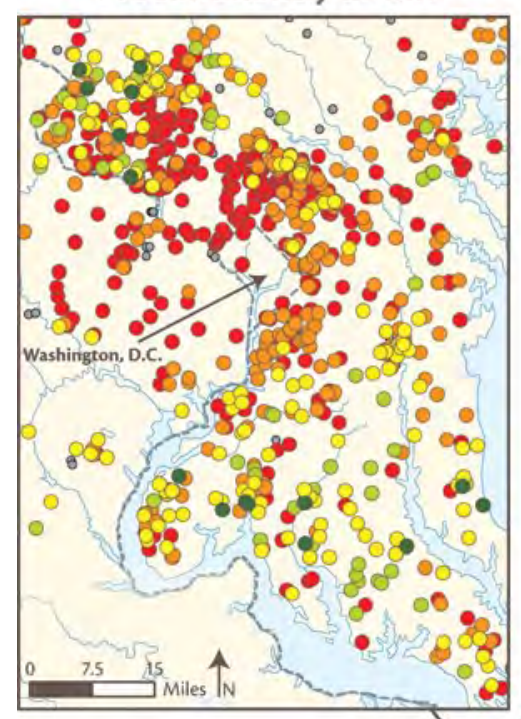

$\sim$ Major streams and rivers

Data being evaluated

Note: District of Columbia, New York Dept. of Env. Conservation, and parts of the Maryland Dept. of Natural Resources data were not available and were not included in this analysis.

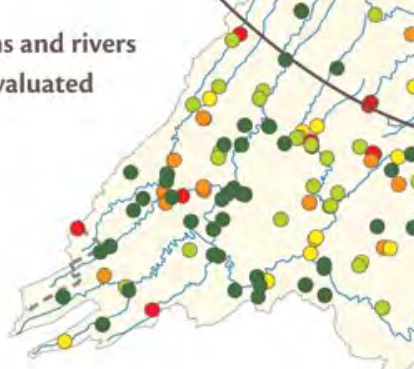




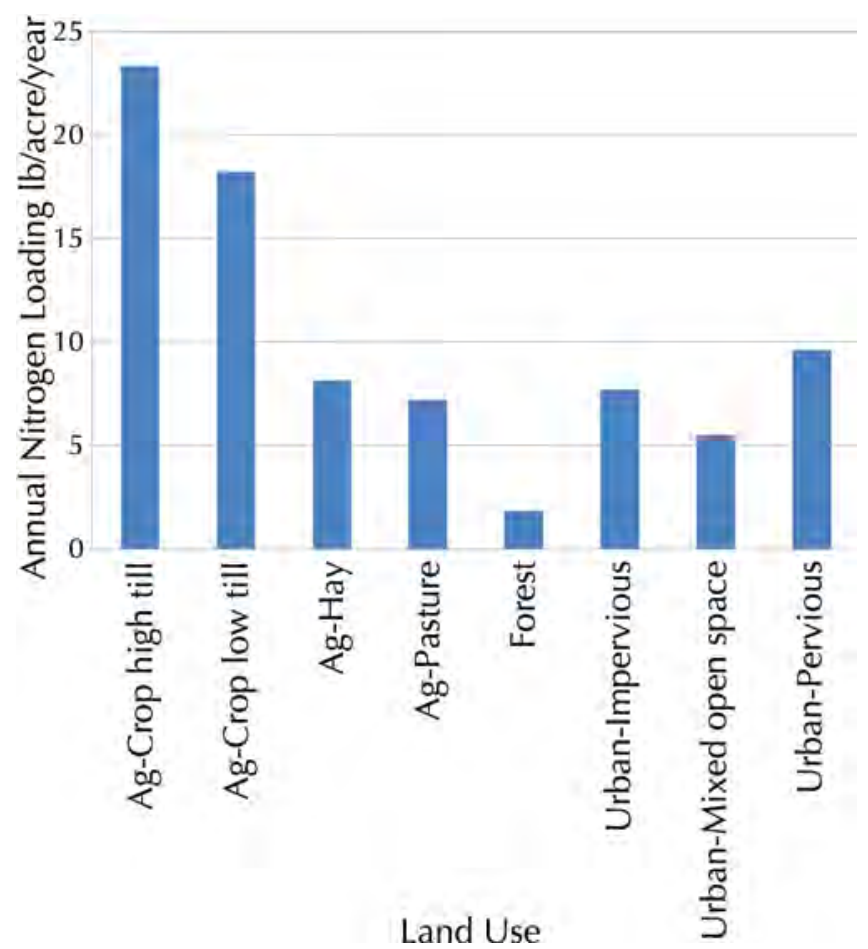

Figure 12.11. Average annual nitrogen washoff loadings for Virginia land uses.

Source: Commonwealth of Virginia 2005.

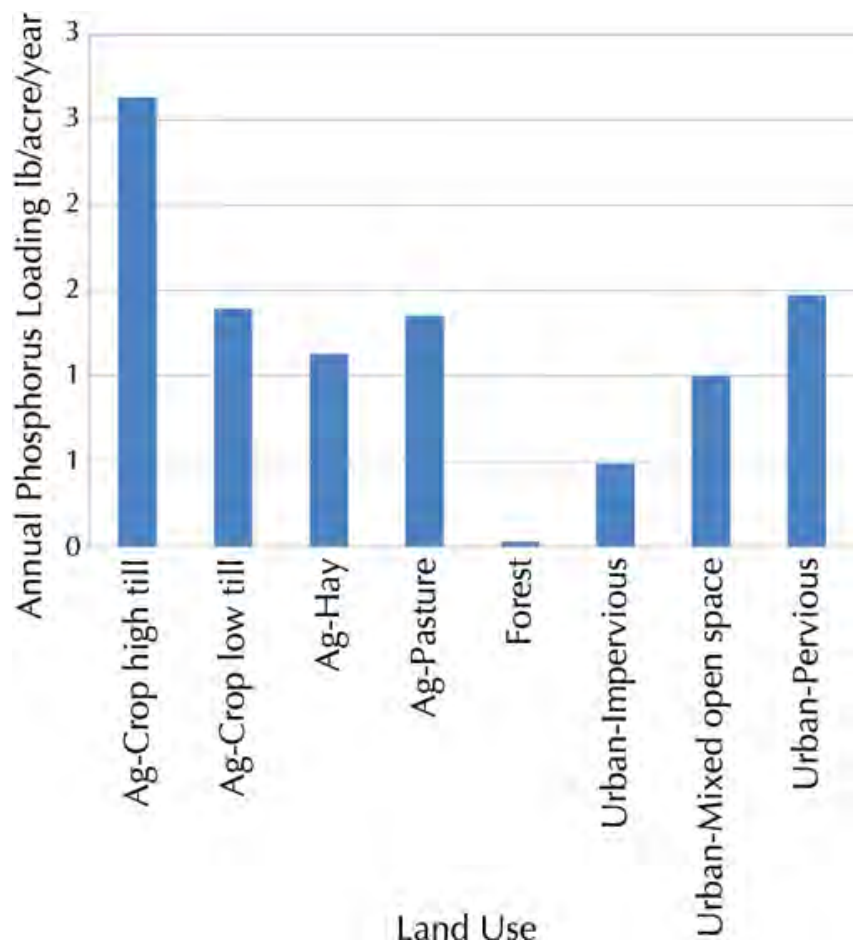

Figure 12.12. Average annual phosphorus washoff loadings for Virginia land uses.

\section{Managing Urban Stormwater}

The Virginia Stormwater Management Program (VSMP) is the regulatory program by which the state and local governments control nonpoint source pollution stemming from urban development. In 2009, in response to the issue of adverse impacts to receiving waters from urban runoff, the VDCR revised the VSMP regulatory program. The program focus shifted from mitigating peak runoff during urban development to managing stormwater volume and water quality. A new process known as the Virginia Runoff Reduction Method (VRRM) was developed by the Center for Watershed Protection (2009) in collaboration with VDCR. The intent of the VRRM is to fundamentally alter the land design process used in urban development through a three-tiered strategy that includes:

Environmental site design (ESD) practices. These are intended to minimize impervious surface area and maximize conservation practices. ESD practices can be employed to reduce runoff by restoring soil infiltrative capacities, restoring and/or preserving riparian buffers, and providing conservation subdivisions to protect critical habitats. The net impact from a stormwater perspective is that impervious surfaces and urban runoff are minimized.

Runoff reduction (RR) or volume control. This consists of implementing a variety of low-impact, density-based source controls on a site. Runoff reduction practices seek to reduce runoff prior to flowing offsite through a variety of mechanisms, predominately infiltration.

Pollutant removal (PR). This means using traditional, larger-scale best management practices to treat the reduced amount of runoff to remove nutrients and sediments.

Figure 12.13 illustrates the use of Virginia Runoff Reduction Method strategies in urban design, with the goal of increasing nutrient removal performance of a site after development.

Table 12.1 in appendix B lists the VDCR-approved BMPs. Each practice includes a brief description, diagram, photograph, and performance data, as well as their characterization as an ESD, RR, and/or PR device. The BMPs listed in this table are compiled from several sources, predominately the VDCR specifications from the Virginia Stormwater BMP Clearinghouse website (VDCR 2011), and are for public use. Most of these BMPs are intended for use in landscaped areas, so some familiarity with their functions may be beneficial. 


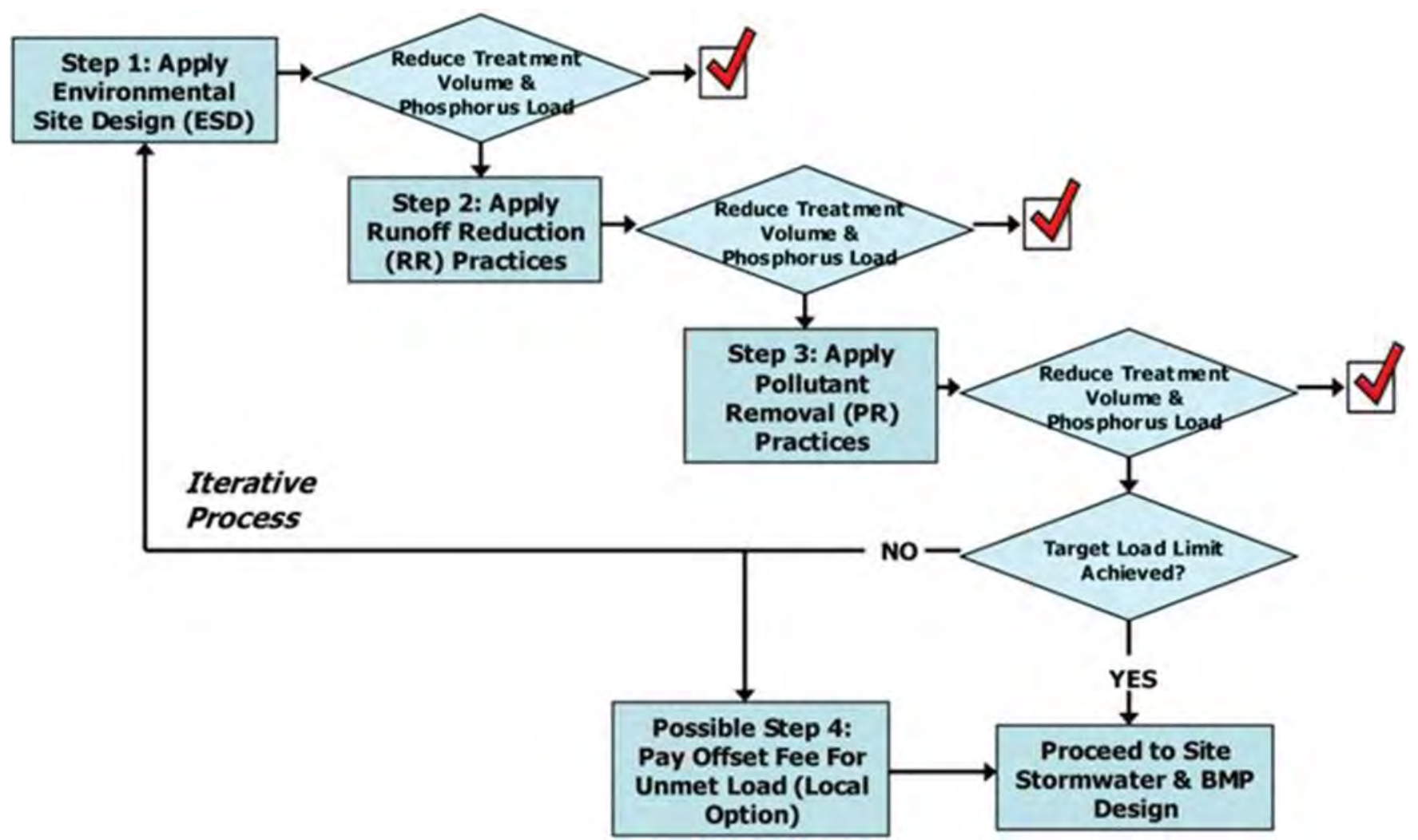

Figure 12.13. Virginia's runoff reduction methodology.

Source: Center for Watershed Protection 2008.

Proprietary BMPs consist of systems developed by specific manufacturers that utilize a variety of treatment technologies to remove pollutants from urban runoff, usually at a smaller scale than public-use BMPs. Proprietary BMPs should be examined individually because limited unbiased information is available.

\section{Managing Stormwater on a Residential Lot}

Until recently, stormwater management focused exclusively on management of impervious areas. As the understanding of nonpoint source pollution from urban areas has improved, it has become apparent that a substantial portion of the pollutants may come from pervious or landscaped areas. So, programs have shifted toward management of both pervious and impervious urban areas at both watershed and single-lot scales.

Many practices are available to reduce nonpoint source pollution at the residential level. Water and nutrient use in both turf and ornamental bed areas should be addressed. These practices require participation from the homeowner, which can sometimes be challenging. The following sections provide an overview of the steps to characterize and reduce runoff and pollutants at a residential scale, identify landscape management practices that can be beneficial, and present a risk-based assessment tool for an owner or contractor to evaluate practices at a single lot scale. This information is based on Shelton and Feehan (2008), Thacker (2009), and the Washington Environmental Council (2009).

\section{Source Control or Reducing Pollutants in Runoff}

One of the most effective means of reducing pollutants in runoff is source control. Addressing the following questions and issues may assist in the characterization of the relative risk a single site poses on downstream urban water quality issues.

\section{Where Does Stormwater Go?}

In order to assess a site, develop a site plan using the following steps:

1. Measure lot boundaries and buildings or obtain a copy of a recent survey of the site. An example of a simple site plan without topography is provided in figure 12.14 .

2. Include topographical information if it is available, but a visual survey of the high and low spots on the site can suffice. 


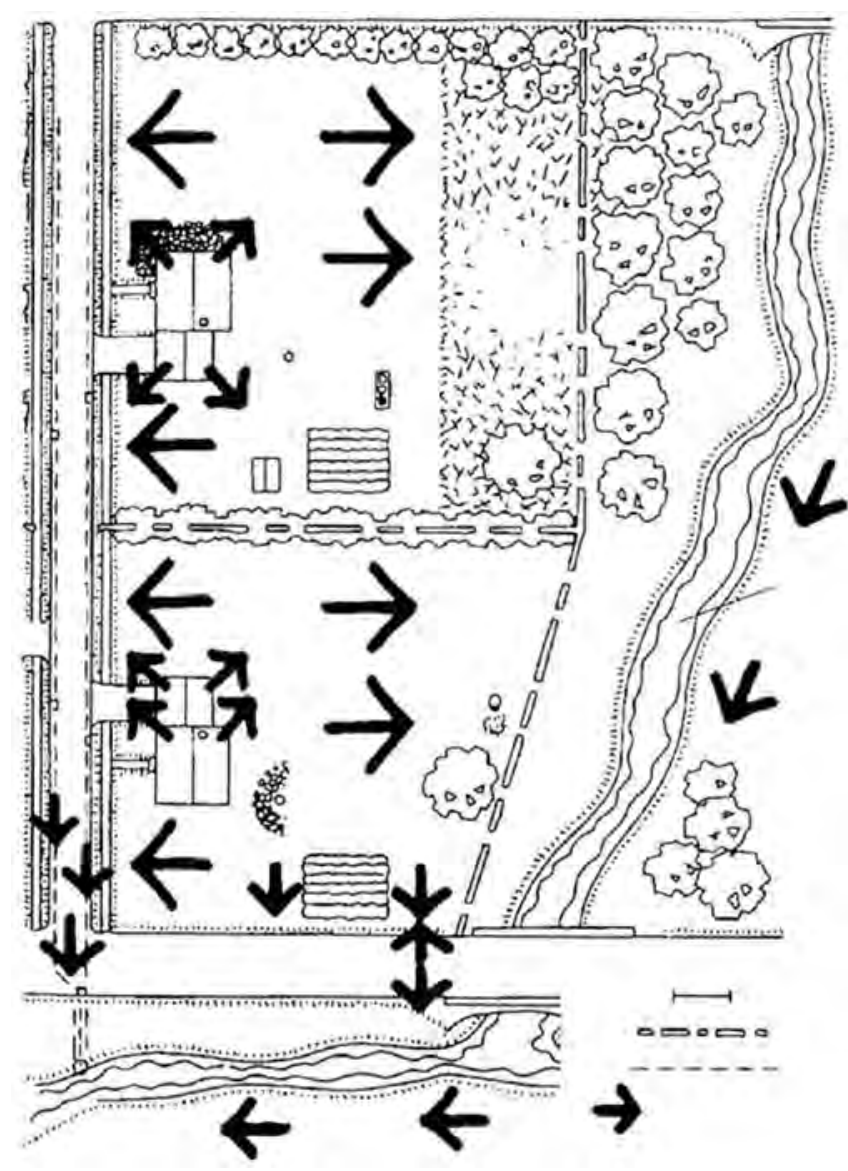

Figure 12.14. Site planning.

Source: Shelton and Feehan 2008

3. Identify impervious areas such as buildings, parking areas, sidewalks, patios, pools, decks, and driveways and how they drain (or if a drain is present).

\section{Show areas of steep slopes.}

5. Identify soil types based on soil test information or local soil maps.

6. Mark and characterize landscaped and vegetated areas.

7. Identify sensitive areas such as creeks, ditches, lakes, wetlands, storm drains, buffers, etc. Usually these would receive runoff from the site.

8. Mark stormwater runoff paths and flow directions.

9. Identify where the runoff leaves the site to adjacent receiving waters, storm drains, and neighboring sites.

It is always a good practice to reduce runoff, but it can also be a good social practice when water flows onto neighboring sites.
Keeping Yard and Garden Wastes

Disposing of leaves, grass, branches, and other yard debris in ditches and storm drains is a common practice that clogs drainage systems, causes flooding, and increases organic loading downstream. Previously, it was explained that for the most part, urban runoff is discharged untreated to receiving waters. As the organic matter from yard debris decomposes in streams, lakes, and estuaries, it depletes oxygen in water that can cause fish kills. Excess nutrients cause algal blooms and aquatic weed growth that lead to an imbalance in the ecosystem. To avoid these problems:

- Sweep/collect yard debris off streets, sidewalks, and driveways.

- Dispose of debris in a compost pile or through a curbside pickup service.

- Use a mulching mower to return grass clippings and their nutrients to the lawn.

- Use compost instead of fertilizer.

\section{Handling Pesticides Safely}

A wide variety of pesticides are available for use in landscapes.

- Keep an updated inventory list of the products stored on site.

- Store products in a dry, locked place.

- Always follow the label instructions. The label is the law!

- Hire certified pesticide applicators when necessary, especially when applying products near bodies of water.

- Avoid applications before a rain or irrigation cycle to prevent runoff contamination.

- Immediately clean up any spills or residues on impervious surfaces and dispose of them properly.

- Purchase only what is needed to avoid storing large amounts.

- Treat only when necessary with the least-toxic product.

- Consider alternative management practices to pesticides.

- Promote beneficial insects and natural predators in the landscape to minimize pesticide applications. 


\section{Fertilizers}

An example of nutrient contamination can sometimes be seen in properties adjacent to stormwater ponds. Excess or misapplied fertilizer runs off before plants can absorb it and causes algae blooms and aquatic weed growth. These plants typically have short life cycles, and when they die and decay, they deplete oxygen needed for aquatic organisms and sometimes release substances that are toxic to aquatic organisms. Responsible fertilizer use can avoid many of these problems.

- See pesticide list above.

- Test soil to determine the fertilizer need (every three years is recommended).

- Use a slow-release fertilizer instead of multiple applications of a quick-release product.

- Apply the total amount recommended in a split application.

- Apply at the correct time for the plants to use it most efficiently.

- Don't use a complete fertilizer if it isn't necessary.

- Consider an organic product instead of a synthetic product.

- Remove fertilizer from impervious surfaces such as driveways and sidewalks.

- Contact the local cooperative Extension office for information on plants, environmental conditions, and educational programs.

\section{Are Car and Truck Wastes Being Carried Away by Stormwater?}

Fluids and residues from our vehicles can be significant pollutants. Used oil from a single oil change can contaminate a large quantity of runoff. Antifreeze is toxic to aquatic organisms and can shut down the kidneys of mammals. Brake dust and tire bits contain toxic metals. Soaps used in car washing contain surfactants that threaten aquatic habitat. These issues are easily addressed.

- Maintain vehicles to prevent leaks.

- Immediately and thoroughly clean up spills.

- Wash vehicles on the lawn or at a car wash with environmentally friendly products.

- Collect spent fluids, waste oils, solvents, etc., and dispose of properly. Many communities have household hazardous waste collection days for these materials.
Animal Waste Disposal

Domestic animals and pets provide companionship and recreation. However, animals produce waste that can contain high concentrations of nitrogen, phosphorus, and harmful pathogens. When this waste is exposed to rainfall, it can easily contaminate runoff and potentially cause human health hazards for recreational and drinking waters downstream. The economic impact on a community is significant when drinking water resources are compromised or recreational activities involving water are banned and beaches closed. Fortunately, this issue is easily resolved through good housekeeping practices.

- Pick up pet waste and dispose of it properly. Many communities have "scoop the poop" programs.

- Compost animal waste. Compost systems are good for treating waste from many animals or from larger animals such as horses.

\section{Salt or Other De-Icing Products}

In order to cope with winter weather, salt and de-icing products are often used. These can be toxic to aquatic organisms and plants. Salts can be corrosive to water pumps and pipes and build up in receiving waters. Because most salts are untreated except for dilution, they can cause issues in drinking water supplies downstream. Simple practices can be used to minimize these impacts.

- Manually clear snow from impervious surfaces and drains.

- Use alternative products such as sand or kitty litter.

\section{Landscape Site Management for Control of Runoff}

There are many practices that can be used in residential landscapes to reduce pollutants in runoff. The following questions are designed to assist in assessing their need and the relative risk of a site for urban water quality issues from erosion and other pollutants.

\section{Are There Areas of Bare Soil?}

Soil left exposed without vegetation easily erodes. When erosion occurs, sediment is transported downstream through runoff. Excess sediment clogs storm drains and reduces channel conveyance capacity, causing flooding. It also buries and destroys downstream underwater habitats, depriving fish of their food sources and living areas. These issues can be easily avoided. 
- Overseed bare spots. Aeration may be necessary on compacted areas.

- Use groundcovers if turf will not grow.

- Use mulch if vegetation will not grow or is not desired.

- Vegetative buffers can be used along sloped or downhill portions of the site (appendix 12-B, table 12.1, BMP No. 2).

\section{Can the Landscape Layout Be Changed to Reduce Runoff?}

Reference the site analysis (figure 12.14). Determine if there are problem areas where the runoff is too concentrated (i.e., many arrows coming together). There are many practices that can be used to slow down and spread out the runoff.

- Improve the soil to improve water infiltration (appendix 12-B, table 12.1, BMP No. 4).

- Terrace slopes and/or add swales (appendix 12-B, table 12.1, BMP Nos. 3, 10, and 11).

- Increase vegetation and/or canopy layers. Add buffers.

- Incorporate a rain garden (appendix 12-B, table 12.1, BMP No. 9).

Adding a rain garden is an excellent BMP that can reduce runoff flows, treat contaminants in runoff, and encourage infiltration. Rain garden resources include:

- Rain Gardens Technical Guide: A Landscape Tool to Improve Water Quality, Virginia Department of Forestry. www.dof.virginia.gov/mgt/resources/pub-RainGarden-Tech-Guide_2008-05.pdf.

- Rain garden design templates, The Low Impact Development Center. www.lowimpactdevelopment. org/raingarden_design/templates.htm.

- Urban Water Quality Management: Rain Garden Plants, Virginia Cooperative Extension publication 426-043. www.pubs.ext.vt.edu/426/426-043/426-043.pdf.

\section{Does Roof Water Flow Onto Pavement or Landscaped Areas?}

The impact of a roof on the drainage of a site cannot be overstated. In many cases, roofs provide the majority of impervious areas. When roofs are directly connected via gutters and downspouts to pavement, runoff peak flows increase, along with the potential for downstream degradation.

- Disconnect gutters and drain them onto a vegetated area or into a rain barrel or rain garden (appendix B, table 12.1, BMP Nos. 1, 6, and 9). The rain barrel can provide a supplemental irrigation source during dry periods.

- Install a green roof (appendix B, table 12.1, BMP No. 5). Most buildings cannot be retrofitted for a green roof without structural improvements, so this practice applies mainly to additions or new buildings.

\section{Can Paved Surfaces Be Reduced?}

On most sites, the controllable impervious areas include walks, porches, patios, decks, and driveways.

- Reduce the total square footage of the impervious area.

- Consider a driveway that uses pavement for the tire tracks only, with turf or gravel in between.

- Use permeable pavement and/or paver systems (appendix B, table 12.1, BMP No. 7). There are many new products available that allow water infiltration through the pavement or joints.

- Consider using steppingstones or mulched or vegetated paths or walks. Some groundcovers can tolerate foot traffic.

- Use wider seams or joints on decks and patios for better water infiltration.

\section{Self-Assessment Tool}

Appendix 12-B, table 12.2 is a self-assessment tool constructed by Shelton and Feehan (2008) that is designed to evaluate a single site and identify water quality concerns for that site. The tool analyzes the relative safety of stormwater and landscape management practices using risk scoring and assists the user in determining which practices are safe and which need modification. Choose the description that best characterizes the site. Each choice has an associated risk level and corresponding score according to the following formula:

- Low risk (1): Ideal, but might not always be practical.

- Moderate-low risk (2): Provides reasonable water quality protection.

- High-moderate risk (3): Does not provide adequate water quality protection.

- High risk (4): Poses a serious danger to water quality. 
The lower the individual and total scores, the better. Higher individual scores and a higher total score suggest that the site could be improved relative to stormwater management and the risk the site poses to downstream contamination.

\section{Acknowledgements}

Figures 12.1, 12.2, 12.3, and 12.5 were constructed using symbols courtesy of the Integration and Application Network, University of Maryland Center for Environmental Science (http://ian.umces. edu/symbols/).

\section{Literature Cited}

Center for Watershed Protection. 2008. The Runoff Reduction Method. Technical Memorandum. www. vwrrc.vt.edu/swc/documents/pdf/TechnicalMemo. $p d f$.

Chesapeake Bay Program. 2005. Map: Chesapeake Bay Record Dead Zone, August 2005. www.chesapeakebay.net

Christian, A. H., and G. K. Evanylo. 2009. Compost: What Is It and What's It to You. Virginia Cooperative Extension Publication 452-231. http://pubs. ext.vt.edu/452/452-231/452-231.html.

Commonwealth of Virginia. Department of Conservation and Recreation. 2005. Chesapeake Bay Nutrient and Sediment Reduction Tributary Strategy for the Shenandoah and Potomac River Basins. www. dcr.virginia.gov/soil_and_water/documents/tsshenpoall032805.pdf.

Gilland, T., L. Fox, M. Andruczyk, S. French, and L. Swanson. 2009. What Is a Watershed? Virginia Cooperative Extension Publication 426-141. http://pubs.ext.vt.edu/426/426-041/426-041.pdf.

Potomac Conservancy. 2007. State of the Nation's River: Potomac Watershed 2007. From U.S. Environmental Protection Agency, Office of Wetlands, Oceans and Watersheds. Adapted from: Pollution Probe. 2004. The Source Water Protection Primer. www.potomac.org/site/state-of-the-nations-river/.

Potomac Conservancy. 2008. State of the Nation's River 2008: Potomac Stormwater Runoff. From: U.S. Environmental Protection Agency, Office of Wetlands, Oceans and Watersheds. www.potomac. org/site/state-of-the-nations-river-2008.
Sample, D. 2009. Stormwater Management Research: Assessing Improvements in Design and Operation on Performance. Virginia Tech College of Agriculture and Life Sciences, Approved Hatch Proposal 200-2015.

Shelton, D. P., and K. A. Feehan. 2008. Stormwater Management on Residential Lots. University of Nebraska-Lincoln Extension Publication EC707.

Smith, D. R. 2006. Permeable Interlocking Concrete Pavement: Selection, Design, Construction, Maintenance. 3rd ed. Herndon, Va.: Interlocking Concrete Pavement Institute.

Thacker, P. 2009. Stormwater Management. Training session for Prince William County, Va.

University of Maryland Center for Environmental Science (UMCES), Integration and Application Network, and EcoCheck. 2008. Chesapeake Bay Report Card 2008. (EcoCheck is a partnership between UMCES and the National Oceanographic and Atmospheric Administration.) http://ian.umces. edu/pdfs/ecocheck_newsletter_209.pdf.

Virginia Department of Conservation and Recreation (VDCR) and Virginia Water Resources Research Center (VWRRC). 2011. Virginia Approved Stormwater BMP Standards and Specifications. Available at the Virginia Stormwater BMP Clearinghouse Website. www.vwrrc.vt.edu/swc.

Virginia Department of Conservation and Recreation (VDCR). 2010. Stormwater Design Specifications. Version 1.9.

Virginia Department of Environmental Quality (VDEQ). 2008. Final 2008 305(b)/303(d) Water Quality Assessment Integrated Report.

Washington Environmental Council. 2009. Stormwater Management: One Backyard at a Time. Video Workshop, Sept. 15, 2009. www.wecprotects.org. 



\section{Appendix 12-A}

Original publication available at: http://pubs.ext.vt.edu/426/426-041/426-041.html

\section{Virginia Cooperative Extension}

PUBLICATION 426-041

\section{Urban Water-Quality Management \\ What Is a Watershed?}

Laurie Fox, Horticulture Associate, Hampton Roads Agricultural Research and Extension Center

Mike Andruczyk, Extension Agent, Chesapeake

Susan French, Extension Agent, Virginia Beach

Lynnette Swanson, Extension Agent, Norfolk

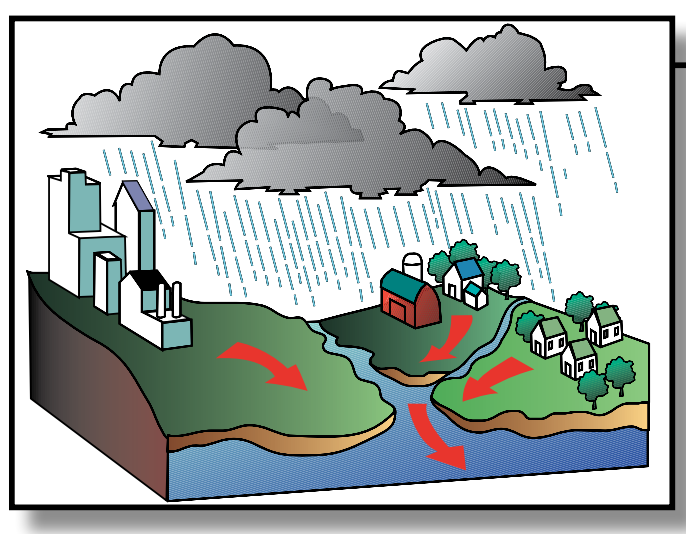

A Watershed Defined

A watershed is an area of land that drains to a lake, river, wetland, or other waterway. When precipitation occurs, water travels over forest, agricultural, or urban/suburban land areas before entering a waterway. Water can also travel into underground aquifers on its way to larger bodies of water. Together, land and water make up a watershed system.

Watersheds can be any size, but generally, the larger the body of water the larger the watershed. For example, the Chesapeake Bay Watershed covers 64,000 square miles and drains from six states, including Virginia. Smaller, local watersheds drain much smaller areas. Even a local stream has a watershed associated with it, perhaps only a few acres in size.

\section{Virginia Watersheds}

No matter where you live in Virginia you are part of one the state's nine major watersheds. You may have even noticed signs identifying the boundaries of each watershed while traveling through the state.

Virginia's watersheds ultimately drain into three main bodies of water. Nearly two-thirds of Virginia drains into the Chesapeake Bay. Southeastern and south-central Virginia drain into the Albemarle Sound in North Carolina. Rivers in Southwest Virginia flow to the Mississippi River and on to the Gulf of Mexico.
There are nine major watersheds in Virginia. Some flow to the Chesapeake Bay. Some go directly into the Atlantic Ocean. Others flow to the Albemarle Sound in North Carolina. Some rivers in Virginia even flow to the Mississippi River and then to the Gulf of Mexico.

1. Shenandoah-Potomac

2. Rappahannock

3. York

4. James

5. Eastern Shore of the Chesapeake Bay and coastal rivers

6. Chowan

7. Roanoke

8. New

9. Tennessee -Big Sandy

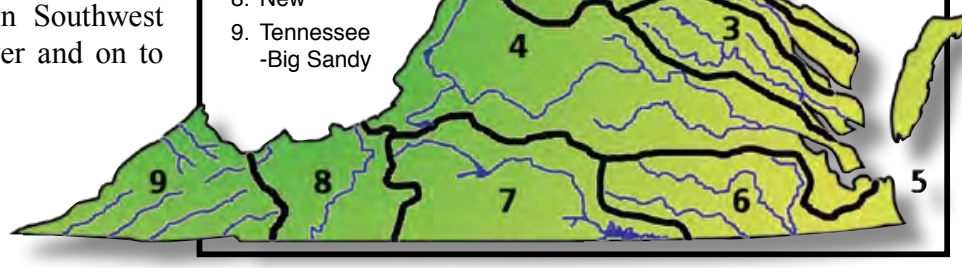

\section{www.ext.vt.edu}

Produced by Communications and Marketing, College of Agriculture and Life Sciences, Virginia Polytechnic Institute and State University, 2009

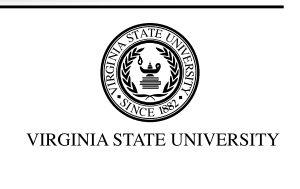




\section{Why Are Watersheds Important?}

Healthy watersheds are a vital component of a healthy environment. Watersheds act as a filter for runoff that occurs from precipitation and snowmelt, providing clean water for drinking, irrigation, and industry. Recreation and leisure are important components of watersheds, with many Virginians taking advantage of boating, fishing, and swimming in our waterways. Watersheds also support a variety of plant and wildlife communities.

Scientists and community leaders recognize the best way to protect our water resources is to understand and manage them on a watershed basis. Human activities as well as natural events that occur in a watershed can affect water quality throughout the entire system.

\section{Human Impacts on Watersheds}

Nearly all watersheds have something in common; they are populated by humans. With humans comes development and, unfortunately, pollution. As development encroaches on natural areas, the filtering system of the watershed is replaced by impervious surfaces such as concrete and asphalt. Water runs off these surfaces in sheets, carrying with it a variety of pollutants. This type of pollution is called non-point source pollution because it comes from multiple sources over a large area. Anything on the impervious surface, such as automobile fluids, litter, leaves, debris, sediments, or animal feces is swept away by the run-off. It is carried directly into a waterway by storm drains and culverts. These non-point source pollutants can have devastating effects on the health of Virginia waterways.

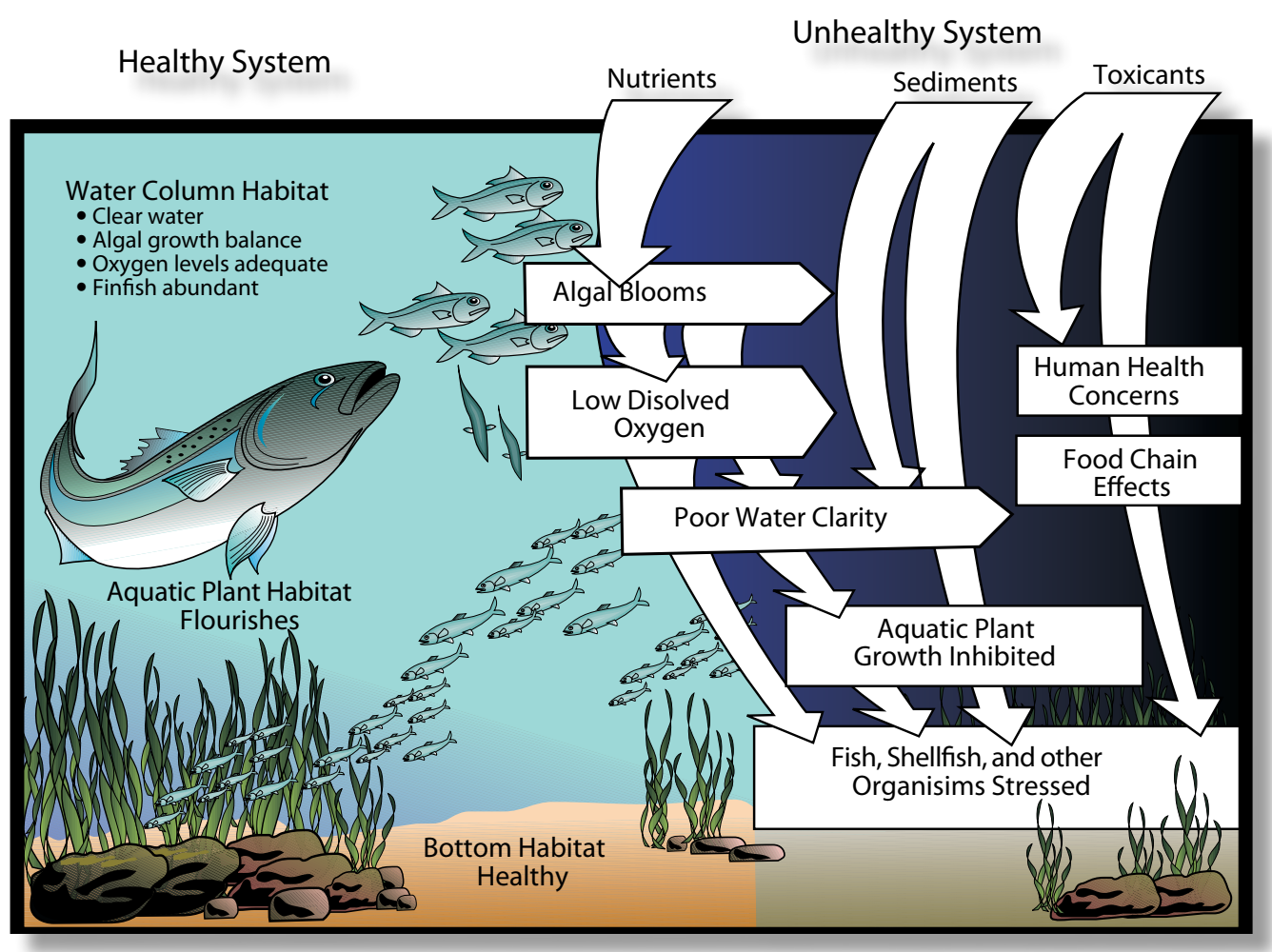


Fertilizer runoff from lawns and landscapes is another part of non-point source pollution. The overuse and incorrect use of fertilizers account for this type of pollution. The adage "if a little is good, then more is better" is not only false, but has serious detrimental effects on water quality. Excess fertilizer in the lawn is easily washed off by rain or irrigation. It travels into waterways, causing algal blooms that block sunlight, smother aquatic plants, and increase bacterial decay. As a result, dissolved oxygen is decreased and the water is unable to provide a healthy environment for aquatic life.

\section{How can you help?}

If everyone in Virginia would do a few simple things, we can greatly improve how our watersheds function in protecting water quality. Below are just a few ways you can help.

- $\quad$ Reduce your daily water usage.

- Never dispose of anything by dumping into a storm drain. Storm drains lead directly to waterways.

- Use the correct amounts of fertilizer at the correct time for your grass species.

- Reduce your use of pesticides and fertilizers by replacing grass with hardy trees and shrubs.

- Follow label directions carefully on all chemicals and use them only when necessary.

- Clean up after your pets.

- Maintain home septic systems.

- Create buffers along waterways on your property.

- Know your watershed address.

- Volunteer for clean up, restoration, and conservation programs.

- Promote sustainable land stewardship throughout your community.
For more details about watersheds and what you can to do to help, please refer to the following agencies.

- Virginia Department of Conservation and Recreation

http://www.dcr.state.va.us/sw/index.htm

- Alliance for the Chesapeake Bay http://www.alliancechesbay.org

- Chesapeake Bay Program http://www.chesapeakebay.net/

Virginia Cooperative Extension offers a wide variety of publications regarding proper fertilizer and pesticide use, plant selection and buffers. Please see our website, http://www.ext.vt.edu, or contact your a local Extension agent for more details.

\section{Editorial Contributors}

Barry Fox, Extension Specialist, Virginia State University

Leanne Dubois, Extension Agent, James City

Peter Warren, Extension Agent, Albemarle County 



\section{Appendix 12-B}

Table 12.1. Descriptions of best management practices (BMPs).

Rose ranges reflect current observations in the literature, not VDCR specifications and design practices.

Source: VDCR 2011. Efficiency ranges provided in Center for Watershed Protection, 2008. The Runoff Reduction Manual, Technical Memorandum.

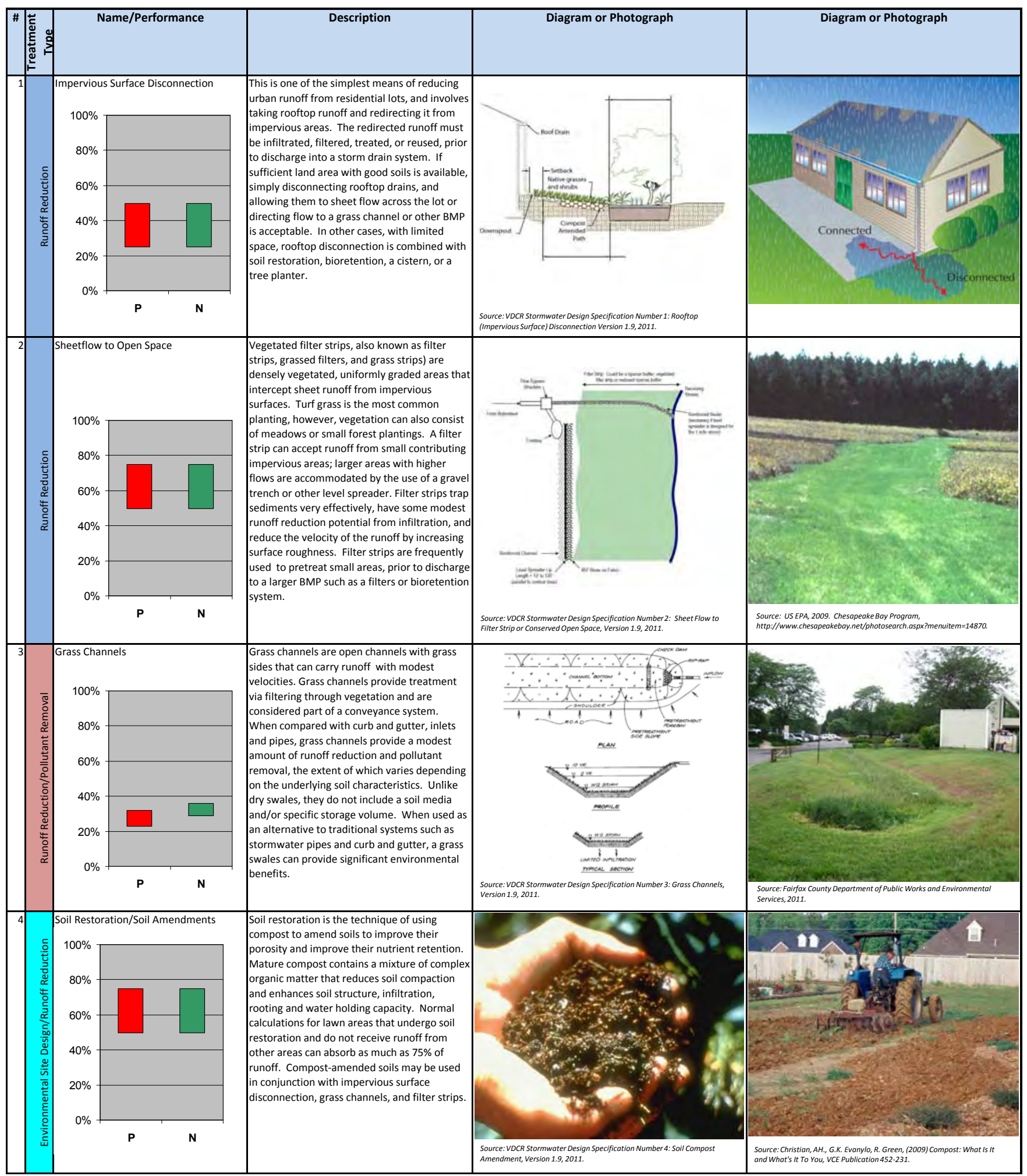


Table 12.1. Descriptions of best management practices (BMPs). (cont.)

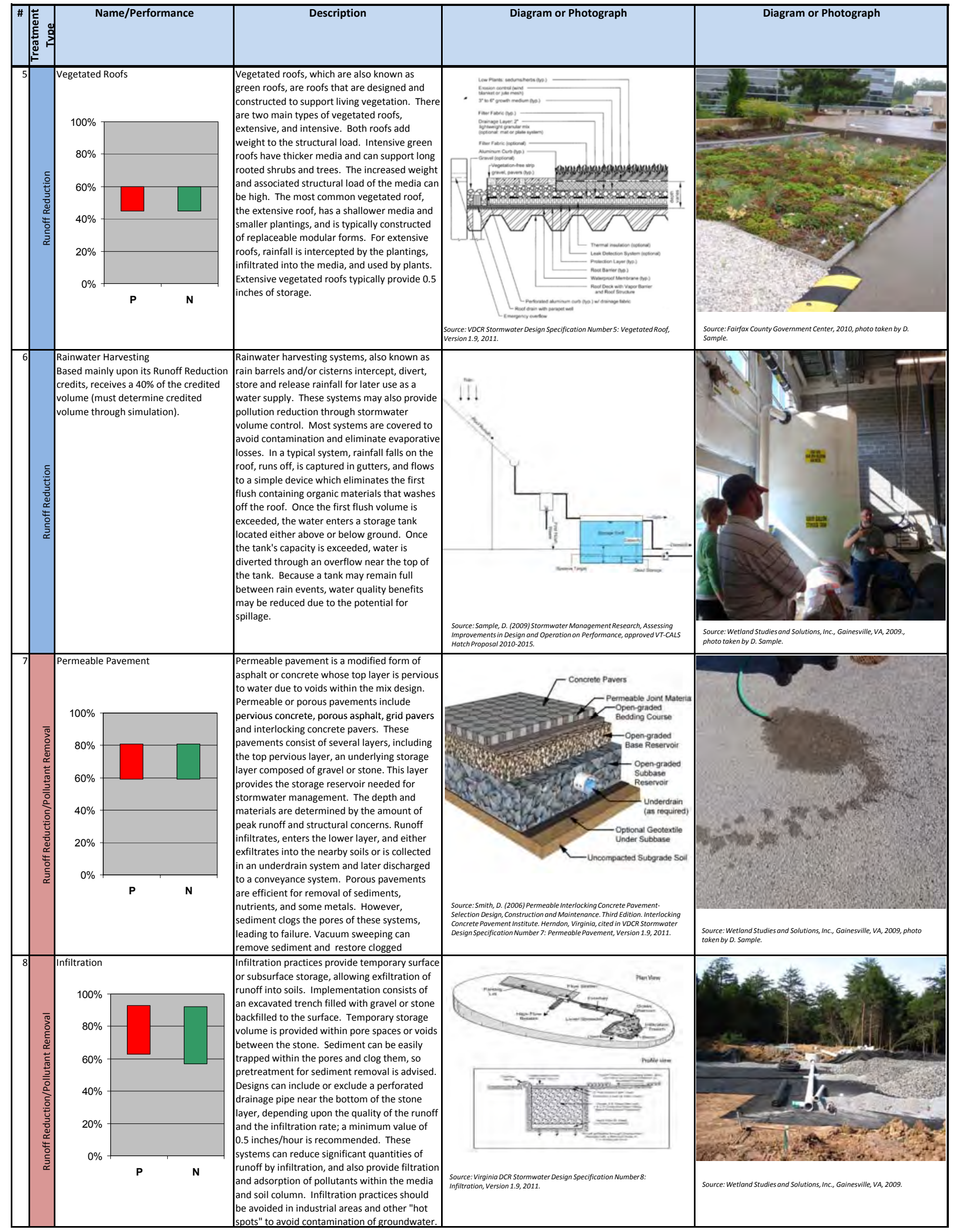


Table 12.1. Descriptions of best management practices (BMPs). (cont.)

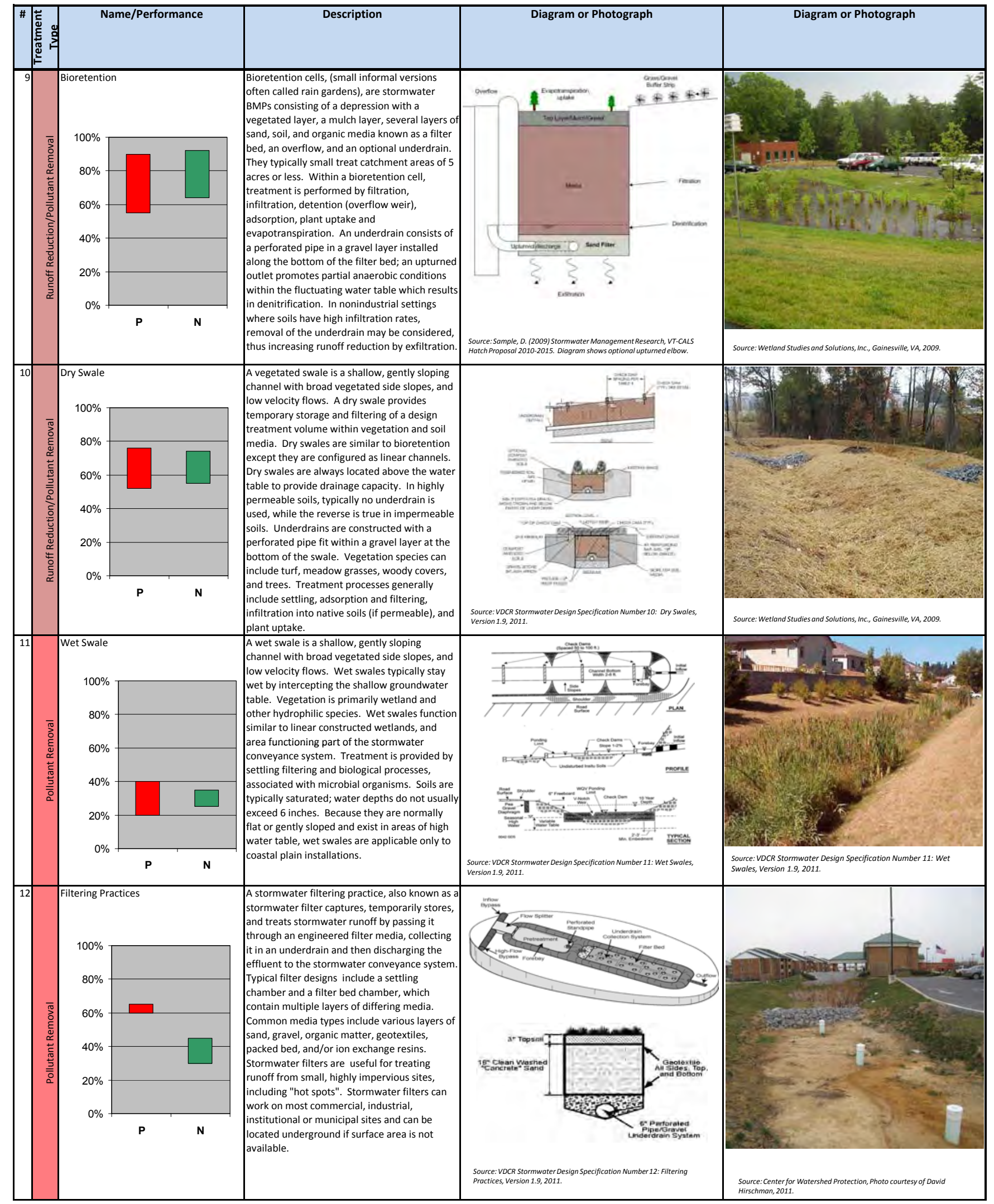


Table 12.1. Descriptions of best management practices (BMPs). (cont.)

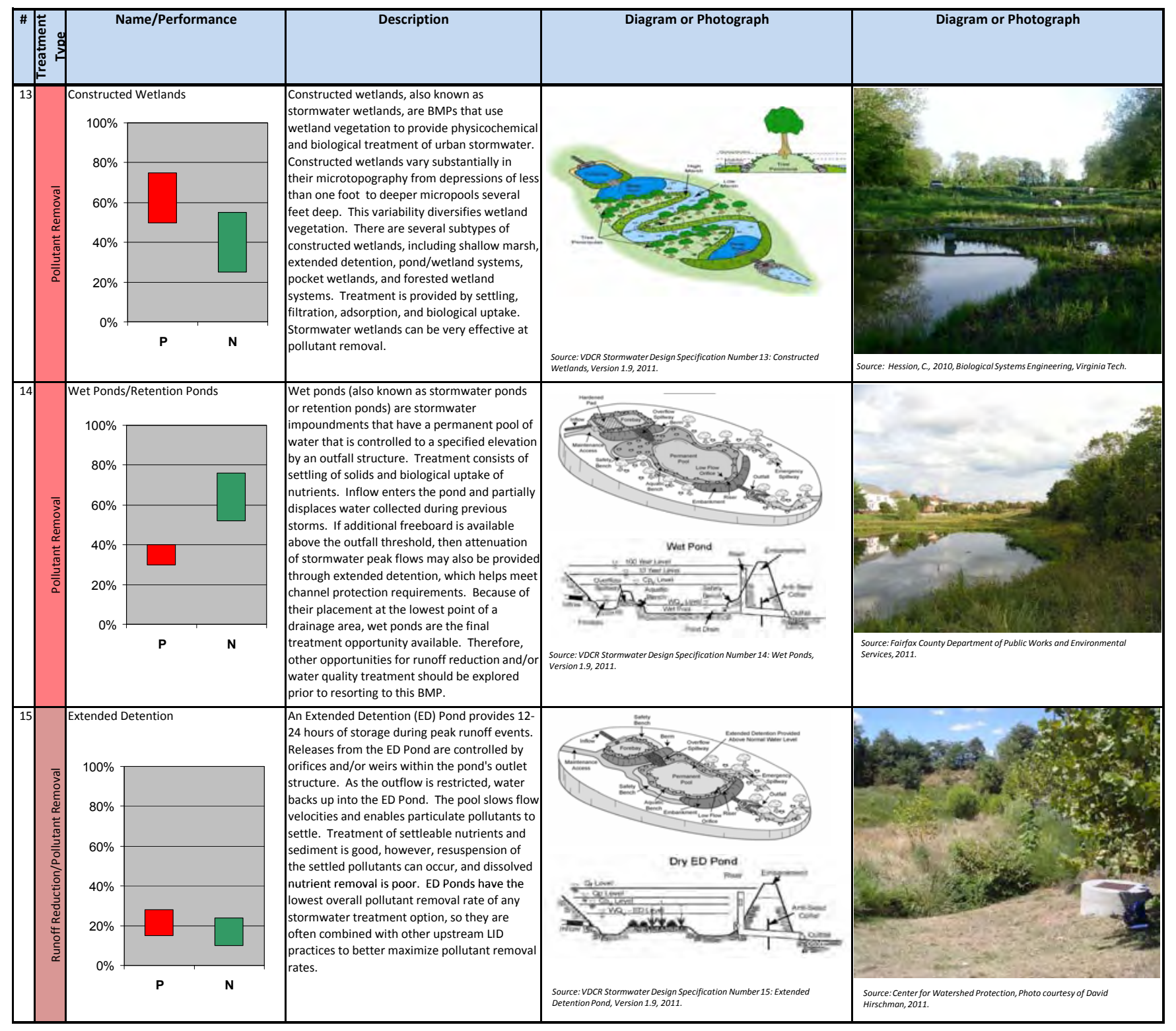


Table 12.2. Site assessment tool.

Stormwater Management on Residential Lots: Assessing the Risk of Surface and Groundwater Contamination

1. For each category listed in the first column that is appropriate to your property, read across and circle the statement that best describes conditions on your property. If there is not a descriptive statement that exactly fits your situation, use your judgment to select the risk level that best applies. (Skip and leave blank any categories that don't apply to your property.)

2. Look above the description you circled to find your "Risk Level Number" (1, 2, 3, or 4) and enter that number in the right-hand column under "Your Risk Score."

\begin{tabular}{|c|c|c|c|c|c|}
\hline Practice & $\begin{array}{c}\text { High Risk } \\
\text { (Risk Level 4) } \\
\end{array}$ & $\begin{array}{c}\text { High-Moderate Risk } \\
\text { (Risk Level 3) }\end{array}$ & $\begin{array}{c}\text { Moderate-Low Risk } \\
\text { (Risk Level 2) }\end{array}$ & $\begin{array}{c}\text { Low Risk } \\
\text { (Risk Level 1) }\end{array}$ & $\begin{array}{l}\text { Your } \\
\text { Risk } \\
\text { Score } \\
\end{array}$ \\
\hline \multicolumn{6}{|c|}{ Potential Contaminants in Runoff } \\
\hline $\begin{array}{l}\text { Grass } \\
\text { clippings, } \\
\text { leaves, and } \\
\text { other yard } \\
\text { waste }\end{array}$ & $\begin{array}{l}\text { Grass clippings, } \\
\text { leaves, and other } \\
\text { yard wastes are } \\
\text { dumped down a } \\
\text { storm drain or near a } \\
\text { surface water body. }\end{array}$ & $\begin{array}{l}\text { Grass clippings, } \\
\text { leaves, and other } \\
\text { yard wastes are left } \\
\text { on driveways, streets, } \\
\text { and other paved } \\
\text { areas to be carried } \\
\text { off by stormwater. }\end{array}$ & - & $\begin{array}{l}\text { Grass clippings, } \\
\text { leaves, and other } \\
\text { yard wastes are } \\
\text { swept off paved } \\
\text { surfaces and onto } \\
\text { lawns away from } \\
\text { water flow routes. } \\
\text { Leaves and other } \\
\text { yard wastes are } \\
\text { composted. }\end{array}$ & \\
\hline $\begin{array}{l}\text { Handling } \\
\text { and use of } \\
\text { pesticides, } \\
\text { fertilizers, } \\
\text { and outdoor } \\
\text { chemicals }\end{array}$ & $\begin{array}{l}\text { Spills are not } \\
\text { cleaned up. Products } \\
\text { are used in greater } \\
\text { amounts than what } \\
\text { is recommended on } \\
\text { the label. }\end{array}$ & $\begin{array}{l}\text { Granules, etc., are } \\
\text { left on driveway, } \\
\text { sidewalks, or other } \\
\text { paved areas to } \\
\text { be carried off by } \\
\text { stormwater. }\end{array}$ & - & $\begin{array}{l}\text { Spills are cleaned } \\
\text { up immediately, } \\
\text { particularly on } \\
\text { paved surfaces. } \\
\text { Recommended } \\
\text { amounts of } \\
\text { chemicals are } \\
\text { applied according to } \\
\text { label instructions. }\end{array}$ & \\
\hline $\begin{array}{l}\text { Timing of } \\
\text { pesticide, } \\
\text { fertilizer, } \\
\text { and outdoor } \\
\text { chemical use }\end{array}$ & $\begin{array}{l}\text { Application is made } \\
\text { when heavy rain is } \\
\text { forecast within the } \\
\text { next } 24 \text { hours and } \\
\text { on saturated soils or } \\
\text { areas where runoff is } \\
\text { likely. }\end{array}$ & $\begin{array}{l}\text { Application is made } \\
\text { when heavy rain is } \\
\text { forecast within the } \\
\text { next } 24 \text { hours and } \\
\text { on unsaturated soils } \\
\text { or areas with little } \\
\text { slope. }\end{array}$ & $\begin{array}{l}\text { Application is made } \\
\text { when light rain is } \\
\text { forecast within the } \\
\text { next } 24 \text { hours and } \\
\text { on saturated soils or } \\
\text { areas where runoff is } \\
\text { likely. }\end{array}$ & $\begin{array}{l}\text { Application is made } \\
\text { when no or only } \\
\text { light rain is forecast } \\
\text { within the next } \\
24 \text { hours and on } \\
\text { unsaturated soils } \\
\text { or areas with little } \\
\text { slope. }\end{array}$ & \\
\hline $\begin{array}{l}\text { Storage of } \\
\text { pesticides, } \\
\text { fertilizers, } \\
\text { and other } \\
\text { potentially } \\
\text { harmful } \\
\text { chemicals }\end{array}$ & $\begin{array}{l}\text { Chemicals are stored } \\
\text { in nonwaterproof } \\
\text { containers outdoors. }\end{array}$ & $\begin{array}{l}\text { Chemicals are } \\
\text { stored in waterproof } \\
\text { containers outdoors, } \\
\text { but within reach of } \\
\text { stormwater. }\end{array}$ & $\begin{array}{l}\text { Chemicals are } \\
\text { stored in waterproof } \\
\text { containers outdoors, } \\
\text { out of the reach of } \\
\text { stormwater. }\end{array}$ & $\begin{array}{l}\text { Chemicals are } \\
\text { stored in waterproof } \\
\text { containers in a } \\
\text { garage, shed, or } \\
\text { basement that is } \\
\text { protected from } \\
\text { stormwater. }\end{array}$ & \\
\hline
\end{tabular}


Table 12.2. Site assessment tool. (cont.)

\begin{tabular}{|c|c|c|c|c|c|}
\hline Practice & $\begin{array}{c}\text { High Risk } \\
\text { (Risk Level 4) }\end{array}$ & $\begin{array}{l}\text { High-Moderate Risk } \\
\text { (Risk Level 3) }\end{array}$ & $\begin{array}{l}\text { Moderate-Low Risk } \\
\quad(\text { Risk Level 2) }\end{array}$ & $\begin{array}{c}\text { Low Risk } \\
\text { (Risk Level 1) }\end{array}$ & $\begin{array}{l}\text { Your } \\
\text { Risk } \\
\text { Score }\end{array}$ \\
\hline \multicolumn{6}{|c|}{ Potential Contaminants in Runoff (cont.) } \\
\hline $\begin{array}{l}\text { Automotive } \\
\text { wastes }\end{array}$ & $\begin{array}{l}\text { Used oil, antifreeze, } \\
\text { or other wastes are } \\
\text { dumped down a } \\
\text { storm drain or on a } \\
\text { paved surface. }\end{array}$ & $\begin{array}{l}\text { Used oil, antifreeze, } \\
\text { or other wastes are } \\
\text { dumped in a ditch or } \\
\text { on the ground. }\end{array}$ & $\begin{array}{l}\text { Drips and spills are } \\
\text { not cleaned up. } \\
\text { Car parts and other } \\
\text { vehicle wastes are } \\
\text { left on unpaved areas } \\
\text { outside. }\end{array}$ & $\begin{array}{l}\text { Oil drips and fluid } \\
\text { spills are cleaned up. } \\
\text { Dirty car parts and } \\
\text { other vehicle wastes } \\
\text { are kept out of reach } \\
\text { of stormwater runoff. }\end{array}$ & \\
\hline $\begin{array}{l}\text { Vehicle } \\
\text { washing }\end{array}$ & $\begin{array}{l}\text { Cars, trucks, or other } \\
\text { items are washed on } \\
\text { a driveway, street, or } \\
\text { other paved area. }\end{array}$ & $\begin{array}{l}\text { Cars, trucks, or other } \\
\text { items are washed on } \\
\text { a gravel or rocked } \\
\text { area. }\end{array}$ & $\begin{array}{l}\text { Cars, trucks, or other } \\
\text { items are washed on } \\
\text { a lawn. }\end{array}$ & $\begin{array}{l}\text { Cars and trucks } \\
\text { are taken to a } \\
\text { commercial car } \\
\text { wash. }\end{array}$ & \\
\hline $\begin{array}{l}\text { Animal and } \\
\text { pet wastes }\end{array}$ & $\begin{array}{l}\text { Animal and pet } \\
\text { wastes are left on } \\
\text { paved surfaces or } \\
\text { dumped down a } \\
\text { storm drain. }\end{array}$ & $\begin{array}{l}\text { Animal and pet } \\
\text { wastes are left to } \\
\text { decompose on grass } \\
\text { or soil. Wastes are } \\
\text { concentrated in a } \\
\text { small area, such as } \\
\text { a pen. }\end{array}$ & $\begin{array}{l}\text { Animal and pet } \\
\text { wastes are left to } \\
\text { decompose on grass } \\
\text { or soil. Wastes are } \\
\text { scattered over a wide } \\
\text { area. }\end{array}$ & $\begin{array}{l}\text { Animal and pet } \\
\text { wastes are flushed } \\
\text { down the toilet or } \\
\text { wrapped and placed } \\
\text { in the garbage for } \\
\text { disposal. }\end{array}$ & \\
\hline \multicolumn{6}{|c|}{ Landscaping and Site Management } \\
\hline Landscaping & $\begin{array}{l}\text { There is no } \\
\text { landscaping to slow } \\
\text { the flow of runoff. } \\
\text { Soils are compacted, } \\
\text { limiting infiltration. } \\
\text { Yard is hilly, allowing } \\
\text { runoff to occur. }\end{array}$ & $\begin{array}{l}\text { No areas are } \\
\text { landscaped to } \\
\text { encourage water to } \\
\text { soak in, and soils } \\
\text { are compacted. Yard } \\
\text { is relatively flat, } \\
\text { reducing the amount } \\
\text { of runoff that occurs. }\end{array}$ & $\begin{array}{l}\text { Yard is landscaped } \\
\text { and soils are } \\
\text { amended to slow the } \\
\text { flow of stormwater } \\
\text { and provide areas } \\
\text { where water soaks } \\
\text { into the ground. Yard } \\
\text { is hilly, allowing } \\
\text { some runoff to occur. }\end{array}$ & $\begin{array}{l}\text { Yard is landscaped } \\
\text { and soils are } \\
\text { amended to slow the } \\
\text { flow of stormwater } \\
\text { and provide areas } \\
\text { where water soaks } \\
\text { into the ground. Yard } \\
\text { is relatively flat and } \\
\text { little runoff occurs. }\end{array}$ & \\
\hline $\begin{array}{l}\text { Yard and } \\
\text { gardens }\end{array}$ & $\begin{array}{l}\text { Large areas of yard } \\
\text { or garden are left } \\
\text { without mulch or } \\
\text { vegetation for long } \\
\text { periods. }\end{array}$ & $\begin{array}{l}\text { Small areas of yard } \\
\text { or garden are left } \\
\text { without mulch or } \\
\text { vegetation for long } \\
\text { periods. }\end{array}$ & $\begin{array}{l}\text { Grass or other } \\
\text { ground cover is } \\
\text { used, but is spotty, } \\
\text { particularly on } \\
\text { slopes. }\end{array}$ & $\begin{array}{l}\text { Bare spots in the } \\
\text { lawn are promptly } \\
\text { seeded and topped } \\
\text { with a layer of straw } \\
\text { or mulch. Bare soil } \\
\text { in gardens is covered } \\
\text { with mulch }\end{array}$ & \\
\hline $\begin{array}{l}\text { Paved } \\
\text { surfaces }\end{array}$ & $\begin{array}{l}\text { Large areas are } \\
\text { paved for walkways, } \\
\text { patios, and other } \\
\text { areas. }\end{array}$ & $\begin{array}{l}\text { Some small areas are } \\
\text { paved for walkways, } \\
\text { patios, and other } \\
\text { areas. }\end{array}$ & $\begin{array}{l}\text { Alternatives such as } \\
\text { gravel, rock, paving } \\
\text { blocks, brick, or } \\
\text { flagstone are used } \\
\text { for walkways, patios, } \\
\text { and other areas. }\end{array}$ & $\begin{array}{l}\text { Alternatives such } \\
\text { as wood chips or } \\
\text { mulch are used for } \\
\text { walkways, patios, } \\
\text { and other areas. }\end{array}$ & \\
\hline
\end{tabular}


Table 12.2. Site assessment tool. (cont.)

\begin{tabular}{|c|c|c|c|c|c|}
\hline Practice & $\begin{array}{c}\text { High Risk } \\
\text { (Risk Level 4) } \\
\end{array}$ & $\begin{array}{l}\text { High-Moderate Risk } \\
\text { (Risk Level 3) }\end{array}$ & $\begin{array}{c}\text { Moderate-Low Risk } \\
\text { (Risk Level 2) }\end{array}$ & $\begin{array}{c}\text { Low Risk } \\
\text { (Risk Level 1) } \\
\end{array}$ & $\begin{array}{l}\text { Your } \\
\text { Risk } \\
\text { Score } \\
\end{array}$ \\
\hline \multicolumn{6}{|c|}{ Landscaping and Site Management (cont.) } \\
\hline $\begin{array}{l}\text { Roof } \\
\text { drainage }\end{array}$ & $\begin{array}{l}\text { Most or all } \\
\text { downspouts are } \\
\text { connected directly to } \\
\text { storm drains. }\end{array}$ & $\begin{array}{l}\text { Most or all eave drip } \\
\text { lines or downspouts } \\
\text { discharge onto paved } \\
\text { surfaces where water } \\
\text { runs off. }\end{array}$ & $\begin{array}{l}\text { Most or all eave drip } \\
\text { lines or downspouts } \\
\text { discharge water onto } \\
\text { grassy or mulched } \\
\text { areas where some } \\
\text { water runs off. }\end{array}$ & $\begin{array}{l}\text { Most or all eave drip } \\
\text { lines or downspouts } \\
\text { discharge water onto } \\
\text { a grassy or mulched } \\
\text { area or rain garden } \\
\text { where water soaks } \\
\text { into the ground. }\end{array}$ & \\
\hline $\begin{array}{l}\text { Lot during } \\
\text { construction }\end{array}$ & $\begin{array}{l}\text { Soil is left bare } \\
\text { until construction is } \\
\text { completed and no } \\
\text { sediment barriers are } \\
\text { used. }\end{array}$ & $\begin{array}{l}\text { Soil is left bare } \\
\text { until construction is } \\
\text { completed. Sediment } \\
\text { barriers are installed, } \\
\text { but are poorly } \\
\text { maintained allowing } \\
\text { some muddy runoff } \\
\text { to leave the site. }\end{array}$ & $\begin{array}{l}\text { Soil is left bare } \\
\text { until construction is } \\
\text { completed. Sediment } \\
\text { barriers are installed } \\
\text { and maintained to } \\
\text { detain muddy runoff } \\
\text { until grass covers } \\
\text { soil. }\end{array}$ & $\begin{array}{l}\text { Bare soil is seeded } \\
\text { and mulched as } \\
\text { soon as possible } \\
\text { (before construction } \\
\text { is completed). } \\
\text { Sediment barriers } \\
\text { are used until grass } \\
\text { covers soil. }\end{array}$ & \\
\hline Buffer strips & $\begin{array}{l}\text { Bare soil, sand, or } \\
\text { gravel exists next } \\
\text { to a stream bank or } \\
\text { lakeshore. Stream } \\
\text { banks or lakeshores } \\
\text { are eroding. }\end{array}$ & $\begin{array}{l}\text { Spotty mowed } \\
\text { vegetation exists next } \\
\text { to a stream bank or } \\
\text { lakeshore. }\end{array}$ & $\begin{array}{l}\text { Mowed grass exists } \\
\text { next to stream bank } \\
\text { or lakeshore. }\end{array}$ & $\begin{array}{l}\text { Buffer strips of thick } \\
\text { vegetation are left } \\
\text { along a stream bank } \\
\text { or lakeshore. }\end{array}$ & . \\
\hline
\end{tabular}





\section{Chapter 13. Turf and Landscape Nutrient Management Planning}

David Kindig, Soil and Water Conservation, Virginia Department of Conservation and Recreation

Timothy Sexton, Soil and Water Conservation, Virginia Department of Conservation and Recreation

\section{Introduction}

This chapter will emphasize the actual steps that a certified nutrient management planner will use to develop and implement a nutrient management plan (NMP). Utilizing the data and recommendations provided in an NMP promotes water quality protection. However, an equally important result of an NMP is its value as a comprehensive tool in planning fertilizer selections and application strategies in terms of optimizing plant responses, nutrient-use efficiency, and economics. While these criteria were specifically developed for the Commonwealth of Virginia, the principles will apply to any mid-Atlantic state.

The primary steps for nutrient management planning are:

1. Collect and evaluate information about the overall area to be planned.

2. Determine realistic expectations of the planting's performance with known conditions, such as soil fertility levels and adaptation of plant species to the area and for the intended use.

3. Establish nutrient requirements for the plant species in each area to be planned.

4. Evaluate planting area limitations based on environmental site sensitivity or other plan implementation concerns.

5. Allocate purchased and any on-site nutrient sources, if any, to available planned areas.

6. Identify nutrient timing and placement methods to maximize nutrient use by plantings and minimize environmental losses.

Prior to initiating plan development, it is critical to obtain some information about the current management practices used by your client. This process of inventorying your client's resources and needs is critical to developing an implementable plan, based on sound agronomics, that improves water quality.

\section{Assessment of Planned Areas}

\section{Land}

The obvious place to begin is with the land. This will vary from small management areas like an urban or residential setting to perhaps several hundred acres, such as golf courses, large parks, and recreation facilities. Planned areas will represent an area that will be managed and fertilized as one distinct unit. It will usually be defined by the type of planting it contains, such as turf, bedding plants, etc. How many planned areas will be needed to address various plant species? How much area is in each of these planned areas? What is the present use of these areas? If they are being used for turf or annual or perennial bedding plants, will that use continue or will the areas be renovated to something else?

\section{Equipment Resources}

Once you know what is normally done (or expected) in each planned area, knowing what type of equipment, if any, your client has will be helpful when developing recommendations. Does your client have seeding equipment, fertilizer spreaders, aerators, sprayers, or tillage equipment? What are the limitations of these machines? You need to consider the availability of equipment when recommending certain management operations and, if unavailable, is there an alternative operation that will be acceptable?

\section{Past Methods of Fertilizer Application}

The use of commercial fertilizer is a similar consideration. You need to know the client's current fertilization program. The rate and timing of applications are important considerations for plan development. Also, be certain to determine how much custom application is done and by whom. If the landowner is a steady customer of a particular dealer, his application capabilities and limitations should be considered, if possible, when developing the final plan.

\section{Soil Resource Assessments}

The most important resource to consider when developing a plan is the soil, or combination of soils, and the location within the landscape of each planned area. For 
undisturbed areas, a soil survey is used to determine the predominant soils in the planned areas. Consider the expected outcomes in trying to grow the various plant species your client wants. If the soils in the planned area have been heavily excavated, what type of soil is present and how deep is it? This may come down to identifying the soil by its texture and physically assessing the soil horizons and any restrictive characteristics that will limit or even prohibit successful plantings.

Steep slopes that are prone to erosion or light-textured soils subject to leaching are two possible examples. These types of factors obviously affect satisfactory seeding but are also additional considerations in developing a thorough plan. Of course, a current soil test will also be important as part of this evaluation.

\section{Nutrient Resources}

Soil testing is critical to nutrient management planning in determining the plant's likely response to applied nutrients and the $\mathrm{pH}$ of the soil for lime needs. The use of water-soluble fertilizer, slow-release materials, and even manures, wastewater, and biosolids needs to be considered in your recommendations regarding timing and rate of applications. You will have preferred materials you would like used; however, your client may have products in stock or a source of these materials he has to use. Know the options you have available to use various materials in the following years and educate your client about the advantages and disadvantages of available materials for his operation. Ultimately, what is used will be the client's decision, so to facilitate plan implementation, try to use as many client-preferred materials as possible.

\section{Nutrient Requirements for Species in Each Planned Area}

Once soils are tested, nutrient recommendations for the plant species in each planned area can be determined by utilizing the tables in Virginia Nutrient Management Standards and Criteria, revised October 2005 (Virginia Department of Conservation and Recreation-VDCR). If the plant species is not contained in Standards and Criteria, use Virginia Cooperative Extension publications or other sources that specifically address management of that species. When a publication is used for this purpose, it should be noted in the plan narrative or noted as a recommendation source on the worksheet for the plan. There are numerous examples of plant materials and their anticipated nutrient requirements presented in preceding chapters of this manual.

\section{Environmentally Sensitive Sites}

An important item to consider in evaluating your client's operation is the presence of environmentally sensitive sites. An environmentally sensitive site is any managed area that is particularly susceptible to nutrient loss to ground or surface water because it contains (or drains to areas that contain) sinkholes, or where at least 33 percent of the area in a specific management area contains one, or any combination of, the following features:

1. Soils with high potential for leaching based on soil texture or excessive drainage.

2. Shallow soils less than 41 inches deep that are likely to be located over fractured or limestone bedrock.

3. Subsurface tile drains.

4. Soils with high potential for subsurface lateral flow based on soil texture and poor drainage.

5. Floodplains as identified by soils prone to frequent flooding in county soil surveys.

6. Land with slopes greater than 15 percent.

Existing best-management practices (BMPs) installed to protect such areas should be noted to ensure their protection and maintenance. The plan writer should also consider the need for recommending additional measures to protect water quality whenever necessary. It is critical that an actual site visit be made to all planned areas that will receive any type of nutrient applications. This is necessary to check for environmentally sensitive areas and to check the general terrain of the application sites. Maps in the plan should clearly identify all environmentally sensitive sites.

\section{Allocation of Nutrients to Planned Areas}

After considering nutrient needs for each planned area and the environmentally sensitive areas, fertilizer applications should be made to meet nutrient needs or to supplement deficiencies in meeting the nutrient needs when other sources of nutrients have been applied first.

Plans shall be written on a nitrogen $(\mathrm{N})$ and phosphorus (P) basis. It is important that nutrient applications be prioritized to meet plan requirements. Nitrogen recommendations should not exceed the need determined by the Virginia Nutrient Management Standards and Criteria (2005) or other appropriate resource as discussed. Soil test levels should be used to make phosphorus and potassium $(\mathrm{K})$ recommendations. 


\section{Initial Client Visit}

\section{Collecting Background Information}

This visit is very important. The complete and detailed information you collect at this time will reduce the number of return visits or calls needed. Plan ahead and be organized. Make an appointment with your clients and let them know this may take several hours or more so that they can schedule the time required. Also let them know what information you will need so they can have it ready when you arrive. The following pages contain an example of an approach for collecting background information (figures 13.1-13.4). It may not be necessary in all cases but could be helpful when working with a client for the first time.

\section{General Information}

Date of visit

Owner name

Phone

E-mail

Manager/superintendent

Phone

E-mail

Address

City/state/zip

Extension agent

Phone

E-mail

Fertilizer supplier

Phone

E-mail

Salesman

Phone

E-mail

Consultant

Phone

E-mail

Are you scheduled to receive biosolids or other organic nutrient sources? $\square$ Yes $\square$ No

If yes, supplier:

Field representative:

Phone

E-mail

Who takes soil samples? $\square$ Client $\square$ Fertilizer dealer $\square$ Consultant $\square$ Other

At what interval are soil samples taken? $\square 1$ year $\square 2$ years $\quad \square 3$ years

Do you have current samples of all areas to be included in plan? $\square$ Yes $\square$ No

What lab is used? $\square \mathrm{VT} \quad \square \mathrm{A} \& \mathrm{~L} \quad \square$ Spectrum $\square$ Waters $\square$ Other

Who makes recommendations? $\square$ Extension $\square$ Laboratory $\square$ Fertilizer dealer $\square$ Consultant $\square$ Yourself

Are tissue samples taken? $\square$ Yes $\square$ No

What plant species? 


\section{Nutrient Application}

\begin{tabular}{|l|l|l|l|l|}
\hline Plant species & Rate/month & Rate/month & Rate/month & Rate/month \\
\hline Bermudagrass & & & & \\
\hline Turf-type tall fescue & & & & \\
\hline Flowering annuals & & & & \\
\hline & & & & \\
\hline & & & & \\
\hline & & & & \\
\hline & & & & \\
\hline & & & & \\
\hline & & & & \\
\hline
\end{tabular}

Figure 13.2. General nutrient application for each plant species (pound per acre plant food).

\section{Management Area Information}

Owner:

Date

Operation name:

Location:

\begin{tabular}{|l|l|l|l|l|}
\hline $\begin{array}{c}\text { Management area } \\
\text { designation ID }\end{array}$ & Sq ft or acres & $\begin{array}{c}\text { Present plant } \\
\text { species }\end{array}$ & $\begin{array}{c}\text { Last lime } \\
\text { Renovate to new } \\
\text { species }\end{array}$ & $\begin{array}{c}\text { Lapplication } \\
\text { rate (month/year) }\end{array}$ \\
\hline & & & & \\
\hline & & & & \\
\hline & & & & \\
\hline & & & & \\
\hline & & & & \\
\hline & & & & \\
\hline & & & & \\
\hline
\end{tabular}

Figure 13.3. Clearly define and label each management area. 


\section{Components of a Nutrient Management Plan}

A nutrient management plan designates proper management of nutrients using proper application rates and timing specific for the species of plant in each management area. Following the plan will result in a cost-effective and environmentally sound use of plant nutrients. A plan may also be used to document the proper rate and timing of nutrient applications. This is used to report the urban community's progress in protecting and improving water quality. A description of the components of an NMP is outlined in Virginia's Nutrient Management Training and Certification Regulations (available at www.dcr.virginia.gov/soil_and_water/nutmgt.shtml). The following information offers a brief outline and explanation of the various parts of a plan. All plans must be written to the criteria set forth in the regulations.

\section{Plan Identification Sheet}

The plan identification sheet is a page at the front of the plan that contains information such as the client's name and address, the planner's name and certificate number, and the county and watershed code for the operation. Information about the square footage or acreage of each plant species is included to give a snapshot view of the plan.

\section{Narrative}

Use this section to describe the operation and to assist with tailoring the plan to the individual.

- Describe the type of operation (athletic field, golf course, recreation area, etc.).

- Describe the location, naming common landmarks or route numbers; this will be helpful to identify the operation on a map or for another planner to drive to the operation.

- Include a general description of the management of each plant species in the operation.

- Make note of the proximity of management areas to streams, erosion control, environmentally sensitive areas, etc., and what precautions address each issue.

- Give directions on where additional help can be obtained for other operation management and water quality objectives that are beyond the scope of this plan.

- Write clear, concise statements that are to the point.

If some information is already included on the balance sheet (e.g., timing, testing, renovation), it is not necessary to include it in the narrative.

\section{Plan Map}

Use a copy of an aerial photograph whenever possible. Generally, these photographs will show established, planned area boundaries and should be a good reference to identify these areas as they are listed in the plan. If aerial photos are not available, take the time to draw a clear, neat map. This map should show planned area identification designations, environmentally sensitive areas (e.g., wells, erosion control structures, drainageways, etc.), and any other features of the landscape that need to be addressed in the plan to minimize the impact of nutrient application to the environment.

\section{Plan Map Legend}

Use a legend to explain any symbols used on the plan map. It can be on the map itself or included on a separate sheet directly following the map.

\section{Soil Map}

Include soil maps for the operation when there is considerable acreage in the plan and the land, for the most part, is undisturbed. Delineate the outside boundaries of the operation matching those used on the plan maps.

\section{Nutrient Application Window}

Timing of nutrient applications is very important. Spring and Summer Lawn Management Considerations for Cool-Season Turfgrasses, Virginia Cooperative Extension (VCE) publication 430-532 (VCE 2009a), and Spring and Summer Lawn Management Considerations for Warm-Season Turfgrasses, VCE publication 430-533 (VCE 2009b) are two publications that give the client a quick view of when various operations in turf maintenance should occur throughout the year. This information may be helpful when clients are putting together a plan implementation strategy.

\section{Organic Nutrient Sources}

Calculating nutrient availability from land-applied organic materials is an important component of an NMP. Most organic materials will either be animal manures or biosolids. A detailed discussion and examples of calculating nutrient availability is covered in Standards and Criteria, pages 109-10, and 117 (VDCR 2005). Refer to this section to become familiar with the formulas and proper coefficients to be used on each planned management area receiving organic nutrient sources. Once the 
plant-available nitrogen, phosphate, and potash have been calculated, the nutrients supplied from the organic material application are deducted from the nutrient needs for the plant species to which the material was applied, and subsequent residual nitrogen credit is given to following spring plant species nitrogen needs.

\section{Nutrient Application Worksheet Header} (figure 13.4)

- The property owner's name.

- The date the plan is prepared and the date it expires.
- Identification of the managed area. The managed area identification needs to exactly match the labeling as it appears on the plan map. Areas can be grouped in any order you think best suits the client's operation. Separate recommendations should be made for each individual planned area unless two or more areas are managed similarly and soil test levels are similar.

- The area of the space identified, either per 1,000 square feet or per acre.

- The plant species in the management area, as either turf or landscape materials.

\section{Nutrient Application Worksheet}

Name:

Prepared:

Expires:

Management Area Identification:

Square Feet:

Landscape Plants:

Turf Species:

\begin{tabular}{|c|c|c|c|c|c|c|c|}
\hline Column 1* & 2 & 3 & 4 & 5 & 6 & 7 & 8 \\
\hline $\begin{array}{c}\text { Nutrient } \\
\text { needs } \\
\mathbf{N}-\mathbf{P}_{2} \mathbf{O}_{5}-\mathbf{K}_{2} \mathbf{O} \\
(\mathrm{lb} / 1,000 \mathrm{sq} \mathrm{ft})\end{array}$ & $\begin{array}{l}\text { Application } \\
\text { month/day }^{+}\end{array}$ & $\begin{array}{c}\text { Fertilizer } \\
\text { material } \\
\mathbf{N}-\mathbf{P}_{2} \mathbf{O}_{5}-\mathbf{K}_{2} \mathbf{O} \\
(\mathrm{lb} / 1,000 \mathrm{sq} \mathrm{ft})\end{array}$ & $\begin{array}{c}\text { \% slowly } \\
\text { available } \\
\text { nitrogen }\end{array}$ & $\begin{array}{c}\text { Nitrogen } \\
(\mathrm{lb} / 1,000 \mathrm{sq} \mathrm{ft})\end{array}$ & $\begin{array}{c}\mathbf{P}_{2} \mathbf{O}_{5} \\
(\mathrm{lb} / 1,000 \mathrm{sq} f t)\end{array}$ & $\begin{array}{c}\mathbf{K}_{2} \mathbf{O} \\
(\mathrm{lb} / 1,000 \mathrm{sq} f \mathrm{ft})\end{array}$ & $\begin{array}{l}\text { Lime recom- } \\
\text { mendation } \\
(\mathrm{lb} / 1,000 \mathrm{sq} \mathrm{ft})\end{array}$ \\
\hline & & & & & & & \\
\hline & & & & & & & \\
\hline & & & & & & & \\
\hline & & & & & & & \\
\hline & & & & & & & \\
\hline & & & & & & & \\
\hline
\end{tabular}

Notes:

'The month and day designations may not always be followed due to weather, etc. Apply as close to the month as possible, using the day designation to determine the interval between applications.

Figure 13.4. Worksheet used to provide client with a ready reference for nutrient management recommendations.

* Row of column numbers added for ease of identification; it is not on worksheet. 


\section{Nutrient Application Worksheet Table}

The columns used in the worksheet table (figure 13.4) are explained below. All recommendations should be designated on a "per 1,000 square feet" or "per acre" basis.

1. Nutrient needs: This is where nutrient needs are shown. The nutrient needs represent the total nitrogen, phosphate, and potash for an annual application. Recommendations should be based upon soil test results for phosphorus and potassium for each plant species. Nitrogen recommendations should be based on those contained in Standards and Criteria (VDCR 2005) or a referenced resource document.

2. Application month/day: There may be several applications of nutrients per year depending on the species being fertilized. This column allows the planner to designate the months in which the nutrient applications should be applied and allows the planner to use the worksheet in two ways:

a. If the management areas are small and will receive the same applications for each year of the plan, only the month and day for the application needs to be entered, along with a note on the worksheet explaining that this annual application program is applicable for all the years of the plan.

b. If the recommendations will vary from year to year, then each year of the plan should be entered into the "Prepared" and "Expires" dates. This will probably increase the number of worksheets in the plan, but it is acceptable when needed to convey the specific applications needed to achieve desired soil fertility levels in the management area.

Note: The month and day designations may not always be followed due to weather, etc. Apply as close to the month as possible, using the day designation to determine the interval between applications.

3. Fertilizer material $\mathrm{N}-\mathrm{P}_{2} \mathrm{O}_{5}-\mathrm{K}_{2} \mathrm{O}$ : This column identifies the fertilizer material and the rate that it should be applied at the designated time period.

4. Percent slowly available nitrogen: This column is used to identify the amount of slowly available nitrogen in the material recommended (Note: slowly available $\mathrm{N}$ is defined in chapter 8 of this manual).

5. Nitrogen ( $\mathrm{lb} / 1,000$ square feet or $1 \mathrm{~b} / \mathrm{acre})$ : This is the amount of plant-available nitrogen supplied by the designated fertilizer material application.
6. $\mathbf{P}_{2} \mathbf{O}_{5}(\mathrm{lb} / 1,000$ square feet or $\mathrm{lb} / \mathrm{acre})$ : This is the amount of plant-available phosphorus - expressed as phosphate - that is supplied by the designated fertilizer material application.

7. $\mathbf{K}_{2} \mathbf{O}(\mathrm{lb} / 1,000$ square feet or $l b / a c r e):$ This is the amount of plant-available potassium - expressed as potash — that is supplied by the designated fertilizer material application.

8. Lime recommendation $(\mathrm{lb} / 1,000$ square feet or $\mathrm{lb} /$ acre): This is the amount of lime recommended for the management area. Most times this recommendation may be the only material application designated; thus, it will have its own "application month/year" because it will probably be applied at a different time than fertilizer materials.

9. Notes: Special considerations regarding nutrient application, special conditions in the managed area, tillage practices, etc., can be footnoted here.

\section{Assistance Notes}

These notes record what transpired during your first and follow-up client visits. Write about such things as alternatives you provided, decisions made based on unusual circumstances, progress on plan implementation, or unusual circumstances anyone should be familiar with when visiting the client. These notes will help you or your successor understand what has already been discussed and what needs further discussion. These notes should only be kept in your copy of the NMP.

\section{Personal Plan Notes}

This is where your personal notes and calculations should be recorded. This will be important and very helpful to you because in some cases you may not update plans for two or three years, depending on the plan's expiration date. You may need some reminders of how and why you wrote the plan. You should keep a record showing details of how the recommendations were derived. Any special condition or unusual circumstances that existed at the time the plan is written should be documented so the information can be referred to when you review the plan at a later date or to justify specific recommendations during an inspection. These notes should only be kept in your copy of the NMP. 



\title{
Sample Nutrient Management Plan
}

\section{Nutrient Management Plan Identification}

\author{
Owner \\ Fairfax County \\ 1100 Cub Run Lane \\ Manassas, VA 22025 \\ (804) 555-1212 \\ Land Manager \\ Mr. William DuPont \\ Watershed Summary \\ Watershed: PL45 \\ County: Prince William
}

Nutrient Management Planner

John Smith

Courthouse Plaza, Suite \#5

Hanover, VA 22555

Certification code: 100

Acreage Use Summary

Total acreage in this plan: 15

Athletic fields: 3.5

Supporting areas: 2

Picnic/recreation: 7

Other turf: 2.5

Plan written 3/18/10

Valid until 3/18/13

Planner signature: 


\section{Narrative for \\ Cub Run Valley Park \\ Manassas, Virginia}

Cub Run Valley Park is located off Rt. 29 in Fairfax County between Rt. 609 and Rt. 620. The park entrance is off of Stillfield Place Road. This park is open to the public from March 1 through November 30. The park consists of three athletic fields - two baseball and one football field, a primitive picnic area, and an adjoining recreation area maintained for the public to use for recreational activities such as pick-up games, Frisbee tossing, and general exercise and play activities. No pets are allowed in the park. Cub Run stream runs through the park and Field No. 3; the football field is accessed from the parking areas by a large cement culvert crossing over the stream. This crossing is used by cars, maintenance equipment, and foot traffic to access this area of the park.

The athletic fields are mainly used for community Little League baseball and elementary football games on weekends, with practices being conducted throughout the season. Field No. 1 has restricted use and is used mainly for weekend games through early summer. Field No. 3 is used for baseball practice in the late summer, with the majority of the baseball season games played on Field No. 2. During the football season, Field No. 2 is used for practices as well. These fields are managed at a high level, with special attention given to mowing heights and intervals, weed control, and compaction. Soil tests are taken regularly to monitor nutrient needs, and nitrogen is applied on a set schedule to keep grass growing as vigorously as possible through the open season. When possible, play is rotated to different areas of the fields to minimize damage to the field in any one area due to concentrated use.

The recreation area is used for all activities while the park is open to the public.

Condition of the athletic fields is usually good at the opening of the park and remains fairly good through the season. If the field conditions deteriorate too much, the park may be closed earlier in November to minimize damage done to the grass stands and keep costs down to renovate and re-establish fields for the next year.

A buffer area of 50 feet on each side of Cub Run is untreated and is mowed occasionally at about 6 to 8 inches to discourage activities in the buffer area.

Because very little excavation was done to build the fields and other park areas, the native soils are still in place for the most part. Athletic Field No. 1 is constructed on Dulles silt loam, which is somewhat poorly drained. Athletic Field No. 2 is constructed on Ashburn silt loam, which is moderately well-drained. The paved parking lot is built on Jackland and Haymarket soils, which are very stony; fortunately, the entrance area to the park runs through a Dulles silt loam.

Field No. 3, the overflow parking area, and the picnic/recreation area are on a Rowland silt loam. This soil is environmentally sensitive because it is listed as "frequent" for the chance of flooding. Application of nutrients in these areas are not scheduled when heavy rainfall events are expected within a week's time. Any soil disturbance associated with renovation or construction is usually stabilized with straw mulch covered with anchored netting after final grading and seeding are completed. In areas where water flow could possibly be more concentrated, soil stabilization blankets may be installed to protect the planting until the grass is fully established.

The park is maintained by the county, which has a minimal budget for fertilizer, lime, and reseeding. Nutrient applications, particularly fall nitrogen applications, may be slightly reduced to save money - especially if the turf has a good appearance.

The worksheets in this plan represent recommendations for each management area for the next three years. Applications will be repeated each year at the same designated times. Lime recommendations are only for one application and the designated date includes the year to be applied. This plan is written for a three-year period and will need to be revised at that time to remain current. Revising a plan takes some time, so the process should begin at least four weeks or more prior to the plan expiration date. 
The following management practices should be utilized where appropriate to protect water quality and enable the client to better implement a nutrient management plan.

1. Soil samples should be analyzed at least once every three years for $\mathrm{pH}$, phosphorus, potassium, calcium, and magnesium in order to maximize the efficient utilization of nutrients. A representative soil sample of each management area should be composed of at least 20 cores randomly sampled from throughout the area. Soil sampling core depth will be 6 inches from the surface. Soil pH should be maintained at appropriate agronomic levels to promote optimum plant growth and nutrient utilization.

2. Spreader calibration is extremely critical to ensure proper application rates.

3. A protective cover of appropriate vegetation should be established and maintained on all disturbed areas. Vegetation such as trees, shrubs, and other woody species are limited to areas considered to be appropriate, such as wind breaks or visual screens.

4. This nutrient management plan should be revised at least once every three years to make adjustments for needed renovations, re-establishment of turf around construction projects, and updated soil test information.

5. If clippings are collected, they should be disposed of properly. They may be composted or spread uniformly as a thin layer over other turf areas or areas where the nutrient content of the clippings can be recycled through actively growing plants. They should not be blown onto impervious surfaces or surface waters, dumped down stormwater drains, or piled outside where rainwater will leach out the nutrients, creating the potential for nutrient loss to the environment.

6. Iron applications (particularly foliar applications) may periodically be used for enhanced greening as an alternative to nitrogen. These applications are most beneficial if applied in late spring through summer for cool-season grasses and in late summer/fall applications for warm-season grasses.

7. Do not apply fertilizers containing nitrogen or phosphorus to impervious surfaces (sidewalks, streets, etc.). Remove any granular material that lands on impervious surfaces by sweeping and collecting it, and either putting the collected material back in the bag or spreading it on the turf and/or using a leaf blower, etc., to return the fertilizer back to the turfgrass canopy.

8. These conditions do not override any local or county ordinances that may be more restrictive. 


\section{Cub Run Valley Park}

\section{Soil Test Summary Report}

Lab: Virginia Tech

Sample date: March 9, 2010

\begin{tabular}{|l|c|c|c|c|c|c|}
\hline Managed area I.D. & $\begin{array}{c}\text { Area } \\
(\mathrm{sq} f \mathrm{ft})\end{array}$ & $\begin{array}{c}\mathbf{P}_{\mathbf{2}} \mathbf{O}_{\mathbf{5}} \\
(\mathrm{lb} / \mathrm{ac})\end{array}$ & $\begin{array}{c}\mathbf{K}_{\mathbf{2}} \mathbf{O} \\
(\mathrm{lb} / \mathrm{ac})\end{array}$ & Soil $\mathbf{~ p H}$ & Buffer index & Turf species \\
\hline Athletic Field No. 1 & 52,800 & $14 / \mathrm{M}$ & $40 / \mathrm{L}$ & 6.2 & - & Bluegrass \\
\hline Athletic Field No. 2 & 52,800 & $33 / \mathrm{M}+$ & $161 / \mathrm{M}+$ & 6.3 & - & Bermudagrass \\
\hline Athletic Field No. 3 & 57,600 & $35 / \mathrm{M}$ & $148 / \mathrm{M}$ & 5.9 & 6.18 & Bermudagrass \\
\hline Support area & 85,120 & $10 / \mathrm{L}+$ & $59 / \mathrm{L}+$ & 6.2 & - & Bermudagrass \\
\hline Overflow parking & 108,900 & $8 / \mathrm{L}$ & $51 / \mathrm{L}+$ & 5.7 & 6.12 & K-31 fescue \\
\hline Picnic/recreation area & 101,360 & $14 / \mathrm{M}-$ & $78 / \mathrm{M}-$ & 6.0 & 6.21 & Tall fescue \\
\hline Entrance area & 1,000 & $10 / \mathrm{L}+$ & $73 / \mathrm{L}+$ & 5.8 & 6.14 & Perennials \\
\hline
\end{tabular}




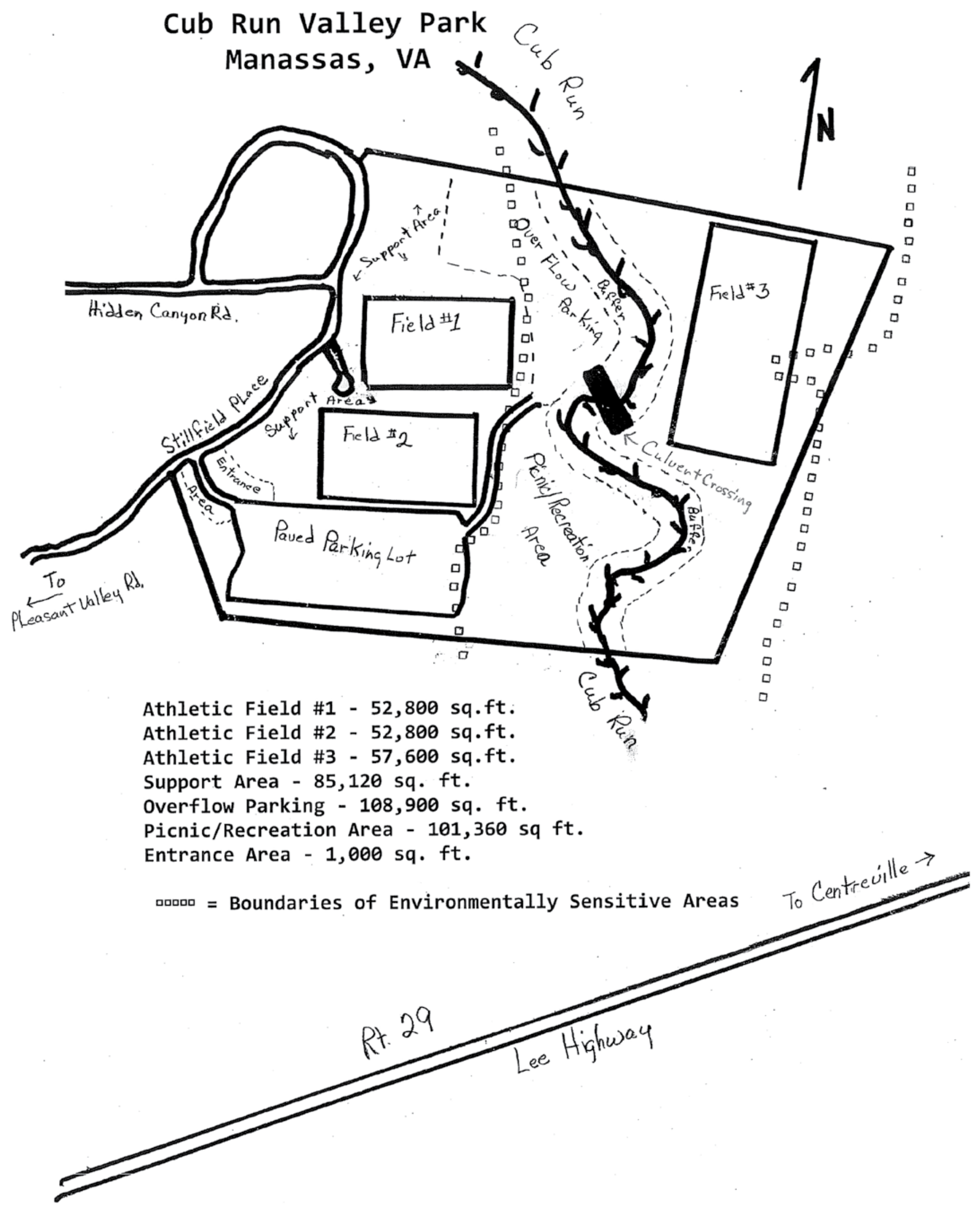




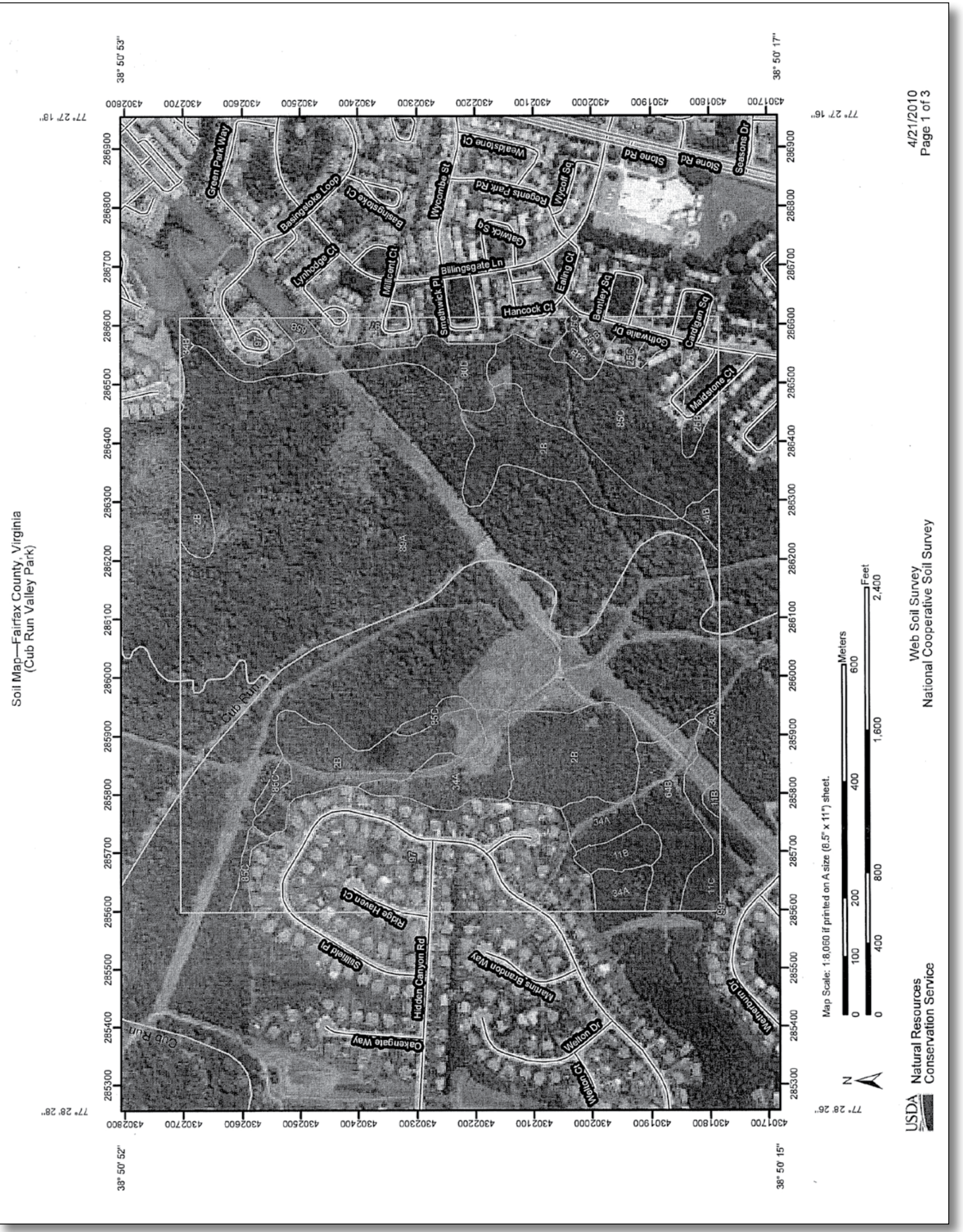




\section{Map Unit Legend}

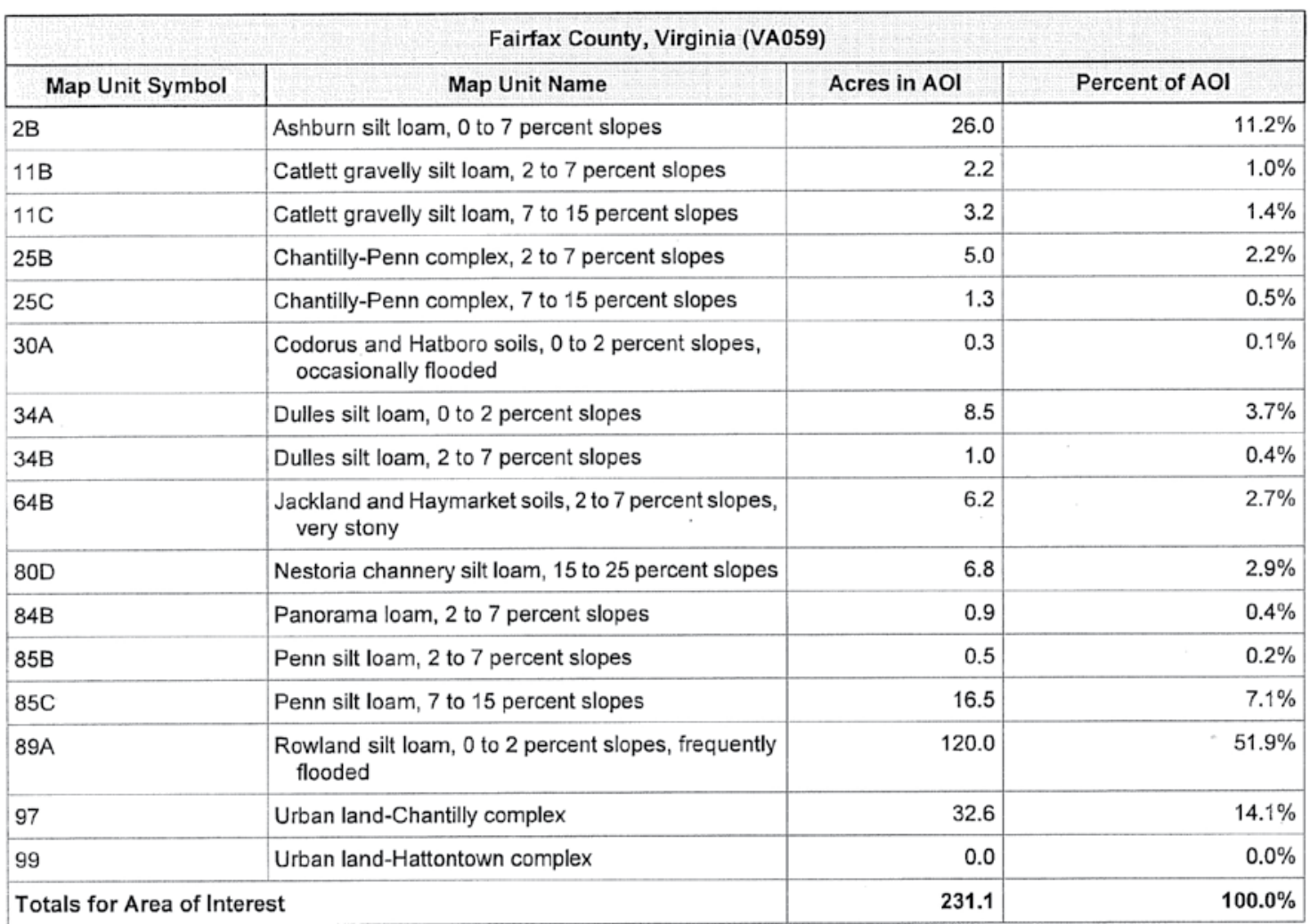




\section{Nutrient Application Worksheet}

Name: Fairfax County

Prepared: $3 / 18 / \underline{10}$ Expires: $\underline{3}, \underline{18} / \underline{13}$

Management Area Identification: Athletic Field No. 1

Square Feet: $52,800-7,000^{*}$ (infietd) $=45,800$

Landscape Plants: Bluegrass

Turf Species: none

\begin{tabular}{|c|c|c|c|c|c|c|c|}
\hline \begin{tabular}{|c|}
$\begin{array}{c}\text { Nutrient } \\
\text { needs } \\
\mathrm{N}^{-} \mathbf{P}_{2} \mathbf{O}_{5}-\mathrm{K}_{2} \mathbf{O} \\
(\mathrm{b} / 1,000 \mathrm{sq} \mathrm{ft})\end{array}$ \\
\end{tabular} & $\begin{array}{l}\text { Appli- } \\
\text { cation month/ } \\
\text { day }^{+}\end{array}$ & $\begin{array}{c}\text { Fertilizer } \\
\text { material } \\
\mathrm{N}-\mathbf{P}_{2} \mathbf{O}_{5}-\mathbf{K}_{2} \mathbf{O} \\
(\mathrm{lb} / 1,000 \mathrm{sq} f \mathrm{ft})\end{array}$ & $\begin{array}{c}\text { \% slowly } \\
\text { available N }\end{array}$ & $\left(\begin{array}{c}\text { Nitrogen } \\
(\mathrm{lb} / 1,000 \mathrm{sq} \mathrm{ft})\end{array}\right)$ & $\begin{array}{c}\mathbf{P}_{2} \mathbf{O}_{5} \\
(\mathrm{lb} / 1,000 \text { sq ft }\end{array}$ & $\begin{array}{c}\mathbf{K}_{2} \mathbf{O} \\
(\mathrm{lb} / 1,000 \mathrm{sq} \mathrm{ft}\end{array}$ & $\begin{array}{l}\text { Lime recom- } \\
\text { mendation } \\
(\mathrm{lb} / 1,000 \mathrm{sq} \mathrm{ft})\end{array}$ \\
\hline \multirow{4}{*}{$3.5-2.0-3.0$} & $4 / 15$ & $\begin{array}{c}18-24-12 \\
2.76 \mho\end{array}$ & $50 \%$ & 0.5 & 0.66 & 0.33 & - \\
\hline & $6 / 1$ & $\begin{array}{c}18-24-12 \\
2.76 u\end{array}$ & $50 \%$ & 0.5 & 0.66 & 0.33 & - \\
\hline & $8 / 15$ & $\begin{array}{c}18-24-12 \\
2.76 w^{2}\end{array}$ & $50 \%$ & 0.5 & 0.66 & 0.33 & - \\
\hline & $9 / 1$ & $\begin{array}{c}23-0-23 \\
4.35 u\end{array}$ & $50 \%$ & 1 & 0 & 1 & - \\
\hline
\end{tabular}

Notes:

*7,000 square feet deducted from treated area for infield, which does not receive any fertitization.

${ }^{\dagger}$ The month and day designations may not always be followed due to weather, etc. Apply as close to the month as possible, using the day designation to determine the interval between applications. 


\section{Nutrient Application Worksheet}

Name: Fairfax County

Prepared: $3 / 18 / 10$ Expires: $3 / 18 / 13$

Management Area Identification: Athletic Field No. 2

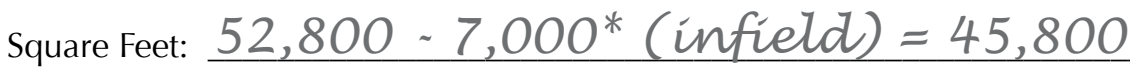

Landscape Plants: Bermudagrass

Turf Species: none

\begin{tabular}{|c|c|c|c|c|c|c|c|}
\hline $\begin{array}{l}\text { Nutrient } \\
\text { needs } \\
\mathrm{N}-\mathrm{P}_{2} \mathbf{O}_{5}-\mathrm{K}_{2} \mathrm{O} \\
(\mathrm{lb} / 1,000 \mathrm{sq} \mathrm{ft}\end{array}$ & $\begin{array}{l}\text { Application } \\
\text { month/day }\end{array}$ & $\begin{array}{c}\begin{array}{c}\text { Fertilizer } \\
\text { material } \\
\mathrm{N}-\mathbf{P}_{2} \mathbf{O}_{5}-\mathbf{K}_{2} \mathbf{O} \\
(\mathrm{lb} / 1,000 \mathrm{sq} \mathrm{ft})\end{array} \\
\end{array}$ & $\begin{array}{c}\% \text { slowly } \\
\text { available N }\end{array}$ & $\begin{array}{c}\text { Nitrogen } \\
(\mathrm{lb} / 1,000 \mathrm{sq} \mathrm{ft})\end{array}$ & $\begin{array}{c}\mathbf{P}_{2} \mathbf{O}_{5} \\
(\mathrm{lb} / 1,000 \mathrm{sq} \mathrm{ft})\end{array}$ & $\begin{array}{c}\mathbf{K}_{2} \mathbf{O} \\
(\mathrm{lb} / 1,000 \mathrm{sq} \mathrm{ft}\end{array}$ & $\begin{array}{c}\text { Lime recom- } \\
\text { mendation } \\
(\mathrm{lb} / 1,000 \mathrm{sq} \mathrm{ft})\end{array}$ \\
\hline \multirow{7}{*}{$4.5-1.5-1.0$} & $4 / 15$ & $\begin{array}{c}18-24-12 \\
2.76 \mho t\end{array}$ & $50 \%$ & 0.5 & 0.66 & 0.33 & - \\
\hline & $6 / 1$ & $\begin{array}{c}30-6-10 \\
3.33 \text { U }\end{array}$ & $50 \%$ & 1.0 & 0.20 & 0.33 & - \\
\hline & $7 / 1$ & $\begin{array}{c}30-6-10 \\
3.33 U\end{array}$ & $50 \%$ & 1.0 & 0.20 & 0.33 & - \\
\hline & $9 / 1$ & $\begin{array}{c}18-24-12 \\
1.83 U \\
\end{array}$ & $50 \%$ & 0.33 & 0.44 & 0.22 & - \\
\hline & $9 / 15$ & $\begin{array}{l}40-0-0 \\
1.25 U\end{array}$ & $85 \%$ & 0.50 & 0.00 & 0.00 & - \\
\hline & $10 / 1$ & $\begin{array}{c}\text { Overseed } \\
\text { ryegrass } \\
2 \text { W }\end{array}$ & - & - & - & - & - \\
\hline & $10 / 15$ & $\begin{array}{c}40-0-0 \\
1.25 \\
\end{array}$ & $85 \%$ & 0.5 & 0.00 & 0.00 & 一 \\
\hline \multicolumn{8}{|l|}{ Notes: } \\
\hline \multicolumn{8}{|c|}{$\begin{array}{l}\text { 10/15 application date is approximate; nitrogen should be } \\
\text { applied as soon as ryegrass has germinated and there is ade- } \\
\text { quate moisture to promote vigorous growth. }\end{array}$} \\
\hline
\end{tabular}

tThe month and day designations may not always be followed due to weather, etc. Apply as close to the month as possible, using the day designation to determine the interval between applications. 


\section{Nutrient Application Worksheet}

Name: Fairfax County

Prepared: $3 / 18 / 10$ Expires: $3 / 18 / 13$

Management Area Identification: Athletic Field No. 3

Square Feet: 57,600

Landscape Plants: Bermudagrass

Turf Species: none

\begin{tabular}{|c|c|c|c|c|c|c|c|}
\hline \begin{tabular}{|c|}
$\begin{array}{c}\text { Nutrient } \\
\text { needs } \\
\mathrm{N}-\mathbf{P}_{2} \mathbf{O}_{5}-\mathbf{K}_{2} \mathbf{O} \\
(\mathrm{lb} / 1,000 \mathrm{sq} \mathrm{ft})\end{array}$ \\
\end{tabular} & $\begin{array}{l}\text { Application } \\
\text { month/day }\end{array}$ & $\begin{array}{c}\begin{array}{c}\text { Fertilizer } \\
\text { material } \\
\mathrm{N}_{-} \mathbf{P}_{2} \mathbf{O}_{5}-\mathrm{K}_{2} \mathrm{O} \\
(\mathrm{lb} / 1,000 \mathrm{sq} \mathrm{ft})\end{array} \\
\end{array}$ & $\begin{array}{c}\text { \% slowly } \\
\text { available N }\end{array}$ & $\begin{array}{c}\text { Nitrogen } \\
\mathrm{(b/} / 1,000 \mathrm{sq} \mathrm{ft}\end{array}$ & $\begin{array}{c}\mathbf{P}_{2} \mathbf{O}_{5} \\
(\mathrm{lb} / 1,00 \mathrm{sq} \mathrm{ft}\end{array}$ & $\begin{array}{c}\mathbf{K}_{2} \mathbf{O} \\
(\mathrm{lb} / 1,000 \text { sq ft }\end{array}$ & $\begin{array}{l}\text { Lime recom- } \\
\text { mendation } \\
(\mathrm{lb} / 1,000 \mathrm{sq} \mathrm{ft})\end{array}$ \\
\hline \multirow{8}{*}{$4.5-1.5-1.5$} & $4 / 15$ & $\left|\begin{array}{c}18-24-12 \\
2.76 U\end{array}\right|$ & $50 \%$ & 0.5 & 0.66 & 0.33 & - \\
\hline & $5 / 1$ & $\begin{array}{c}\text { Pulverized } \\
\text { lime }\end{array}$ & - & - & - & - & $57 U$ \\
\hline & $6 / 1$ & $\begin{array}{c}30-6-10 \\
3.33 t\end{array}$ & $50 \%$ & 1.0 & 0.20 & 0.33 & - \\
\hline & $7 / 1$ & $\begin{array}{c}30-6-10 \\
3.33 t \\
\end{array}$ & $50 \%$ & 1.0 & 0.20 & 0.33 & - \\
\hline & $9 / 1$ & $\begin{array}{c}18-24-12 \\
1.83 \mathrm{U}\end{array}$ & $50 \%$ & 0.33 & 0.44 & 0.22 & - \\
\hline & $9 / 15$ & $\begin{array}{l}40-0-0 \\
1.25 \mathrm{U}\end{array}$ & $85 \%$ & 0.50 & 0.00 & 0.00 & - \\
\hline & $10 / 1$ & $\begin{array}{c}\text { overseed } \\
\text { ryegrass } \\
2 \text { u }\end{array}$ & - & - & - & - & - \\
\hline & $10 / 15$ & $\begin{array}{l}40-0-0 \\
1.25 U\end{array}$ & $85 \%$ & 0.5 & 0.00 & 0.00 & - \\
\hline
\end{tabular}

Notes:

10/15 application date is approximate; nitrogen should be applied as soon as ryegrass has germinated and there is adequate moisture to promote vigorous growth.

${ }^{+}$The month and day designations may not always be followed due to weather, etc. Apply as close to the month as possible, using the day designation to determine the interval between applications. 


\section{Nutrient Application Worksheet}

Name: Fairfax County

Prepared: 3 /18/ 10 Expires: 3 /18/ 10

Management Area Identification: Support Area/Overflow Parking

Square Feet: 194,020

Landscape Plants: Tall Fescue

Turf Species: none

\begin{tabular}{|c|c|c|c|c|c|c|c|}
\hline \begin{tabular}{|c|}
$\begin{array}{c}\text { Nutrient } \\
\text { needs } \\
\mathrm{N}-\mathbf{P}_{2} \mathbf{O}_{5}-\mathbf{K}_{2} \mathbf{O} \\
(\mathrm{lb} / 1,000 \mathrm{sq} \mathrm{ft})\end{array}$ \\
\end{tabular} & $\begin{array}{l}\text { Application } \\
\text { month/day }\end{array}$ & $\begin{array}{c}\begin{array}{c}\text { Fertilizer } \\
\text { material } \\
\mathrm{N} \mathbf{P}_{2} \mathbf{O}_{5}-\mathrm{K}_{2} \mathrm{O} \\
(\mathrm{lb} / 1,000 \mathrm{sq} \mathrm{ft})\end{array} \\
\end{array}$ & $\begin{array}{c}\text { \% slowly } \\
\text { available N }\end{array}$ & $\begin{array}{c}\text { Nitrogen } \\
(\mathrm{lb} / 1,000 \mathrm{sq} \mathrm{ft})\end{array}$ & $\begin{array}{c}\mathbf{P}_{2} \mathbf{O}_{5} \\
(\mathrm{lb} / 1,000 \mathrm{sq} \mathrm{ft})\end{array}$ & $\begin{array}{c}\mathbf{K}_{2} \mathbf{O} \\
(\mathrm{lb} / 1,000 \mathrm{sq} \mathrm{ft})\end{array}$ & $\begin{array}{c}\text { Lime recom- } \\
\text { mendation } \\
(\mathrm{lb} / 1,000 \mathrm{sq} \mathrm{ft})\end{array}$ \\
\hline \multirow{4}{*}{$3.0-2.5-2.0$} & $9 / 1$ & $\begin{array}{c}10-20-15 \\
10 \psi\end{array}$ & - & 1.0 & 2.0 & 1.5 & - \\
\hline & $10 / 1$ & $\begin{array}{c}30-6-10 \\
3.33 t\end{array}$ & $50 \%$ & 1.0 & 0.2 & 0.33 & - \\
\hline & $11 / 1$ & $\begin{array}{l}40-0-0 \\
2.5 \mho\end{array}$ & $50 \%$ & 1.0 & 0.00 & 0.00 & - \\
\hline & $4 / 11 / 10$ & $\begin{array}{l}\text { Pulverized } \\
\text { limestone }\end{array}$ & - & - & - & - & $\begin{array}{c}69 \text { Ub } \\
\text { overflow } \\
\text { parking } \\
\text { onty }\end{array}$ \\
\hline
\end{tabular}

Notes:

${ }^{+}$The month and day designations may not always be followed due to weather, etc. Apply as close to the month as possible, using the day designation to determine the interval between applications. 


\section{Nutrient Application Worksheet}

Name: Fairfax County

Prepared: $3 / 18 / 10$ Expires: 3 /18/10

Management Area Identification: Picnic/Recreation Area

Square Feet: 101,360

Landscape Plants: Tall Fescue

Turf Species: none

\begin{tabular}{|c|c|c|c|c|c|c|c|}
\hline \begin{tabular}{|c|}
$\begin{array}{c}\text { Nutrient } \\
\text { needs } \\
\mathrm{N}^{-} \mathbf{P}_{2} \mathbf{O}_{5}-\mathbf{K}_{2} \mathbf{O} \\
(\mathrm{lb} / 1,000 \mathrm{sq} \mathrm{ft})\end{array}$ \\
\end{tabular} & $\begin{array}{l}\text { Application } \\
\text { month/day }\end{array}$ & $\begin{array}{c}\begin{array}{c}\text { Fertilizer } \\
\text { material } \\
\mathrm{N}-\mathbf{P}_{2} \mathbf{O}_{5}-\mathbf{K}_{2} \mathbf{O} \\
(\mathrm{lb} / 1,000 \mathrm{sq} f \mathrm{ft})\end{array} \\
\end{array}$ & $\begin{array}{c}\% \text { slowly } \\
\text { available N }\end{array}$ & $\begin{array}{c}\text { Nitrogen } \\
(\mathrm{lb} / 1,000 \mathrm{sq} \mathrm{ft}\end{array}$ & $\begin{array}{c}\mathbf{P}_{2} \mathbf{O}_{5} \\
(\mathrm{lb} / 1,000 \mathrm{sq} \mathrm{ft}\end{array}$ & $\begin{array}{c}\mathbf{K}_{2} \mathbf{O} \\
(\mathrm{lb} / 1,000 \mathrm{sq} \mathrm{ft})\end{array}$ & $\begin{array}{l}\text { Lime recom- } \\
\text { mendation } \\
(\mathrm{lb} / 1,000 \mathrm{sq} \mathrm{ft})\end{array}$ \\
\hline \multirow{4}{*}{$3.0-2.0-2.0$} & $9 / 1$ & $\begin{array}{c}10-20-15 \\
10 \mathrm{U}\end{array}$ & - & 1.0 & 2.0 & 1.5 & - \\
\hline & $10 / 1$ & $\begin{array}{c}23-0-23 \\
4.3 \mathrm{U} \\
\end{array}$ & $50 \%$ & 1.0 & 0.00 & 1.0 & - \\
\hline & $11 / 1$ & $\begin{array}{c}40-0-0 \\
2.5 \mathrm{~W}\end{array}$ & $50 \%$ & 1.0 & 0.00 & 0.00 & - \\
\hline & $4 / 1 / 11$ & $\begin{array}{l}\text { Pulverized } \\
\text { limestone }\end{array}$ & - & - & - & - & $46 \mathrm{~W}$ \\
\hline
\end{tabular}

Notes:

${ }^{+}$The month and day designations may not always be followed due to weather, etc. Apply as close to the month as possible, using the day designation to determine the interval between applications. 


\section{Nutrient Application Worksheet}

Name: Fairfax County

Prepared: $3,18,10$ Expires: $3,18,10$

Management Area Identification: Entrance Plantings

Square Feet: 1,000

Landscape Plants: Herbaceous Perennials

Turf Species: none

\begin{tabular}{|c|c|c|c|c|c|c|c|}
\hline 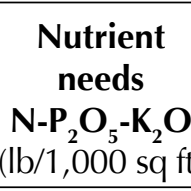 & $\begin{array}{l}\text { Application } \\
\text { month/day }\end{array}$ & $\begin{array}{c}\begin{array}{c}\text { Fertilizer } \\
\text { material } \\
\mathrm{N}-\mathrm{P}_{2} \mathrm{O}_{5}-\mathrm{K}_{2} \mathrm{O} \\
(\mathrm{lb} / 1,000 \mathrm{sq} \mathrm{ft})\end{array} \\
\end{array}$ & $\begin{array}{c}\% \text { slowly } \\
\text { available N }\end{array}$ & $\begin{array}{c}\text { Nitrogen } \\
(\mathrm{lb} / 1,000 \mathrm{sq} \mathrm{ft})\end{array}$ & $\begin{array}{c}\mathbf{P}_{2} \mathbf{O}_{5} \\
(\mathrm{lb} / 1,000 \mathrm{sq} \mathrm{ft})\end{array}$ & $\begin{array}{c}\mathbf{K}_{2} \mathbf{O} \\
(\mathrm{lb} / 1,000 \mathrm{sq} \mathrm{ft}\end{array}$ & $\begin{array}{l}\text { Lime recom- } \\
\text { mendation } \\
(\mathrm{lb} / 1,000 \mathrm{sq} \mathrm{ft}\end{array}$ \\
\hline \multirow{5}{*}{$\begin{array}{c}1.25-1.0 \\
1.0\end{array}$} & $3 / 1$ & $\begin{array}{c}10-10-10 \\
5 \mathrm{U}\end{array} \mid$ & - & 0.5 & 0.5 & 0.5 & - \\
\hline & $3 / 15$ & $\begin{array}{l}\text { Pulverized } \\
\text { limestone }\end{array}$ & - & - & - & - & $39 U$ \\
\hline & $4 / 15$ & $\begin{array}{c}10-10 \sim 10 \\
5 \mathrm{w}\end{array}$ & - & 0.5 & 0.5 & 0.5 & - \\
\hline & $5 / 30$ & $\begin{array}{c}30-6-10 \\
2.5 t\end{array}$ & $50 \%$ & 0.75 & 0.15 & 0.25 & - \\
\hline & $6 / 15$ & $\begin{array}{l}\text { Pulverized } \\
\text { limestone }\end{array}$ & - & - & - & - & $39 U$ \\
\hline \multicolumn{8}{|c|}{$\begin{array}{l}\text { Notes: } \\
\text { A } 3 \text { - 1-1 fertilizer ratio is suggested, but based on low soil test } \\
\text { results for phosphorus and potassium, this ratio for } P \text { and } K \\
\text { was increased based on an annual } N \text { rate of } 1.25 \mathrm{lb} \text {. Lime } \\
\text { applied in two applications to adjust } p 7 t \text { to } 6.2 \text {. }\end{array}$} \\
\hline
\end{tabular}

'The month and day designations may not always be followed due to weather, etc. Apply as close to the month as possible, using the day designation to determine the interval between applications.

References: Perennials: Culture, Maintenance, Propagation; Fertilizing Landscape Trees and Shrubs. 



\section{Plan Discussion}

The following information is NOT part of an actual plan; its purpose is to help the reader understand what information was used to write this plan and the reasoning behind some of the recommendations.

When you begin to work with clients, they may have some fertilizer materials on hand that they want to use before buying other products, so you may be forced to use some analysis that does not exactly match your recommendations. Try to use as few products as possible to make the plan a little easier for your client to follow. To aid in understanding the recommendations in the example plan, the specimen labels that follow (figure 13.5) were used.

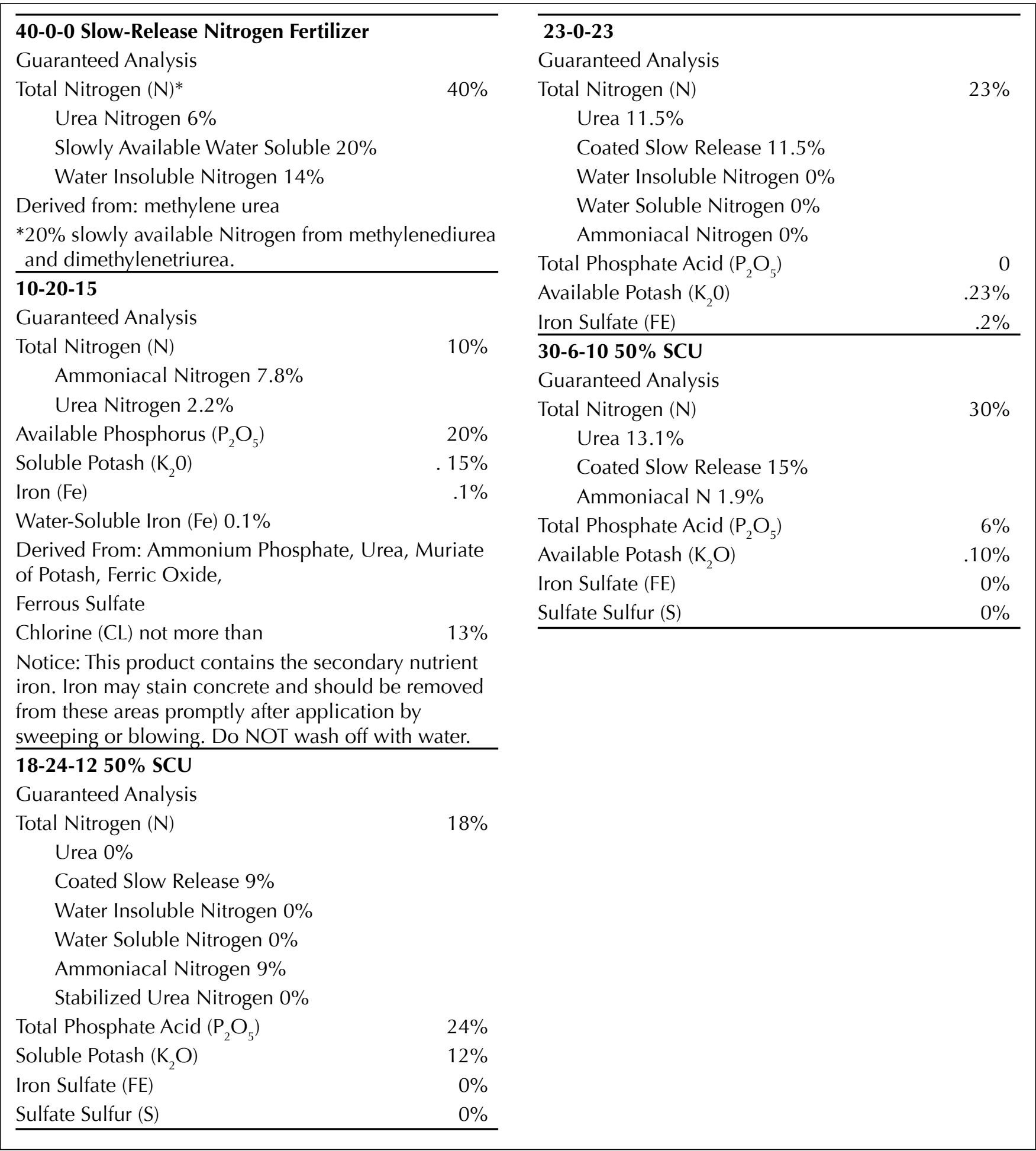

Figure 13.5. The five sample specimen labels, as stated earlier, may not be part of a plan you would take back to your clients. They are provided here as a reference to help in your understanding of how to interpret the information contained in them to make recommendations. 
How do I know if my fertilizer material is considered slowly available, and if so, how do I calculate the percentage of slowly available nitrogen to use in making recommendations? To determine this, divide the percentage of slowly available nitrogen material by the percentage of total nitrogen listed on the label. Slowly available nitrogen will be listed on the label as "coated slow release," "water insoluble nitrogen," etc.

Looking at the materials used on Athletic Field No. 2 and from the label information, here are the calculations:

$$
\begin{gathered}
18-24-12: 9 \% \div 18 \%=50 \% \\
30-6-10: 15 \% \div 30 \%=50 \% \\
40-0-0:(20 \%+14 \%) \div 40 \%=85 \%
\end{gathered}
$$

In the last fertilizer, there are two different materials making up the slowly available component of the total nitrogen. (Note: A complete discussion on slowly available nitrogen sources, their characteristics, and their uses is provided in chapter 8 of this manual.)

For athletic fields No. 1, 2, and 3, the nutrient needs were determined using the Virginia Nutrient Management Standards and Criteria (2005; available through the Virginia Department of Conservation and Recreation website at www.dcr.virginia.gov/soil_and_water/ nutmgt.shtml). The nitrogen program followed the "intensive" maintenance program shown on page 102 of Standards and Criteria. How an area is managed determines whether you should use the normal or intensive program. You determine how an area is managed by talking to your client about the nitrogen rate they have been using, how much play the fields have to handle, and how quickly they heal in season and postseason. The phosphorus and potash recommendations are from soil test results. Those recommendations for athletic fields are found on page 104 of Standards and Criteria.

Because the financial budget is always tight at the county and the fields look good late in the season, it was decided - in consultation with the client - not to make the third fall nitrogen application. Such decisions are acceptable but should be made with the client's full understanding of what it is being done and why. Otherwise, the recommendations in the plan do not match those in Standards and Criteria, making it appear that the planner did not completely follow the Standards and Criteria recommendations.

In general, the nitrogen rates are close to the nutrient needs. In some areas, the phosphorus applications may be under the recommendations. Because plans cannot exceed the nitrogen or the phosphorus nutrient needs, it was easiest to come close to the nitrogen needs while not exceeding the phosphorus needs.

Lime applications are shown on the worksheets as well. It was easy to list the lime material and show the application rate in the far-right column.

Because the recommendations for each year of the three-year plan were going to be similar, one worksheet was developed for each managed area and labeled to be good for three years - see "prepared" and "expires" dates in the first column of the header section of the worksheet. IF the managed areas would have had significantly different fertility for each of the three years, then the planner may choose to develop a worksheet for each management area for each year. Using the worksheets for either option is acceptable; fill them out so it is clear to the client what needs to be done and when.

The worksheet on the entrance plantings area is fairly simple. It basically shows a nitrogen application and the phosphorus and potash recommendations based on a soil test. While perhaps not necessary, this adds to the plan in that the planner is addressing possible fertilizer applications to all managed areas of the property. Again, talk with your client about what they do in these areas and how satisfied they are with their performance and/or appearance. Although you may find they do not have any formal program in place, your interest in managing such areas will improve the overall appearance of the property, which increases the value of your service to your client.

A map of the property showing the various features described in the nutrient management regulations is required to be part of the plan; however, the soils map and legend may be useful information in the plan, but the soils map and legend needs to be information contained in the client's office file.

\section{Plan Implementation}

After the initial plan has been delivered, the client should begin to implement it. The degree to which it is implemented will depend on several factors. The most obvious is whether it will benefit the client either in cost savings or improved appearance of the managed area(s). Secondly, how easily can changes suggested in the plan be adapted to the client's current methods of operation? If the recommendations in the plan are similar to what is already being done, the client is more likely to follow them. A well-written plan that 
addresses the specific needs of a property with a practical and realistic approach is also more likely to be successfully implemented. Finally, the client's acceptance of the plan, willingness to change, and trust in the plan writer will strongly affect the degree of plan adoption.

For those plans (or portions thereof) that are adopted, three tasks are important to its ongoing success.

\section{Future Nutrient Testing}

Where appropriate, the soil and tissue testing described earlier are key tools to manage the application of nutrients. Without these measures of nutrient availability balanced with plant needs, it will be difficult to accurately determine plant nutrient needs and to develop relevant, justifiable recommendations. The client should be strongly encouraged to maintain this test-critical information. Not only is it needed for developing credible nutrient management plans, it is also important in the operation management decision-making process.

\section{Equipment Calibration}

Equipment calibration represents another area critical to plan implementation. The plan recommendations will do little to save money and protect water quality if they cannot be followed due to inaccurate nutrient application. Calibration of all application equipment should be checked on a regular basis, especially if your client owns his own application equipment. Without the necessary adjustments indicated by calibration, the result may be to apply either too little or too much plant nutrients. The first may result in an unacceptable turf durability and turf/landscape appearance. The latter may be costly, not only because of the unnecessary expense, but also because of a negative impact on water quality. Equipment calibration is detailed in chapter 10 of this manual.

\section{Application and Maintenance Records}

A final area to emphasize during plan implementation is record keeping. Without good records, it is impossible to know what has been done and if any progress or improvements are being made. Examples of important information to retain are soil tests; spreader calibration settings; dates of fertilizer application and rates applied; seeding or renovation of specific areas; and any usual stresses on the areas due to disease, drought, etc., that would also impact the health and appearance of the turf. This information provides the background needed for fine-tuning future plan updates or revisions.

\section{Plan Revision}

Several factors can and will result in the need for revising the nutrient management plan. The most obvious is that the life of the plan has expired. Plans can be written for up to a three-year period. Start working with clients well ahead of the expiration date so your client will have a current plan in place at all times.

Even the best-written plan can be refined to take advantage of what has been learned in the last season. For that reason, plans will always be going through some degree of evolution. Some specific factors may result in the need for significant revisions. Changes in the predominant land use on (or adjacent to) the managed areas may require modification of the existing plan. If managed areas are dramatically changed by renovations to the landscape or construction of new buildings, roads, etc., such changes may require the plan to be revised.

\section{Summary}

The number of factors that can alter a nutrient management plan is substantial. For that reason, a sincere effort on the part of the client who manages a sizeable operation may be needed to reassess decisions made when the plan was first developed. Follow-up visits are important to the success of the planning process. Because the performance of various managed areas varies due to season conditions, it is important to continue to follow up until the client is comfortable with the plan implementation. Once the client has an understanding of the concepts and is capable of interpreting the plan, the amount of support required should significantly lessen. Having your clients increase their understanding of nutrient management and its importance creates a desire to do their best to follow the plan. More importantly, it indicates that you are delivering a good and beneficial service to your clients.

\section{Literature Cited}

Virginia Cooperative Extension (VCE). 2009a. Spring and Summer Lawn Management Considerations for Cool-Season Turfgrasses. VCE Publication 430-532. http://pubs.ext.vt.edu.430/430-532/430-532.html.

Virginia Cooperative Extension. 2009b. Spring and Summer Lawn Management Considerations for WarmSeason Turfgrasses. VCE Publication 430-533. http://pubs.ext.vt.edu.430/430-533/430-533.html.

Virginia Department of Conservation and Recreation (VDCR). Division of Soil and Water Conservation. 2005. Virginia Nutrient Management Standards and Criteria. 




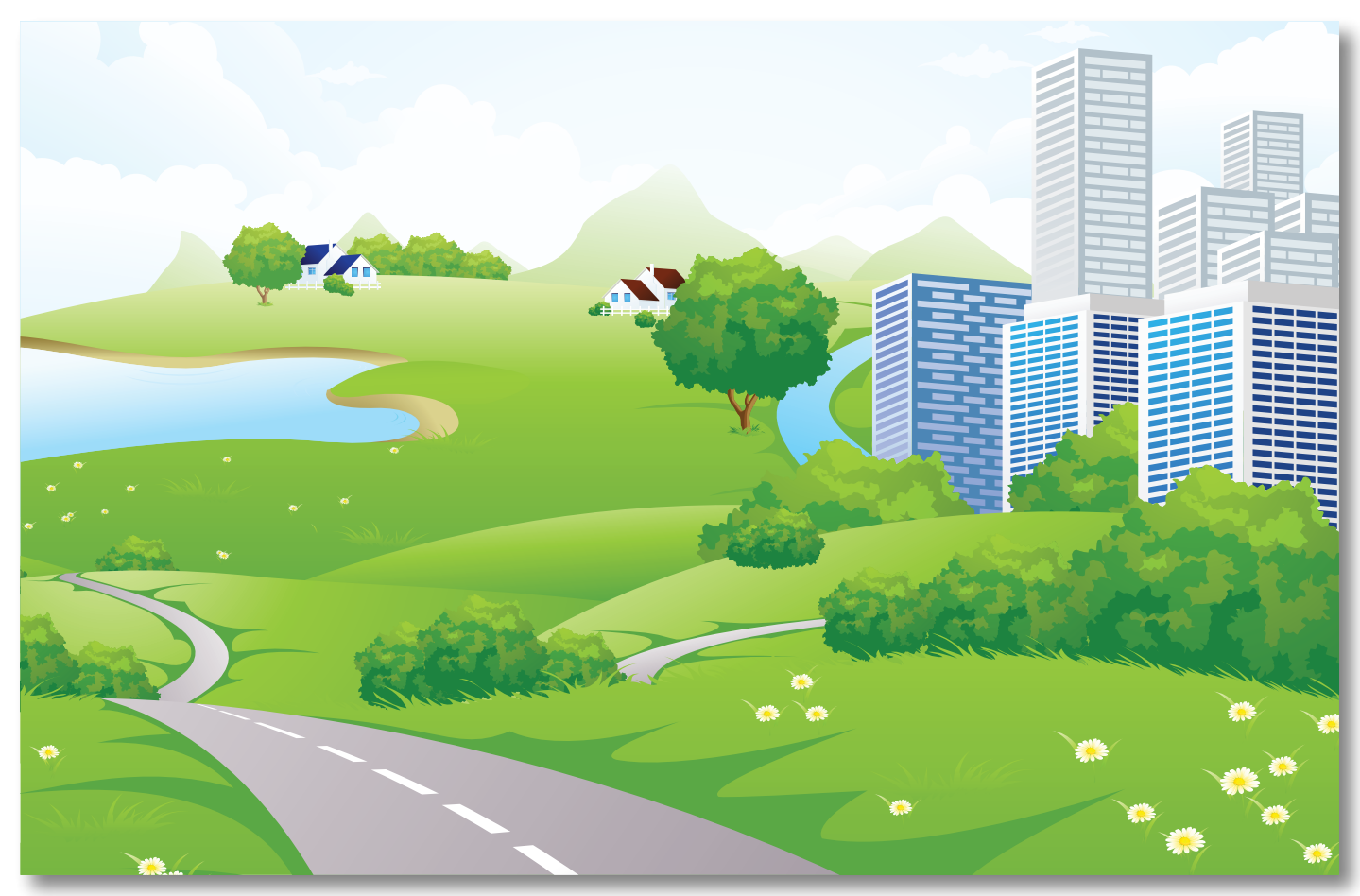

www.ext.vt.edu

PUBLICATION 430-350

Produced by Communications and Marketing, College of Agriculture and Life Sciences, Virginia Polytechnic Institute and State University, 2011 Virginia Cooperative Extension programs and employment are open to all, regardless of race, color, national origin, sex, religion, age, disability, political beliefs, sexual orientation,
or marital or family status. An equal opportunity/affirmative action employer. Issued in furtherance of Cooperative Extension work, Virginia Polytechnic Institute and State University, Virginia State University, and the U.S. Department of Agriculture cooperating. Alan L. Grant, Dean, College of Agriculture and Life Sciences, and Interim Director, Virginia Cooperative Extension, Virginia Tech, Blacksburg; Wondi Mersie, Interim Administrator, 1890 Extension Program, Virginia State, Petersburg. 